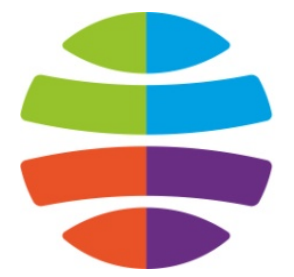

СГУГиТ

СИБИРСКИЙ

ГОСУДАРСТВЕННЫЙ УНИВЕРСИТЕТ

ГЕОСИСТЕМ И ТЕХНОЛОГИЙ
Учредитель федеральное государственное бюджетное образовательное учреждение высшего образования «Сибирский государственный университет геосистем и технологий» (СГУГиТ)

\title{
Вестник СГУГиТ
}

Научный журнал

Издается с 1996 г.

Tом 26, № 5, 2021

Выходит 6 раз в год

\author{
Главный редактор \\ Д. т. н., проф. \\ Карпик Александр Петрович
}

Заместители главного редактора:

Д. т. н., проф. Д. В. Лисицкий

Д. т. н., проф. Г. А. Уставич

Редакционная коллегия:

Д. т. н., проф. В. С. Айрапетян

Д. б. н. К. С. Байков

К. т. н., проф. Г. Гиенко (США)

Д. т. н., проф. С. Златанова

(Нидерланды)

Д. т. н., доц. А. В. Комиссаров

Д. т. н., проф. М. Конечны (Чехия)

Д. ф.-м. н., проф. С. М. Копейкин

(США)

Д. б. н., проф. Ю. В. Кравцов

К. ф.-м. н., доц. Е. Левин (США)

Д. т. н., проф. Е. М. Мазурова

Акад. РАН Н. П. Похиленко

Д. ф.-м. н., проф. О. А. Романовский

Д. т. н., проф. А. П. Сизов

Д. г. н., проф. В. С. Тикунов

Д. ф.-м. н., проф. В. Ю. Тимофеев

Д. т. н., проф. А. С. Толстиков

Д. т. н., проф. Л. К. Трубина

Д. т. н., доц. В. С. Хорошилов

Д. т. н., проф. Ю. В. Чугуй

Д. т. н., проф. Д. А. Шаповалов

Акад. РАН М. И. Эпов

Д. т. н., проф. Р. Ягер (Германия)

До 2015 г. журнал выходил под названием «Вестник СГГА»

С 2017 г. нумерация журнала включает номер тома (порядковый номер года издания) и номер выпуска в текущем году

СГУГиТ, 2021
DOI: $10.33764 / 2411-1759-2021-26-5$

\section{СОДЕРЖАНИЕ}

\section{ГЕОДЕЗИЯ И МАРКШЕЙДЕРИЯ}

А. В. Елагин, Н. Н. Кобелева. Алгоритмы вычисления геодезических высот и широт пунктов по прямоугольным координатам в плоскости меридианного эллипса. .5

Б. Т. Мазуров, А. А. Панжин, Д. А. Абжапарова. Оценка геодинамической ситуации Воронежского кристаллического массива по геодезическим данным ..

В. И. Обиденко, С. Р. Горобиов. Преобразования пространственных данных в государственную геодезическую систему координат 2011 года в ПО ГИС.

В. Ю. Тимофеев, Д. Г. Ардюков, А. В. Тимофеев, П. Ю. Горнов, Ю. Ф. Стусь, В. М. Семибаламут. Вариации объёмной деформации и уровня воды в скважинах, их влияния на результаты гравиметрических измерений

Г. А. Уставич, Н. С. Косарев, Д. А. Баранников, И. А. Мезенщев, Д. В. Бирюков. Методика передачи координат тахеометром на пункты внутренней разбивочной сети инженерного сооружения.

Н. К. Шендрик. Методика определения согласующих параметров Гельмерта для локальных территорий.

\section{ДИСТАНЦИОННОЕ ЗОНДИРОВАНИЕ ЗЕМЛИ, ФОТОГРАММЕТРИЯ}

О. В. Купчова, И. И. Лобищева, А. А. Верхотуров, $B$. А. Мелкий. Исследование влияния зон разломов территории заказника «Долинский» (о. Сахалин) на состояние его растительного покрова с использованием материалов дистанционного зондирования Земли 
Журнал зарегистрирован Федеральной службой по надзору в сфере связи, информационных технологий и массовых коммуникаций свидетельство ПИ № ФС 77-62654 от 10 августа 2015 г.

Журнал входит в Перечень рецензируемых научных изданий, в которых должны быть опубликованы основные научные результаты диссертаций на соискание ученой степени кандидата и доктора наук

Журнал включен в Российский индекс научного цитирования (РИНЦ)

Подписные индексы

в каталогах:

«Пресса России» - 43809

Электронный каталог

«Российская периодика»

(www.ideg.ru) - 43809э

Технический редактор журнала

А. В. Конева

Адрес редакции и издателя:

630108, Новосибирск,

ул. Плахотного, 10

E-mail: vestnik@ssga.ru

Тел. (383)361-06-55

http://vestnik.ssga.ru

Перевод на английский язык

Д. В. Романова

Редакторы:

Е. К. Деханова

О. В. Георгиевская

Компьютерная верстка

О. И. Голиков

Свободная цена.

Дата выхода в свет 27.10.2021.

Формат $60 \times 84$ 1/8.

Усл. печ. л. 23,25.

Тираж 1000 экз. Заказ 145.

Редакционно-издательский отдел СГУГиТ

630108, Новосибирск,

ул. Плахотного, 10.

Отпечатано в картопечатной лаборатории СГУГиТ 630108, Новосибирск, ул. Плахотного, 8.

\section{КАРТОГРАФИЯ И ГЕОИНФОРМАТИКА}

А. А. Басаргин, П. Ю. Бугаков, Т. Ю. Бугакова. Расчет и визуализация картографических маршрутов с использованием программного обеспечения QGIS и PGROUTING. 86

К. С. Батырова, Я. Г. Пошивайло. История дополненной реальности и перспективы ее применения в картографии

Т. Е. Елиина, И. П. Кокорина, А. В. Сысоев. Создание и использование $3 \mathrm{D}$-модели горного рельефа для геоинформационного обеспечения туризма.

Оюунханд Бямба, Е. Л. Касьянова. Использование Д3З и ГИС при создании географических основ для тематических карт

\section{ЗЕМЛЕУСТРОЙСТВО, КАДАСТР И МОНИТОРИНГ ЗЕМЕЛЬ}

Аврунев Е. И., Гиниятов А. И., Калениџкий А. И. Проектирование и уравнивание пространственных геодезических построений, предназначенных для создания трехмерного кадастра

И. А. Басова, Д. О. Прохоров, С. В. Пьянков. Предложения по охране земель при негативном воздействии техногенных минеральных образований

А. О. Белоусов, В. Л. Богданов. Прогноз динамики площадей земель сельскохозяйственного назначения и оптимизация земельных отношений на территории Новгородской области

А. В. Дубровский, Е. А. Скоринская, А. Р. Батуев, В. Г. Колмогоров, Л. А. Пластинин, В. И. Татаренко. Актуальные вопросы нормативно-правового и технологического обеспечения кадастровых работ по установлению границ зон затопления и подтопления для защиты объектов недвижимости от чрезвычайных ситуаций.....

Ю. С. Ларионов, К. С. Байков, В. Б. Жарников. Методологические и теоретические основы охраны земель в системе биологического земледелия

Н. О. Митрофанова, Е. Н. Лосева. О применении искусственных нейронных сетей при государственной кадастровой оценке земельных участков

И. В. Пархоменко, Д. В. Пархоменко. Судебная землеустроительная экспертиза в отношении здания, самовольно реконструированного в контуре отдельного помещения. 
SSUGT

SIBERIAN STATE

UNIVERSITY OF GEOSYSTEMS

AND TECHNOLOGIES
Founder Federal State Budgetary

Educational Institution of Higher Education

"Siberian State University

of Geosystems and Technologies"

\section{Vestnik SSUGT}

Scientific journal

Published since 1996

Issued 6 times a year
Volume 26(5), 2021

DOI: $10.33764 / 2411-1759-2021-26-5$

\section{CONTENTS}

\section{GEODESY AND MINE SURVEY}

\section{Editorial team:}

D. Sc. (Eng.), Prof. V. S. Ajrapetyan

D. Sc. (Biol.) K. S. Baikov

Ph. D. (Eng.), Prof. G. Gienko (USA)

D. Sc. (Eng.), Prof. S. Zlatanova

(Netherlands)

D. Sc. (Eng.), Assoc. Prof.

A. V. Komissarov

D. Sc. (Eng.), Prof. M. Konečný

(Czech Republic)

D. Sc. (Phys.-Math.), Prof.

S. M. Kopeikin (USA)

D. Sc. (Biol.), Prof. Yu. V. Kravtsov

Ph. D. (Phys.-Math.), Assoc. Prof.

E. Levin (USA)

D. Sc. (Eng.), Prof. E. M. Mazurova

Member of RAS N. P. Pokhilenko

D. Sc. (Phys.-Math.), Prof.

O. A. Romanovskij

D. Sc. (Eng.), Prof. A. P. Sizov

D. Sc. (Geogr.), Prof. V. S. Tikunov

D. Sc. (Phys.-Math.), Prof.

V. Yu. Timofeev

D. Sc. (Eng.), Prof. A. S. Tolstikov

D. Sc. (Eng.), Prof. L. K. Trubina

D. Sc. (Eng.), Assoc. Prof.

V. S. Horoshilov

D. Sc. (Eng.), Prof. Yu. V. Chugui

D. Sc. (Eng.), Prof. D. A. Shapovalov

Member of RAS M. I. Epov

D. Sc. (Eng.), Prof. R. Jäger (Germany)

Before 2015 journal

was published under the name

«Vestnik SSGA»

Starting from 2017 numbering of the volume refers to the number of years the journal has been circulated. The number of the issue refers to how many times the journal was published during the year

\section{A. V. Elagin, N. N. Kobeleva. Algorithms for Calculating}

Geodetic Heights and Latitudes by Rectangular Coordinates in the Meridian Ellipse Plane

B. T. Mazurov, A. A. Panzhin. D. A. Abzhaparova. Assessment of the Geodynamic Situation of the Voronezh Crystalline Massif from Geodetic Data

V. I. Obidenko, S. R. Gorobtsov. Transformation of Spatial Data into the State Geodetic Coordinate System of 2011 in GIS Software

V. Y. Timofeev, D. G. Ardyukov, A. V. Timofeev, P. Y. Gornov, Y. F. Stus, V. M. Semibalamut. Volume Deformation Variations and Well-Aquifer Response, Its Connection with Gravity Measurements

G. A. Ustavich, N. S. Kosarev, D. A. Barannikov, I. A. Mezentsev, D. V. Birukov. Method of Transmitting the Coordinates of the Total Station to the Points of the Internal Central Network of an Engineering Construction.

N. K. Shendrick. Methodology for Determining Helmert's Consistent Parameters for Local Territories.

\section{REMOTE SENSING, PHOTOGRAMMETRY}

O. V. Kuptsova, I. I. Lobishcheva, A. A. Verkhoturov, $V$. A. Melkiy. Study of Influence of the Fault Zones on Vegetation Cover of State Territory of the Nature Sanctuary "Dolinsky" (Sakhalin Island) Using Earth's Remote Sensing Data 


\section{Registration certificate}

The journal is registered in the Federal Service for Supervision of Communications Information Technology, and Mass Media - Certificate PI No. 77-62654 of August 10, 2015

The journal is included in the List of refereed scientific journals, recommended by HAC for publishing the scientific results of dissertations in candidacy for a degree of Candidate or Doctor of Science degree

Journal included in Russian Science Citation Index (RSCI)

Subscription indexes in catalogues: «Russian press» - 43809

Electronic catalogue

«Russian periodicals»

(www.ideg.ru) - 43809э

Layout editor of journal

A. V. Koneva

Editors office and publisher address: 630108, Novosibirsk,

10 Plakhotnogo St.

E-mail: vestnik@ssga.ru

Phone: (383)361-06-55

http://vestnik.ssga.ru

English translation

D. V. Romanov

Editors:

E. K. Dehanova

O. V. Georgievskaia

\section{Desktop publishing}

O. I. Golikov

Free price

Issue data 27.10.2021.

Format $60 \times 84$ 1/8 .

Conv. pr. sheets 23,25 .

Circulation 1000 copies.

Order 145.

Printing and publication department SSUGT 630108, Novosibirsk, 10 Plakhotnogo St.

Printed in map printing laboratory SSUGT 630108, Novosibirsk, 8 Plakhotnogo St.

\section{CARTOGRAPHY AND GEOINFORMATICS}

A. A. Basargin, P. Yu. Bugakov, T. Yu. Bugakova. Calculation and Visualization of Map Routes Using QGIS and pgRouting Software 86

K. S. Batyrova, Ya. G. Poshivaylo. History of Augmented Reality and Further Trends of Its Use in Cartography

T. E. Elshina, I. P. Kokorina, A. V. Sysoev. Building and Using a 3D Model of a Mountainous Landform for Geoinformational Support of Tourism

Oyunkhand Byamba, E. L. Kasyanova. Using Remote Sensing and GIS to Create Geographical Bases for Thematic Maps

\section{LAND MANAGEMENT, CADASTRE AND LAND MONITORING}

E. I. Avrunev, A. I. Giniyatov, A. I. Kalenitsky. Design and Equalization of Spatial Geodetic Constructions Intended for Creating a Three-Dimensional Cadastre.

I. A. Basova, D. O. Prokhorov, S. V. Pyankov. Proposals for the Protection of Land from the Negative Impact of Technogenic Mineral Formations

A. O. Belousov, V. L. Bogdanov. Method for Calculating the Forecast of the Dynamics of Agricultural Land Areas in the Novgorod Region

A. V. Dubrovsky, E. A. Skorinskaya, A. R. Batuev, V. G. Kolmogorov, L. A. Plastinin, V. I. Tatarenko. Relevant Issues of Legal and Regulatory and Technological Support of Cadastral Works for Determiing Flooding and Underflooding Zone Boundaries for the Protection of Real Estate Objects in Emergencies

Yu. S. Larionov, K. S. Baykov, V. B. Zharnikov. Theoretical and Methodological Basis of Agricultural Areas Protection in the System of Biological Farming.

E. N. Loseva, N. O. Mitrofanova. Use of Artificial Neural Networks in the State Cadastral Valuation of Land Plots ...... 180

I. V. Parkhomenko, D. V. Parkhomenko. Geodetic Expert Evidence of a Building after Unauthorised Renovation in the Circuit of a Separate Room 


\section{ГЕОДЕЗИЯ И МАРКШЕЙДЕРИЯ}

УДК 528.063:528.236.5

DOI: $10.33764 / 2411-1759-2021-26-5-5-16$

\section{АЛГОРИТМЫ ВЫЧИСЛЕНИЯ ГЕОДЕЗИЧЕСКИХ ВЫСОТ И ШИРОТ ПУНКТОВ ПО ПРЯМОУГОЛЬНЫМ КООРДИНАТАМ В ПЛОСКОСТИ МЕРИДИАННОГО ЭЛЛИПСА}

\section{Александр Викторович Елагин}

Сибирский государственный университет геосистем и технологий, 630108, Россия, г. Новосибирск, ул. Плахотного, 10, кандидат технических наук, доцент кафедры космической и физической геодезии, тел. (383)361-01-59, e-mail: kaf.astronomy@ssga.ru

\section{Наталья Николаевна Кобелева}

Сибирский государственный университет геосистем и технологий, 630108, Россия, г. Новосибирск, ул. Плахотного, 10, кандидат технических наук, доцент кафедры космической и физической геодезии, тел. (383)361-01-59, e-mail: n.n.kobeleva@mail.ru

В связи с широким применением ГНСС-технологий в геодезической практике возникает задача перехода от прямоугольных пространственных координат точек к пространственным геодезическим координатам, которые необходимы для перехода к плоским прямоугольным координатам в проекции Гаусса - Крюгера. Авторами предложены пять алгоритмов преобразования прямоугольных координат пунктов в плоскости меридианного эллипса в геодезические высоты и широты. Первые два алгоритма связаны геометрическими соотношениями точки пересечения эллипса с нормалью, проходящей через пункт, в котором были получены прямоугольные пространственные координаты. В основе формул других трех алгоритмов лежат геометрические соотношения точки пересечения меридианного эллипса с прямой, соединяющей пункт с центром кривизны меридиана. В результате экспериментов получены отклонения вычисленных широт и высот от эталонных значений заданной сетки геодезических координат. Формулы тестировались не только для пунктов под земной поверхностью и на ней, но и вне Земли на разных высотах вплоть до высоты 20000 км.

Ключевые слова: меридианный эллипс, геодезические высоты и широты, прямоугольные координаты меридианного эллипса, нормаль, центр кривизны меридиана, алгебраические уравнения четвертой степени, радиус-вектор

\section{Введение}

В настоящее время в научной литературе и учебниках представлено более полутора десятков способов вычисления геодезических высот и широт пунктов по прямоугольным координатам [1-20]. Способы вычисления геодезических широт по пространственным прямоугольным координатам, выполненные путем использования дифференциальных поправок, описаны в [21, 22].

В данной работе экспериментально исследована точность и выполнено сравнение пяти алгоритмов преобразования прямоугольных координат пунктов в системе координат меридианного эллипса в геодезические широты и высоты (по критериям точности и простоте формул). Известно, что формулы прямого перехода от геодезических широт и высот к прямоугольным координатам меридианного эллипса являются точными и имеют вид [2]

$$
\begin{gathered}
X=(N+H) \cos B ; \\
Y=\left(N+H-N e^{2}\right) \sin B .
\end{gathered}
$$


Путем изменения широт и высот $(B=15$, $30,45,60,75^{\circ} ; H=-1,0,1,10,100,1000$, 10 000, 20000 км), по формулам (1) и (2) определяется сетка эталонных значений прямоугольных координат в плоскости меридианного эллипса. Решая обратную задачу перехода от прямоугольных координат к геодезическим, в зависимости от точности формул алгоритмов преобразования, будут получены различные отклонения вычисленных широт и высот от эталонных значений заданной сетки геодезических широт и высот. Ниже представлены формулы, реализованные в пяти алгоритмах.

\section{Алгоритм 1}

На рис. 1 изображена нормаль к эллипсоиду, проходящая через заданную точку.

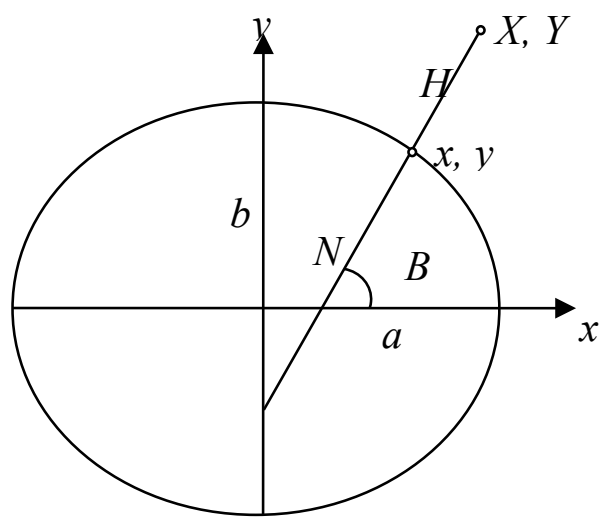

Рис. 1. Нормаль к эллипсоиду, проходящая через заданную точку

В первом алгоритме из решения системы двух уравнений (3), (4) с двумя неизвестными определяется точка пересечения меридианного эллипса с нормалью, проходящей через заданный пункт:

$$
\left.\begin{array}{c}
\frac{a^{2}(X-x)}{x}-\frac{b^{2}(Y-y)}{y}=0 \\
\frac{x^{2}}{a^{2}}+\frac{y^{2}}{b^{2}}=1
\end{array}\right\}
$$

где $X, Y$ - координаты пункта; $x, y$ - искомые координаты точки пересечения нормали (уравнение (3)) и эллипса (уравнение (4)); $a$, $b-$ большая и малая полуоси эллипсоида.
Здесь выражение (3) является уравнением нормали, а выражение (4) - уравнением эллипса.

Для решения системы уравнений требуется замена переменных. Если сделать замену переменных в выражениях (3) и (4)

$$
\tilde{X}=\frac{X}{x} ; \quad \tilde{Y}=\frac{Y}{y},
$$

то, в результате подстановки, осуществляется переход к алгебраическому уравнению четвертой степени

$$
\begin{gathered}
\tilde{X}^{4}-2 e^{2} \tilde{X}^{3}+\left(e^{4}-\frac{X^{2}+Y^{2}}{a^{2}}+e^{2} \frac{Y^{2}}{a^{2}}\right) \times \\
\times \tilde{X}^{2}+2 \frac{e^{2}}{a^{2}} X^{2} \tilde{X}-\frac{e^{2}}{a^{2}} X^{2}=0,
\end{gathered}
$$

где $e^{2}-$ квадрат первого эксцентриситет эллипсоида вращения.

В зависимости от вида подстановки, уравнения четвертой степени у разных авторов [4, $17,20]$ немного отличаются от уравнения (6). По-видимому, первым предложил выполнять преобразование координат с использованием алгебраического уравнения четвертой степени H. Vermeille [20]. Для решения используется способ Феррари [23].

После определения $\tilde{X}$ из решения уравнения (6), вычисляются координаты точки пересечения по формулам

$$
x=\frac{X}{\tilde{X}} ; y=\frac{\tilde{X}-e^{2}}{\left(1-e^{2}\right)} .
$$

Широта и высота определяются из соотношений

$$
\begin{gathered}
B=\operatorname{arctg}\left[\frac{y}{x\left(1-e^{2}\right)}\right] ; \\
H=X \cos B+Y \sin B-N\left(1-e^{2} \sin ^{2} B\right),
\end{gathered}
$$

где $N$ - радиус кривизны первого вертикала, для определения которого может использоваться формула 


$$
N=\frac{a}{\sqrt{1-e^{2} \sin ^{2} B}}
$$

Необходимо отметить, что формулы данного перехода являются, с одной стороны, строгими, но с другой стороны, - сложными из-за необходимости решения алгебраического уравнения четвертой степени.

\section{Алгоритм 2}

Второй алгоритм получен на основе связи координаты $x$ точки пересечения нормали с меридианным эллипсом с приведенной широтой

$$
x=a \cos U \text {. }
$$

Подставляя это соотношение в формулы (5) и (6), также получено алгебраическое уравнение четвертой степени

$$
\begin{gathered}
\bar{A} \cos ^{4} U+\bar{B} \cos ^{3} U+\bar{C} \cos ^{2} U+ \\
+\bar{D} \cos U+\bar{E}=0,
\end{gathered}
$$

где $\bar{A}=a^{4} e^{4} X^{2} ; \quad \bar{B}=-2 a^{3} e^{2} X^{3} ; \quad \bar{C}=-a^{2} X^{2}\left[a^{2} e^{4}-\right.$ $\left.-X^{2}-\left(1-e^{2}\right) Y^{2}\right] ; \bar{D}=-a^{4} e^{4} X^{2} ; \bar{E}=-a^{2} X^{4}$.

Однако в этом случае легко находятся производные по приведенной широте $U$ и можно не решать уравнение четвертого порядка, а уточнить приближенное значение приведенной широты с использованием производных. В работе уточнялась широта только по первой производной.

Вычислим приведенную широту точки пересечения с эллипсоидом радиуса-вектора пункта

$$
U_{0}=\operatorname{arctg}\left(\frac{Y}{X \sqrt{1-e^{2}}}\right)
$$

и подставим ее в уравнение (12). Правая часть уравнения уже не будет равна нулю, а будет равна невязке

$$
\begin{aligned}
& F_{0}=\bar{A} \cos ^{4} U_{0}+\bar{B} \cos ^{3} U_{0}+ \\
& +\bar{C} \cos ^{2} U_{0}+\bar{D} \cos U_{0}+\bar{E}
\end{aligned}
$$

Вычислив первую производную от уравнения (14)

$$
\begin{aligned}
& d F_{0} / d U_{0}=-\left(4 \bar{A} \cos ^{3} U_{0}+\right. \\
& \left.+3 \bar{B} \cos ^{2} U_{0}+2 \bar{C} \cos U_{0}+D\right) \sin U_{0}
\end{aligned},
$$

получаем выражение для вычисления поправки в приведенную широту

$$
\Delta U=\frac{-F}{d F_{0} / d U_{0}} .
$$

Уточнив приведенную широту

$$
U=U_{0}+\Delta U
$$

вычисляется геодезическая широта и высота по формулам

$$
\begin{gathered}
B=\operatorname{arctg}\left(\frac{\operatorname{tg} U}{\sqrt{1-e^{2}}}\right) \\
H=X \cos B+Y \sin B-N\left(1-e^{2} \sin ^{2} B\right) .
\end{gathered}
$$

Достоинство формул данного алгоритма заключается в их простом виде.

\section{Алгоритм 3}

Третий алгоритм основан на использовании координат $x_{c}, y_{c}$ центра кривизны меридиана в точке пересечения радиуса-вектора пункта с меридианным эллипсом (рис. 2).

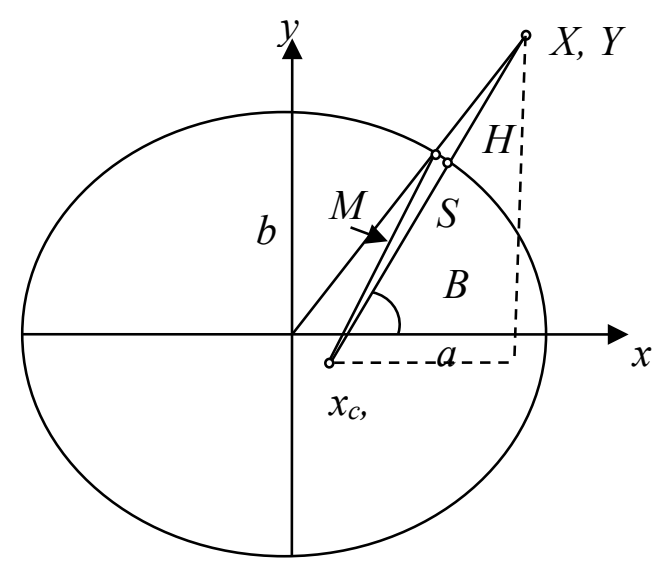

Рис. 2. Использование центра кривизны меридиана 
Координаты центра кривизны определяются по формулам:

$$
\begin{aligned}
& U_{0}=\operatorname{arctg}\left(\frac{Y}{X \sqrt{1-e^{2}}}\right) \\
& x_{c}=a e^{2} \cos ^{3} U_{0} ; \\
& y_{c}=-b e^{\prime 2} \sin ^{3} U_{0} .
\end{aligned}
$$

Вычисление расстояния по координатам от центра кривизны до пункта

$$
S=\sqrt{\left(X-x_{c}\right)^{2}+\left(Y-y_{c}\right)^{2}}
$$

позволяет получить выражения для вычисления геодезической широты и высоты

$$
B=\arcsin \left(\frac{Y-y c}{S}\right)
$$

$$
H=X \cos B+Y \sin B-N\left(1-e^{2} \sin ^{2} B\right) .
$$

Широту можно также определить и по формуле

$$
B=\arccos \left(\frac{X-x_{c}}{S}\right)
$$

Формулы (22) и (24) позволяют получить известную формулу Боуринга [19], которая связывает геодезическую широту с прямоугольными координатами пункта

$$
\begin{gathered}
B=\operatorname{arctg}\left(\frac{\sin B}{\cos B}\right)= \\
=\operatorname{arctg}\left(\frac{Y+b e^{\prime 2} \sin ^{3} U_{0}}{X-a e^{2} \cos ^{3} U_{0}}\right) .
\end{gathered}
$$

Результаты вычисления геодезической широты по формулам (22), (24) и формуле Боуринга (25) являются идентичными.

\section{Алгоритм 4}

Четвертый алгоритм основан на тригонометрических соотношениях (используются теоремы синуса и косинуса) между углами и сторонами треугольника, образованного тремя точками: пункт - центр кривизны меридиана - точка пересечения меридианного эллипса с радиусом-вектором пункта (рис. 3).

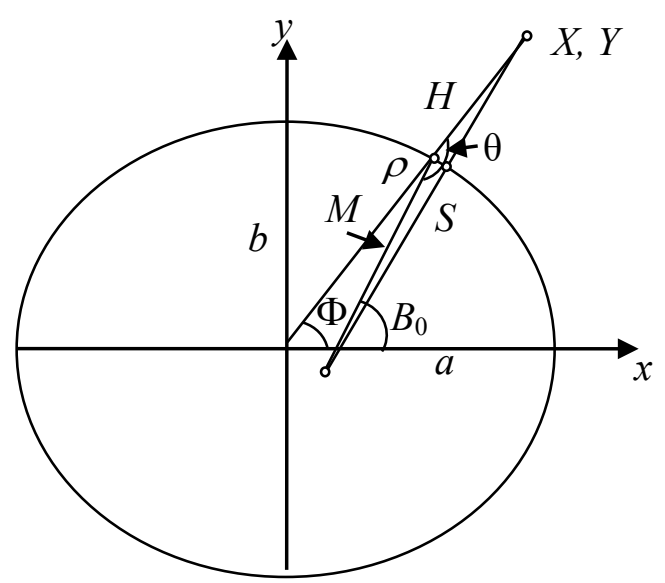

Рис. 3. Использование центра кривизны меридиана

Вначале вычисляется длина радиуса-вектора и геоцентрическая широта пункта и радиус вектор точки пересечения радиуса-вектора пункта с меридианным эллипсом по формулам

$$
\begin{gathered}
r=\sqrt{X^{2}+Y^{2}} \\
\Phi=\arccos \left(\frac{X}{r}\right) \\
\rho=\frac{a}{\sqrt{1+e^{\prime 2} \sin ^{2} \Phi}}
\end{gathered}
$$

затем определяются углы и стороны треугольника

$$
H_{0}=r-\rho
$$

$$
\begin{gathered}
B_{0}=\operatorname{arctg}\left(\frac{\operatorname{tg} \Phi}{1-e^{2}}\right) \\
\theta=\pi+\Phi-B_{0}
\end{gathered}
$$

$$
M=\frac{a\left(1-e^{2}\right)}{\left(1-e^{2} \sin ^{2} B_{0}\right)^{\frac{3}{2}}}
$$




$$
S=\sqrt{M^{2}+H_{0}^{2}-2 M H_{0}^{2} \cos \theta} .
$$

Высота с достаточной для практического применения точностью определяется из разности сторон треугольника

$$
H=S-M \text {. }
$$

С использованием теоремы синусов вычисляется поправка в широту, вычисленную по формуле (30), и приближенная широта $B_{1}$

$$
\begin{gathered}
\Delta B=\arcsin \left(\frac{H_{0}}{S} \sin \theta\right) ; \quad B_{1}=B_{0}+\Delta B . \\
S=\sqrt{M^{2}+H_{0}^{2}-2 M H_{0}^{2} \cos \theta} .
\end{gathered}
$$

Высота с достаточной для практического применения точностью определяется из разности сторон треугольника

$$
H=S-M \text {. }
$$

С использованием теоремы синусов вычисляется поправка в широту, вычисленную по формуле (30), и приближенная широта $B_{1}$

$$
\Delta B=\arcsin \left(\frac{H_{0}}{S} \sin \theta\right) ; \quad B_{1}=B_{0}+\Delta B
$$

Далее широта уточняется по стандартным формулам

$$
B=\arccos \left(\frac{X}{H+N}\right) .
$$

\section{Алгоритм 5}

Пятый алгоритм также основан на использовании координат центра кривизны меридиана $x_{c}, y_{c}$ (рис. 4).

Вычисление коэффициента уравнения нормали может быть найдено из соотношений

$$
U_{0}=\operatorname{arctg}\left(\frac{Y}{X \sqrt{1-e^{2}}}\right)
$$

$$
\begin{gathered}
x_{c}=a e^{2} \cos ^{3} U_{0} ; \\
y_{c}=-b e^{2} \sin ^{3} U_{0} ; \\
k=\frac{Y-y_{c}}{X-x_{c}} .
\end{gathered}
$$

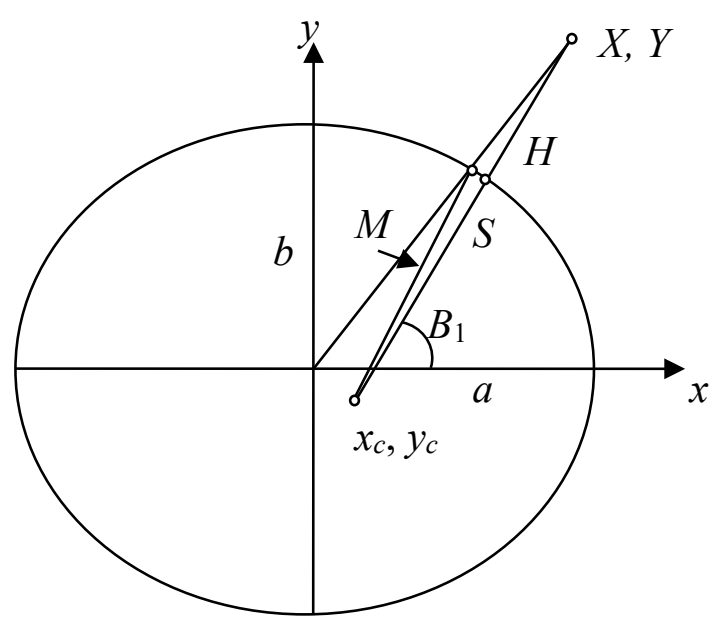

Рис. 4. Применение центра кривизны меридиана

Для определения точки пересечения нормали и меридианного эллипса с координатами необходимо решить систему двух уравнений (приближенное уравнение нормали (41) и точное уравнение меридианного эллипса (42)) с двумя неизвестными координатами $x$ и $y$

$$
\begin{gathered}
y=k x+\bar{b} \\
\frac{x^{2}}{a^{2}}+\frac{y^{2}}{b^{2}}=1,
\end{gathered}
$$

где $\bar{b}=y_{c}-k x_{c}$.

Подстановка уравнения (41) в уравнение (42) позволяет получить алгебраическое уравнение второй степени

$$
\bar{A} x^{2}+\bar{B} x+\bar{C}=0
$$

где $\bar{A}=b^{2}+a^{2} k^{2} ; \bar{B}=2 a^{2} k \bar{b} ; \bar{C}=a^{2} \bar{b}+a^{2} b^{2}$. 
Координаты точки пересечения нормали и меридианного эллипса могут быть найдены из решения алгебраического уравнения (43)

$$
\begin{aligned}
& x=\frac{-\bar{B}+\sqrt{\bar{B}^{2}-4 \bar{A} \bar{C}}}{2 \bar{A}} \\
& y=k x+\bar{b}
\end{aligned}
$$

По полученным координатам определяются геодезические высота $H$ и широта $B_{1}$

$$
\begin{aligned}
& H=\sqrt{\left(X^{2}-x^{2}\right)+(Y-y)^{2}} \\
& B_{1}=\operatorname{arctg}\left(\frac{Y-y}{X-x}\right)
\end{aligned}
$$

Найденную геодезическую широту рекомендуется уточнить по стандартным формулам

$$
B=\arccos \left(\frac{X}{H+N}\right) .
$$

\section{Результаты экспериментов}

Результаты экспериментов представлены в табл. 1-5. Как было упомянуто выше, точные значения прямоугольных координат пункта $X$ и $Y$ в системе координат меридианного эллипса были вычислены по заданной сетке широт и высот. В представленных ниже таблицах приведены результаты решения обратной задачи перехода от прямоугольных координат к геодезическим высотам и широтам.

Таблица 1

Расхождения вычисленных геодезических высот и широт с эталонными значениями для широты $B=15^{\circ}$

\begin{tabular}{|r|c|c|c|c|c|}
\hline \multirow{2}{*}{ H, км } & \multicolumn{5}{|c|}{$\Delta H$, мм $/ \Delta B^{\prime \prime} \cdot 10^{5}$} \\
\cline { 2 - 6 } & Алгоритм 1 & Алгоритм 2 & Алгоритм 3 & Алгоритм 4 & Алгоритм 5 \\
\hline \multirow{2}{*}{0} & $9 \cdot 10^{-7}$ & $9 \cdot 10^{-7}$ & 0 & 0 & $-5 \cdot 10^{-7}$ \\
& $-7 \cdot 10^{-6}$ & $2 \cdot 10^{-3}$ & $3 \cdot 10^{-6}$ & $-1 \cdot 10^{-6}$ & $-2 \cdot 10^{-5}$ \\
\hline 0 & 0 & 0 & 0 & $2 \cdot 10^{-6}$ & $-9 \cdot 10^{-7}$ \\
& $-2 \cdot 10^{-5}$ & $-7 \cdot 10^{-6}$ & 0 & $2 \cdot 10^{-5}$ & $-1 \cdot 10^{-5}$ \\
\hline 1 & $-9 \cdot 10^{-7}$ & $9 \cdot 10^{-7}$ & $-9 \cdot 10^{-7}$ & 0 & $-3 \cdot 10^{-7}$ \\
& $3 \cdot 10^{-6}$ & $2 \cdot 10^{-3}$ & $3 \cdot 10^{-6}$ & $8 \cdot 10^{-6}$ & $8 \cdot 10^{-6}$ \\
\hline 10 & $-9 \cdot 10^{-7}$ & $-9 \cdot 10^{-7}$ & $-9 \cdot 10^{-7}$ & 0 & $-3 \cdot 10^{-7}$ \\
& $-3 \cdot 10^{-6}$ & $2 \cdot 10^{-1}$ & $4 \cdot 10^{-4}$ & $-1 \cdot 10^{-6}$ & $-1 \cdot 10^{-6}$ \\
\hline 100 & 0 & $-9 \cdot 10^{-7}$ & 0 & 0 & $-3 \cdot 10^{-7}$ \\
& $1 \cdot 10^{-6}$ & $2 \cdot 10^{+1}$ & $3 \cdot 10^{-2}$ & $2 \cdot 10^{-4}$ & $2 \cdot 10^{-4}$ \\
\hline 1000 & $-9 \cdot 10^{-7}$ & $-3 \cdot 10^{-5}$ & 0 & $-6 \cdot 10^{-5}$ & $1 \cdot 10^{-7}$ \\
& $3 \cdot 10^{-6}$ & $2 \cdot 10^{+3}$ & 2 & $1 \cdot 10^{-2}$ & $1 \cdot 10^{-2}$ \\
\hline 10000 & 0 & $-3 \cdot 10^{-2}$ & 0 & $-6 \cdot 10^{-3}$ & 0 \\
& $-6 \cdot 10^{-5}$ & $4 \cdot 10^{+4}$ & $2 \cdot 10^{+1}$ & $2 \cdot 10^{-2}$ & $5 \cdot 10^{-2}$ \\
\hline 20000 & $4 \cdot 10^{-6}$ & $-1 \cdot 10^{-1}$ & 0 & $-1 \cdot 10^{-2}$ & $4 \cdot 10^{-6}$ \\
& $-6 \cdot 10^{-5}$ & $6 \cdot 10^{+4}$ & $2 \cdot 10^{+1}$ & $-1 \cdot 10^{-3}$ & $3 \cdot 10^{-2}$ \\
\hline
\end{tabular}


Расхождения вычисленных геодезических высот и широт с эталонными значениями для широты $B=30^{\circ}$

\begin{tabular}{|r|c|c|c|c|c|}
\hline \multirow{2}{*}{ H, км } & \multicolumn{5}{|c|}{$\Delta H$, мм $/ \Delta B^{\prime \prime} \cdot 10^{5}$} \\
\cline { 2 - 6 } & Алгоритм 1 & Алгоритм 2 & Алгоритм 3 & Алгоритм 4 & Алгоритм 5 \\
\hline-1 & $-9 \cdot 10^{-7}$ & 0 & 0 & $-9 \cdot 10^{-7}$ & $-1 \cdot 10^{-7}$ \\
& $-5 \cdot 10^{-6}$ & $3 \cdot 10^{-3}$ & $2 \cdot 10^{-5}$ & $-7 \cdot 10^{-6}$ & $2 \cdot 10^{-6}$ \\
\hline 0 & 0 & 0 & 0 & 0 & $-9 \cdot 10^{-7}$ \\
& $-8 \cdot 10^{-5}$ & $-2 \cdot 10^{-6}$ & 0 & $-2 \cdot 10^{-6}$ & $7 \cdot 10^{-6}$ \\
\hline 1 & 0 & $9 \cdot 10^{-7}$ & 0 & $-9 \cdot 10^{-7}$ & $1 \cdot 10^{-7}$ \\
& $-8 \cdot 10^{-5}$ & $3 \cdot 10^{-3}$ & $2 \cdot 10^{-5}$ & $-7 \cdot 10^{-6}$ & $-2 \cdot 10^{-6}$ \\
\hline 10 & 0 & 0 & 0 & 0 & $1 \cdot 10^{-6}$ \\
& $-7 \cdot 10^{-6}$ & $2 \cdot 10^{-1}$ & $2 \cdot 10^{-3}$ & $7 \cdot 10^{-6}$ & $1 \cdot 10^{-5}$ \\
\hline 100 & 0 & 0 & $9 \cdot 10^{-7}$ & 0 & $7 \cdot 10^{-7}$ \\
& $-5 \cdot 10^{-6}$ & $2 \cdot 10^{+1}$ & $2 \cdot 10^{-1}$ & $9 \cdot 10^{-4}$ & $9 \cdot 10^{-4}$ \\
\hline 1000 & 0 & $-3 \cdot 10^{-5}$ & 0 & $-6 \cdot 10^{-4}$ & $-2 \cdot 10^{-7}$ \\
& $5 \cdot 10^{-5}$ & $2 \cdot 10^{+3}$ & $1 \cdot 10^{+1}$ & $5 \cdot 10^{-2}$ & $5 \cdot 10^{-2}$ \\
\hline 10000 & $2 \cdot 10^{-6}$ & $-3 \cdot 10^{-2}$ & 0 & $-5 \cdot 10^{-2}$ & 0 \\
& $7 \cdot 10^{-5}$ & $4 \cdot 10^{+4}$ & $1 \cdot 10^{+2}$ & $1 \cdot 10^{-2}$ & $2 \cdot 10^{-1}$ \\
\hline 20000 & 0 & $-1 \cdot 10^{-1}$ & 0 & $-1 \cdot 10^{-1}$ & 0 \\
& $-2 \cdot 10^{-4}$ & $6 \cdot 10^{+4}$ & $1 \cdot 10^{+2}$ & $-6 \cdot 10^{-3}$ & $1 \cdot 10^{-1}$ \\
\hline
\end{tabular}

Таблица 3

Расхождения вычисленных геодезических высот и широт с эталонными значениями для широты $B=45^{\circ}$

\begin{tabular}{|r|c|c|c|c|c|}
\hline \multirow{2}{*}{ H, км } & \multicolumn{5}{|c|}{$\Delta H$, мм $/ \Delta B^{\prime \prime} \cdot 10^{5}$} \\
\cline { 2 - 6 } & Алгоритм 1 & Алгоритм 2 & Алгоритм 3 & Алгоритм 4 & Алгоритм 5 \\
\hline \multirow{2}{*}{0} & 0 & 0 & 0 & 0 & $2 \cdot 10^{-8}$ \\
& $-3 \cdot 10^{-1}$ & $7 \cdot 10^{-5}$ & $3 \cdot 10^{-5}$ & 0 & 0 \\
\hline & 0 & 0 & 0 & $9 \cdot 10^{-7}$ & 0 \\
\hline 1 & $-8 \cdot 10^{-2}$ & $2 \cdot 10^{-6}$ & 0 & $-2 \cdot 10^{-6}$ & 0 \\
\hline \multirow{2}{*}{10} & $-9 \cdot 10^{-7}$ & 0 & 0 & $9 \cdot 10^{-7}$ & $-7 \cdot 10^{-7}$ \\
& $-4 \cdot 10^{-1}$ & $7 \cdot 10^{-5}$ & $3 \cdot 10^{-5}$ & $5 \cdot 10^{-6}$ & $-2 \cdot 10^{-6}$ \\
\hline 100 & 0 & $9 \cdot 10^{-7}$ & 0 & $-9 \cdot 10^{-7}$ & $5 \cdot 10^{-7}$ \\
& $-2 \cdot 10^{-1}$ & $7 \cdot 10^{-3}$ & $3 \cdot 10^{-3}$ & $7 \cdot 10^{-6}$ & $1 \cdot 10^{-5}$ \\
\hline 1000 & 0 & 0 & $-9 \cdot 10^{-7}$ & $-2 \cdot 10^{-6}$ & $-3 \cdot 10^{-7}$ \\
& $2 \cdot 10^{-1}$ & $6 \cdot 10^{-1}$ & $3 \cdot 10^{-1}$ & $9 \cdot 10^{-4}$ & $9 \cdot 10^{-4}$ \\
\hline 10000 & $9 \cdot 10^{-7}$ & $9 \cdot 10^{-7}$ & $9 \cdot 10^{-7}$ & $-1 \cdot 10^{-3}$ & $2 \cdot 10^{-6}$ \\
& $8 \cdot 10^{-2}$ & $4 \cdot 10^{+1}$ & $2 \cdot 10^{+1}$ & $5 \cdot 10^{-2}$ & $5 \cdot 10^{-2}$ \\
\hline 20000 & 0 & $-4 \cdot 10^{-6}$ & $-2 \cdot 10^{-6}$ & $-1 \cdot 10^{-1}$ & $-2 \cdot 10^{-6}$ \\
& -3 & $3 \cdot 10^{+2}$ & $2 \cdot 10^{+2}$ & $1 \cdot 10^{-1}$ & $2 \cdot 10^{-1}$ \\
\hline & $4 \cdot 10^{-6}$ & 0 & 0 & $-2 \cdot 10^{-1}$ & $4 \cdot 10^{-6}$ \\
\end{tabular}


Расхождения вычисленных геодезических высот и широт с эталонными значениями для широты $B=60^{\circ}$

\begin{tabular}{|r|c|c|c|c|c|}
\hline \multirow{2}{*}{ H, км } & \multicolumn{5}{|c|}{$\Delta H$, мм $/ \Delta B^{\prime \prime} \cdot 10^{5}$} \\
\cline { 2 - 6 } & Алгоритм 1 & Алгоритм 2 & Алгоритм 3 & Алгоритм 4 & Алгоритм 5 \\
\hline \multirow{2}{*}{0} & 0 & 0 & 0 & $9 \cdot 10^{-7}$ & $-1 \cdot 10^{-7}$ \\
& $-3 \cdot 10^{-5}$ & $-2 \cdot 10^{-3}$ & $1 \cdot 10^{-5}$ & $-5 \cdot 10^{-6}$ & $-5 \cdot 10^{-6}$ \\
\hline \multirow{2}{*}{1} & $9 \cdot 10^{-7}$ & $9 \cdot 10^{-7}$ & $9 \cdot 10^{-7}$ & 0 & $1 \cdot 10^{-6}$ \\
& $-6 \cdot 10^{-5}$ & 0 & 0 & $-5 \cdot 10^{-6}$ & $-5 \cdot 10^{-6}$ \\
\hline & $9 \cdot 10^{-7}$ & 0 & $9 \cdot 10^{-7}$ & 0 & $1 \cdot 10^{-6}$ \\
& $9 \cdot 10^{-6}$ & $-2 \cdot 10^{-3}$ & $2 \cdot 10^{-5}$ & $-5 \cdot 10^{-6}$ & 0 \\
\hline 10 & $9 \cdot 10^{-7}$ & $2 \cdot 10^{-6}$ & $2 \cdot 10^{-6}$ & $9 \cdot 10^{-7}$ & $2 \cdot 10^{-6}$ \\
& $5 \cdot 10^{-6}$ & $-2 \cdot 10^{-1}$ & $2 \cdot 10^{-3}$ & 0 & $5 \cdot 10^{-6}$ \\
\hline 100 & $9 \cdot 10^{-7}$ & $9 \cdot 10^{-7}$ & $9 \cdot 10^{-7}$ & 0 & $9 \cdot 10^{-7}$ \\
& $-3 \cdot 10^{-5}$ & $2 \cdot 10^{+1}$ & $2 \cdot 10^{-1}$ & $3 \cdot 10^{-4}$ & $3 \cdot 10^{-4}$ \\
\hline 1000 & $9 \cdot 10^{-7}$ & $-3 \cdot 10^{-5}$ & 0 & $-6 \cdot 10^{-4}$ & $2 \cdot 10^{-6}$ \\
& $1 \cdot 10^{-5}$ & $-2 \cdot 10^{+3}$ & $1 \cdot 10^{+1}$ & $2 \cdot 10^{-2}$ & $2 \cdot 10^{-2}$ \\
\hline 10000 & 0 & $-3 \cdot 10^{-2}$ & 0 & $-5 \cdot 10^{-2}$ & 0 \\
& $3 \cdot 10^{-4}$ & $4 \cdot 10^{+4}$ & $1 \cdot 10^{+2}$ & $3 \cdot 10^{-2}$ & $7 \cdot 10^{-2}$ \\
\hline 20000 & $4 \cdot 10^{-6}$ & $-1 \cdot 10^{-1}$ & $7 \cdot 10^{-6}$ & $-1 \cdot 10^{-1}$ & 0 \\
& $-2 \cdot 10^{-4}$ & $-5 \cdot 10^{+4}$ & $1 \cdot 10^{+2}$ & $-2 \cdot 10^{-3}$ & $4 \cdot 10^{-2}$ \\
\hline
\end{tabular}

Таблица 5

Расхождения вычисленных геодезических высот и широт с эталонными значениями для широты $B=75^{\circ}$

\begin{tabular}{|c|c|c|c|c|c|}
\hline \multirow{2}{*}{$H$, км } & \multicolumn{5}{|c|}{$\Delta H$, мм $/ \Delta B^{\prime \prime} \cdot 10^{5}$} \\
\hline & Алгоритм 1 & Алгоритм 2 & Алгоритм 3 & Алгоритм 4 & Алгоритм 5 \\
\hline-1 & $\begin{array}{c}0 \\
5 \cdot 10^{-6}\end{array}$ & $\begin{array}{l}-9 \cdot 10^{-7} \\
-2 \cdot 10^{-3}\end{array}$ & $\begin{array}{c}0 \\
-5 \cdot 10^{-6}\end{array}$ & $\begin{array}{c}-9 \cdot 10^{-7} \\
0\end{array}$ & $\begin{array}{c}3 \cdot 10^{-7} \\
0\end{array}$ \\
\hline 0 & $\begin{array}{l}0 \\
0\end{array}$ & $\begin{array}{l}0 \\
0\end{array}$ & $\begin{array}{c}0 \\
-5 \cdot 10^{-6}\end{array}$ & $\begin{array}{c}9 \cdot 10^{-7} \\
0\end{array}$ & $\begin{array}{c}1 \cdot 10^{-6} \\
0\end{array}$ \\
\hline 1 & $\begin{array}{c}0 \\
-9 \cdot 10^{-6} \\
\end{array}$ & $\begin{array}{l}-9 \cdot 10^{-7} \\
-2 \cdot 10^{-3}\end{array}$ & $\begin{array}{l}9 \cdot 10^{-7} \\
5 \cdot 10^{-6}\end{array}$ & $\begin{array}{l}0 \\
0\end{array}$ & $\begin{array}{c}6 \cdot 10^{-7} \\
0\end{array}$ \\
\hline 10 & $\begin{array}{c}0 \\
-5 \cdot 10^{-6}\end{array}$ & $\begin{array}{c}0 \\
-2 \cdot 10^{-1}\end{array}$ & $\begin{array}{c}0 \\
4 \cdot 10^{-4}\end{array}$ & $\begin{array}{c}-9 \cdot 10^{-7} \\
0\end{array}$ & $\begin{array}{c}-4 \cdot 10^{-7} \\
0\end{array}$ \\
\hline 100 & $\begin{array}{c}9 \cdot 10^{-7} \\
-2 \cdot 10^{-5}\end{array}$ & $\begin{array}{c}9 \cdot 10^{-7} \\
-2 \cdot 10^{+1}\end{array}$ & $\begin{array}{c}0 \\
3 \cdot 10^{-2}\end{array}$ & $\begin{array}{r}-9 \cdot 10^{-7} \\
1 \cdot 10^{-5}\end{array}$ & $\begin{array}{l}4 \cdot 10^{-7} \\
1 \cdot 10^{-5}\end{array}$ \\
\hline 1000 & $\begin{array}{c}9 \cdot 10^{-7} \\
-4 \cdot 10^{-6}\end{array}$ & $\begin{array}{l}-3 \cdot 10^{-5} \\
-2 \cdot 10^{+3}\end{array}$ & $\begin{array}{l}0 \\
2\end{array}$ & $\begin{array}{r}-6 \cdot 10^{-5} \\
9 \cdot 10^{-4}\end{array}$ & $\begin{array}{r}-1 \cdot 10^{-7} \\
9 \cdot 10^{-4}\end{array}$ \\
\hline 10000 & $\begin{array}{l}-2 \cdot 10^{-6} \\
-9 \cdot 10^{-6}\end{array}$ & $\begin{array}{l}-3 \cdot 10^{-2} \\
-4 \cdot 10^{+4}\end{array}$ & $\begin{array}{l}2 \cdot 10^{-6} \\
2 \cdot 10^{+1}\end{array}$ & $\begin{array}{r}-6 \cdot 10^{-3} \\
1 \cdot 10^{-3}\end{array}$ & $\begin{array}{c}0 \\
4 \cdot 10^{-3}\end{array}$ \\
\hline 20000 & $\begin{array}{c}0 \\
-5 \cdot 10^{-5}\end{array}$ & $\begin{array}{l}-1 \cdot 10^{-1} \\
-6 \cdot 10^{+4}\end{array}$ & $\begin{array}{l}3 \cdot 10^{-6} \\
2 \cdot 10^{+1}\end{array}$ & $\begin{array}{l}-1 \cdot 10^{-2} \\
-8 \cdot 10^{-5}\end{array}$ & $\begin{array}{c}0 \\
2 \cdot 10^{-3}\end{array}$ \\
\hline
\end{tabular}


Из анализа представленных результатов вычислений по пяти алгоритмам преобразования прямоугольных координат пунктов в системе координат меридианного эллипса в геодезические широты и высоты (по критериям точности и простоте формул), можно сделать следующие выводы.

1. Если важным критерием является только погрешность вычисления, то точность алгоритмов 1, 4 и 5 является приемлемой для решения почти всех практических задач геодезии до высот 20000 км.

2. Если важно, чтобы алгоритм обладал приемлемой точностью до высот 20000 км и формулы имели простой вид, то таким алгоритмом является алгоритм 4.

3. Алгоритмы 2 и 3 имеют простые формулы, но пригодны только для высот, не превышающих 10 км.

\section{Заключение}

В статье рассмотрены пять алгоритмов преобразования прямоугольных координат точек, заданных в системе координат мери- дианного эллипса в геодезическую высоту и широту.

Самым строгим с точки зрения аналитической геометрии является алгоритм 1. Однако в нем требуется решить алгебраическое уравнение четвертого порядка по сложным формулам.

Алгоритм 2 также связан с уравнением четвертого порядка, но оно решается приближенным методом Ньютона, что повлияло на точность метода, и он оказался пригодным только для высот, не превышающих 10 км.

В основе алгоритмов 3, 4 и 5 лежит вычисление центра кривизны меридиана в точке пересечения радиуса-вектора заданной точки и меридианного эллипса.

Из формул алгоритма 3 выводится широко известная формула Боуринга. Результаты вычислений по алгоритму 3 и формуле Боуринга совпадают. Однако по алгоритму 3 грубо вычисляются широты для высот более 10 км. Тем не менее, использование координат центра кривизны меридиана приводит к простым алгоритмам 4 и 5, точность которых достаточна для решения почти всех задач геодезии до высот 20000 км.

\section{БИБЛИОГРАФИЧЕСКИЙ СПИСОК}

1. Афонин К. Ф. Высшая геодезия. Системы координат и преобразования между ними : учеб.-метод. пособие. - Новосибирск : СГГА, 2011. - 66 с.

2. Телеганов Н. А., Елагин А. В. Высшая геодезия и основы координатно-временных систем : учеб. пособие. - Новосибирск : СГГА, 2004. - 238 с.

3. Лапинг К. А. Вычисление координат и высот по измеренным азимутам нормальных сечений и углам наклона хорд на двух исходных пунктах // Геодезия и аэрофотосъемка. -1962 . - № $1 .-$ С. 3-8.

4. Медведев П.А. Определение широты точки способом решения алгебраического уравнения // Изв. вузов. Геодезия и аэрофотосъемка. - 1993. - № 4. - С. 66-72.

5. Медведев П. А. Исследования способов вычисления геодезической широты и высоты точек земной поверхности по прямоугольным координатам // Геодезия и аэрофотосъемка. - 2016. № 3. - С. 24-28.

6. Медведев П. А., Мазуров Б. Т. Алгоритмы непосредственного вычисления геодезиче-ской широты и геодезической высоты по прямоугольным координатам // Вестник СГУГиТ. - 2016. № 2 (34). - С. 5-13.

7. Медведев П. А., Кенжегузинова М. М. Вычисление геодезической высоты по прямоугольным пространственным координатам точек земной поверхности // Вестник Омского государственного аграрного университета. - 2016. - № 3 (23). - С. 146.

8. Медведев П. А. Математические модели преобразований пространственных координат // Геодезия и картография. - 2016. - № 3. - С. 2-7.

9. Медведев П. А., Новородская М. В., Шаров С. А. Неитеративный алгоритм вычисления геодезической широты по пространственным прямоугольным координатам // Вестник Омского государственного аграрного университета. - 2017. - № 2 (26). - С. 60-64.

10. Максимова М. В. Преобразования координат при инженерно-геодезических изысканиях // Инженерные изыскания. - 2013. - № 2. - С. 18-21. 
11. Алгоритм вычисления геодезической высоты по пространственным прямоугольным координатам / В. Н. Баландин, М. Я. Брынь, С. П. Имшенецкий, А. Ю. Матвеев, А. В. Юскевич // Геодезия и картография. - 2006. - № 6. - С. 15-16.

12. Курченко Л. А.,Таран В. В., Шлапак В. В. К вопросу о преобразовании геодезических прямоугольных координат в криволинейные // Геодезия и аэрофотосъемка. - 2016. - № 3. - С. 29-33.

13. Шануров Г. А., Манилова А. Д. О перевычислении пространственных декартовых координат в геодезические // Геодезия. - 2017. - № 1. - С. 13-17.

14. Шануров Г. А., Половнев О. В., Манилова А. Д. Преобразования пространственных координат при геодезическом обеспечении работы сканирующего комплекса // Геодезия и аэрофотосъемка. 2015. - № 1. - С. 15-18.

15. Огородова Л. В. Совместное вычисление геодезической широты и высоты точек поверхности Земли // Геодезия. - 2011. - № 9. - С. 11-15.

16. Гафиатулин Х. Г., Новоселов О. Г. Решения геодезической задачи обратного преобразования плоских прямоугольных и полярных координат, определяемых системой чисел из одной сети в другую посредством проекции условно вспомогательной системы координат // Интернет-журнал Науковедение. -2017 . - № 3. - С. 1-8.

17. Полещенков В.Н. Преобразование геоцентрических декартовых координат в геодезические // Геодезия и картография. - 2011. - №2. - С.15-19.

18. Bowring B. R. The accuracy of geodetic latitude and height equations // Survey Review. - 1985. Vol. 38. - P. 200-206.

19. Bowring B. R. Transformation from spatial to geodetic coordinates // Survey Review. - 1976. Vol. 23. - P. 323-327.

20. Vermeille H. Direct transformation from geocentric coordinates to geodetic coordinates // Journal of Geodesy. - 2002. - № 76. - P. 451-454.

21. Афонин К. Ф., Трифонова Ю. С. Определение геодезической широты по пространственным прямоугольным координатам путем использования дифференциальной поправки // Интерэкспо ГЕОСибирь. XV Междунар. науч. конгр., 24-26 апреля 2019 г., Новосибирск : сб. материалов в 9 т. Т. 1 : Междунар. науч. конф. «Геодезия, геоинформатика, картография, маркшейдерия». - Новосибирск : СГУГиТ, 2019. № 2. - С. 3-8.

22. Афонин К. Ф Использование дифференциальных поправок для вычисления геодезических широт по пространственным прямоугольным координатам координатам // Вестник СГУГиТ. - 2020. Вып. 1 (25). - С. 7-13.

23. Бронштейн И. Н., Семендяев К. А. Справочник по математике для инженеров и учащихся вузов. - 13-е изд., исправленное. - М. : Наука, 1986. - 544 с.

Получено 23.06.2021

(C) А. В. Елагин, Н. Н. Кобелева, 2021

\section{ALGORITHMS FOR CALCULATING GEODETIC HEIGHTS AND LATITUDES BY RECTANGULAR COORDINATES IN THE MERIDIAN ELLIPSE PLANE}

\section{Alexander $V$. Elagin}

Siberian State University of Geosystems and Technologies, 10, Plakhotnogo St., Novosibirsk, 630108, Russia, Ph. D., Associate Professor, Department of Space and Physical Geodesy, phone: (383)361-01-59, e-mail: kaf.astronomy@ssga.ru

\section{Natalia N. Kobeleva}

Siberian State University of Geosystems and Technologies, 10, Plakhotnogo St., Novosibirsk, 630108, Russia, Ph. D., Associate Professor, Department of Space and Physical Geodesy, phone: (383)361-01-59, e-mail:n.n.kobeleva@mail.ru

Owing to the widespread use of GNSS technologies in geodetic practice, the problem arises of transition from rectangular spatial coordinates of points to spatial geodetic coordinates, which are necessary for the transition to flat rectangular coordinates in the Gauss-Kruger projection. The authors proposed five algorithms for 
converting rectangular coordinates of points in the plane of the meridian ellipse into geodetic heights and latitudes. The first two algorithms are geometrically related to the intersection point of the ellipse with the normal passing through the point at which the rectangular spatial coordinates were obtained. The formulas of the other three algorithms are based on the geometric relationships of the point of intersection of the meridian ellipse with the straight line connecting the point with the center of curvature of the meridian. As a result of the experiments, deviations of the calculated latitudes and heights from the reference values of the given grid of geodetic coordinates were obtained. The formulas were tested not only for points under and on the earth's surface, but also outside the earth at different heights up to an altitude of $20,000 \mathrm{~km}$.

Keywords: meridian ellipse, geodesic heights and latitudes, rectangular coordinates of the meridian ellipse, normal, center of curvature of the meridian, algebraic equations of the fourth degree, radius vector

\section{REFERENCES}

1. Afonin, K. F. (2011). Vysshaya geodeziya. Sistemy koordinat i preobrazovaniya mezhdu nimi [Higher Surveying. Coordinate systems and transformations between them]. Novosibirsk: SSGA Publ., 66 p. [in Russian].

2. Teleganov, N. A., \& Elagin, A. V. (2004). Vysshaya geodeziya i osnovy koordinatno-vremennykh system [Higher geodesy and the basics of coordinate-time systems]. Novosibirsk: SSGA Publ., 238 p. [in Russian].

3. Laping, K. A. (1962). Calculation of coordinates and heights from the measured azimuths of normal sections and the angles of inclination of the chords at two starting points. Izvestiya vuzov. Geodeziya i aerofotos"emka [Izvestiya vuzov. Geodesy and Aerophotosurveying], 1, 3-8 [in Russian].

4. Medvedev, P. A. (1993). Determining the latitude of a point by solving an algebraic equationвнения Izvestiya vuzov. Geodeziya i aerofotos"emka [Izvestiya vuzov. Geodesy and Aerophotosurveying], 4, 66-72 [in Russian].

5. Medvedev, P. A. (2016). Research on methods for calculating the geodetic latitude and height of points on the earth's surface in rectangular coordinates. Izvestiya vuzov. Geodeziya i aerofotos"emka [Izvestiya vuzov. Geodesy and Aerophotosurveying], 3, 24-28 [in Russian].

6. Medvedev, P. A., \& Mazurov, B. T. (2016). Algorithms for the direct calculation of geo-desic latitude and geodesic height from rectangular coordinates. Vestnik SGUGiT [Vestnik SSUGT], 3(34), 5-13 [in Russian].

7. Medvedev P. A., \& Kenzheguzinova M. M. (2016). Calculation of the geodetic height from the rectangular spatial coordinates of the points on the earth's surface. Vestnik Omskogo gosudarstvennogo agrarnogo universiteta [Bulletin of the Omsk State Agrarian University], 3(23), p. 146.

8. Medvedev, P. A. (2016). Mathematical models of transformations of spatial coordinates. Geodeziya $i$ kartografiya [Geodesy and Cartography], 3, 2-7 [in Russian].

9. Medvedev, P. A., Novorodskaya, M. V., \& Sharov, S. A. (2017). Non-iterative algorithm for calculating geodetic latitude using spatial rectangular coordinates. Vestnik Omskogo gosudarstvennogo agrarnogo universiteta [Bulletin of the Omsk State Agrarian University], 2(26), 60-64.

10. Maksimova, M. V. (2013). Century Transformations of coordinates in engineering and geodetic surveys. Inzhenernye izyskaniya [Engineering Surveys], 2, 18-21 [in Russian].

11. Balandin, V. N., \& Bryn, M. Ya., Imshenetskiy, S. P., Matveev, A. Yu., \& Yuskevich, A. V. (2006). Algorithm for calculating the geodetic height from spatial rectangular coordinates. Geodeziya i kartografiya [Geodesy and Cartography], 6, 15-16 [in Russian].

12. Kurchenko, L. A., Taran, V. V., \& Shlapak, V. V. (2016). On the question of the trans-formation of geodesic rectangular coordinates into curved. Izvestiya vuzov. Geodeziya i aerofotos"emka [Izvestiya vuzov. Geodesy and Aerophotosurveying], 3, 29-33 [in Russian].

13. Shanurov G. A., Manilova A. D. (2017). On the recalculation of spatial Cartesian coordi-nates into geodesics. Izvestiya vuzov. Geodeziya i aerofotos"emka [Izvestiya vuzov. Geodesy and Aerophotosurveying], 1, 13-17 [in Russian].

14. Shanurov, G. A., Polovnev, O. V., \& Manilova, A. D. (2015). Transformations of spatial coordinates during geodetic support of the scanning complex. Izvestiya vuzov. Geodeziya i aerofotos"emka [Izvestiya vuzov. Geodesy and Aerophotosurveying], 1, 15-18 [in Russian].

15. Ogorodova, L. V. (2011). Joint calculation of the geodetic latitude and height of points on the surface of the earth. Izvestiya vuzov. Geodeziya i aerofotos"emka [Izvestiya vuzov. Geodesy and Aerophotosurveying], 9, 11-15 [in Russian]. 
16. Gafiatulin, Kh. G., \& Novoselov, O. G. (2017). Solutions of the geodesic problem of the inverse transformation of plane rectangular and polar coordinates, determined by a system of num-bers from one network to another through the projection of a conditionally auxiliary coordinate sys-tem. Internet-zhurnal Naukovedenie [Internet Journal of Science], 3, 1-8 [in Russian].

17. Poleshenkov, V. N. (2011). Converting geocentric cartesian coordinates to geodetic coordinates. Geodeziya i kartografiya [Geodesy and Cartography], 2, 15-19 [in Russian].

18. Bowring, B. R. (1985). The accuracy of geodetic latitude and height equations. Survey Review, 38, 200-206.

19. Bowring, B. R. (1976). Transformation from spatial to geodetic coordinates. Survey Review, 23, $323-327$.

20. Vermeille H. (2002). Direct transformation from geocentric coordinates to geodetic coordinates. Journal of Geodesy, 76, 451-454.

21. Afonin, K. F., \& Trifonova, Yu. S. (2019). Determination of geodetic latitude by spatial rectangular coordinates using differential correction. In Sbornik materialov Interekspo GEO-Sibir'-2019: Mezhdunarodnoy nauchnoy konferentsii: T. 1, No. 2. Geodeziya, geoinformatika, kartografiya i marksheyderiya [Proceedings of Interexpo GEO-Siberia-2019: International Scientific Conference: Vol. 1, No. 2. Surveying, Geoinformatics, Cartography and Mine Surveying] (pp. 3-8). Novosibirsk: SSUGT Publ. [in Russian].

22. Afonin, K. F. (2020). Using differential corrections to calculate geodetic latitudes from spatial rectangular coordinates. Vestnik SGUGiT [Vestnik SSUGT], 25(1), 7-13 [in Russian].

23. Bronshtein, I. N., \& Semendyaev, K. A. (1986). Spravochnik po matematike dlja inzhenerov $i$ uchashhihsja vuzov [A guide to mathematics for engineers and college students] (13th ed.). Moscow: Nauka Publ., 544 p. [in Russian].

Received 23.06.2021

(C) A. V. Elagin, N. N. Kobeleva, 2021 
УДК [551.2/.3:553.2]+528(470.324)

DOI: $10.33764 / 2411-1759-2021-26-5-17-26$

\section{ОЦЕНКА ГЕОДИНАМИЧЕСКОЙ СИТУАЦИИ ВОРОНЕЖСКОГО КРИСТАЛЛИЧЕСКОГО МАССИВА ПО ГЕОДЕЗИЧЕСКИМ ДАННЫМ}

\section{Борис Тимофеевич Мазуров}

Сибирский государственный университет геосистем и технологий, 630108, Россия, г. Новосибирск, ул. Плахотного, 10 , доктор технических наук, профессор кафедры космической и физической геодезии, тел. (383)343-29-11, e-mail: btmazurov@mail.ru

\section{Андрей Алексеевич Панжин}

Институт горного дела Уральского отделения РАН, 620075, Россия, г. Екатеринбург, ул. Мамина-Сибиряка, 58, кандидат технических наук, ученый секретарь, тел (343)350-44-76, e-mail: panzhin@igduran.ru

\section{Динара Амалбековна Абжапарова}

Ошский государственный университет, 714000, Киргизия, г. Ош, ул. Ленина, 331, кандидат технических наук, доцент, тел. (996-03-222)5-46-65, e-mail: ada23121970@yandex.ru

Повторные геодезические измерения позволяют оценить такие геодезические элементы, как координаты, высоты, направления, а также представить дискретно поле векторов смещения геодезических пунктов. Полученные векторы позволяют согласно принятой модели определять напряженно-деформированное состояние земной поверхности. Есть обоснованное мнение о значительном присутствии в геодинамических процессах вращательных (вихревых) движений. Показано использование соответствующих алгоритмов для территории Воронежского кристаллического массива. Отдельно возможно вычислять дифференциальные характеристики векторного поля, называемые дивергенцией (div) и ротором (вихрь, rot, curl). В статье предлагается определять поле ротора по дискретным геодезическим наблюдениям векторов смещений на поверхности изучаемой территории. Важнейшим продолжением данной исследовательской работы является методика математического моделирования геодинамических систем в прогнозных целях. Для исследования сложных (нелинейных) геодинамических процессов должна быть выбрана соответствующая математическая основа. Здесь обращено внимание на привлечение математических основ теории поля. Для оценки характеристик векторных полей при использовании повторных геодезических измерений может быть использован метод конечных элементов. Разбиение изучаемой территории на треугольники позволяет определять характеристики деформирования после вычисления элементов тензора деформации. В том числе, находится значение угловой скорости разворота треугольника относительно его центра тяжести. Далее легко вычислить значение ротора. Приведенный в статье пример реальных геодезических наблюдений на Воронежском кристаллическом массиве подтверждает возможность прогноза места готовящегося сейсмического события землетрясения.

Ключевые слова: векторное поле, геодезические данные, геодинамические полигоны, метод конечных элементов, крайгинг, ротор

\section{Введение}

Геодезические методы общепризнаны в связи с эффективностью количественной оценки движений земной поверхности, как плановых, так и высотных [1]. Отметим, что решение геодинамических задач нетривиально ввиду сложности самоорганизующейся природной системы, которой является Земля и ее приповерхностный слой [2]. Классические способы измерения до сих пор применяются и иногда является единственно возможными. В случаях наблюдаемых территорий регионального и глобального масштаба наиболее эффективными являются ГНСС-технологии [3, 4], особенно для плановых измерений. Высокоточное определение отметок до сих пор выполняется более точно высокоточным геометрическим нивелированием [5]. Комплексный мониторинг перечисленными выше методами выполняется также на территориях, 
испытывающих техногенное влияние, в местах разработки полезных ископаемых, на крупных инженерных комплексах, в экологически опасных регионах и др. [4, 6, 7].

Оценка геодинамической ситуации территории предполагает математическую обработку геодезических измерений и ее интерпретацию. Существует множество результатов научных исследований на эту тему. В любом случае главным итогом изучения конкретного объекта является возможность прогноза. Собственно, это важнейшая цель любого мониторинга.

\section{Исходные данные и методика}

Здесь рассмотрены возможности использования оценки вихревых поверхностных движений $[8,9]$ и построения поля ротора [10]. Ротор наряду с дивергенцией [6] является дифференциальной характеристикой векторного поля движений. Эти методы обладают новизной и направлены на качественное исследование движений на плоскости [11]. Для иллюстрации этих методов оценки геодинамической ситуации использованы результаты мониторинга по ГНСС-технологии. Это юг Урала - Воронежский кристаллический массив (ВКМ) (рис. 1). Мониторинг выпол- нялся постоянно действующими ГНСС-станциями.

Также на исследуемом участке зафиксирован эпицентр сейсмического события, отнесенного к природным землетрясениям. Магнитуда землетрясения, произошедшего 31.03.2000, составила 3.9, глубина очага - 10 километров. По последствиям землетрясения такой магнитуды не представляют серьезной опасности, но они, являясь динамической реализацией предшествующих деформационных процессов, в определенной мере характеризуют современную геодинамическую активность района.

Всего на исследуемой территории, на площади размерами $200 \times 300$ км расположено 18 пунктов GNSS, которые производят накопление данных, что позволяет выполнить их высокоточную геодезическую привязку к общемировой сети IGS в режиме цикловых мониторинговых измерений. Вопрос возможности исследования современных геодинамических движений с использованием данных деформационного мониторинга, проводимых постоянно действующими станциями Global Navigation Satellite System (GNSS, ГНCC), неоднократно рассматривался в связи с исследованием современной геодинамики Уральского региона, вызванной как естественными, так и техногенными факторами [7].

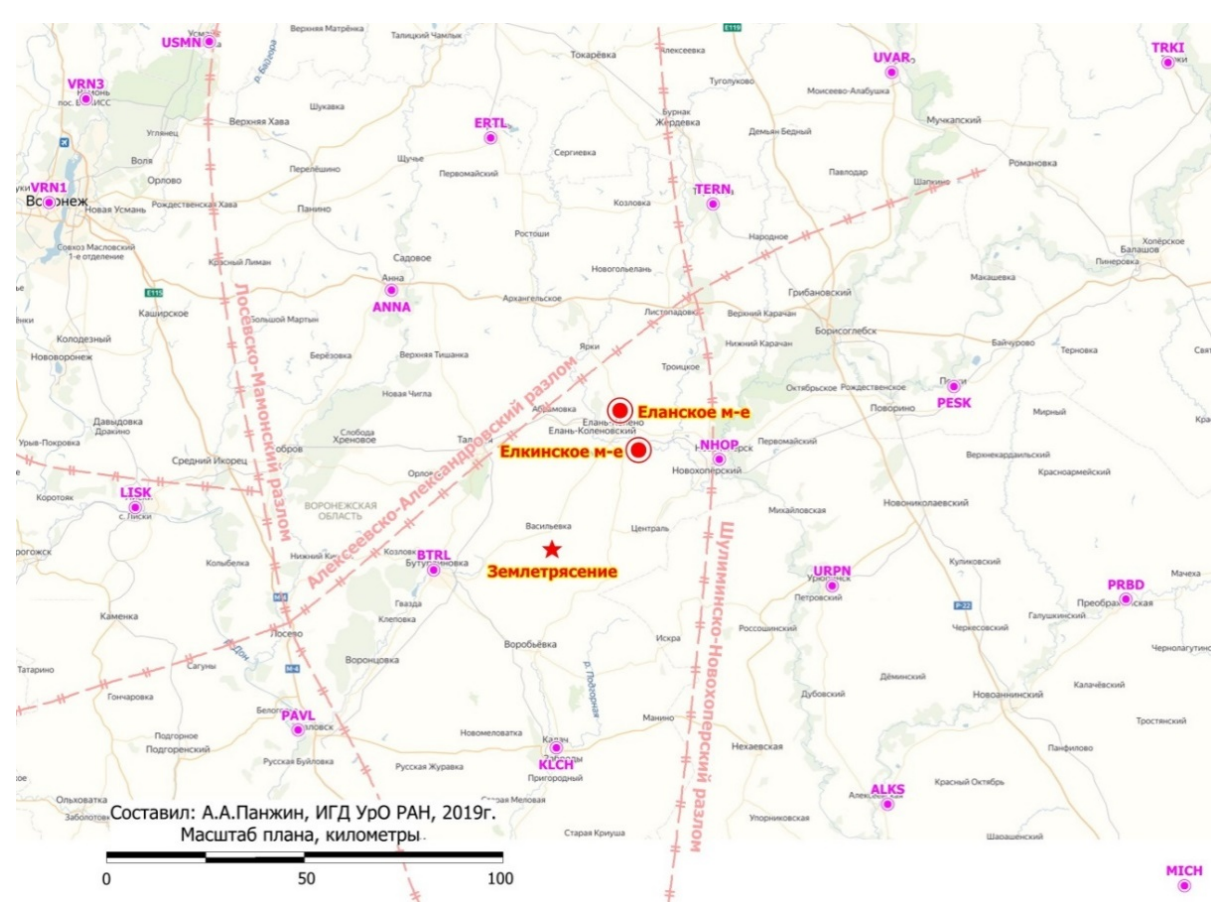

Рис. 1. Ситуационная карта расположения станций GNSS, по которым определялись современные геодинамические движения 
Цикловые координаты станций GNSS, участвующих в геодинамическом мониторинге, определялись из трех серий суточных измерений. Сырые исходные данные в виде суточных RINEX с дискретностью накопления 30 секунд были предоставлены российским компаниями, поддерживающими в районе ВКС сети постоянно действующих геодезических станций. В качестве исходных, в каждой серии, использовались 12-15 станций IGS, пространственные координаты которых и скорости сдвижений в различных системах отсчета периодически переопределяются с целью поддержки научных исследований в области изучения Земли. Обработка ГНСС-измерений производилась относительно сети геодезических станций, расположенных на территории России, Украины и Турции, с использованием онлайнсервиса AUSPOS. Погрешность определения координат мониторинговых пунктов в горизон- тальной плоскости, по результатам камеральной обработки, составляет, в 95-процентном доверительном интервале, 3-4 мм для каждой серии суточных наблюдений.

Годовые скорости векторов трендовых движений пунктов были определены на основе анализа изменений их пространственных приращений координат $\Delta X, \Delta Y, \Delta Z$, происшедших в промежутках между повторными циклами измерений (таблице), и представлены на рис. 2. Направления и величины векторов достаточно однородны, что отражает общее преимущественно восточное трендовое направление литосферной плиты, включающей ВКМ.

Как видно из таблицы, на исследуемом участке, на фоне трендовой составляющей, также отмечается неоднородность скоростей геодинамических движений в горизонтальной и вертикальной плоскостях.

Геодинамические движения пунктов GNSS за период наблюдений 20.03.2019-09.10.2019 (203 суток)

\begin{tabular}{|c|c|c|c|c|c|c|c|}
\hline \multirow{2}{*}{ Станция GNSS } & \multicolumn{2}{|c|}{ Координаты станции } & \multicolumn{5}{|c|}{ Геодинамические движения, мм/год } \\
\hline & В (широта) & L (долгота) & $\Delta \mathbf{B}$ & $\Delta \mathbf{L}$ & $\Delta \mathrm{H}$ & 2D & $3 \mathrm{D}$ \\
\hline PESK & $51^{\circ} 15^{\prime} 13^{\prime \prime}$ & $42^{\circ} 27^{\prime} 25^{\prime \prime}$ & 11.3 & 27.8 & 21.0 & 30.0 & 36.6 \\
\hline NHOP & $51^{\circ} 05^{\prime} 28^{\prime \prime}$ & $41^{\circ} 36^{\prime} 24^{\prime \prime}$ & 3.7 & 39.0 & 23.9 & 39.2 & 45.9 \\
\hline TERN & $51^{\circ} 41^{\prime} 07^{\prime \prime}$ & $41^{\circ} 35^{\prime} 34^{\prime \prime}$ & 6.8 & 34.1 & 4.9 & 34.8 & 35.1 \\
\hline MIHA & $50^{\circ} 04^{\prime} 49^{\prime \prime}$ & $43^{\circ} 13^{\prime} 53^{\prime \prime}$ & 8.3 & 30.0 & 4.2 & 31.1 & 31.4 \\
\hline PAVL & $50^{\circ} 27^{\prime} 39^{\prime \prime}$ & $40^{\circ} 05^{\prime} 55^{\prime \prime}$ & 4.1 & 34.6 & 5.4 & 34.9 & 35.3 \\
\hline VRN3 & $51^{\circ} 55^{\prime} 07^{\prime \prime}$ & $39^{\circ} 17^{\prime} 45^{\prime \prime}$ & 6.5 & 37.8 & -1.2 & 38.3 & 38.3 \\
\hline ALKS & $50^{\circ} 17^{\prime} 06^{\prime \prime}$ & $42^{\circ} 11^{\prime 2} 21^{\prime \prime}$ & 7.4 & 38.7 & 12.5 & 39.4 & 41.3 \\
\hline ANNA & $51^{\circ} 29^{\prime} 07^{\prime \prime}$ & $40^{\circ} 25^{\prime} 21^{\prime \prime}$ & 14.1 & 32.2 & 15.0 & 35.1 & 38.2 \\
\hline BTRL & $50^{\circ} 50^{\prime} 09^{\prime \prime}$ & $40^{\circ} 34^{\prime} 41^{\prime \prime}$ & 14.8 & 42.2 & 5.4 & 44.8 & 45.1 \\
\hline ERTL & $51^{\circ} 50^{\prime} 24^{\prime \prime}$ & $40^{\circ} 46^{\prime} 53^{\prime \prime}$ & 5.2 & 34.8 & 3.6 & 35.2 & 35.4 \\
\hline KLCH & $50^{\circ} 25^{\prime} 22^{\prime \prime}$ & $41^{\circ} 01^{\prime} 00^{\prime \prime}$ & 9.3 & 35.0 & 5.4 & 36.2 & 36.6 \\
\hline LISK & $50^{\circ} 58^{\prime} 21^{\prime \prime}$ & $39^{\circ} 30^{\prime} 22^{\prime \prime}$ & 7.8 & 35.8 & -2.4 & 36.6 & 36.7 \\
\hline PRBD & $50^{\circ} 44^{\prime} 56^{\prime \prime}$ & $43^{\circ} 03^{\prime} 21^{\prime \prime}$ & 6.3 & 40.9 & 0.6 & 41.4 & 41.4 \\
\hline TRKI & $51^{\circ} 59^{\prime} 33^{\prime \prime}$ & $43^{\circ} 16^{\prime} 19^{\prime \prime}$ & 5.6 & 41.2 & 6.0 & 41.5 & 42.0 \\
\hline URPN & $50^{\circ} 47^{\prime} 42^{\prime \prime}$ & $42^{\circ} 00^{\prime} 22^{\prime \prime}$ & 6.1 & 29.9 & hurr & 30.5 & hurr \\
\hline USMN & $52^{\circ} 03^{\prime} 29^{\prime \prime}$ & $39^{\circ} 44^{\prime} 43^{\prime \prime}$ & 7.8 & 35.8 & 3.0 & 36.6 & 36.7 \\
\hline UVAR & $51^{\circ} 59^{\prime} 10^{\prime \prime}$ & $42^{\circ} 15^{\prime} 22^{\prime \prime}$ & 6.5 & 36.7 & 13.3 & 37.2 & 39.5 \\
\hline VRN1 & $51^{\circ} 40^{\prime} 36^{\prime \prime}$ & $39^{\circ} 10^{\prime} 13^{\prime \prime}$ & 8.7 & 39.5 & 7.8 & 40.5 & 41.2 \\
\hline
\end{tabular}

Как видно из таблицы, на исследуемом участке, на фоне трендовой составляющей, также отмечается неоднородность скоростей геодинамических движений в горизонтальной и вертикальной плоскостях. 


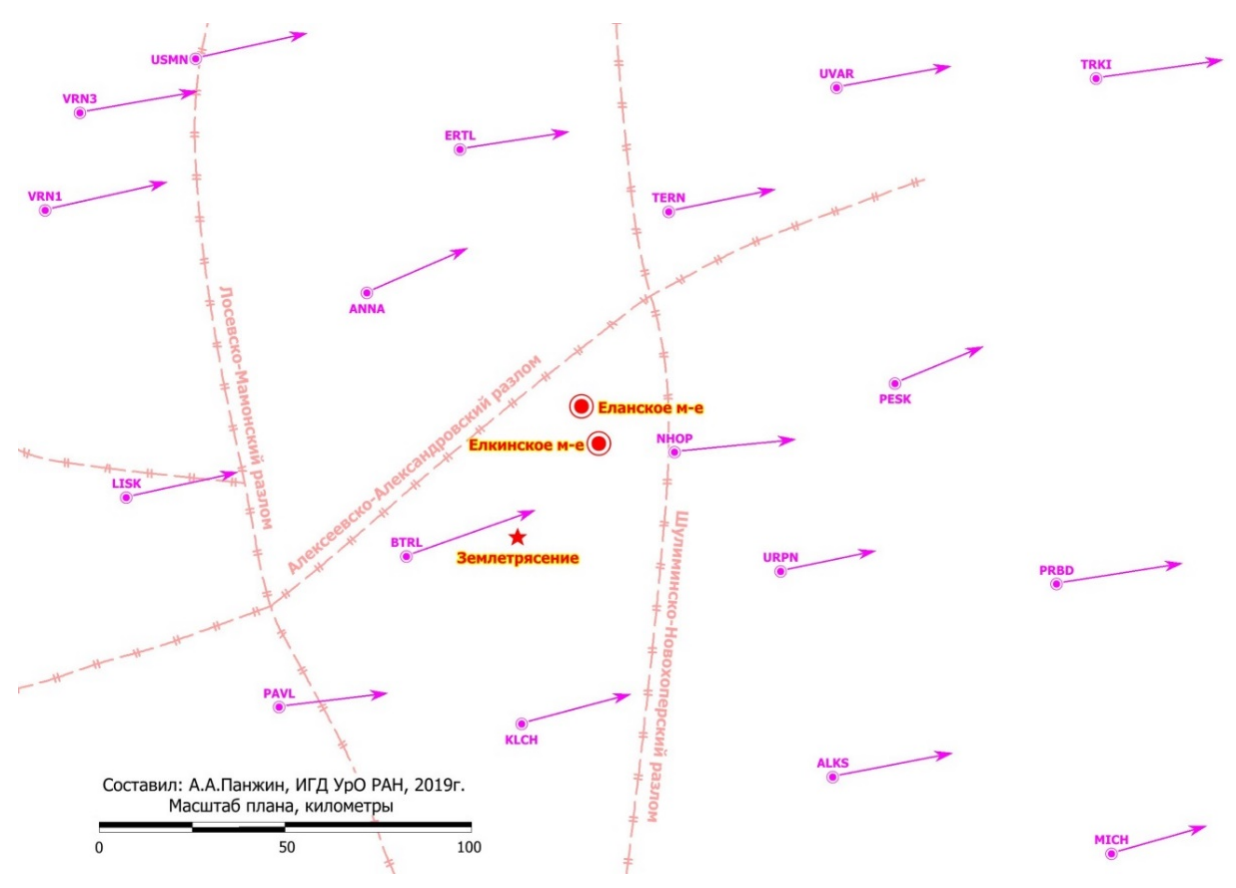

Рис. 2. Векторы трендовых горизонтальных современных геодинамических движений

\section{Результатьи}

Определено и графически построено освобожденное от трендовой составляющей поле векторов геодинамических движений исследуемой территории ВКМ, в котором визуально определяются вихревые сдвижения (рис. 3). Важность визуализации вихревых (ротационных) геодинамических движений $[8,9]$ объясняется тем, что границы вихрей формируются по границам крупных подвижных структурных нарушений, что позволяет идентифицировать активные тектонические структуры района.

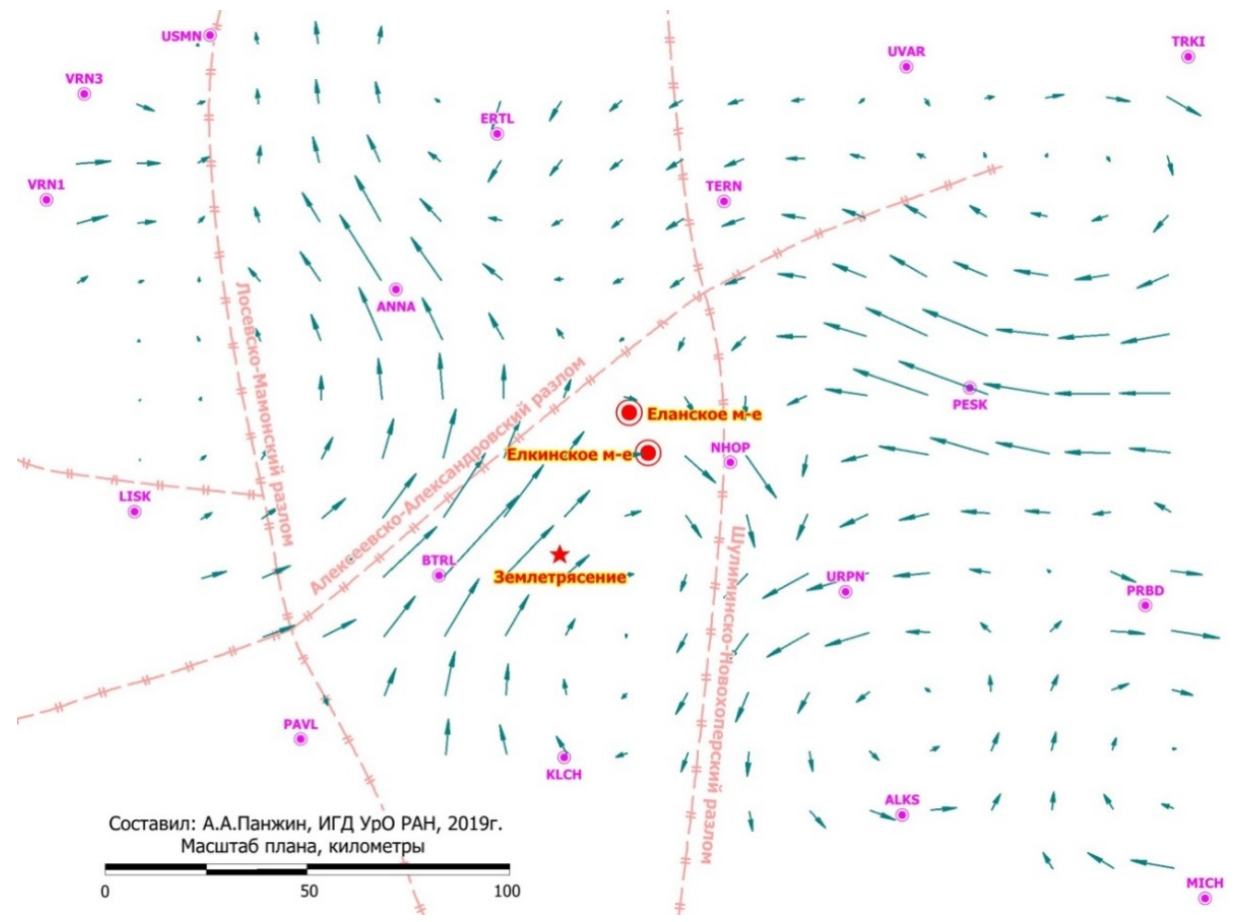

Рис. 3. Вихревые движения на исследуемой территории 
Важной характеристикой векторного поля геодинамических движений является дивергенция, которая характеризует степень сходимости или расходимости векторного потока, знание закономерностей распределения ее характеристик позволяет идентифицировать источники формирования и стока деформационных процессов и определить их пространственное положение. Разработан и алгоритмически реализуется математический аппарат [6], позволяющий определять дивергенцию по результатам исходных данных [12], представленных как в виде равномерной Крайгинг-модели [13], так и в виде данных, представленных в вершинах единичных элементов триангуляции Делоне.

Теоретические и практические результаты исследования векторных полей основаны на теории дифференциальных уравнений [14-17]. Некоторые достижения ученых в математической теории поля $[14,15]$ могут быть использованы не только для описания течений в жидкостях и газах, но и для изучения потоков вещества в мантии и ядре Земли. Существуют обоснованные теоретически алгоритмы при исследовании деформаций в сильно текущих горных породах осадочного покрова и в массах пород, испытывающих региональный метаморфизм в глубине земной коры. Сложнейшие деформации слоев в гнейсах развивались при значительном протекании масс, закономерности которых можно понять, лишь опираясь на математическую теорию потоков в жидкостях. Эта же теория вполне применима и для познания роли магматических расплавов в развитии тектонических процессов, а также может быть использована для изучения современных смещений крупных деформированных массивов приповерхностных структур земной коры.

В статье [6] предложен алгоритм определения одной из дифференциальных характеристик точек векторных полей - дивергенции (div). Алгоритм определения связан с фактом возможности периодических дискретных геодезических наблюдений векторов смещений на поверхности изучаемой территории. Необходимое для дальнейших вычислений векторное поле восстанавливается аппроксимацией полиномиальными моделями с неизбежной, но не критичной, методической погрешностью. Коэффициенты полиномов вычисля- ются по упомянутым выше дискретным геодезическим измерениям приращений координат пунктов, распределенных на территории изучаемого объекта. Полученные уравнения векторного поля позволяют вычислять векторы смещений в любой точке территории, формировать векторные трубки малого объема и вычислять дивергенцию [6].

Второй дифференциальной характеристикой при рассмотрении циркуляции векторного поля является ротор (вихрь, rot, curl).

В качестве интуитивного образа ротора можно использовать представление о вращении брошенной в поток маленькой пылинки (увлекаемой потоком с собой, без его заметного возмущения) или о вращении помещенного в поток с закрепленной осью маленького (без инерции, вращаемого потоком, заметно не искажая его) колеса с прямыми (не винтовыми) лопастями. Если то или другое при взгляде на него вращается против часовой стрелки, то это означает, что вектор ротора поля скорости потока в данной точке имеет положительную проекцию в направлении на нас.

Для физической интерпретации вспомним теорему Коши - Гельмгольца, согласно которой распределение скоростей сплошной среды вблизи точки $O$ задается уравнением

$$
v(r)=v_{O}+\omega r+\nabla \varphi+o(r),
$$

где $₫$ - вектор углового вращения элемента среды в точке $O ; \varphi$ - квадратичная форма от координат - потенциал деформации элемента среды.

Таким образом, движение сплошной среды вблизи точки $O$ складывается из поступательного движения (вектор $v_{O}$ ), вращательного движения (вектор $\omega r$ ) и потенциального движения - деформации (вектор $\nabla \varphi$ ). Применяя к формуле Коши - Гельмгольца операцию ротора, получим, что в точке $O$ справедливо равенство rot $=2 @$ и, следовательно, можно заключить, что когда речь идет о векторном поле, являющемся полем скоростей некоторой среды, ротор этого векторного поля в заданной точке равен удвоенному вектору углового вращения элемента среды с центром в этой точке.

Если некоторая территория исследуется в геодинамическом отношении, очень важную информацию о движениях земной поверхности дают геодезические методы. Рассмотрим 
возможность восстановления поля ротора векторного поля по результатам повторных геодезических наблюдений на примере Воронежского кристаллического массива.

В геодинамических исследованиях часто актуальны вопросы изучения вращательных, вихревых движений $[8,9]$. Основой нашего ана- лиза данных о горизонтальных смещениях являлись метод конечных элементов и современные компьютерные программы визуализации поверхности, в частности Surfer. Вся территория разбивается на конечные элементы - треугольники [12], вершины которых являются пунктами наблюдательной сети (рис. 4).

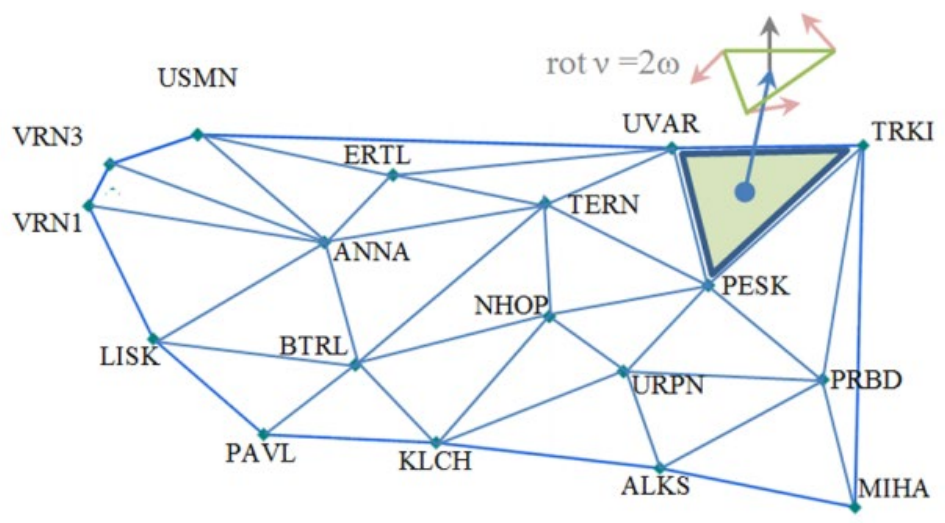

Рис. 4. Разбиение территории на конечные элементы

В контексте нашей задачи для каждого треугольника по координатам вершин и их смещениям вычисляется инвариантная характеристика - угловая скорость Ф. Для геометрического центра треугольника значение ротора определяется по упомянутой выше формуле $\operatorname{rot}=2 \curvearrowleft$. По полученным значениям путем интерполяции может быть построена цифровая модель поля ротора векторного поля. Для этого может быть использован, например, метод крайгинга (Krige) [13].

При вычислении использовались формулы для оценки параметров модели локально-однородной деформации для плоскости. В вычислении для ротора каждого треугольного конечного элемента исходными данными были плоские координаты $x$, $y$ и величины смещений вершин треугольника $u_{x}, u_{y}$

$$
\left.\begin{array}{l}
u_{x_{i}}=e_{10}+e_{11} x_{i}+e_{12} y_{i} ; \\
u_{y_{i}}=e_{20}+e_{21} x_{i}+e_{22} y_{i} \\
u_{x_{j}}=e_{10}+e_{11} x_{j}+e_{12} y_{j} \\
u_{y_{j}}=e_{20}+e_{21} x_{j}+e_{22} y_{j} \\
u_{x_{k}}=e_{10}+e_{11} x_{k}+e_{12} y_{k} \\
u_{y_{k}}=e_{20}+e_{21} x_{k}+e_{22} y_{k}
\end{array}\right\}
$$

Система (1) состоит из шести линейных уравнений с шестью неизвестными - коэффициентами линейной модели перемещений:

$$
\begin{aligned}
& e=\left[\begin{array}{llllll}
e_{10} & e_{11} & e_{12} & e_{20} & e_{21} & e_{22}
\end{array}\right]^{T} . \\
& e_{11}=\frac{\left(u_{x_{1}}-u_{x_{2}}\right)\left(y_{1}-y_{3}\right)-\left(u_{x_{1}}-u_{x_{3}}\right)\left(y_{1}-y_{2}\right)}{\left(x_{1}-x_{2}\right)\left(y_{1}-y_{3}\right)-\left(x_{1}-x_{3}\right)\left(y_{1}-y_{2}\right)} ; \\
& e_{12}=\frac{\left(u_{x_{1}}-u_{x_{2}}\right)\left(x_{1}-x_{3}\right)-\left(u_{x_{1}}-u_{x_{3}}\right)\left(x_{1}-x_{2}\right)}{\left(y_{1}-y_{2}\right)\left(x_{1}-x_{3}\right)-\left(y_{1}-y_{3}\right)\left(x_{1}-x_{2}\right)} \text {; } \\
& e_{21}=\frac{\left(u_{y_{1}}-u_{y_{2}}\right)\left(y_{1}-y_{3}\right)-\left(u_{y_{1}}-u_{y_{3}}\right)\left(y_{1}-y_{2}\right)}{\left(x_{1}-x_{2}\right)\left(y_{1}-y_{3}\right)-\left(x_{1}-x_{3}\right)\left(y_{1}-y_{2}\right)} \text {; } \\
& e_{22}=\frac{\left(u_{y_{1}}-u_{y_{2}}\right)\left(x_{1}-x_{3}\right)-\left(u_{y_{1}}-u_{y_{3}}\right)\left(x_{1}-x_{2}\right)}{\left(y_{1}-y_{2}\right)\left(x_{1}-x_{3}\right)-\left(y_{1}-y_{3}\right)\left(x_{1}-x_{2}\right)} \text {. } \\
& \left.\begin{array}{l}
e_{10}=u_{x_{1}}-e_{11} x_{1}-e_{12} y_{1} \\
e_{20}=u_{y_{1}}-e_{21} x_{1}-e_{22} y_{1}
\end{array}\right\}
\end{aligned}
$$

Инвариантные (независящие от начала системы координат и ориентации ее осей) свойства конечного элемента отражают четыре коэффициента (2). Они обычно записываются в виде квадратной матрицы - тензора деформации 


$$
T=\left(\begin{array}{ll}
e_{11} & e_{12} \\
e_{21} & e_{22}
\end{array}\right) .
$$

В тензоре $T$ выделяется симметричная часть $T_{\varepsilon}$, отражающая чистую деформацию конечного элемента, и кососимметричная часть $T_{\omega}$, отражающая вращение конечного элемента как абсолютно твердого тела

$$
\begin{gathered}
T=T_{\varepsilon}+T_{\omega} ; \\
T_{\varepsilon}=\left(\begin{array}{cc}
e_{11} & \frac{e_{12}+e_{21}}{2} \\
\frac{e_{21}+e_{12}}{2} & e_{22}
\end{array}\right) ; \\
T_{\omega}=\left(\begin{array}{cc}
0 & \frac{e_{12}-e_{21}}{2} \\
\frac{e_{21}-e_{12}}{2} & 0
\end{array}\right) .
\end{gathered}
$$

Разворот треугольного конечного элемента вычисляется как

$$
\omega=\frac{e_{12}-e_{21}}{2} ; \omega^{\prime \prime}=\rho^{\prime \prime} \omega
$$

Для жесткого плоского тела умножение $\omega$ на 2 дает значение ротора и его направление (плюс - вверх; минус - вниз от площадки).

Результаты определения поля роторов каждого конечного элемента и интерполяция на всю территорию исследуемого Воронежского кристаллического массива представлены на рис. 5, 6.

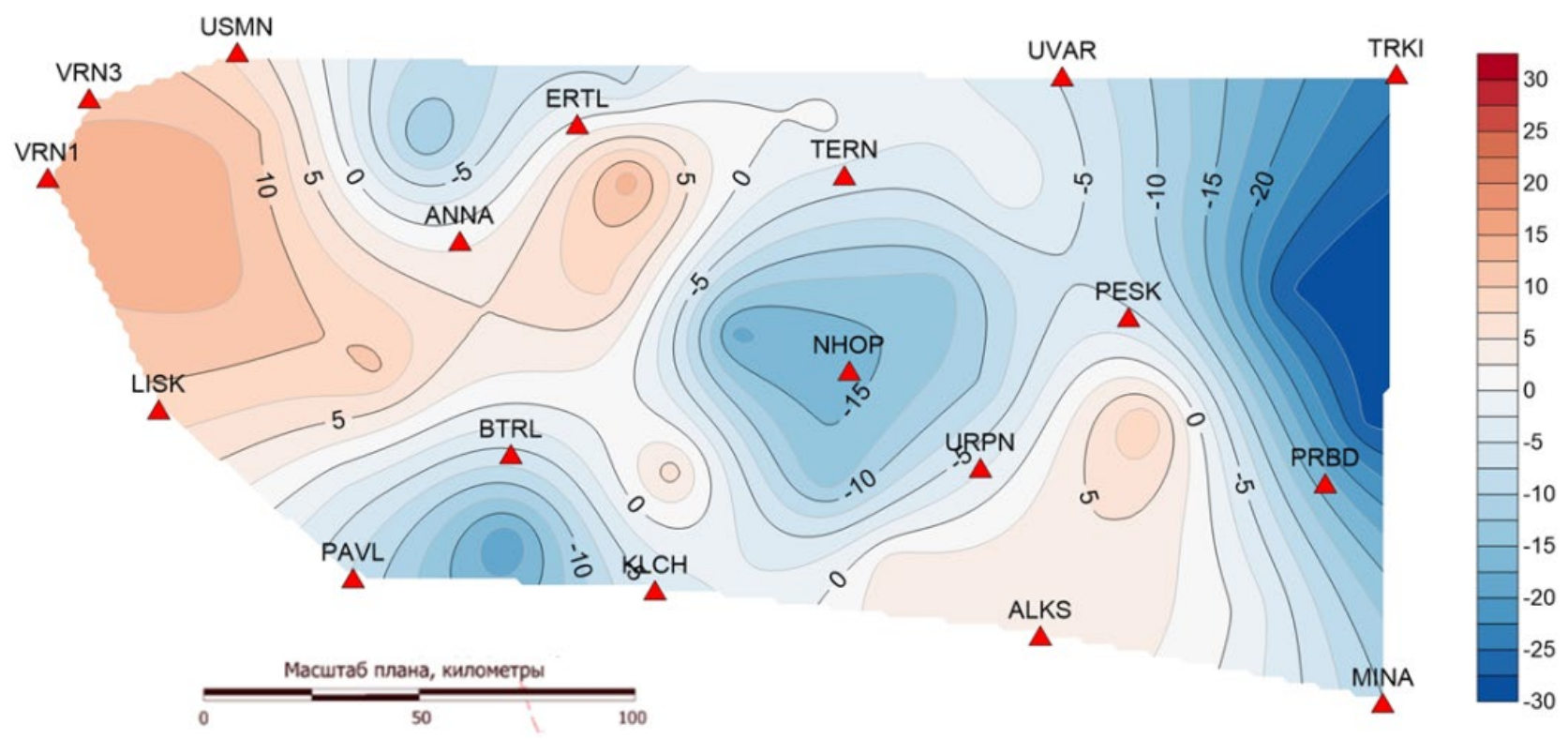

Рис. 5. Поле ротора поверхностных движений в изолиниях 


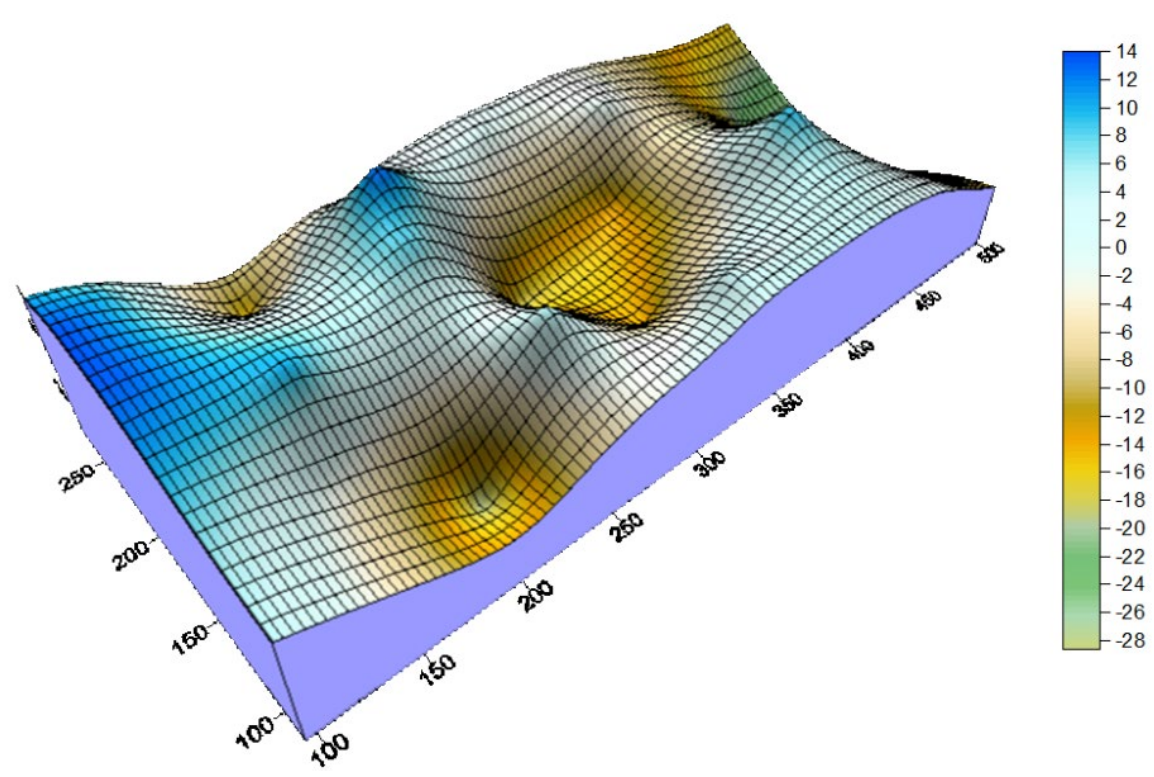

Рис. 6. Поле ротора поверхностных движений в ЗД-представлении

Возвышенности поверхности соответствуют положительному знаку (направление ротора вверх), впадины - отрицательному знаку (направление ротора вниз).

\section{Заключение}

Определение такого свойства поля роторов с достаточной уверенностью говорит о возможности нахождения одного из важнейших предвестников готовящихся землетрясений, а именно - его места. Заметим, что этот результат совпадает с выводами в работе [7]. И он в очередной раз подтверждает значимость геодезического метода, ГНСС-определений в вопросе решения проблемы современных движений земной коры и прогноза землетрясений.

Благодарности: авторы выражают глубокую признательность коллективам компаний: Эффективные технологии EFT (www.eftgroup.ru), HIVE (www.hive.geosystems.aero), Геoстройизыскания ГСИ (www.gsi.ru), АО «ПРИН» (www.prin.ru) за предоставленные исходные данные и содействие при выполнении исследований.

\section{БИБЛИОГРАФИЧЕСКИЙ СПИСОК}

1. Мазуров Б. Т., Кафтан В. И. Обзор развития геодинамики и геодезических методов решения геодинамических задач // Геодезия и картография. - 2020. - Т. 81, № 2. - С. 25-39.

2. Мазуров Б. Т. Геодинамические системы (теоретические основы качественного исследования горизонтальных движений) // Вестник СГУГиТ. - 2016. - Вып. 1 (33). - С. 26-35.

3. Уткин В. И., Белоусова А. А., Тягунов Д. С., Баландин Д. В. Исследование геодинамики Северного и Среднего Урала по данным GPS // Доклады Академии наук. - 2010. - Т. 431, № 2. - С. 246-251.

4. Кузьмин Ю. О. Идентификация результатов повторных геодезических наблюдений при оценке геодинамической опасности объектов недропользования // Вестник СГУГиТ. - 2018. - Т. 23, № 4. C. $46-64$.

5. Дорогова И. Е., Кобелева Н. Н. Исследование и моделирование движений земной коры в окрестностях действующего вулкана по результатам повторного высокоточного нивелирования // Вестник СГУГиТ. - 2020. - Т. 25, № 1. - С. 16-27

6. Мазуров Б. Т., Мустафин М. Г., Панжин А. А. Метод оценки дивергенции векторных полей деформаций земной поверхности при разработке месторождений полезных ископаемых // Записки Горного института. - 2019. - Т. 238, № 4. - С. 376-382. 
7. Панжин А. А. Экспериментальные исследования и визуализация современных тектонических движений восточной части Воронежского кристаллического массива // Вестник Воронежского государственного университета. Серия: Геология. - 2020. - № 4. - С. 4-11.

8. Викулин А. В. Ротационные волны в блоковых вращающихся средах (на примере геологической среды) // Процессы в геосредах. - 2016. - № 7. - С. 194-206.

9. Викулин А. В. Мир вихрей. - Петропавловск-Камчатский : КамчатГТУ, 2008. - 230 с.

10. Мазуров Б. Т. Алгоритм оценки ротора векторных полей движений земной поверхности по геодезическим данным // Геодезия и картография. - 2019. - Т. 80, № 7. - С. 51-56.

11. Баутин Н. Н, Леонтович Е. А. Методы и приемы качественного исследования динамических систем на плоскости. - М. : Наука, 1990. - 486 с.

12. Маркович К. И. Влияние конфигурации конечных элементов на точность определения компонентов деформации // Вестник СГУГиТ. - 2019. - Т. 24, № 3. - С. 37-51.

13. Krige D. G. A statistical approach to some mine valuations and allied problems at the Witwatersrand : Master's thesis. - South Africa: University of Witwaterstand, 1951.

14. Гзовский М. В. Математика в геотектонике. - М. : Недра, 1971. - 240 с.

15. Гольдфайн И. А. Векторный анализ и теория поля. - М. : Наука, Главная редакция физико-математической литературы, 1968. - 128 с.

16. Derrick W. R., Grossman S. I. Elementary differential equations with applications. - 2nd. ed. - Reading. Mass.: Addison-Wesley, 1981. -532 p.

17. Spiegel M. R. Applied differential equatons. - Englewood Cliffs, N.J.: Prentice-Hall, 1981. - 654 p.

Получено 19.04.2021

(C) Б. Т. Мазуров, А. А. Панжин, Д. А. Абжапарова, 2021

\section{ASSESSMENT OF THE GEODYNAMIC SITUATION OF THE VORONEZH CRYSTALLINE MASSIF FROM GEODETIC DATA}

\section{Boris T. Mazurov}

Siberian State University of Geosystems and Technologies, 10, Plakhotnogo St., Novosibirsk, 630108, Russia, D. Sc., Professor, Department of Space and Physical Geodesy, phone: (383)343-29-11, e-mail: btmazurov@mail.ru

\section{Andrey A. Panzhin}

Institute of Mining of the Ural Branch of the Russian Academy Sciences (IM UB RAS), 58, Mamin-Sibiriak St., Ekaterinburg, 620075, Russia, Ph. D., Scientific Secretary, phone: (343)350-44-76, e-mail: panzhin@igduran.ru

\section{Dinara A. Abzhaparova}

Osh State University, 331, Lenin St., Osh, 714000, Kyrgyzstan, Ph. D., Associate Professor, phone: (996-03-222)5-46-65, e-mail: ada23121970@yandex.ru

Repeated geodetic measurements allow you to evaluate such geodetic elements as coordinates, heights, and directions. And also represent discretely the field of displacement vectors of geodesic points. The obtained vectors allow us to determine the stress-strain state of the earth's surface according to the accepted model. There is a reasonable opinion about the significant presence of rotational (vortex) movements in geodynamic processes. Here, the corresponding algorithms are used for the territory of the Voronezh Crystal massif. Separately, it is possible to calculate the differential characteristics of the vector field, called divergence (div) and rotor (vortex, rot, curl). The article proposes to determine the rotor field from discrete geodetic observations of displacement vectors on the surface of the studied territory. The most important continuation of this research work is the method of mathematical modeling of geodynamic systems for predictive purposes. For the study of complex (nonlinear) geodynamic processes, an appropriate mathematical basis should be chosen. Here, attention is drawn to the involvement of the mathematical foundations of field theory. To evaluate the characteristics of vector fields when using repeated geodetic measurements, the method of finite elements can be used. Dividing the territory under study into triangles allows us to determine the deformation characteristics after calculating the elements of the strain tensor. In particular, the value of the angular velocity of the triangle rotation relative to its center of gravity is found. Next, it is easy to calculate the value of the rotor. The example 
given in the article of real geodetic observations on the Voronezh crystal massif confirms the possibility of predicting the location of an upcoming seismic event - an earthquake.

Keywords: Vector field, geodesic data, geodynamic polygons, finite element method, kriging, rotor

\section{REFERENCES}

1. Mazurov, B. T., \& Kaftan, V. I. (2020). Review of the development of geodynamics and geodetic methods for solving geodynamic problems. Geodeziya i kartografiya [Geodesy and Cartography], 81(2), 25-39 [in Russian].

2. Mazurov, B. T. (2016). Geodynamic systems (theoretical foundations of the qualitative study of horizontal movements). Vestnik SGUGiT [Vestnik SSUGT], 1(33), 26-35 [in Russian].

3. Utkin, V. I., Belousova, A. A., Tyagunov, D. S., \& Balandin, D. V. (2010). A study of the geodynamics of the Northern and Middle Urals according to GPS data. Doklady Akademii nauk [Reports of the Academy of Sciences], 431(2), 246-251 [in Russian].

4. Kuzmin, $\mathrm{Yu}$. O. (2018). Identification of the results of repeated geodetic observations when assessing the geodynamic hazard of subsoil use objects. Vestnik SGUGiT [Vestnik SSUGT], 23(4), 46-64 [in Russian].

5. Dorogova, I. E, \& Kobeleva, N. N. (2020). Research and modeling of movements of the earth's crust in the vicinity of an active volcano based on the results of repeated high-precision leveling. Vestnik SGUGiT [Vestnik SSUGT], 25(1), 16-27 [in Russian].

6. Mazurov, B. T., Mustafin, M. G., \& Panzhin, A. A. (2019). A method for assessing the divergence of vector fields of deformations of the earth's surface in the development of mineral deposits. Zapiski Gornogo instituta [Notes of the Mining Institute], 238(4), 376-382 [in Russian].

7. Panzhin, A. A. (2020). Experimental studies and visualization of modern tectonic movements in the eastern part of the Voronezh crystalline massif. Vestnik Voronezhskogo gosudarstvennogo universiteta. Seriya: Geologiya [Voronezh State University Bulletin. Series: Geology], 4, 4-11 [in Russian].

8. Vikulin, A. V. (2016). Rotational waves in block rotating media (for example, geological environment). Protsessy v geosredakh [Processes in Geomedia], 7, 194-206.

9. Vikulin, A. V. (2008). Mir vihrej [A world of whirlwinds]. Petropavlovsk-Kamchatsky: Kamchatka State Technical University Publ. 230 p. [in Russian].

10. Mazurov, B. T. (2019). Algorithm for evaluating the rotor of vector fields of movements of the earth's surface according to geodesic data. Geodeziya i kartografiya [Geodesy and Cartography], 80(7), 51-56 [in Russian]

11. Bautin, N. N., \& Leontovich, E. A. (1990). Metody i priemy kachestvennogo issledovaniya dinamicheskih sistem na ploskosti [Methods and techniques for the qualitative study of dynamical systems on a plane]. Moscow: Nauka Publ., 486 p. [in Russian]

12. Markovich, K. I. (2019). Influence of the configuration of finite elements on the accuracy of determining the components of deformation. Vestnik SGUGiT [Vestnik SSUGT], 24(3), 37-51 [in Russian].

13. Krige, D. G. (1951). A statistical approach to some mine valuations and allied problems at the Witwatersrand. Master's thesis. South Africa: University of Witwaterstand.

14. Gzovskiy, M. V. (1971). Matematika v geotektonike [Mathematics in geotectonics]. Moscow: Nedra Publ., 240 p. [in Russian]

15. Gol'dfajn, I. A. (1968). Vektornyj analiz i teoriya polya [Vector analysis and field theory]. Moscow: Nauka, Glavnaya redakciya fiziko-matematicheskoj literatury Publ, 128 p. [ in Russian].

16. Derrick, W. R., \& Grossman, S. I. (1981). Elementary differential equations with applications. (2nd. ed.). Reading. Mass.: Addison-Wesley, 532 p.

17. Spiegel, M. R. (1981). Applied differential equatons. Englewood Cliffs, N. J.: Prentice-Hall, 654 p.

Received 19.04.2021

(C) B. T. Mazurov, A. A. Panzhin, D. A. Abzhaparova, 2021 
УДК 528.236

DOI: $10.33764 / 2411-1759-2021-26-5-27-39$

\section{ПРЕОБРАЗОВАНИЯ ПРОСТРАНСТВЕННЫХ ДАННЫХ В ГОСУДАРСТВЕННУЮ ГЕОДЕЗИЧЕСКУЮ СИСТЕМУ КООРДИНАТ 2011 ГОДА В ПО ГИС}

\section{Владимир Иванович Обиденко}

Сибирский государственный университет геосистем и технологий, 630108, Россия, г. Новосибирск, ул. Плахотного, 10, кандидат технических наук, проректор по СПО - директор НТГиК, e-mail: ovi62@yandex.ru

\section{Сергей Романович Горобцов}

Сибирский государственный университет геосистем и технологий, 630108, Россия, г. Новосибирск, ул. Плахотного, 10, кандидат технических наук, доцент кафедры инженерной геодезии и маркшейдерского дела, e-mail: sergey@gorobtsov.com

В статье описаны процедуры осуществления координатных преобразований в ПО ГИС (на примepe MapInfo Professional) между существующими в нашей стране системами координат (СК-42, СК-95, МСК, созданные на их основе) и ГСК-2011, позволяющие самостоятельно научиться вычислять параметры преобразования Гельмерта между этими системами координат с использованием ГОСТ 32453-2017. Отмечается проблема точности преобразования по глобальным параметрам, установленным ГОСТ 32453-2017, и вызванная этим необходимость определения локальных версий этих параметров, приводящая к созданию несогласованных наборов пространственных данных в ГСК-2011, дополнительных затрат и усложнению работы потребителей. С целью решения данной проблемы предлагается рассматривать постановку задачи перехода к выполнению кадастровых работ от систем координат, основанных на СК-42, к МСК, созданных на ГСК-2011, как актуальную проблему совершенствования геодезического обеспечения страны.

Ключевые слова: государственная геодезическая система координат 2011 года, ГСК-2011, программное обеспечение геоинформационных систем, ПО ГИС, пространственные данные, системы координат, координатные преобразования, датум

\section{Введение}

С 01.01.2021 геодезическая система координат 2011 года (ГСК-2011) является единственной государственной системой координат, в которой, в соответствии с постановлением Правительства [1], выполняются геодезические и картографические работы. Очевидно, что главной целью отмены ранее действовавших систем координат 1942 года (СК42) [2], 1995 года (СК-95) [3] и введения государственной системы координат ГСК-2011 является создание в Российской Федерации единого высокоточного однородного координатного пространства и обеспечение совместимости всех пространственных данных, создаваемых на территории страны.

Однако, к сожалению, установление ГСК2011 только создает необходимые предпосылки для создания в стране согласованных в необходимой для всех сфер деятельности сте- пенью точности пространственных данных. Достижение целей установления ГСК-2011 гарантированно обеспечивается только решением следующих основных задач ее введения в действие: построение соответствующего уровня точности, однородности (гомогенности) и плотности координатной основы ГСК2011; разработка точных методик преобразования в ГСК-2011 пространственных данных, ранее созданных в СК-42, СК-95 и местных системах координат, сформированных на их основе; создание местных систем координат, базирующихся на ГСК-2011; методическое и технологическое сопровождение процесса перехода на выполнение работ в ГСК-2011 со стороны регулятора геопространственной отрасли.

Проблемам геодезического обеспечения нашей страны в части создания координатной основы государственной системы координат, созданию местных систем координат и их ка- 
чества посвящено множество публикаций российских ученых [4-14]. Целью настоящей работы является исследование некоторых из вышеуказанных проблем практического применения ГСК-2011, сдерживающих процесс построения единого высокоточного гомогенного координатного пространства на территории страны и создания пространственных данных, согласованных в необходимой степени точности.

\section{Проблемы применения ГСК-2011 в ПО ГИС}

С января 2021 г. в СГУГиТ, имеющий широкие партнерские связи с предприятиями реального сектора экономики, стали активно обращаться представители производственных компаний нефтегазового сектора с просьбой помочь в решении методических вопросов и практических задач выполнения работ в ГСК-2011, в том числе преобразования пространственных данных между СК-42, СК-95, местными системами координат, созданными на их основе и ГСК-2011 с использованием различного программного обеспечения геоинформационных систем (ПО ГИС).

Проблемы в данной сфере деятельности возникли в связи с тем, что с января 2021 г., когда выполнение работ в СК42/СК-95 стало невозможным, появились сложности сдачи документов (по горным отводам, оформлению лицензионных участков и т. д.) в контрольно-разрешительные и надзорные органы (Министерство природных ресурсов, Ростехнадзор, Роснедра и т. д.). Даже при том, что обе стороны процесса для работы с пространственными данными (каталоги координат, карты, схемы и т. д.) использовали последние версии идентичного программного обеспечения (в нижеприведенных случаях это было ПО MapInfo Professional версии 19), поддерживающие работу в ГСК-2011, имели место случаи существенного (до десятков метров) несовпадения координат объектов в ГСК-2011 у сдающей и принимающей инстанции.

По тем случаям, в которых СГУГиТ был привлечен в качестве арбитра для разрешения технологических проблем, стало очевидным, что первопричиной их возникновения стала слабая информированность практикующего геодезического сообщества о произошедших кардинальных изменениях в геодезическом обеспечении страны, вызванных введением ГСК-2011.

Тот факт, что в ГСК-2011 используется собственный набор исходных геодезических дат (свой эллипсоид ГСК-2011 с его параметрами и ориентировкой в пространстве - в терминологии ПО ГИС это «датум»), требует от пользователей четкого понимания того, что для СК-42 и СК-95 также имеются собственные (не совпадающие с ГСК-2011) датумы. И взаимные преобразования между системами координат СК-42, СК-95, производных от них МСК и ГСК-2011 возможны только при условии корректного задания и правильного использования в этих преобразованиях таких датумов.

То, что все системы координат, применявшиеся в Российской Федерации до ввода ГСК2011 (СК-42, СК-95, МСК на их основе), были привязаны к единой поверхности относимости (эллипсоиду Красовского), избавляло пользователей от необходимости задания датумов в ПО ГИС для этих СК. В таких случаях в ПО ГИС задавались только параметры проекции с поверхности эллипсоида Красовского на плоскость в проекции (в большинстве случаев это проекция Гаусса-Крюгера). Например, в ПО ГИС MapInfo Professional это была привычная всем проекция «Гаусса - Крюгера (Пулково 1942)», корректно реализовывавшая этот алгоритм преобразования с эллипсоида Красовского на плоскость проекции ГауссаКрюгера во всех тех случаях, когда не требовалось преобразований в другую СК, имеющую собственный датум. И если такая необходимость теперь, с появлением ГСК-2011, возникла, то нужно четко осознавать, что датум традиционно использовавшейся в нашей стране системы координат «Проекция "Гаусса - Крюгера (Пулково 1942)”» для здания СК42/CК-95 в ПО MapInfo фактически определяет параметры ориентировки эллипсоида Красовского относительно эллипсоида WGS84 (не относительно эллипсоида ГСК-2011) на территории Германии (а не на территории России). Таким образом присвоение в ПО MapInfo 
карте, созданной в СК-42 (СК-95), этой проекции с дальнейшей попыткой преобразовать ее в ГСК-2011 по параметрам ГОСТ 32453-2017 [15] (используя имеющуюся в стандартной поставке ПО MapInfo, поддерживающей ГСК2011, СК «Проекции Гаусса - Крюгера (ГСК2011 ГОСТ 32453-2017)») приведет к отрицательному результату, который будет отличаться от истинного на несколько десятков метров.

Для правильного преобразования из СК42/СК-95 в ГСК-2011 нужно корректно выбирать исходную СК, которые в версиях ПО MapInfo, поддерживающих ГСК-2011, именуются соответственно «Проекции Гаусса Крюгера (Пулково 1942 ГОСТ 32453-2017)», «Проекции Гаусса-Крюгера (Пулково 1995 ГОСТ 32453-2017)». При этом проекции для CK-95 в стандартной поставке ПО MapInfo отсутствуют, и пользователь должен уметь их сформировать самостоятельно.

Приведенный пример методических неточностей в применении систем координат в ПО ГИС, поддерживающих возможность преобразования в ГСК-2011, показывает, что в геодезическом сообществе еще только формируется менталитет работы с привычными системами координат (СК-42, СК-95, МСК на их основе) в их новом, пространственном формате. Этот формат требует даже для местной системы координат корректное задание датума, правильное определение референцной системы координат в соответствующем ПО ГИС (в ПО MapInfo это CK WGS-84) и исходя из этого - точного задания значений семипараметрического преобразования Гельмерта от исходной СК к референцной СК.

\section{Задание в ПО ГИС ГСК-2011 с помощью глобальных датумов}

Для корректного осуществления координатных преобразований важно понимать, как в конкретном ПО ГИС реализован переход от исходной (например, СК-42) к целевой (например, ГСК-2011) системе координат. Так в некоторых ПО ГИС и САПР (например, в MapInfo, Civil 3D) отсутствует возможность осуществить требуемое пользователю преобразование координат между исходной и целевой СК напрямую. Эта процедура в таких ПО ГИС может быть реализована только через промежуточную (референцную) СК, в качестве которой обычно выступает CK WGS-84, рис. 1.

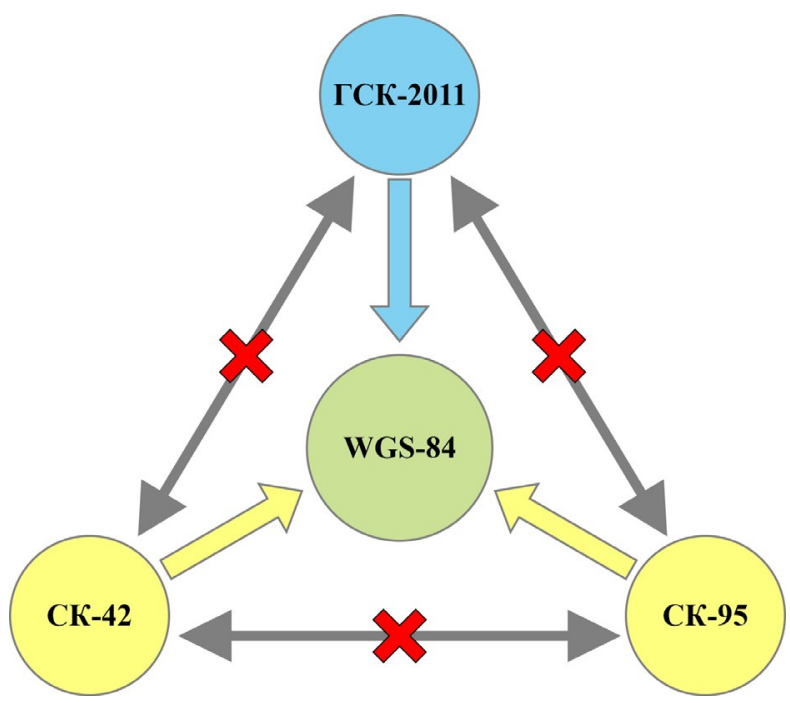

Рис. 1. Схема координатных преобразований между СК в ПО ГИС MapInfo Professional

При этом в ПО ГИС критически важно, чтобы параметры Гельмерта в датуме задавали преобразование строго в определенном направлении по отношению к референцной СК (в ПО MapInfo, Civil 3D это направление к CK WGS-84, см. рис. 1). И это правило касается как исходной, так и целевой системы координат. То есть если датумы систем координат СК-42, СК-95, МСК на их основе, ГСК-2011 предполагается создавать для взаимного преобразования (прямо и обратно) в этих ПО ГИС, то 7 параметров Гельмерта в датумах всех этих СК должны задавать направление преобразования от «локальной СК» (так в этих ПО ГИС обычно называются все СК, кроме WGS-84) к WGS-84. Таким образом, например, процесс преобразования из СК-42 в ГСК2011 в этих ПО осуществляется в два этапа по цепочке CK-42 $\rightarrow$ WGS-84 $\rightarrow$ ГСК-2011, при этом на этапе перехода WGS-84 $\rightarrow$ ГСК-2011 параметры датума ГСК-2011 (задающие направление пересчета от ГСК-2011 к WGS84) будут взяты с обратным знаком.

Важно также отметить, что задаваемые ГОСТ 32453-2017 параметры преобразования используют СК ПЗ-90.11 в качестве референцной. При этом связь с CK WGS-84 в них 
также задана через СК ПЗ-90.11. В этой связи пользователям ПО ГИС, предполагающим осуществлять координатные преобразования в этом ПО, необходимо уметь правильно вычислять 7 параметров Гельмерта преобразования от СК-42, СК-95, ГСК-2011 к СК WGS84 и корректно вводить их в соответствующее ПО ГИС.

Безусловно, поставщики ПО ГИС в своих файлах настройки систем координат стараются задавать параметры связи СК-42, СК-95, ГСК-2011 с CK WGS-84, установленные ГОСТ 32453-2017 и позволяющие осуществлять преобразования между ними (например, в стандартной поставке ПО MapInfo Professional версии 19.3 имеются датумы для СК-42 и ГСК-2011). Однако пользователи должны уметь самостоятельно вычислять параметры датума и корректно формировать файлы систем координат для соответствующих ПО ГИС, как минимум, для решения следующих задач: формирования датумов для местных систем координат; формирования датумов для ПО, позволяющих осуществлять прямое преобразование (без референцной СК); формирования датумов для всех систем координат по параметрам, не совпадающих с установленными ГОСТ 32453-2017. Рассмотрим эти случаи подробнее.

Параметры связи местных систем координат (МСК) и государственных систем координат (ГСК) относятся к сведениям закрытого характера, поэтому поставщики ПО ГИС не могут включать в стандартную поставку ПО файлы СК, содержащие эти сведения. Однако, как было сказано ранее, преобразование между МСК и ГСК-2011 возможно только в формате представления всех участвующих в процессе СК как пространственных систем координат и полноценного задания датума и для МСК. И пользователь должен уметь корректно сформировать датум МСК, включающий в себя 7 параметров Гельмерта (фактически они идентичны параметрам Гельмерта связи родительской ГСК и референцной СК) и параметры проекции МСК.

Существует класс ПО (ПО ГИС «Панорама», GeoMedia Professional, ArcGIS; специальное ПО, например, CooTransf [16] и т. д.), которое позволяет осуществлять требуемые пользователю координатные преобразования между исходной и целевой СК напрямую, без использования референцной СК, или, фактически, в качестве таковой выступает целевая система координат. Для этих случаев пользователь также должен уметь формировать датумы исходной и целевой СК, так как в ГОСТ 32453-2017 не приводятся Гельмертовы параметры этих датумов непосредственно, а их необходимо вычислить самостоятельно.

Еще более распространенным представляется круг задач, требующих умения самостоятельно вычислять 7 параметров преобразования Гельмерта между СК-42, СК-95, ГСК2011, связанных с созданием локальных датумов. Класс пространственных данных, которые могут быть корректно преобразованы из исходной в целевую СК с использованием параметров, установленных ГОСТ 32453-2017, зависит от точности этих пространственных данных. Очевидно, что нецелесообразно преобразовывать данные, имеющие сантиметровую точность, из СК-42 в ГСК-2011 по параметрам ГОСТ 32453-2017, если при этом не ставится цель загрубить их в целевой СК до точности параметров ГОСТ. Однако точность параметров преобразования между соответствующими СК, установленных в ГОСТ 32453-2017, требуют оценки, так как непосредственно в ГОСТ их точность не указана. Сделаем такую оценку точности параметров преобразования между СК-42 и ГСК-2011, СК-95 и ГСК-2011.

Очевидно, что точность параметров преобразования между вышеуказанными СК и ГСК-2011 в преобладающей степени зависит от точности СК-42/СК-95.

В Руководстве пользователя по выполнению работ в системе координат 1995 года степень деформации СК-95 оценивается так: «средняя квадратическая ошибка передачи координат от исходного пункта на пункты на краях сети по каждой координате составляет 1 м [17].

В этом же документе дается следующая оценка точности СК-42: «В целом по сети деформации СК-42 могут быть оценены величинами средних квадратических ошибок координат, равными примерно 3,5-4 м. Именно с такой точностью (СКО) в среднем могут быть преобразованы координаты СК-42 в СК-95 
при использовании единого для всей ГГС набора параметров ортогонального преобразования. При этом абсолютные величины ошибок могут достигать 10 и более метров» [17].

Таким, образом, исходя из оценок величин деформации СК-42 и СК-95, приведенных в [17], максимальные погрешности параметров преобразования в ГСК-2011 из СК-42/СК95 могут достигать величин порядка \pm 10 м и \pm 1 м соответственно.

Очевидно, что такая точность может быть приемлема для преобразования в ГСК-2011 топографических карт масштаба 1:25000 и мельче (из СК-42) и топографических карт и планов масштаба $1: 5000$ и мельче (из СК95). Однако преобразование пространственных данных между СК-42/СК-95 и ГСК-2011 с более высокой точностью по глобальным параметрам преобразования, установленным ГОСТ 32453-2017, невозможно. Для повышения точности такого преобразования потребители вынуждены прибегать к определению локальных параметров преобразования, точность которых зависит от размеров территории, в отношении которой они определяются, степени и характера деформации СК-42/CK95 на этой территории.

И если такое преобразование предполагается осуществлять в ПО ГИС, то здесь будут востребованы навыки вычисления локальных параметров преобразования Гельмерта между СК-42, СК-95 и ГСК-2011 и создания с их использованием локальных датумов для соответствующего ПО.

Рассмотрим процесс вычисления параметров Гельмертова преобразования детальнее. Схема вычисления глобальных параметров преобразования Гельмерта между СК-42 и ГСК2011 для ПО ГИС (на примере ПО MapInfo Professional) с использованием их соответствующих значений, задаваемых в ГОСТ 32453-2017, приведена на рис. 2. На этой схеме буквенноцифровой аббревиатурой A1, A5, Г1 обозначены параметры преобразования между соответствующими системами координат в соответствии с тем, как они обозначены в ГОСТ 32453-2017.

Из схемы видно, что для вычисления 7 параметров Гельмерта датума требуемой СК необходимо соответствующие параметры, указанные в ГОСТ 32453-2017 с использованием СК ПЗ-90.11 как референцной СК, сложить. При этом знак в соответствующих параметрах A1, A5, Г1 следует брать в зависимости от того, совпадает ли направление преобразования по пути от локальной СК к референцной СК (CK WGS-84) с направлением преобразования, задаваемым в ГОСТ 324532017 этими параметрами, или нет.

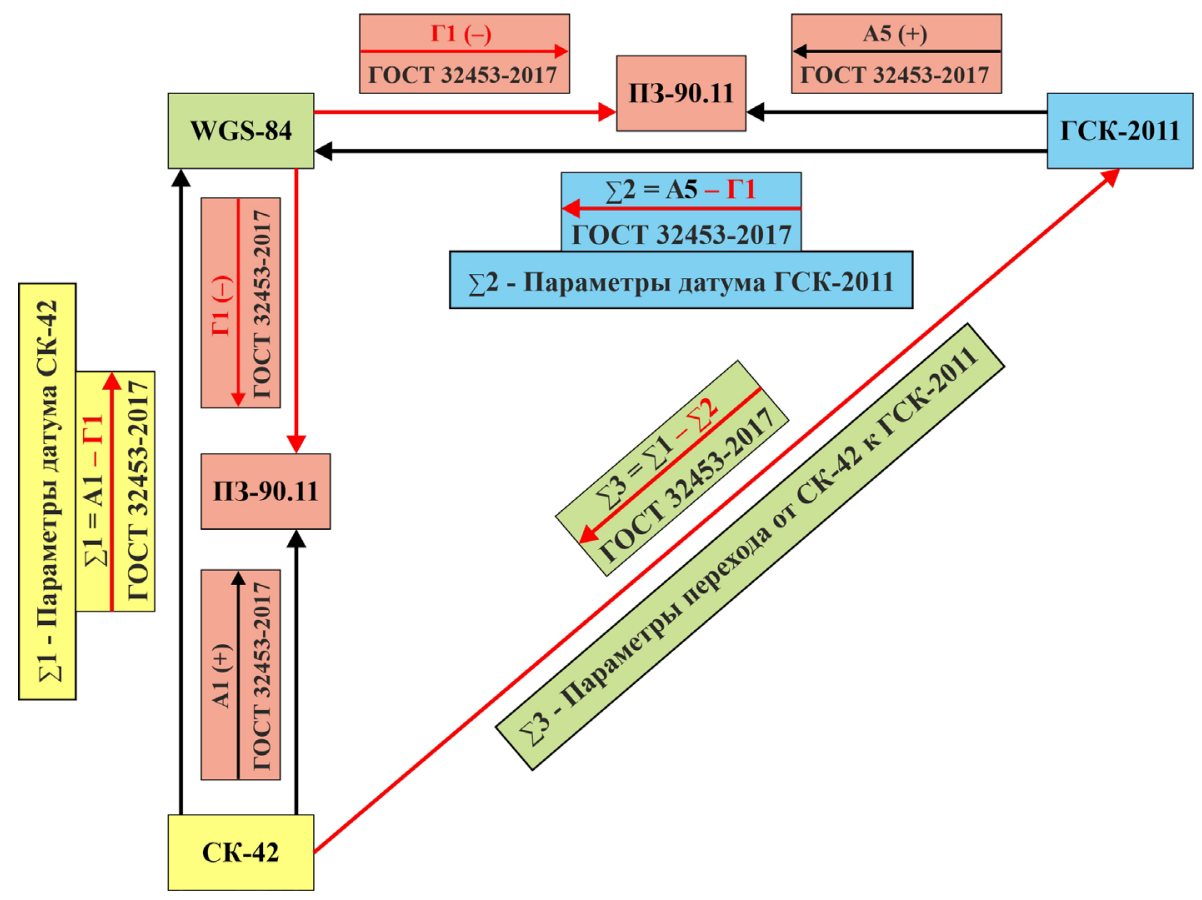

Рис. 2. Схема вычисления глобальных параметров датума СК-42 и ГСК-2011 в ПО ГИС MapInfo Professional 
Так, при вычислении параметров преобразования Гельмерта от СК-42 к СК WGS-84 (см. рис. 2) параметры A1 берутся с положительным знаком (здесь направление преобразования от СК-42 к СК П3-90.11, задаваемое в ГОСТ 32453-2017, совпадает с направлением преобразования от CK-42 к CK WGS-84), рис. 2.

И наоборот, параметры Г1 берутся с обратным знаком, так как направление преобразования от CK WGS к CK ПЗ-90.11, задаваемое этими параметрами в ГОСТ 32453-2017, противоположно направлению преобразования от CK-42 к CK WGS-84 (см. рис. 2).

Таким образом, сумма параметров Гельмерта А1, Г1, задаваемых в ГОСТ 32453-2017 для преобразования между СК-42 и П3-90.11, WGS-84 и П3-90.11 соответственно, вычисленная с учетом их знаков, формирует параметры преобразования $\sum 1$ из СК-42 в СК WGS-84.

Аналогично вычисляются параметры Гельмерта $\sum 2$ (используя параметры ГОСТ 32453-2017 А5, Г1) для задания датума ГСК2011 (см. рис. 2).

Параметры прямого преобразования между СК-42 и ГСК-2011 $\sum 3$, необходимые для использования в тех ПО ГИС, где такое координатное преобразование возможно, вычисляются как сумма параметров Гельмерта $\sum 1, \sum 2$, взятых с соответствующими знаками: знак $\sum 2$ будет отрицательным, так как задаваемое им направление Гельмертова преобразования от ГСК-2011 к СК WGS-84 противоположно направлению преобразования от СК-42 к ГСК-2011 по цепочке СК-42 $\rightarrow$ WGS-84 $\rightarrow$ ГСК-2011 (см. рис. 2).

По аналогии с СК-42, на рис. 3 показан порядок определения параметров Гельмерта для СК-95 ( $\left.\sum 4\right)$, вычисляемых на основе приведенных в ГОСТ 32453-2017 значений, с целью формирования датума СК-95 в ПО MapInfo Professional, а также алгоритм определения параметров прямого преобразования между СК95 и ГСК-2011 $\sum 5$.

Приведенные на рис. 2, 3 схемы дают наглядное представление об алгоритме вычисления глобальных параметров преобразования между системами координат СК-42, СК-95 и ГСК-2011, установленных ГОСТ 32453-2017, с целью формирования файлов этих СК в ПО ГИС, осуществляющих координатные преобразования через промежуточную референцную систему координат WGS-84.

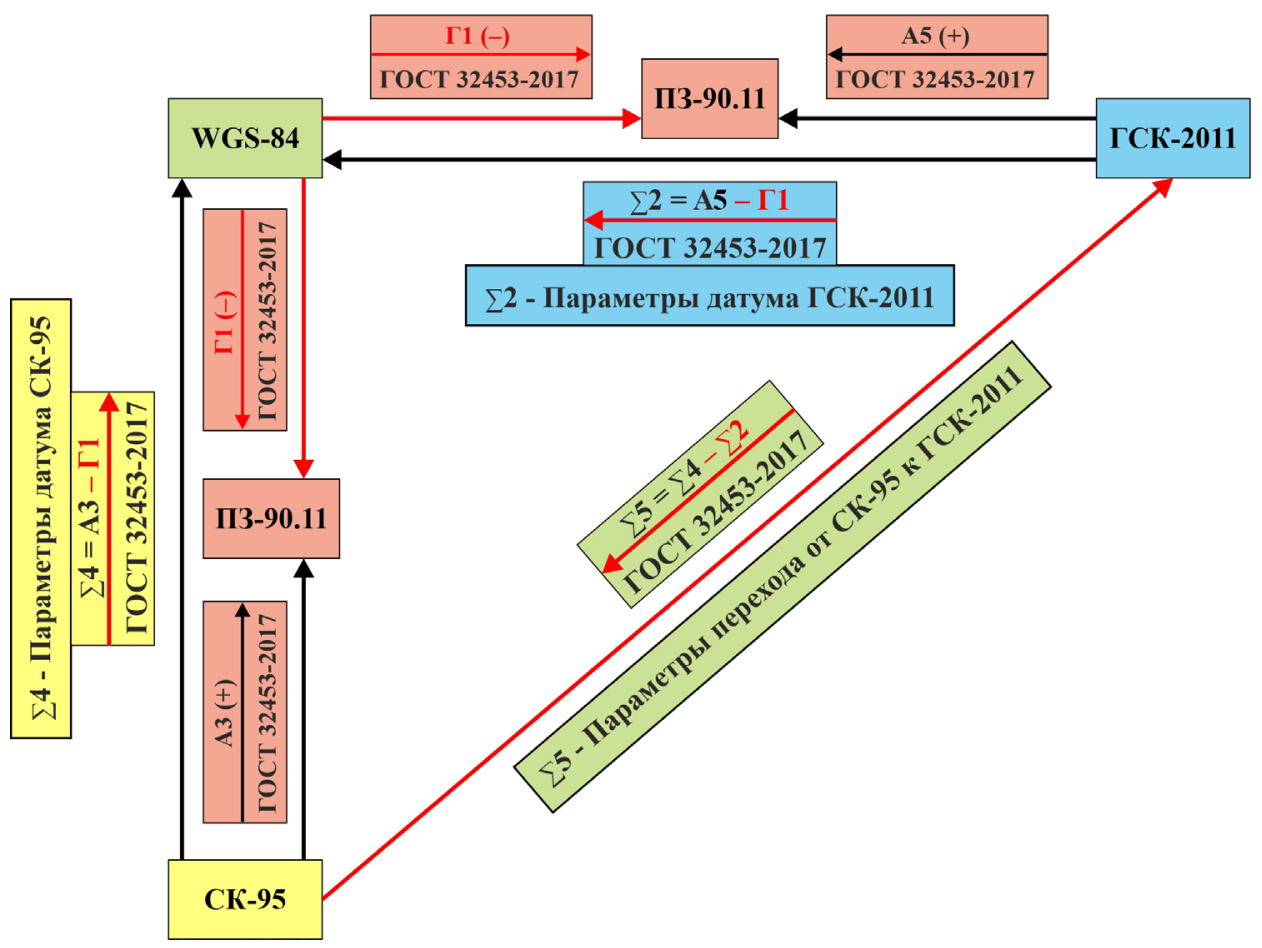

Рис. 3. Схема вычисления глобальных параметров датума СК-95 и ГСК-2011 в ПО ГИС MapInfo Professional 
Приведенные на рис. 2, 3 схемы дают наглядное представление об алгоритме вычисления глобальных параметров преобразования между системами координат СК-42, СК-95 и ГСК2011, установленных ГОСТ 32453-2017, с целью формирования файлов этих СК в ПО ГИС, осуществляющих координатные преобразования через промежуточную референцную систему координат WGS-84.

\section{Задание в ПО ГИС ГСК-2011 с помощью локальных датумов}

Как было сказано ранее, глобальные параметры преобразования, установленные ГОСТ 32453-2017, вследствие деформации СК-42 и СК-95 не обеспечивают преобразование пространственных данных из этих систем координат в ГСК-2011 с геодезической (на уровне сантиметров) точностью. В этой связи необходимо осуществлять определение локальных параметров преобразования из СК-42 и СК-95 в ГСК-2011 с целью задания на их основе датумов этих систем координат в соответствии со схемой, приведенной (на примере СК-42) на рис. 4.

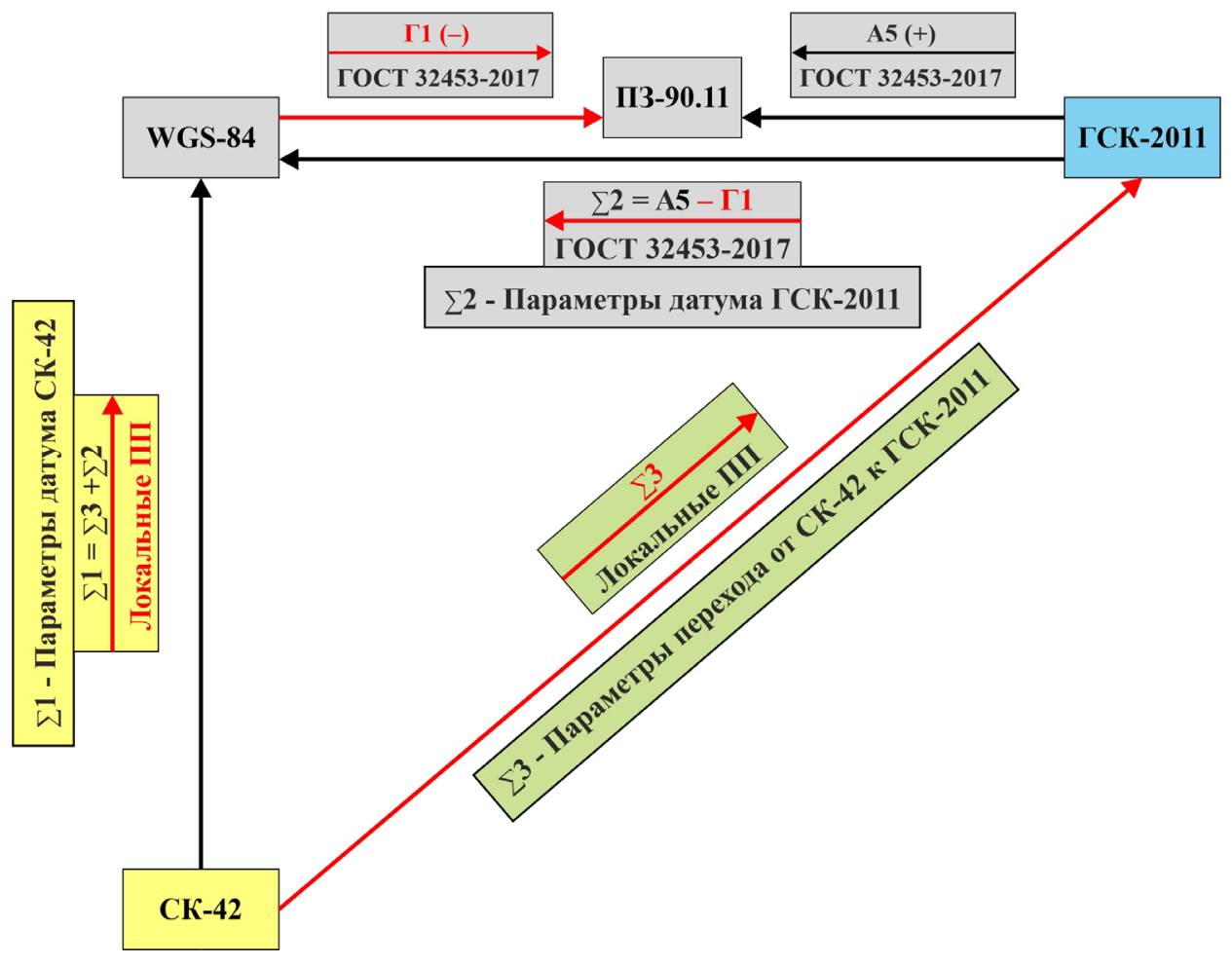

Рис. 4. Схема определения локальных параметров преобразования из СК-42 в CK WGS-84 для задания локального датума СК-42 в ПО ГИС MapInfo Professional

Для этого локальные параметры на данном участке местности $\sum 3$ определяются на основе набора опорных пунктов, имеющих координаты в исходной и целевой системах координат (для случая, показанного на рис. 4, таковыми являются СК-42 и ГСК-2011). Используя эти локальные параметры прямого преобразования из СК-42 в ГСК-2011 ( $\left.\sum 3\right)$, а также глобальные параметры преобразования координат из ГСК-2011 в CK WGS-84 ( $\left.\sum 2\right)$, установленные ГОСТ 32453-2017, локальные параметры преобразования из СК-42 в СК WGS-84 $\sum 1$ вычисляются как их сумма: $\sum 3$ $+\sum 2$ (см. рис. 4). Эти параметры используются для формирования локального датума СК-42 в ПО ГИС MapInfo Professional.

По аналогии решается задача повышения точности преобразования пространственных данных из СК-95 в ГСК-2011 путем определения (по опорным пунктам) локальных параметров прямого преобразования из СК-95 в ГСК-2011 $\sum 5$, а с их использованием вычис- 
ления локальных параметров преобразования из СК-95 в СК WGS-84 ( $\left.\sum 4\right)$ как суммы: $\sum 5+\sum 2$ (рис. 5). Эти параметры используются для формирования локального датума СК-95 в ПО ГИС MapInfo Professional.

Безусловно, использование локальных параметров для преобразования пространственных данных между СК-42/СК-95, а также созданными на их основе местными системами координат, и ГСК-2011 имеет то преимущество, что точность такого преобразования наиболее высокая. В то же время локальные параметры преобразования нарушают согла- сованность пространственных данных в целевой системе координат в том случае, если таковая согласованность была в исходной СК. Так, например, если границы смежных участков (допустим, лицензионных участков недропользования) были топологически согласованы в исходной системе координат (как правило, в СК-42), а при сдаче в надзорные органы этих же участков в ГСК-2011, преобразованных отдельными недропользователями по своим (несовпадающим) локальным параметрам, эти границы в целевой системе координат не совпадут.

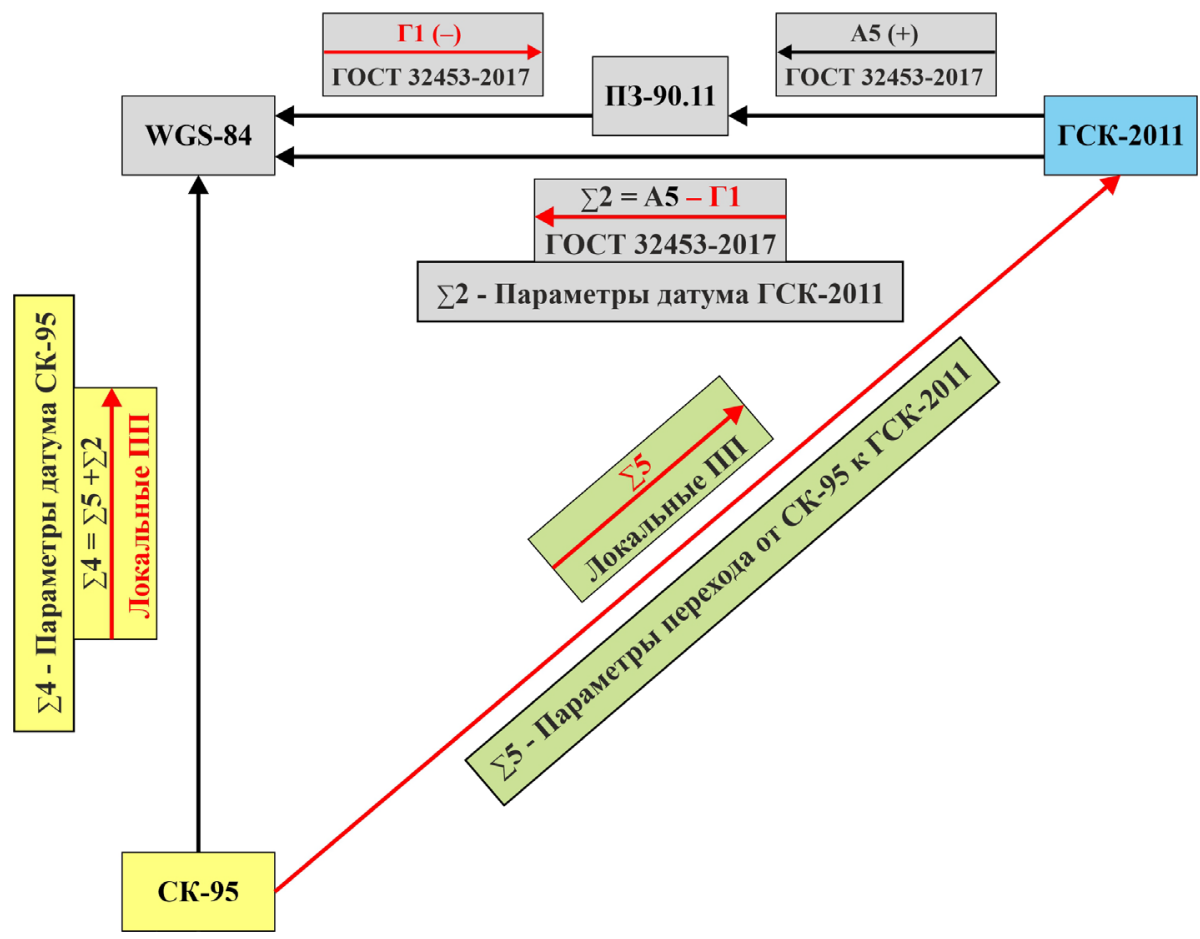

Рис. 5. Схема определения локальных параметров преобразования из CK-95 в CK WGS-84 для задания локального датума СК-95 в ПО ГИС MapInfo Professional

Таким образом, вследствие применения локальных параметров преобразования из исходной СК в ГСК-2011 может быть нарушено единство и согласованность (непротиворечивость) существующих наборов пространственных данных. В то же время применение глобальных параметров, установленных ГОСТ 32453-2017, пусть и дающих большую абсолютную погрешность (максимально до \pm 10 м из СК-42), позволяет преобразовать в равной степени неточно весь набор пространственных данных, сохраняя при этом их взаимную согласованность.
В этой связи следует дифференцировать применение локальных и глобальных параметров преобразования между СК-42, СК-95 и ГСК-2011 в зависимости от точности набора пространственных данных и их предназначения в целевой СК: глобальные параметры следует применять для задач, требующих меньшей точности и сохранения существующей согласованности (вплоть до топологической) пространственных данных; локальные параметры целесообразно применять для достижения геодезической точности преобразования (вплоть до сантиметров), 
а также для массивов данных ПД, по территориальному охвату сопоставимые с зоной действия локальных параметров.

Очевидно, что такая альтернатива в преобразовании существующих пространственных данных в ГСК-2011 (с сохранением согласованности, но с потерей абсолютной точности или с высокой точностью, но только на незначительную территорию) не может рассматриваться иначе как недостаток существующей системы геодезического обеспечения нашей страны. Выполнять геодезические работы современными высокоточными приборами с привязкой к координатной основе ГСК-2011 в виде спутниковых сетей с тем, чтобы загрублять их результаты как минимум на порядок до точности координатной основы МСК субъектов РФ, в которых ведется в настоящее время большинство практических работ (во главе с кадастровой деятельностью) и которые, в большинстве своем, построены на недопустимо неточной системе координат СК-42 - это печальная практика современной геодезической деятельности в нашей стране. Радикальным решением этой проблемы стало бы введение, в соответствии с приказом Росреестра [18], для осуществления кадастровой деятельности местных систем координат субъектов РФ, построенных на ГСК-2011 (МСК_NN_2011), и пересчет в нее АИС ЕГРН, а вслед за ним всех региональных пространственных данных. Подобный опыт успешного перехода от СК-42 к СК95 был отработан в ряде регионов РФ [19], в том числе в Новосибирской области [20]. Переход к MCK_NN_2011 позволил бы создать на территории субъектов Российской Федерации единое гомогенное координатное пространство, в котором не было бы слабых звеньев и в котором система координат, ее координатная основа и применяемые современные спутниковые приборы и технологии стали бы сопоставимы по точности, удовлетворяющей потребителей из всех сфер деятельности.

При этом реализацию данного подхода можно было бы осуществить как путем подбора новых параметров связи MCK_NN_2011 и ГСК-2011, которые решали бы задачу минимизации различия координат существующих пространственных данных в действующих местных системах координат (MCK_NN_42) и новой MCK_NN_2011 (схема модернизации МСK_NN_42 до МCK_NN_2011), так и путем применения существующих ключей MCK_NN_42 к координатам в ГСК-2011 (схема ввода новой МCK_NN_2011), приводящей к изменению координат в MCK_NN_2011 по сравнению с MCK_NN_42 на величины разности между их материнскими системами координат (СК-42 и ГСК-2011).

В то же время реализация вышеизложенного подхода модернизации МCK_NN_42 до MCK_NN_2011 потребует существенных временных затрат. Однако субъектам геодезической деятельности, имеющим в СК-42, СК-95 и в созданных на их основе МСК базы пространственных данных на значительные территории, в том числе крупномасштабные топографические планы, уже сегодня дискомфортно работать в условиях существующей альтернативы координатных преобразований. Определение множества (с целью сохранения точности ПД) локальных параметров преобразования из этих МСК в ГСК-2011 затратно (так как в большинстве случаев для этого требуются полевые работы) и неудобно в применении. В используемом такими потребителями ПО ГИС потребуется создавать массу файлов систем координат, применяемых в отношении отдельных территорий зоны деятельности компании, что создает риски путаницы и накопления ошибок их применения.

Выходом для таких компаний может стать определение региональных параметров на зону их деятельности. Наиболее очевидным приемом решения данной задачи стало бы определение региональных параметров на территорию соответствующих зон местных координат субъектов Российской Федерации. При этом для параметров связи МСК_NN_42 и ГСК-2011, вновь определяемых на территорию трехградусных координатных зон, наиболее вероятно получение искомых параметров, обеспечивающих координатное преобразование из МСK_NN 42 в ГСК-2011 с максимальной погрешностью в 20-30 см. Для шестиградусных координатных зон, применяемых в MCK_NN_42 на северных территориях (на широтах свыше $60^{\circ}$ ), в общем 
случае достижение таких показателей маловероятно.

Для регионов, уже перешедших к выполнению кадастровых работ в местных системах координат, построенных на СК-95 (MCK_NN_95), вероятно определение региональных параметров связи СК-95 и ГСК-2011 как на территорию трехградусных координатных зон, так и на территорию субъектов РФ в целом со среднеквадратической погрешностью порядка 5-10 см.

С точки зрения обеспечения совместимости пространственных данных целесообразно, чтобы такие вновь определяемые региональные параметры использовались всеми участниками профессионального сообщества на данной территории. Реализация этого может быть осуществлена введением таких параметров в стандартный алгоритм преобразования из геоцентрических в референцные системы координат на дифференциальных геодезических станциях, осуществляющих координатное обеспечение территории; решением территориального управления Росреестра; заключением общественного договора среди участников профессионального сообщества.

\section{Заключение}

В статье на примере ПО MapInfo Professional описана процедура осуществления координатных преобразований в ПО ГИС между существующими в нашей стране системами координат (СК-42, СК-95, МСК, созданные на их основе) и ГСК-2011, позволяющая научиться вычислять параметры преобразования Гельмерта между этими системами координат.

При этом отмечается, что, в связи с недостаточной точностью установленных ГОСТ
32453-2017 глобальных параметров преобразования между системами координат СК-42, СК-95, созданных на их основе МСК и ГСК2011, пользователи вынуждены прибегать к определению локальных версий этих параметров. Такой подход ведет к созданию в ГСК-2011 несогласованных наборов пространственных данных, увеличению затрат и неудобств в работе для субъектов геодезической деятельности и не может рассматриваться иначе как недостаток геодезического обеспечения нашей страны.

Существующая в нашей стране ситуация с применением местных систем координат, основанных на СК-42 (МСK_NN_42), для ведения кадастровых работ, а вместе с ними и для создания основных наборов пространственных данных на территории большинства субъектов РФ, является парадоксом геодезического обеспечения нашей страны. Координаты, полученные в ГСК-2011 от ее высокоточной (спутниковой) координатной основы современными спутниковыми же методами, в процессе преобразования в MCK_NN_42 теряются (как минимум на порядок) до точности координатной основы СК-42, не обеспечивающей многие практические приложения экономической и хозяйственной деятельности.

Очевидно, что кардинальным решением данной проблемы стал бы переход на выполнение кадастровых работ в местных системах координат, созданных на ГСК-2011 (МСK_NN_2011). И, в свете повышения требований потребителей в части точности позиционирования, в том числе федеральных органов исполнительной власти $[21,22]$, постановка и решение такой задачи должно рассматриваться как актуальная задача геодезического обеспечения Российской Федерации.

\section{БИБЛИОГРАФИЧЕСКИЙ СПИСОК}

1. Об установлении единых государственных систем координат [Электронный ресурс] : постановление Правительства Российской Федерации от 28.07.2000 г. № 586. - Доступ из справ.-правовой системы «КонсультантПлюс».

2. Об установлении государственных систем координат, государственной системы высот и государственной гравиметрической системы [Электронный ресурс] : постановление Правительства Российской Федерации от 24.11.2016 № 1240. - Доступ из справ.-правовой системы «КонсультантПлюс».

3. О введении единой системы геодезических координат и высот на территории СССР [Электронный ресурс] : Постановление Совета Министров СССР от 07.04.1946 № 760. - Доступ из справ.-правовой системы «КонсультантПлюс». 
4. Демьянов Г. В., Майоров А. Н., Побединский Г. Г. Местные системы координат, существующие проблемы и возможные пути их решения // Геопрофи. - 2009. - № 2. - С. 52-57.

5. Аврунев Е. И., Метелева М. В. О совершенствовании системы координатного обеспечения государственного кадастра недвижимости // Вестник СГГА. - 2011. - Вып. 1 (25). - С. 60-66.

6. Аврунев Е. И., Вылегжанина В. В., Гиниятов И. А., Колмогоров В. Г., Ямбаев Х. К., Совершенствование аналитического способа вычисления границ земельных участков // Вестник СГУГиТ. 2019. - T. 24, № 4. - C. 126-135.

7. Афонин К. Ф. Преобразование плоских прямоугольных координат Гаусса - Крюгера из МСК-54 в СК НСО // Вестник СГГА. - 2010. - Вып. 1 (12). - С. 57-62.

8. Виноградов А. В., Мазуров Б. Т. Перспективы использования специальных геодезических проекций и местных систем координат // Вестник СГУГиТ. - 2017. - Т. 22, № 1. - С. 18-29.

9. Горобец В. П., Демьянов Г. В., Майоров А. Н., Побединский Г. Г. Современное состояние и направления развития геодезического обеспечения РФ. Системы координат // Геопрофи. - 2013. № 6. - C. 4-9.

10. Карпик А. П., Обиденко В. И. Формирование единого геопространства территорий для повышения качества геодезического обеспечения государственного кадастра недвижимости // Интерэкспо ГЕО-Сибирь-2013 : IX Междунар. науч. конгр. : Пленарное заседание : сб. материалов в 2 т. (Новосибирск, 15-26 апреля 2013 г.). - Новосибирск : СГГА, 2013. Т. 1. - С. 3-11.

11. Демьянов Г. В., Майоров А. Н., Побединский Г. Г. Проблемы непрерывного совершенствования ГГС и геоцентрической системы координат России // Геопрофи. - 2011. - № 4. - С. 15-21.

12. Попадьев В. В., Ефимов Г. Н., Зубинский В. И. Геодезическая система координат 2011 года // Науч.-техн. сб. Астрономия, геодезия и геофизика. - М. : Изд-во ФГБУ «Центр геодезии, картографии и ИПД», 2018. - С. 139-228.

13. Обиденко В. И. Методология геодезического обеспечения цифровой экономики Российской Федерации // Геодезия и картография. - 2019. - Т. 80. - № 12. - С. 42-55.

14. Басманов А. В., Горобец В. П., Забнев В. И., Кафтан В. И., Побединский Г. Г., Столяров И. А., Ходаков П. А. О геодезическом обеспечении территории России. К 80-летию Г. В. Демьянова // Геопрофи. - 2019. - № 6. - С. 10-15.

15. ГОСТ 32453-2017. Глобальная навигационная спутниковая система. Системы координат. Методы преобразований координат определяемых точек. - М. : Изд-во стандартов, 2017.

16. Обиденко В. И., Нефедов С. П. СоoTransf «Преобразование координат». Программа для ЭВМ. // Номер регистрации (свидетельства): 2020614948. Дата регистрации: 29.04.2020 г.

17. Руководство пользователя по выполнению работ в системе координат 1995 года (СК-95). ГКИНП (ГНТА)-06-278-04 (утверждено приказом Роскартографии от 01.03.2004 № 29-пр.) [Электронный ресурс]. - Доступ из справ.-правовой системы «КонсультантПлюс».

18. Об утверждении порядка установления местных систем координат [Электронный ресурс] : приказ Росреестра 20.10.2020 № п/0387. - Доступ из справ.-правовой системы «КонсультантПлюс».

19. Шавук В. С. Введение в действие местных систем координат в Северо-Кавказском федеральном округе // Геодезия и картография. - 2012. - № 10. - С. 10-13.

20. Карпик А. П., Ламерт Д. А., Обиденко В. И. Реализация «дорожной карты»: пути повышения качества пространственного описания объектов государственного кадастра недвижимости // Геодезия и картография. - 2013. - № 12. - С. 45-49.

21. Карпик А. П., Обиденко В. И., Побединский Г. Г. Исследование потребности федеральных органов исполнительной власти Российской Федерации в пространственных данных// Геодезия и картография. - 2019. - Т. 80, № 12. - С. 49-63.

22. Карпик А. П., Обиденко В. И. Исследование потребности федеральных органов исполнительной власти Российской Федерации в пространственных данных : монография. - Новосибирск : СГУГиТ, 2021. - $216 \mathrm{c}$.

Получено 03.08.2021

(C) В. И. Обиденко, С. Р. Горобиов, 2021 


\section{TRANSFORMATION OF SPATIAL DATA INTO THE STATE GEODETIC COORDINATE SYSTEM OF 2011 IN GIS SOFTWARE}

\section{Vladimir I. Obidenko}

Siberian State University of Geosystems and Technologies, 10, Plakhotnogo St., Novosibirsk, 630108, Russia, $\mathrm{Ph}$. D., Vice-rector for Secondary Professional Education - Director of Novosibirsk Technical School of Geodesy and Cartography, e-mail: ovi62@yandex.ru

\section{Sergey R. Gorobtsov}

Siberian State University of Geosystems and Technologies, 10, Plakhotnogo St., Novosibirsk, 630108, Russia, $\mathrm{Ph}$. D., Associate Professor, Department of Engineering Geodesy and Mine Surveying, e-mail: sergey@gorobtsov.com

The article describes the implementation of the coordinate transformation procedures in GIS (on the example MapInfo Professional) between the existing in the country coordinate systems (SC-42, SC-95, MCS, based on them) and SCS-2011, allowing the reader to learn how to calculate the parameters of Helmert transformations between these coordinate systems using GOST 32453-2017. The article notes the problem of the transformation accuracy on the global parameters established by GOST 32453-2017 and the resulting need to determine local versions of these parameters, leading to the creation of uncoordinated spatial data sets in GSK2011, additional costs and complicating work of consumers. In order to solve this problem, it is proposed to consider the formulation of the task of transition to the implementation of cadastral work from coordinate systems based on SC-42 to MCS, created at SCS-2011, as an actual problem of improving the geodetic support of the country

Keywords: The State Geodetic Coordinate System of 2011, SCS-2011, Geographic Information Systems software, GIS software, spatial data, coordinate systems, coordinate transformations, datum

\section{REFERENCES}

1. Decree of the Government of the Russian Federation of July 28, 2000 No. 586. On the establishment of unified state coordinate systems. Retrieved from ConsultantPlus online database [in Russian].

2. Decree of the Government of the Russian Federation of November 24, 2016 No. 1240. On the establishment of state coordinate systems, state system of heights and state gravimetric system. Retrieved from ConsultantPlus online database [in Russian].

3. Decree of the Council of Ministers of the USSR of April 7, 1946 No. 760. On the introduction of a unified system of geodetic coordinates and heights on the territory of the USSR. Retrieved from ConsultantPlus online database [in Russian].

4. Dem'yanov, G. V., Majorov, A. N., \& Pobedinskij, G. G. (2009). Local coordinate systems, existing problems and possible solutions. Geoprofi, 2, 52-57 [in Russian].

5. Avrunev, E. I., \& Meteleva, M. V. (2011). On improving the system of coordinate support of the state real estate cadaster. Vestnik SGGA. [Vestnik SGGA], 1(25), 60-66 [in Russian].

6. Avrunev, E. I., Vleglegzhanina, V. V., Giniyatov, I. A., Kolmogorov, V. G., \& Yambaev, Kh. K. (2019). Improving the analytical method for calculating land boundaries. Vestnik SGUGiT [Vestnik SSUGT], 22(4), $126-135$ [in Russian].

7. Afonin, K. F. (2010). Conversion of flat rectangular Gauss-Krueger coordinates from MSK-54 to SK NSO. Vestnik SGUGiT [Vestnik SSUGT], 1(12), 57-62 [in Russian].

8. Vinogradov, A. V., \& Mazurov, B. T. (2017). Prospects for the use of special geodetic projections and local coordinate systems. Vestnik SGUGiT [Vestnik SSUGT], 22(1), 18-29 [in Russian].

9. Gorobets, V. P., Demyanov, G. V., Mayorov, A. N., \& Pobedinsky, G. G. (2013). Current state and directions of development of geodetic support of the Russian Federation. Coordinate systems. Geoprofi, 6, 49 [in Russian].

10. Karpik, A. P., \& Obidenko, V. I. (2013). Formation of a single geospatial territory to improve the quality of geodetic support of the state real estate cadaster. In Sbornik materialov Interekspo GEO-Sibir'-2013: T. 1. Plenarnoe zasedanie [Proceedings of Interexpo GEO-Siberia-2013: Vol. 1. Plenary Session] (pp. 3-11). Novosibirsk: SSGA Publ. [in Russian]. 
11. Dem'yanov, G. V., Majorov, A. N., \& Pobedinskij, G. G. (2011). Problems of continuous improvement of the GHS and the geocentric coordinate system of Russia. Geoprofi, 4, 15-21 [in Russian].

12. Popad'ev, V. V., Efimov, G. N., \& Zubinskii, V. I. (2018). The geodetic coordinate system of 2011. In Nauchno-tehnicheskij sbornik: Astronomija, geodezija i geofizika [Scientific and Technical Collection: Astronomy, Geodesy and Geophysics] (pp. 139-228). Moscow: FSBI "Center for Geodesy, Cartography and SDI" Publ. [in Russian].

13. Obidenko, V. I. (2019). The methodology of geospatial support of the digital economy of the Russian Federation. Geodezia i kartografia [Geodesy and Cartography], 80(12), 42-55. doi: 10.22389/0016-71262019-954-12-00-00 [in Russian].

14. Basmanov, A. V., Gorobec, V. P., Zabnev, V. I., Kaftan, V. I., Pobedinskij, G. G., Stolyarov, I. A., \& Hodakov, P. A. (2019). On the geodetic support of the territory of Russia. To the 80th anniversary of G. V. Demyanov. Geoprofi, 6, 10-15 [in Russian].

15. Standarts Russian Federation. (2017). GOST 32453-2017. Global navigation satellite system. Coordinate systems. Methods for transforming the coordinates of the determined points. Moscow: Standards Publ. [in Russian].

16. Obidenko, V. I., \& Nefedov, S. P. (2020). CooTransf "Coordinate Transformation". Computer program. No. 2020614948 [in Russian].

17. Geodetic, Cartographic Instructions, Norms and Regulations. (2004). User manual for the performance of work in the coordinate system of 1995 (SK-95). GKINP (GNTA)-06-278-04 (approved by order of Roskartografiya of March 01, 2004 No. 29-pr.) [in Russian].

18. On approval of the procedure for establishing local coordinate systems. Rosreestr's order of October 20, 2020 No. p/0387. Retrieved from ConsultantPlus online database [in Russian].

19. Shavuk, V. S. (2012). Implementation of local coordinate systems in the North Caucasus Federal District. Geodezia i kartografia [Geodesy and Cartography], 10, 10-13 [In Russian].

20. Karpik, A. P., Lamert, D. A., \& Obidenko, V. I. (2013). Implementation of the Road Map: ways to improve the quality of the spatial description of objects of the state real estate cadastre. Geodezia $i$ kartografia [Geodesy and Cartography], 12, 45-49 [In Russian].

21. Karpik, A. P., Obidenko, V. I., \& Pobedinskij G. G. (2019). Research of the need of the federal executive authorities of the Russian Federation in spatial data. Geodezia i kartografia [Geodesy and Cartography], 80(12), 49-63 [in Russian].

22. Karpik, A. P. \& Obidenko, V. I. (2021). Issledovanie potrebnosti federal'nyh organov ispolnitel'noj vlasti Rossijskoj Federacii v prostranstvennyh dannyh [Research of the need of the federal executive authorities of the Russian Federation in spatial data]. Novosibirsk: SSUGT Publ., 216 p. [in Russian].

Received 03.08.2021

(C) V. I. Obidenko, S. R. Gorobtsov, 2021 
УДК 550.831:556.3

DOI: $10.33764 / 2411-1759-2021-26-5-40-51$

\section{ВАРИАЦИИ ОБЪЕМНОЙ ДЕФОРМАЦИИ И УРОВНЯ ВОДЫ В СКВАЖИНАХ, ИХ ВЛИЯНИЯ НА РЕЗУЛЬТАТЫ ГРАВИМЕТРИЧЕСКИХ ИЗМЕРЕНИЙ}

\section{Владимир Юрьевич Тимофеев}

Институт нефтегазовой геологии и геофизики им. А. А. Трофимука СО РАН, 630090, Россия, г. Новосибирск, пр. Академика Коптюга, 3 , доктор физико-математических наук, главный научный сотрудник, тел. (383) 330-53-75, e-mail: timofeevvy@ipgg.sbras.ru

\section{Дмитрий Геннадьевич Ардюков}

Институт нефтегазовой геологии и геофизики им. А. А. Трофимука СО РАН, 630090, Россия, г. Новосибирск, пр. Академика Коптюга, 3 , кандидат физико-математических наук, старший научный сотрудник, тел. (383) 330-53-75, e-mail: ardyukovdg@ipgg.sbras.ru

\section{Антон Владимирович Тимофеев}

Институт нефтегазовой геологии и геофизики им. А. А. Трофимука СО РАН, 630090, Россия, г. Новосибирск, пр. Академика Коптюга, 3, кандидат физико-математических наук, научный сотрудник, тел. (383) 330-53-75, e-mail: timofeevav@ipgg.sbras.ru

\section{Павел Юрьевич Горнов}

Институт тектоники и геофизики им. Ю. А. Косыгина ДВО РАН, 680000, Россия, г. Хабаровск, ул. Ким Ю. Чена, 65, кандидат геолого-минералогических наук, старший научный сотрудник, e-mail.gornov@itig.as.khb.ru

\section{Юрий Федорович Стусь}

Институт автоматики и электрометрии СО РАН, 630090, Россия, г. Новосибирск, пр. Академика Коптюга, 1, кандидат технических наук, старший научный сотрудник, e-mail: yfstus@academ.org

\section{Владимир Михайлович Семибаламут}

ФГБУН ФИЦ «Единая геофизическая служба РАН» Сибирский филиал, 630090, Россия, г. Новосибирск, пр. Академика Лаврентьева, 13/3, кандидат физико-математических наук, директор, тел. (383)330-88-48, e-mail: wladim28@yandex.ru

Высокоточные гравиметрические измерения на наноуровне (при ошибке измерений $\mathrm{g}_{0} \cdot 10^{-9}$ ) требуют учета изменений плотности, вызванной деформацией земной коры и движением и положением флюида в слое. Работа посвящена анализу результатов наблюдений за уровнем воды в трех скважинах, расположенных в Приморье, на Камчатке и в Байкальском регионе. Вариации уровня в основном связаны с приливным воздействием, вариациями атмосферного давления, косейсмическими эффектами и сезонными влияниями осадков. С использованием приливного анализа данных получены коэффициенты связи вариаций уровня и объемной деформации от 0,1 до 1,6 мм $/ 10^{-9}$. Проведена оценка вклада вариаций объемной деформации в результаты гравиметрических мониторинговых наблюдений. Для скважины, пробуренной в коренных породах с использованием эффекта фазового запаздывания приливной деформации определена ориентация системы трещиноватости в горной долине Прибайкалья. Анализ многолетней серии гравиметрических измерений, полученной на сейсмостанции Талая, показывает, что для гравиметрических пунктов, расположенных на монолитных горных породах, вклад вариаций уровня вод значительно меньше ошибки абсолютных гравиметрических наблюдений. Быстрые косейсмические эффекты землетрясений хорошо регистрируются уровнемерными, деформографическими и абсолютными гравиметрическими методами.

Ключевые слова: измерения абсолютным гравиметром ГАБЛ и оценка вклада внешних эффектов, уровень воды в скважинах, объемная деформация, наблюдения вариаций водного уровня, Приморье, Камчатка, Прибайкалье, косейсмические, приливные, барические и сезонные эффекты, учет гравиметрических поправок при измерениях в Прибайкалье 


\section{Введение}

Мониторинг вариаций силы тяжести на наноуровне требует учета вклада изменений плотности, вызванных вариациями деформации и движением флюида в слоях земной коры. Известно, что одним из методов изучения объемной деформации является измерение водного уровня в глубоких скважинах и колодцах. В этом случае жидкость в скважине действует как объемный деформограф. При этом появляется возможность регистрировать эффекты, связанные с тектонической составляющей, приливным воздействием Луны и Солнца и атмосферным давлением [1-5]. Используя цифровые методы и теорию приливной деформации Земли, появляется возможность откалибровать такой естественный инструмент. Объемные деформации порядка $10^{-8}$ вызывают наблюдаемые современной аппаратурой приливные колебания водного уровня. В гравиметрии при мониторинге поля силы тяжести, помимо изучения вариаций объемной деформации, важное значение имеет задача учета вариаций уровня грунтовых вод. Этот процесс сложен в расчетах, связан с понятиями «проводимость», «пористость горных пород» и «время воздействия». Так, для района Токио (Япония) при $20 \%$ пористости горных пород изменение уровня на 1 метр приводит к изменению силы тяжести на 11 микрогал [6]. Но в целом вариации уровня грунтовых вод очень разнообразны и с трудом поддаются оценке. Наиболее остро задача расчета гравиметрических поправок встала в последние десятилетия, с развитием в Западной Европе и странах мира систематических измерений стационарными криогенными гравиметрами (относительными гравиметрами с использованием эффекта сверхпроводимости $\mathrm{SG})$, с точностью регистрации вариаций силы тяжести до сотых микрогала [7, 8]. Известно, что сезонные изменения уровня грунтовых вод имеют естественный и искусственный характер. Изучая изменения в тектоническиспокойном районе, можно определить уровень нормальных вариаций. Так, по данным европейских станций для вариаций, зарегистрированных в Нидерландах за 45 лет [8], сезонные изменения носят регулярный характер и достигают 1 м, при этом долговременный линейный ход, видимо, связанный с климатическими изменениями в регионе, составляет 2 см в год (рис. 1).

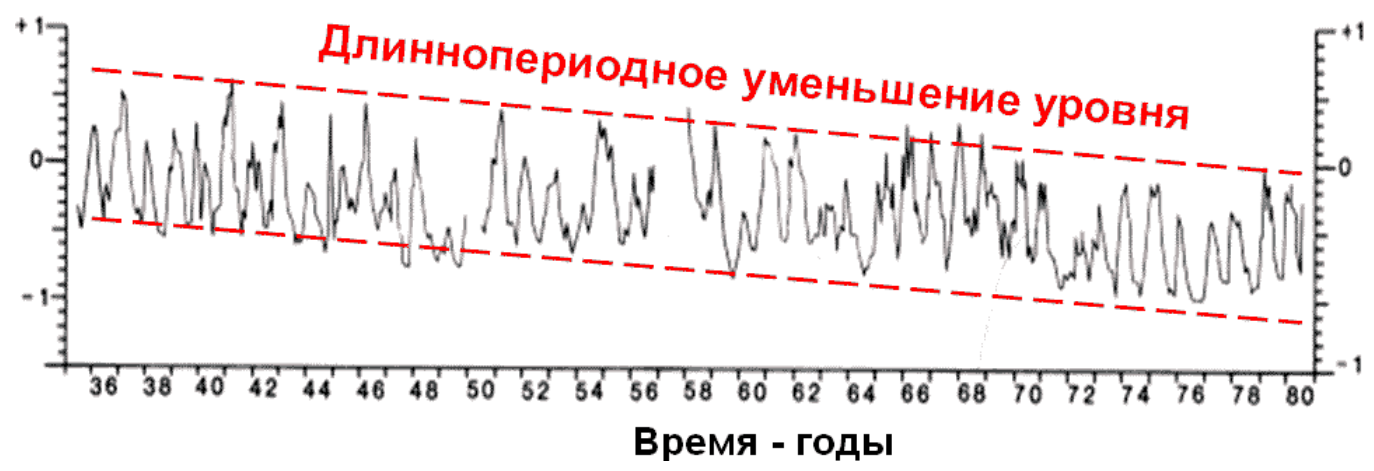

Рис. 1. Сезонные и долгопериодные вариации уровня грунтовых вод в Нидерландах (1935-1980 гг.). Вертикальная шкала в метрах $(-1 ; 0 ;+1)$

Задачами нашей работы являются изучение отражения геодинамических и сейсмических эффектов в флуктуациях водного уровня, на примере трех глубоких скважин, расположенных в Приморском, Камчатском и Байкальском регионах, оценка вклада изменений объемной деформации в результатах гравиметрических измерений.

\section{Методы анализа}

Изучение объемной деформации земной коры, отражающееся в изменениях уровня грунтовых вод проводилось нами на основе данных, полученных на скважинах Сибири и Дальнего Востока России, расположенных в Приморье, на полуострове Камчатка и в рай- 
оне озера Байкал. Приливные эффекты являются одним из редких явлений в геофизике, где точно известна сила. Используя известные приливные модели, можно определить чувствительность отдельных скважин к деформациям.

Известны три модели водоносных систем: замкнутый пласт, незамкнутый пласт и ограниченная полость [9].

Замкнутый водоносный пласт состоит из проницаемого пористого слоя, покрытого сверху и снизу непроницаемым материалом. В этом случае изменение гидростатического напора $d p$ в слое $d h$, вызванное дилатацией $\Delta$, будет

$$
d h=\frac{d p}{\rho \cdot g}=\frac{\Delta \cdot K}{n},
$$

где $n$ - пористость; $\rho$ - плотность воды; $g$ ускорение свободного падения; $K$ - объемный модуль упругости воды.

Водоносный слой снизу ограничен водоупором (водонепроницаемым слоем) - незамкнутый пласт. В этом случае деформация среды меняет положение водоносного горизонта, т. е. вызывает изменения в высоте поверхности $d b$

$$
d b=\left(\frac{\Delta}{n}\right) \cdot b,
$$

где $b$ - высота уровня вод.

В водоносных системах такого типа пористость должна быть малой, или толщина слоя должна быть большой для того, чтобы можно было наблюдать значимые приливные вариации.

Для модели «ограниченная полость» в монолитных породах при рассмотрении изменений водного уровня, вызванных приливной деформацией, исходили из следующего соотношения:

$$
d H=\frac{d V}{\pi r^{2}+\rho \cdot g \cdot \frac{V}{K}}
$$

где $d H$ - перемещение воды, вызванное изменением $d V$ в объеме $V$ ограниченной полости; $r-$ радиус скважины.
Таким образом, для скважины глубиной 1000 м приблизительные оценки приливной амплитуды (при деформации $\Delta=3 \cdot 10^{-8}$ ) соответственно дают: $90 \mathrm{Mм}, 0,6 \cdot 10^{-3}$ мм и 6 мм. Для одних типов моделей главным предметом изучения является пористость и реакция на прохождение сейсмических волн $[10,11]$, для других предмет изучения - эффекты, связанные с современной сейсмичностью и изменением геодинамических условий, а для третьих это особенности структуры - разломы и параметры системы трещин в массивах горных пород.

\section{Результаты наблюдений и интерпретация}

В работе проводится анализ данных наблюдений вариаций водного уровня в следующих скважинах: Бычиха (№ 1401, в районе пос. Бычиха, Хабаровский край координаты $\varphi=48^{\circ} 19^{\prime} \mathrm{N}, \quad \lambda=134^{\circ} 49^{\prime} \mathrm{E}, \quad$ глубина 1000 м), Ю3-5 (полуостров Камчатка, $\varphi=53^{\circ} 169^{\prime} \mathrm{N}, \lambda=158^{\circ} 41^{\prime} \mathrm{E}$, глубина $\left.1001 \mathrm{~m}\right)$, Талая (скв. № 1608, Прибайкалье, $\varphi=51^{\circ} 41^{\prime} \mathrm{N}, \lambda=103^{\circ} 38^{\prime} \mathrm{E}$, глубина $\left.110 \mathrm{M}\right)$. Регистрация изменений водного уровня в последние десятилетия проводилась с помощью установленных в скважинах датчиков типа «Кедр-2» и его модификаций, чувствительность систем составляет от 0,1 до 1 мм. Цифровая запись атмосферного давления проводилась датчиками с чувствительностью 1 мбар и лучше. Приливный анализ выполнялся с помощью программы ETERNA [12], использованы известные параметры приливной деформации Земли [13]. Датчики расположены в изотермических условиях, опрос - от минут до часа, серии от 3 до 18 лет. Рассмотрим результаты, полученные на глубоких скважинах (1000 м). Скважина Бычиха расположена в 300 км от морского побережья (в 600-700 километрах от Тихоокеанского сейсмического кольца и зоны субдукции - Курильских островов и Японии, вне зоны влияния активных разломов). Здесь, исходя из описания геологического разреза и регистрируемого уровня приливных вариаций, актуальна модель «замкнутый пласт». Примеры записи вариаций для скважины приведены на рис. $2,3$. 


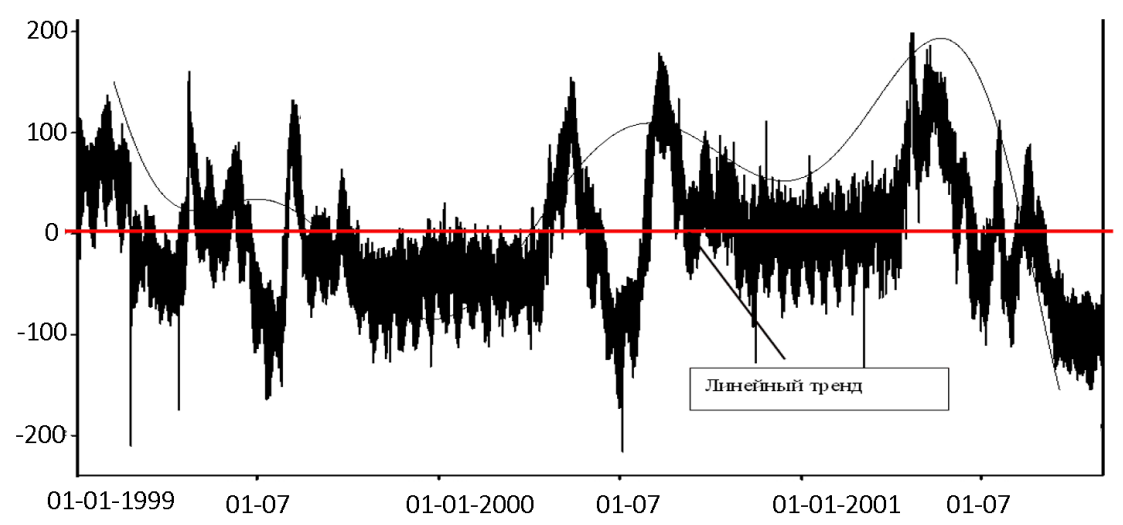

Рис. 2. Трехлетний ряд вариации уровня воды в скважине Бычиха

(01.01.1999-01.01.2002). Вертикальная шкала в миллиметрах.

Сезонные вариации, зарегистрированные в летний период, связаны с осадками

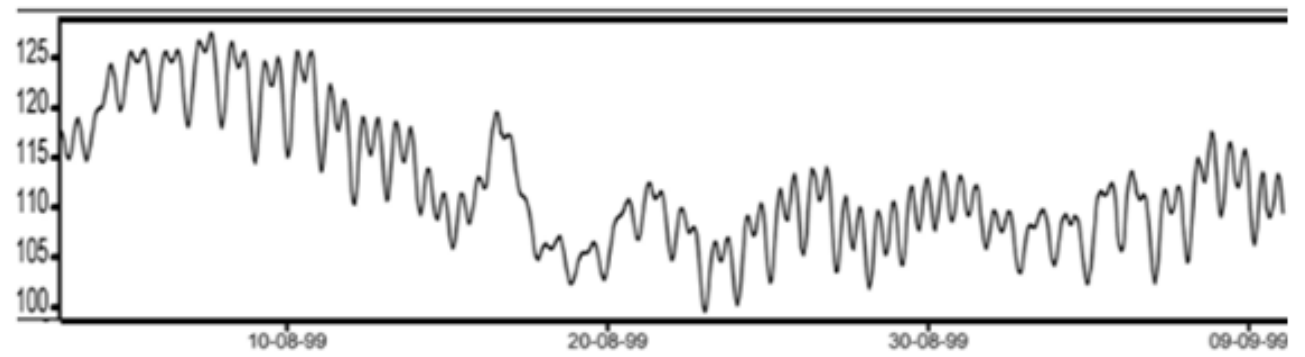

a)

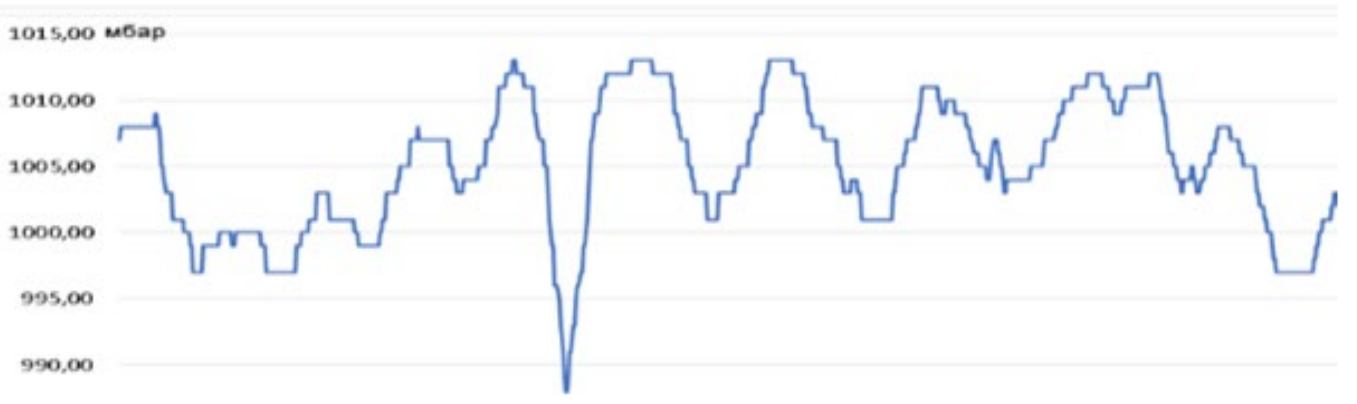

б)

Рис. 3. Результаты измерений уровня в скважине и вариаций атмосферного давления в Хабаровском крае:

a) вариации уровня в скважине Бычиха, время с 03.08.1999 по 10.10.1999. Вертикальная шкала в сантиметрах. Амплитуда приливных вариации до 5 см; б) вариации атмосферного давления в миллибарах. Курьезным фактом является аномалия уровня воды в период сильного землетрясения в Турции $\left(17.08 .1999\right.$, координаты $29,9^{\circ} \mathrm{N}, 40.7^{\circ} \mathrm{E}, \mathrm{M}=7,8, \mathrm{H}=17$ км). В этот период аномалия уровня вызвана вариациями атмосферного давления

Из анализа по полусуточной волне М2 получено соотношение для чувствительности водного уровня скважины от величины деформации: 1,590 мм/ $10^{-9}$. Полученный коэффициент хорошо соответствует результатам, полученным в других регионах, например, в Китае для пятнадцати скважин значение коэффици- ента связи меняется от 0,52 до 2,03 мм/10 $0^{-9}$ [14]. На графике многолетних изменений (рис. 3) выделяются сезонные вариации в летний период (до 200 мм), связанные с периодом муссонных дождей. Линейный многолетний тренд на этом пункте наблюдается на уровне приливных деформаций $3 \cdot 10^{-8}$. Оценивая связь вариа- 
ций $g$ и изменений плотности $\rho$, вызванных деформацией среды, можно использовать известную формулу для притяжения бесконечного плоского слоя

$$
\Delta g=2 \pi \cdot k \cdot \Delta \rho \cdot d=2 \pi \cdot k \cdot \Delta \varepsilon \cdot \rho \cdot d,
$$

где $\Delta g$-изменение значения силы тяжести; $k-$ гравитационная постоянная; $\Delta \rho-$ изменение плотности $\rho$ из-за вариации объемной деформации $\Delta \varepsilon$ земной коры $(\Delta \rho=\Delta \varepsilon \cdot \rho) ; d$ - толщина деформированного слоя земной коры; $\rho$ - средняя плотность земной коры. При деформации $3 \cdot 10^{-8}$, мощности земной коры 50 км и ее плотности $2,3 \cdot 10^{3}$ кг $/ \mathrm{m}^{3}$, получаем $\Delta g=0,1$ мкГал, ме- нее ошибки высокоточных гравиметрических измерений.

Скважина Ю3-5 расположена на полуострове Камчатка в 15 км от залива Авача (Тихий океан), в 100 км от зоны субдукции. Описание и анализ параметров водоносного слоя достаточно полно представлены в работах $[2,15]$. Для скважины используем модель типа «замкнутый пласт». На многолетних графиках вариаций уровня преобладает сезонная компонента амплитудой до 0,5 м (рис. 4, 5). Из приливного анализа по полусуточной волне М2 для скважины нами получен коэффициент связи с объемной деформацией 0,890 мм/ $/ 10^{-9}$.

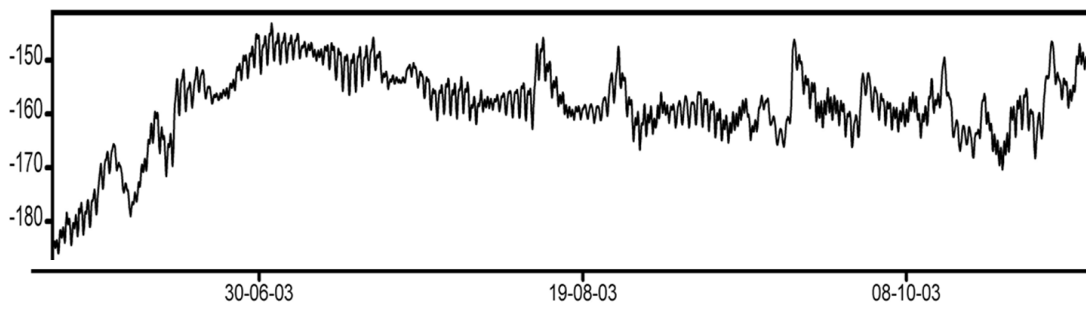

Рис. 4. Вариации уровня воды в скважине Ю3-5 за период 01.06.2003 - 10.11.2003. Вертикальная шкала в сантиметрах. Приливные вариации до 3 см

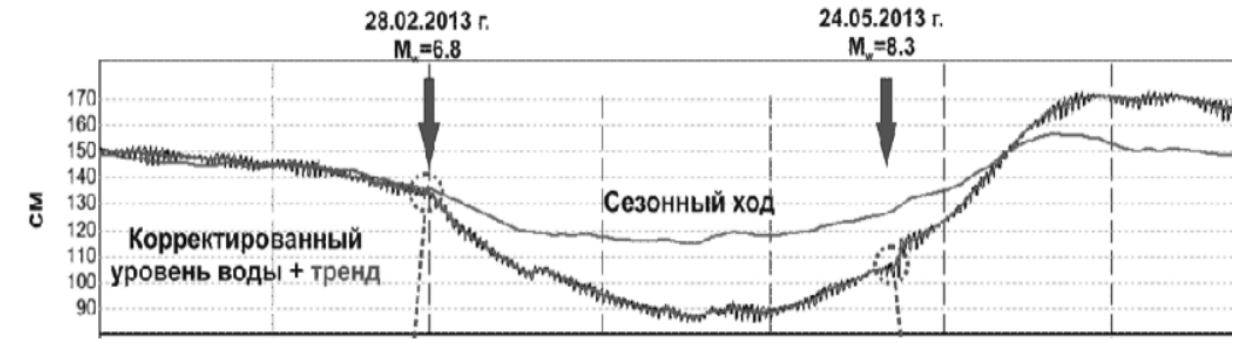

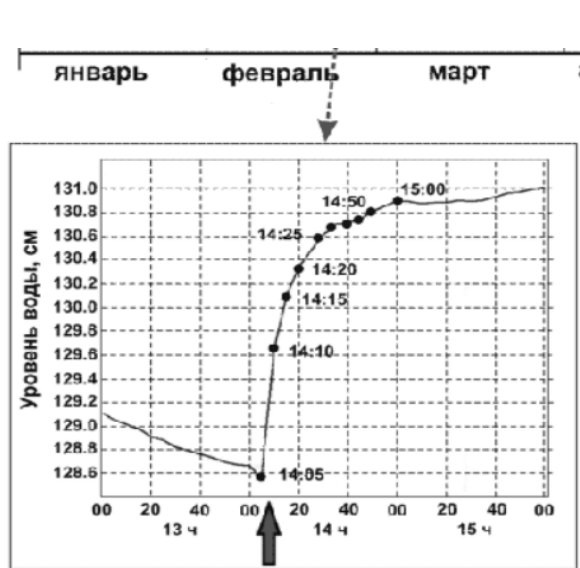

б)

a)

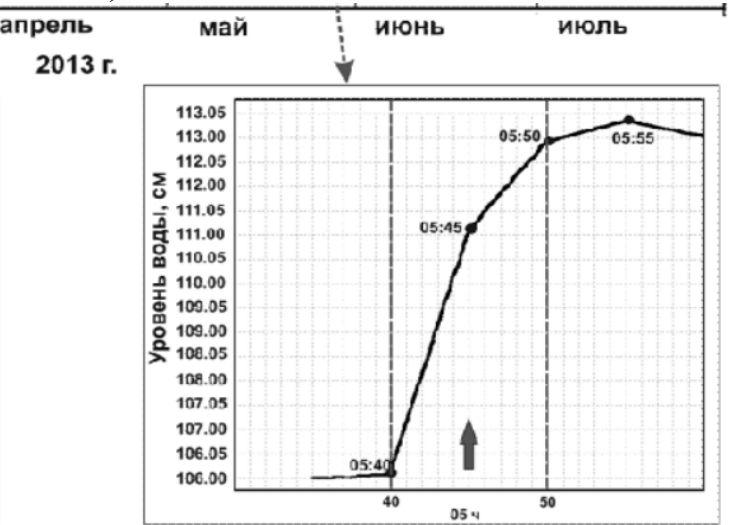

в)

Рис. 5. Результаты измерений в скважине на Камчатке:

a) вариации уровня в скважине Ю3-5 на период 01.01.2013 - 01.08.2013; б) косейсмические вариации уровня при землетрясении 28.02.2013, с 00 минут 13 часов до 00 минут 16 часов, время минута и часы, магнитуда 6,$8 ; 8)$ косейсмические вариации уровня при землетрясении 24.05 .2013 , с 30 минут 05 часов до 00 минут 06 часов, время часы и минуты, магнитуда 8,3 [14] 
Интересна косейсмическая реакция уровня на сильные землетрясения. Так, в период сильнейших землетрясений 2013 г.- 28 февраля $\left(\mathrm{M}_{\mathrm{w}}=6,8\right.$, расстояние до эпицентра $\mathrm{R}=280$ км, гипоцентр на глубине 45 км) и 24 мая $\left(\mathrm{M}_{\mathrm{w}}=8,3\right.$, $\mathrm{R}=370$ км, гипоцентр на глубине 611 км), в изменениях уровня воды в скважине Ю3-5 были зарегистрированы скачки с амплитудами 2,3 и 7,3 см соответственно, или $2,5 \cdot 10^{-8}$ и $8,2 \cdot 10^{-8}$ для деформации (рис. 5). В обоих случаях наблюдалось повышение уровня, отражающее сжатие горных пород. Используя сейсмологические данные и дислокационную модель землетрясения [16], получены оценки косейсмической деформации в районе скважины Ю3-5 (для землетрясения 28 февраля 2013 г. $1,5 \cdot 10^{-8}$; для землетрясения 24 мая 2013 г. $\left.6,2 \cdot 10^{-8}\right)$. Эти величины неплохо соответствуют результатам наблюдений водного уровня.

Скважина на сейсмостанции Талая расположена в Байкальской рифтовой зоне (БРЗ), известной своей сейсмической активностью, в 7 км от берега в юго-западной части озера Байкал. Центральная часть БРЗ по геологическим и сейсмологическим данным - это область растяжения, являющаяся западной границей Амурской тектонической плиты. На сейсмостанции 110-метровая скважина пробурена в скальных породах. Приливный анализ результатов наблюдений показал малую амплитуду прилива (2 мм). Исходя из геологии и амплитуды прилива, в этом случае используем модель «ограниченная полость» (рис. 6). Из приливного анализа уровня для полусуточной волны М2 для Талой получено соотношение с деформацией $0,1 \mathrm{~mm} / 10^{-9}$.
Многолетние вариации водного уровня (1993-2009 гг.) показывают значительные сезонные флуктуации, связанные с периодом выпадения осадков разной интенсивности (июль - август) и многомесячных со спадом уровня. Многолетний график вариаций уровня можно сравнить с данными измерений деформаций в 90-метровой штольне, построенной на склоне долины в 200 м от скважины, расположенной у другого борта долины. Деформографами зарегистрированы многолетние изменения объемной деформации (рис. 7) величиной до $1 \cdot 10^{-6}[17]$, что должно привести к изменениям уровня в $10 \mathrm{~cm}$. К сожалению, такие изменения на фоне сезонных вариаций 50-150 см практически невозможно выделить (рис. 7). Как и для скважины Ю3-5, расположенной на Камчатке, наблюдения водного уровня оказались наиболее полезны при регистрации быстрых - косейсмических вариаций.

Так, на рис. 8 приведен скачок уровня после локального Култукского землетрясения 27.08.2008 $(\mathrm{M}=6,5$, расстояние до эпицентра, расположенного на дне озера Байкал, 25 км, гипоцентр - на глубине 15 км), свидетельствующий о эффекте растяжения. Такой результат вместе с данными о смещениях пункта, полученными по GPS измерениям на сейсмостации

Талая, позволяет уточнить положение эпицентра. В этом случае в рамках дислокационной модели использовано решение прямой задачи с сейсмологическими параметрами. Уточнение позиции очага особенно полезно в случае, если сейсмический разрыв не выходит на земную поверхность или находится на дне озера.

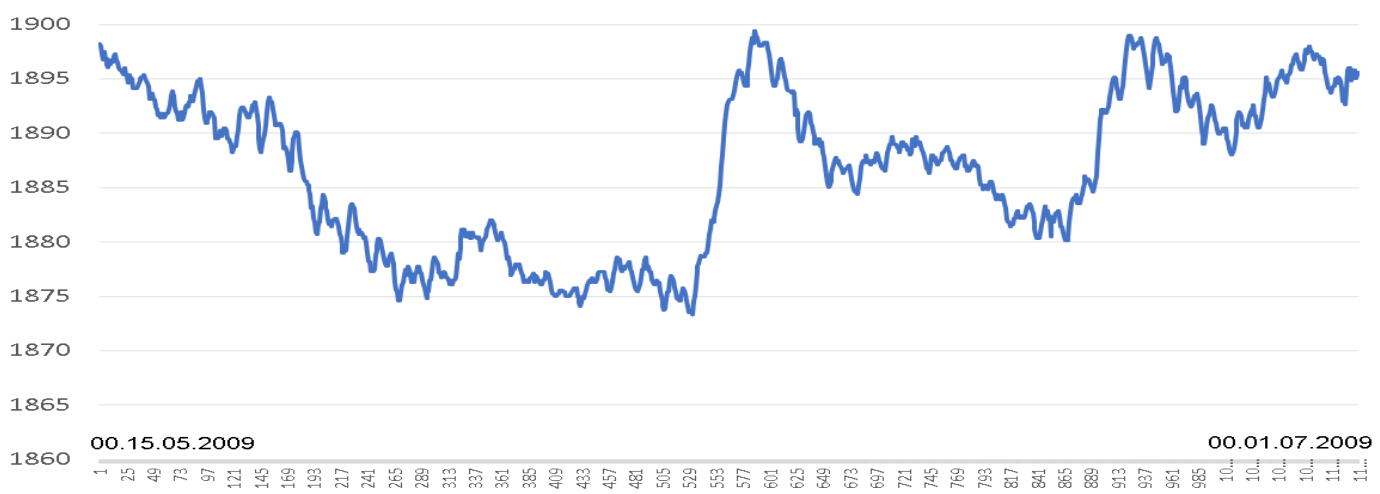

Рис. 6. Пример приливных вариации водного уровня, почасовые данные, зарегистрированные с 15 мая по 1 июля 2009 гг. в скважине Талая. Вертикальная шкала в миллиметрах. Приливная амплитуда 2 мм 


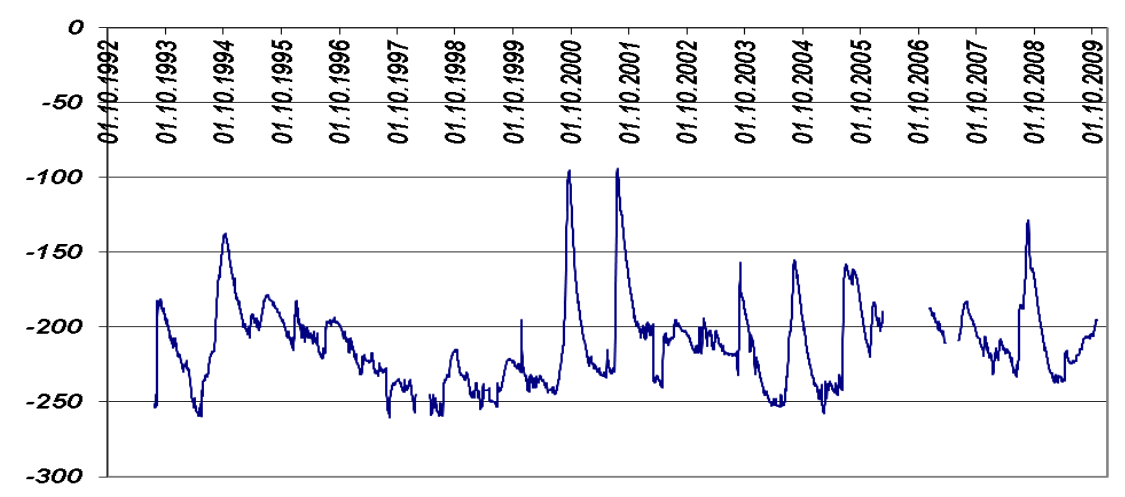

a)

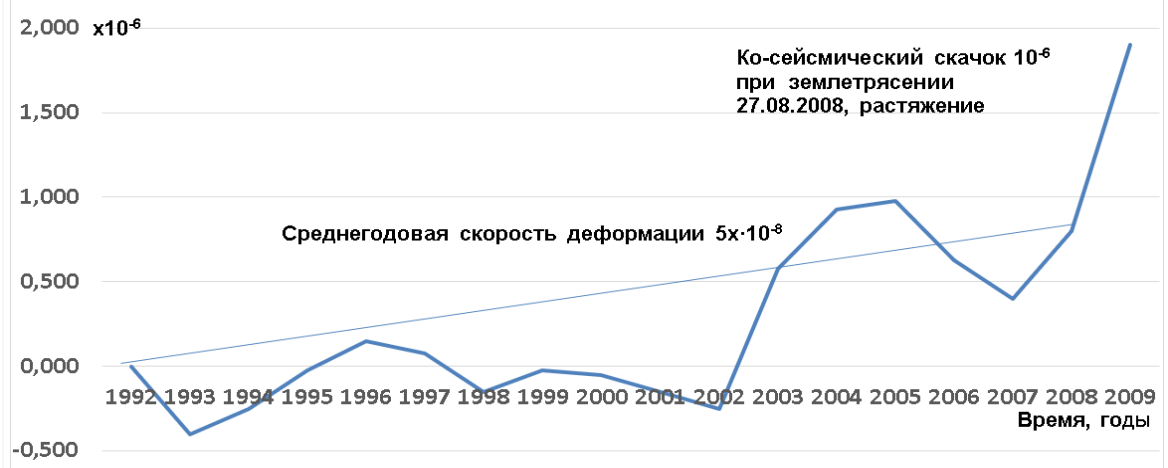

б)

Рис. 7. Результаты одновременных измерений уровня воды и вариаций объемной деформации на сейсмостанции Талая (Байкал):

a) многолетние вариации водного уровня в скважине Талая (1993-2009 гг.) по ежесуточным определениям, период наблюдений с годах с 1993-2009 гг. Вертикальная шкала в сантиметрах; б) изменения объемной деформции, полученные штанговыми и лазерными системами в штольне сейсмостанции. График построен по годовым измерениям. Время - годы, вертикальная шкала деформация построена с шагом $0,5 \cdot 10^{-6}$. Вклад годовых изменений деформации в результаты гравиметрических измерений по формуле (4) дает оценку $\Delta g=0,2$ микрогал, что на порядок меньше ошибки гравиметрических измерений

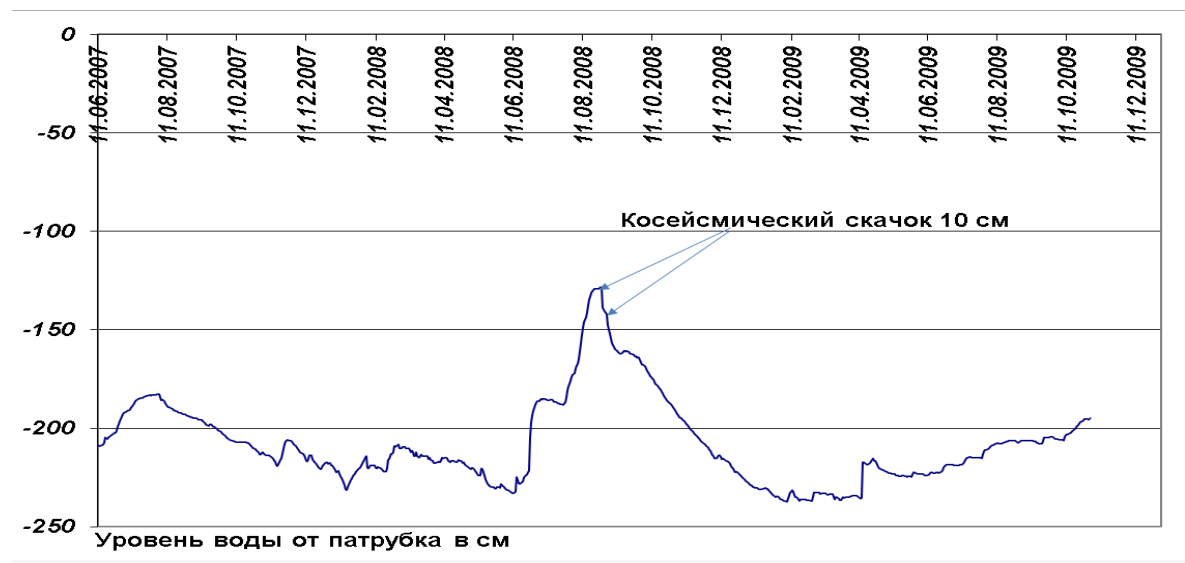

Рис. 8. Сезонные и косейсмические изменения водного уровня в скважине Талая

в см за период: июнь 2007 - декабрь 2009, по ежесуточным определениям.

Показан косейсмический скачок 10 см $\left(1 \cdot 10^{-6}\right)$ при Култукском землетрясении 27.08.2008.

Быстрая косейсмическая деформация по измерениям уровня хорошо соотвествует деформографическим измерениям в штольне 
Наш интерес к вариациям водного уровня в первую очередь был вызван необходимостью оценки их вклада в результаты гравиметрических измерений, выполняемых с помощью абсолютного гравиметра ГАБЛ на сейсмостанции Талая, в специальном подвале. Расстояние между гравиметрическим подвалом, расположенным под зданием сейсмостанции на коренных породах, и скважиной, расположенной у противоположного склона долины, составляет 100 м. Коренные породы (архейский мрамор) на дне долины перекрыты моренными отложениями мощностью от 0 до 2 м. Анализ многолетних вариаций поля силы тяжести и флуктуаций водного уровня показал полное отсутствие корреляции (рис. 9), что связано с размещением гравиметрических постаментов на коренных породах. В момент сильного близкого землетрясения обнаруживается сложная связь вертикальных смещений, деформации и силы тяжести [18].

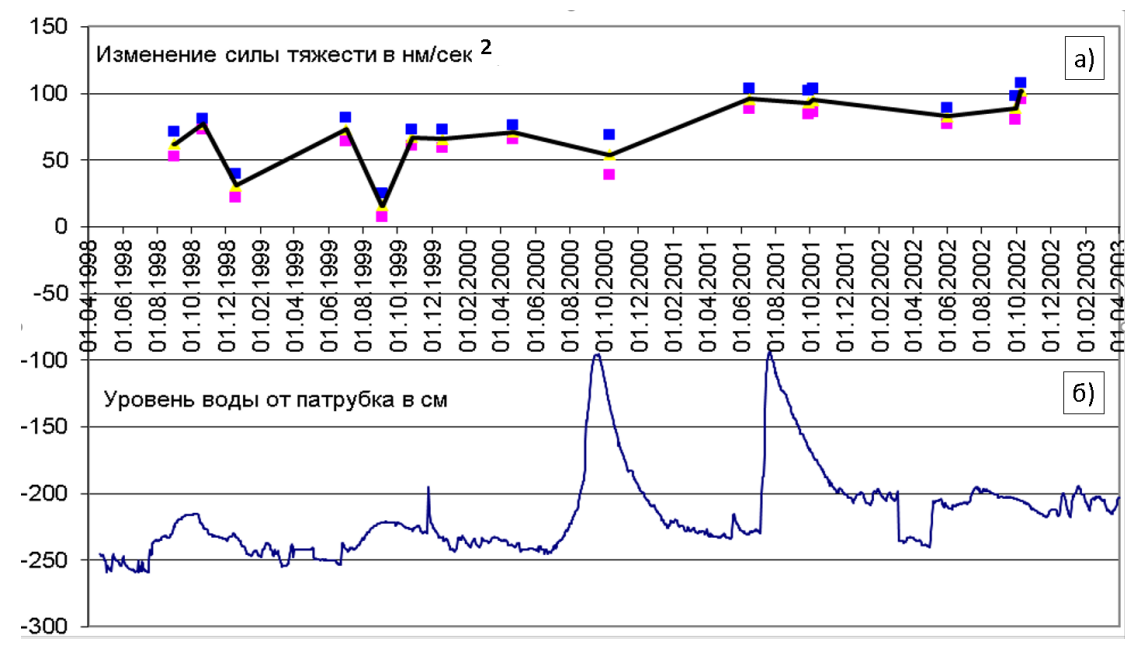

Рис. 9. Данные многолетних измерений уровня воды в скважине и силы тяжести на сейсмостанции Талая (Байкал):

a) вариации силы тяжести по данным абсолютного гравиметра ГАБЛ, вертикальная шкала в нм/c $\left(10 \mathrm{Hм} / \mathrm{c}^{2}=1\right.$ мкгал), по горизонтальной шкале время с 01.04.1998 по 01.04.2003, деления шкалы - 2 месяца; б) изменения водного уровня, вертикальная шкала в сантиметрах

Еще одной особенностью, выделенной в результате приливного анализа, являлся положительный фазовый сдвиг, полученный для объемной деформации (волна $\mathrm{M} 2:+79,40^{\circ} \pm 0,09^{\circ}$ ). Заметим, что положительный фазовый сдвиг, т. е. опережение реакции относительно силы физически невозможно. В приливных исследованиях такой эффект может наблюдаться только на побережье океана, где динамический эффект прилива в океанах и прибрежных морях может вызвать резонансы на отдельных частотах и в итоге изменить и амплитуду, и фазовый отклик [13]. Отметим, что на Талой скважина глубиной 110 м пробурена в монолитных мраморах, расположена у борта горной долины. В долине имеются мелкие водные источники, один из них протекает в нескольких метрах от скважины. Ориентация долины составляет около $\mathrm{N} 40^{\circ} \mathrm{E}$. Чтобы получить нулевую фазу с помощью приливного анализа, было подобрано решение для горизонтальной деформации с минимизацией фазового запаздывания в азимуте $130^{\circ}$ (рис. 10). Исходя из модели «ограниченная полость» (3) получен объем воды $\mathrm{V}=3 \cdot 10^{3} \mathrm{~m}^{3}$, которая заполняет систему близь поверхностных трещин. Полученному результату соответствует физическая модель - система ориентированных трещин, работающая как сильфон. Зона трещиноватости (ориентация около $\mathrm{N} 40^{\circ} \mathrm{E}$ ) расположена в 100 м от гравиметрического пункта, простирается вдоль борта горной в 100 м по горизонтали от гравиметрического пункта. В таком случае, даже при вариациях водного уровня в 1-2 м, эффект притяжения будет много меньше 1 микрогала. 

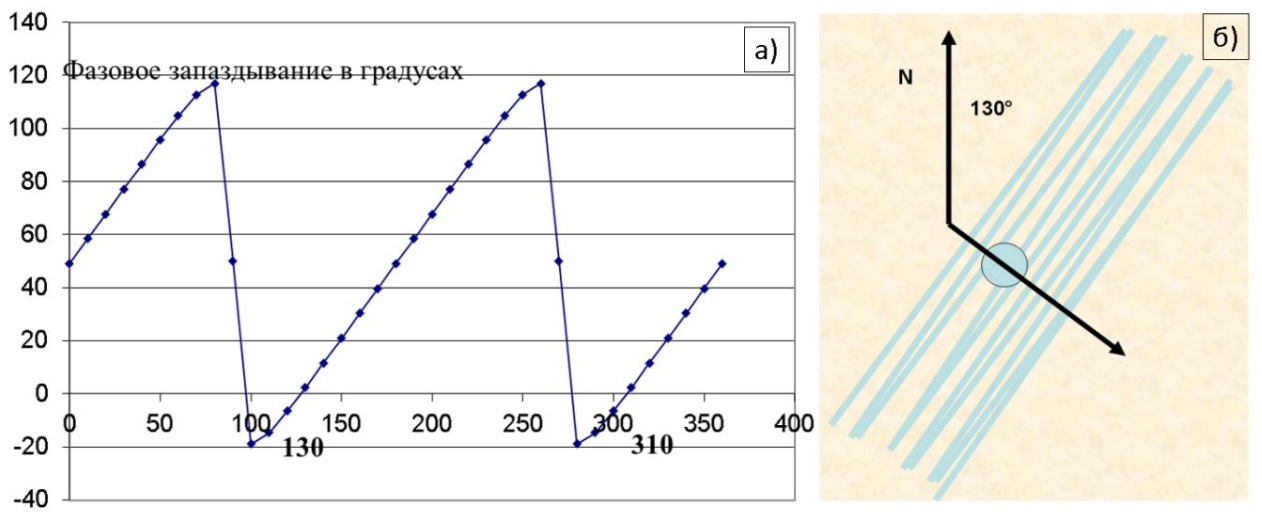

Рис. 10. Результаты анализа вариаций уровня воды в скважине и модель процесса:

a) изменение фазового запаздывания по результатам приливного анализа данных от -20 градусов до 120 градусов (вертикальная шкала). Вариация азимутов от 0 до 360 градусов (горизонтальная шкала). Фазовое запаздывание минимизируется при значении азимута $130^{\circ} \pm \mathrm{n} \cdot \pi$; б) модель области скважины, работающая как сильфон. Система трещин, ориентированных в азимуте $\mathrm{N} 40^{\circ} \mathrm{E}$, направление линейной деформации с нулевой фазой $\mathrm{N} 130^{\circ} \mathrm{E}$

\section{Вblводы}

Проведены оценки вклада вариаций деформации земной коры в результаты гравиметрических измерений микрогального уровня. Вариации деформации могут измеряться разными методами. Для оценки изменений объемной деформации были проанализированы результаты измерений уровня воды, полученные в разных геологических условиях на трех скважинах, расположенных в Приморье, на Камчатке и в Прибайкалье. Флуктуации уровня в основном связаны с приливным воздействием, вариациями атмосферного давления и сезонным вкладом осадков. Приливные амплитуды на глубоких скважинах с замкнутым ограниченным пластом, пробуренных в осадочных породах, составляют 30-50 мм. Для скважины, расположенной в монолитных коренных породах, полученные амплитуды меньше 2 мм. Исследование годовых вариаций уровня грунтовых вод по измерениям в глубоких скважинах (1 км) дает оценку вклада в изменения силы тяжести 0,1 микрогал.

$\mathrm{B}$ сейсмоактивных районах Прибайкалья и Камчатки выделены ко-сейсмические изменения уровня. Быстрые вариации уровня (минуты - часы) в моменты сильных землетрясений (М от 6,5 до 8,3) составляли от 2 до $10 \mathrm{~cm}$. Используя приливный коэффициент, проведена оценка косейсмического скачка деформаций. Она составила от $2,5 \cdot 10^{-8}$ и $1 \cdot 10^{-6}$, в зави- симости от расстояния до очага, энергии и глубины гипоцентра. Вклад в вариации силы тяжести составит от 0,1 до 5 микрогал. Такие оценки хорошо соответствуют модельным значениям, полученным с помощью дислокационной модели землетрясения и сейсмологических данных. Оценки скачка деформации дают дополнительную информацию о косейсмических эффектах в разных сейсмоактивных регионах. Для скважины Талая (Байкал), пробуренной в монолитных породах (архейский мрамор), используя приливный анализ и значение фазового запаздывания, определены направление системы (зон) трещиноватости $\left(\mathrm{N} 40^{\circ} \mathrm{E}\right.$, вдоль долины) и ее объем.

Анализ показывает, что для гравиметрических пунктов, расположенных на монолитных коренных горных породах, вклад годовых вариаций грунтовых вод значительно меньше ошибки абсолютных гравиметрических наблюдений (1 микрогал). Быстрые косейсмические деформации хорошо отражаются в результатах водных уровневых, деформографических и гравиметрических измерениях сопоставимого уровня точности. Медленные перетекания флюидов сложны для оценки вклада в гравиметрические результаты и для пунктов, расположенных на осадочных породах, вопрос об учете вариаций уровня грунтовых вод остается открытым для дискуссий. 


\section{БИБЛИОГРАФИЧЕСКИЙ СПИСОК}

1. Багмет А. Л., Багмет М. И., Барабанов В. Л., Гриневский А. О., Киссин И. Г., Малугин В. А., Рукавишникова Т. А., Савин И. В. Исследование земноприливных колебаний уровня подземных вод на скважине «Обнинск» // Физика Земли. - 1989. - № 11. - С. 84-96.

2. Копылова Г. Н., Болдина С. В. Оценка пороупругих параметров резервуара подземных вод (по данным уровнемерных наблюдений на скважине Ю35, Камчатка) // Вулканология и сейсмология. 2006. - № 2. - C. 17-28.

3. Cutillo P. A., Bredehoeft J. D. Estimating Aquifer Properties from the Water Level Response to Earth Tides // Ground Water. - 2011. - Vol. 49, No. 4. - P. 600-610. doi: 10.1111/j.1745-6584.2010.00778.x.

4. Xue L., Li Y-B., Brodsky E. E., Xu Z-Q., Kano Y., Wang H., Mori J. J., Si J-L., Pei J-L., Zhang W., Yang G., Sun Z-M., Huang Y. Continuous Permeability Measurements Record Healing Inside the Wenchuan Earthquake Fault Zone // Science. - 2013 - Vol. 340. - P. 1555-1559.

5. Rahi K. A., Halihan T. Identifying Aguifer Type in Fractured Rock Aquifers using Harmonic Analysis // Ground Water. - 2013. - Vol. 51, No. 1 - P. 76-82. doi: 10.1111/j.1745-6584.2012.00925.x.

6. Цубои Т. Гравитационное поле Земли. - М. : Мир, 1982. - С. 286.

7. Van Camp M., Francis O. Is the instrumental drift of superconducting gravimeters a linear or exponential function of time? // Journal of Geodesy. - 2007. - Vol. 81. - P. 337-344. doi: 10.1007/s00190006-0110-4/.

8. Hinderer J., Crossley D. Two Decades of High Precision Gravimetry // NEWSLETTER. - 5 June 2006. - No. 17. - P. 2-12.

9. Melchior P. Die gezeiten in unterirdischen flussigkerten // Erdoel Kohle. - 1960. - Vol. 13. - P. 312317.

10. Cooper H. H., Bredehoeft J. D., Papadopulos I. S., Bennett R. R. The response of well-aquifer systems to seismic waves. // Journal of Geophysical Research. - 1965. - Vol. 71. - P. 3915-3926.

11. Bredehoeft J. D. Response of well-aquifer systems to Earth Tides // Journal of Geophysical Research. - 1967. - Vol. 72, No 12. - P. 3076-3087.

12. Wenzel H. G. Earth tide analysis package ETERNA 3.0 // BIM (MareesTerrestres, Bull. D'Informations). - Belgium, 1994. - No. 118. - P. 8719-8721.

13. Timofeev V. Y., Valitov M. G., Ardyukov D. G., Timofeev A. V., Ducarme B., Kulinich R. G., Kolpashikova T. N., Proshkina Z. N., Boyko E. V. Ocean Tidal Models and Tidal Gravity Observation // Oceanology. - 2020. - Vol. 60. - No. 1. - P. 29-39. doi: 10.1134/S0001437020010221.

14. Lai G., H. Ge, W. Wang. Transfer functions of the well-aquifer system response to atmospheric loading and Earth tide from low to high-frequency band // Journal of Geophysical Research. Solid Earth. - 2013. No. 118. - P. 1904-1924. doi: 10.1002/jgrb.50165/.

15. Болдина С. В., Копылова Г. Н. Косейсмические эффекты сильных камчатских землетрясений 2013 г. в изменениях уровня воды в скважине ЮЗ-5 // Вестник КРАУНЦ. Серия: Науки о Земле. - 2016. - Вып. 30, № 2. - С. 66-76.

16. Okada Y. Surface deformation due to shear and tensile faults in a half-space // Bulletin of the Seismological Society of America. - 1985. - Vol. 75, No. 4. - P. 1135-1154.

17. Timofeev V. Y., Ardyukov D. G., Timofeev A. V., Boyko E. V., Semibalamut V. M., Fomin Y. N., Panov S. V., Parushkin M. D. The Use of Strainmeters to Study Oscillation Processes in a Wide Frequency Range // Seismic Instruments. - 2020. - Vol. 56, No. 4. - P. 380-393. doi: 10.3103/S0747923920040106.

18. Timofeev V. Y., Kalish E. N., Stus Y. F., Ardyukov D. G., Valitov M. G., Timofeev A. V., Nosov D. A., Sizikov I. S., Boiko E. V., Gornov P. Y., Kulinich R. G., Kolpashchikova T. N., Proshkina Z. N., Nazarov E. O., Kolmogorov V. G. Gravity and Displacement Variations in the Areas of Strong Earthquakes in the East of Russia // Izvestiya, Physics of the Solid Earth. - 2018. - Vol. 54. No. 3. - P. 430-443.

Получено 26.04.2021

(C) В. Ю. Тимофеев, Д. Г. Ардюков, А. В. Тимофеев, П. Ю. Горнов, Ю. Ф. Стусь, В. М. Семибаламут, 2021 


\section{VOLUME DEFORMATION VARIATIONS AND WELL-AQUIFER RESPONSE, ITS CONNECTION WITH GRAVITY MEASUREMENTS}

\section{Vladimir Yu. Timofeev}

Trofimuk Institute of Petroleum Geology and Geophysics SB RAS, 3, Prospect Akademik Koptyug St., Novosibirsk, 630090, Russia, D. Sc., Chief Researcher, phone: (383)330-53-75, e-mail: timofeevvy@ipgg.sbras.ru

\section{Dmitriy G. Ardyukov}

Trofimuk Institute of Petroleum Geology and Geophysics SB RAS, 3, Prospect Akademik Koptyug St., Novosibirsk, 630090, Russia, Ph. D., Senior Researcher, phone: (383)330-53-75, e-mail: ardyukovdg@ipgg.sbras.ru

\section{Anton V. Timofeev}

Trofimuk Institute of Petroleum Geology and Geophysics SB RAS, 3, Prospect Akademik Koptyug St., Novosibirsk, 630090, Ph. D., Researcher, phone: (383)330-53-75, e-mail: timofeevav@ipgg.sbras.ru

\section{Pavel Yu. Gornov}

Kosigin Institute of Tectonics and Geophysics Far Eastern Branch of RAS, 65, Kim Yu. Chen St., Khabarovsk, 680000, Russia, Ph. D, Senior Researcher, e-mail: gornov@itig.as.khb.ru

\section{Yurii F. Stus}

Institute of Automation and Electrometry SB RAS, 1, Prospect Akademik Koptyug St., Novosibirsk, 630090, Russia, Ph. D., Senior Researcher, e-mail: yfstus@academ.org

\section{Vladimir M. Semibalamut}

Siberian Branch of the Federal Research Center "United Geophysical Service of the Russian Academy of Sciences", 13/3, Prospect Akademik Lavrentiev St., Novosibirsk, 630090, Russia, Ph. D., Director, phone: (383)330-88-48, e-mail: wladim28@yandex.ru.

Precise gravity measurements at $\mathrm{g}_{0} \cdot 10^{-9}$ level requires taking into account density change, caused by the Earth's crust deformation and the movement and position of the fluid in the layer. The paper presents analysis of water level observation in three boreholes situated at Primorie, at Kamchatka and at Baikal region. Waterlevel fluctuations were influenced by earth tides, barometric pressure, co-seismic effects and season precipitations. Water tidal signal was analyzed for calculations of level-strain coefficients, its values changed from $0.1 \mathrm{~mm} / 10^{-9}$ to $1.6 \mathrm{~mm} / 10^{-9}$. Gravity corrections were developed by volume variation. For borehole drilled at monolithic rock we used the phase-lag effect for tidal strain and crack-system orientation was studied in Pribaikalie mountain valley. Long-term gravity results were tested with water level data at Talaya station (Pribaikalie). Talaya gravity point situated at monolithic rock had no influence from water level variation. Level-correction was less than absolute gravity measurement error. Quick co-seismic effects of earthquakes are well registered by level measuring, deformation graphical and absolute gravimetric methods.

Keywords: absolute gravity observation by GABL and different kind correction, water level into borehole, volume deformation, Primorie, Kamchatka, Pribaikalie, co-seismic, tidal, barometric, and season effects, , gravity correction for Pribaikalie measurements

\section{REFERENCES}

1. Bagmet, A. L., Bagmet, M. I., Barabanov, V. L., Grinevskii, A. O., Kissin, I. G., Malygin, V. A., Rukavishnikova, T. A., \& Savin, I. V. (1989). Investigation of earth-tidal fluctuations in the level of groundwater at the well "Obninsk". Fizika Zemli [Physics of the Earth], 11, 84-96 [in Russian].

2. Kopylova, G. N., \& Boldina, S. V. (2006). Estimation of the poroelastic parameters of the groundwater reservoir (according to level observation data at the well YuZ5, Kamchatka). Vulkanologia i seismologia [Volcanology and Seismology], 2, 17-28 [in Russian]

3. Cutillo, P. A., \& Bredehoeft, J. D. (2011). Estimating Aquifer Properties from the Water Level Response to Earth Tides. Ground Water, 49(4), 600-610. doi: 10.1111/j.1745-6584.2010.00778.x 
4. Xue, L., Li, Y-B., Brodsky, E. E., Xu, Z-Q., Kano, Y., Wang, H., Mori, J. J., Si, J-L., Pe,i J-L., Zhang, W., Yang, G., Sun, Z-M., \& Huang, Y. (2013). Continuous Permeability Measurements Record Healing Inside the Wenchuan Earthquake Fault Zone. Science, 340, 1555-1559.

5. Rahi, K. A., \& Halihan, T. (2013). Identifying Aguifer Type in Fractured Rock Aquifers using Harmonic Analysis. Ground Water, 51(1), 76-82. doi: 10.1111/j.1745-6584.2012.00925.x.

6. Tsuboie, T. (1982). Gravitatsionnoe pole Zemli [Earth's gravitational field]. Moscow: Mir Publ., 286 p. [in Russian]

7. Van Camp, M., \& Francis, O. (2007). Is the instrumental drift of superconducting gravimeters a linear or exponential function of time? Journal of Geodesy, 81, 337-344. doi: 10.1007/s00190-006-0110-4

8. Hinderer, J., \& Crossley, D. (2006). Two Decades of High Precision Gravimetry. Newsletter, 17, $2-12$.

9. Melchior, P. (1960). Die gezeiten in unterirdischen flussigkerten. Erdoel Kohle, 13, 312-317.

10. Cooper, H. H., Bredehoeft, J. D., Papadopulos, I. S., \& Bennett, R. R. (1965). The response of wellaquifer systems to seismic waves. Journal of Geophysical Research, 71, 3915-3926.

11. Bredehoeft, J. D. (1967). Response of well-aquifer systems to Earth Tides. Journal of Geophysical Research, 72(12), 3076-3087.

12. Wenzel, H. G. (1994). Earth tide analysis package ETERNA 3.0. BIM (MareesTerrestres, Bull.D'Informations), 118, 8719-8721.

13. Timofeev, V. Y., Valitov, M. G., Ardyukov, D. G., Timofeev, A. V., Ducarme, B., Kulinich, R. G., Kolpashikova, T. N., Proshkina, Z. N., \& Boyko, E. V. (2020). Ocean Tidal Models and Tidal Gravity Observation. Oceanology, 60(1), 29-39. doi: 10.1134/S0001437020010221.

14. Lai, G., Ge, H., \& Wang, W. (2013). Transfer functions of the well-aquifer system response to atmospheric loading and Earth tide from low to high-frequency band. Journal of Geophysical Research, Solid Earth, 118, 1904-1924. doi: 10.1002/jgrb.50165.

15. Boldina, S. V., \& Kopylova, G. N. (2016). Coseismic effects of strong Kamchatka earthquakes in 2013 in water level changes in the YuZ-5 well. Vestnik KRAUNS. Seria: Nayki o Zemle [Bulletin of Kamchatka Regional Association"Educational-Scientific Center". Earth Sciences], 30(2), 66-76 [in Russian]

16. Okada, Y. (1985). Surface deformation due to shear and tensile faults in a half-space. Bulletin of the Seismological Society of America, 75(4), 1135-1154.

17. Timofeev, V. Y., Ardyukov, D. G., Timofeev, A. V., Boyko, E.V., Semibalamut, V. M., Fomin, Y. N., Panov, S. V., \& Parushkin, M. D. (2020). The Use of Strainmeters to Study Oscillation Processes in a Wide Frequency Range. Seismic Instruments, 56(4), 380-393. doi: 10.3103/S0747923920040106.

18. Timofeev, V. Y., Kalish, E. N., Stus, Y. F., Ardyukov, D. G., Valitov, M. G., Timofeev, A. V., Nosov, D. A., Sizikov, I. S., Boiko, E. V., Gornov, P. Y., Kulinich, R. G., Kolpashchikova, T. N., Proshkina, Z. N., Nazarov, E. O., \& Kolmogorov, V. G. (2018). Gravity and Displacement Variations in the Areas of Strong Earthquakes in the East of Russia. Izvestiya, Physics of the Solid Earth, 54(3), 430-443.

Received 26.04.2021

(C) V. Y. Timofeev, D. G. Ardyukov, A. V. Timofeev, P. Y. Gornov, Y. F. Stus, V. M. Semibalamut, 2021 
УДК [528.236:528.531]+528.48

DOI: $10.33764 / 2411-1759-2021-26-5-52-62$

\section{МЕТОДИКА ПЕРЕДАЧИ КООРДИНАТ ТАХЕОМЕТРОМ НА ПУНКТЫ ВНУТРЕННЕЙ РАЗБИВОЧНОЙ СЕТИ ИНЖЕНЕРНОГО СООРУЖЕНИЯ}

\section{Георгий Афанасьевич Уставич}

Сибирский государственный университет геосистем и технологий, 630108, Россия, г. Новосибирск, ул. Плахотного, 10, доктор технических наук, профессор кафедры инженерной геодезии и маркшейдерского дела, тел. (383)343-29-55, e-mail: ystavich@mail.ru

\section{Николай Сергеевич Косарев}

Сибирский государственный университет геосистем и технологий, 630108, Россия, г. Новосибирск, ул. Плахотного, 10, кандидат технических наук, доцент кафедры инженерной геодезии и маркшейдерского дела, тел. (913)706-91-95, e-mail: kosarevnsk@yandex.ru

\section{Дмитрий Андреевич Баранников}

Сибирский государственный университет геосистем и технологий, 630108, Россия, г. Новосибирск, ул. Плахотного, 10, аспирант кафедры инженерной геодезии и маркшейдерского дела, тел. (913)753-95-82, e-mail: eddieogilvie@yandex.ru

\section{Иван Абид огль Мезенцев}

Сибирский государственный университет геосистем и технологий, 630108, Россия, г. Новосибирск, ул. Плахотного, 10, аспирант кафедры инженерной геодезии и маркшейдерского дела, тел. (923)241-80-42, e-mail: vania.mezentzew@yandex.ru

\section{Дмитрий Витальевич Бирюков}

Сибирский государственный университет геосистем и технологий, 630108, Россия, г. Новосибирск, ул. Плахотного, 10, аспирант кафедры инженерной геодезии и маркшейдерского дела, тел. (913)895-78-66, e-mail: birykovdmitriy1@gmail.com

При создании внешнего планово-высотного обоснования на строительных площадках, а затем и внутренних разбивочных сетях с целью передачи координат в целом ряде случаев, выполнение геодезических измерений производится через оптическую среду, которая на отдельных участках имеет разный коэффициент преломления. Это имеет место при выполнении таких измерений в зимнее время года, когда передача производится через технологические ворота временного торца инженерного сооружения, например, атомной или тепловой электростанции. Недостатком такой методики является влияние в зимнее время значительной турбулентности воздуха на границе резкого перепада температур. Для исключения данного влияния предлагается производить передачу координат внутрь инженерного сооружения через оконные проемы. В этом случае тахеометр может находиться внутри инженерного сооружения или вне его. При реализации предлагаемой методики практически полностью исключается влияние резкого перепада температур на результаты измерений. Исследованиями установлено, что при передаче через стекло координат на пункты внутреннего обоснования происходит параллельный перенос визирного луча. Для его исключения визирование необходимо выполнять при горизонтальном положении зрительной трубы тахеометра. В статье приводятся результаты исследований точности измерения расстояний и углов при прохождении визирного (лазерного) луча тахеометра через две оптические среды (воздух - стекло - воздух) при разных перепадах температур воздуха.

Ключевые слова: тахеометр, определение координат, перепад температур, коэффициент преломления оптических сред 


\section{Введение}

Выполнение высокоточных инженерногеодезических измерений на строительных площадках с целью создания внешнего и внутреннего планово-высотного обоснования производится при влиянии различных возмущающих воздействий, к которым относятся вибрация от работающих механизмов и оборудования, турбулентность воздуха, недостаточная освещенность и запыленность воздуха [1-4]. Одним из таких факторов, затрудняющих выполнение измерений, является резкий перепад температур в районе проведения работ. Например, при выполнении высокоточного нивелирования короткими лучами в зимнее время с целью определения осадок и деформаций инженерных сооружений и технологического оборудования, передача отметки может производиться при перепаде температур до $50^{\circ} \mathrm{C}$ $\left(+20{ }^{\circ} \mathrm{C}\right.$ внутри здания и $-30{ }^{\circ} \mathrm{C}$ вне его) [5-8]. Такой же перепад температур будет возникать при передаче координат от пунктов внешнего обоснования (ПВО) на пункты внутренней разбивочной сети. В обоих случаях измерения проводятся через открытые технологические ворота, расположенные в торце инженерного сооружения. В результате выполнения измерений на границе двух сред возникает локальное облако тумана, а также турбулентность воздуха, что, в конечном итоге, приводит к значительному увеличению средней квадратической ошибки (СКО) измерений, как линейных, так и угловых $[9,10]$. Так, при передаче координат от пунктов внешнего обоснования на пункты внутренней разбивочной сети через открытые технологические ворота, как показывает практика выполнения производственных работ, СКО измерения горизонтальных углов и углов наклона может достигать 20,0 $30,0 "$, а СКО определения координат (при $S=30-50$ м) - 7,0-10,0 мм $[11,12]$. Такая СКО определения координат является недопустимой величиной при создании внутренней разбивочной сети, которая применяется для обеспечения монтажа строительных конструкций. Следует отметить, что в целом ряде случаев при резком перепаде температур воздуха не представляется возможным выполнять визирование на нивелирную рейку или отражатель, так как турбулентность воздуха не позволяет четко различать визирную цель [13].
Уменьшение величины СКО определения координат может быть достигнуто путем выполнения измерений тахеометром или нивелиром через стекло оконного пролета, который всегда имеется на первом этаже инженерного сооружения.

По своей конструкции стеклопакет представляет собой прозрачную конструкцию строительного назначения, состоящую из двух и более стекол, скрепленных между собой по контуру с помощью дистанционных рамок (металлических или пластиковых) и герметиков. Обычно используют бутиловый герметик.

Между стеклами часто находится сухой воздух, зачастую для улучшения характеристик сопротивления теплопередаче внутрь стеклопакета закачивают инертные газы (аргон, ксенон, криптон) или углекислый газ.

Таким образом, прохождение лазерного луча через стеклопакет необходимо рассматривать как его прохождение через некоторое число плоскопараллельных пластин, между которыми находится воздушная среда.

Вследствие этого на величину СКО будут оказывать влияние следующие факторы [14-16]:

- угол наклона визирного луча зрительной трубы тахеометра по отношению к плоскости оконного пакета;

- количество пластин стекла в оконном пакете;

- разность температур воздуха вне и внутри инженерного сооружения;

- отличие коэффициентов преломления стекла и воздуха.

Целью проведения исследования является определение влияния вышеуказанных факторов на передачу координат с пунктов внешнего обоснования на пункты внутренней разбивочной сети. Ниже представлена методика проведения исследования с полученными результатами и сделанными по итогу исследования выводами.

\section{Методы и средства измерений}

Рассмотрим методику передачи координат с ПВО промплощадки на пункты внутренней разбивочной сети инженерного сооружения тахеометром путем выполнения измерений через стекло оконного пакета (рис. 1). 


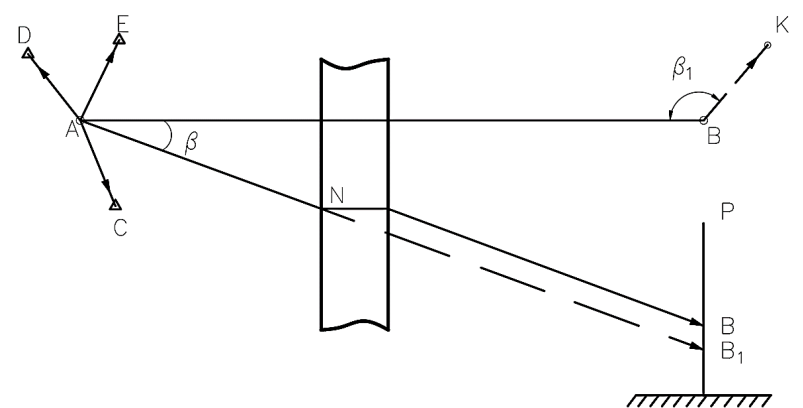

Рис. 1. Схема передачи координат через стекло оконного пакета

Пусть через стекло оконного пакета требуется передать координаты с пункта $A$ ПВО промплощадки на пункт $B$ внутренней разбивочной сети инженерного сооружения. Для этого в точке А (см. рис. 1) устанавливается (или центрируется) тахеометр и решением обратной линейноугловой засечки от трех исходных пунктов $\mathrm{C}, \mathrm{D}$ и Е определяются его координаты, а в точке В, расположенной внутри здания, устанавливается отражатель или рейка с наклеенной отражательной пленкой (для измерений в безотражательном режиме). После этого визированием через стекло способом полярных координат (засечки) определяются координаты точки В.

Необходимо отметить, что передача координат может быть выполнена и в обратном направлении - от пункта В внутренней разбивочной сети инженерного сооружения на пункт А внешнего обоснования. Для получения этих данных необходимо на пункте В измерить горизонтальный угол, а с него, через стекло, - угол наклона и расстояние.

При выполнении измерений через стекло необходимо, чтобы оно было чистым и прозрачным, а также не имело выраженных оптических дефектов, которые могут привести к искажению направления прохождения визирного (лазерного) луча. Поэтому перед началом измерений выбирается участок оконного пакета, который будет удовлетворять указанным требованиям.

Рассмотрим влияние основных факторов, возникающих в методике передачи координат через стекло оконного пакета с пунктов внешнего обоснования промплощадки на пункты внутренней разбивочной сети инженерного сооружения.

В качестве первого фактора выступает влияние угла наклона визирного луча зрительной трубы тахеометра по отношению к плоскости оконного пакета. Рассмотрим данный фактор на примере нивелира. При передаче отметки (координаты $h$ ) через стекло геометрическим нивелированием отсчет по рейке будет равен О. В этом случае угол наклона луча AO (рис. 2) будет равен значению угла $i$ нивелира, который, как правило, не превышает 10,0-15,0".

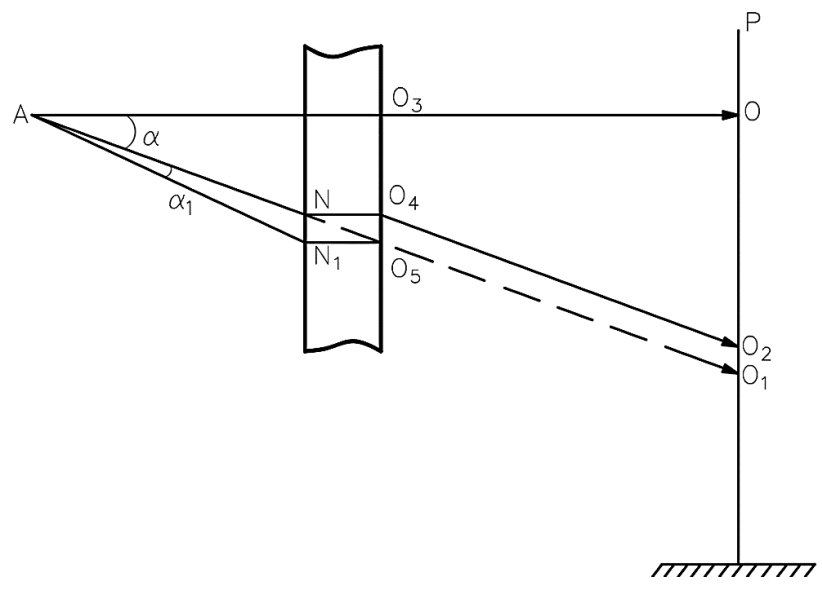

Рис. 2. Схема прохождения визирного луча через одну стеклянную пластину

Следовательно, визирный луч будет располагаться практически горизонтально и перпендикулярно плоскости стекла (предположим, что стеклянная пластина окна расположена вертикально).

В этом случае, согласно формуле Вильда

$$
l=d \frac{n-1}{n} \operatorname{tg} \alpha,
$$

где $d$ - толщина стеклянной пластинки; $n-$ показатель преломления стекла; $\alpha$ - угол наклона стекла окна; $l$ - величина смещения визирного луча.

При передаче координат тахеометром визирный луч зрительной трубы в общем случае не будет располагаться горизонтально, и, следовательно, не будет перпендикулярен плоскости стекла. При этом визирный луч зрительной трубы тахеометра также может быть не перпендикулярен стеклу и в вертикальной плоскости.

Предположим, что при передаче высотной отметки в качестве визирной цели используется рейка, на которую в точке $\mathrm{O}_{1}$ наклеена светоотражающая пленка (применяется безотражательный режим измерений). При отсутствии 
на пути визирного луча стеклянной пластины он пошел бы по направлению $\mathrm{ANO}_{1}$. Если же на пути визирного луча будет стеклянная пластина, то после попадания его в точку $\mathrm{N}$ он преломится и после выхода попадет на рейку в точку $\mathrm{O}_{2}$. Для наведения на отсчет $\mathrm{O}_{1}$ по рейке необходимо зрительную трубу дополнительно опустить на некоторый малый угол $\alpha_{1}$.

Изменение направления визирного луча приведет к его смещению и изменению отсчета по рейке. Предположим, что угол наклона визирного луча в вертикальной плоскости равен $\alpha=20^{\circ}$ (см. рис. 2). Тогда, при $n=1,52$ и $d=10,0$ мм получим $\mathrm{O}_{1} \mathrm{O}_{2}=l=0,6$ мм. Данная ошибка измерения превышения носит систематический характер и будет заметной при создании высотной высокоточной внутренней разбивочной сети строящегося инженерного сооружения. Из этого следует, что для уменьшения данной ошибки необходимо передачу высотной отметки производить при минимальном угле $\alpha$ наклона зрительной трубы тахеометра.

Если визирный луч будет не перпендикулярен плоскости стекла в вертикальной плоскости (см. рис. 1), то также при угле $\beta_{1}=20^{\circ}$ получим величину $\mathrm{BB}_{1}=0,6$ мм. Это приведет к систематической ошибке в плановом положении начального пункта внутренней разбивочной сети.

Вторым фактором, влияющим на проведение измерений, является количество пластин стекла в оконном пакете. Влияние данного фактора заключается в том, что оконные пакеты состоят из нескольких стеклянных пластин. Ход лучей через две стеклянные пластины и их смещение показаны на рис. 3.

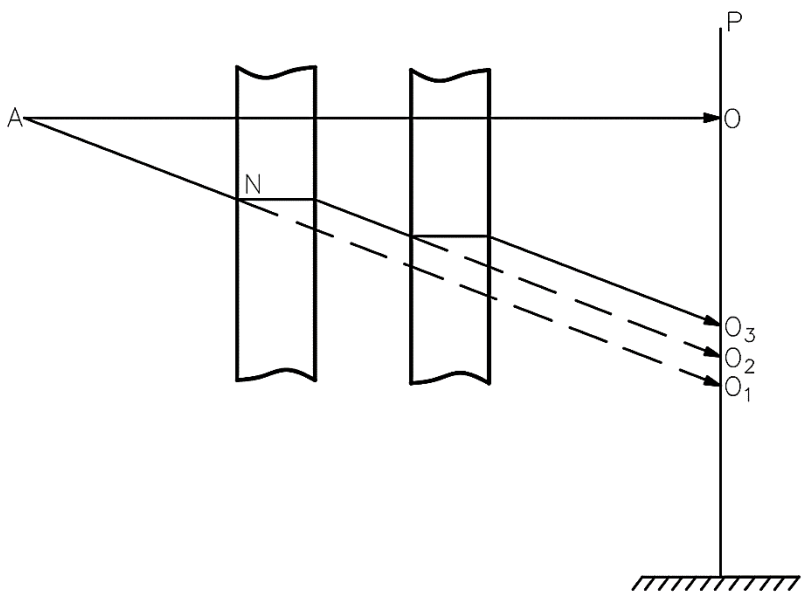

Рис. 3. Схема прохождения луча через две стеклянные пластины
Согласно формуле (1) и рис. 2 при одинаковой толщине стеклянных пластин эта величина смещения увеличивается в два раза, следовательно, систематическая ошибка передачи координат увеличится в два раза. Некоторые конструкции окон имеют три-четыре стеклянные пластины, таким образом, систематическая ошибка передачи координат также будет увеличена в три-четыре раза.

Следует отметить, что в оконных пакетах могут быть разные по величине расстояния между стеклянными пластинами (рис. 4).

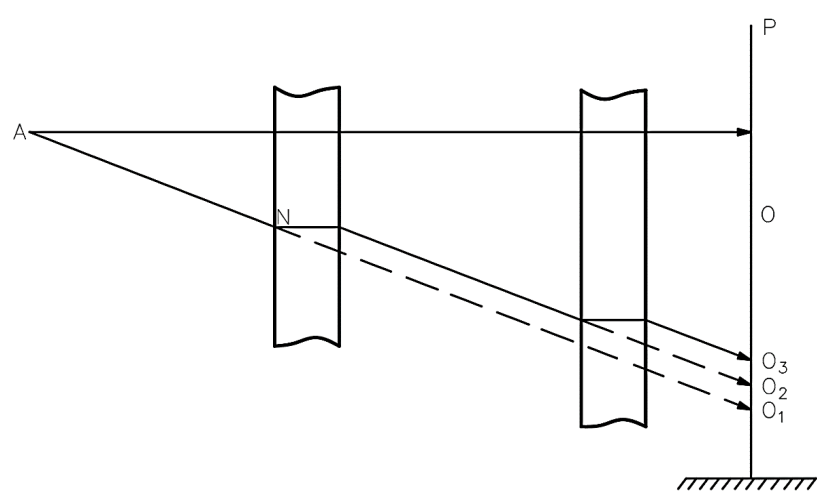

Рис. 4. Влияние расстояния между стеклянными пластинами на смещение луча

Однако, в данном случае характер преломления визирного луча не изменится, и величина его смещения также не изменится, так как независимо от взаимного расположения стеклянных пластин происходит только параллельный перенос этого луча. Однако с увеличением количества стеклянных пластин увеличивается коэффициент рассеивания лазерного луча, что может привести к значительному уменьшению уровня отраженного сигнала.

Третьим фактором будет выступать влияние разности температур воздуха снаружи и внутри инженерного сооружения. Для определения степени влияния данного фактора были выполнены производственные работы. На первом этапе выполнялись исследования влияния разности температур и наличия стекла оконного пакета на измеряемое расстояние. Измерения выполнялись из двух точек:

- точка А располагалась внутри инженерного сооружения на расстоянии 1,5 м от стекла;

- точка В располагалась вне сооружения на расстоянии 23,5 м от стекла (рис. 5). Угол наклона между точками составлял $24^{\circ} 28^{\prime}$. 


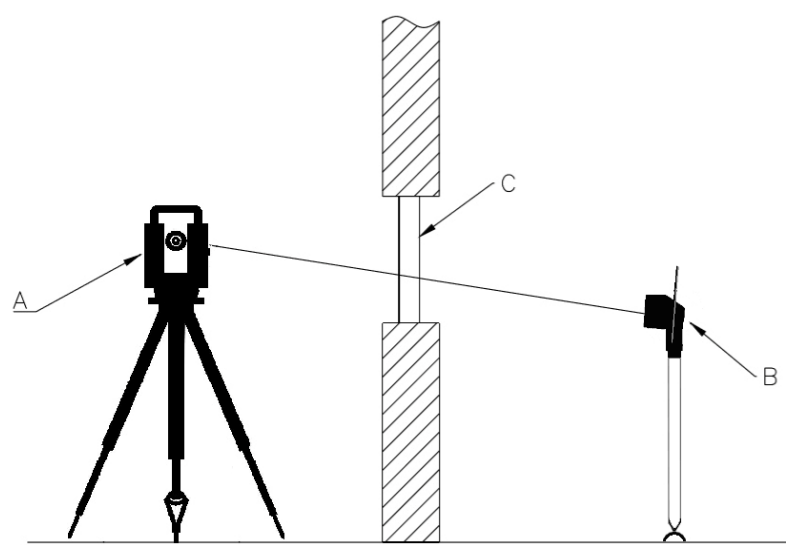

Рис. 5. Схема выполнения измерений

\section{Результаты измерений}

В ходе исследования измерения были проведены при четырех различных условиях:
- окно закрыто, и тахеометр находится в тепле (1-й вариант);

- окно открыто, и тахеометр находится в тепле (2-й вариант);

- окно закрыто, и тахеометр находится на улице (3-й вариант);

- окно открыто, и тахеометр находится на улице (4-й вариант).

Измерения выполнялись при температуре окружающего воздуха вне сооружения $-12{ }^{\circ} \mathrm{C}$ и $+22{ }^{\circ} \mathrm{C}$ внутри его. В точке А устанавливался тахеометр Leica TCR-405 и при закрытом окне его зрительная труба визировалась на отражатель В и измерялось расстояние АВ. Всего было выполнено две серии измерений по 20 расстояний в каждой серии (табл. 1). После этого окно открывалось, и измерения по аналогичной схеме повторялись (табл. 2).

Таблица 1

Измерение расстояния при закрытом окне и установке тахеометра внутри здания

\begin{tabular}{|c|c|c|c|c|c|c|c|}
\hline \multicolumn{8}{|c|}{ 1-я установка, точка $\mathrm{A}$} \\
\hline \multicolumn{8}{|c|}{ Окно закрыто, тахеометр внутри здания } \\
\hline \multicolumn{4}{|c|}{ 1-я серия } & \multicolumn{4}{|c|}{ 2-я серия } \\
\hline $\begin{array}{l}\text { Номер } \\
\text { приема }\end{array}$ & $\mathrm{S}(\mathrm{M})$ & $\begin{array}{c}\text { Номер } \\
\text { приема }\end{array}$ & $\mathrm{S}(\mathrm{M})$ & $\begin{array}{c}\text { Номер } \\
\text { приема }\end{array}$ & $\mathrm{S}(\mathrm{M})$ & $\begin{array}{c}\text { Номер } \\
\text { приема }\end{array}$ & $\mathrm{S}(\mathrm{M})$ \\
\hline 1 & 25,2554 & 11 & 25,2559 & 1 & 25,2561 & 11 & 25,2563 \\
\hline 2 & 25,2556 & 12 & 25,2557 & 2 & 25,2560 & 12 & 25,2563 \\
\hline 3 & 25,2557 & 13 & 25,2558 & 3 & 25,2558 & 13 & 25,2561 \\
\hline 4 & 25,2557 & 14 & 25,2559 & 4 & 25,2555 & 14 & 25,2562 \\
\hline 5 & 25,2562 & 15 & 25,2558 & 5 & 25,2556 & 15 & 25,2557 \\
\hline 6 & 25,2561 & 16 & 25,2560 & 6 & 25,2558 & 16 & 25,2558 \\
\hline 7 & 25,2564 & 17 & 25,2561 & 7 & 25,2557 & 17 & 25,2557 \\
\hline 8 & 25,2562 & 18 & 25,2563 & 8 & 25,2558 & 18 & 25,2557 \\
\hline 9 & 25,2562 & 19 & 25,2564 & 9 & 25,2560 & 19 & 25,2557 \\
\hline 10 & 25,2560 & 20 & 25,2563 & 10 & 25,2562 & 20 & 25,2559 \\
\hline \multicolumn{4}{|c|}{ Cp. $=25$ м $256,0 \mathrm{MM}$} & \multicolumn{4}{|c|}{ Cp. $=25$ м 255,9 мм } \\
\hline \multicolumn{8}{|c|}{ Итоговое среднее = 25м 256,0 мм } \\
\hline
\end{tabular}

Таблица 2

Измерение расстояния при открытом окне и установке тахеометра внутри здания

\begin{tabular}{|c|c|c|c|c|c|c|c|}
\hline \multicolumn{7}{|c|}{ Окно открыто, тахеометр внутри здания } \\
\hline \multicolumn{7}{|c|}{1 -я серия } \\
\hline $\begin{array}{c}\text { Номер } \\
\text { приема }\end{array}$ & $\mathrm{S}(\mathrm{M})$ & $\begin{array}{c}\text { Номер } \\
\text { приема }\end{array}$ & $\mathrm{S}(\mathrm{m})$ & $\begin{array}{c}\text { Номер } \\
\text { приема }\end{array}$ & $\mathrm{S}(\mathrm{м})$ & $\begin{array}{c}\text { Номер } \\
\text { приема }\end{array}$ & $\mathrm{S}$ (м) \\
\hline 1 & 25,2501 & 11 & 25,2500 & 1 & 25,2501 & 11 & 25,2501 \\
\hline 2 & 25,2501 & 12 & 25,2501 & 2 & 25,2502 & 12 & 25,2501 \\
\hline 3 & 25,2502 & 13 & 25,2500 & 3 & 25,2500 & 13 & 25,2502 \\
\hline 4 & 25,2500 & 14 & 25,2500 & 4 & 25,2499 & 14 & 25,2502 \\
\hline 5 & 25,2501 & 15 & 25,2500 & 5 & 25,2498 & 15 & 25,2501 \\
\hline 6 & 25,2502 & 16 & 25,2501 & 6 & 25,2501 & 16 & 25,2503 \\
\hline 7 & 25,2501 & 17 & 25,2501 & 7 & 25,2499 & 17 & 25,2502 \\
\hline 8 & 25,2500 & 18 & 25,2499 & 8 & 25,2502 & 18 & 25,2502 \\
\hline 9 & 25,2501 & 19 & 25,2499 & 9 & 25,2499 & 19 & 25,2502 \\
\hline 10 & 25,2501 & 20 & 25,2500 & 10 & 25,2500 & 20 & 25,2504 \\
\hline
\end{tabular}


По окончании измерений при установке тахеометра внутри здания вычислялись величины средних расстояний для двух положений окна. Исследованиями было установлено, что разность измеренных расстояний при закрытом и открытом окне при установке тахеометра внутри здания составляет 5,8 мм.

После этого тахеометр центрировался в точке $B$, а отражатель в точке $A$ и измерения выполнялись по аналогичной методике. Результаты исследований приведены в табл. 3 и 4, из которых следует, что и при установке тахеометра снаружи здания разность измеренных расстояний составляет 5,7 мм.

Таблица 3

Измерение расстояния при закрытом окне и установке тахеометра вне здания

\begin{tabular}{|c|c|c|c|c|c|c|c|}
\hline \multicolumn{8}{|c|}{ 2-я установка, точка В } \\
\hline \multicolumn{8}{|c|}{ Окно закрыто, тахеометр снаружи здания } \\
\hline \multicolumn{4}{|c|}{ 1-я серия } & \multicolumn{4}{|c|}{ 2-я серия } \\
\hline $\begin{array}{l}\text { Номер } \\
\text { приема }\end{array}$ & $\mathrm{S}(\mathrm{M})$ & $\begin{array}{c}\text { Номер } \\
\text { приема }\end{array}$ & $\mathrm{S}(\mathrm{M})$ & $\begin{array}{c}\text { Номер } \\
\text { приема }\end{array}$ & $\mathrm{S}(\mathrm{M})$ & $\begin{array}{l}\text { Номер } \\
\text { приема }\end{array}$ & S (M) \\
\hline 1 & 25,2562 & 11 & 25,2556 & 1 & 25,2558 & 11 & 25,2558 \\
\hline 2 & 25,2557 & 12 & 25,2557 & 2 & 25,2557 & 12 & 25,2555 \\
\hline 3 & 25,2558 & 13 & 25,2558 & 3 & 25,2558 & 13 & 25,2558 \\
\hline 4 & 25,2556 & 14 & 25,2556 & 4 & 25,2558 & 14 & 25,2555 \\
\hline 5 & 25,2556 & 15 & 25,2557 & 5 & 25,2557 & 15 & 25,2556 \\
\hline 6 & 25,2558 & 16 & 25,2560 & 6 & 25,2557 & 16 & 25,2564 \\
\hline 7 & 25,2557 & 17 & 25,2561 & 7 & 25,2558 & 17 & 25,2558 \\
\hline 8 & 25,2557 & 18 & 25,2557 & 8 & 25,2559 & 18 & 25,2555 \\
\hline 9 & 25,2555 & 19 & 25,2557 & 9 & 25,2557 & 19 & 25,2564 \\
\hline 10 & 25,2557 & 20 & 25,2558 & 10 & 25,2556 & 20 & 25,2555 \\
\hline \multicolumn{4}{|c|}{ Cp. $=25$ м 255,8 мм } & \multirow{2}{*}{\multicolumn{4}{|c|}{ Cp. $=25$ м 255,8 мм }} \\
\hline & & & $\mathrm{cpe}$ & & & & \\
\hline
\end{tabular}

Таблица 4

Измерение расстояния при открытом окне и установке тахеометра вне здания

\begin{tabular}{|c|c|c|c|c|c|c|c|}
\hline \multicolumn{8}{|c|}{ 2-я установка, точка В } \\
\hline \multicolumn{8}{|c|}{ Окно открыто, тахеометр снаружи здания } \\
\hline \multicolumn{4}{|c|}{ 1-я серия } & \multicolumn{4}{|c|}{ 2-я серия } \\
\hline $\begin{array}{l}\text { Номер } \\
\text { приема }\end{array}$ & $\mathrm{S}(\mathrm{м})$ & $\begin{array}{l}\text { Номер } \\
\text { приема }\end{array}$ & $\mathrm{S}(\mathrm{M})$ & $\begin{array}{l}\text { Номер } \\
\text { приема }\end{array}$ & $\mathrm{S}(\mathrm{M})$ & $\begin{array}{l}\text { Номер } \\
\text { приема }\end{array}$ & $\mathrm{S}(\mathrm{M})$ \\
\hline 1 & 25,2502 & 11 & 25,2501 & 1 & 25,2500 & 11 & 25,2500 \\
\hline 2 & 25,2503 & 12 & 25,2502 & 2 & 25,2499 & 12 & 25,2499 \\
\hline 3 & 25,2501 & 13 & 25,2503 & 3 & 25,2500 & 13 & 25,2500 \\
\hline 4 & 25,2502 & 14 & 25,2502 & 4 & 25,2501 & 14 & 25,2500 \\
\hline 5 & 25,2504 & 15 & 25,2504 & 5 & 25,2500 & 15 & 25,2500 \\
\hline 6 & 25,2503 & 16 & 25,2501 & 6 & 25,2502 & 16 & 25,2501 \\
\hline 7 & 25,2504 & 17 & 25,2501 & 7 & 25,2501 & 17 & 25,2500 \\
\hline 8 & 25,2503 & 18 & 25,2500 & 8 & 25,2500 & 18 & 25,2499 \\
\hline 9 & 25,2503 & 19 & 25,2501 & 9 & 25,2501 & 19 & 25,2499 \\
\hline 10 & 25,2504 & 20 & 25,2502 & 10 & 25,2501 & 20 & 25,2500 \\
\hline \multicolumn{4}{|c|}{ Cp. $=25$ м 250,2 мм } & \multicolumn{4}{|c|}{ Cp. $=25$ м 250,0 мм } \\
\hline & & & 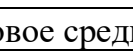 & 25 м 2 & & & \\
\hline
\end{tabular}

По результатам выполненных исследований были построены графики отклонения измеренных величин от среднего для каждого варианта. На графике все циклы измерений для каждого варианта объединены в один цикл (рис. 6). 


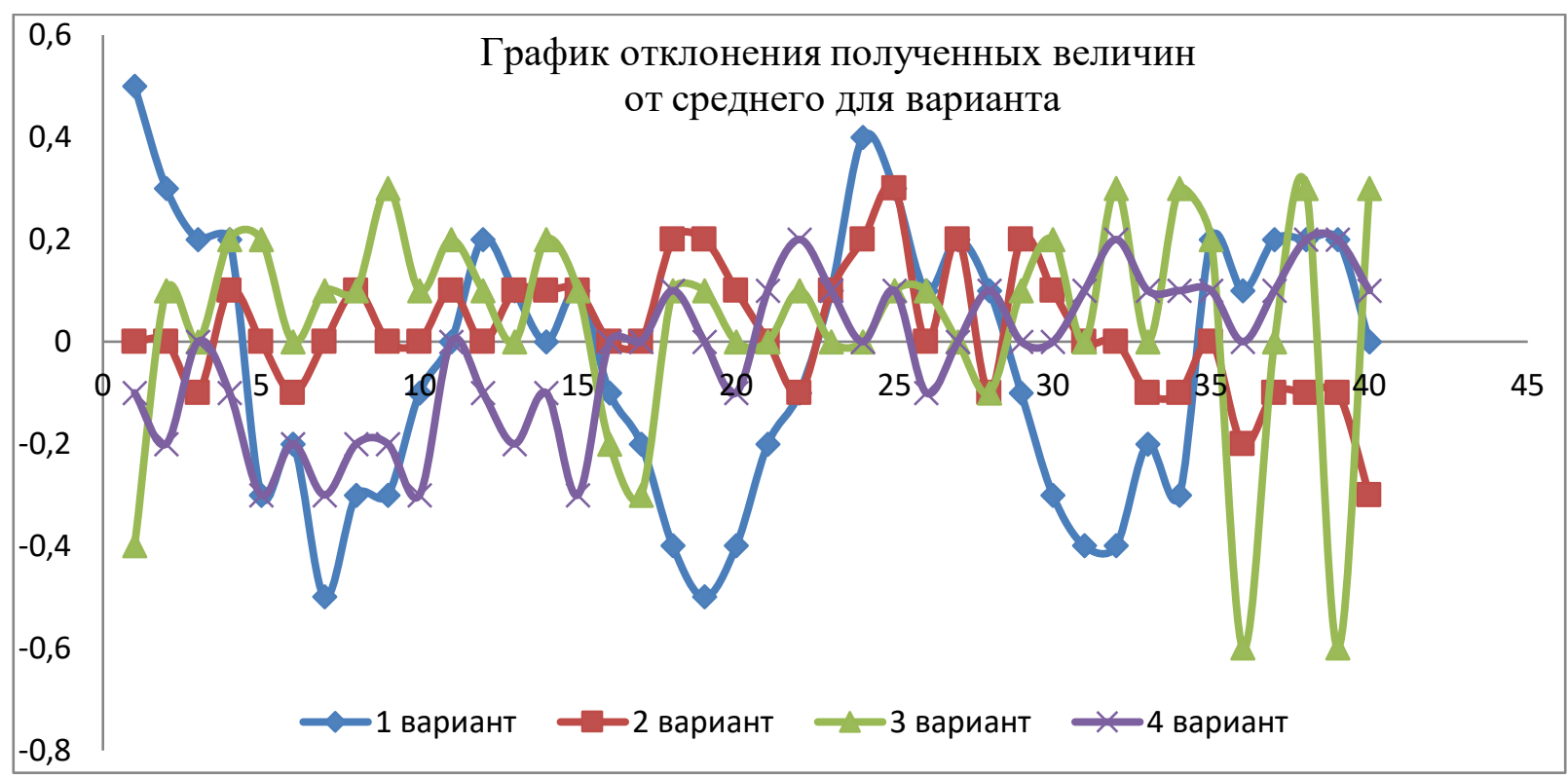

Рис. 6. График отклонения полученных величин от среднего для каждого варианта

Из рис. 6 следует, что окно создает одинаковую «задержку» для лазерного луча вне зависимости от того, где именно расположен прибор: в тепле или на холоде. Из этого можно сделать вывод о том, что изменения свойств стеклопакета, созданные перепадом температур, следует рассматривать именно как целостную систему.

Важной особенностью данных исследований является тот факт, что при закрытом окне измеряемое расстояние оказалось больше, что свидетельствует об удлинении этого расстояния вследствие изменения направления луча лазера оптической средой стекла.

Результаты исследований показали, что при прохождении луча через стекло измеряемое расстояние увеличивается, в нашем случае на 5,8 мм. Влияние разности температур при небольших расстояниях практически не сказывается на величине измеренного расстояния.

Определим величину СКО определения координат $x, y$ и $h$ с учетом ошибки измерения расстояния, равной 5,8 мм.

Координаты $x, y$ точки $B$ будут определяться способом полярной засечки. В этом случае СКО их определения можно найти по формуле

$$
m_{\rho}^{2}=m_{l}^{2}+\left(\frac{m_{\beta}}{\rho}\right)^{2} l^{2}+m_{\text {ц.p. }}^{2}+m_{\text {и }}^{2}+m_{\phi}^{2} .
$$

При $m_{\mathrm{u}}=2,0 \mathrm{MM}, m_{l}=5,8 \mathrm{MM}, m_{\phi}=2,0 \mathrm{MM}$, $m_{\text {и.p. }}=1,0$ мм, $m_{\beta}=2,0$ " получим $m_{\rho}=6,8$ мм.

Данная величина не будет позволять создавать внутреннюю разбивочную сеть с необходимой точностью при выполнении измерений через стекло.

Величину СКО определения превышения тригонометрическим нивелированием, вызванную влиянием только измерения расстояния и угла наклона, можно найти по формуле

$$
m_{h}=\sqrt{m_{s}^{2} \sin ^{2} \alpha+\frac{m_{\alpha}^{2}}{\rho^{2}} S^{2} \cos ^{2} \alpha}
$$

где $S$-расстояние до визирной цели; $\alpha$-угол наклона визирной оси тахеометра.

При $m_{\mathrm{s}}=5,8$ мм, $S=25,0$ м и $m_{\alpha}=2,0$ " получим $m_{h}=3,7$ мм. Данная величина также не будет позволять создавать внутреннюю высокоточную высотную сеть с необходимой точностью при выполнении измерений через стекло.

\section{Обсуждение}

В результате проведенных исследований были получены следующие результаты:

- резкий перепад температур воздуха на границе двух оптических сред (воздух стекло) не оказывает заметного влияния на величину измеряемого расстояния; 
- прохождение наклоненного луча лазера тахеометра через стеклянную оптическую среду существенно удлиняет измеряемое расстояние, изменяет величину измеряемого горизонтального угла и угла наклона, что, в конечном итоге, приводит к искажению координат $x, y$ и $h$ определяемого пункта внутренней разбивочной сети;

- величина ошибки получения координат является постоянной для заданной толщины стеклянных пластин и угла наклона (величины горизонтального угла), и она не зависит от того, в какую сторону производятся измерения. Данное обстоятельство необходимо учитывать при создании высокоточной внутренней разбивочной сети инженерного сооружения и передачу координат производить при горизонтальном положении зрительной трубы тахеометра;

- данную методику передачи координат внутрь инженерного сооружения с целью создания внутренней высокоточной разбивочной сети целесообразно применять при значительных (свыше 35-40 ${ }^{\circ} \mathrm{C}$ ) перепадах температур; необходимость в такой передаче координат имеет место при строительстве реакторных блоков АЭС;

- в летнее время передачу координат внутрь инженерного сооружения можно производить и через технологические ворота инженерного сооружения. однако в целом ряде случаев это приведет к значительному увеличению числа пунктов внешнего обоснования или увеличению длины нивелирных ходов, так как длина инженерного сооружения может достигать 450 м (длина главного корпуса АЭС).

Также необходимо отметить, что для контроля передачи координат внутрь инженерного сооружения измерения можно выполнить и через другой оконный проем. В этом случае разность полученных координат внутренней разбивочной сети должна соответствовать требованиям нормативных документов [2].

\section{Заключение}

Для обеспечения передачи координат в зимнее время на пункты внутреннего обоснования с сохранением требуемой точности целесообразно визирование производить через оконные пролеты. В этом случае влияние основного источника ошибок - турбулентности воздуха практически - полностью исключается. При этом передача координат может производиться с установкой тахеометра внутри или вне инженерного сооружения. Для исключения параллельного переноса визирного луча передачу координат необходимо производить при горизонтальном положении зрительной трубы тахеометра.

\section{БИБЛИОГРАФИЧЕСКИЙ СПИСОК}

1. Беспалов Ю. И., Дьяконов Ю. П., Терещенко Т. Ю. Наблюдение за осадками зданий и сооружений способом тригонометрического нивелирования // Геодезия и картография. - 2010. - № 8. - С. 8-10.

2. Геодезические работы в строительстве. Актуализированная редакция СНиП 3.01.03-84 : СП 126.13330.2012. - М. : Минрегион России, 2012. - 84 с.

3. Инструкция по нивелированию I, II, III и IV классов. ГКИНП (ГНТА) - 03-010-03.2004. - М. : ЦНИИГАиК, 2004. - 226 с.

4. Никонов A. В. Исследование влияния вертикальной рефракции на результаты тригонометрического нивелирования короткими лучами способом из середины // Изв. вузов. Геодезия и аэрофотосъемка. - 2014. - № 1. - С. 28-34.

5. Никонов А. В. Исследование точности тригонометрического нивелирования способом из середины с применением электронных тахеометров // Вестник СГГА. - 2013. - Вып. 2 (22). - С. 26-35.

6. Никонов А. В., Чешева И. Н., Лифашина Г. В. Влияние перепадов температуры окружающей среды на главное условие цифрового нивелира при наблюдениях за осадками фундаментов зданий и сооружений // Вестник СГУГиТ. - 2016. - № 2 (34). - С. 24-33.

7. Никонов А. В. Методика тригонометрического нивелирования первого и второго разрядов // Изв. вузов. Геодезия и аэрофотосъемка. - 2015. - № 5/С. - С. 39-45.

8. Новоселов Д. Б., Новоселов Б. А. Исследование работы высокоточного цифрового нивелира в условиях недостаточной освещенности // Интерэкспо ГЕО-Сибирь-2013. IX Междунар. науч. конгр. 
: Междунар. науч. конф. «Геодезия, геоинформатика, картография, маркшейдерия» : сб. материалов в 3 т. (Новосибирск, 15-26 апреля 2013 г.). - Новосибирск: СГГА, 2013. Т. 1. - С. 117-121.

9. Сальников В. Г., Скрипников В. А., Скрипникова М. А., Хлебникова Т. А. Применение современных автоматизированных геодезических приборов для мониторинга гидротехнических сооружений ГЭС // Вестник СГУГиТ. - 2018. - Т. 23, № 3. - С. 108-124.

10. Рябова Н. М. Исследование влияния различной освещенности на отсчеты по рейке // Интерэкспо ГЕО-Сибирь-2013. IX Междунар. науч. конгр. : Междунар. науч. конф. «Геодезия, геоинформатика, картография, маркшейдерия» : сб. материалов в 3 т. (Новосибирск, 15-26 апреля 2013 г.). - Новосибирск : СГГА, 2013. Т. 1. - С. 42-45.

11. Уставич Г. А., Китаев Г. Г., Никонов А. В., Сальников В. Г. Создание геодезической основы для строительства объектов энергетики // Изв. вузов. Геодезия и аэрофотосъемка. - 2013. - № 6. - С. 8-13.

12. Соболева Е. Л., Рябова Н. М., Сальников В. Г. Исследование влияния рефракции на результаты нивелирования цифровыми нивелирами // ГЕО-Сибирь-2011. VII Междунар. науч. конгр. : сб. материалов в 6 т. (Новосибирск, 19-29 апреля 2011 г.). - Новосибирск : СГГА, 2011. Т. 1, ч. 1. - С. 32-36.

13. Руководство по эксплуатации V.5.5 Leica TPS1200+. - Heerbrugg, Switzerland, Leica Geosystems AG, 2005. - $215 \mathrm{c}$.

14. Уставич Г. А. О совершенствовании технологий нивелирования // Геодезия и картография. 2005. - № 3. - C. 11-13.

15. Уставич Г. А., Рахымбердина М. Е., Никонов А. В., Бабасов С. А. Разработка и совершенствование технологии инженерно-геодезического нивелирования тригонометрическим способом // Геодезия и картография. - 2013. - № 6. - С. 17-22.

16. Шоломицкий А. А., Лагутина Е. К., Соболева Е. Л. Высокоточные геодезические измерения при деформационном мониторинге аквапарка // Вестник СГУГиТ. - 2017. - Т. 22, № 3. - С. 45-59.

Получено 05.04.2021

(C) Г. А. Уставич, Н. С. Косарев, Д. А. Баранников, И. А. Мезенцев, Д. В. Бирюков,

\section{METHOD OF TRANSMITTING THE COORDINATES OF THE TOTAL STATION TO THE POINTS OF THE INTERNAL CENTRAL NETWORK OF AN ENGINEERING CONSTRUCTION}

\section{Georgij A. Ustavich}

Siberian State University of Geosystems and Technologies, 10, Plakhotnogo St., Novosibirsk, 630108, Russia, D. Sc., Professor, Department of Engineering Geodesy and Mine Surveying, phone: (383)343-29-55, e-mail: ystavich@mail.ru

\section{Nikolay S. Kosarev}

Siberian State University of Geosystems and Technology, 10 Plakhotnogo St., Novosibirsk, 630108, Russia, Ph. D., Associate Professor, Department of Engineering Geodesy and Mine Surveying, phone: (913)706-91-95, e-mail: kosarevnsk@yandex.ru

\section{Dmitriy A. Barannikov}

Siberian State University of Geosystems and Technologies, 10, Plakhotnogo St., Novosibirsk, 630108, Russia, $\mathrm{Ph}$. D. Student, Department of Engineering Geodesy and Mine Surveying, Surveying, phone: (913)753-95-82, e-mail: eddieogilvie@yandex.ru

\section{Ivan A. Mezentsev}

Siberian State University of Geosystems and Technologies, 10, Plakhotnogo St., Novosibirsk, 630108, Russia, $\mathrm{Ph}$. D. Student, Department of Engineering Geodesy and Mine Surveying, Surveying, phone: (923)241-80-42, e-mail: vania.mezentzew@yandex.ru

\section{Dmitriy V. Birukov}

Siberian State University of Geosystems and Technologies, 10, Plakhotnogo St., Novosibirsk, 630108, Russia, $\mathrm{Ph}$. D. Student, Department of Engineering Geodesy and Mine Surveying, Surveying, phone: (913)895-78-66, e-mail: birykovdmitriy1@gmail.com 
When creating an external planning and high-altitude justification on construction sites, and then internal center networks for the purpose of transmitting coordinates in a number of cases, geodetic measurements are performed through an optical medium, which in some areas has a different refractive index. This is the case when performing such measurements in the winter season, when the transmission is made through the technological gate of the temporary end of an engineering structure, for example, a nuclear or thermal power plant. The disadvantage of this method is the influence of significant air turbulence at the border of a sharp temperature drop in winter. To eliminate this influence, it is proposed to transmit coordinates inside the engineering structure through window openings. In this case, the total station can be located inside the engineering structure or outside it. When implementing the proposed method, the influence of a sharp temperature drop on the measurement results is almost completely excluded. Studies have established that when the coordinates are transmitted through the glass to the points of internal justification, a parallel transfer of the sighting beam occurs. To exclude it, the sighting must be performed at the horizontal position of the total station telescope. The article presents the results of studies of the accuracy of measuring distances and angles when the sighting (laser) beam of the total station passes through two optical media (air-glass-air) at different air temperature differences.

Keywords: total station, determination of coordinates, temperature difference, refractive index of optical media

\section{REFERENCES}

1. Bespalov, Yu. I., Diakonov, Yu. P., \& Tereshchenko, T. Yu. (2010). Observation of precipitation of buildings and structures by the method of trigonometric leveling. Geodeziia i kartografiia [Geodesy and Cartography], 8, 8-10 [in Russian].

2. Code of Practice. (2012). Geodetic works in construction. Updated version of SNiP 3.01.03-84: SP 126.13330.2012. Moscow: Minregion of Russia Publ., 84 p. [in Russian].

3. Geodetic, Cartographic Instructions, Norms and Regulations. (2004). Instructions for leveling classes I, II, III and IV. GKINP (GNTA) 03-010-03. 2004. Moscow: TsNIIGAiK Publ., 226 p. [in Russian].

4. Nikonov, A. V. (2014). Investigation of the influence of vertical refraction on the results of trigonometric leveling by short beams using the method from the middle. Izvestiya vuzov. Geodeziya i aerofotos"emka [Izvestiya vuzov. Geodesy and Aerophotosurveying], 1, 28-34 [in Russian].

5. Nikonov, A. V. (2013). Investigation of the accuracy of trigonometric leveling by the method from the middle with the use of electronic total stations. Vestnik SGGA [Vestnik SSGA], 2(22), 26-35 [in Russian].

6. Nikonov, A. V., Chesheva, I. N., \& Lifashina, G. V. (2016). Influence of ambient temperature differences on the main condition of the digital level during observations of precipitation of foundations of buildings and structures. Vestnik SGUGiT [Vestnik SSUGT], 2(34), 24-33 [in Russian].

7 Nikonov, A. V. (2015). Technique of trigonometric leveling of the first and second digits. Izvestiya vuzov. Geodeziya i aerofotos"emka [Izvestiya vuzov. Geodesy and Aerophotosurveying], 5/S, 39-45 [in Russian]..

8. Novoselov, D. B., \& Novoselov, B. A. (2013). Investigation of the operation of a high-precision digital level in low-light conditions. In Sbornik materialov Interekspo GEO-Sibir'-2015: Mezhdunarodnoy nauchnoy konferentsii: T. 1. Geodezija, geoinformatika, kartografija, markshejderija [Proceedings of Interexpo GEOSiberia-2013: International Scientific Conference: Vol. 1. Geodesy, Geoinformatics, Cartography, Mine Surveying] (pp. 117-121). Novosibirsk: SSGA Publ. [in Russian].

9. Salnikov, V. G., Skripnikov, V. A., Skripnikova, M. A., Khlebnikova, T. A. (2018). The use of modern automated geodetic monitoring devices waterworks HPP. Vestnik SGUGiT [Vestnik SSUGT], 23(3), 108-124 [in Russian].

10. Ryabova, N. M. (2013). The influence of different light conditions on the counts on the rod. In Sbornik materialov Interekspo GEO-Sibir'-2013: Mezhdunarodnoy nauchnoy konferentsii: T. 1. Geodezija, geoinformatika, kartografija, markshejderija [Proceedings of Interexpo GEO-Siberia-2013: International Scientific Conference: Vol. 1. Geodesy, Geoinformatics, Cartography, Mine Surveying] (pp. 42-45). Novosibirsk: SSGA Publ. [in Russian].

11. Ustavich, G. A., Kitaev, G. G., Nikonov, A. V., \& Salnikov, V. G. (2013). Creating a geodetic basis for the construction of energy facilities. Izvestiya vuzov. Geodeziya i aerofotos"emka [Izvestiya vuzov. Geodesy and Aerophotosurveying], 6, 8-13 [in Russian]. 
12. Soboleva, E. L., Ryabova, N. M., \& Salnikov, V. G. (2011). Investigation of the influence of refraction on the results of leveling with digital levels. In Sbornik materialov GEO-Sibir'-2011: T. 1, ch. 1 [Proceedings of GEO-Siberia-2011: Vol. 1, Part 1] (pp. 32-36). Novosibirsk: SSGA Publ. [in Russian].

13. User manual V. 5. 5 Leica TPS1200+. (2005). Heerbrugg, Switzerland, Leica Geosystems AG, 215 p.

14. Ustavich, G. A. (2005). On improving leveling technologies // Geodesy and cartography. - 2005. - No. 3. - p. 11-13.

15. Ustavich G. A., Rakhymberdina M. E., Nikonov A. V., \& Babasov S. A. Development and improvement of the technology of engineering-geodetic leveling by the trigonometric method. Geodeziia i kartografiia [Geodesy and Cartography], 6, 17-22 [in Russian].

16. Sholomitsky, A. A., Lagutina, E. K., \& Soboleva, E. L. (2017). High-precision geodetic measurements in the deformation monitoring of the water park. Vestnik SGUGiT [VestnikSSUGT], 22(3), 45-59 [in Russian].

Received 05.04.2021

(C) G. A. Ustavich, N. S. Kosarev, D. A. Barannikov, I. A. Mezentsev, D. V. Birukov, 2021 
УДК 550.83

DOI 10.33764/2411-1759-2021-26-5-63-74

\section{МЕТОДИКА ОПРЕДЕЛЕНИЯ СОГЛАСУЮЩИХ ПАРАМЕТРОВ ГЕЛЬМЕРТА ДЛЯ ЛОКАЛЬНЫХ ТЕРРИТОРИЙ}

\section{Николай Кириллович Шендрик}

Сибирский государственный университет геосистем и технологий, Россия, 630108, г. Новосибирск, ул. Плахотного, 10, заведующий лабораторией кафедры космической и физической геодезии, тел. (913)739-55-17, e-mail: snk_aig@mail.ru

Разработана методика определения согласующих параметров Гельмерта для преобразования координат пунктов из общеземной в референцную систему координат. Методика основана на максимальном совмещении поверхностей общеземного и референцного эллипсоидов в пределах некоторой локальной территории и не предполагает знания высот квазигеоида. Радиус локальной территории ограничивается заданной методичесой погрешностью преобразования координат из общеземной системы в проекцию Гаусса - Крюгера. Для методической погрешности $\pm 2-3$ см радиус локальной территории составляет порядка 200 км. Приведены два варианта определения согласующих параметров Гельмерта для четвертой трехградусной зоны местной системы координат (МСК) Новосибирской области: по реконструированным координатам и высотам спутниковых дифференциальных геодезических станций $(С Д Г С)$ и по каталожным координатам и высотам пунктов государственной геодезической сети (ГГС), расположенных на этой же территории.

Ключевые слова: методика, согласующие параметры Гельмерта, локальная территория, преобразование координат, общеземная и референцная система координат, сближение поверхностей эллипсоидов, высоты квазигеоида, цифровая модель геоида, геодезическая и нормальная высота, проекция Гаусса - Крюгера, местная система координат, ключ перехода

\section{Введение}

Семипараметрическое преобразование пространственных прямоугольных координат по способу Гельмерта является неотъемлемой составной частью алгоритмов обработки спутниковых геодезических измерений, в том числе, для обеспечения связи между общеземными и референцными системами координат $[1,2]$. Общая схема преобразования координат из общеземной в референцную систему отображена на рис. 1.

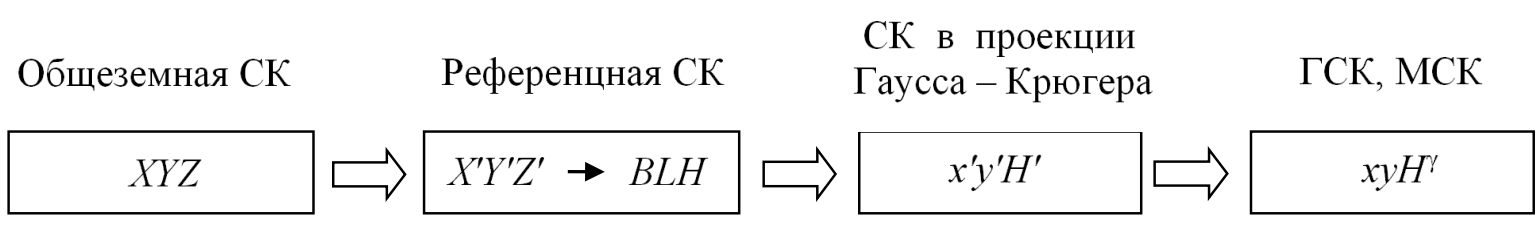

Рис. 1. Общая схема преобразования координат из общеземной системы в референцную

Основными этапами преобразований являются:

1) преобразование пространственных прямоугольных координат (XYZ) из

общеземной системы в референцную прямоугольную пространственную систему координат $\left(X^{\prime} Y^{\prime} Z^{\prime}\right)$ по способу Гельмерта с использованием семи параметров $(\Delta X o, \Delta Y o$,
$\Delta Z o, W x, W y, W z, m)$, где $\Delta X o, \Delta Y o, \Delta Z o-$ линейные параметры смещения начал координат для общеземной и референцной систем; $W x, W y, W z$ - углы разворота осей абсцисс, ординат и аппликат; $m$ - разность линейных масштабов;

2) преобразование референцных пространственных прямоугольных координат $\left(X^{\prime} Y^{\prime} Z^{\prime}\right)$ 
в геодезические $(B L H)$ координаты для референцного эллипсоида;

3) преобразование референцных геодезических координат $(B L H)$ в прямоугольные плоские координаты $\left(x^{\prime} y^{\prime}\right)$ в проекции Гаусса Крюгера на референц-эллипсоиде и ортометрические высоты $\left(H^{\prime}\right)$;

4) преобразование из плоских прямоугольных координат и высот в проекции Гаусса Крюгера $\left(x^{\prime} y^{\prime} H^{\prime}\right)$ в государственную (ГСК) или местную систему координат (МСК).

При «неточных» параметрах Гельмерта преобразование в проекцию Гаусса - Крюгера приводит к несоответствию вычисленных координат $\left(x^{\prime} y^{\prime} H^{\prime}\right)$ с их каталожными значениями $\left(x y H^{\prime}\right)$. Переход от геодезических высот к нормальным возможен при наличии модели высот квазигеоида относительно референцного эллипсоида. На практике, из-за проблем с наличием модели высот квазигеоида, вычисляют ортометрические высоты с использованием глобальной цифровой модели высот геоида, например, EGM2008, а затем разности каталожных нормальных и вычисленных ортометрических высот аппроксимируются плоскостью, после чего выполняется переход к нормальным высотам [3]. Преобразование от вычисленных в проекции Гаусса - Крюгера плоских координат к каталожным осуществляется путем вычисления ключей перехода к ГСК или МСК.

Для определения параметров Гельмерта требуется, чтобы для опорных (участвующих в решении задачи) пунктов имелись пространственные прямоугольные координаты в двух системах - общеземной и референцной. Количество опорных пунктов должно быть не менее трех, но для повышения надежности и точности их количество должно быть более представительным. Точность определения параметров Гельмерта в значительной мере зависит от точности исходных координат в двух системах, от конфигурации расположения и числа опорных пунктов. В общеземной системе опорные пункты могут быть определены с максимально возможной точностью от пунктов международной геодинамической сети (МГС). Точность референцных $\left(X^{\prime} Y^{\prime} Z^{\prime}\right)$ лимитируется точностью плоских прямоугольных координат и нормальных высот в каталогах и точностью используемой модели высот квазигеоида. Решение проблем, связанных с точностью представления координат пунктов в референцной пространственной системе координат, является важнейшей предпосылкой успешного решения задачи определения параметров Гельмерта. Вариантами решения для систем координат малой точности (СК-42, СК95) могут быть способы высокоточной реконструкции координат и высот пунктов [4], либо переход на новую высокоточную ГСК-2011 или иной ее аналог. Предполагается, что для ограниченных по площади территорий решение задачи определения параметов Гельмерта будет более простым, чем для территорий, значительных по площади [2].

\section{Цель работы и исходные предпосылки}

Целью настоящей работы является рассмотрение методики определения согласующих параметров Гельмерта для локальных территорий, которые могли бы позволить осуществлять цепочку координатных преобразований в проекцию Гаусса - Крюгера потенциально с точностью спутниковых определений или хотя бы с точностью каталожных значений координат и нормальных высот. Для определения параметров Гельмерта важно решить проблему обратного перехода от плоских прямоугольных координат и нормальных высот к пространственным прямоугольным координатам в референцной системе с необходимой точностью. Здесь неопределенным звеном является отсутствие доступной цифровой модели высот квазигеоида относительно референцного эллипсоида. Для эллипсоида Красовского, который до настоящего времени имеет широкое распространение в России, опубликована графическая картосхема высот квазигеоида [5], но она не обладает необходимой детализацией и точностью. В этой связи актуальной задачей может быть создание такой методики определения параметров Гельмерта, в которой не были бы задействованы высоты квазигеоида.

\section{Методика решения задачи определения согласующих параметров Гельмерта}

Исключить использование высот квазигеоида для определения согласующих параметров Гельмерта предлагается путем сближения (соприкосновения) поверхностей об- 
щеземного и референцного эллипсоидов в пределах некоторой локальной территории. Соприкосновение возможно в двух случаях: в точке при совпадении нормалей эллипсои- дов (рис. 2) и вдоль некоторой замкнутой кривой, близкой к окружности при небольшом частичном «погружении» поверхности одного эллипсоида под другой (рис. 3).

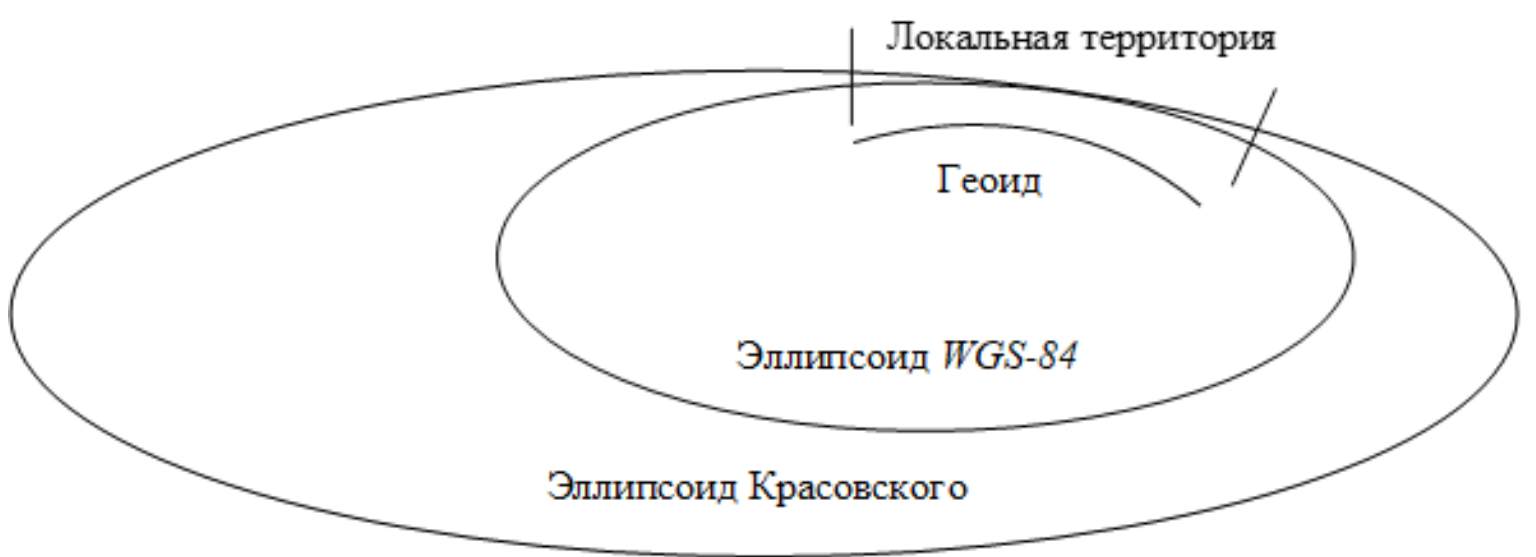

Рис. 2. Принципиальная схема для определения согласующих параметров Гельмерта для локальных территорий без привлечения информации о модели высот квазигеоида при совмещении поверхностей эллипсоидов в точке

Из-за несовпадения формы и размеров эллипсоидов по мере удаления от точки касания (рис. 2) будет нарастать методическая погрешность. В табл. 1 приведен расчет на соответствие методической погрешности и радиуса локальной территории для Новосибирской области. Числовые данные получены с учетом средних радиусов кривизны поверхностей обще- земного эллипсоида WGS-84 и эллипсоида Красовского, примерно для центра области. Из табл. 1 следует, что в радиусе локальной территории до 200 км теоретически методическая погрешность не превышает \pm 26 мм. Очевидно, что чем более близкими будут размеры и формы эллипсоидов, тем в большей мере будет увеличиваться площадь локальной области.

\section{Таблища 1}

Соответствие методической погрешности и радиуса локальной территории для Новосибирской области для эллипсоидов WGS-84 и Красовского

\begin{tabular}{|c|c|c|c|c|c|c|c|c|c|c|c|c|c|c|}
\hline $\begin{array}{c}\text { Методическая } \\
\text { погрешность } \\
\text { (мм) }\end{array}$ & \pm 2 & \pm 3 & \pm 4 & \pm 5 & \pm 7 & \pm 8 & \pm 10 & \pm 12 & \pm 14 & \pm 16 & \pm 18 & \pm 21 & \pm 24 & \pm 26 \\
\hline $\begin{array}{c}\text { Радиус } \\
\text { локальной тер- } \\
\text { ритории } \\
\text { (км) }\end{array}$ & 55 & 66 & 78 & 89 & 100 & 111 & 122 & 133 & 144 & 156 & 167 & 178 & 189 & 200 \\
\hline
\end{tabular}

В реальности, алгоритм сближения поверхностей эллипсоидов осуществляется через приравнивание нулю геодезических высот опорных пунктов в общеземной и референцной системах координат и решения задачи определения параметров Гельмерта в соответствии с критерием метода наименьших квадратов (МНК) [6], как это графически условно изображено на рис. 3. В этом случае влияние методической ошибки может быть уменьшено примерно вдвое. Максимальные значения методических погрешностей будут распределены в центральной и периферийной зонах, а близкие к нулю -- в средней полосе в районе 0,5 радиуса от центра локальной территории. 


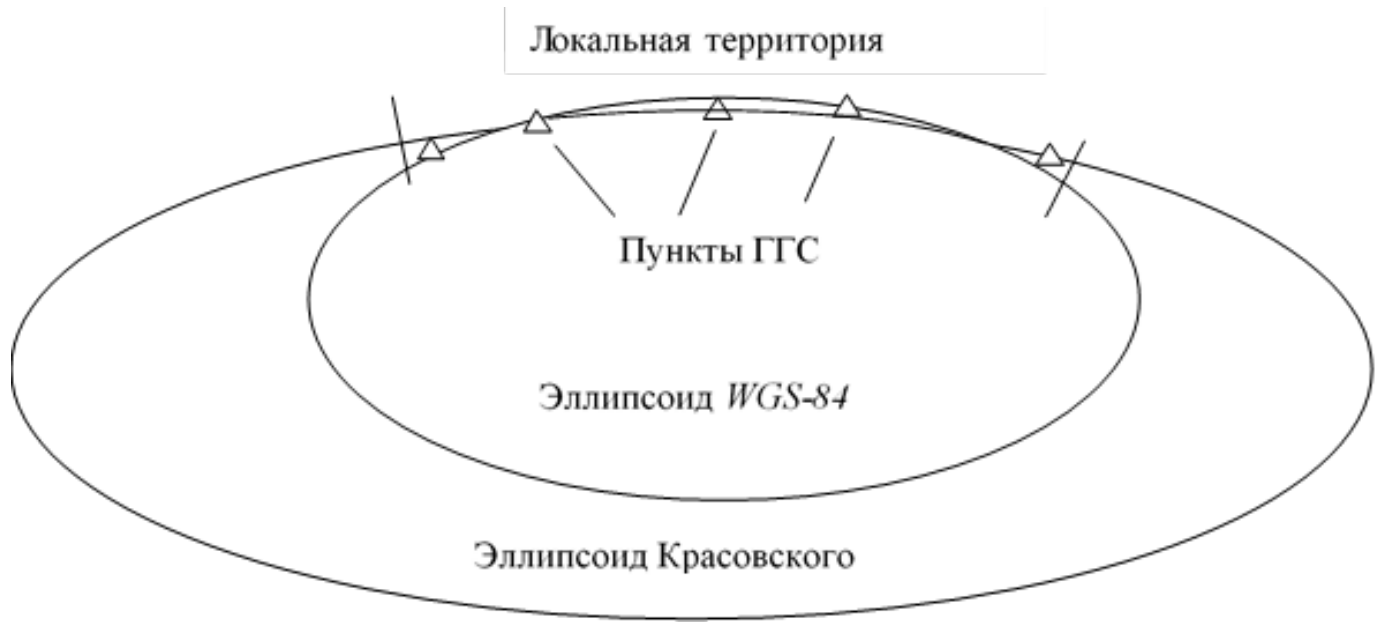

Рис. 3. Сближение поверхностей общеземного и референцного эллипсоидов по опорным пунктам по методу наименьших квадратов

Благодаря точному заданию геодезических высот пунктов в референцной и общеземной системах координат появляется возможность исключить из цепочки преобразований высоты квазигеоида и, тем самым, максимально повысить точность определения параметров Гельмерта для локальных территорий. Согласующие параметры Гельмерта, позволяют осуществлять переход координат из общеземной системы в референцную в пределах любых трехградусных зон и в широтной полосе порядка 400 км.

Нормальные высоты рекомендуется вычислять с использованием глобальной модели высот геоида EGM2008 по формулам:

$$
\begin{gathered}
H^{\gamma}=H-\varsigma+\Delta H ; \\
\Delta H=A x+B y+C,
\end{gathered}
$$

где $H^{\gamma}$ - нормальная высота в референцной системе координат; $H$ - геодезическая высота в WGS-84; ऽ - высота геоида для эллипсоида WGS-84 по модели EGM2008;

$\Delta H$ - поправка за систематическое смещение и наклон плоскости для разностей нормальных и ортометрических высот;

$A, B, C$ - коэффициенты для плоскости, аппроксимирующие, соответственно, наклоны $(w N, w E)$ и систематическое смещение разностей нормальных и ортометрических высот $\left(\Delta H_{o}\right)$ в пределах локальной территории.
Для решения задачи определения согласующих параметров Гельмерта создан пакет из алгоритмических программ. Исходными данными служат геодезические координаты в системе WGS-84 или в иной общеземной системе координат и плоские прямоугольные координаты в проекции Гаусса - Крюгера и нормальные высоты опорных пунктов. Выходными данными являются согласующие параметры Гельмерта и контрольная таблица разностей вычисленных и каталожных значений для плоских прямоугольных координат и нормальных высот. Для вычисления нормальных высот на этапе преобразования от геодезических высот в общеземной системе координат необходимо, в дополнение к перечисленным исходным данным, иметь цифровую модель высот геоида EGM2008 [7], являющуюся, на данный момент, одной из лучших глобальных моделей [8-12].

\section{Апробация методики определения согласующих параметров Гельмерта}

Для апробации методики взята локальная территория в диапазоне $4^{\circ}$ по долготе и $2^{\circ}$ по широте, в пределах которой располагается восточная часть Новосибирской области, в том числе четвертая зона МСК региона. Для упрощения, координаты в МСК моделировались путем пересчета координат пунктов в СК-95 с осевого меридиана 14-й шестиградусной зоны на осевой меридиан 4-й трехградусной зоны МСК региона. 
Для этой территории представлено два варианта вычисления согласующих параметров Гельмерта:

1) для 14 пунктов СДГС, имеющих реконструированные (сопоставимые с точностью спутниковых измерений) нормальные высоты и координаты;

2) для 20 пунктов ГГС с нереконструированными (каталожными) нормальными высотами и координатами.

Схема расположения пунктов СДГС на территории показана на рис. 4. Пункты ГГС практически повторяют конфигурацию пунктов СДГС.

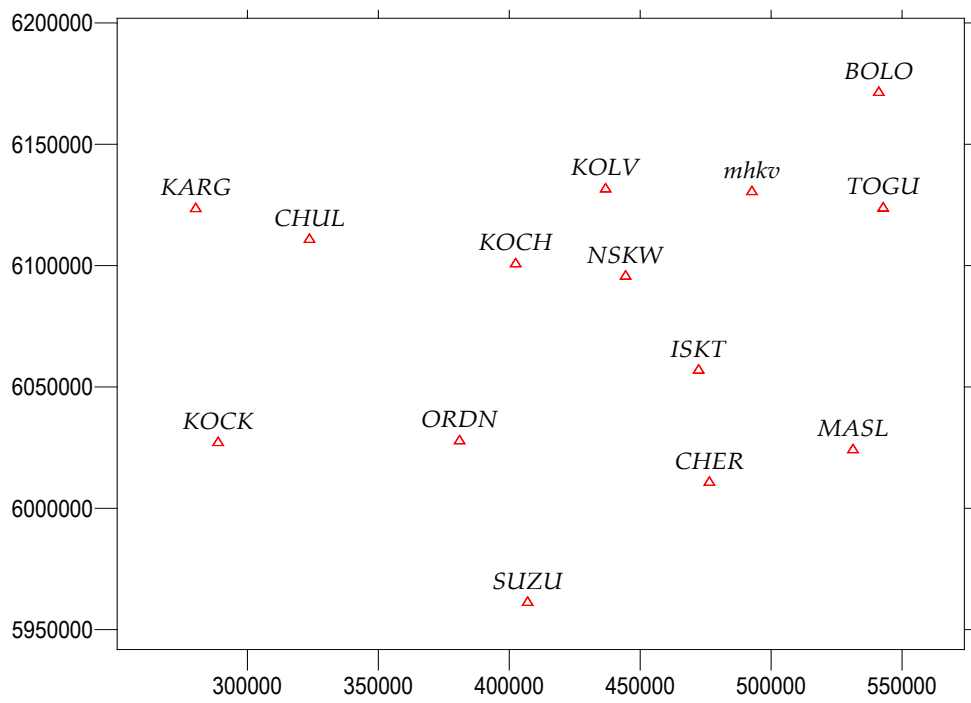

Рис. 4. Схема размещения пунктов СДГС в восточной части Новосибирской области

Координаты СДГС и ГГС в системе WGS-84 определены из геодезической привязки к пунктам МГС с точностью субсантиметра (величины в интервале менее $\pm 1,5$ см). Вычисленные согласующие параметры Гельмерта для обоих вариантов представлены в табл. 2.

Таблища 2

Согласующие параметры Гельмерта для 4-й зоны МСК Новосибирской области для реконструированных координат СДГС (вариант 1) и каталожных значений для пунктов ГГС (вариант 2)

\begin{tabular}{|c|c|c|c|c|c|c|c|c|}
\hline $\begin{array}{c}\text { Обозначение } \\
\text { параметра }\end{array}$ & $\Delta X(\mathrm{м})$ & $\Delta Y(\mathrm{M})$ & $\Delta Z(\mathrm{м})$ & $\begin{array}{c}m \\
\left(10^{-6}\right)\end{array}$ & $\begin{array}{c}W x \\
\text { (угл. } \\
\text { секунд) }\end{array}$ & $\begin{array}{c}W y \\
\text { (угл. } \\
\text { секунд) }\end{array}$ & $\begin{array}{c}W z \\
\text { (угл. } \\
\text { секунд) }\end{array}$ & $\begin{array}{c}\text { СКП } \\
\text { ед. веса } \\
\text { (м) }\end{array}$ \\
\hline $\begin{array}{c}\text { Числовое зна- } \\
\text { чение } \\
\text { вариант 1) }\end{array}$ & $-9,8518$ & $-75,6208$ & $-112,4879$ & 4,06513 & $-2,0394$ & $-0,8358$ & 0,6211 & $\pm 0,012$ \\
\hline $\begin{array}{c}\text { Числовое зна- } \\
\text { чение } \\
\text { (вариант 2) }\end{array}$ & $-9,6713$ & $-75,8708$ & $-112,9235$ & 4,14064 & $-2,0490$ & $-0,8945$ & 0,5265 & $\pm 0,041$ \\
\hline
\end{tabular}

Отличия в линейных параметрах Гельмерта между вариантами достигают порядка $\pm 0,18-0,44$ м. Такие результаты указывают на существенное влияние ошибок исходных данных за счет увеличенного, для локальной области, значения числа обусловленности матрицы коэффициентов системы параметрических уравнений, из решения которой по МНК определяются параметры Гельмерта. Опытным путем определено, что для территории Новосибирской области число обусловленности имеет значение примерно на два по- 
рядка больше, чем при глобальном расположении опорных пунктов $(\approx 150 / 1,4)$. Но также выявлена важная особенность семипараметрического преобразования Гельмерта. Несмотря на заметный разброс значений отдельных параметров, их совокупное влияние на результат преобразования в значительной мере взаимно компенсируется. Это будет показано ниже, при сравнении точности преоб- разования для пунктов ГГС по двум вариантам определения согласующих параметров Гельмерта.

Для вычисленных по согласующим параметрам Гельмерта и реконструированным значениям получены разности координат и нормальных высот для выборки из 14 пунктов СДГС, информация о которых представлена в табл. 3.

Разности, вычисленные по согласующим параметрам Гельмерта (вариант 1)

Таблицุа 3

и реконструированным значениям координат и нормальных высот пунктов СДГС в 4-й зоне МСК

\begin{tabular}{|c|c|c|c|c|c|}
\hline $\begin{array}{c}\text { Номер } \\
\Pi / \Pi\end{array}$ & $\begin{array}{c}\text { Название } \\
\text { Пункта }\end{array}$ & $\Delta \mathrm{x}(\mathrm{MM})$ & $\Delta \mathrm{y}(\mathrm{MM})$ & $\Delta \mathrm{H}^{\gamma}(\mathrm{MM})$ & $\Delta|\mathrm{xy}|($ мм $)$ \\
\hline 1 & 2 & 3 & 4 & 5 & 6 \\
\hline 1 & $B O L O$ & -20 & 17 & 1 & 26 \\
\hline 2 & CHER & 14 & 01 & 6 & 14 \\
\hline 3 & CHUL & -06 & -8 & -4 & 10 \\
\hline 4 & ISKT & 4 & 1 & 4 & 4 \\
\hline 5 & $K A R G$ & -13 & -13 & 4 & 18 \\
\hline 6 & $\mathrm{KOCH}$ & 2 & 9 & 1 & 9 \\
\hline 7 & KOCK & -14 & 11 & 4 & 18 \\
\hline 8 & $K O L V$ & -3 & 11 & -1 & 11 \\
\hline 9 & $M A S L$ & 7 & -13 & -1 & 15 \\
\hline 10 & $m h k v$ & -9 & 8 & -9 & 12 \\
\hline 11 & $N S K W$ & -4 & 7 & -4 & 8 \\
\hline 12 & ORDN & 1 & 12 & -2 & 12 \\
\hline 13 & SUZU & 20 & 15 & -5 & 25 \\
\hline 14 & $T O G U$ & -19 & 5 & 6 & 20 \\
\hline \multicolumn{2}{|c|}{ Минимум } & -20 & -13 & -9 & 4 \\
\hline \multicolumn{2}{|c|}{ Максимум } & 20 & 17 & 6 & 26 \\
\hline \multicolumn{2}{|c|}{ Среднее } & -3 & 5 & 0 & 14 \\
\hline \multicolumn{2}{|c|}{ СКП } & 12 & 10 & 5 & 6 \\
\hline
\end{tabular}

В последнем столбце помещены разности в положении пунктов в плане. Наиболее точное преобразование из общеземной WGS-84 в референцную систему получено для нормальных высот. СКП разностей вычисленных и каталожных значений для нормальных высот соответствует \pm 5 мм, для плоских прямоугольных координат - порядка $\pm 6-12$ мм с максимальной амплитудой до \pm 20 мм.

На рис. 5 графически показано пространственное распределение разностей геодезических высот в WGS-84 и референцной системе эллипсоида Красовского для данного варианта согласующих параметров Гельмерта. Можно заметить, что распределение разностей геодезических высот соответствует теоретическому распределению методических погрешностей в пределах локальной территории (см. рис. 3). Максимальные разности геодезических высот распределены по периферии и в центре, а минимальные разности - по замкнутой кривой близкой к окружности в средней полосе локальной области.

По второму варианту разности, вычисленные по согласующим параметрам Гельмерта и каталожным значениям, приведены в табл. 4. СКП разностей имеют порядок величин \pm 50 60 мм, что для каталожных значений координат соответствует точности МСК в Новосибирской области, образованной от СК-95 [13]. Преобразованные по согласующим параметрам Гельмерта координаты и высоты отличаются от каталожных значений, но эти отличия находятся в пределах случайных ошибок каталога. 


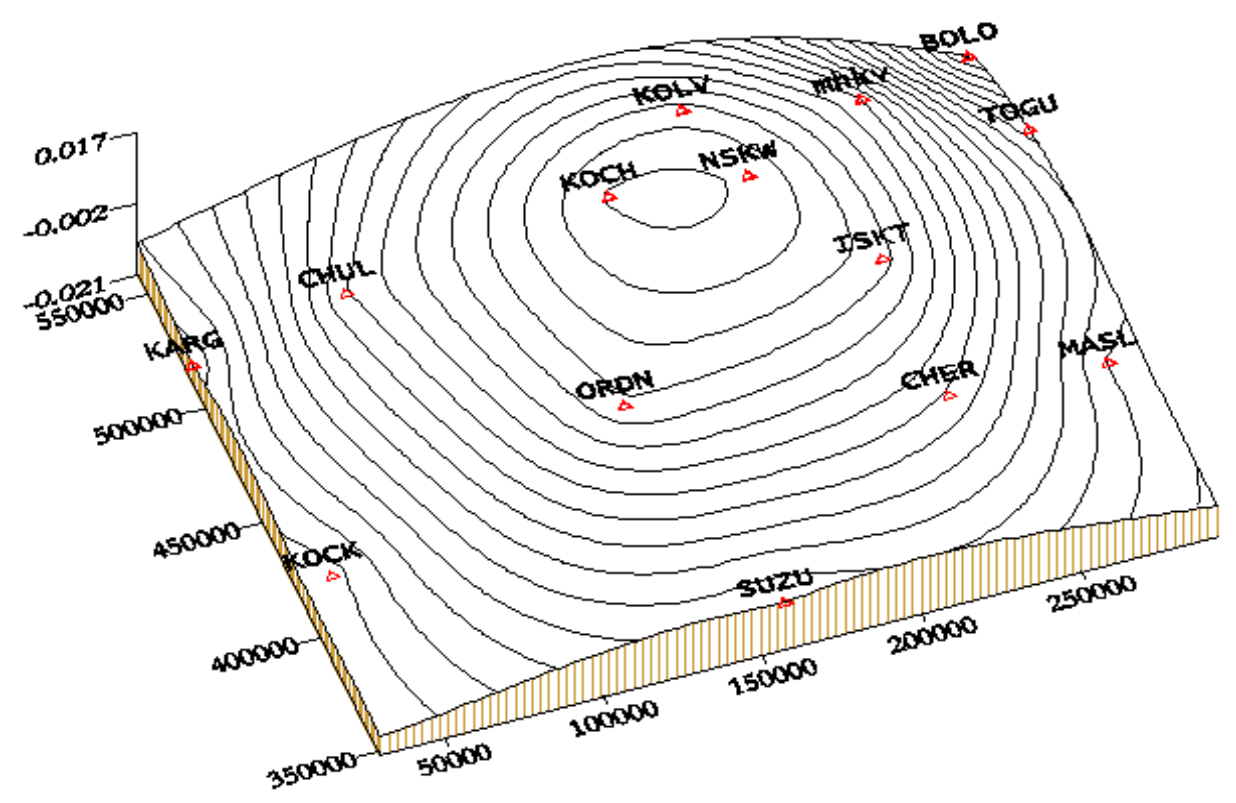

Рис. 5. Пространственное распределение разностей геодезических высот в WGS-84 и референцной системе эллипсоида Красовского для варианта согласующих параметров Гельмерта по пунктам СДГС

Таблицุа 4

Разности, вычисленные по согласующим параметрам Гельмерта (вариант 2)

и каталожным значениям координат и нормальных высот пунктов ГГС в 4-й зоне МСК

\begin{tabular}{|c|c|c|c|c|c|}
\hline $\begin{array}{c}\text { Номер } \\
\Pi / \Pi\end{array}$ & $\begin{array}{c}\text { Название } \\
\text { пункта }\end{array}$ & $\Delta \mathrm{x}(\mathrm{MM})$ & $\Delta y($ мм $)$ & $\Delta \mathrm{H}^{\gamma}(\mathrm{MM})$ & $\Delta|\mathrm{xy}|(\mathrm{MM})$ \\
\hline 1 & 2 & 3 & 4 & 5 & 6 \\
\hline 1 & $a l a b$ & -13 & -78 & 7 & 79 \\
\hline 2 & bashins & 16 & 18 & 101 & 24 \\
\hline 3 & borc & -29 & 16 & -13 & 33 \\
\hline 4 & bugr & 45 & 52 & 73 & 69 \\
\hline 5 & chilino & -107 & 64 & 2 & 125 \\
\hline 6 & chuk & -56 & 70 & 37 & 90 \\
\hline 7 & frm 2 & -22 & -8 & -2 & 23 \\
\hline 8 & holo & 49 & 4 & -50 & 49 \\
\hline 9 & isktm & 48 & 12 & -103 & 49 \\
\hline 10 & jana & -11 & -29 & 17 & 31 \\
\hline 11 & kroz & -11 & -12 & 9 & 16 \\
\hline 12 & $\log o$ & -25 & -19 & -115 & 31 \\
\hline 13 & medy & -55 & -80 & 68 & 97 \\
\hline 14 & mstv & 25 & 9 & 9 & 27 \\
\hline 15 & porot & 5 & 51 & 79 & 51 \\
\hline 16 & poselok & 85 & 71 & -4 & 111 \\
\hline 17 & rtul & 40 & 8 & -43 & 41 \\
\hline 18 & salamatovo & -35 & -15 & -3 & 38 \\
\hline 19 & vorv & -56 & 23 & -37 & 61 \\
\hline 20 & zelklin & 50 & -80 & -29 & 94 \\
\hline \multicolumn{2}{|c|}{ Минимум } & -107 & -80 & -115 & 16 \\
\hline \multicolumn{2}{|c|}{ Максимум } & 85 & 71 & 101 & 125 \\
\hline \multicolumn{2}{|c|}{ Среднее } & -3 & 4 & 0 & 57 \\
\hline \multicolumn{2}{|c|}{ СКП } & 48 & 46 & 56 & 32 \\
\hline
\end{tabular}


Для контроля результатов, представленных в табл. 4, выполнена калибровка для тех же исходных данных, что и при определении согласующих параметров Гельмерта для пунктов ГГС (вариант 2), и аналогичным образом получены разности координат и нормальных высот, которые приведены в табл. 5.

Таблицุа 5

Разности вычисленных координат и нормальных высот пунктов ГГС по результатам калибровки и согласующим параметрам Гельмерта (вариант 2)

\begin{tabular}{|c|c|c|c|c|c|}
\hline $\begin{array}{c}\text { Номер } \\
\Pi / \Pi\end{array}$ & $\begin{array}{c}\text { Название } \\
\text { пункта }\end{array}$ & $\Delta \mathrm{x}($ мм $)$ & $\Delta y($ мм $)$ & $\Delta \mathrm{H}^{\gamma}(\mathrm{MM})$ & $\Delta|\mathrm{xy}|(\mathrm{Mм})$ \\
\hline 1 & 2 & 3 & 4 & 5 & 6 \\
\hline 1 & $a l a b$ & -19 & 2 & -13 & 19 \\
\hline 2 & bashins & 3 & -14 & 19 & 14 \\
\hline 3 & borc & -8 & 1 & 3 & 8 \\
\hline 4 & bugr & 9 & 11 & 13 & 14 \\
\hline 5 & chilino & 0 & 14 & -10 & 14 \\
\hline 6 & chuk & -2 & 10 & -8 & 10 \\
\hline 7 & frm 2 & -3 & 4 & -10 & 5 \\
\hline 8 & holo & 3 & -5 & 10 & 6 \\
\hline 9 & isktm & 3 & 0 & 11 & 3 \\
\hline 10 & jana & -13 & -4 & -17 & 14 \\
\hline 11 & kroz & -11 & 19 & -10 & 22 \\
\hline 12 & $\log o$ & -7 & 15 & 18 & 17 \\
\hline 13 & medy & -6 & -18 & -28 & 19 \\
\hline 14 & mstv & -2 & -18 & 29 & 18 \\
\hline 15 & porot & 11 & 21 & 20 & 24 \\
\hline 16 & poselok & 19 & 18 & 23 & 26 \\
\hline 17 & rtul & 1 & 3 & 6 & 3 \\
\hline 18 & salamatovo & -17 & -1 & 9 & 17 \\
\hline 19 & vorv & -6 & 9 & -8 & 11 \\
\hline 20 & zelklin & -10 & 12 & 4 & 16 \\
\hline \multicolumn{2}{|c|}{ Минимум } & -19 & -18 & -28 & 3 \\
\hline \multicolumn{2}{|c|}{ Максимум } & 19 & 21 & 29 & 26 \\
\hline \multicolumn{2}{|c|}{ Среднее } & -3 & 4 & 3 & 14 \\
\hline \multicolumn{2}{|c|}{ СКП } & 9 & 12 & 15 & 7 \\
\hline
\end{tabular}

Результаты отражают хорошую согласованность преобразований координат и высот из общеземной системы координат WGS-84 в MCK с СКП порядка $\pm 7-15$ мм двумя независимыми способами. Это может служить реальным подтверждением правильности разработанной методики с использованием согласующих параметров Гельмерта.

Заслуживает внимания заключительный эксперимент по сравнению результатов преобразований координат и высот пунктов ГГС по согласующим параметрам Гельмерта, определенных по первому и второму вариантам. Разности координат показаны в табл. 6 . Так как преобразование по нормальным высотам выполнялось по идентичным данным их разности априори равны нулю и по этой причине в таблице не приведены.
Полученные в табл. 6 разности координат могут быть объяснены более низкой точностью исходных данных в МСК для второго варианта и, в некоторой мере, отличиями в количестве опорных пунктов ГГС и в геометрии их расположения на территории, по сравнению с пунктами СДГС. Результаты, отраженные в табл. 46, подтверждают, что в процессе преобразований координат из общеземной в референцную систему происходит взаимная компенсация «грубых» значений параметров Гельмерта (вариант 2) по сравнению с «эталонными» результатами, полученными в результате калибровки и по согласующим параметрам Гельмерта по варианту 1. Отличия линейных параметров порядка $\pm 0,18-0,44$ м между двумя вариантами согласующих параметров Гельмерта не проявили себя в преобразованных в рефернцную 
систему плоских координат и, соответственно, в их разностях.

С целью анализа расхождений координат, представленных в табл. 6, был образован ключ преобразования для плоских координат в проекции Гаусса - Крюгера [14], вычисленных по варианту 1 и варианту 2. Получены следующие параметры ключа: смещение начала координат по оси абсцисс $-0,010$ м, ординат $-0,016$ м, угол разворота осей $-0,1114$ угловых секунды и разность линейных масштабных коэффициентов $+0,07625$ РРМ. Разности координат в результате преобразования по ключу не превысили $\pm 1-2$ мм (рис. 6), что указывает на сохранение высокой степени ортогональности и взаимной точности координат пунктов в процессе преобразований по разным вариантам согласующих параметров Гельмерта.

Разности координат пунктов ГГС в 4-й зоне МСК, вычисленные по согласующим параметрам Гельмерта для двух вариантов

\begin{tabular}{|c|c|c|c|c|}
\hline $\begin{array}{c}\text { Номер } \\
\Pi / \Pi\end{array}$ & $\begin{array}{c}\text { Название } \\
\text { пункта }\end{array}$ & $\Delta \mathrm{x}(\mathrm{MM})$ & $\Delta \mathrm{y}($ мм) & $\Delta|\mathrm{xy}|$ (мм) \\
\hline 1 & 2 & 3 & 4 & 5 \\
\hline 1 & $a l a b$ & -85 & -22 & 88 \\
\hline 2 & bashins & 45 & 19 & 49 \\
\hline 3 & borc & 45 & -29 & 54 \\
\hline 4 & bugr & -30 & 27 & 40 \\
\hline 5 & chilino & 29 & -75 & 80 \\
\hline 6 & chuk & 23 & -65 & 69 \\
\hline 7 & frm 2 & -42 & -18 & 46 \\
\hline 8 & holo & 24 & 5 & 25 \\
\hline 9 & isktm & 9 & 0 & 9 \\
\hline 10 & jana & -73 & -39 & 83 \\
\hline 11 & kroz & 56 & -72 & 91 \\
\hline 12 & $\log o$ & -67 & 11 & 68 \\
\hline 13 & medy & -76 & -72 & 105 \\
\hline 14 & mstv & 60 & 16 & 62 \\
\hline 15 & porot & -42 & 43 & 60 \\
\hline 16 & poselok & -30 & 55 & 63 \\
\hline 17 & rtul & -10 & -16 & 19 \\
\hline 18 & salamatovo & 66 & -27 & 71 \\
\hline 19 & vorv & 38 & -53 & 65 \\
\hline 20 & zelklin & -69 & 1 & 69 \\
\hline \multicolumn{2}{|c|}{ Минимум } & -85 & -75 & 9 \\
\hline \multicolumn{2}{|c|}{ Максимум } & 66 & 55 & 105 \\
\hline \multicolumn{2}{|c|}{ Среднее } & -6 & -16 & 61 \\
\hline \multicolumn{2}{|c|}{ СКП } & 52 & 39 & 24 \\
\hline
\end{tabular}

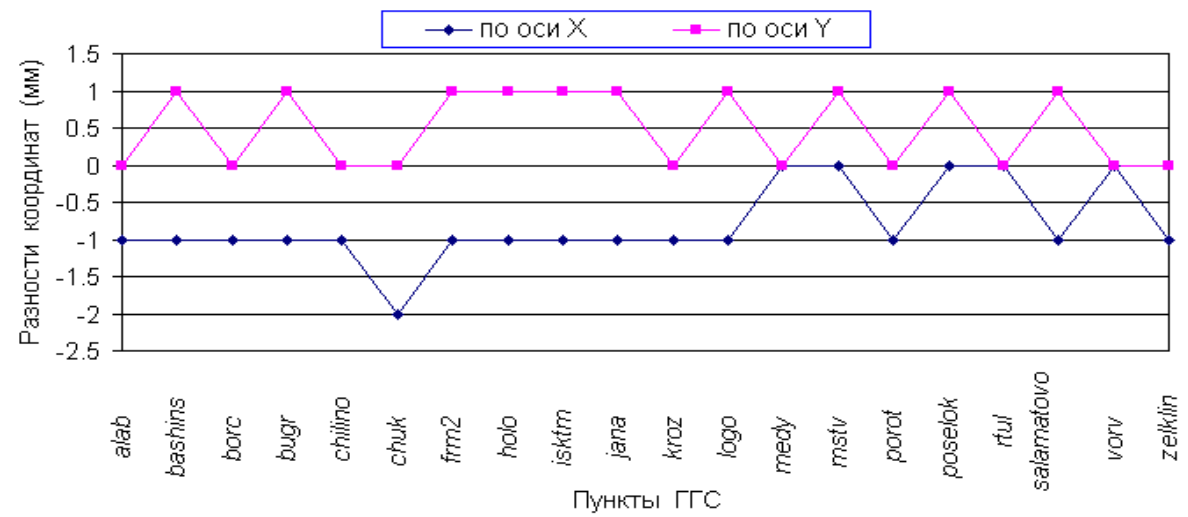

Рис. 6. Разности преобразованных по ключу плоских координат в проекции

Гаусса - Крюгера для пунктов ГГС по двум вариантам согласующих параметров Гельмерта 


\section{Заключение}

Разработана методика определения согласующих параметров Гельмерта между общеземными и референцными системами координат для локальных территорий без привлечения информации о высотах квазигеоида. Данная методика основана на сближении локальных участков поверхностей общеземного и референцного эллипсоидов путем задания нулю геодезических высот опорных пунктов в обеих системах координат и решения задачи определения параметров Гельмерта в соответствии с критерием МНК. Размеры локальной территории зависят от заданных предельных методических погрешностей, присущих данному способу определения параметров Гельмерта. Для предельных значений методических погрешностей порядка $\pm 2-3$ см, радиус локальной территории составляет порядка 200 км от центра территории, что соответствует размерам трехградусных зон МСК и полосе широт до 400 км.

Выполнена апробация методики для локальной территории в восточной части Новосибирской области размерами $4^{\circ}$ по долготе и $2^{\circ}$ по широте для 4-й трехградусной зоны МСК региона. Вычислены два варианта согласующих параметров - для 14 пунктов СДГС с реконструированными плоскими координатами и нормальными высотами и для 20 пунктов ГГС с не реконструированными (каталожными) координатами и нормальными высотами. Отличие линейных параметров Гельмерта между двумя вариантами составили $\pm 0,18-0,44$ м. Отмечена компенсационная особенность семипараметрического преобразования координат по совокупному влиянию «грубых» значений параметров Гельмерта на окончательный результат в референцной системе.

Для контроля преобразованных координат и нормальных высот по согласующим параметрам Гельмерта для варианта с пунктами ГГС применен способ калибровки. СКП для разностей, полученных двумя независимыми способами, составили $\pm 7-15$ мм, что является подтверждением правильности разработанной методики.

Для сравнения результатов преобразования для пунктов ГГС по двум вариантам согласующих параметров Гельмерта был создан ключ перехода в проекции Гаусса - Крюгера. Точность преобразования по ключу для плоских координат составила $\pm 1-2$ мм. Таким образом, применение согласующих параметров Гельмерта позволяет получать из высокоточных общеземных систем координат варианты реконструированных референцных плоских координат, которые будут иметь высокую степень точности взаимных положений пунктов и могут быть с высокой точностью преобразованы между собой в проекции Гаусса - Крюгера с помощью ключа перехода. Благодаря этому возможно с минимальными издержками преобразовывать «прежние, неточные» МСК в их точные аналоги, для которых «легко» устанавливать связи с любыми другими точными общеземными или референцными системами координат, например, между WGS-84 и ГСК2011, WGS-84 (ГСК2011) и МСК на основе СК-42 или СК-95.

Методически более наглядным становится вычисление нормальных высот благодаря замене высот квазигеоида высотами геоида, хотя фактически алгоритм преобразования высот не изменился.

Следует также отметить, что использование согласующих параметров Гельмерта значительно упрощает создание калибровочных участков, где необходимыми параметрами должны быть параметры проекции пользователя, согласующие параметры Гельмерта, модель высот геоида относительно общеземного эллипсоида и параметры калибровки по высоте. Параметры калибровки в плане вычислять нет необходимости.

Автор выражает искреннюю благодарность за сотрудничество в обсуждении вопросов по тематике статьи главному технологу АО «ПО Инжгеодезия» П.К.Шитикову, доцентам СГУГиТ В. И. Обиденко и А. В. Елагину

\section{БИБЛИОГРАФИЧЕСКИЙ СПИСОК}

1. ГОСТ Р 51794-2008. Глобальные навигационные спутниковые системы. Системы координат. Методы преобразований координат определяемых точек. - М. : Изд-во стандартов, 2008.

2. Горобец В. П. Определение связи между геоцентрической системой координат и СК-95 // Научно-технический сборник «Физическая геодезия». - М. : Научный мир, 2013. - С. 95-101.

3. Topcon Tools. Руководство оператора. Номер по каталогу 7010-0612. Редакция «G». - Topcon Positioning Systems, Inc. Май, 2006. - С. 27-34. 
4. Шендрик Н. К. Способ итераций для высокоточной реконструкции координат пунктов локальных геодезических сетей // Геопрофи. - 2014. - № 5. - С. 44-48.

5. ГКИНП (ГНТА)-06-278-04. Руководство пользователя по выполнению работ в системе координат 1995 года (СК-95). - Москва : ЦНИИГАиК, 2004. - 138 с.

6. Сурнин Ю. В., Ащеулов В. А., Кужелев С. В., Михайлович Е. В., Шендрик Н. К. Совершенствование и практическая реализация динамического метода космической геодезии : монография / под общей редакцией Ю. В. Сурнина. - Новосибирск : СГУГиТ, 2015. - С. 147-149.

7. Шендрик Н. К. Формирование локальной цифровой модели высот геоида на территорию Новосибирской области // Вестник СГУГиТ. - 2016. - Вып.4 (36). - С. 66-73.

8. Баранов В. Н., Королевич В. В. Пример оценки точности модели EGM 2008 по астрономо-геодезическим данным // Науки о Земле. - 2011. - № 2. - С. 39-43.

9. Голдобин Д. Н., Мазурова Е. М., Канушин В. Ф., Ганагина И. Г., Косарев Н. С., Косарева А. М. Одномерное сферическое преобразование Фурье и его реализация для расчета глобальной модели квазигеоида в нулевом приближении теории Молоденского // Вестник СГУГиТ. - 2015. - Вып. 3 (31). - C. $45-52$.

10. Обиденко В. И., Опритова О. А., Решетов А. П. Разработка методики получения нормальных высот на территорию Новосибирской области с использованием глобальной модели геоида EGM2008 // Вестник СГУГиТ. - 2016. - Вып. 1 (33). - С. 14-25.

11. Ганагина И. Г., Челнокова Д. С., Голдобин Д. Н. Создание модели квазигеоида на локальном участке средствами ГИС // Вестник СГУГиТ. - 2016. - Вып. 3 (31). - С. 14-25.

12. Канушин В. Ф., Ганагина И. Г., Голдобин Д. Н., Мазурова Е. М., Косарев Н. С., Косарева А. М. Современные глобальные модели квазигеоида: точностные характеристики и разрешающая способность // Вестник СГУГиТ. - 2017. - Т. 22, № 1. - С. 30-49.

13. Шендрик Н. К. Исследование точности геодезической сети активных базовых станций Новосибирской области в государственной системе координат и высот // Геодезия и картография. - 2014. № 1. - С. 2-7.

14. Шендрик Н.К. Методика выноса проектных точек на местность в WGS-84 // Геопрофи. - 2016 № $5 .-$ C. $40-42$.

Получено 29.06.2021

(C) Н. К. Шендрик, 2021

\section{METHODOLOGY FOR DETERMINING HELMERT'S CONSISTENT PARAMETERS FOR LOCAL TERRITORIES}

\section{Nikolay K. Shendrik}

Siberian State University of Geosystems and Technologies, 10, Plakhotnogo St., Novosibirsk, 630108, Russia, Head of the Laboratory, Department of Space and Physical Geodesy, phone: (913)739-55-17, e-mail: snk_aig@mail.ru

A method for determining the Helmert matching parameters for converting the coordinates of points from the common terrestrial to the reference coordinate system has developed. The technique is based on the maximum alignment of the surfaces of the common terrestrial and reference ellipsoids within a certain local territory and does not imply knowledge of the heights of the quasigeoid. The radius of the local area is limited by a given methodological error in the transformation of coordinates from general terrestrial system to Gauss-Kruger projection. For a methodical error of $\pm 2-3 \mathrm{~cm}$, the radius of the local area is about $200 \mathrm{~km}$. Two options for determining the Helmert matching parameters for the fourth three-degree zone of the MSC of the Novosibirsk region are given: according to the reconstructed coordinates and heights of the SDGN, and according to the catalog coordinates and heights of the SGN points located in the same territory.

Keywords: technique, Helmert matching parameters, local territory, coordinate transformation, general terrestrial and reference coordinate system, convergence of ellipsoid surfaces, quasigeoid heights, digital geoid model, geodetic and normal height, Gauss-Kruger projection, local coordinate system, transition key 


\section{REFERENCES}

1. Standards Russian Federation. (2008). GOST R 51794-2008. Global navigation satellite systems. Coordinate systems. Methods for transforming coordinates determined points. Moscow: Standards Publ. [in Russian].

2. Gorobets, V. P. (2013). Determination of the relationship between the geocentric coordinate system and the SK-95. In Nauchno-tehnicheskij sbornik "Fizicheskaja geodezija»Scientific" [Science and Technical Collection "Physical Geodesy"] (pp. 95-101). Moscow: Nauchnyj mir Publ. [in Russian].

3. Topcon Tools. Operator's manual. (2006). Catalog number 7010-0612. Revision "G" (p. 27-34). Topcon Positioning Systems, Inc. [in Russian].

4. Shendrik, N. K. (2014). Method of iterations for high-precision reconstruction of coordinates of points of local geodetic networks. Geoprofi, 5, 44-48 [in Russian].

5. Geodetic, Cartographic Instructions, Norms and Regulations. (2004). User's manual for work in the coordinate system of 1995 (SK-95). GKINP (GNTA) - 06-278-04. Moscow: TsNIIGAiK Publ., 138 p. [in Russian].

6. Surnin, Yu. V., Ashcheulov, V. A., Kuzhelev, S. V., Mikhailovich, E. V., \& Shendrick, N. K. (2015). Sovershenstvovanie i prakticheskaja realizacija dinamicheskogo metoda kosmicheskoj geodezii [Improvement and practical implementation of the dynamic method of space geodesy] (p. 147-149). Yu. V. Surnin (Ed.). Novosibirsk: SSUGT Publ. [in Russian].

7. Shendrik, N. K. (2016). Formation of a local digital model of geoid heights to the territory of the Novosibirsk region. Vestnik SGUGiT [Vestnik SSUGT], 4(36), 66-73 [in Russian].

8. Baranov, V. N., \& Korolevich, V. V. (2011). An example of estimating the accuracy of the EGM model 2008 on astronomical and geodetic data. Nauki o Zemle [Earth Sciences], 2, 39-43 [in Russian].

9. Goldobin, D. N., Mazurova, E. M., Kanushin, V. F., Ganagina, I. G., Kosarev, N. S., \& Kosareva A. M. (2015). One-dimensional spherical Fourier transform and its implementation for calculating the global quasigeoid model in the zero approximation of the theory Molodensky. Vestnik SGUGiT [Vestnik SSUGT], 3(31), 45-52 [in Russian].

10. Obidenko, V. I., Opritova, O. A., \& Reshetov, A. P. (2016). Method development obtaining normal heights to the territory of the Novosibirsk region from using the global geoid model EGM2008. Vestnik SGUGiT [Vestnik SSUGT], 1(33), 14-25 [in Russian].

11. Ganagina, I. G., Chelnokova, D. S., \& Goldobin, D. N. (2016). Model creation quasigeoid on a local site by means of GIS. Vestnik SGUGiT [Vestnik SSUGT], 3(31), 14-25 [in Russian].

12. Kanushin, V. F., Ganagina, I. G., Goldobin, D. N., Mazurova, E. M., Kosarev, N. S., \& Kosareva, A. M. (2017). Modern global quasigeoid models: accuracy characteristics and resolution. Vestnik SGUGiT [Vestnik SSUGT], 22(1), 30-49 [in Russian].

13. Shendrik, N. K. (2014). Investigation of the accuracy of the geodetic network of active base stations of the Novosibirsk region in the state system of coordinates and heights. Geodeziya i kartografiya [Geodesy and Cartography], 1, 2-7 [in Russian].

14. Shendrik, N. K. (2016). Methodology for setting out design points on the ground in WGS-84. Geoprofi, 5, 40-42 [in Russian].

Received 29.06.2021

(C) N. K. Shendrick, 2021 


\section{ДИСТАНЦИОННОЕ ЗОНДИРОВАНИЕ ЗЕМЛИ, ФОТОГРАММЕТРИЯ}

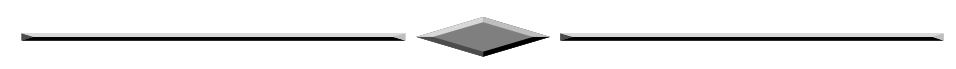

УДК: 528.8:551.24(571.642)

DOI $10.33764 / 2411-1759-2021-26-5-75-85$

\section{ИССЛЕДОВАНИЕ ВЛИЯНИЯ ЗОН РАЗЛОМОВ ТЕРРИТОРИИ ЗАКАЗНИКА ДОЛИНСКИЙ» (О. САХАЛИН) НА СОСТОЯНИЕ ЕГО РАСТИТЕЛЬНОГО ПОКРОВА С ИСПОЛЬЗОВАНИЕМ МАТЕРИАЛОВ ДИСТАНЦИОННОГО ЗОНДИРОВАНИЯ ЗЕМЛИ}

\section{Олеся Витальевна Купцова}

Сахалинский государственный университет, 693023, Россия, г. Южно-Сахалинск, ул. Пограничная, 2, аспирант кафедры геологии и нефтегазового дела, тел. (924)190-00-08, e-mail: Korsuncevaolesy@gmail.com

\section{Инна Ивановна Лобищева}

Сахалинский государственный университет, 693023, Россия, г. Южно-Сахалинск, ул. Пограничная, 2, старший преподаватель кафедры геологии и нефтегазового дела, тел. (914)757-99-26, e-mail: slalinna@mail.ru

\section{Алексей Александрович Верхотуров}

Институт морской геологии и геофизики Дальневосточного отделения Российской академии наук, 693022, г. Южно-Сахалинск, ул. Науки, 1Б, кандидат технических наук, старший научный сотрудник Центра коллективного пользования, e-mail: ussr-91@mail.ru

\section{Вячеслав Анатольевич Мелкий}

Институт морской геологии и геофизики Дальневосточного отделения Российской академии наук, 693022, г. Южно-Сахалинск, ул. Науки, 1Б, доктор технических наук, ведущий научный сотрудник лаборатории вулканологии и вулканоопасности, e-mail: vamelkiy@mail.ru

Зоны разломов земной коры на территории Сахалина характеризуются высокой геодинамической активностью и в большинстве своем хорошо просматриваются на материалах космических съемок. Поэтому, выделяя на подобных территориях разнообразные растительные сообщества и определяя их состояние по содержанию фитомассы, используя значения вегетационного индекса NDVI, возможно сделать заключение о роли указанных разломов в оценке состояния указанных ценозов и ландшафтов в целом. Цель исследования, в этой связи, состоит в проверке достоверности гипотезы о формировании обильного растительного покрова в пределах разломных зон с использованием анализа материалов дистанционного зондирования Земли (ДЗ3), обеспечивающих требуемую информационную полноту данных по объему фитомассы различных растительных сообществ. Методы: дешифрирование и анализ данных дистанционного зондирования Земли с Sentinel, Landsat и аппарата «Шаттл» при формировании SRTM, геоинформационное картографирование на платформе ArcGIS. В процессе исследования проанализировано состояние территории заказника «Долинский» (о. Сахалин) по материалам спутниковых съемок Landsat-8, Sentinel-2A, а также данные SRTM. Разломные зоны выявлены с помощью программных комплексов ArcGIS, QGIS и PyLEFA методами линеаментного анализа, классификация растительности осуществлена методом максимального правдоподобия, а ее состояние определено по значениям индекса NDVI, отражающего содержание фитомассы на исследуемом участке. В итоге выявлена достаточная информативность материалов Д33, продемонстрирована методика их обработки и использования полученных результатов, подтверждена достоверность гипотезы увеличения фитомассы ценозов и адекватных условий их развития, приуроченных к зонам разломов земной коры.

Ключевые слова: дистанционное зондирование Земли, дешифрирование аэрокосмических изображений, геоинформационное тематическое картографирование, геодинамическая активность, Sentinel, Landsat, SRTM, NDVI, PyLEFA 


\section{Введение}

Под воздействием внешних и внутренних сил земная кора делится на блоки, которые отделяют друг от друга разломные зоны [14]. Горные породы в пределах разломной зоны представлены, как правило, зонами дробления, брекчирования, катаклаза, рассланцевания и милонитизации. С увеличением глубины по разлому увеличивается роль рассланцевания и милонитизации, а также количество оперяющих трещин.

Тектонические брекчии, как правило, сложены меланжем, сцементированным тонко раздробленным или жильным материалом, которые формируются в зонах глубинных разломов. Раздробленные породы обладают хорошей проницаемостью, пористостью и фильтрационной способностью. Такими породами выполняются днища горных котловин и речных долин, приуроченных к разломным зонам и ограниченных ими $[5,6]$. Наиболее активное накопление рыхлого материала твердого стока рек происходит при выходе на предгорные равнины. Все поверхности этих геологических образований покрывают почвы с относительно хорошим матриксом. На территориях, прилегающих к разломам, растительные сообщества не похожи на растительный покров остальной территории [7]. Соответственно, в таких территориях наблюдается формирование обильного растительного покрова, отличающегося повышенным содержанием фитомассы, которая, в свою очередь, находит проявление в отражательных способностях земной поверхности, фиксируемых на аэрокосмических изображениях.

\section{Материалы и методы исследования}

В качестве материалов для анализа состояния территории заказника «Долинский» (о. Сахалин) использовались спутниковые снимки Landsat-8, Sentinel-2A, а также данные радарной интерферометрической съемки SRTM, произведенной радиолокационными сенсорами X-SAR и SIR-C с помощью аппарата «Шаттл» [8-10]. Анализ выполнялся с использованием исходных материалов за период с 2018 по 2021 г. Данные спутников Landsat и Sentinel находятся в свободном доступе на различных интер- нет-pecypcax (https://earthexplorer.usgs.gov/) и (https://www.sentinel-hub.com/). Спутниковые снимки отбирались с условием отсутствия облачности над интересующей территорией. Снимки прошли все процедуры первичной обработки.

Снимки подбирались с учетом программы LEFA, в которой анализировались исходные данные. Основные требования для работы в программе - формат изображений *.tif и соответствие разрешения снимка масштабу территории. Дальнейшую обработку по коррекции или изменению размера пиксела провели в ArcGIS. Исходные данные прошли необходимую коррекцию, в том числе и атмосферную. Разрешение исходных данных 30 м соответствует поставленным задачам анализа территории. Изображения были обработаны в программе ArcGIS для выделения необходимого участка с целью детального линеаментного анализа исследуемой территории.

Цифровая модель рельефа, полученная в результате съемки SRTM, необходима при создании математически определенной модели разрывных нарушений, так как она отображает незначительные уступы в рельефе для их выявления.

Исходные данные обрабатывались в программном обеспечении ArcGIS [11], QGIS [12] и PyLEFA [13]. При работе с изображениями использовались методы математической обработки изображений, в число которых входит метод линеаментного анализа, линейная обработка операции морфологической эрозии, алгоритмы Кэнни и Хафа, а также метод максимального правдоподобия для классификации растительности [14-20]. Существует множество способов классификации растровых изображений $[21,22]$.

Выявление разрывных нарушений происходило с учетом особенностей геологического строения региона с помощью выделения линий на изображениях поверхности Земли. Для статистической обработки линеаментов с помощью роз-диаграммы использовался плагин QGIS Line Direction Histogram.

Обработка изображений в программе LEFA производилась по нескольким алгоритмам, таких как Кэнни, Хафа и операция эрозии. При выборе чувствительности поиска линий для алгоритмов основополагающим является наличие шума на изображении. 
Формулы для алгоритма эрозии, применяемого к изображению $(A)$, определяют структурный элемент $(B)$, с помощью которого «убирается» лишнее среди множества $(A)$ точек $(z)$, и определяются линейные границы исходных материалов

$$
A \ominus B=\{z \mid(B) z \subseteq A\},
$$

где $A \in Z^{2} ; B \in Z^{2}$.

Алгоритм Кэнни с помощью матрицы, применяемой к изображению, определяет выбор чувствительности к шуму, ищет градиент снимка, по производной определяет градиент края, после чего использует метод истончения и метод двойного порога для точного определения границ изображения.

Формула алгоритма Хафа описывается линейными параметрами углового коэффициента $(k)$ и свободного члена $(b)$ известного уравнения прямой $y=k x+b$.

Начальным этапом выделения линеаментов является выделение границ изображения по одному из алгоритмов, описанных выше. После обнаружения границ наступает этап выделения штрихов-линеаментов в режимах разной чувствительности к шуму. При малой чувствительности выделяются только сильно выраженные в рельефе линеаменты. При средней и максимальной чувствительности выделяется большее количество штрихов для анализа. После выделения штрихов-линеаментов программа ищет так называемые «вероятностные разломы». Программа считывает длину, количество и направление штрихов-линеаментов, выраженных в рельефе, производит их анализ и оценку, подбирая наиболее подходящие вероятности линий разломов, к которым могут быть приурочены имеющиеся линии-штрихи модифицированного изображения.

Дешифрирование снимков позволило также оценить состояние почвенно-растительного покрова и геолого-геоморфологические характеристики района исследования. В работе для выделения участков, занятых растительными сообществами в различном состоянии, проведена процедура классификации с последовательным использованием методов классификации без обучения и с обучением. Обучающая выборка по методу максимального правдоподобия составлена из наборов пикселей, соответствующих местам выполнения геоботанических описаний. Процедура «обучения» основывалась на наборе пикселей эталонных участков территорий геоботанических исследований. Статистический анализ изображений позволяет получить свои спектральные характеристики для каждого типа растительного покрова территории $[23,24]$. Комбинация спектральных каналов 11-8-4 спутника Sentinel-2А использовалась для разделения растительных формаций, тогда как каналы 4, 7, 8 спутника Landsat-8 для выделения дизъюнктивных нарушений сплошности земной коры. Для изображений исследуемой территории выполнена процедура расчета индекса NDVI.

Для оценки зависимости объемов фитомассы от близости к зонам распространения разломов земной коры в процессе работы разработан алгоритм операций (рис. 1).
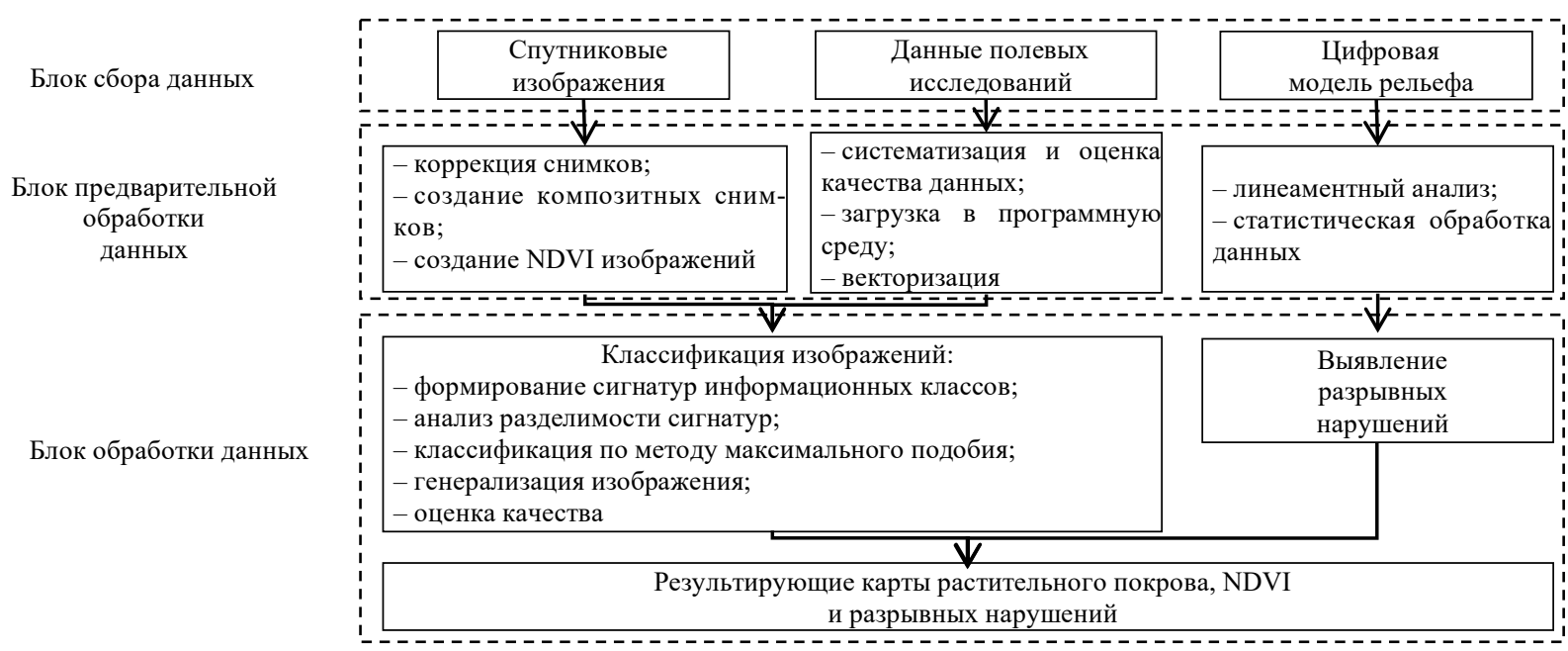

Рис. 1. Технологическая схема дешифрирования при выявлении взаимосвязи между разломными зонами и обилием растительности 
Многоуровневый анализ исходных изображений на базе ГИС с использованием данных дистанционного зондирования Земли из космоса позволяет выявить особенности растительности и определяющих ее регионального геологического строения исследуемой территории.

\section{Результаты и обсуждение}

При обработке исходных спутниковых изображений заказника «Долинский» были выявлены системы линеаментов, характерные для зон повышенной трещиноватости (рис. 2).
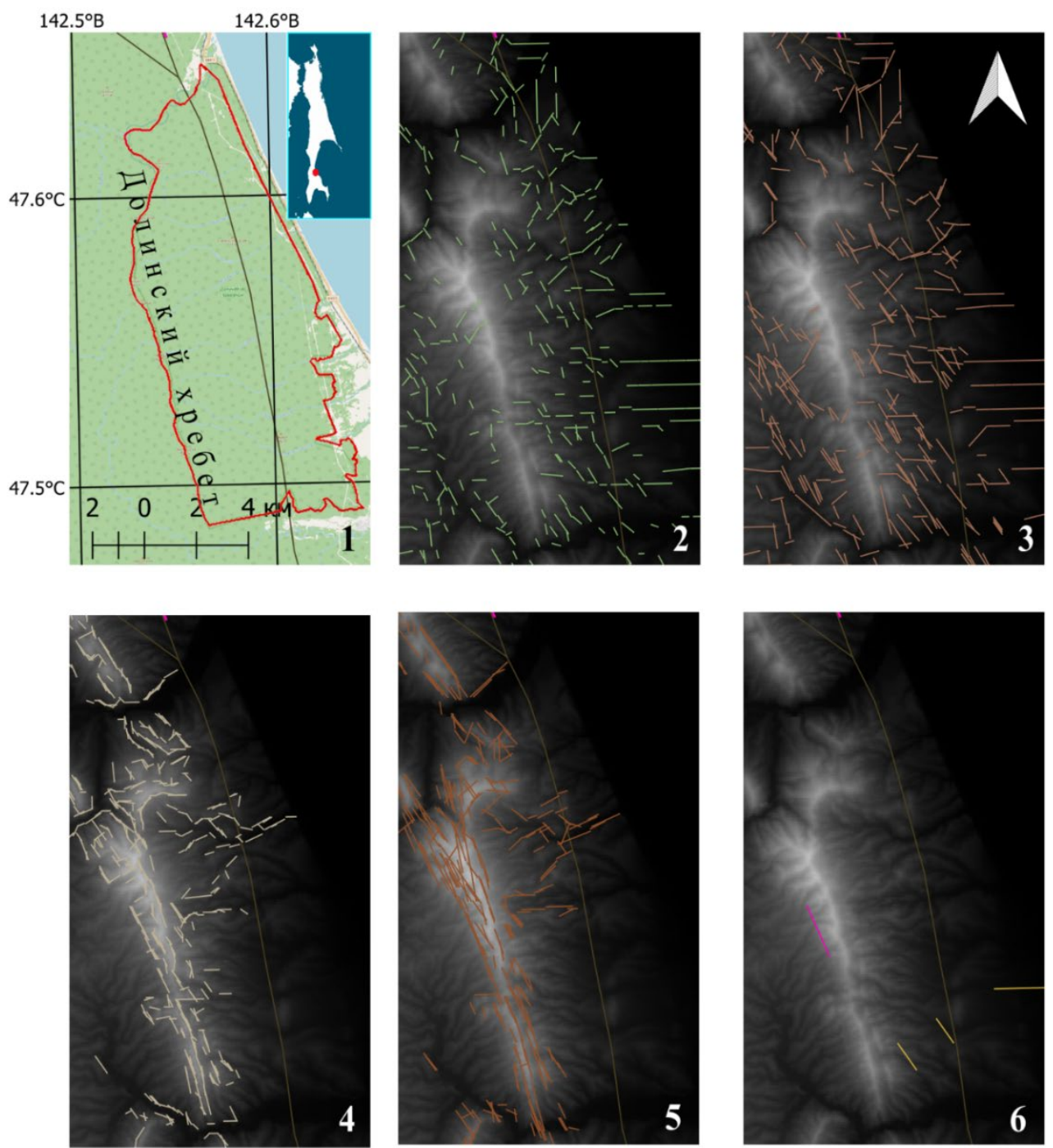

Рис. 2. Фрагменты изображения с линеаментами, выделенными в программе LEFA при использовании различных алгоритмов:

1 - заказник «Долинский» на карте Сахалина; 2 - Erosion many; 3 - Erosion medium; 4 - Canny many; 5 - Canny medium; 6 - Canny small (красные линии); Erosion small (желтые линии)

На изображениях, анализируемых с помощью алгоритма Erosion, линии распределены достаточно равномерно, однако на модифицированном материале, полученном с помощью алгоритма Canny, можно четко определить территориальное местоположение зоны наиболее ярко выраженных линеа- ментов, которые свидетельствуют о напряженно-деформированном состоянии земной поверхности. Результаты анализа сохраняются в формате shape-файлов с привязкой системы координат исходных изображений, дальнейшая их обработка происходит в ГИС. 
Наиболее информативным для исследуемой территории и выбранного масштаба в плане распространения линеаментов является использование алгоритма Canny medium. Другие способы обработки показывают либо очень малое, либо большое количество разломов.

На основе серии космических снимков за летний период времени были подготовлены NDVI-изображения и карты растительного покрова на территорию заказника «Долинский». Классификация «с обучением» методом максимального правдоподобия космических снимков Sentinel-2A с помощью инструментария ПО ArcМар позволила выделить семь типов растительных сообществ, в том числе пихтово-еловые леса, ивово-ольховые долинные леса и посадки хвойных культур сосны и лиственницы (рис. 3).

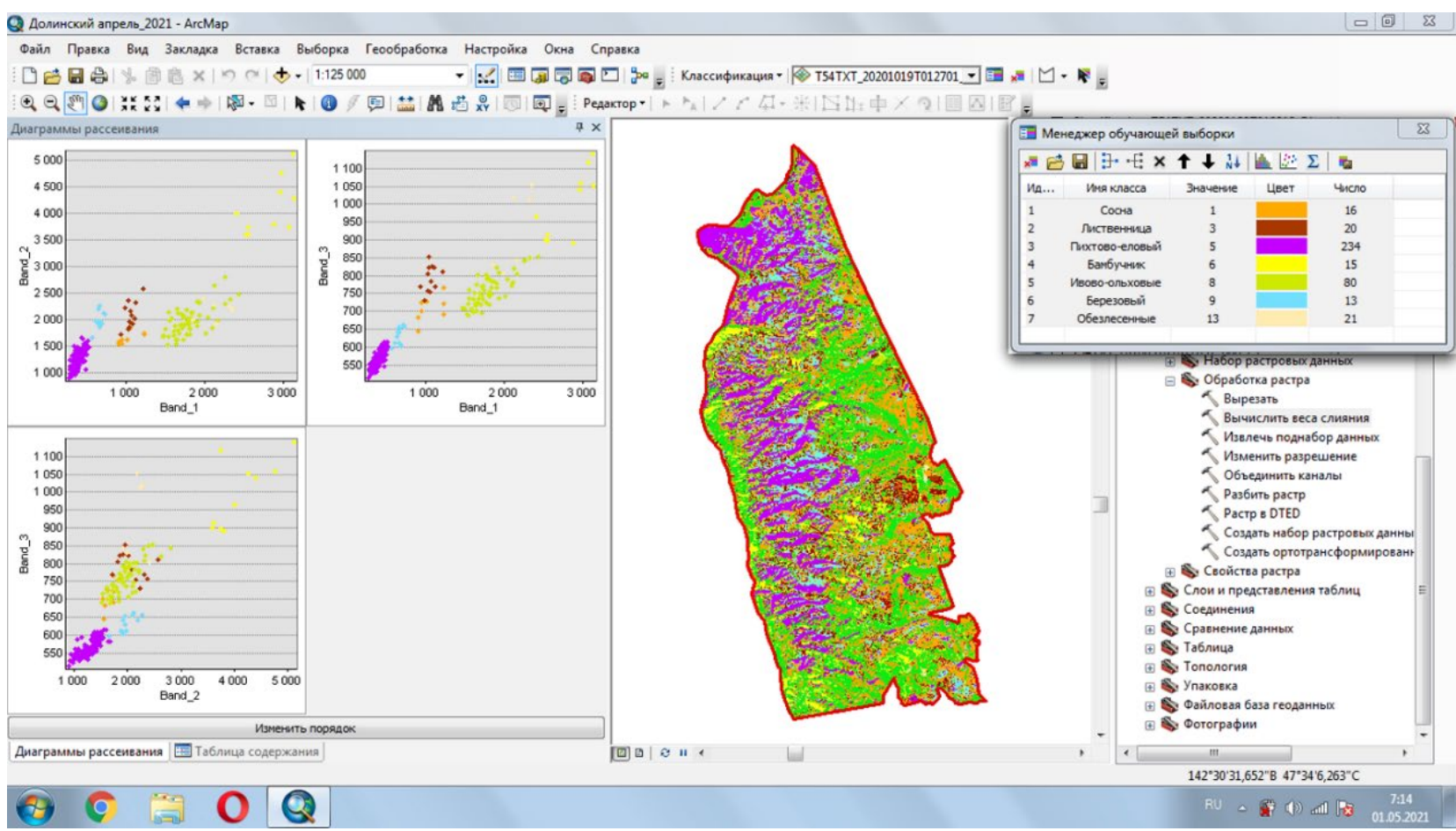

Рис. 3. Классификация изображения территории заказника в ArcMap

Результирующие карты, полученные в результате обработки информации о местоположении разломов и состояния растительности, позволяют судить о характере взаимообусловленности значений фитомассы и трещиноватости массивов горных пород в разломных зонах (рис. 4).

На полученной карте можно отметить четкую приуроченность линеаментов к предгорьям Долинского хребта, верховьям и долинам наиболее крупных рек Фирсовки, Рыбной, Лиственницы и Кирпичной. К этой же территории зачастую приурочены высокие значения NDVI, обусловленные высокой продуктивностью пихтово-еловых (I-II класс бонитета) и долинных ивово-ольховых лесов. Увеличение фитомассы наблюдается в зонах распро- странения разломов земной коры в шлейфе осадочных отложений, примыкающих к восточным склонам Долинского хребта.

Воздействие разломных зон на живые организмы может носить как положительный, так и отрицательный характер. В зонах активных разломов отмечаются высокие концентрации радона. В связи с этим по статистическим данных возрастает число болезней растительности. Значительное количество мутаций, описанное Е. К. Мельниковым, В. А. Рудником и Ю. И. Мусийчуком, привело к увеличению видового разнообразия культурных растений [25].

Смещения в разломных зонах могут быть причиной аварийных ситуаций на объектах промышленности с последующим негатив- 
ным воздействием на окружающую среду, жизнь и здоровье людей [25]. Для предотвращения негативных последствий необходимо проведение превентивных исследований, результатом которых должно быть составление специальных геолого-структурных карт мас- штаба $1: 100000$ и крупнее с нанесенными на них зонами разломов, дифференцированных по степени опасности, на геодинамически опасных участках, выявленных по результатам анализа полученных материалов, $1: 25000$ и крупнее [26-31].

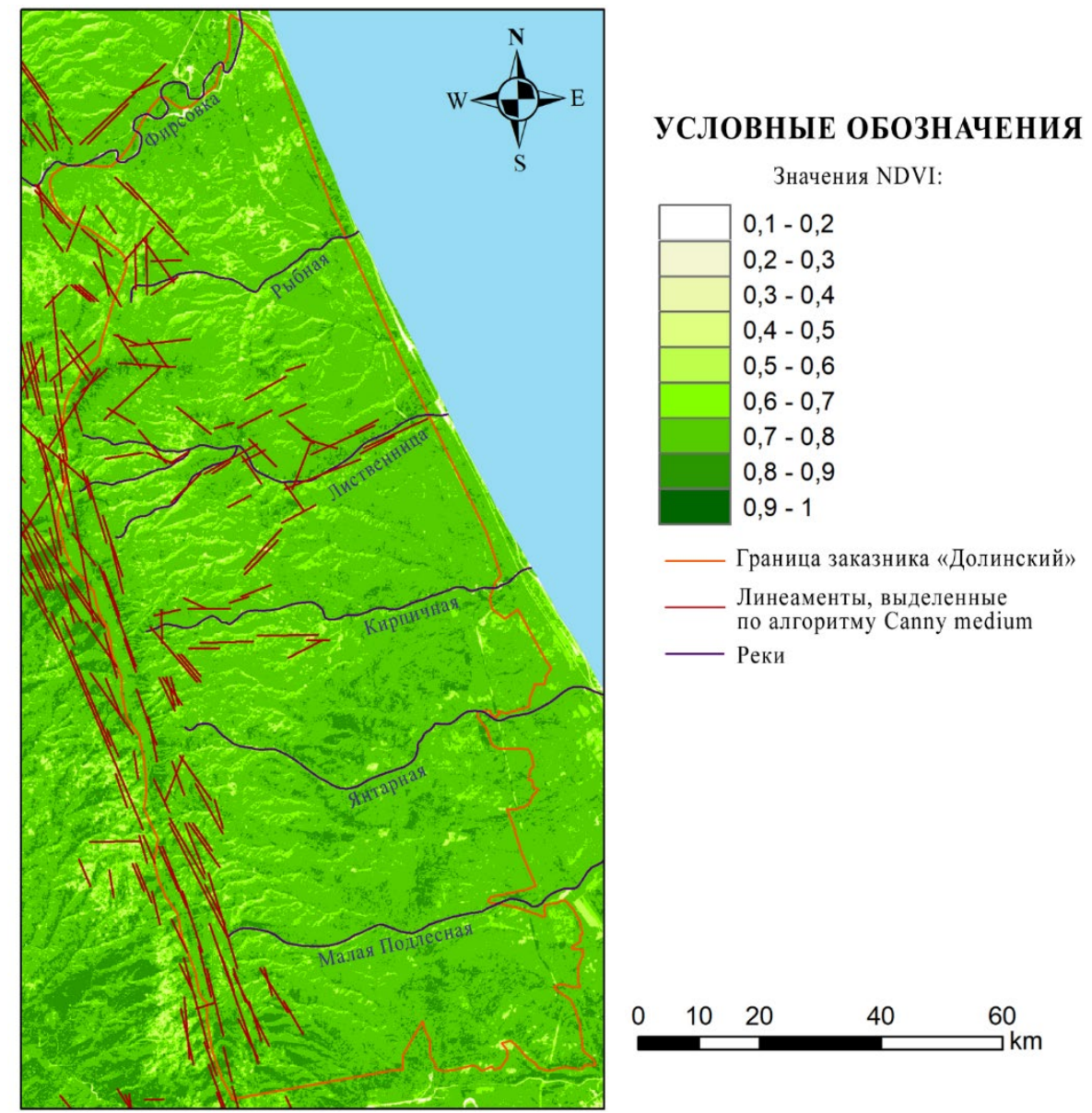

Рис. 4. Результирующая карта взаимообусловленности значений фитомассы и активных разломных зон

Вместе с тем активность разломов определяла разнообразие и биопродуктивность природных ландшафтов, которые наблюдается в шлейфах выноса осадочных отложений у подножия хребтов. Выпадение осадков на склонах способствует увлажнению предгорных равнин малыми водотоками с хребтов.

\section{Заключение}

Большинство разломов на Сахалине активно изучалось и ранее при поисках полезных ископаемых, а также после сильных землетрясений, таких, в частности, как Нефте- горское (1995 г.) и Невельское (2007 г.). Проведенное исследование, результаты которого представлены в настоящей статье, позволило получить и сопоставить высоко информативные разновременные карты линеаментов и фитомассы растительности заказника «Долинский», составленные по данным дистанционного зондирования Земли с использованием авторских разработок. В итоге подтверждена достоверность утверждения о том, что зонах активных разломов формируются ландшафты, благоприятные для развития растительного покрова. Наиболее высокие значения NDVI, обусловленные высокой продук- 
тивностью пихтово-еловых (I-II класс бонитета) и долинных ивово-ольховых лесов отмечаются в верховьях долин наиболее крупных рек исследованной территории: Фирсовки, Рыбной, Лиственницы и Кирпичной в восточных предгорьях Долинского хребта.

\section{БИБЛИОГРАФИЧЕСКИЙ СПИСОК}

1. Аплонов С. А. Геодинамика. - СПб. : Изд-во СПбГУ, 2001. - 360 с.

2. Короновский Н. В. Общая геология : учебник. - 2-е изд., стереотип. - Москва : ИНФРА-М, 2017. $-474 \mathrm{c}$.

3. Зверев А. Т. Инженерная геодинамика : учебник для студентов высших учебных заведений. Москва : Изд-во МИИГАиК, 2013. - 324 с.

4. Парначёв В. П. Основы геодинамического анализа : учебное пособие. - Томск : Изд-во НТЛ, 2011. $-308 \mathrm{c}$.

5. Трифонов В. Г. Особенности развития активных разломов // Геотектоника. $-1985 .-\mathrm{T}, 19$, № 2. - C. 16-26.

6. Трифонов В. Г. Живые разломы земной коры // Соросовский образовательный журнал. 2001. - T. 7, № 7. - С. 66-74.

7. Жмакин Е. Я., Давыдова Е. Г. Разломы земной коры и особенности растительности в зоне их влияния на территории Калужской области // Вестник Калужского университета. - 2010. - № 3. C. 57-60.

8. USGS EROS Archive. Digital Elevation - Shuttle Radar Topography Mission (SRTM) Void Filled. GloVis Website USGS (U.S. Geological Survey) [Electronic resource]. - Mode of access : https://glovis.usgs.gov/aP (accessed 15.06.2021).

9. United States Geological Survey (USGS) [Electronic resource]. - Mode of access : https://doi.org/earthexplorer.usgs.gov/ (accessed 15.06.2021).

10. Sentinel Missions. Website ESA (European Space Agency) [Electronic resource]. - Mode of access : https://sentinel.esa.int/web/sentinel/missions/sentinel-2 (accessed 15.06.2021).

11. Ресурсы для ArcMap // ESRI.com [Электронный ресурс]. - Режим доступа : https://www.esri.com/ru-ru/arcgis/products/arcgis-desktop/resources (дата обращения: 15.06.2021).

12. The QGIS Line Direction Histogram Plugin. Håvard Tveite. Created using Sphinx 1.6.7 [Electronic resource]. - Mode of access : http://plugins.qgis.org/plugins/LineDirectionHistogram/ (accessed 15.06.2021).

13. Шевырёв С. Л. Программа LEFA: автоматизированный структурный анализ космической основы в среде Matlab // Успехи современного естествознания. - 2018. - № 10. - С. 138-143.

14. Richards J. A. Remote sensing digital image analysis. An introduction. - Sekond, revised and enlarged edition. - Berlin Heidelberg: Springer - Verlag, 1993. - $339 \mathrm{c}$.

15. Шовенгердт Р. А. Дистанционное зондирование. Модели и методы обработки изображений. - М. : Техносфера, 2010. -560 c.

16. Кашницкий А. В., Балашов И. В., Лупян Е. А, Толпин В. А., Уваров И. А. Создание инструментов для удаленной обработки спутниковых данных в современных информационных системах // Современные проблемы дистанционного зондирования Земли из космоса. $-2015 .-$ T. 12 , № 1. - C. 156-170.

17. Классификации по методу максимального подобия // ArcGIS Desktop. Краткий обзор справочника по инструментам геообработки [Электронный ресурс]. - Режим доступа : https://desktop.arcgis.com/ru/arcmap/10.5/tools/spatial-analyst-toolbox/maximum-likelihood-

classification.htm (дата обращения: 15.06.2021).

18. Canny J. F. A. A Computational Approach to Edge Detection [Electronic resource] // IEEE transactions on pattern analysis and machine intelligence. - 1986. - Vol. pami-8, No.6. - P. 679-698. - Mode of access: http://perso.limsi.fr/vezien/PAPIERSACS/canny1986.pdf (accessed: 15.06.2021).

19. Galamhos C., Matas J., Kittler J. Progressive probabilistic Hough transform for line detection [Electronic resource] // IEEE Computer Society Conference on Computer Vision and Pattern Recognition. 1999. - P. 554-560. - Mode of access: https://dspace.cvut.cz/bitstream/handle/10467/9451/1999-Progressiveprobabilistic-Hough-Transform-for-line-detection.pdf?sequence=1 (accessed 15.06.2021).

20. Hobbs W. H. Lineaments of the Atlantic border region // Geological Society of America Bulletin. 1904. - Vol. 15. - P. 483-506.

21. Shahtahmassebi A., Yang N., Wang K., Moore N., Shen Z. Review of shadow detection and deshadowing methods in remote sensing // Chinese Geographical Science. - 2013. - Vol. 23 (4). - P. 403-420. doi: https://doi.org/10.1007/s11769-013-0613-x. 
22. Корзников К. А., Беляева Н. Г., Сандлерский Р. Б. Моделирование лесного покрова бассейна реки Венгери на острове Сахалин с применением данных дистанционного зондирования // Лесоведение. - 2020. - № 5. - С. 399-411. doi: 10.31857/S002411482005006X.

23. Верхотуров А. А., Мелкий В. А. Картографирование растительных сообществ подзоны темнохвойных лесов юга Сахалина на основе космических съемок // ИнтерКарто. ИнтерГИС. - 2020. T. 26, № 4. - C. 60-72. doi: 10.35595/2414-9179-2020-4-26-60-72.

24. Лобищева И. И. Растительность альпийского пояса Западно-Сахалинских гор в заказнике «Макаровский» // Известия вузов. Геодезия и аэрофотосъемка. - 2011. - № 6. - С. 61-63.

25. Мельников Е. К., Рудник В. А., Мусейчук Ю. И., Рымарев В. И. Патогенное воздействие зон активных разломов земной коры Санкт-Петербургского региона // Геоэкология. Инженерная геология, гидрогеология, геокриология. - 1994. - № 4. - С. 52-69.

26. Мельников Е. К., Шабаров А. Н. Оценка роли геодинамического фактора в аварийности трубопроводных систем // Записки Горного Института. - 2010. - Т. 188. - С. 203-206.

27. Долгополов Д. В. Использование данных дистанционного зондирования Земли при формировании геоинформационного пространства трубопроводного транспорта // Вестник СГУГиТ. - 2020. -Т. 25, № 3. С. 151-159. doi: 10.33764/2411-1759-2020-25-3-151-159.

28. Долгополов Д. В., Никонов Д. В., Полуянова А. В., Мелкий В. А. Возможности визуального дешифрирования магистральных трубопроводов и объектов инфраструктуры по спутниковым изображениям высокого и сверхвысокого пространственного разрешения // Вестник СГУГиТ. - 2019. Т. 24, № 3. - С. 65-81.

29. Маркелов Д. А., Маркелов А. В., Минеева Н. Я., Акользин А. П., Кочуров Б. И., Шаповалов Д. А., Хуторова А. О., Григорьева М. А., Чукмасова Е. А. Нефтяное загрязнение ландшафтов Чечни: распознавание на местности - «Технологии с одного взгляда» // Экология урбанизированных территорий. - 2018. - № 2. - С. 52-60. doi: 10.24411/1816-1863-2018-12052

30. Карпик А. П., Середович В. А., Дубровский А. В., Ким Э. Л., Малыгина О. И. Анализ природных и техногенных особенностей геопространства чрезвычайной ситуации // Интерэкспо ГЕОСибирь-2012. VIII Междунар. науч. конгр. : Междунар. науч. конф. «Геодезия, геоинформатика, картография, маркшейдерия» : сб. материалов в 3 т. (Новосибирск, 10-20 апреля 2012 г.). Новосибирск : СГГА, 2012. Т. 3. - С. 178-184.

31. Жарников В. Б. Рациональное использование земель и основные условия его реализации // Вестник СГУГиТ. - 2017. - Т. 22, № 3. - С. 171-179.

Получено 13.07.2021

(C) О. В. Купиова, И. И. Лобищева, А. А. Верхотуров, В. А. Мелкий, 2021

\section{STUDY OF INFLUENCE OF THE FAULT ZONES ON VEGETATION COVER OF STATE TERRITORY OF THE NATURE SANCTUARY "DOLINSKY" (SAKHALIN ISLAND) USING EARTH'S REMOTE SENSING DATA}

\section{Olesya V. Kuptsova}

Sakhalin State University, 2, Pogranichnaya St., Yuzhno-Sakhalinsk, 693023, Russia, Ph. D. Student, Department of Geology and Oil and Gas Business, phone: (924)190-00-08, e-mail: Korsuncevaolesy@gmail.com

\section{Inna I. Lobishcheva}

Sakhalin State University, 2, Pogranichnaya St., Yuzhno-Sakhalinsk, 693023, Russia, Senior Lecturer, Department of Geology and Oil and Gas Business, phone: (914)757-99-26, e-mail: slalinna@mail.ru

\section{Alexey A. Verhoturov}

Institute of Marine Geology and Geophysics of the Far Eastern branch of the Russian Academy of Sciences, 1B, Nauki St., Yuzhno-Sakhalinsk, 693022, Russia, Ph. D., Senior Researcher, Center for Collective Use, e-mail: ussr-91@mail.ru 


\section{Vyacheslav A. Melkiy}

Institute of Marine Geology and Geophysics of the Far Eastern branch of the Russian Academy of Sciences, 1B, Nauki St., Yuzhno-Sakhalinsk, 693022, Russia, D. Sc., Leading Researcher, Laboratory of Volcanology and Volcanic Hazards, e-mail: vamelkiy@mail.ru

Fault zones on the territory of Nature Sanctuary "Dolinsky" (Sakhalin Island), which are characterized by high geodynamic activity, are generally well distinguished when analyzing satellite imagery materials. In any territory, it is not difficult to identify the various plant communities that occupy it, as well as to determine their state by the content of phytomass determined by the vegetation index NDVI. The aim of the study is to test the validity of the hypothesis about the formation of abundant vegetation cover within the fault zones by analyzing the state of various plant communities by the volume of phytomass. Methods: decryption and analysis of Earth remote sensing data from Sentinel, Landsat and SRTM generation, geoinformation mapping on the ArcGIS platform. Results. In the course of the study, the state of the Nature Sanctuary "Dolinsky" analyzed by Landsat8, Sentinel-2A satellite surveys, as well as SRTM data. Fault zones identified using the software systems ArcGIS, QGIS, and PyLEFA by lineament analysis, vegetation was classified by the maximum likelihood method, and its condition was determined by the values of the NDVI index, which reflects the content of phytomass in the study area. As result of the work carried out, an increase in phytomass revealed, and, consequently, good conditions for the growth of plant communities confined to the zones of distribution of faults of the earth's crust, and the reliability of the working hypothesis confirmed.

Keywords: Earth's remote sensing, aerospace image decoding, geographic information thematic mapping, geodynamic activity, Sentinel, Landsat, SRTM, NDVI, PyLEFA

\section{REFERENCES}

1. Aplonov, S. A. (2001). Geodinamika [Geodynamics]. St. Petersburg: St. Petersburg State University Publ., 360 p. [in Russian].

2. Koronovsky, N. V. (2017). Obshchaya geologiya [General geology] (2nd ed., stereotype). Moscow: INFRA-M Publ., 474 p. [in Russian].

3. Zverev, A. T. (2013). Inzhenernaya geodinamika [Engineering geodynamics]. Moscow: MIIGAiK Publ., 324 p. [in Russian].

4. Parnachev, V. P. (2011). Osnovy geodinamicheskogo analiza [Fundamentals of geodynamic analysis]. Tomsk: NTL Publ., 308 p. [in Russian].

5. Trifonov, V. G. (1985). Features of the development of active faults. Geotektonika [Geotectonics], 19(2), 16-26. [in Russian].

6. Trifonov, V. G. (2001). Living faults of the Earth's crust. Sorosovsky obrazovatelny zhurnal [Soros Educational Magazine], 7(7), 66-74 [in Russian].

7. Zhmakin, E. Ya., \& Davydova, E. G. (2010). Faults of Earth's crust and vegetation features in zone of their influence on territory of the Kaluga region. Vestnik Kaluzhskogo universiteta [Bulletin of the Kaluga University], 3, 57-60 [in Russian].

8. USGS EROS Archive. Digital Elevation - Shuttle Radar Topography Mission (SRTM) Void Filled. GloVis Website USGS (U.S. Geological Survey). (n. d.). Retrieved from https://glovis.usgs.gov/aP (accessed 15.06.2021).

9. United States Geological Survey (USGS). (n. d.). Retrieved from https://doi.org/earthexplorer.usgs.gov/ (accessed 15.06.2021).

10. Sentinel Missions. Website ESA (European Space Agency). (n. d.). Retrieved from https://sentinel.esa.int/web/sentinel/missions/sentinel-2 (accessed 15.06.2021).

11. Resources for ArcMap. ESRI.com. (n. d.). Retrieved from https://www.esri.com/enus/arcgis/products/arcgis-desktop/resources (accessed 15.06.2021).

12. The QGIS Line Direction Histogram Plugin. Håvard Tveite. Created using Sphinx 1.6.7. (n. d.). Retrieved from http://plugins.qgis.org/plugins/LineDirectionHistogram/ (accessed 15.06.2021). 
13. Shiverev, S. L. (2018). LEFA software: an automatized structural analysis of remote sensing imagery in MATLAB environment. Uspekhi sovremennogo estestvoznaniya [Advances in Current Natural Sciences], 10, 138-143 [in Russian].

14. Richards, J. A. (1993). Remote sensing digital image analysis. An introduction (2nd, revised and enlarged ed.). Berlin Heidelberg: Springer - Verlag, 339 p.

15. Shovengerdt, R. A. (2010). Distantsionnoe zondirovanie. Modeli i metody obrabotki izobrazheniy. [Remote sensing. Models and methods of image processing.]. Moscow: Tekhnosfera Publ., 560 p. [in Russian].

16. Kashnitskiy A. V., Balashov I. V., Lupyan E. A., Tolpin V. A., \& Uvarov I. A. (2015). Creating tools for remote processing of satellite data in modern information systems. Sovremennye problemy distantsionnogo zondirovaniya Zemli iz kosmosa [Modern Problems of Remote Sensing of the Earth from Space], 12(1), 156170 [in Russian].

17. Classifications by the maximum similarity method. In ArcGIS Desktop. Kratkiy obzor spravochnika po instrumentam geoobrabotki [ArcGIS Desktop. A brief overview of the handbook of geoprocessing tools]. Retrieved from https://desktop.arcgis.com/ru/arcmap/10.5/tools/spatial-analyst-toolbox/maximum-likelihoodclassification.htm (accessed: 15.06.2021).

18. Canny, J. F. A. (1986). A Computational Approach to Edge Detection. IEEE Transactions on Pattern Analysis and Machine Intelligence, pami-8(6), 679-698. Retrieved from http://perso.limsi.fr/vezien/PAPIERSACS/canny1986.pdf (accessed: 25.03.2021).

19. Galamhos, C., Matas, J., \& Kittler, J. (1999). Progressive probabilistic Hough transform for line detection. IEEE Computer Society Conference on Computer Vision and Pattern Recognition (pp. 554-560). Retrieved from https://dspace.cvut.cz/bitstream/handle/10467/9451/1999-Progressive-probabilistic-Hough-Transform-for-linedetection.pdf?sequence=1 (accessed 15.06.2021).

20. Hobbs, W. H. (1904). Lineaments of the Atlantic border region. Geological Society of America Bulletin, 15, 483-506.

21. Shahtahmassebi, A., Yang, N., Wang, K., Moore, N., \& Zhangquan, Sh. (2013). Review of shadow detection and de-shadowing methods in remote sensing. Chinese Geographical Science, 23(4), 403-420. doi: https://doi.org/10.1007/s11769-013-0613-x.

22. Korznikov, K. A., Belyaeva, N. G., \& Sandlersky, R. B. (2020). Modeling the Forest Cover of the Vengeri River Basin on the Sakhalin Island Using the Remote Sensing Data. Lesovedenie [Russian Journal of Forest Science], 5, 399-411. doi: https://doi.org/10.31857/S002411482005006X [in Russian].

23. Verkhoturov, A. A., \& Melkiy, V. A. (2020). Mapping of vegetation communities of the subzone of dark coniferous forests of the South Sakhalin based on space surveys. InterCarto. InterGIS. Proceedings of the International Conference, 26(2), 60-72. doi: https://doi.org/10.35595/2414-9179-2020-4-26-60-72.

24. Lobishcheva, I. I. (2011). Vegetation of the alpine belt of the Western Sakhalin Mountains in the reserve "Makarovsky". Izvestiya vuzov. Geodeziya i aerofotos"emka [Izvestiya Vuzov. Geodesy and Aerophotosurveying], 6, 61-63 [in Russian].

25. Melnikov, E. K., Rudnik, V. A., Museychuk, Yu. I., \& Rymarev, V. I. (1994). Pathogenic impact of zones of active faults of the Earth's crust of the St. Petersburg region. Geoekologiia. Inzhenernaia geologiia, gidrogeologiia, geokriologiia [Geoecology. Engineering Geology, Hydrogeology, Geocryology], 4, $52-69$ [in Russian].

26. Melnikov, E. K., \& Shabarov, A. N. (2010). Assessment of the role of geodynamic factor in the accident rate of pipeline systems. Zapiski Gornogo Instituta [Notes of the Mining Institute], 188, 203-206 [in Russian].

27. Dolgopolov, D. V. (2020). Use of earth remote sensing data for formation of geodata space of pipeline transport. Vestnik SGUGiT [Vestnik SSUGT], 25(3), 151-159. doi: https://doi.org/10.33764/2411-1759-202025-3-151-159 [in Russian].

28. Dolgopolov, D. V. Nikonov, D. V., Poluyanova, A. V., \& Melkiy, V. A. (2019). Possibilities of visual interpretation of trunk pipelines and infrastructure facilities using satellite images of high and ultra-high spatial resolution. Vestnik SGUGiT [Vestnik SSUGT], 24(3), 65-81. doi: 10.33764/2411-1759-2019-24-3-65-81 [in Russian].

29. Markelov, D. A., Markelov, A. V. Mineeva, N. Ya., Akolzin, A. P., Kochurov, B. I., Shapovalov, D. A., Khutorova, A. O., Grigorieva, M. A., \& Chukmasova, E. A. (2018). Oil pollution of the landscapes of Chechnya: recognition on the ground - "Technologies at a glance". Ekologiia urbanizirovannykh territorii 
[Ecology of urbanized territories], 2, 52-60. doi: https://doi.org/10.24411/1816-1863-2018-12052 [in Russian].

30. Karpik, A. P., Seredovich, V. A., Dubrovskij, A. V., Kim, E. L., \& Malygina, O. I. (2012). Analysis of natural and man-made features of the emergency geospace. In Sbornik materialov Interekspo GEO-Sibir'2012: Mezhdunarodnoy nauchnoy konferentsii: T. 3. Geodeziya, geoinformatika, kartografiya, markshejderiya [Proceedings of Interexpo GEO-Siberia-2012: International Scientific Conference: Vol. 3. Geodesy, Geoinformatics, Cartography, Mine Surveying] (pp. 178-184). Novosibirsk: SSGA Publ. [in Russian].

31. Zharnikov, V. B. (2017) Rational use of land and the main conditions for its implementation. Vestnik SGUGiT [Vestnik SSUGT], 22(3), 171-179 [in Russian].

Received 13.07.2021

(C) O. V. Kuptsova, I. I. Lobishcheva, A. A. Verkhoturov, V. A. Melkiy, 2021 


\title{
КАРТОГРАФИЯ И ГЕОИНФОРМАТИКА
}

УДК 528.9:004.4

DOI: $10.33764 / 2411-1759-2021-26-5-86-98$

\section{РАСЧЕТ И ВИЗУАЛИЗАЦИЯ КАРТОГРАФИЧЕСКИХ МАРШРУТОВ С ИСПОЛЬЗОВАНИЕМ ПРОГРАММНОГО ОБЕСПЕЧЕНИЯ QGIS И PGROUTING}

\author{
Андрей Александрович Басаргин \\ Сибирский государственный университет геосистем и технологий, 630108, Россия, г. Новосибирск, \\ ул. Плахотного, 10, кандидат технических наук, доцент кафедры прикладной информатики и инфор- \\ мационных систем, тел. (383)343-18-53, e-mail: abaspirant@mail.ru
}

\section{Петр Юрьевич Бугаков}

Сибирский государственный университет геосистем и технологий, 630108, Россия, г. Новосибирск, ул. Плахотного, 10, кандидат технических наук, доцент кафедры картографии и геоинформатики, тел. (383)343-18-53, e-mail: peter-bugakov@yandex.ru

\section{Татьяна Юрьевна Бугакова}

Сибирский государственный университет геосистем и технологий, 630108, Россия, г. Новосибирск, ул. Плахотного, 10, кандидат технических наук, зав. кафедрой прикладной информатики и информационных систем, тел. (383)343-18-53, e-mail: kaf.pi@ssga.ru

В последнее время создаются новые инструменты для работы с геоданными, применяемые в различных областях человеческой деятельности. Особое значение имеет программное обеспечение для сетевого анализа и решения задач маршрутизации. Примером является программный продукт pgRouting, pacпространяемый по лицензии GPLv2. Данная программа расширяет возможности геопространственных баз данных PostGIS / PostgreSQL. B статье рассматриваются общие принципы построения маршрутов по графам дорожной сети. Описывается порядок работы с базой геопространственных данных и программным обеспечением pgRouting для построения маршрута. Целью работы является построение корректного маршрута одного лишь графа дорог при маршрутизации по территориям с большим количеством объектов и слабо выраженной сетью дорог. Данная задача реализуется на основе алгоритма нахождения кратчайшего пути Дейкстры, алгоритмов Джонсона и Флойда - Уорсхолла, позволяет решать задачу коммивояжера и многие другие. Задача решена средствами программного обеспечения pgRouting и QGIS. B качестве эксперимента приводится решение задачи, в которой для построения корректного маршрута одного лишь графа дорог недостаточно. Такие ситуации могут возникнуть при маршрутизации по территориям с большим количеством объектов и слабо выраженной сетью дорог. В ходе эксперимента, описанного в статье, было выяснено, что программное обеспечение pgRouting совместно с QGIS позволяет достаточно эффективно решать поставленную задачу по вычислению и визуализации кратчайшего маршрута между двумя точками на карте.

Ключевые слова: маршрутизация, маршрут, кратчайший путь, граф, дорожная сеть, геоданные, визуализация, геоинформационная система

\section{Введение}

Решение задач по планированию, управлению и контролю движения материальных ресурсов всегда занимало особое место в жизни человека. Организация современных транспортных систем основана на использовании алгоритмов оптимизации финансовых расходов и сокращении времени, затрачиваемого на перемещение объекта в пункт назначения. В свою 
очередь применение таких алгоритмов невозможно без картографической основы, которая содержит большую часть исходных данных, необходимых для их функционирования.

В последнее время создаются новые инструменты для работы с геоданными, применяемые в различных областях человеческой деятельности [1-6]. Особое значение имеет программное обеспечение для сетевого анализа и решения задач маршрутизации. Одним из наиболее интересных примеров является pgRouting - программное обеспечение, доступное под лицензией GPLv2 и поддерживаемое растущим сообществом частных лиц, предприятий и организаций. Данная программа расширяет возможности геопространственных баз данных PostGIS / PostgreSQL, реализует алгоритм нахождения кратчайшего пути Дейкстры, алгоритмы Джонсона и Флойда - Уорсхолла, позволяет решать задачу коммивояжера и многие другие. Использование pgRouting совместно с геоинформационными системами позволяет существенно упростить и автоматизировать процессы решения задач сетевого анализа на основе графов.

\section{Общие принципы построения марщрутов}

Исходными данными для построения маршрута является взвешенный граф дорожной сети. Весовые коэффициенты в таких графах присваиваются дугам и отражают определенную характеристику, необходимую для решения поставленной задачи. В качестве весового коэффициента может быть выбрано время, стоимость проезда, качество дорожного покрытия и т. д.

В картографии граф дорог может быть представлен цифровой векторной картой, которая состоит из топологически связанных дуг (ребер) и узлов (вершин). Положение узлов и дуг определяется с точностью, соответствующей точностным характеристикам картографической основы. Как правило, векторные объекты, описывающие граф дорог и дорожные инженерные сооружения, выносятся на отдельный слой карты, что позволяет структурировать тематическую информацию, а также упрощает работу с ней.
Поскольку дороги могут быть с односторонним и двусторонним движением, то граф должен быть ориентированным. Для обеспечения топологической корректности дуги графа строятся по осевым линиям дорог и дорожных сооружений. Оцифровка ориентированных дуг должна выполняться строго по направлению дорожного движения. Дороги с двусторонним движением представляются в виде неориентированных ребер графа и оцифровываются в произвольном направлении.

Для обозначения перекрестков и развилок, имеющих различную конфигурацию, дуги каждой примыкающей дороги соединяются вместе общей узловой точкой, которая формирует вершину графа. Если дороги пересекаются на разном уровне, но не соединяются перекрестком, то при оцифровке графа дуги не прерываются, строятся друг над другом и узлами не соединяются.

Запреты поворотов на перекрестках могут быть обозначены с использованием нескольких параллельных дуг, соединяющих только те узлы, между которыми разрешено движение транспорта. В этом случае формируется ориентированный мультиграф.

Таким образом, с использованием ориентированных дуг, неориентированных ребер, а также вершин, их соединяющих, можно однозначно описать различные виды перекрестков, одноуровневые и многоуровневые развязки. Прокладка маршрута между двумя точками дорожного графа при использовании соответствующих алгоритмов может осуществляться автоматически. Пример дуг и узлов дорожного графа показан на рис. $1,2$.

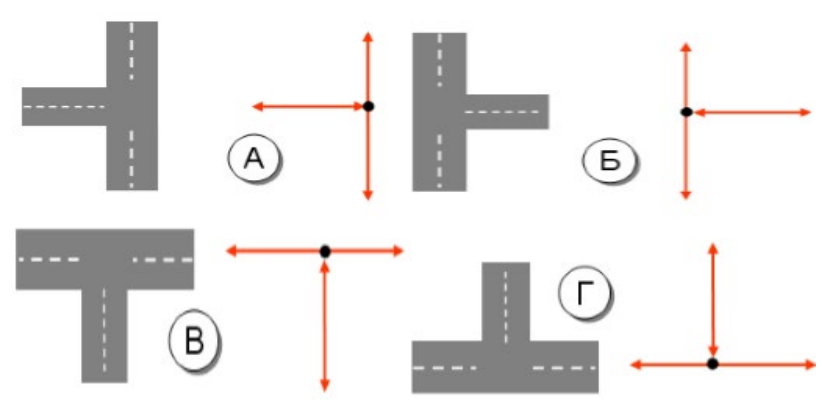

Рис. 1. Т-образные перекрестки 


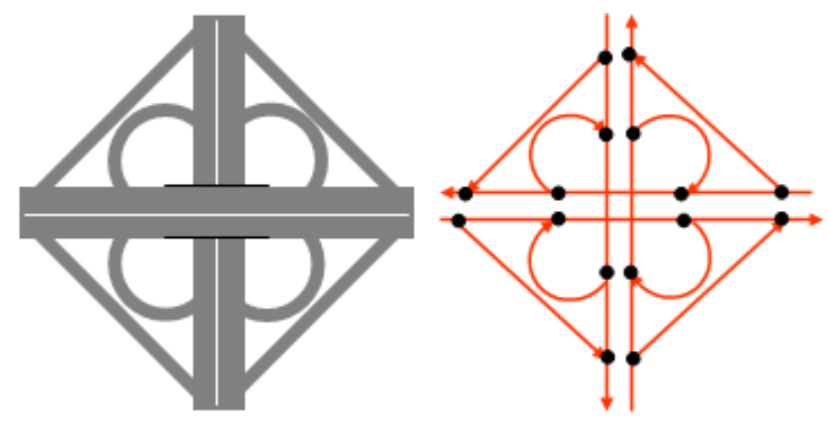

Рис. 2. Пересечение двух дорог на разных уровнях с полным набором съездов

Каждому узлу отдельно присваивается «вес» дороги. «Вес» дороги включает в себя информацию о типе покрытия дороги, максимально разрешенной скорости на данном участке дороги, качестве дороги и т. д. Делается это для того, чтобы пользователь, перед тем как создать запрос на построение маршрута, мог выбрать нужные ему свойства. Например, пользователю необходимо показать маршрут с максимально разрешенной скоростью 90 км/ч, программа постарается проложить маршрут, исключая участки дороги, на которых максимально разрешенная скорость, составляет меньше 90 км/ч.

Предположим, необходимо построить маршрут из точки А в точку В. Алгоритм прокладывает маршрут на один шаг (до следующего узла графа) по всем возможным направлениям от точки А. Затем вычисляется количество времени, которое потребуется на преодоление этих участков. Далее алгоритм выбирает вершину графа, до которой временные затраты оказались минимальными. В данном примере это вершина С. На рис. 3 представлен начальный перебор вариантов проезда.

Затем алгоритм строит маршрут еще на один шаг - во все стороны от точки C и снова анализирует, в какую из точек можно было бы попасть быстрее всего. На этот раз это точка D. На следующем шаге алгоритм будет строить маршрут уже от нее. На рис. 4 представлен следующий шаг в переборе вариантов проезда.

В результате алгоритм находит конфигурацию дорог, которая оказалась наиболее выгодной по времени проезда (рис. 5).

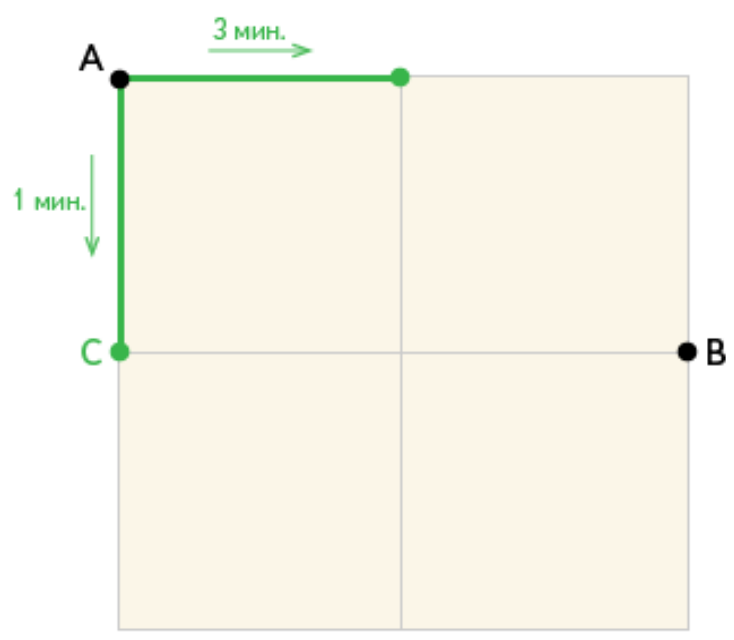

Рис. 3. Перебор вариантов проезда

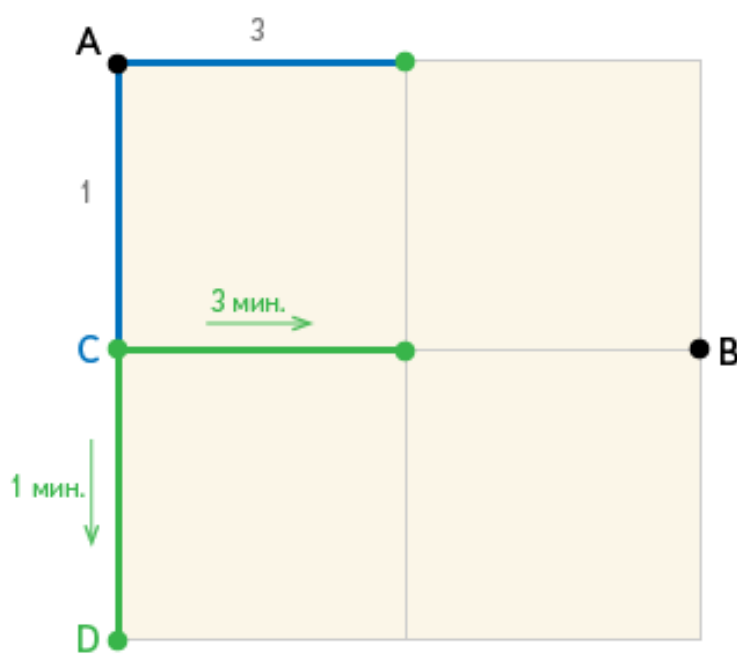

Рис. 4. Следующий шаг в переборе вариантов проезда

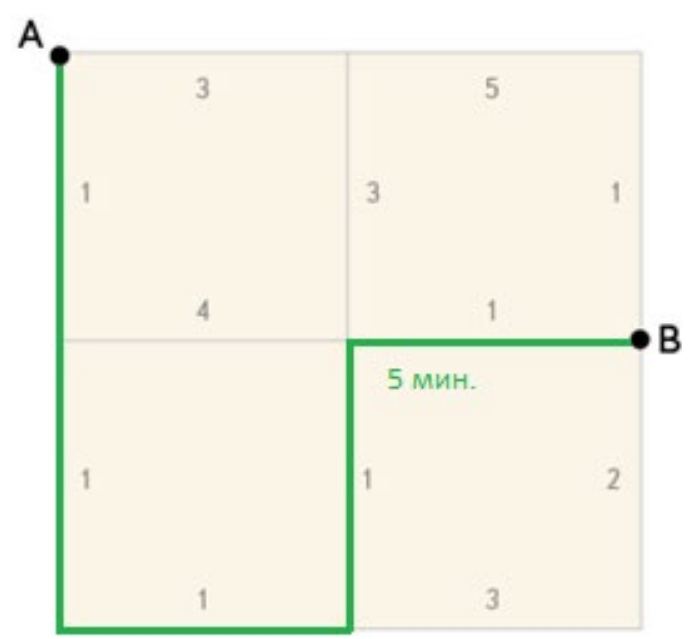

Рис. 5. Найденный вариант проезда 


\section{Использование программного обеспечения pgRouting для построения маршрута}

PgRouting представляет собой программный модуль, добавляющий функции маршрутизации в базы геопространственных данных, построенных на основе СУБД PostgreSQL и PostGIS. Также pgRouting может быть использован для проведения сетевого анализа.

Для функционирования pgRouting необходимо загрузить данный программный модуль в базу данных. На рис. 6 представлен фрагмент кода с подключением pgRouting к PostgreSQL.

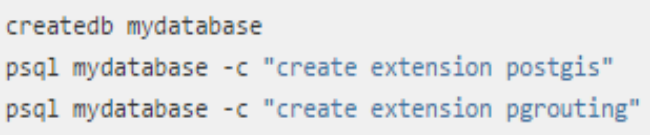

Рис. 6. Загрузка pgRouting в базу для версий PostgreSQL 9

Для загрузки данных в базу данных существуют различные OpenSource инструменты:

- shp2pgsql: преобразуем данные из shapeфайла в формат, понятный PostgreSQL;

- ogr2ogr: утилита преобразования векторных данных;

- osm2pgsql: инструмент для загрузки OpenStreetMap данных в PostgreSQL.

Эти инструменты позволяют читать векторные данные и загружать данные в базу данных в виде таблиц.

Далее была построена топология карты. Когда файлы ГИС загружены в базу данных для использования с pgRouting, они не имеют информации о топологии. Чтобы создать топологию, данные должны быть узловые. Это означает, что любое соединение улиц будет образовывать узел. Результатом соединения всех узлов будет график маршрутов, который можно использовать в маршрутизации pgRouting. Фрагмент кода с созданием топологии представлен на рис. 7.

При создании топологии можно использовать функции анализа графика, чтобы помочь увидеть ошибки в топологии.

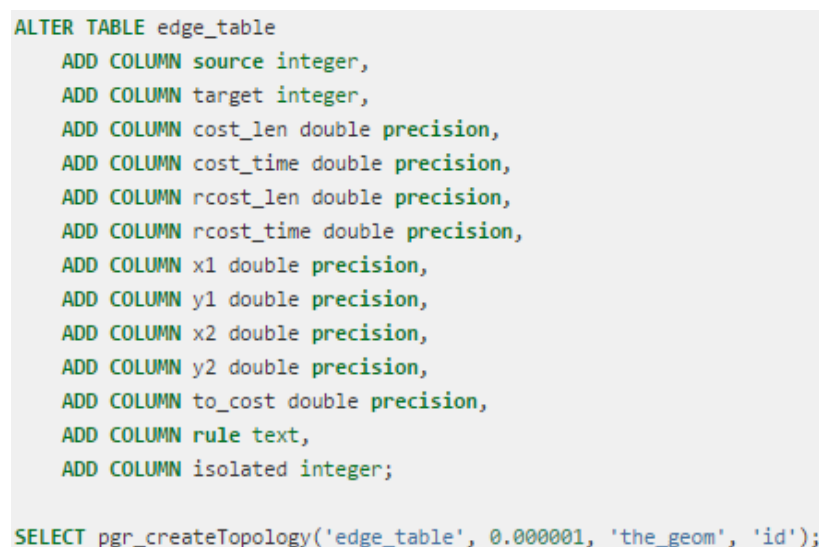

Рис. 7. Создание топологии

При создании топологии могут возникнуть ошибки: например, соединение дорог не образует узел, тем самым при создании маршрута pgRouting исключит данное пересечение дорог. Также при создании топологии может возникнуть трудность с односторонним движением; ошибка может заключаться в том, что в топологии не будет указано направление одностороннего движения, тем самым может быть проложен неверный маршрут. Для проверки топологий существуют различные инструменты, такие как pgr_analyzeGraph, pgr_analyzeOneway.

Инструмент pgr_analyzeGraph анализирует всю топологию на наличие ошибок. Фрагмент кода с поиском ошибок с использованием инструмента pgr_analyzeGraph представлен на рис. 8 .

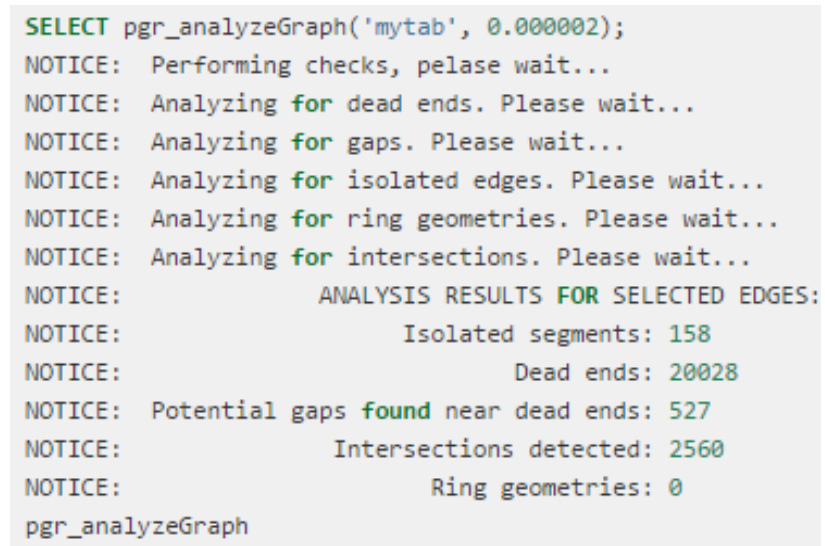

Рис. 8. Поиск ошибок

Инструмент pgr analyzeOneway анализирует топологию одной улицы на наличие ошибок. 
Фрагмент кода с использованием инструмента pgr_analyzeOneway представлен на рис. 9.

Построение маршрутов в pgRouting - достаточно простая задача. Для этого используются специальные алгоритмы, которые считывают данные с загруженной топологии. Фрагмент кода с построением маршрута представлен на рис. 10.

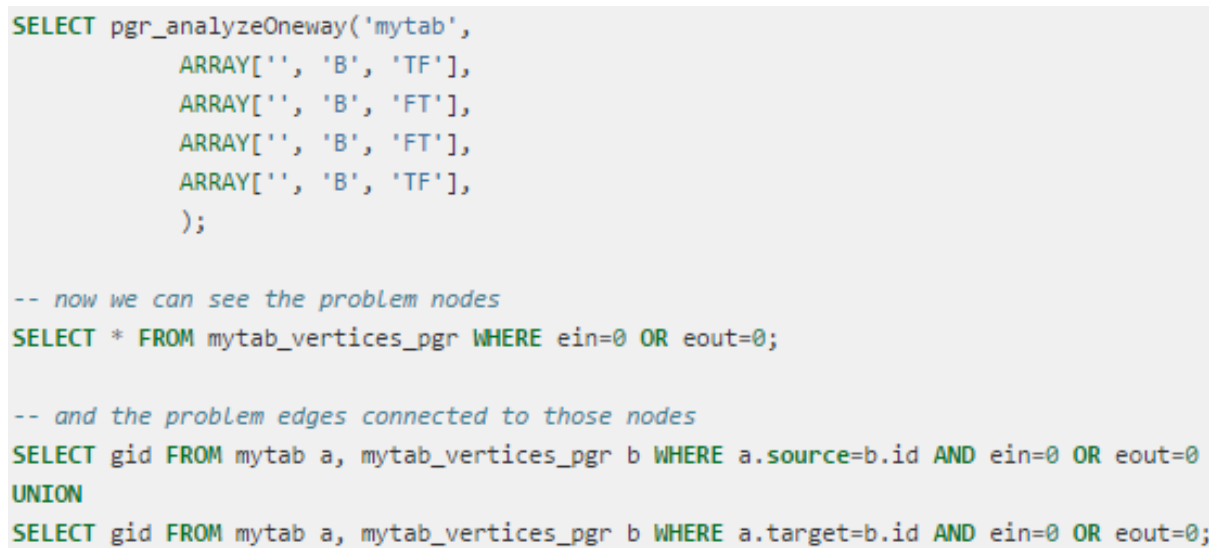

Рис. 9. Проверка на наличие ошибок

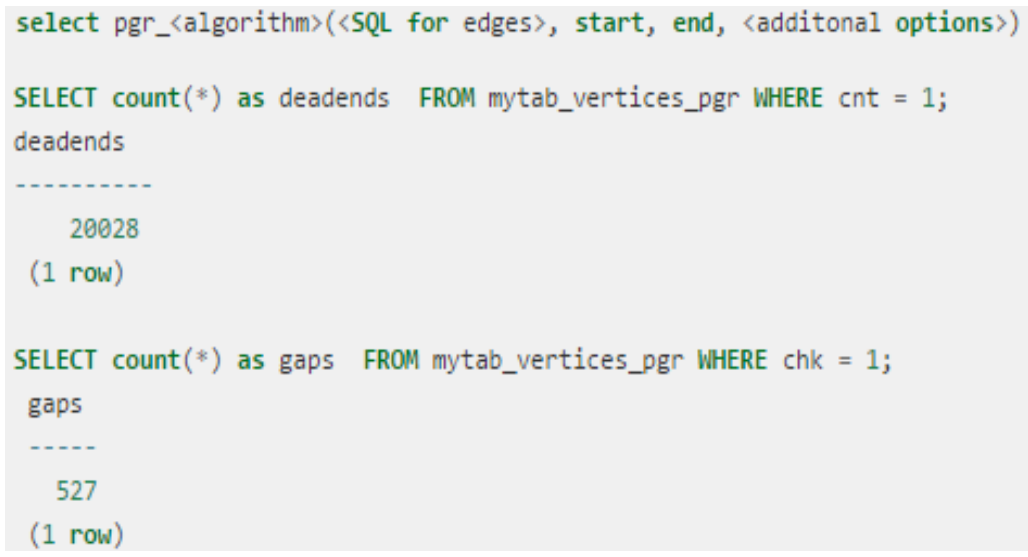

Рис. 10. Построение маршрута

В результате работы алгоритма получен готовый маршрут с информацией о начале и конце маршрута, среднем времени прохождения маршрута.

\section{Выполнение расчета и визуализации маршрута средствами pgRouting и QGIS}

Главной составляющей функции маршрутизации является граф дорог. Но могут возникнуть такие ситуации, когда одного лишь графа дорог будет недостаточно для построения корректного маршрута (деревни, кладбища и т. д.).

В связи с этим необходимо решать данную проблему, так как в некоторых случаях программным продуктам необходимо строить маршруты именно в таких местах [7-8].
Предлагается кроме создания графа дорог наложить на карту регулярную сетку, представляющую собой совокупность плотно располагающихся пересекающихся векторных линий. Регулярная сетка в совокупности с графом дорог позволит создавать более точные маршруты. При наложении регулярной сетки на карту главное - правильно подобрать интервал между линиями: чем больше на карте объектов и чем ближе они находятся друг к другу, тем меньше нужно брать интервал, так как при маленьком интервале между векторными линиями регулярной сетки построение маршрутов будет более точным.

На рис. 11 представлен пример, когда для построения маршрута необходимо использовать регулярную сетку. 


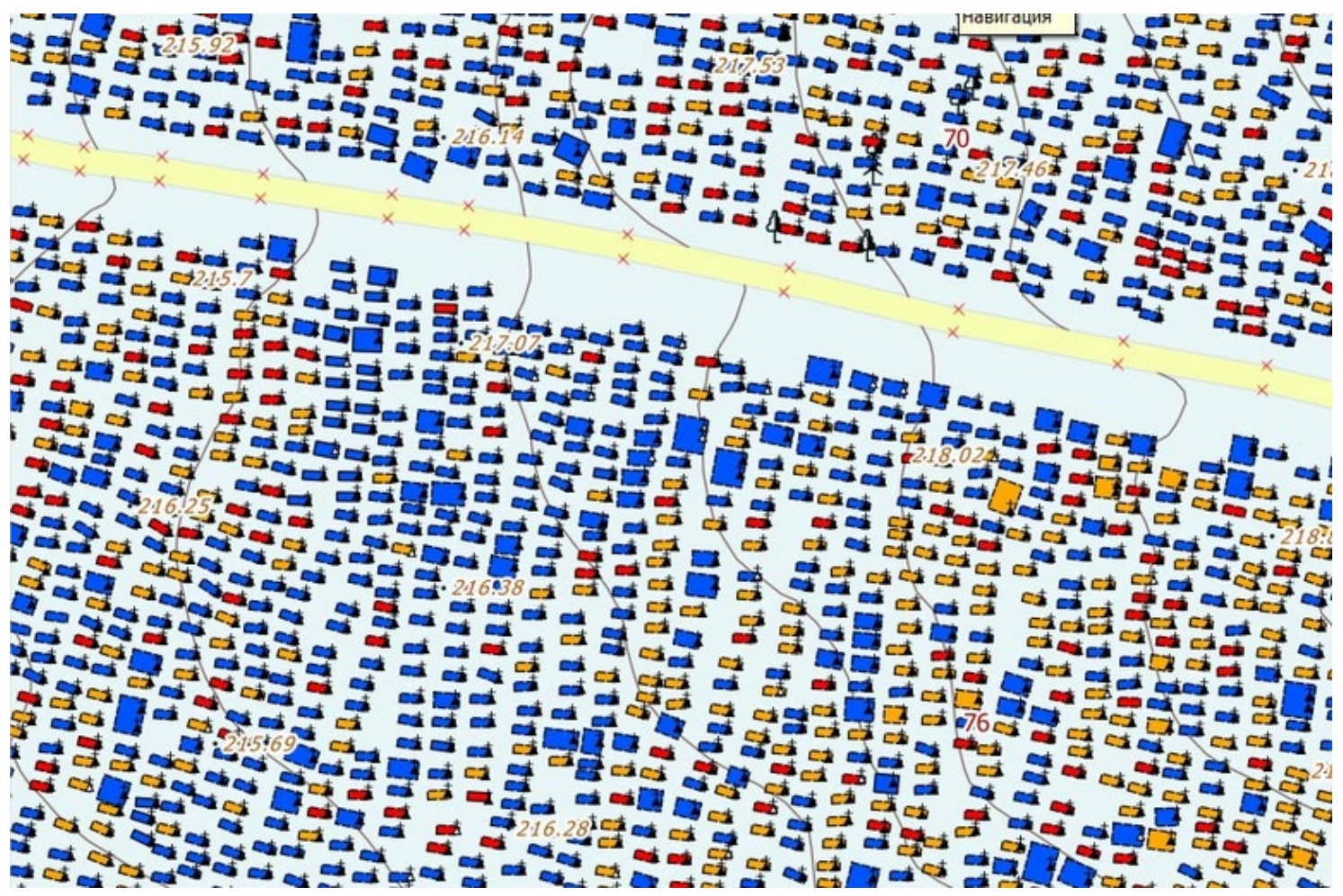

Рис. 11. Пример построения маршрута на основе регулярной сетки

Первым шагом при построении маршрута является создание полигона по границам карты. Это делается для того, чтобы в дальнейшем с помощью команды makegrid сде- лать точки, на основе которых будет построена регулярная сетка.

Что бы создать полигон, необходимо выполнить запрос, представленный на рис. 12.

insert into polygon_bounds(the_geom) select st_setsrid(st_ex-
tent(the_geom), 3785) from kvartals

Рис. 12. Запрос на построение полигона

В результате выполнения данного запроса в таблицу polygon_bounds будет вставлен полигон. Команда st_setsrid отвечает за построение полигона. Для того, чтобы полигон построился по границе всей карты, используют команду st_extent.

Следующим шагом требуется вставить в таблицу grid точки, созданные с помощью функции makegrid. Они нужны для построения регулярной сетки. Кроме этого, необходимо выставить значение интервала 1000 между точками.Чтобы ускорить процесс создания точек можно воспользоваться командой ST_Dump - она позволяет вставить в таблицу сразу весь массив. Это в значительной степени ускорит выполнение запроса. Точки регулярной сетки строятся исключительно в пределах полигона polygon_bounds, именно поэтому первым делом необходимо его создать.

Чтобы вставить в таблицу grid массив точек, необходимо выполнить запрос, представленный на рис. 13.

insert into grid(the_geom) SELECT (ST_Dump (makegrid(the_geom, 1000, 3785))).geom as the_geom from polygon_bounds

Рис. 13. Запрос на построения регулярной сетки точек 
Результат выполнения данного запроса представлен на рис. 14.

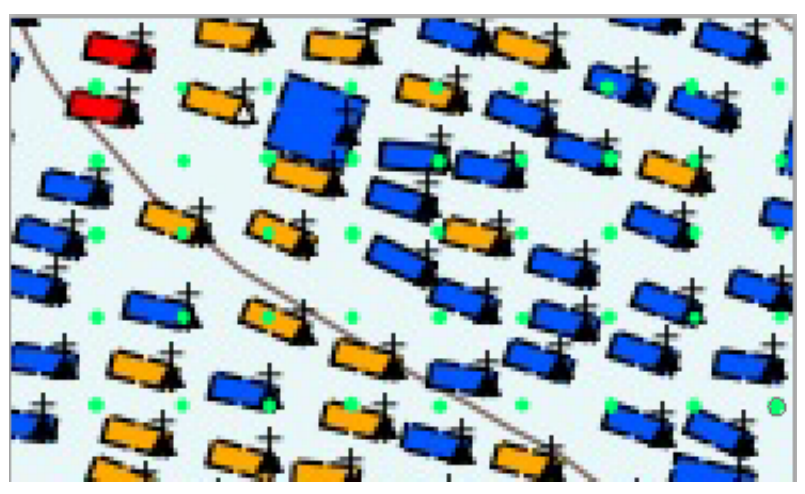

Рис. 14. Результат запроса на вставку точек

Как видно на рис. 14, некоторые точки регулярной сетки пересекаются с геометрией захоронений. Следующим шагом необходимо удалить точки пересечения двух геометрий. Лишние точки необходимо удалять, потому что именно на их основе в регулярной сетке будет построена топология карты. В итоге будет происходить создание маршрутов, и если не удалить лишние точки, то маршруты будут строиться неверно.

Чтобы убрать лишние точки, необходимо выполнить запрос, представленный на рис. 15.

В результате выполнения данного запроса создается таблица open_space_grid с помощью команды ST_Intersects для про- верки двух геометрий. После проверки в таблицу вставляются только те точки, которые не имеют пересечений с объектами таблицы polygons.

Результат выполнения запроса представлен на рис. 16.

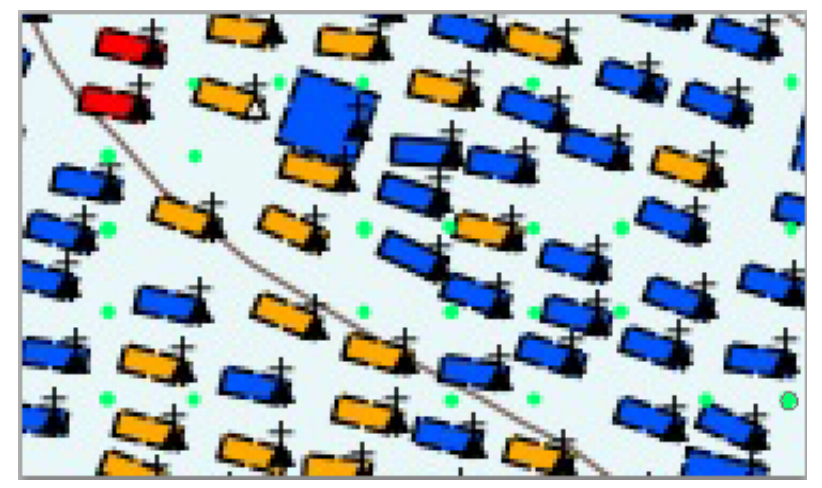

Рис. 16. Проверка пересечения двух геометрий

После того как были убраны лишние точки, можно приступать к созданию узлов. Узлами будут являться векторные линии, соединяющие точки регулярной сетки. Узлы необходимы, чтобы в дальнейшем их с помощью построить топологию карты.

Чтобы создать узлы, необходимо выполнить запрос, представленный на рис. 17.

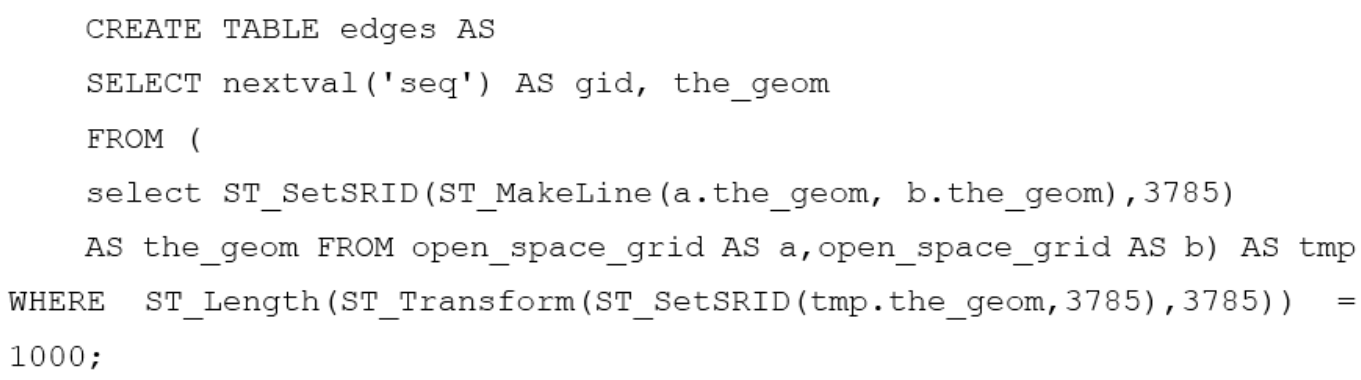

Рис. 17. Запрос на создание узлов

В результате выполнения запроса будет создана новая таблица edges, в которой будут находиться проложенные между точками дуги. С помощью команды ST_Lenght необходимо установить длину линий, проложенных между точками регулярной сетки. Так как интервал между точками был выбран 1 000, то и длину линий необходимо установить 1000. После того как был задан размер линий, необходимо построить их. Построение линий осуществляется командой ST_Transform; для того, чтобы линии построились в пределах раннее созданного полигона используется команда ST_SetSRID. 
Результат выполнения запроса представлен на рис. 18.

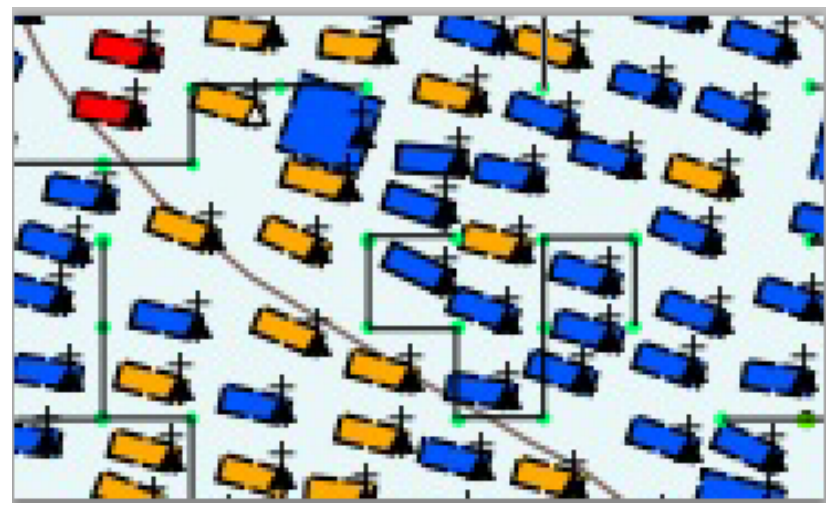

Рис. 18. Сформированные узлы

При создании узлов может возникнуть проблема в виде дублирующихся узлов. Для того чтобы удалить такие узлы, необходимо выполнить запрос, представленный на рис. 19.

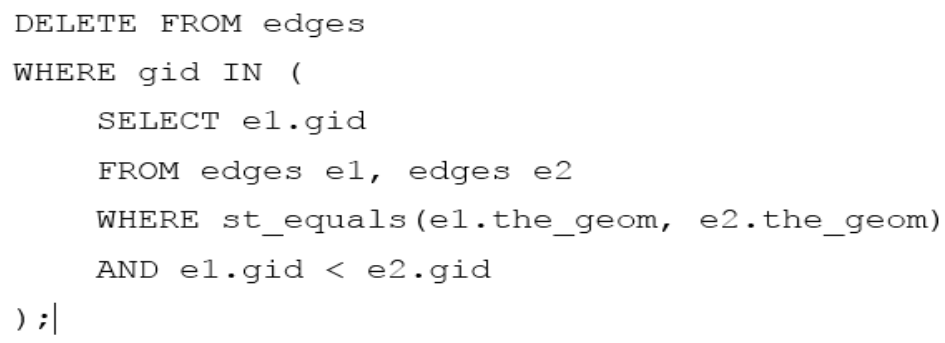

Рис. 19. Запрос на удаление дуг

Следующим шагом необходимо создать топологию, которая создает соответствующие отношения между общими частями объектов, что позволяет редактировать объекты с общей геометрией одновременно. Топологию карты можно создать для точечных, линейных или полигональных слоев из шейп-файлов, или клас- сов объектов базы геоданных. Объекты могут находиться в одном или нескольких слоях различных типов. Создать топологию карты очень легко, необходимо только выбрать таблицы, участвующие в топологии.

Чтобы создать топологию, необходимо выполнить запрос, представленный на рис. 20.

SELECT pgr_createTopology('edges', 0.00001, 'the_geom', 'gid');

Рис. 20. Запрос на создание топологии

Следующим шагом после построения топологии является построение маршрута. Построение маршрута осуществляется с помощью команды pgr_dijkstra, позволяющей высчитывать кратчайший маршрут с помощью алгоритма Дейкстры. Данные для построения маршрута берутся из разных таблиц базы дан- ных, номера узлов берутся из таблицы edges, стоимость прохождения одного участка маршрута берется из таблицы cost, номера узлов, через которые проходит маршрут берутся из таблицы node.

Запрос на построение маршрута представлен на рис. 21. 


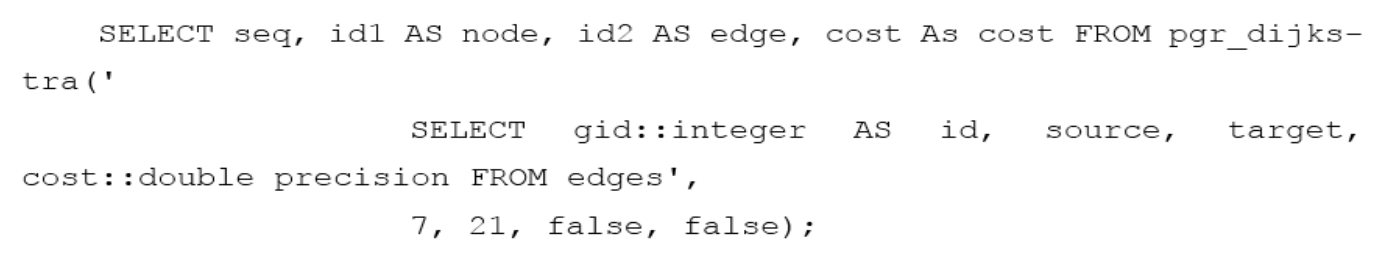

Рис. 21. Запрос на построение маршрута

Результатом построения маршрута будет таблица, в которой по порядку будут записаны точки, узлы, дуги, через которые проходит маршрут, а также стоимость прохождения одного участка маршрута. Стоимость участка маршрута зависит от разных факторов (типа покрытия дороги, максимально разрешенной скорости, стоимости проезда, пропускной способности и т. д.). Чем выше стоимость участка маршрута, тем больше времени потребуется для его преодоления. Тем самым кратчайший маршрут может оказаться достаточно время затратным из-за плохого качества дороги. Результат выполнения запроса представлен в таблице.

Данные маршрута

\begin{tabular}{|c|c|c|c|}
\hline seq & node & edge & cost \\
\hline 1 & 122234 & 12678 & 1 \\
\hline 2 & 12456 & 13489 & 1 \\
\hline 3 & 14561 & 13687 & 1 \\
\hline 4 & 16789 & 14014 & 1 \\
\hline 5 & 16701 & 14591 & 1 \\
\hline 6 & 18782 & 14876 & 1 \\
\hline 7 & 19123 & 14989 & 1 \\
\hline 7 & 16432 & 15601 & 1 \\
\hline 8 & 18553 & 16331 & \\
\hline
\end{tabular}

После того как была получена таблица с данными о маршруте, необходимо визуализировать данные из таблицы в маршрут. Для визуализации построенных маршрутов используется ГИС QGIS (Quantum GIS).

QGIS (Quantum GIS) - свободная кроссплатформенная геоинформационная система. $\mathrm{C}$ ее помощью пользователь имеет возможность просматривать, а также накладывать друг на друга векторные и растровые данные, представленные в различных форматах и проекциях без преобразования во внутренний или общий формат. QGIS работает с пространственными таблицами PostgreSQL/PostGIS [9-11]. Главной причиной выбора QGIS как средства визуализации построенных маршрутов является возможность разработки собственных плагинов, удобный и понятный интерфейс даже для начинающих пользователей, ко всему прочему QGIS является абсолютно бесплатным программным продуктом [12-15]. Изначально в стандартные функции QGIS не входит функция визуализации маршрутов, для реализации этой функции было необходимо разработать собственный плагин. Набор функциональных возможностей такого плагина должен включать наличие графического интерфейса для выбора начальной и конечной точки маршрута, а также возможность визуализации маршрута, построенного по заданным критериям оценки стоимости проезда. Программная реализация такого плагина возможна при использовании языка программирования Python и SQL запросов.

Для визуализации построенного маршрута на основании данных SQL-запроса необходимо активировать инструмент «Навигация», после чего на основе данных SQL-запроса построенный маршрут будет визуализирован (рис. 22). 


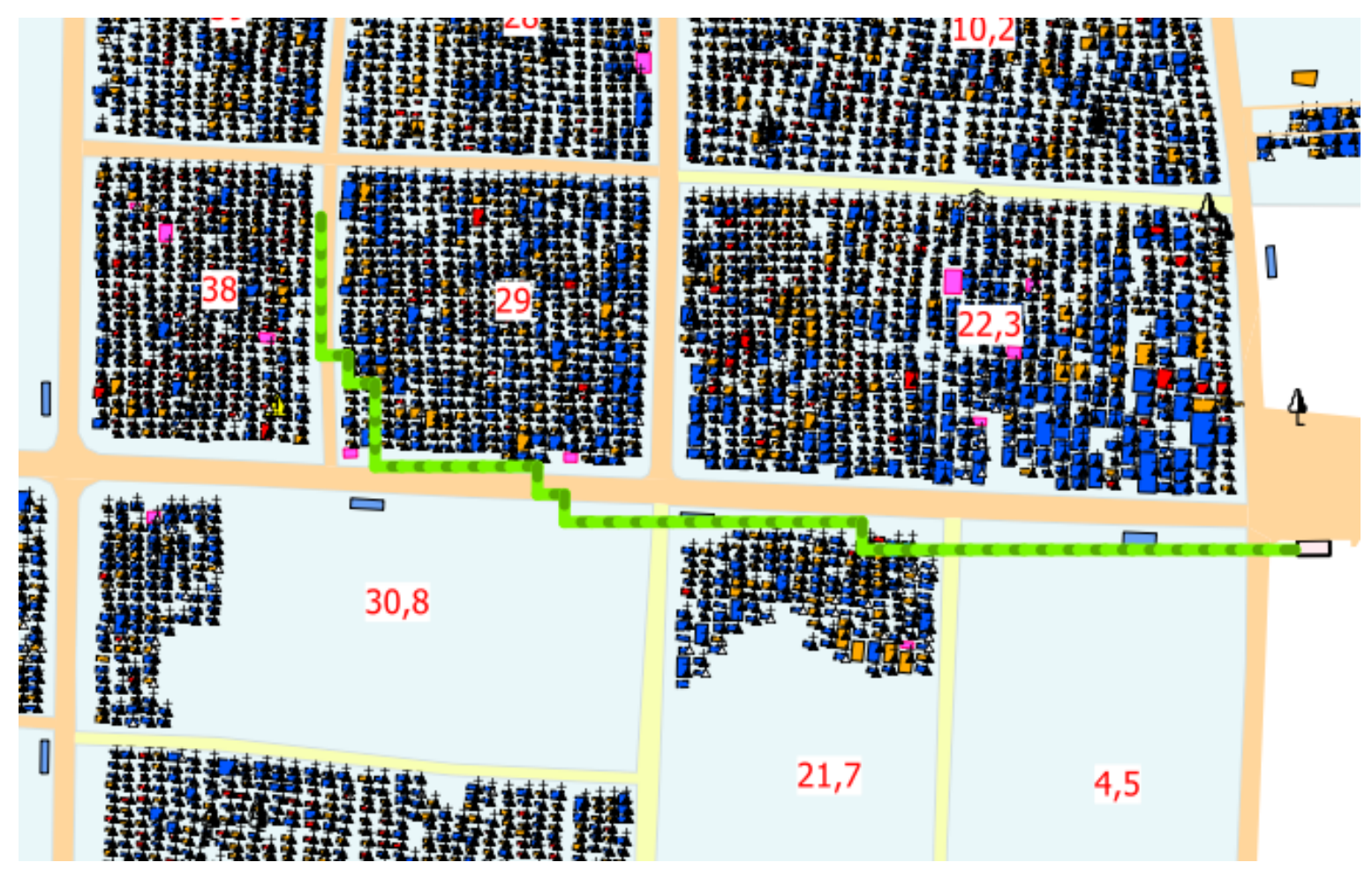

Рис. 22. Визуализированный маршрут

\section{Заключение}

Эффективность и корректность решения задач, связанных с построением маршрутов, в большинстве случаев зависит от качества исходных данных, которые представляют собой ориентированный взвешенный граф дорог. На территориях с большим количеством наземных объектов и слабо выраженной дорожной сетью построение графа будет затруднено, что приведет к необходимости наложения на карту регулярной сетки, представляющей собой совокупность плотно располагающихся пересекающихся векторных линий. Дальнейшее решение задачи должно выполняться с использованием современного программного обеспечения, позволяющего выполнить расчет маршрута на основе имеющейся совокупности геоданных.

В ходе эксперимента, описанного в статье, было выяснено, что программное обеспечение pgRouting совместно с QGIS позволяет достаточно эффективно решать поставленную задачу по вычислению и визуализации кратчайшего маршрута между двумя точками на карте.

Описанный опыт может быть полезен при создании навигационных систем на основе геоинформационной системы QGIS.

\section{БИБЛИОГРАФИЧЕСКИЙ СПИСОК}

1. Геопортал инфраструктуры пространственных данных РФ [Электронный ресурс]. - Режим доступа : http://nsdi.ru/geoportal/catalog/main/home.page.

2. Дубровский А. В. Геоинформационные системы: управление и навигация : учеб.-метод. пособие. - Новосибирск : СГГА, 2013. - 96 с.

3. Карпик А. П. Основные принципы формирования геодезического информационного пространства // Изв. вузов. Геодезия и аэрофотосъемка. - 2013. - № 4/С. - С. 73-76.

4. Карпик А. П. Современное состояние и проблемы геоинформационного обеспечения территорий // Интерэкспо ГЕО-Сибирь-2012. VIII Междунар. науч. конгр. : Пленарное заседание : сб. материалов (Новосибирск, 10-20 апреля 2012 г.). - Новосибирск : СГГА, 2012. - С. 3-8.

5. О Концепции создания и развития инфраструктуры пространственных данных Российской Федерации [Электронный ресурс] : Распоряжение Правительства РФ от 21.08.2006 № 1157-р. - Режим доступа: http://base.consultant.ru/cons/cgi/online.cgi?req=doc;base=EXP;n=372580. 
6. Шокин Ю. И., Потапов В. П. ГИС сегодня: состояние, перспективы, решения [Электронный ресурс] // Вычислительные технологии. - 2015. - Т. 20, № 5. - Режим доступа: https://cyberleninka.ru/article/v/gis-segodnya-sostoyanie-perspektivy-resheniya.

7. Кикин П. М., Хабибуллин Р. Р. Разработка инструментов расчета и визуализации картографических маршрутов на базе программного обеспечения pgRouting // Интерэкспо ГЕО-Сибирь-2017. XIII Междунар. науч. конгр. : Магистерская научная сессия «Первые шаги в науке» : сб. материалов в 2 т. (Новосибирск, 17-21 апреля 2017 г.). - Новосибирск : СГУГиТ, 2017. Т. 2. - С. 63-66.

8. Яндекс карты: технологии маршрутизации [Электронный ресурс]. - Режим доступа: https://company.yandex.ru/technologies/routes/. - Загл. с экрана.

9. Ригс С. Администрирование PostgreSQL 9. - СПб. : Питер, 2013. - 368 с.

10. Уорсли Дж., Дрейк Дж. PostgreSQL для профессионалов. - СПб. : Питер, 2003. - 496 с.

11. Дроздов А. Ю. Решение задач сетевого анализа с применением PostgreSQL/PostGIS // «Строительство и архитектура - 2015». Современные информационно-экономические технологии: тенденции и перспективы развития : материалы Междунар. науч.-практ. конф. - Ростов н/Д. : Рост. гос. строит. ун-т, 2015. - С. 71-72.

12. Ермолаев Н. Р. Использование программного обеспечения QGIS при подготовке картографических материалов // Ломоносов-2018 : тезисы докладов XXV Междунар. науч. конф. студентов, аспирантов и молодых ученых. - 2018. - С. 250-251.

13. Пашковская О. В., Новоселов О. В., Потапенко И. А. Анализ данных в геоинформационной системе QGIS // Решетневские чтения : материалы XXIV Междунар. науч.-практ. конф., посвящ. памяти генерального конструктора ракетно-космических систем академика М. Ф. Решетнева (10-13 ноября 2020, г. Красноярск) : в 2 ч. - Красноярск : СибГУ им. М. Ф. Решетнева, 2020. Ч. 2. - С. 345-346. Режим доступа: https://reshetnev.sibsau.ru/page/materialykonferentsii. - Загл. с экрана.

14. Установка модулей расширения для QGIS [Электронный ресурс]. - Режим доступа : http://gislab.info/qa/qgis-install-plugin.html. - Загл. с экрана.

15. Хританькова А. А., Ковальчик Н. В. Сравнение возможностей программных средств ArcGis и QGIS для сетевого анализа в сфере транспортной логистики (на примере г. Минска) // ГИСтехнологии в науках о Земле : материалы республиканского науч.-практ. семинара студентов и молодых ученых. - Минск, 2020. - С. 9-13.

Получено 05.04.2021

(C) А. А. Басаргин, П. Ю. Бугаков, Т. Ю. Бугакова, 2021

\title{
CALCULATION AND VISUALIZATION OF MAP ROUTES USING QGIS AND PGROUTING SOFTWARE
}

\author{
Andrei A. Basargin \\ Siberian State University of Geosystems and Technologies, 10, Plakhotnogo St., Novosibirsk, 630108, Russia, \\ Ph. D., Associate Professor, Department of Applied Informatics and Information Systems, phone: (383)343-18-53, \\ e-mail: abaspirant@mail.ru
}

\section{Petr Yu. Bugakov}

Siberian State University of Geosystems and Technologies, 10, Plakhotnogo St., Novosibirsk, 630108, Russia, Ph. D., Associate Professor, Department of Cartography and Geoinformatics, phone: (383)343-18-53, e-mail: peter-bugakov@yandex.ru

\section{Tatyana Yu. Bugakova}

Siberian State University of Geosystems and Technologies, 10, Plakhotnogo St., Novosibirsk, 630108, Russia, Ph. D., Head of the Department of Applied Informatics and Information Systems, phone: (383)343-18-53, e-mail:kaf.pi@ssga.ru

Recently, new tools have been created for working with geodata, which are used in various fields of human activity. Software for network analysis and routing solutions is of particular importance. The software product pgRouting is an example, distributed under the GPLv2 license. This program extends the capabilities of Post- 
GIS / PostgreSQL geospatial databases. The article discusses the general principles of constructing routes on the graphs of the road network. It describes how to work with the geospatial database and the pgRouting software for building a route. The purpose of the work is to build a correct rout of a road graph in routing areas with a big number of objects and a poorly developed road network. The problem is solved by software pgRouting and QGIS on the basis of the Dijkstra shortest path algorithm, Johnson and Floyd-Warshall algorithms and allows you to solve the traveling salesman problem, and many others. The task is solved by means of software pgRouting и QGIS. As an experiment the article shows the solution for the task in which it is not enough to use only a road graph for building a correct route. Such situations may occur when routing the areas with a big number of objects and a poorly developed road network. In the process of the experiment described in the article it was found out that software pgRouting together with QGIS allows to rather effectively solve the task on calculation and visualization of the shortest route between two points on the map.

Keywords: routing, route, shortest path, graph, road network, geodata, visualization, geographic information system

\section{REFERENCES}

1. Geoportal of the spatial data infrastructure of the Russian Federation. (n. d.). Retrieved from http://nsdi.ru/geoportal/catalog/main/home.page [in Russian].

2. Dubrovsky, A. V. (2013). Geoinformatsionnye sistemy: upravlenie i navigatsiya [Geoinformation systems: management and navigation]. Novosibirsk: SSGA Publ., 96 p. [in Russian].

3. Karpik, A. P. (2013). Basic principles of the formation of geodesic information space. Izvestiya vuzov. Geodeziya i aerofotos"emka [Izvestiya Vuzov. Geodesy and Aerophotosurveying], 4/S, 73-76 [in Russian].

4. Karpik, A. P. (2012). The current state and problems of geoinformation provision of territories. In Sbornik materialov Interekspo GEO-Sibir'-2012: Plenarnoe zasedanie [Proceedings of Interexpo GEOSiberia-2012: Plenary Session] (pp. 3-8). Novosibirsk: SSGA Publ. [in Russian].

5. Order of the Government of the Russian Federation of August 21, 2006 No. 1157-p. About the Concept of creation and development of spatial data infrastructure of the Russian Federation Retrieved from http://base.consultant.ru/cons/cgi/online.cgi?req=doc;base=EXP; $\mathrm{n}=372580$.

6. Shokin, Yu. I., \& Potapov, V. P. (2015). GIS today: state, prospects, solutions. Vychislitel'nye tekhnologii [Computational Technologies], 20(5). Retrieved from https://cyberleninka.ru/article/v/gis-segodnya-sostoyanie-perspektivy-resheniya.

7. Kikin, P. M., \& Khabibullin, R. R. (2017). Development of tools for calculating and visualizing cartographic routes based on pgRouting software. In Sbornik materialov Interekspo GEO-Sibir'-2017: T. 2. Magisterskaya nauchnaya sessiya "Pervye shagi v nauke" [Proceedings of Interexpo GEO-Siberia-2017: Vol. 2. Master's Scientific Session "First Steps in Science"] (pp. 63-66). Novosibirsk: SSGA Publ. [in Russian].

8. Yandex maps: routing technologies. (n. d.). Retrieved from https://company.yandex.ru/technologies/routes/ [in Russian].

9. Rigs, C. (2013). Administrirovanie PostgreSQL 9 [Administration of PostgreSQL 9]. Saint Petersburg: Piter Publ., 368 p. [in Russian].

10. Worsley, J., \& Drake, J. (2003). PostgreSQL dlya professionalov [PostgreSQL for professionals]. Saint Petersburg: Piter Publ., 496 p [in Russian].

11. Drozdov, A. Yu. (2015). Solving problems of network analysis using PostgreSQL/PostGIS. In Sbornik materialov Mezhdunarodnoy nauchno-prakticheskoy konferentsii: "Stroitel'stvo i arkhitektura - 2015". Sovremennye informatsionno-ekonomicheskie tekhnologii: tendentsii i perspektivy razvitiya [Proceedings of the International Scientific and Practical Conference: "Construction and Architecture-2015". Modern Information and Economic Technologies: trends and Prospects of Development] (pp. 71-72). Rostov on Don: Rostov State University of Civil Engineering Publ. [in Russian].

12. Ermolaev, N. R. (2018). The use of QGIS software in the preparation of cartographic materials. In Tezisy dokladov XXV Mezhdunarodnoy nauchnoy konferentsii studentov, aspirantov i molodykh uchenykh: Lomonosov-2018 [Abstracts of the XXV International Scientific Conference of Students, Postgraduates and Young Scientists: Lomonosov-2018] (pp. 250-251) [in Russian].

13. Pashkovskaya, O. V., Novoselov, O. V., \& Potapenko, I. A. (2020). Analysis of data in the geoinformation system QGIS. In Sbornik materialov XXIV Mezhdunarodnoy nauchno-prakticheskoy konferentsii, posvyashchennoy pamyati general'nogo konstruktora raketno-kosmicheskikh sistem akademika M. F. Resh- 
etneva: Ch. 2. Reshetnevskie chteniya [Proceedings of the XXIV International Scientific and Practical Conference dedicated to the memory of the General Designer of Rocket and Space Systems Academician MF Reshetnev: Part 2. Reshetnev Readings] (pp. 345-346). Krasnoyarsk: Reshetnev Siberian State University of Science and Technology Publ. Retrieved from https://reshetnev.sibsau.ru/page/materialykonferentsii [in Russian].

14. Installing extension modules for QGIS. (n. d.). Retrieved from http://gis-lab.info/qa/qgis-installplugin.html [in Russian].

15. Hritankova, A. A., \& Kovalchik, N. V. (2020). Comparison of the capabilities of the software tools ArcGIS and QGIS for network analysis in the field of transport logistics (on the example of Minsk). In Sbornik materialov respublikanskogo nauchno-prakticheskogo seminara studentov i molodykh uchenykh: GIStekhnologii v naukakh o Zemle [Proceedings of the Republican Scientific and Practical Seminar of Students and Young Scientists: GIS Technologies in Earth Sciences] (pp. 9-13). Minsk [in Russian].

Received 05.04.2021

(C) A. A. Basargin, P. Yu. Bugakov, T. Yu. Bugakova, 2021 
УДК 528.9:004.9

DOI: $10.33764 / 2411-1759-2021-26-5-99-107$

ИСТОРИЯ ДОПОЛНЕННОЙ РЕАЛЬНОСТИ

И ПЕРСПЕКТИВЫ ЕЕ ПРИМЕНЕНИЯ В КАРТОГРАФИИ

\section{Каршия Сериковна Батырова}

ООО «Центр мониторинга транспорта», 630559, Россия, Новосибирская область, р. п. Кольцово, ул. Технопарковая, 1, специалист технической поддержки, тел. (999)465-74-09, e-mail: karshiya2011@mail.ru

\section{Ярослава Георгиевна Пошивайло}

Сибирский государственный университет геосистем и технологий, 630108, Россия, г. Новосибирск, ул. Плахотного, 10, кандидат технических наук, зав. кафедрой картографии и геоинформатики, тел. (383)361-06-35, e-mail: yaroslava_po@mail.ru

Статья посвящена вопросам применения технологии дополненной реальности (Augment Reality, $\mathrm{AR}$ в в картографии. Проведен обзор основных этапов становления указанной технологии и значимых достижений в различных сферах деятельности человека. Сделан обзор производителей устройств и технологий, занимающих лидирующие позиции на рынке дополненной реальности. Выделены два основных направления применения AR в картографии: расширение содержания аналоговых карт и усовершенствование навигационных приложений. Дан сравнительный анализ навигационных картографических приложений с дополненной реальностью с точки зрения их функционала. Приведена схема использования AR-технологии в картографии, в которой рассмотрены маркерные, безмаркерные и пространственные варианты технологии дополненной реальности. Сделан вывод о необходимости более широкого внедрения технологий дополненной реальности в тематическую картографию.

Ключевые слова: картография, дополненная реальность, навигация, виртуальные отметки, тематические карты, маркерная и безмаркерная технологии, аналоговые карты

\section{Введение}

С каждым годом общество развивается все более динамично, при этом закономерно возрастает информационная нагрузка на человека. Для облегчения восприятия увеличивающихся потоков информации разрабатываются новые цифровые технологии, одной из которых является технология дополненной реальности.

Технология дополненной реальности помогает сформировать наглядное представление о явлениях и процессах окружающего мира, мысленно воссоздать особенности размещения, взаимного расположения объектов и установить взаимосвязи между различными формами их представления.

В период пандемии началось активное развитие целого ряда областей информационных технологий, в частности, дополненной реальности, которая стала применяться при организации дистанционной работы, удаленном обучении и оказании помощи сотрудникам в работе.
Применяя технологию дополненной реальности в образовании, можно обеспечить визуальные эффекты, практически невозможные для привычных способов визуализации, что, в свою очередь, делает обучение более эффективным. Эта технология позволяет добавить выразительную анимацию на страницы книг, дополняя видео- и аудиоинформацию книжного носителя.

Одной из перспективных областей применения дополненной реальности является картография. Карта как инструмент отображения и анализа геопространства с внедрением элементов дополненной реальности приобретает новые свойства и функции, которые будут рассмотрены в статье.

\section{Определение дополненной реальности и история ее появления}

Дополненная реальность - это технология, совмещающая слой виртуальной реальности с физическим окружением в реальном времени при помощи компьютера, при этом дополняю- 
щая информация может быть представлена в виде текста, изображения, видео, звука, трехмерных объектов. Управление контентом происходит посредством сканирования специальных меток дополненной реальности, нанесенных на какую-либо поверхность.

Стоит различать дополненную реальность (Augment Reality), виртуальную реальность (Virtual Reality) и смешанную реальность (Mixed Reality). Виртуальная реальность создает свой мир с погружением пользователя в него, а дополненная реальность добавляет виртуальные составляющие в реальный мир. Становление дополненной реальности неразрывно связано с разработками и изучением виртуальной реальности.

Дополненная реальность является одной из составляющих частей смешанной реальности, объекты реального мира интегрируются в виртуальную среду. Здесь совмещаются виртуальные сцены и объекты. Пространство может быть как виртуальным, так и реальным.

История AR-технологии началась в 50-х гг. XX в., когда Мортон Хейлинг запатентовал симулятор Sensorama, названый им самим театром погружения. Изобретатель также сконструировал специальную 3D-камеру, чтобы осуществлять съемку фильмов для Sensorama [1].

Первым устройством дополненной реальности считается разработанная в 1968 г. профессором Гарварда Айваном Сазерлендом система на основе головного дисплея (названный «Дамоклов Меч»). Устройство крепилось к потолку из-за тяжелого веса очков со стереоэффектом, на которые транслировалось изображение с компьютера. Перспектива наблюдения за объектами менялась в зависимости от движения головы пользователя.

В 1974 г. Майрон Крюгер создал лабораторию искусственной реальности Videoplace. Ее основной идеей было избавление пользователей от специальных шлемов, очков и других приспособлений, позволяющих взаимодействовать с виртуальной реальностью. В 1978 г. Стив Манн изобрел первое носимое ARприспособление - ЕуеТар [1].

Первым термин «дополненная реальность» сформулировал ученый Том Коделл, который разработал специальные шлемы для инженеров завода «Боинг».
Технология описания реальных и виртуальных объектов с помощью маркеров была внедрена в 1966 г. Джуном Рекимото и Южди Аятцука, что позволило добавить виртуальные вещи в реальный мир, просто перенося метки.

Затем Хироказу Като разработал открытую библиотеку данных для написания приложений ARToolKit, в которой применялась система распознавания положения и ориентации камеры в режиме реального времени. Это позволило точнее разместить слой компьютерной графики на маркеры окружающего мира. Выпуск этой библиотеки положил начало современному этапу активного развития дополненной реальности.

Отправной точкой развития массового сегмента технологии дополненной реальности можно считать презентацию компанией Google продукта «умные очки» в 2012 г. Потребительская версия данного продукта потерпела неудачу и компания переключила свои усилия на производственную версию Glass Enterprise Edition [1].

В свою очередь, весьма перспективным и выгодным примером являются очки смешанной реальности HoloLens, разработчиком которых является компания Microsoft. HoloLens не требуют подключения к какому-либо устройству, полностью автономны. Изначально устройство предназначалось для игр, но сейчас целевой аудиторией является бизнес [2].

Следующим этапом развития технологии, судя по публикациям, станут контактные линзы с дополненной реальностью.

Таким образом, в доступе будут три варианта: шлем (ориентирован на работу со смешанной реальностью), очки и линзы (для дополненной реальности) [3].

Период пандемии оказал положительное влияние на развитие некоторых направлений ИТ, например, стимулировал активное развитие дополненной реальности как средства, применяемого при организации дистанционной работы, при удаленном обучении рабочим процессам и оказании помощи в работе сотрудников. Таким образом, рыночный потенциал технологии дополненной реальности весьма значителен. По данным экспертов ABI Research, к 2025 г. совокупный объем рынка дополнен- 
ной реальности превысит \$140 млрд. Такие выводы они сделали на основе анализа рынка дополненной и смешанной реальности. Лидерами рынка на сегодняшний день являются: Apple, Google, Facebook, PTC, Atheer, Microsoft, Lenovo, Teamviewer. Технологические гиганты, вовлеченные в AR, намерены усовершенствовать аппаратное обеспечение указанной технологии в ближайшие 2-3 года, что в конечном итоге приведет к переориентированию рынка дополненной реальности от предприятия к потребителю. Рост числа и качества моделей ARоборудования и контента в ближайшие пять лет будет поддерживать эту тенденцию $[4,5]$.

\section{Использование дополненной реальности в картографии}

Исходя из публикаций по тематике дополненной реальности, наиболее перспективными областями применения AR-технологий являются: розничная торговля и маркетинг, здравоохранение, образование, печатная отрасль, автомобилестроение, военная отрасль, туризм [6-14]. Однако стоит учитывать возможный рост спроса данной технологии в других производственных сферах.
В картографию технологии дополненной реальности начали внедряться не так давно, при этом сформировались два основных направления применения AR: расширение содержания аналоговых карт и усовершенствование навигационных приложений.

Наибольшее развитие AR-технологии получили в сфере навигационной картографии. Следует отметить, что при этом используется электронная карта, в которую интегрируется ряд виртуальных объектов (цифровое изображение дополняется виртуальными объектами). Ряд приложений для автонавигации успешно использует возможности дополненной реальности. Также весьма велик вклад многофункциональных (комбо) устройств, которые начали появляться на отечественном рынке несколько лет назад.

В качестве примера приведем использование компанией Яндекс технологии дополненной реальности в приложении Яндекс.Карты (рис. 1), что позволяет пользователям увидеть виртуальные метки, наложенные на панораму местности и обозначающие проложенный маршрут, и ознакомиться с дополнительной информацией [15].
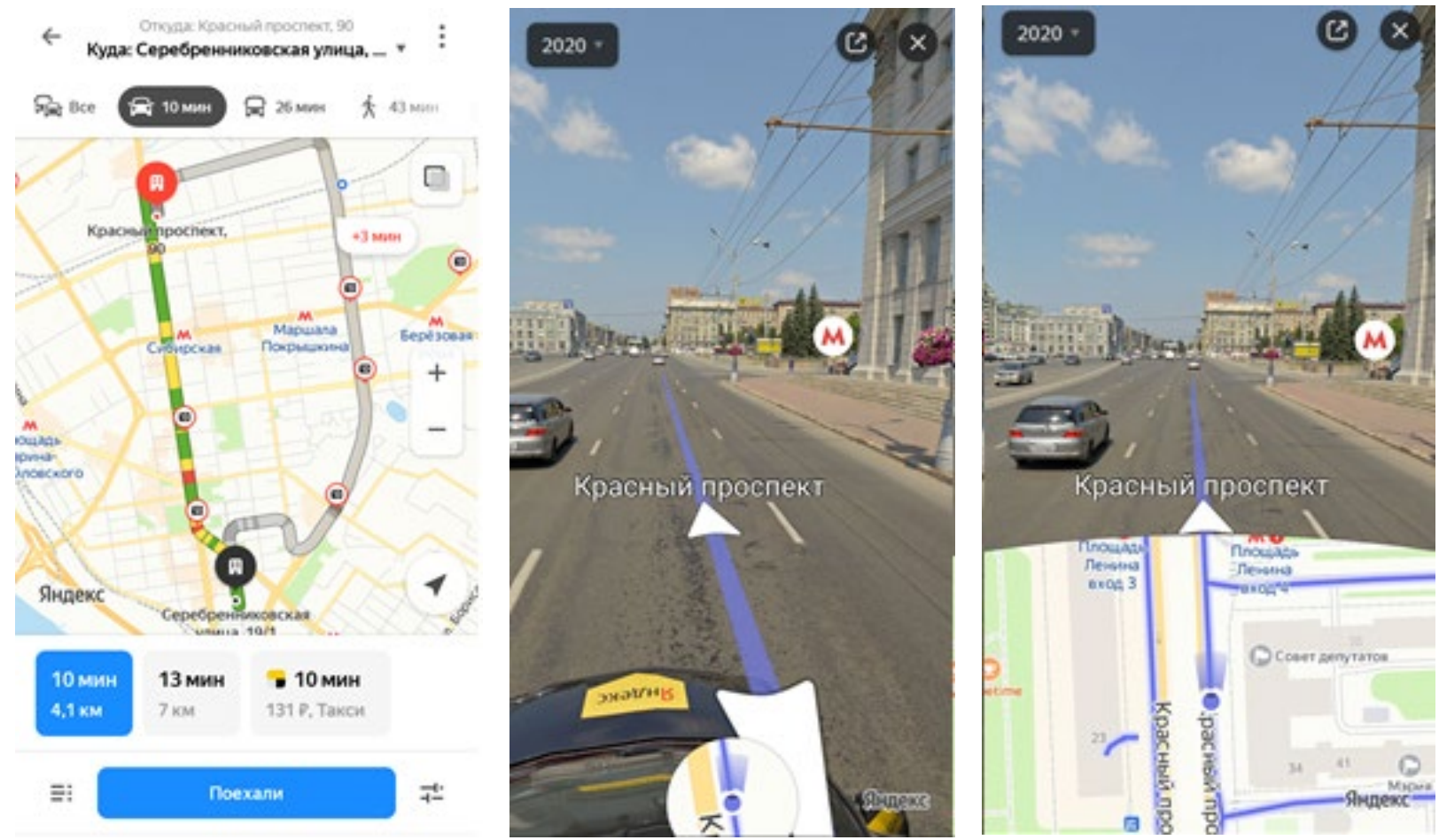

Рис. 1. Пример построения маршрута и его отображение в режиме дополненной реальности в приложении Яндекс.Карты 
Приложение Gaode, разработчиком которой является китайская компания AutoNavi, успешно совмещает навигацию с дополненной реальностью. Ожидается спрос со стороны водителей, не имеющих возможность приобрести автомобили премиум-класса с продвинутым навигационными системами и проекционными дисплеями. Интерфейс напоминает популярное во всем мире приложение Google Maps [16].

В транспортных средствах уже применяется дополненная реальность в навигационных системах путем наложения направляющих стрелочек на видеоряд пути движения. Существуют также разработки, позволяющие проецировать на лобовом стекле навигационные подсказки. Программа «Навител Навигатор» в одном из своих последних обновлений реализовала функцию HUD (Head-up Display), позволяющую всю необходимую информацию отображать на лобовом стекле автомобиля в прямую зону видимости водителя. Благодаря таким подсказкам пользователь, быстрее обрабатывая информацию, получает возможность сфокусировать внимание на вождении. Доступ к этой опции осуществляется после дополнительной оплаты [17].

Одним из AR-устройств является многофункциональное устройство NAVITEL RE900, использующее технологию дополнен- ной реальности при выборе видеорегистратора в качестве основного режима работы устройства. Навигационные подсказки (местоположение, скорость движения, направление движения, расчетное время прибытия и др.) появляются на экране при запуске режима видеорегистратора. Стоит отметить, что устройство работает одновременно в двух режимах: видеорегистратор и навигатор [18].

Современный рынок устройств готов предложить большое количество моделей с HUDфункцией. В линейке подобных устройств выделяется легкое крепление HUDWAY Glass, использующееся для работы смартфона в качестве проекционного дисплея. Благодаря этому устройству водителю доступны подсказки без отвлечения от дороги. На сайте производителя доступен список приложений, с которыми устройство может взаимодействовать (HUDWAY GO, Navmii GPS и другие). C точки зрения функционала важно то, что HUDWAY Glass можно использовать в темное время суток [19].

Большинство навигационных приложений, поддерживающих технологии дополненной реальности, имеют схожие возможности; выявленные отличия проанализированного программно-аппаратного обеспечения представлены в таблице.

Использование технологий дополненной реальности в картографических сервисах

\begin{tabular}{|c|c|c|c|c|}
\hline Критерий & Google карты & Яндекс.Карты & «Навител Навигатор» & AutoNavi \\
\hline \begin{tabular}{|l} 
Отображение \\
подсказок \\
на лобовом стекле \\
автомобиля \\
\end{tabular} & Отсутствует & Отсутствует & $\begin{array}{l}\text { Функционал поддержи- } \\
\text { вается. Обязательна } \\
\text { оплата и получение } \\
\text { ключа }\end{array}$ & Отсутствует \\
\hline Подписи & $\begin{array}{l}\text { Направление движе- } \\
\text { ния указывают дина- } \\
\text { мические графиче- } \\
\text { ские подсказки }\end{array}$ & $\begin{array}{l}\text { Направление дви- } \\
\text { жения указывают } \\
\text { динамические гра- } \\
\text { фические подсказки }\end{array}$ & $\begin{array}{l}\text { Визуализируются: ско- } \\
\text { рость движения, расстоя- } \\
\text { ние до следующего пово- } \\
\text { рота, оставшееся время } \\
\text { в пути, название улиц. } \\
\text { Реализовано только } \\
\text { в NAVITEL RE900 }\end{array}$ & $\begin{array}{l}\text { Визуализируются указа- } \\
\text { ния поворотов и дистан- } \\
\text { ции, которые накладыва- } \\
\text { ются на дорогу }\end{array}$ \\
\hline $\begin{array}{l}\text { Курсор } \\
\text { направления } \\
\text { движения }\end{array}$ & $\begin{array}{l}\text { Направление пока- } \\
\text { зывается с помощью } \\
\text { стрелки }\end{array}$ & $\begin{array}{l}\text { Курсор присутст- } \\
\text { вует в нижней ча- } \\
\text { сти экрана }\end{array}$ & $\begin{array}{l}\text { При выборе режима ви- } \\
\text { деорегистратора уст- } \\
\text { ройство с дополненной } \\
\text { реальностью NAVITEL } \\
\text { RE900 не отображает } \\
\text { курсор }\end{array}$ & $\begin{array}{lr}\text { Курсор } & \text { накладывается } \\
\text { прямо на } \\
\text { дороги }\end{array}$ \\
\hline $\begin{array}{l}\text { Дорожные знаки, } \\
\text { информация } \\
\text { о последующем } \\
\text { маневре } \\
\end{array}$ & $\begin{array}{l}\text { Выводит на экран } \\
\text { информацию о бли- } \\
\text { жайшем маневре }\end{array}$ & $\begin{array}{l}\text { Выводит информа- } \\
\text { цию о следующем } \\
\text { маневре }\end{array}$ & $\begin{array}{l}\text { Выводит на экран ин- } \\
\text { формацию о ближай- } \\
\text { шем маневре }\end{array}$ & $\begin{array}{l}\text { Подсвечивает дорожные } \\
\text { знаки в режиме реального } \\
\text { времени }\end{array}$ \\
\hline \begin{tabular}{|l} 
Безопасность \\
при использовании
\end{tabular} & $\begin{array}{l}\text { Экран периодически } \\
\text { гаснет, что обезопа- } \\
\text { сит движение поль- } \\
\text { зователя }\end{array}$ & $\begin{array}{l}\text { Информация отсут- } \\
\text { ствует }\end{array}$ & Информация отсутствует & $\begin{array}{l}\text { Функционал не реализо- } \\
\text { ван }\end{array}$ \\
\hline
\end{tabular}


Рассмотрим применение технологий дополненной реальности в целях расширения содержания аналоговой карты. В данном варианте применения AR «цифра накладывается на бумагу», то есть специальные метки наносятся на тиражный оттиск карты (так называемая маркерная технология), при этом возникают следующие дополнительные возможности, связанные со свойствами карты. Рассмотрим свойства карты, которые даны в Межгосударственном стандарте «Картография. Термины и определения» [20]: качество, наглядность, современность и нагрузка карты, а также суть дополнительных возможностей, которые дает внедрение AR.

Повышается качество карты как расширение свойств карты, обусловливающих ее пригодность удовлетворять определенные потребности в соответствии с ее назначением. Например, учебные карты могут быть дополнены моделями объектов местности, которые позволят школьнику установить связь условного знака с реальным объектом. По карте можно производить измерения виртуальной линейкой, получать дополнительную информацию о картографируемых объектах в буквенно-цифровой, аудио-, видео- и других формах.

Повышается наглядность карты как возможность зрительного восприятия пространственных форм, размеров и размещения объектов картографирования. Здесь в первую очередь важна трехмерность. Обучающийся может легко изучать окружающий мир и взаимо- действовать с ним через виртуальную карту, основанную на реальной системе координат.

Повышается современность карты как соответствие карты современному состоянию объектов картографирования. Бумажную карту можно «обновить» актуальной цифровой информацией.

Увеличивается нагрузка карты как заполненность карты условными знаками и надписями.

Информационное пространство сегодня чрезвычайно динамично и изменчиво. Бумажная картографическая продукция быстро устаревает. Также многие пользователи испытывают трудности с ориентированием на местности с помощью традиционных аналоговых карт $[21,22]$. Одним из возможных решений данной проблемы является нанесение на карту в процессе ее составления и печати маркера (маркеров) дополненной реальности, наводясь на который камерой мобильного устройства, пользователь будет получать полную и актуальную информацию по тематике карты, которая может постоянно обновляться [23-26].

Наглядно представить применение дополненной реальности в картографии можно, обратившись к схеме на рис. 2, в которой приводятся сущность и основные направления применения AR-технологий с подразделением по способу определения объекта (точки) привязки. Среди перечисленных технологий наиболее стабильной является маркерная технология.
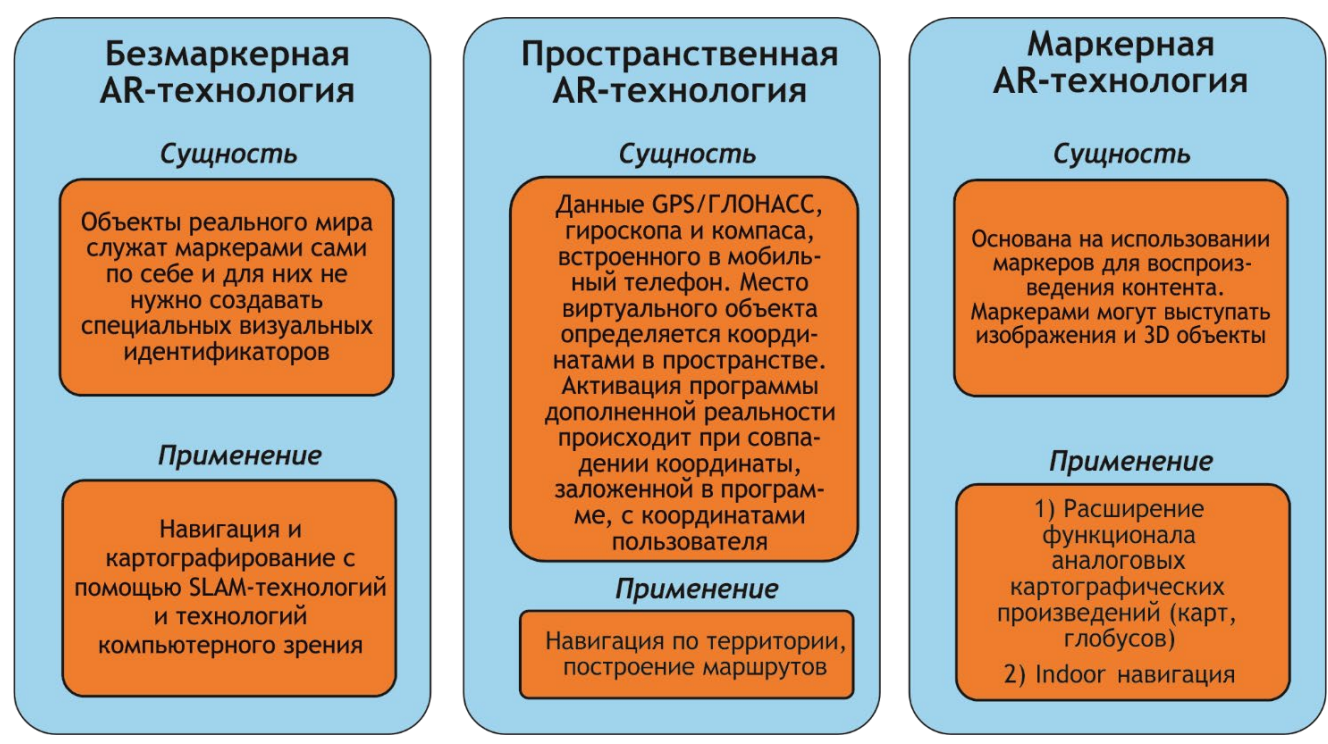

Рис. 2. Применение AR в картографии 
Поскольку на данный момент технология дополненной реальности для большинства устройств не обеспечивает точностные параметры, требуемые при топографическом картографировании, следует говорить о ее применении в тематической картографии, в том числе для обеспечения потребностей в геопространственной информации широкого круга населения.

\section{Заключение}

Цифровизация в экономике, образовании, производстве, медицине и других сферах требует постоянного совершенствования технологического и научно-методического обеспечения.
На наш взгляд, наиболее перспективным является использование AR в тематической картографии для обновления картографического обеспечения программы средней школы. Вторым важным направлением является туристская картография.

Решение данных задач требует более глубокого анализа и систематизации имеющихся технических средств и технологий и разработки адаптированных методик, которые в дальнейшем могли бы позволить широкому кругу картографов, в сотрудничестве с представителями образования и туризма готовить современную картографическую продукцию на базе современных информационных и геопространственных технологий.

\section{БИБЛИОГРАФИЧЕСКИЙ СПИСОК}

1. AR - Дополненная реальность [Электронный pecypc]. - Режим доступа: https://ai-news.ru/ 2020/12/ar dopolnennaya realnost.html.

2. Microsoft HoloLens [Электронный pecypc]. https://ru.wikipedia.org/wiki/Microsoft_HoloLens.

3. Apple планирует выпустить контактные линзы с дополненной реальностью [Электронный ресурс]. - Режим доступа: https://ai-news.ru/2021/03/apple_planiruet_vypustit_kontaktnye_linzy_s_ dopolnennoj_realnostu_n.html.

4. ABI Research: рынок дополненной реальности переключится с предприятий на потребителя [Электронный ресурс]. - Режим доступа: https://news.myseldon.com/ru/news/index/244276194.

5. Lobo M. J., Christophe, S. Opportunities and challenges for augmented reality situated geographical visualization [Electronic resource] // ISPRS Annals of the Photogrammetry, Remote Sensing and Spatial Information Sciences. - 2020. -Vol. 4. - P. 163-170. - Mode of access: https://doi.org/10.5194/isprs-annalsV-4-2020-163-2020.

6. Разработка ученых ВШТМ позволила провести первую в России операцию с использованием технологии дополненной реальности года [Электронный ресурс]. - Режим доступа: https://hstm.spbstu.ru/news/razrabotka_uchenyh_vshtm_pozvolila_provesti_pervuu_v_rossii_operaciu_s_isp olzovaniem_tehnologiy_dopolnennoy_realnosti/.

7. Черкасов К. В., Чистякова Н. С., Чернов В. В. Применение дополненной реальности в образовании [Электронный ресурс]. - Режим доступа: https://cyberleninka.ru/article/n/primenenie-dopolnennoyrealnosti-v-obrazovanii.

8. Гаврилова И. В. Организация защиты персональных данных в образовательных учреждениях // Новые информационные технологии в образовании : материалы VII междунар. науч.-практ. конф. Екатеринбург : Российский государственный профессионально педагогический университет, 2014. C. 509.

9. Work with augmented reality (AR) and the web [Electronic resource] // Transformation through education 2012. - Mode of access : https://www.edx.org/course/work-with-augmented-reality-ar-and-theweb?index $=$ product\&queryID $=7 \mathrm{~b} 9 \mathrm{~d} 2 \mathrm{~b} 0891445 \mathrm{~b} 96 \mathrm{~b} 1 \mathrm{cab} 13 \mathrm{ed} 1 \mathrm{a} 4 \mathrm{a} 7 \mathrm{~d} 0$ \&position $=1$.

10. Chou Y. Y., Wu P. F., Huang C. Y., Chang S. H., Huang H. S., Lin W. M., Lin M. L., See. Effect of Digital Learning Using Augmented Reality with Multidimensional Concept Map in Elementary Science Course // Asia-Pacific Education Researcher, 2021. doi: 10.1007/s40299-021-00580-y.

11. Chen C. H., Huang C. Y., Chou Y. Y. Effects of augmented reality-based multidimensional concept maps on students' learning achievement, motivation and acceptance // Universal Access in the Information Society. - 2019. - Vol. 18 (2). - P. 257-268. 
12. Ramos F., Trilles S., Torres-Sospedra J., Perales F. J. New Trends in Using Augmented Reality Apps for Smart City Contexts [Electronic resource] // ISPRS International Journal of Geo-Information. - 2018. Vol. 7. - P. 478. - Mode of access: https://doi.org/10.3390/ijgi7120478/.

13. Loureiro S. M. C., Guerreiro J., Ali F. 20 years of research on virtual reality and augmented reality in tourism context: A text-mining approach [Electronic resource] // Tourism Management. - 2020. - Vol. 77. P. 104028. - Mode of access: https://doi.org/10.1016/j.tourman.2019.104028.

14. Yovcheva Z., Buhalis D., Gatzidis C. Engineering Augmented Tourism Experiences // Information and Communication Technologies in Tourism 2013 / Cantoni L., Xiang Z. (Phil) (Eds.). - Springer Berlin Heidelberg, 2013. - P. 24-35.

15. Как работает дополненная реальность в яндекс картах. Яндекс.Карты - режим дополненной реальности (AR) [Электронный pесурс]. - Режим доступа: https://crmnetsurfing.ru/kak-rabotaetdopolnennaya-realnost-v-yandeks-kartah-yandeks.html. re900.

16. NAVITEL RE900! [Электронный ресурс]. - Режим доступа: https://navitel.ru/ru/devices/combo/navitel-

17. Автомобильная навигация с дополненной реальностью теперь есть и в телефонах [Электронный pecypc]. - Режим доступа: https://matador.tech/news/avtomobilnaa-navigacia-s-dopolnennoj-realnostuteper-est-i-v-telefonah).

18. Навител Навигатор 11 теперь и на Android! [Электронный ресурс]. - Режим доступа: https://navitel.ru/ru/about/news/2021/02/nn11-android-release

19. HUDWAY Glass. [Электронный ресурс]. - Режим доступа : https://hudway.co/glass.

20. ГОСТ 21667-76. Картография. Термины и определения: Межгосударственный стандарт: издание официальное: утвержден и введен в действие Постановлением Государственного комитета стандартов Совета Министров СССР от 31.03.76 N 730: дата введения 1977-07-01 [Электронный ресурс]. Режим доступа: https://docs.cntd.ru/document/1200006865.

21. Koletsis E., van Elzakker C. P., Kraak M. J., Cartwright W., Arrowsmith C. Field K. An investigation into challenges experienced when route planning, navigating and wayfinding // International Journal of Cartography. - 2017. - Vol. 3(1). - P. 1-15. doi: 10.1080/23729333.2017.1300996.

22. Anbaroğlu B., Coşkun İ. B., Gürler H. H. Which way is 'yildiz amfi'? Augmented reality vs. paper map on pedestrian wayfinding [Electronic resource] // 5th International Conference on Smart City Applications «The International Archives of the Photogrammetry, Remote Sensing and Spatial Information Sciences» (7-8 October 2020). - Turkey, 2020. Vol. XLIV-4/W3-2020. - P. 53-60. - Mode of access: https://doi.org/10.5194/isprs-archives-XLIV-4-W3-2020-53-2020.

23. Дополненная реальность и 3D-карты [Электронный ресурс]. - Режим доступа: https://www.wrld3d.com/3d-maps/augmented-reality-3d-maps.

24. MRIIAR [Электронный pecypc]. - Режим доступа: https:/play.google.com/store/apps/ details?hl=ru\&id=com.mmlab.MRIIARBuklet.

25. Лисицкий Д. В. Перспективы развития картографии: от системы «Цифровая Земля» к системе виртуальной геореальности // Вестник СГГА. - 2013. - Вып. 2 (22). - С. 8-15.

26. de Almeida Pereira G. H., Stock K., Stamato Delazari L., Centeno J. A. S. Augmented Reality and Maps: New Possibilities for Engaging with Geographic Data // The Cartographic Journal. - 2017. - Vol. 54 (4). - P. 313-321. doi: 10.1080/00087041.2017.1411417.

Получено 02.07.2021

(C) К. С. Батырова, Я. Г. Почивайло, 2021

\section{HISTORY OF AUGMENTED REALITY AND FURTHER TRENDS OF ITS USE IN CARTOGRAPHY}

\section{Karshiya S. Batyrova}

Transport Monitoring Center LLC, 1, Technoparkovaya St., Settlement Koltsovo, Novosibirsk Region, 630559, Russia, Technical Support Specialist, phone: (999)465-74-09, e-mail: karshiya2011@mail.ru

\section{Yaroslava G. Poshivaylo}

Siberian State University of Geosystems and Technologies, 10, Plakhotnogo St., Novosibirsk, 630108, Russia, $\mathrm{Ph}$. D., Head of the Department of Cartography and Geoinformatics, phone: (383)343-25-21, e-mail: yaroslava_po@mail.ru 
The article is devoted to the application of augmented reality (Augment Reality, AR) technologies in cartography. A review of the main stages of the formation of technologies and significant achievements in various spheres of human activity is carried out. An overview of the manufacturers of devices and technologies holding leading positions in the augmented reality market is made. Two main directions of AR application in cartography are highlighted: expansion of analog maps and improvement of navigation applications. A comparative analysis of navigation cartographic applications with augmented reality from the point of view of their functionality is given. A scheme of the use of AR technology in cartography is given, in which marker-based, markerless and spatial variants of augmented reality technology are considered. The conclusion about the need for wider introduction of augmented reality technologies into thematic cartography is made.

Keywords: cartography, augmented reality, navigation, virtual markers, thematic maps, marker-based and markerless technology, analog maps

\section{REFERENCES}

1. AR-Augmented reality. (n. d.). Retrieved from https://ai-news.ru/2020/12/ ar_dopolnennaya_realnost.html [in Russian].

2. Microsoft HoloLens. (n.d.). Retrieved from https://ru.wikipedia.org/wiki/Microsoft_HoloLens [in Russian].

3. Apple plans to release contact lenses with augmented reality, but they will not be released until 2030. (n. d.). Retrieved from https://ai-news.ru/2021/03/apple_planiruet_vypustit_kontaktnye_linzy_s_dopolnennoj_ realnostu_n.html [in Russian].

4. ABI Research: the augmented reality market will switch from enterprises to consumers. (n. d.). Retrieved from https://news.myseldon.com/ru/news/index/244276194 [in Russian].

5. Lobo, M. J., \& Christophe, S. (2020). Opportunities and challenges for augmented reality situ-ated geographical visualization. ISPRS Annals of the Photogrammetry, Remote Sensing and Spatial Information Sciences, 4, 163-170. Retrieved from https://doi.org/10.5194/isprs-annals-V-4-2020-163-2020.

6. The development of scientists of the High School of Technology has made it possible to carry out the first operation in Russia using the technology of augmented reality of the year. (n. d.). Retrieved from https://hstm.spbstu.ru/news/razrabotka_uchenyh_vshtm_pozvolila_provesti_pervuu_v_rossii_operaciu_s_isp olzovaniem_tehnologiy_dopolnennoy_realnosti/[in Russian].

7. Cherkasov, K. V., Chistyakova, N. S., \& Chernov, V. V. (2017). Application of augmented reality in education. Retrieved from https://cyberleninka.ru/article/n/primenenie-dopolnennoy-realnosti-v-obrazovanii [in Russian].

8. Gavrilova, I. V. (2014). Organization of personal data protection in educational institutions. In Sbornik materialov VII mezhdunarodnoy nauchno-prakticheskoy konferentsii: Novye informatsionnye tekhnologii $v$ obrazovanii [Proceedings of the VII International Scientific and Practical Conference: New Information Technologies in Education] (P. 509). Ekaterinburg: Russian State Professional Pedagogical University Publ. [in Russian].

9. Work with augmented reality (AR) and the web. (2012). Transformation through education. Retrieved from https://www.edx.org/course/work-with-augmented-reality-ar-and-the-web?index = product \& queryID = 7b9d2b0891445b96b1cab13ed1a4a7d0 \& position $=1$.

10. Chou, Y. Y., Wu, P. F., Huang, C. Y., Chang, S. H., Huang, H. S., Lin, W. M., \& Lin, M. L. (2021). Effect of Digital Learning Using Augmented Reality with Multidimensional Concept Map in Elementary Science Course. Asia-Pacific Education Researcher. doi: 10.1007/s40299-021-00580-y.

11. Chen, C. H., Huang, C. Y., \& Chou, Y. Y. (2019). Effects of augmented reality-based multidimensional concept maps on students 'learning achievement, motivation and acceptance. Universal Access in the Information Society, 18(2), 257-268.

12. Ramos, F., Trilles, S., Torres-Sospedra, J., \& Perales, F. J. (2018). New Trends in Using Aug-mented Reality Apps for Smart City Contexts. ISPRS International Journal of Geo-Information, 7, P. 478. Retrieved from https://doi.org/10.3390/ijgi7120478/.

13. Loureiro, S. M. C., Guerreiro, J., \& Ali, F. (2020). 20 years of research on virtual reality and augmented reality in tourism context: A text-mining approach. Tourism Management, 77, P. 104028. Retrieved from https://doi.org/10.1016/j.tourman.2019.104028. 
14. Yovcheva, Z., Buhalis, D., \& Gatzidis, C. (2013). Engineering Augmented Tourism Experiments. In Information and Communication Technologies in Tourism (pp. 24-35). L. Cantoni \& Z. Xiang (Phil) (Eds.). Springer Berlin Heidelberg.

15. How does augmented reality work in Yandex maps. Yandex.Maps - augmented reality (AR) mode. (n. d.). Retrieved from https://crmnetsurfing.ru/kak-rabotaet-dopolnennaya-realnost-v-yandeks-kartahyandeks.html [in Russian].

16. NAVITEL RE900! (n. d.). Retrieved from https://navitel.ru/ru/devices/combo/navitel-re900 [in Russian].

17. Car navigation with augmented reality is now available in telephones. (n. d.). Retrieved from https://matador.tech/news/avtomobilnaa-navigacia-s-dopolnennoj-realnostu-teper-est-i-v-telefonah) [in Russian].

18. Navitel Navigator 11 is now on Android! (n. d.). Retrieved from https://navitel.ru/ru/about/news/ 2021/02/nn11-android-release [in Russian].

19. HUDWAY Glass. (n. d.). Retrieved from https://hudway.co/glass [in Russian].

20. GOST 21667-76 Cartography. Terms and definitions: Interstate standard: official edition: approved and put into effect by the Resolution of the State Committee of Standards of the Council of Ministers of the USSR of March 31, 1976 No. 730. Retrieved from https://docs.cntd.ru/document/1200006865 [in Russian].

21. Koletsis, E., van Elzakker, C. P., Kraak, M. J., Cartwright, W., Arrowsmith, C. \& Field, K. (2017). An investigation into challenges experienced when route planning, navigating and wayfinding. International Journal of Cartography, 3(1), 1-15. doi: 10.1080/23729333.2017.1300996.

22. Anbaroğlu, B., Coşkun, İ. B., \& Gürler, H. H. (2020): Which way is 'yildiz amfi'? Augmented reality vs. paper map on pedestrian wayfinding. In 5th International Conference on Smart City Applications: Vol. XLIV-4/W32020. The International Archives of the Photogrammetry, Remote Sensing and Spatial Information Sciences (pp. 53-60). Turkey. Retrieved from https://doi.org/10.5194/isprs-archives-XLIV-4-W3-2020-53-2020.

23. Augmented reality and 3D maps. (n. d.). Retrieved from https://www.wrld3d.com/3dmaps/augmented-reality-3d-maps [in Russian].

24. MRIIAR . (n. d.). Retrieved from https://play.google.com/store/apps/details?hl=ru\&id= com.mmlab.MRIIARBuklet [in Russian].

25. Lisitsky, D. V. (2013). Prospects for the development of cartography: from the "Digital Earth" system to the system of virtual georeality. Vestnik SGUGiT [Vestnik SSUGT], 2(22), 8-15 [in Russian].

26. de Almeida Pereira, G. H., Stock, K., Stamato Delazari, L., \& Centeno, J. A. S. (2017). Augmented Reality and Maps: New Possibilities for Engaging with Geographic Data. Cartographic Journal, 54(4), 313321. doi: 10.1080 / 00087041.2017 .1411417$. 
УДК [004.94:379.85]+528.94

DOI: $10.33764 / 2411-1759-2021-26-5-108-118$

\section{СОЗДАНИЕ И ИСПОЛЬЗОВАНИЕ ЗD-МОДЕЛИ ГОРНОГО РЕЛЬЕФА ДЛЯ ГЕОИНФОРМАЦИОННОГО ОБЕСПЕЧЕНИЯ ТУРИЗМА}

\section{Татьяна Евгеньевна Елиина}

Сибирский государственный университет геосистем и технологий, 630108, Россия, г. Новосибирск, ул. Плахотного, 10, кандидат технических наук, доцент кафедры картографии и геоинформатики, тел. (383)361-06-35, e-mail: dony2005@mail.ru

\section{Ирина Петровна Кокорина}

Сибирский государственный университет геосистем и технологий, 630108, Россия, г. Новосибирск, ул. Плахотного, 10, кандидат технических наук, доцент кафедры картографии и геоинформатики, тел. (383)361-06-35, e-mail: irusha2008@gmail.com

\section{Александр Владимирович Сысоев}

2ГИС, 630048, Россия, г. Новосибирск, пл. К. Маркса, 7, инженер-картограф, тел. (999)468-89-50, e-mail: sasha.sysoev.94@mail.ru

В статье рассмотрены вопросы создания и использования 3D-модели горного рельефа для геоинформационного обеспечения туризма Российской Федерации на примере территории Республики Ингушетии. Целью работы является разработка и применение цифровой 3D-модели горного рельефа для ее использования при создании туристской интерактивной карты на web-cервисах, а также туристских и административных сайтах республик Кавказа. Использовались методы геоинформационного картографирования, моделирования рельефа, картографический метод исследования и современное программное обеспечение: 3D Spatial Analysts, WorldMachine, Unity 3D. Выполнена классификация видов туризма и объектов природного и культурного наследия в Республике Ингушетии. В результате анализа туристских и административных сайтов, а также web-сервисов республик Кавказа, сделан вывод об их недостаточном геоинформационном обеспечении. Представлены возможности применения 3D-моделей горного рельефа на web-картах для целей туризма. Создана цифровая модель горного рельефа Республики Ингушетии с анимацией естественного окружения. Разработана 3D-сцена, которая передает основные формы рельефа и расположение объектов на местности.

Ключевые слова: горный рельеф, туризм, Северный Кавказ, Республика Ингушетия, web-карты, цифровая модель рельефа, геоинформационное картографирование, гипсометрическая шкала, светотеневое изображение рельефа, 3D-сцена

\section{Введение}

Создание туристско-ориентированных ГИСсистем на территории России соответствует задачам стратегии развития туризма в Российской Федерации на период до 2035 года [1].

Цель работы - создание и применение цифровой 3D-модели горного рельефа для последующего использования при размещении туристской интерактивной карты на web-cepвисах, а также соответствующих сайтах республик Кавказа.

Для этого необходимо решить следующие задачи: проанализировать состояние геоинформационного обеспечения туризма и способы отображения рельефа на web-картах и сервисах; выполнить классификацию видов туризма и объектов природного и культурного наследия в Республике Ингушетии; создать 3D-модель горного рельефа и разработать 3D-сцену с объектами общегеографического и тематического содержания на территорию Республики Ингушетии.

Web-карты представлены на сайтах на базе платформ OpenStreetMap и коммерческих, принадлежащих сервисам Here, Google Maps, Яндекс.Карты [2]. На этих сайтах, кроме прочей информации, встречаются картографические модели, отображающие территорию для различных видов хозяйственной деятельности [2]. Огромную роль здесь играет привлекательность и наглядность подачи информации, которая позволяет расширить круг потребителей сайтов. 3D-модели используются для показа 
объектов местности, которые достоверно передают расположение объектов, сохраняют характерный внешний облик земной поверхности, показывают особенности рельефа и дают возможность для выполнения измерений морфометрических показателей [3-5].

Цифровые модели рельефа (ЦМР), которые могут быть получены с помощью методов пространственного анализа, позволяют создавать карты различной направленности и имеют большое значение для изображения рельефа. Наборы пространственных данных и многообразие компьютерных средств позволяют визуализировать глобальные трехмерные модели местности в web-среде. Оформление рельефа осуществляется при помощи отмывки, послойной гипсометрической окраски или наложением космического снимка [6-9].

Просматривая сайты и web-сервисы республик Северного Кавказа в целом и Республики Ингушетии в частности, можно сделать вывод о недостаточном геоинформационном обеспечении данного региона. Это связано с тем, что информация об имеющихся туристских направлениях представлена частично, не отражает современного состояния рассматриваемого вопроса (нет подробных информационных ресурсов о развитии сферы туризма в регионе и его видах). В Ингушетии мало таких сайтов, а 3D-моделей горного рельефа на данную территорию на сайтах кроме Google нет. Таким образом, значительно увеличивается спрос на геоинформационное обеспечение территории, и на сегодняшний момент создание современно системы геоинформационного обеспечения туристской деятельности в Российской Федерации в целом и в Республике Ингушетии в частности весьма актуально.

В структуре административного либо туристского сайта необходима карта, в основу тематического содержания которой положена классификация видов туризма. С этой целью рассмотрены самые распространенные виды туризма в Республике Ингушетии [10].

Для разработки классификации видов туризма были рассмотрены природно-климатические особенности и культурно-историческое наследие Республики Ингушетии. Уникальность и живописное разнообразие природноклиматических условий территории Кавказа создали благоприятные условия для развития туризма. Республика Ингушетия включена в туристический кластер Северного Кавказа. В республике приоритетным видом туризма является внутренний. Согласно классификации туризма Всемирной туристической организации по видам транспорта, в республике можно выделить авиационный и наземный туризм. Имеет место самостоятельный (самодеятельный) туризм, который организуется туристскими клубами и т. д. в форме походов, экспедиций, туристских слетов и туристско-спортивных соревнований. Транспортная система региона хорошо развита. На территории республики есть внутренний аэропорт «Магас», с запада на восток проходит участок Северо-Кавказской железной дороги и участок автомобильной дороги федерального значения «Ростов - Баку». Пеший туризм по тропам возможен с помощью проводников. Активный туризм связан с горным рельефом.

В Республике Ингушетии в соответствии с Федеральным законом «Об основах туристической деятельности в РФ» от 24.11.1996 присутствуют и развиваются следующие виды внутреннего туризма: культурно-исторический, рекреационный (курортно-оздоровительный, в том числе лечебный), спортивный туризм, а также экотуризм в границах особо охраняемых природных территорий.

Туризм наследия (культурно-исторический туризм) имеет цель ознакомления с историей и архитектурой: познавательный, музейный, этнический и религиозный (паломнический). Согласно постановлению «О перечне расположенных на территории Республики Ингушетия объектов, обладающих признаками объекта культурного наследия» от 01.04.2015 [11], культурное наследие Республики Ингушетии очень богато и представлено историческими местностями: Ассинское, Джейрахское, Армхинское ущелья, Таргимская котловина и др. Здесь находятся средневековые башенные комплексы, памятники истории и культуры федерального значения, например, древнейший в России христианский храм Тхаба-Ерды. Джейрахско-Ассинский государственный историко-архитектурный и природный музей-заповедник объединяет памятники архитектуры, например, замковые комплексы Таргим, Эгикал, Хамхи, Ний, Лейми, Оздик и др.; замок-крепость - башенный комплекс «Вовнушки». Общее количество башен в Ингушетии - около двух тысяч. 
Многофункциональные крепости в Ингушетии послужили стилевой базой для создания монументов, например, башня согласия в Магасе, Аланские ворота, мемориальный комплекс «Девять башен» в Назрани.

Рекреационные путешествия (лечебные, оздоровительные, познавательные, спортивные) стали основой развития рекреационного туризма. Лечебно-оздоровительный туризм включает в себя оздоровительный отдых, лечебный туризм (курортное дело): горный и лыжный туризм. Альпинизм развит в горах, на горных хребтах и перевалах. Санаторно-курортный туризм включает в себя путешествия с целью лечения. На территории республики находятся бальнеологические и климатические курорты. Термальные источники: Ачалукское месторождение минеральных вод, расположенное между селениями Средние и Нижние Ачалуки Малгобекского района.

Зимний экстремальный отдых связан с развлечениями в горнолыжных комплексах «Архни» и «Цори». «Армхи» внесен в реестр международных и российских спортивных объектов, стал местом проведения чемпионата России по скоростному спуску на горных велосипедах и республиканских соревнований по легкой атлетике. Курорт оснащен профессиональной велотрассой для бейсджампинга с трамплинами и другими препятствиями.

Приключенческий туризм связан с организацией нестандартных туров, например, посещением пещер, охотой, рыбалкой, фотоохотой и др., рафтингом, спелеотуризмом. Рыбалка возможна круглый год (кроме периода нереста), так как речная сеть густая и сильно разветвленная, почти все реки горные и большинство не замерзает. Крупнейшие реки - Сунжа, Армхи, Асса, Терек. Также имеются водопады.

Спортивный (спортивно-оздоровительный туризм) включает в себя спортивное ориентирование, рафтинг, туристское многоборье. Широко развит туризм обзорный (культурно-ознакомительный или экскурсионный), а также событийный туризм, включающий в себя посещение национальных фестивалей, праздников и спортивных событий.

Этнотуризм является видом познавательного туризма и преследует цель посещения объекта этнографии для познания быта, тра- диций и культуры этноса, живущего ныне или проживавшего ранее.

\section{Материалы и методы исследования}

В работе использовалось ПО ArcGIS Pro: 3D Analyst, Spatial Analysts, WorldMachine, Unity 3D. Spatial Analysts были применены для создания самой модели, WorldMachine для улучшения визуального качества модели, Unity 3D - для создания 3D-сцены [12-15].

Для решения поставленных задач использовались: картографический метод исследования, теория картографии, методы и теория моделирования рельефа, современное программное и аппаратное обеспечение, геоинформационное картографирование [16].

Может быть использована растровая цифровая модель рельефа. Такая модель быстро обрабатывается и является более простой для визуализации, так как требует меньше вычислительных ресурсов. Устройства вывода, такие как мониторы, также имеют растровый формат, в результате чего изображение GRID быстро визуализируется на экране. К недостаткам данной модели можно отнести ограниченное на сегодняшний день качество визуализации - сглаживание горных форм рельефа не передает особенностей горных территорий, а при изменении масштаба изображения происходит ухудшение качества растра.

Так как туристские карты используются большим количеством потребителей, то визуальная составляющая ЦМР, помимо точности, имеет большое значение. Средства ГИС не всегда позволяют создать визуально качественное изображение ЦМР. Для улучшения наглядности изображения модели были улучшены с использованием программ из сферы моделирования и дизайна.

Для создания трехмерной модели горного рельефа использована геоинформационная система ArcGIS, программа моделирования WorldMachine, а для визуализации - мультиплатформенный 3D-редактор Unity.

Цифровая модель рельефа была создана на основе цифровых данных топографической съемки, представляющих собой высоты из базы данных отметок высот с координатами (в метрах) в формате MapInfo, предоставленными ООО «КАРТИНФОРМ», г. Пятигорск, 
2014 г., на территорию Республики Ингушетии. Координаты крайних точек территории картографирования: 42.52, 44.40; 42.94, 44.40; 42.94, 45.08; 42.52, 45.08.

В дополнительном модуле программы ArcGIS Spatial Analysts с помощью инструментов пространственного анализа, в частности, метода триангуляции Делоне, были проинтерполированы высотные данные, которые далее преобразованы в 3D-модель горного рельефа. Также на их основе получены горизонтали с высотой Z. C помощью модуля 3D Analyst создана TIN-модель. Для переноса этой модели в Unity использовались DXF-и FBXформаты. Из двух форматов был выбран DXF как основной формат обмена геометрическими данными и более подходящий для трехмерных моделей. Формат FBX замедляет обработку [17-19].

Цифровая модель рельефа, полученная методом триангуляции, была загружена в приложение Google Earth (Планета Земля) для сравнения изображения полученного горного рельефа местности с уже имеющимся изображением этой территории [20-24].

\section{Результаты исследования и их обсуждение}

Проанализировано состояние геоинформационного обеспечения туризма и способы отображения рельефа на web-картах и webсервисах. Выполнена классификация видов туризма и объектов природного и культурного наследия в Республике Ингушетии. Ото- браны объекты туристского назначения, характеризующие туризм в республике.

На цифровой модели рельефа, выполненной в программе ArcGIS, сделана отмывка и получен полутеневой цифровой оригинал с помощью инструмента Hillshade, который позволяет визуализировать гипотетическое освещение поверхности путем определения освещенности для каждой ячейки растра. Применение данной функции значительно улучшает визуальное представление поверхности для дальнейшего анализа и отображения.

Осуществлен перенос данной модели в высоком разрешении с улучшенным качеством отображения растра в формат TMD для обработки в программе WorldMachine. После добавлены основные формы рельефа, такие как террасы у подножия гор. Приблизительный возраст гор составляет 23-28 млн лет. Далее добавлены формы рельефа, созданные под влиянием эрозионных процессов, которые на модели выделены белым цветом. В данном ПО этапы создания и внесения данных в модель рельефа представлены в виде блоков, которые несут информацию о каждой характеристике модели: эрозия, уровень склонов, послойная окраска, направление света и т. д. Например, блок Erosion показывает эрозию в зависимости от возраста рельефа. Используя данную схему, также можно добавлять информацию о залегающих горных породах данной местности, деятельности поверхностных и подземных вод, деятельности ветра, выветривании, деятельности ледников (рис. 1, 2).

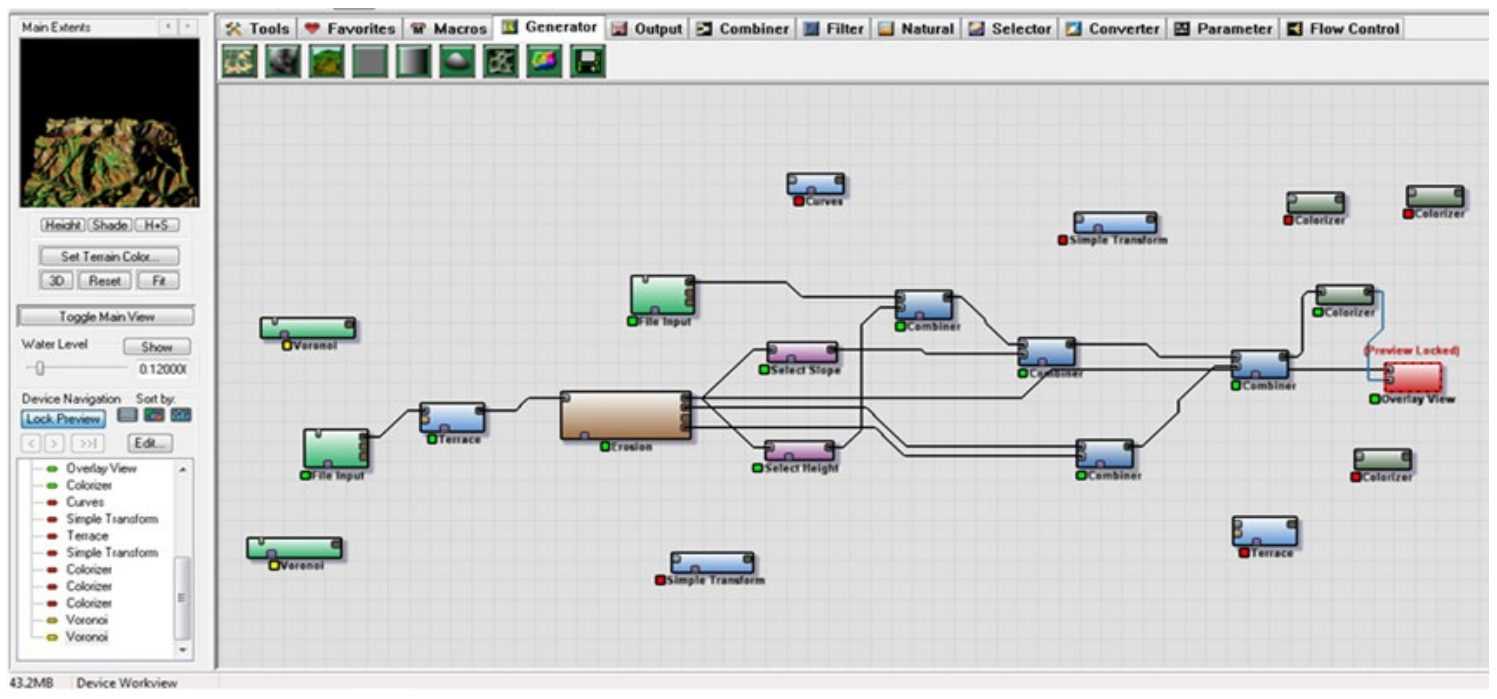

Рис. 1. Схема блоков, составленная для модели в World Machine 


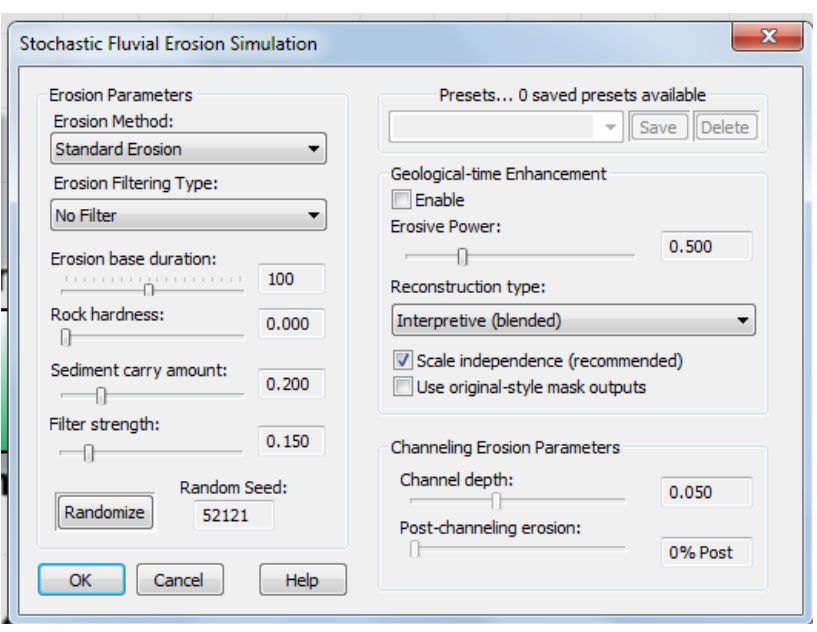

Рис. 2. Интерфейс блока Erosion

Данную модель можно редактировать: например, изменять гипсометрическую окраску рельефа, основные формы рельефа, возраст и твердость горных пород. На основе этих данных в перспективе возможно вычисление эрозионных процессов и применение их на модели. При моделировании рельефа необходимо иметь в виду, что модель может содержать различные элементы местности, которые будут придавать ей наглядность и уникальность. Проведено сравнение с космическим снимком в местах, где разрешение снимка позволяло увидеть особенности рельефа. Модель имеет хорошую наглядность и демонстрирует основные формы рельефа, например, террасы, пики, скалы, ледники, морены.

Полученная ЦМР подходит для создания тематических карт, в том числе и туристских. Модель можно использовать и в других областях, так как есть возможность спрогнозировать изменения рельефа с учетом различных природных факторов (рис. 3, 4).

В настоящее время широкое распространение получили 3D-модели рельефа с сочетанием 3D-сцен, которые передают реальную картину местности. 3D-сцены широко используются в ГИС, где моделируется окружающая среда, которая придает наглядность и удобство использования.

Была разработана 3D-сцена в следующей последовательности:

1) моделирование (создание геометрии);

2) создание карты рельефа на основе отметок высот и ее обработка;
3) нанесение цвета для более качественного отображения модели;

4) добавление источников света северо-западного направления;

5) нанесение общегеографических и тематических 3D-объектов.

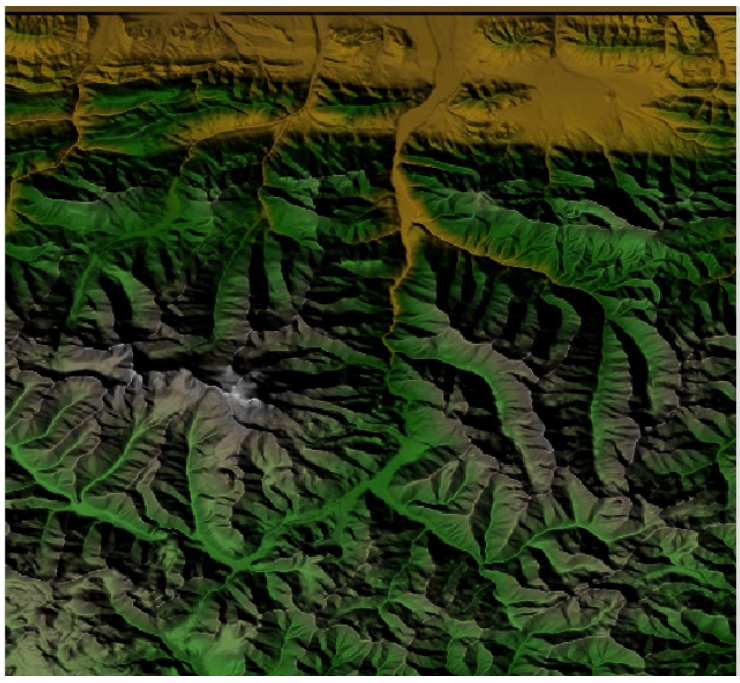

Рис. 3. Цифровая модель рельефа растровая модель (горизонтальная проекция)

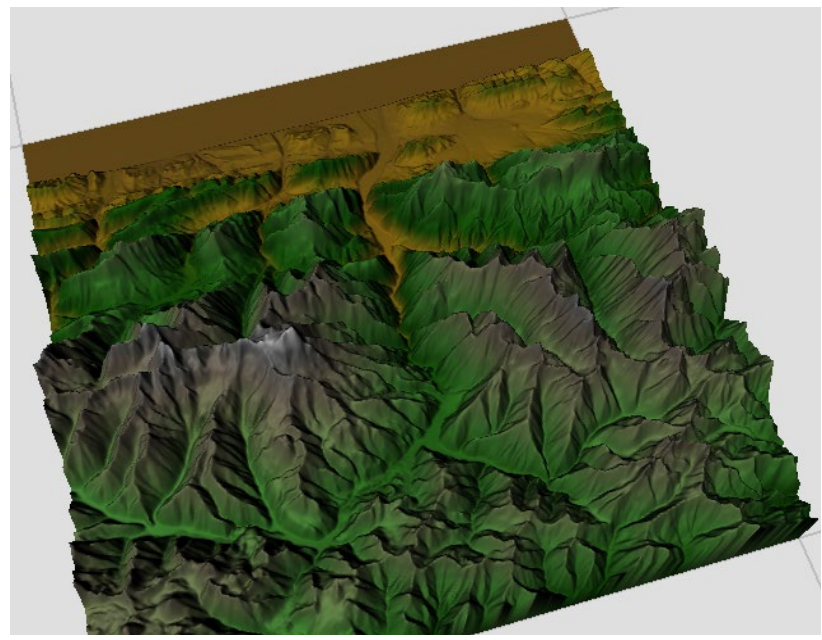

Рис. 4. Цифровая модель рельефа растровая модель (перспектива)

Для еe создания использовалась программа Unity - мультиплатформенный инструмент для разработки трехмерных приложений. Модель рельефа была импортирована в программу Unity3D в формате DXF из World Machine для создания 3D-сцены на основе данной модели (рис. 5, 6). 


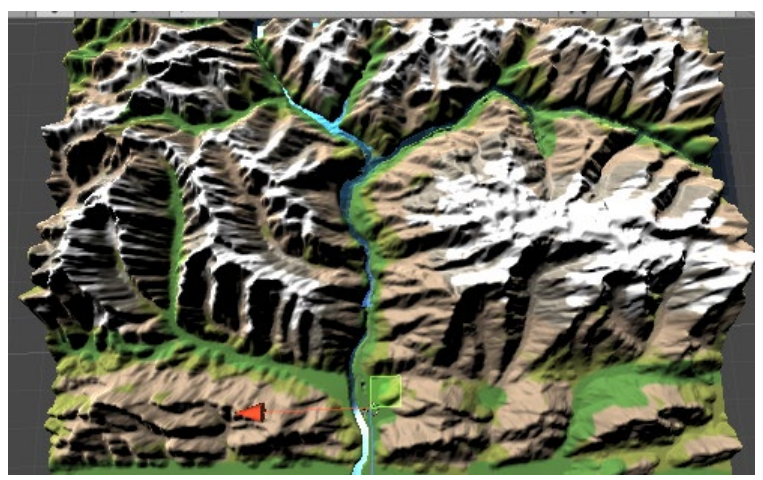

Рис. 5. Модель территории Ингушетии (горизонтальная проекция)

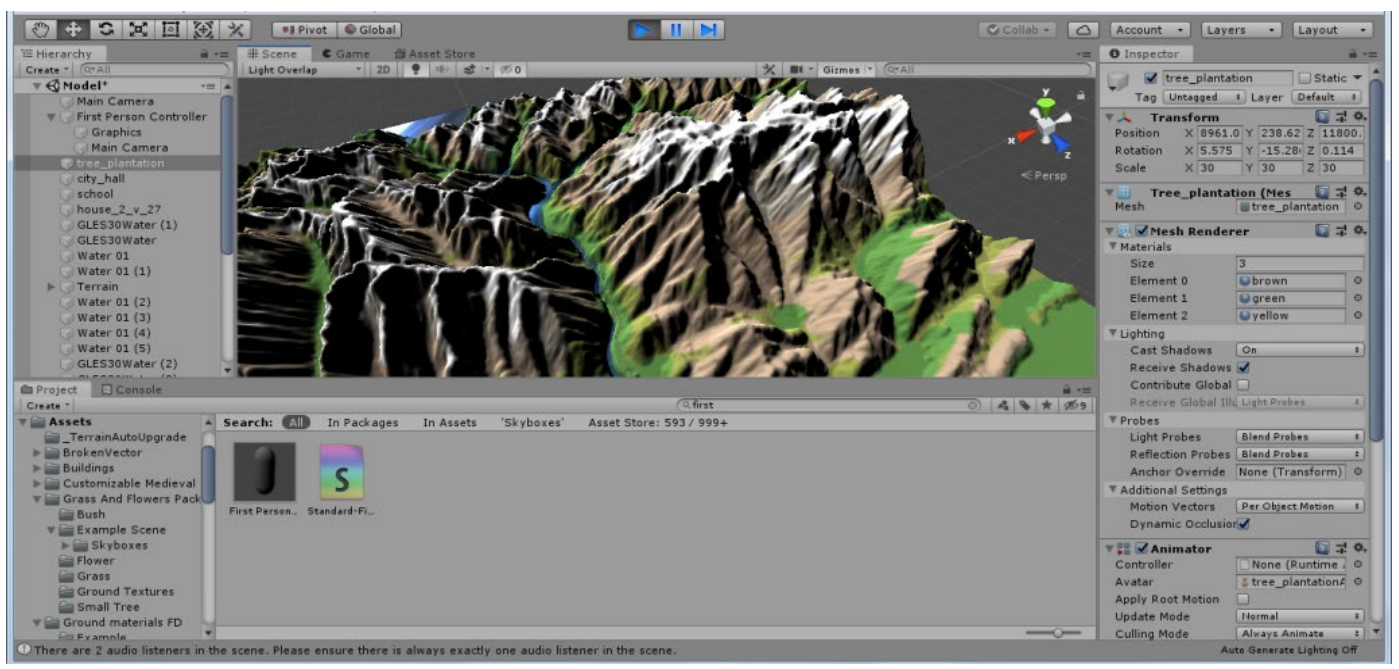

Рис. 6. Модель территории Ингушетии (перспектива)

B Unity работа выполняется над 3D-сценой (трехмерной моделью местности); возникает разница между фактическим количеством вершин до экспорта в Unity и после. Суть проблемы заключается в информации, которая для обработки требует высокого объема оперативной памяти компьютера, а также требовательна к его графическим возможностям. Поэтому для того, чтобы минимизировать искажения в Unity, модель переносится в программу World Machine для визуальной доработки. Для качественного отображения 3D-сцены рельеф окрашивается методом светотеневой пластики. Также программа Unity позволяет воссоздавать модели источника света для более корректного отображения горного рельефа. Главным фактором при создании теней в 3D сцене для конкретной территории является расположение Солнца на небе, которое задается в настройках сцены. Кроме основного освещения была использована технология Ambient Occlusion. Эта технология позволяет программе создавать эффект затенения в углах, трещинах, узких проемах, что придает наглядность и реализм горной территории. Также была использована послойная окраска модели рельефа для улучшения визуального качества и корректной передачи основных форм рельефа (рис. 7).

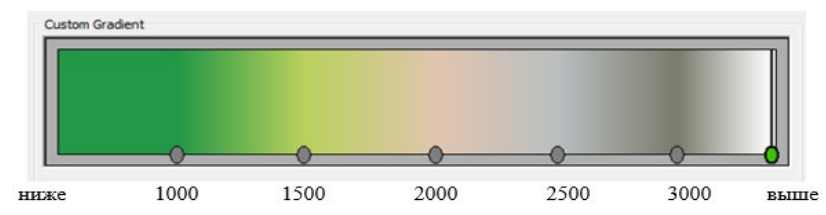

Рис. 7. Шкала послойной окраски рельефа, выполненная в программе Unity 
Используя методы создания и оптимизации 3D-модели горного рельефа, была разработана 3Dсцена, которая передает основные формы рельефа и расположение объектов на местности (населенные пункты, пути сообщения, ледники, растительность, туристские объекты и т. д.) (рис. 8, 9).

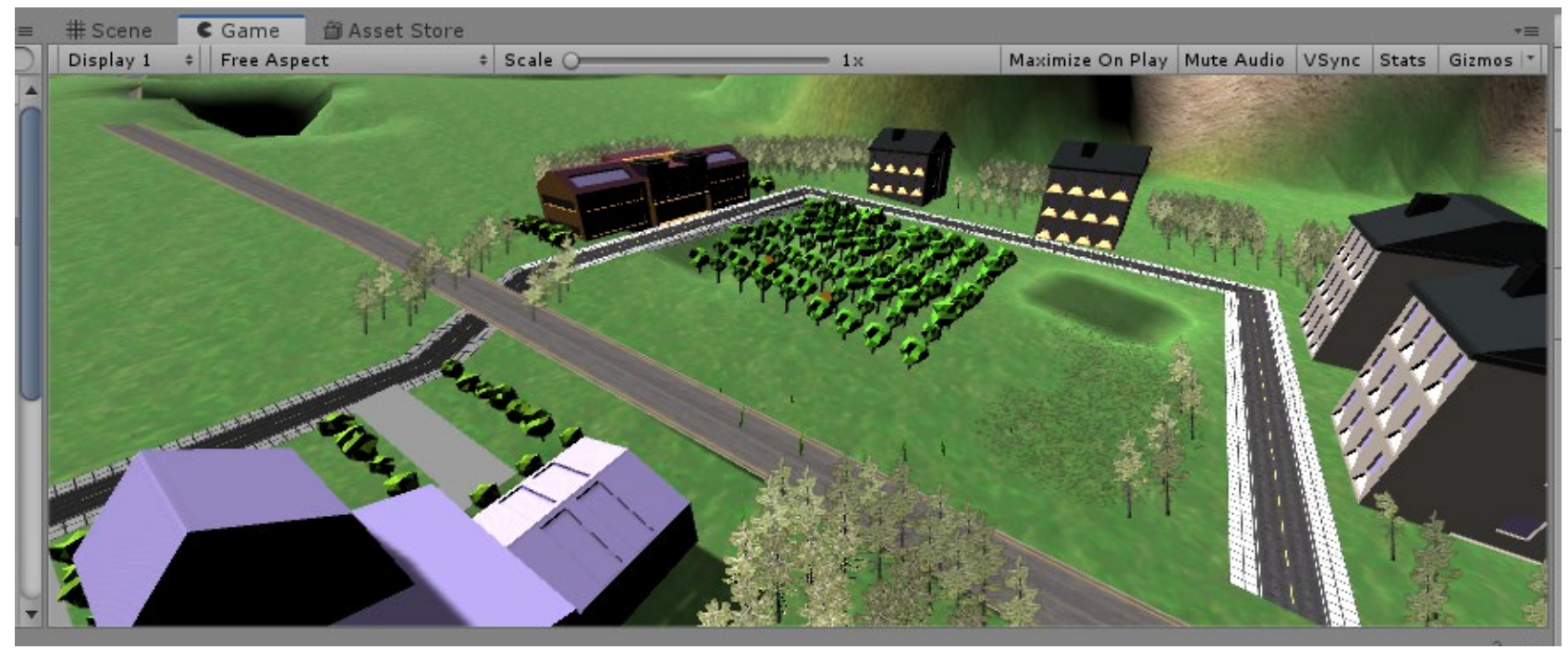

Рис. 8. Трехмерная модель местности в Unity 3D. Точка обзора 1

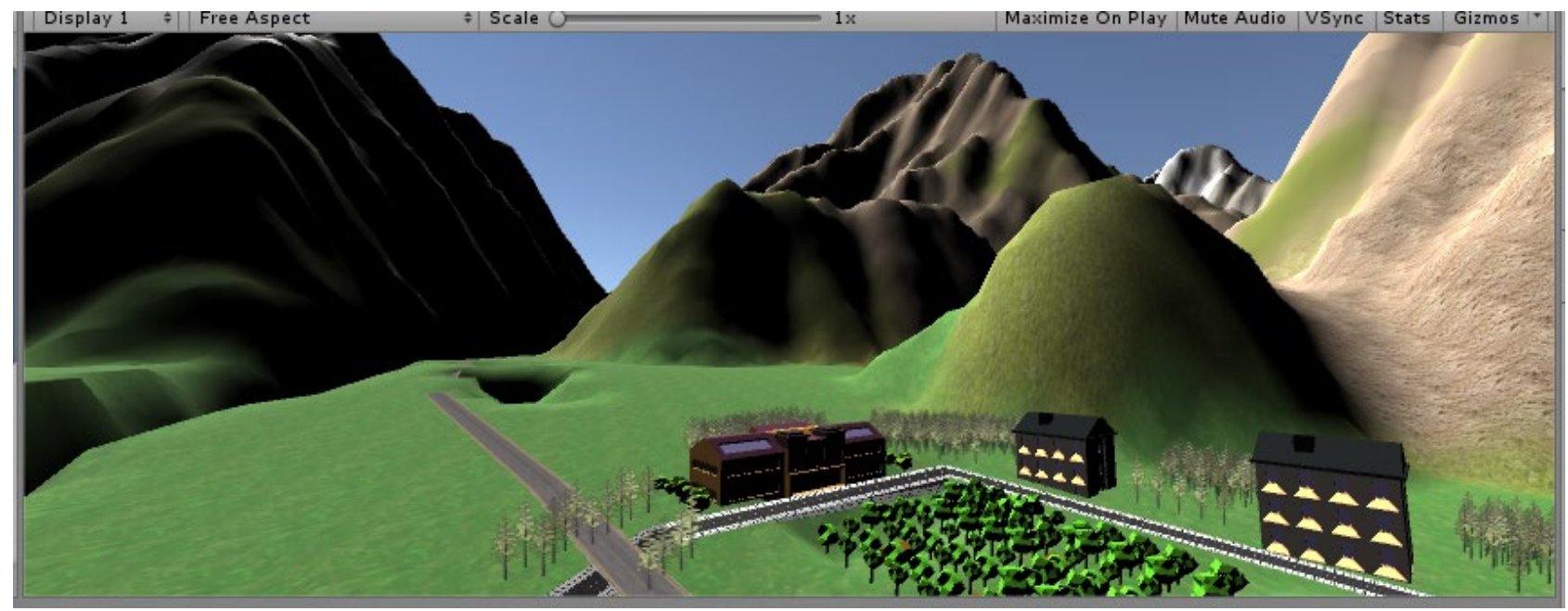

Рис. 9. Трехмерная модель местности в Unity 3D. Точка обзора 2

В перспективе, при увеличении ресурса компьютеров пользователей, возможна загрузка данной модели на серверы открытых web-сервисов, в мобильные картографические приложения. Использование данного подхода (обмен данными между сервисом, webприложением и пользователем) позволяет сэкономить временные и финансовые затраты за счет использования подготовленных данных и картографической информации с серверов для развития геоинформационного обеспечения туризма.

\section{Выводы}

Результатом работы является разработанная цифровая 3D-модель горного рельефа Республики Ингушетии, на базе которой разработана туристская интерактивная карта. На основе созданной модели разработана 3Dсцена, на которой показаны гидрография, рельеф, ледники, населенные пункты, пути сообщения, места культурного и исторического наследия, оздоровительные и спортивные курорты. 
Полученная модель может быть успешно применена для обеспечения как организованного, так и самостоятельного туризма и включать сервисные услуги по данному направлению; в целях навигации, для прокладки маршрута в горной местности, для симуляции перемещения по местности и демонстрации облета. Возможно применить модель для показа виртуальных 3D-туров, для динамики развития ледников, схода лавин на web-cервисах, а также туристских и административных сайтах республик Кавказа.

На основе полученной модели можно выполнить туристскую, геоморфологическую модель и др., оперативно добавляя данные по видам развивающегося туризма, логистике, инфраструктуре и др.

Данную методику моделирования можно использовать в любой сфере деятельности, включая онлайн-, мобильное, оперативное картографирование для территорий с горным и равнинным рельефом, а также для других регионов. На основе исследования возможно создание современной системы информационного и научно-методического обеспечения туристской деятельности.

\section{БИБЛИОГРАФИЧЕСКИЙ СПИСОК}

1. Об утверждении Стратегии развития туризма в Российской Федерации на период до 2035 года. [Электронный ресурс] : Распоряжение Правительства РФ от 20.09.2019 № 2129-р (ред. от 23.11.2020). Режим доступа: http://www.consultant.ru/document/cons_doc_LAW_333756/.

2. Here [Electronic resource]. - Mode of access: https://www.here.com/navteq.

3. Wilson J. P. Environmental Applications of Digital Terrain Modeling. - John Wiley \& Sons Ltd., 2018. $-360 \mathrm{p}$.

4. Елшина Т. Е., Нольфина М. А. Отображение рельефа светотенью на топографических картах средствами ГИС // ИнтерэкспоГЕО-Сибирь-2015. ХІ Междунар. науч. конгр. : Междунар. науч. конф. «Геодезия, геоинформатика, картография, маркшейдерия» : сб. материалов в 2 т. (13-25 апреля 2015 г., Новосибирск). - Новосибирск : СГУГиТ, 2015. Т. 2. - С. 172-174.

5. Татаренко В. И., Елшина Т. Е., Утробина Е. С. Интеграция разнородных данных в геоморфологическом картографировании // Изв. вузов. Геодезия и аэрофотосъемка. -2019 . - № 4/С. - С. 103-108.

6. Елшина Т. Е., Сысоев А. В. Создание цифровых моделей горного рельефа в программе ArcGIS 10 // От карты прошлого - к карте будущего : сб. науч. тр. в 3 т. / Отв. ред. С. В. Пьянков. - Пермь : Перм. гос. нац. исслед. ун-т, 2017. Т. 2. - С. 56-61.

7. Хромых О. В. Цифровые модели рельефа : учеб. пособие. - Томск : ТМЛ-Пресс, 2007. $178 \mathrm{c}$.

8. Бугаков П. Ю. Зарубежный опыт в области картографической генерализации трехмерных моделей городских территорий // Вестник СГУГиТ. - 2017. - Т. 22, № 1. - С. 151-159.

9. Верещака Т. В., Ковалева О. В. Обзор и классификация методов и способов изображения рельефа на картах : монография. - М. : Научный мир, 2016. - 181 с.

10. Якубайлик О. Э., Кадочников А. А., Попов В. Г., Токарев А. В. Модель геоинформационной аналитической Интернет-системы для анализа состояния и презентации региона. // Вестник СибГАУ. 2009. - Вып. 4 (25). - С. 61-66.

11. Правительство Республики Ингушетия. Постановление от 1 апреля 2015 года № 59 о перечне расположенных на территории Республики Ингушетия объектов, обладающих признаками объекта культурного наследия [Электронный ресурс] : Электронный фонд нормативно-технической и нормативно-правовой информации Консорциума «Кодекс». - Режим доступа: https://docs.cntd.ru/document/ 424089660.

12. Gorr W. L., Kurland K. S. GIS Tutorial 1 for ArcGIS Pro: A Platform Workbook (GIS Tutorials). Esri Press, 2017. -482 p.

13. Allen D. W. GIS Tutorial 2: Spatial Analysis Workbook (GIS Tutorials). - Esri Press, 2016. - 344 p.

14. Carrivik J. L., Smith M. W., Quincey D. J. Structure from Motion in the Geosciences. - Chichester, UK: Wiley-Blackwell, 2016. - 208 p.

15. Florinsky I. V. Digital Terrain Analysis in Soil Science and Geology. - Oxford, UK: Academic Press is an imprint of Elsevier, 2012. - $432 \mathrm{p}$.

16. Берлянт А. М. Картографический словарь. - М. : Научный мир, 2005. - 424 с. 
17. Li Z., Zhu C., Gold C. Digital Terrain Modeling: Principles and Methodology. - CRC Press, 2004. $340 \mathrm{p}$.

18. Shaimi N. E., Valeo K., Habib A. Digital terrain modeling: collection, processing and application. Boston, Mass.; London : Publishing house Artech House, 2005. -257 p.

19. Кадочников А. А. Веб-сервисы и приложения для геоинформационного интернет-портала Института вычислительного моделирования Сибирского отделения РАН // Материалы Междунар. конф. ИнтерКарто / ИнтерГИС 17. Устойчивое развитие территорий: теория ГИС и практический опыт (Белокуриха, Денпасар 14-19 декабря 2011 г.). - С. 93-97.

20. Никулин А. А. Компьютерная геометрия и алгоритмы машинной графики : учеб. пособие. M. : BHV, 2005. $-263 \mathrm{c}$.

21. Елшина Т. Е., Утробина Е. С., Сысоев А. В. Визуализация модели горного рельефа для WEBкарт // Вестник СГУГиТ. - 2020. - Т. 25, № 1. - С. 145-155. doi: 10.33764/2411-1759-2020-25-1-145-155.

22. Бут Б. ArcGIS 3D Analyst: Руководство пользователя. - М. : Дата+, 2002. - 243 с.

23. Wilson J. P. Environmental Applications of Digital Terrain Modeling. - John Wiley \& Sons Ltd., 2018. $-360 \mathrm{p}$.

24. Леонидова Е. Г. Совершенствование информационного обеспечения сферы туризма региона // Научный вестник Южного института менеджмента. - 2018. - № 3. - С. 18-23 [Электронный ресурс]. Режим доступа: https://doi. org/10.31775/2305-3100-2018-3-18-23.

Получено 24.06.2021

(C) T. Е. Елиина, И. П. Кокорина, А. В. Сысоев, 2021

\section{BUILDING AND USING A 3D MODEL OF A MOUNTAINOUS LANDFORM FOR GEOINFORMATIONAL SUPPORT OF TOURISM}

\section{Tatyana E. Elshina}

Siberian State University of Geosystems and Technologies, 10, Plakhotnogo St., Novosibirsk, 630108, Russia, $\mathrm{Ph}$. D., Associate Professor, Department of Cartography and Geoinformatics, phone: (383)361-06-35, e-mail: dony2005@mail.ru

\section{Irina P. Kokorina}

Siberian State University of Geosystems and Technologies, 10, Plakhotnogo St., Novosibirsk, 630108, Russia, Ph. D., Associate Professor, Department of Cartography and Geoinformatics, phone: (383)361-06-35, e-mail: irusha2008@gmail.com

\section{Alexander V. Sysoev}

2GIS, 7, K. Marx Square, Novosibirsk, 630048, Russia, Engineer-Cartographer, phone: (999)468-89-50, e-mail: sasha.sysoev.94@mail.ru

The article deals with the creation and use of a 3D model of mountain terrain for geoinformation support of tourism in the Russian Federation on the example of the territory of the Republic of Ingushetia. The aim of the work is to develop and apply a digital 3D model of mountain terrain for use in creating an interactive tourist map on web services, as well as tourist and administrative sites of the republics of the Caucasus. Methods of geoinformational mapping, terrain modeling, cartographic research method and modern software were used: 3D Spatial Analysts, WorldMachine, Unity 3D. The classification of tourism types and objects of natural and cultural heritage in the Republic of Ingushetia is carried out. As a result of the analysis of tourist and administrative sites, as well as web-services of the republics of the Caucasus, a conclusion is made about their insufficient geoinformation support. The possibilities of using 3D models of mountain terrain on web maps for tourism purposes are presented. A digital model of mountainous landform in the Republic of Ingushetia is created. A 3D scene, which shows basic relief forms and objects' location is developed.

Keywords: mountainous landform, tourism, North Caucasus, Republic of Ingushetia, web maps, digital elevation model, geoinformation mapping, hypsometric scale, chiaroscuro relief image, 3D scene 


\section{REFERENCES}

1. Order of the Government of the Russian Federation of September 20, 2019 No. 2129-r (as amended of November 23, 2020). On the approval of the Strategy for the development of tourism in the Russian Federation for the period up to 2035. Retrieved from https: http://www.consultant.ru/document/cons_doc_LAW_333756/.

2. Here. (n. d.). Retrieved from https://www.here.com/navteq.

3. Wilson, J. P. (2018). Environmental Applications of Digital Terrain Modeling. John Wiley \& Sons Ltd., $360 \mathrm{p}$.

4. Elshina, T. E., Nolfina, M. A. (2015). Representation of the relief shading on topographic maps by a GIS. In In Sbornik materialov Interekspo GEO-Sibir'-2015: Mezhdunarodnoy nauchnoy konferentsii: T. 2. Geodeziya, geoinformatika, kartografiya, marksheyderiya [Proceedings of Interexpo GEO-Siberia-2015: International Scientific Conference: Vol. 2. Geodesy, Geoinformatics, Cartography, Mine Surveying] (pp. 172174). Novosibirsk: SSUGT Publ. [in Russian].

5. Tatarenko, V. I., Elshina, T. E., \& Utrobina, E. S. (2019). Heterogeneous data integration in geomorphological mapping. Izvestiya vuzov. Geodeziya i aerofotos"emka [Izvestiya vuzov. Geodesy and Aerophotosurveying], 4/S, 103-108 [in Russian].

6. Elshina, T. E., \& Sysoev, A. V. (2017). Creation of digital models of mountainous terrain in the ArcGIS 10 application. In Sbornik nauchnykh trudov: ot karty proshlogo - k karte budushchego [Collection of Scientific Papers: from a Map of the Past to a Map of the Future] (pp. 56-61).

S. V. Pyankov (Ed.). Perm: Permian State University Publ. [in Russian].

7. Khromykh, O. V. (2007). Tsifrovye modeli rel'efa [Digital relief models]. Tomsk: TML-Press, 178 p. [in Russian].

8. Bugakov, P. Y. (2017). Foreign experience in the field of cartographic generalization of three-dimensional models of urban areas. Vestnik SGUGiT [Vestnik SSUGT], 22(1), 151-159 [in Russian].

9. Vereshchaka, T. V., \& Kovaleva, O. V. (2016). Obzor i klassifikatsiya metodov i sposobov izobrazheniya rel'efa na kartakh [Review and classification of methods and methods of image on the map]. Moscow: Scientific world Publ., 181 p. [in Russian].

10. Yakubaylik, O. E., Kadochnikov, A. A., Popov, V. G., \& Tokarev, A. V. (2009). A model of a geographic information analytical Internet system for analyzing the state and presentation of a region. Vestnik SibGAU [Vestnik SibSAU], 4(25), 61-66 [in Russian].

11. The Government of the Republic of Ingushetia. Resolution No. 59 of April 1, 2015 on the list of objects located on the territory of the Republic of Ingushetia that have the characteristics of a cultural heritage object. Electronic Fund of Normative-technical and Regulatory information of the "Codex" Consortium. Retrieved from https://docs.cntd.ru/document/424089660.

12. Gorr, W. L., \& Kurland, K. S. (2017). GIS Tutorial 1 for ArcGIS Pro: A Platform Workbook (GIS Tutorials). Esri Press, 482 p.

13. Allen, D. W. (2016). GIS Tutorial 2: Spatial Analysis Workbook (GIS Tutorials). Esri Press, 344 p.

14. Carrivik, J. L., Smith, M. W., \& Quincey, D. J. (2016). Structure from Motion in the Geosciences. Chichester, UK: Wiley-Blackwell, 208 p.

15. Florinsky, I. V. (2012). Digital Terrain Analysis in Soil Science and Geology. Oxford, UK: Academic Press is an imprint of Elsevier, $432 \mathrm{p}$.

16. Berlyant, A. M. (2005). Kartograficheskiy slovar' [Cartographic Dictionary]. Moscow: Scientific World, 424 p. [in Russian].

17. Li, Z., Zhu, C., \& Gold, C. (2004). Digital Terrain Modeling: Principles and Methodology. CRC Press, $340 \mathrm{p}$.

18. Shaimi, N. E., Valeo, K., \& Habib, A. (2005). Digital terrain modeling: collection, processing and application. Boston, Mass.; London: Artech House Publ., 257 p.

19. Kadochnikov, A. A. (2011). Web services and appendices for the geoinformation internet portal of Institute of computing modeling of the Siberian branch of the Russian academy of science. In Sbornik materialov Mezhdunarodnoy konferentsii InterKarto/InterGIS 17. Ustoychivoe razvitie territoriy: teoriya GIS i prakticheskiy opyt [Proceedings of the International Conference InterCarto/InterGIS 17. Sustainable Development of Territories: GIS Theory and Practical Experience] (pp. 93-97). Belokurikha, Denpasar [in Russian].

20. Nikulin, A. A. (2005). Komp'yuternaya geometriya i algoritmy mashinnoy grafiki [Computer geometry and computer graphics algorithms]. Moscow: BHV Publ., 263 p. [in Russian]. 
21. Elshina, T. E., Utrobina, E. S., \& Sysoev, A. V. (2020). Visualization of a mountain terrain model for WEB maps. Vestnik SGUGiT [Vestnik SSUGT], 25(1), 145-155. doi: 10.33764/2411-1759-2020-25-1-145155 [in Russian].

22. Booth, B. (2002). ArcGIS 3D Analyst: Rukovodstvo pol'zovatelya [ArcGIS 3D Analyst: User Guide]. Moscow: Data+ Publ. 243 p. [in Russian].

23. Wilson, J. P. (2018). Environmental Applications of Digital Terrain Modeling. John Wiley \& Sons Ltd., $360 \mathrm{p}$.

24. Leonidova, E. G. (2018). Improvement of information support for the tourism sector of the region. Nauchny̌ vestnik Yuzhnogo instituta menedzhmenta [Scientific Bulletin of the Southern Institute of Management], 3, 18-23. https://doi.org/10.31775/2305-3100-2018-3-18-23 [in Russian].

Received 24.06.2021

(C) T. E. Elshina, I. P. Kokorina, A. V. Sysoev, 2021 
УДК 528.944:528.8

DOI: $10.33764 / 2411-1759-2021-26-5-119-125$

\section{ИСПОЛЬЗОВАНИЕ ДЗЗ И ГИС ПРИ СОЗДАНИИ ГЕОГРАФИЧЕСКИХ ОСНОВ ДЛЯ ТЕМАТИЧЕСКИХ КАРТ}

\section{Оюунханд Бямба}

Сибирский государственный университет геосистем и технологий, 630108, Россия, г. Новосибирск, ул. Плахотного, 10, аспирант кафедры картографии и геоинформатики, тел. +976-11-96028580, e-mail: oyunkhand_55@yahoo.com,b.oyunkhand@num.edu.mn

\section{Елена Леонидовна Касьянова}

Сибирский государственный университет геосистем и технологий, 630108, Россия, г. Новосибирск, ул. Плахотного, 10, кандидат технических наук, доцент кафедры картографии и геоинформатики, тел. (383)361-06-35, e-mail: helenkass@mail.ru

Наука картография стремительно меняется и развивается с внедрением новых компьютерных технологий, таких как геоинформационные системы (ГИС) и дистанционное зондирование Земли. Для тематических карт необходимы общегеографические основы, один из основных элементов которых - рельеф. Цель работы - создать географическую основу для туристских карт с 3D-моделью. В статье рассматривается метод создания трехмерной цифровой модели рельефа местности с использованием нерегулярной триангуляционной сети на основе данных SRTM и технологии ГИС. В результате создана основа с 3D-моделью Хентийского аймака Восточной Монголии.

Ключевые слова: тематическая карта, дистанционное зондирование Земли, цифровая модель рельефа, трехмерное отображение

\section{Введение}

Понятие «тематическое картографирование» весьма обширно, подразумевает в своем составе создание карт природы и населения, карты экономических, политических, исторических, зоогеографических и многих других. Тематические карты - это карты, раскрывающие определенную тему, передающие размещение многообразия природных и социально-экономических объектов и явлений; характеризующие их в качественном и количественном отношении, показывающие взаимосвязи этих объектов и явлений, их развитие во времени, динамику. При составлении тематических карт картографируемые объекты и явления проектируются на земную поверхность и привязываются к картографической сетке, рельефу, гидрографии, населенным пунктам, дорогам, границам и другим общегеографическим элементам. Именно поэтому на любой тематической карте обязательно присутствуют отдельные элементы общегеографической карты, которые называются географической основой [1].
Традиционно в картографии и картпроизводстве все элементы географической основы составлялись вручную. С появлением компьютерной техники и специализированных программ составление и оформление выполняется с их помощью. Одна из самых сложных, трудоемких и длительных работ - составление и оформление рельефа для тематических карт различного назначения. Эта проблема является важной и актуальной в области картографирования территории Монголии.

\section{Методы и материаль}

На современном этапе наиболее эффективным способом изображения рельефа считаются цифровые модели рельефа, которые позволяют успешно и оперативно решать поставленные задачи во многих областях человеческой деятельности [2].

В тематической картографии широко применяются современные и оперативные способы картографирования рельефа, которые предполагают его создание в виде цифровой модели, впоследствии выводимой на экран 
монитора или печать. Согласно теории картографии, при изображении рельефа к нему предъявляются основные требования:

- сохранение характерного внешнего облика и региональных особенностей конкретных районов;

- привлекательность и наглядность для широкого круга потребителей [3].

Цифровая модель рельефа - одна из важных моделирующих функций геоинформационных систем. Под цифровой моделью рельефа (ЦМР) принято понимать средство цифрового представления трехмерных пространственных объектов (поверхностей) в виде трехмерных данных, образующих множество высотных отметок и иных значений аппликат (координаты Z) в узлах регулярной или нерегулярной сети или совокупность записей горизонталей (изогипс, изобат) [4].

С появлением спутниковых систем дистанционного зондирования Земли (ДЗ3) процесс создания картографических материалов стал менее трудоемким и более наукоемким.

На сегодняшний день доступные для использования спутниковые снимки очень разнообразны по разрешению, охвату, спектральному диапазону, технологии получения и другим свойствам. Аэрокосмические снимки используются в различных картографических продуктах, объединяющихся с наложенными векторными картографическими слоями, что позволяет выполнять требования, предъявляемые к карте: точность, читаемость, современность данных с актуальностью отображения местности.

Использование данных дистанционного зондирования (ДДЗ) в картографии обусловлено тем, что снимок является фактографической моделью местности, т. е. отражает реальные виды и формы рельефа, полученные в конкретный момент времени.

Использование современных компьютерных технологий в картографии также способствовало появлению качественно новых видов картографической продукции, в частности, 3D-моделей местности на основе разновременных данных. Данные Д33, а именно материалы спутниковых съемок, выступают как источники для создания географической основы при составлении и обновлении топографических и тематических карт [5].
Основная задача статьи - рассмотреть современные и наиболее эффективные способы изображения рельефа на основе цифровых моделей, использующиеся как основа для тематических карт, которая может быть в базе данных и использоваться не только для туристских карт. Объект исследования - Хентийский аймак Восточной Монголии, который описывается следующими географическими координатами: $46^{0} 15^{\prime} 00^{\prime \prime}$ и $49^{0} 20^{\prime} 00^{\prime \prime}$ северной широты; $108^{0} 30^{\prime} 00^{\prime \prime}$ и $112^{0} 40^{\prime} 00^{\prime \prime}$ восточной долготы. Предмет исследования создание цифровой модели рельефа для тематического картографирования с использованием данных Д3З, в том числе спутниковых снимков SRTM [Геологическая служба США] и программы ArcGIS 10.3 (ESRI Inc) [6].

В ходе исследования использовались спутниковые снимки SRTM [Геологическая служба США]. В 2003 г. Национальное управление по аэронавтике и исследованию космического пространства (NASA) опубликовало материалы спутниковой радиолокационной съемки Земли (Shuttle Radar Topography Mission, SRTM) в виде цифровой модели рельефа (Digital elevation model, DEM) с пространственными разрешением от 30 до 90 м. В открытом доступе (http://earthexplorer.usgs.gov) публиковались матрицы высот с шагом $30 \times 30$ м на всю территорию земной поверхности в виде файлов ArcGIS и в формате Geotiff (рис. 1).

Прежде чем использовать данные со спутниковых снимков SRTM, необходимо проконтролировать их качество и пространсвенное разрешение. Их пространственное разрешение должно соответствовать масштабу создаваемой карты. Наиболее высокие требования предъявляются при создании топографических карт: размер пиксела на местности должен соответствовать графической точности карты $(0,1$ мм). Так, для используемого снимка с пространственным разрешением 30 м на пиксел соответствующий масштаб карты составит $1: 300000$. Для создания тематических карт требование к пространственному разрешению намного ниже [7], поэтому выбранного SRTMизображения спутника с шагом $30 \times 30$ м достаточно для дальнейшего исследования. В результате обработки спутниковых снимков получается фотомозаика (фотокарта) $[8,9]$ (рис. 2, a, б). 


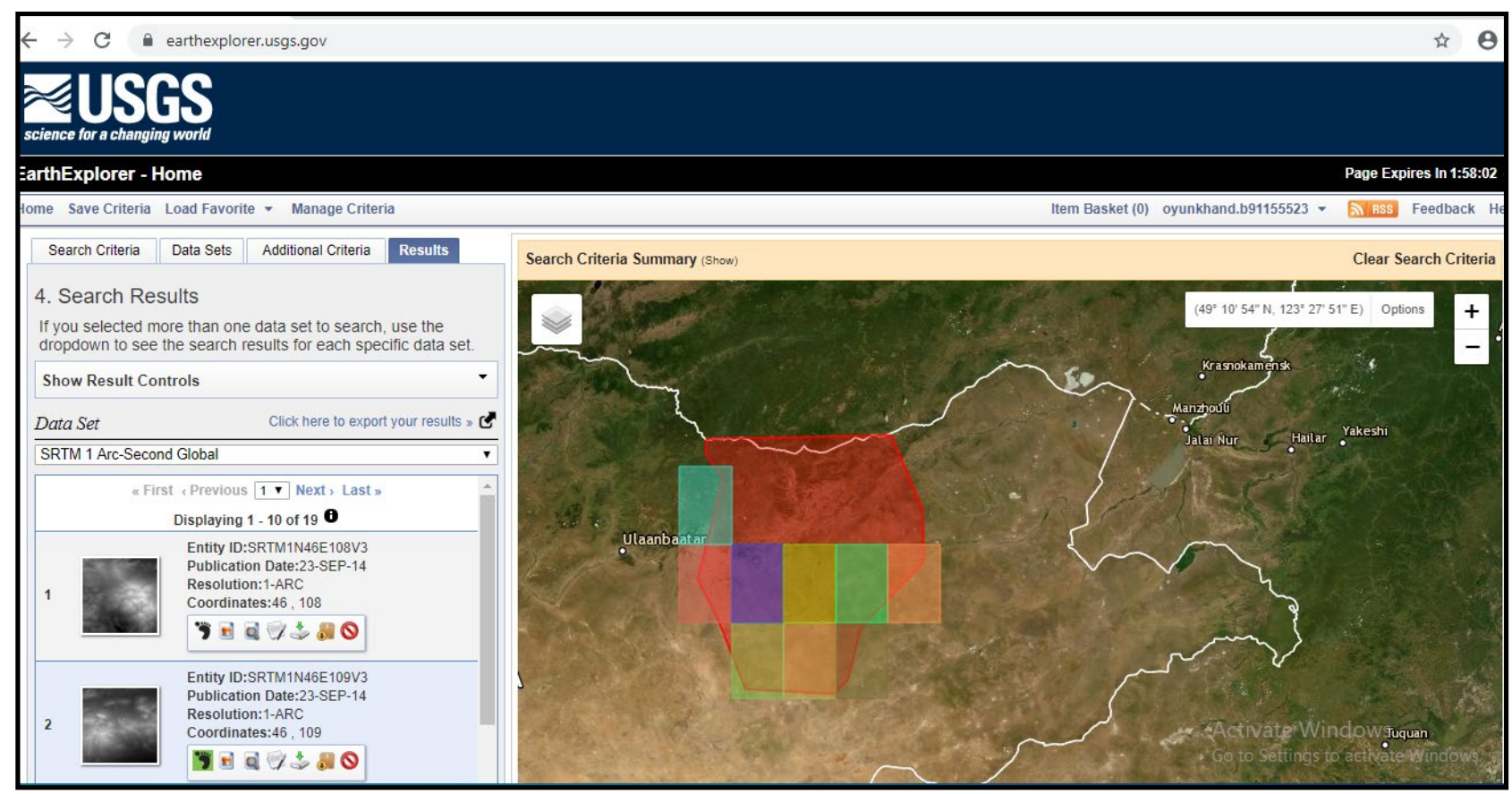

Рис. 1. Спутниковые снимки исследуемой территории на сайте USGS

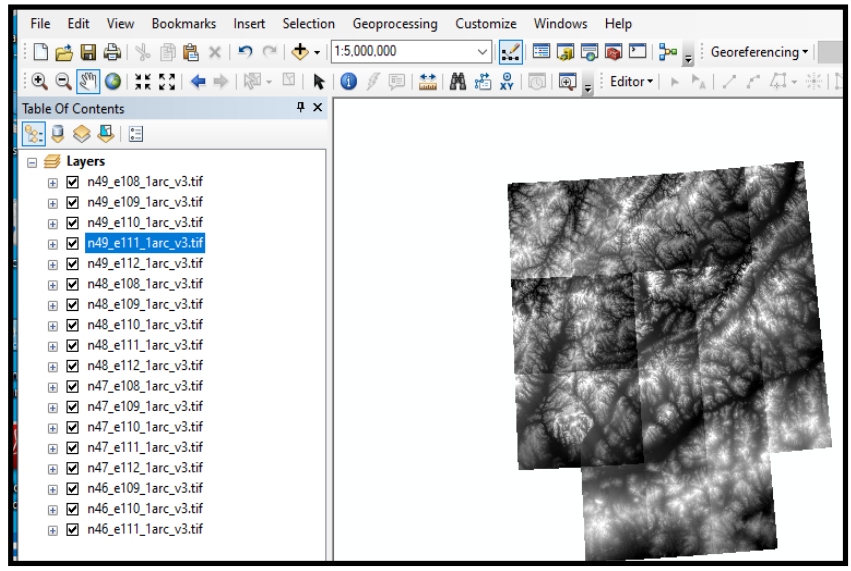

a)

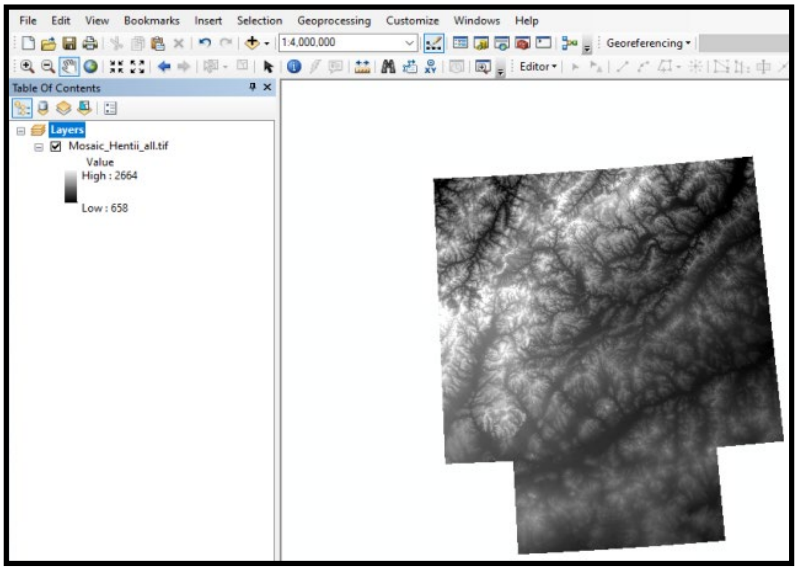

б)

Рис. 2. Спутниковые снимки SRTM с пространственными разрешением $30 \times 30$ м:

a) до фотомозаики; б) после фотомозаики

После фотомозаики из файла в формате *.tiff для создания контурных линий используется средний интервал 100 м (create contour line) и выполняется построение модели рельефа с помощью следующих инструментов в определенной последовательности, представленной на рис. 3. После действия ArcToolsBox по работе с дугами и кривыми нужно выполнить действия 3D-аналитики, затем построить растровую поверхность, после чего составить линии контура.
В создании и обработке ЦMP в ArcGIS cуществует два типа цифровой модели: регулярная сеть высот (Grid) и нерегулярная триангуляционная сеть (TIN) [10]. На практике наиболее точной и часто используемой считается TIN-модель, которая используется в дальнейшем построении. При создании TIN- модели рельефа Хентийского аймака Восточной Монголии горизонтали проведены с высотой сечения рельефа 100 м в следующей последовательности (рис. 4). 


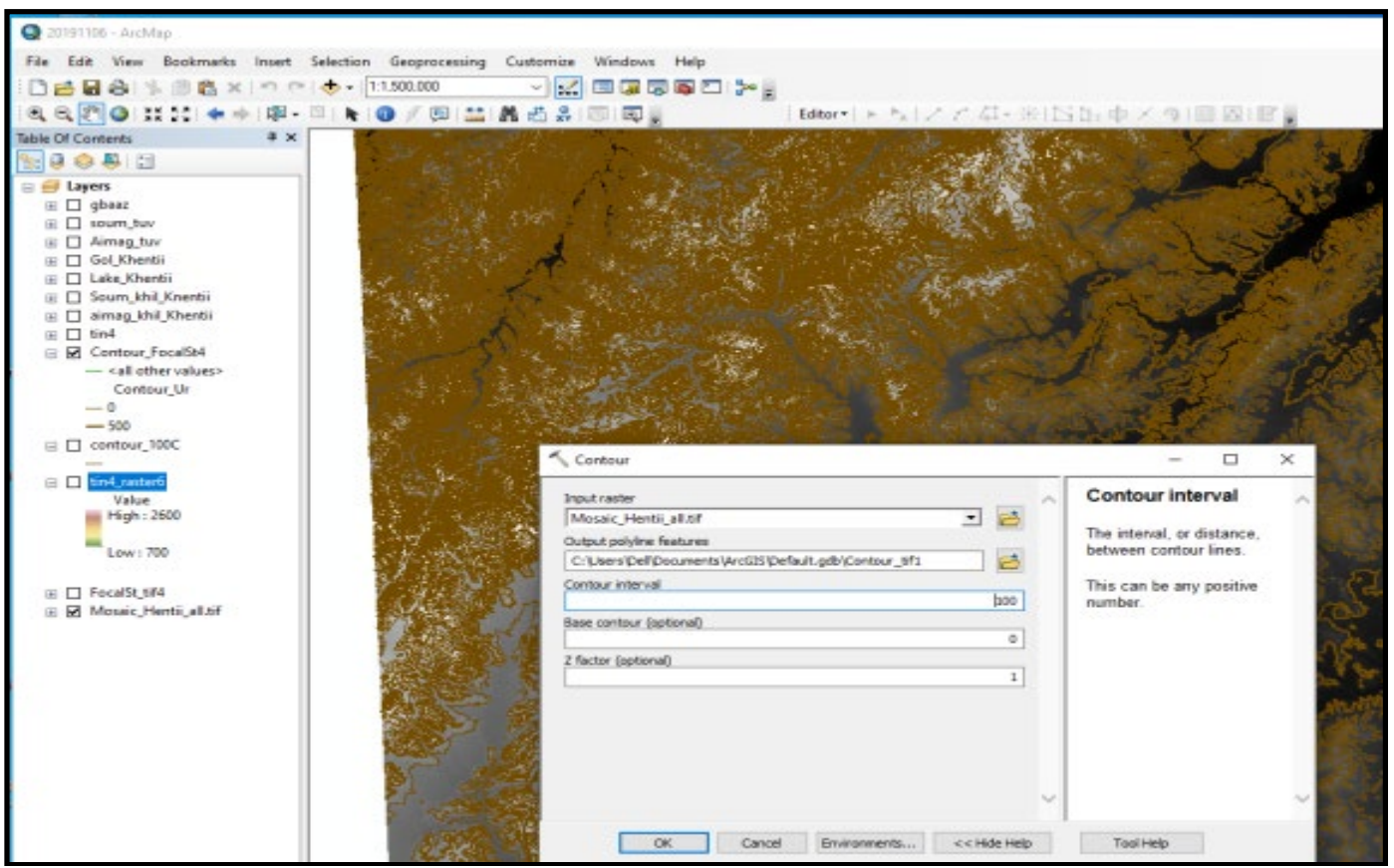

Рис. 3. Отображение рельефа в виде горизонталей по данным ДЗ3 (SRTM)

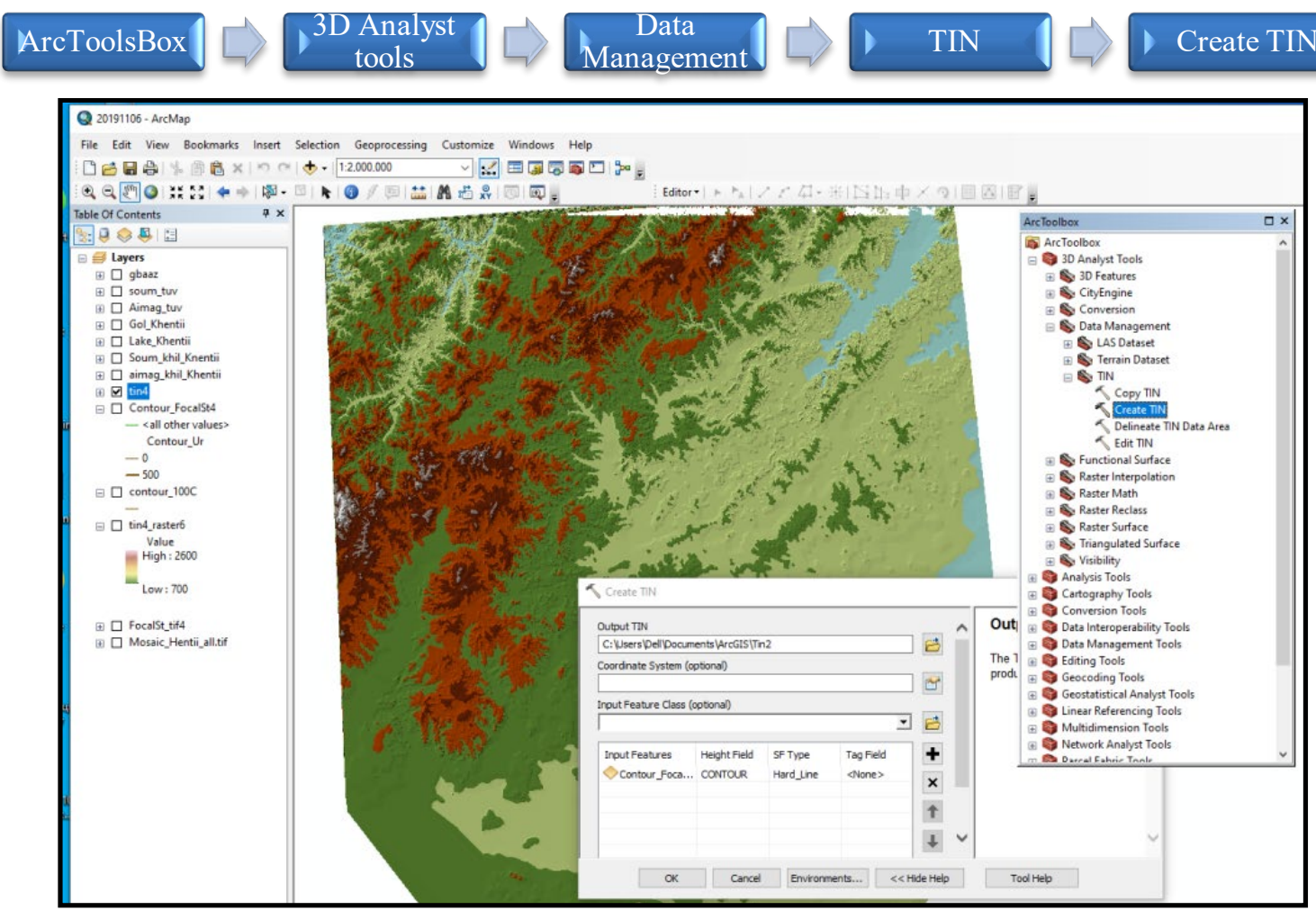

Рис. 4. Модель TIN (нерегулярная триангуляционная сеть)

После того как TIN-модель готова, для большей наглядности изменяется цветовой фон гипсометрической окраски. Далее TIN-модель преобразуется в растр (TIN to Raster) (рис. 5), чтобы в дальнейшем строить 3D-модель рельефа местности [11]. 


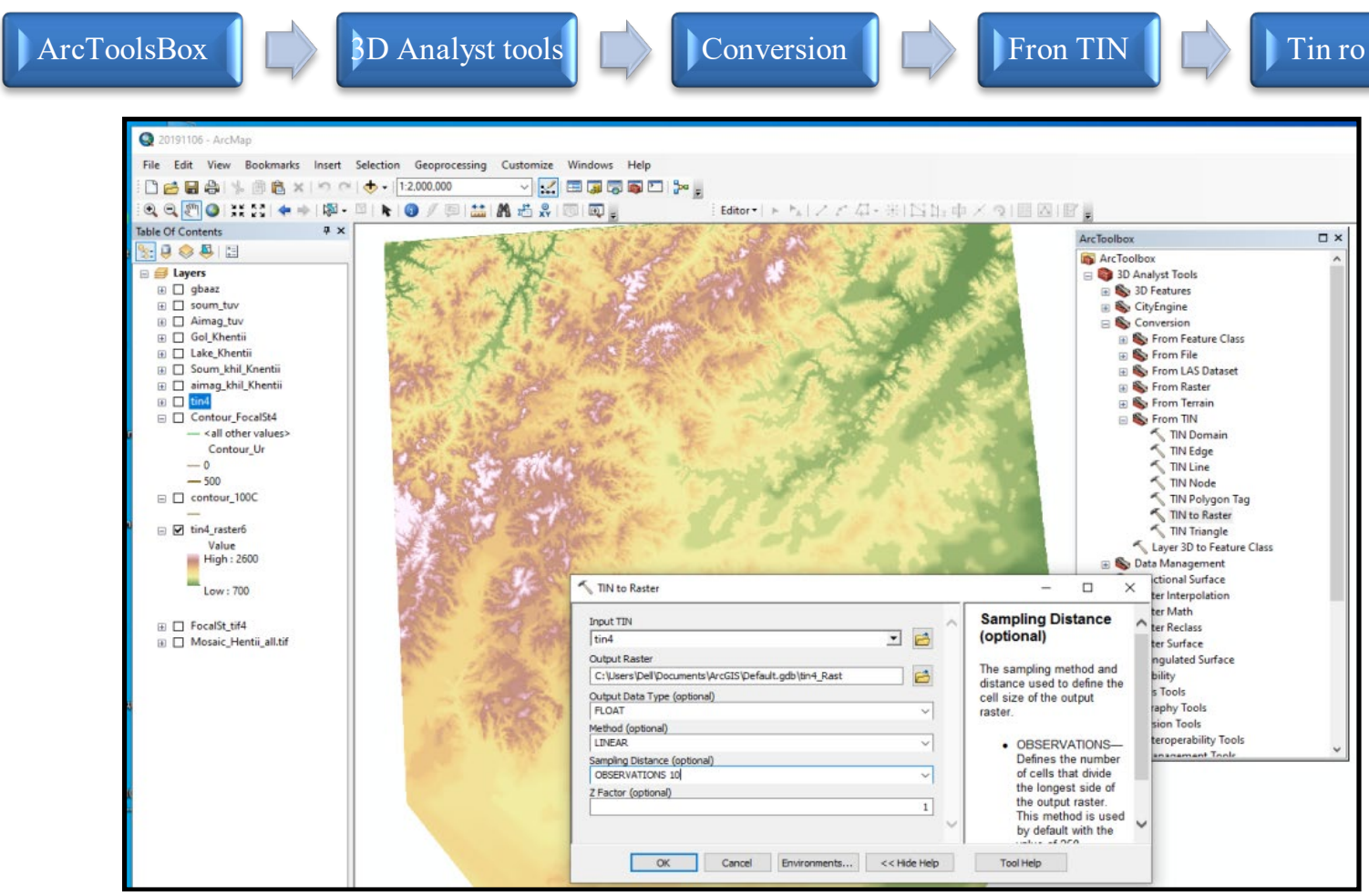

Рис. 5. Трехмерная цифровая модель рельефа местности с изменением цветовой гаммы и переобразованием TIN в растр

\section{Результаты}

Для трехмерного отображения рельефа (3D) используется приложение ArcScene программы ArcGIS, с помощью которого визуализируется слой созданной ранее модели рельефа местности и устанавливаются параметры ее отображения [12] (рис. 6).

В результате обработки данных ДЗЗ получается цифровая модель рельефа, которую можно использовать как географическую основу для тематической карты, например, туристской.

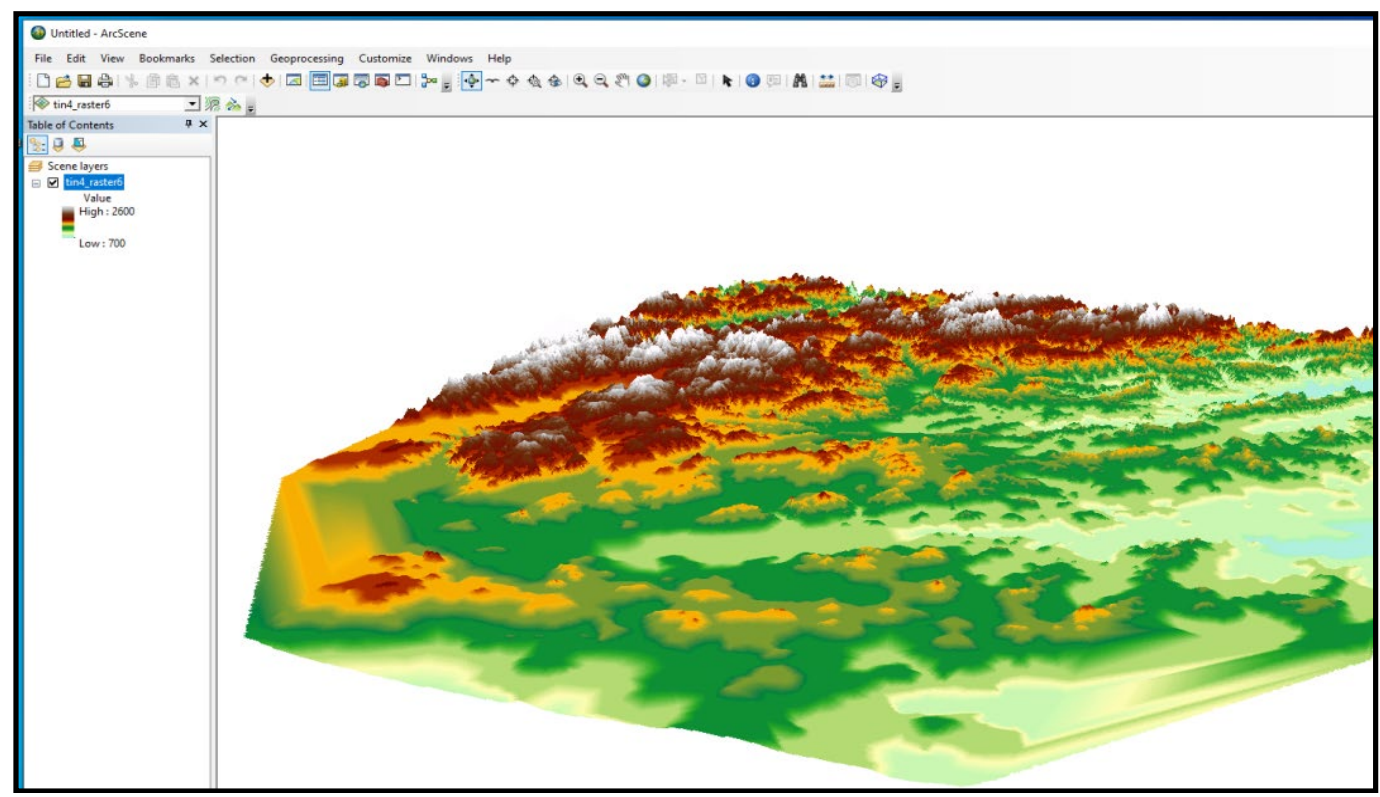

Рис. 6. Трехмерное отображение рельефа в приложении ArcScene 


\section{Заключение}

В исследовании при создании цифровой модели рельефа местности использовались данные SRTM с пространственным разрешением $30 \times 30$ м, с применением ГИС-технологий. В результате можно сделать выводы:

- во-первых, создание цифровой модели рельефа на основе ДЗЗ и ГИС-технологии требует значительно меньше времени и материальных затрат по сравнению с другими методами;

- во-вторых, удобнее производить оперативные вычисления и трансформирование информации в различные форматы, брать информацию из внешних источников;
- в-третьих, при создании базы данных закладывается основа для изображения рельефа, ее обработка и использование наиболее современными методами;

- в-четвертых, данные, полученные с использованием ДДЗ, их точность при формировании модели рельефа местности для решаемой задачи можно считать достаточной;

- в-пятых, данные о рельефе местности можно использовать при создании географической основы для составления тематических карт (в том числе туристских), использующих трехмерные модели поверхностей и различные методы пространственного анализа на основе разновременных данных.

\section{БИБЛИОГРАФИЧЕСКИЙ СПИСОК}

1. Радченко Л. К., Николаева О. Н. Основы тематической картографии. - Новосибирск : СГГА, 2018. - 102 c.

2. Хромых В. В., Хромых О. В. Цифровые модели рельефа. - Томск : ТМЛ-Пресс, 2007.- 178 с.

3. Елшина Т. Е., Сысоев А. В. Создание цифровых моделей горных рельефов в программе ArcGIS 10 // От карты прошлого - к карте будущего : сб. науч. тр. в 2 т. / отв. ред. С. В. Пьянков; Перм. гос. нац. исслед. ун-т. - Пермь, 2017. Т. 2. - С. 56-61.

4. Капралов Е. Г., Кошкарев А. В., Тикунов В. С. и др. Основы геоинформатики / под ред. В. С. Тикунова. - М. : Издательский центр «Академия», 2004.- 352 с.

5. Берлянт А. М, Востокова А. В. и др. Картоведение. - М. : Аспект Пресс, 2003. - 477 с.

6. Хлебникова Т. А., Опритова О. А. Экспериментальные исследования современных программных продуктов для моделирования геопространства // Вестник СГУГиТ. - Т. 22, № 1. - 2017. - С. 119-132.

7. Пономарчук А. И., Черепанова Е. С., Шихов А. И. Дистанционное зондирование в картографии. - Пермь, 2013. - 100 с.

8. Берлянт А. М. Теория геоизображений. - М. : ГЕОС, 2006. -262 с.

9. Шовенгердт Р. А. Дистанционное зондирование. Модели и методы обработки изображений. M., 2010. - $560 \mathrm{c}$.

10. Цэцэгмээ Б., Бямба-Эрлэнэ У. Руководство по ARSGIS 10.5 n ENVI. - Уланбатор, 2019. - 200 с.

11. Амарсайхан Д., Ганзориг М., Адъяасүрэн., Саандарь М. Дистанционное зондирование и ГИС. Уланбатор, 2002. - 160 с.

12. Аш Е. В. Общие принципы и методика создания карты береговых морфосистем на основе анализа картографических источников информации // Геодезия и картография. - 2014. - № 7. - С. 20-26.

Получено 13.04.2021

(C) Оюунханд Бямба, Е. Л. Касьянова, 2021

\section{USING REMOTE SENSING AND GIS TO CREATE GEOGRAPHICAL BASES FOR THEMATIC MAPS}

\section{Oyunkhand Byamba}

Siberian State University of Geosystems and Technologies, 10, Plakhotnogo St., Novosibirsk, 630108, Russia, $\mathrm{Ph}$. D. Student, Department of Cartography and Geoinformatics, phone: +976-11-96028580, e-mail: oyunkhand_55@yahoo.com, b.oyunkhand@num.edu.mn

\section{Elena L. Kasyanova}

Siberian State University of Geosystems and Technologies, 10, Plakhotnogo St., Novosibirsk, 630108, Russia, Ph. D., Associate Professor, Department of Cartography and Geoinformatics, phone: (383)361-06-35, e-mail: helenkass@mail.ru 
The development of science always depends on technological progress. Cartography is rapidly changing and developing with the introduction of new computer technologies, such as GIS and remote sensing of the Earth. Recently, there have been qualitatively new types of cartographic products, in particular 3D terrain models, which in cartography are becoming a universal, optimal and operational method for displaying terrain. The article discusses a method for creating a three-dimensional digital terrain model in the form of an irregular triangulation network based on SRTM data and GIS technology on the example of the Khenti aimag of Eastern Mongolia.

Keywords: thematic map, remote sensing of the Earth, digital terrain model, three-dimensional mapping

\section{REFERENCES}

1. Radchenko, L. K., \& Nikolaeva, O. N. (2018). Osnovy tematicheskoy kartografii [Fundamentals of thematic cartography]. Novosibirsk: SSGA Publ., 102 p. [in Russian].

2. Khromykh, V. V., \& Khromykh, O. V. (2007). Tsifrovye modeli rel'efa [Digital relief models]. Tomsk: TML-Press, 178 p. [in Russian].

3. Elshina, T. E., \& Sysoev, A. V. (2017). Creation of digital models of mountainous reliefs in the ArcGIS 10 program. In Sbornik nauchnykh trudov: T. 2. Ot karty proshlogo - $k$ karte budushchego [Collection of Scientific Papers: Vol. 2. From the Map of the Past to the Map of the Future] (pp. 56-61). S. V. Pyankov (Ed.). Perm: Permian State National Research University Publ. [in Russian].

4. Kapralov, E. G., Koshkarev, A. V., Tikunov, V. S., \& et al. (2004). Osnovy geoinformatiki [Fundamentals of geoinformatics]. V. S. Tikunov (Ed.). Moscow: Akademiya" Publ., 352 p. [in Russian].

5. Berlant, A. M, Vostokova, A. V., \& et al. (2003). Kartovedenie [Cartography]. Moscow: Aspekt Press Publ, 477 p. [in Russian].

6. Khlebnikova, T. A., \& Opritova, O. A. (2017). Experimental research of modern software products for geospace modeling. Vestnik SGUGiT [Vestnik SSUGT], 22(1), 119-132 [in Russian].

7. Ponomarchuk, A. I., Cherepanova, E. S., \& Shikhov, A. I. (2013). Distantsionnoe zondirovanie v kartografii [Remote sensing in cartography]. Perm, 100 p. [in Russian].

8. Berlyant, A. M. (2006). Teoriya geoizobrazheniy [Theory of geo-images]. Moscow: GEOS Publ., 262 p. [in Russian].

9. Shovengerdt, R. A. (2010). Distantsionnoe zondirovanie. Modeli i metody obrabotki izobrazheniy [Remote sensing. Models and methods of image processing]. Moscow, 560 p. [in Russian].

10. Tsetsegmee, B., \& Byamba-Erlene, U. (2019). Rukovodstvo po ARSGIS 10.5 n ENVI [Guidelines for ARSGIS $10.5 n$ ENVI]. Ulanbator, 200 p. [in Russian].

11. Amarsaykhan, D., Ganzorig, M., Adyaasuren., \& Saandar, M. (2002). Distantsionnoe zondirovanie $i$ GIS [Remote sensing and GIS]. Ulanbator, 160 p. [in Russian].

12. Ash, E. V. (2014). General principles and methods of creating a map of coastal morphosystems based on the analysis of cartographic sources of information. Geodeziya i kartografiya [Geodesy and Cartography], 7, 20-26 [in Russian].

Received 13.04.2021

(C) Oyunkhand Byamba, E. L. Kasyanova, 2021 


\title{
ЗЕМЛЕУСТРОЙСТВО, КАДАСТР И МОНИТОРИНГ ЗЕМЕЛЬ
}

\author{
$\longrightarrow$
}

УДК 528.236.4:528.44

DOI: $10.33764 / 2411-1759-2021-26-5-126-134$

\section{ПРОЕКТИРОВАНИЕ И УРАВНИВАНИЕ ПРОСТРАНСТВЕННЫХ ГЕОДЕЗИЧЕСКИХ ПОСТРОЕНИЙ, ПРЕДНАЗНАЧЕННЫХ ДЛЯ СОЗДАНИЯ ТРЕХМЕРНОГО КАДАСТРА}

\section{Евгений Ильич Аврунев}

Сибирский государственный университет геосистем и технологий, 630108, Россия, г. Новосибирск, ул. Плахотного, 10, кандидат технических наук, доцент, советник при ректорате по научной деятельности, тел. (383)344-31-73, e-mail: kadastr204@yandex.ru

\section{Артур Ильгизович Гиниятов}

Сибирский государственный университет геосистем и технологий, 630108, Россия, г. Новосибирск, ул. Плахотного, 10, аспирант кафедры кадастра и территориального планирования, тел. (913)767-73-49, e-mail: ita1095@mail.ru

\section{Анатолий Иванович Каленицкий}

Сибирский государственный университет геосистем и технологий, 630108, Россия, г. Новосибирск, ул. Плахотного, 10, доктор технических наук, профессор кафедры космической и физической геодезии, тел. (913)767-73-49, e-mail: kadastr204@yandex.ru

В статье предложен основанный на методе наименьших квадратов математический алгоритм предвычисления необходимой точности измерений в пространственном геодезическом построении, предназначенном для выполнения кадастровых работ при ведении 3D-кадастра в территориальном образовании. Предложенный алгоритм позволяет, исходя из заданной нормативной точности взаимного положения объектов недвижимости в кадастровом квартале, выбрать необходимое технологическое измерительное оборудование для построения на местности пространственной межевой сети сгущения (MCC) для геодезического обеспечения кадастровых работ. Использование разработанного алгоритма при уравнивании результатов геодезических измерений обеспечит достоверность вычисляемых параметров объектов капитального строительства и создание на их основе единого геопространства, необходимого для решения разнообразных научно-технических задач, соответствующего территориального образования.

Ключевые слова: 3D-кадастр, объекты недвижимости, алгоритм, матрица, межевая сеть сгущения, параметры, координаты, пространственная система координат, средняя квадратическая ошибка, нормативная точность

\section{Введение}

Одним из основных направлений создания 3D-кадастра в Российской Федерации является разработка его геодезического обеспечения, основная задача которого заключается в определении пространственного положения объектов недвижимости $(\mathrm{OH})$ в территори- альном образовании с заданной нормативной точностью.

Ведущими российскими учеными в области создания единого геопространства территориального образования и построения пространственных геодезических сетей для его обеспечения выполнены фундаментальные научные исследования [1-11]. Однако применительно 
к геодезическому обеспечению кадастровых работ, особенно, выполняемых при создании 3D-кадастра, ряд научно-технических вопросов не получил окончательного решения.

Одним из основных, на наш взгляд, не реализованных в настоящее время научных направлений, является проектирование межевой сети сгущения (МСC), которая должна позволять с заданной нормативной точностью определять пространственное положение совокупности объектов недвижимости в кадастровом квартале соответствующего территориального образования. Исходя из этого концептуального положения, актуальной научно-технической задачей является разработка математического алгоритма и его компьютерной реализации для предвычисления необходимой точности измерений при проектировании, а затем и построении в кадастровом квартале пространственной МСС, относительно пунктов которой в дальнейшем будут координироваться характерные точки, определяющие в пространственной системе координат местоположение объектов недвижимости (объектов капитального строительства (ОКС) и земельных участков).

Математический алгоритм должен обеспечивать решение данной научно-технической задачи применительно к пространственным геодезическим построениям произвольной конфигурации и структуры. Кроме этого, он должен соответствовать вычислительной схеме, которая в дальнейшем будет реализовываться при математической обработке результатов натурных геодезических измерений и вычислении уравненных координат определяемых пунктов МСС в пространственной системе координат.

\section{Решение поставленной научно-технической задачи}

В соответствии с работой $[12,13]$ средняя квадратическая ошибка (СКО) взаимного положения характерных точек, определяющих в пространственной системе координат местоположение объектов капитального строительства (ОКС), должна быть не грубее значения

$$
m_{\mathrm{OKC}}=\sqrt{m_{x, y}^{2}+m_{H}^{2}}=\sqrt{5_{\mathrm{cM}}^{2}+5_{\mathrm{cM}}^{2}}=7,1 \mathrm{~cm} .
$$

Установление такого допуска обеспечит, в случае необходимости, заданную нормативную точность восстановления утраченных характерных точек (XT), закрепляющих на местности границы земельного участка, на котором располагается ОКС.

Задаваясь таким допуском, нормативная точность определения параметров МСC в пределах заданного кадастрового квартала в пространственной системе координат будет определяться по формуле

$$
m_{(X, Y, Z)_{\mathrm{HOPM}}}=\frac{m_{\mathrm{OKC}}}{t}=\frac{\sqrt{m_{X, Y}^{2}+m_{Z}^{2}}}{t}=\frac{\sqrt{5_{\mathrm{cM}}^{2}+5_{\mathrm{cM}}^{2}}}{2}=3,6 \mathrm{cM},
$$

где $m_{X, Y}-\mathrm{CКО} \mathrm{взаимного} \mathrm{положения} \mathrm{пунктов}$ в плане; $m_{Z}-$ СКО взаимного положения пунктов по высоте; $t$ - коэффициент пренебрегаемого влияния ошибок исходных данных (который при доверительной вероятности $\beta=0,95$ рекомендуется принять $t=2$ ).

Точность параметров пространственного геодезического построения произвольной конструкции определяется при наличии корреляционной матрицы

$$
K_{X, Y, Z}=\mu^{2} \cdot\left(\mathrm{A}^{\mathrm{T}} \cdot \mathrm{P} \cdot \mathrm{A}\right)^{-1},
$$

где $\mu$ - СКО единицы веса, которая на этапе оценки точности проекта, как правило, прини- мается равной СКО измеренного горизонтального угла проектируемого измерительного технологического оборудования $[14,15]$

$$
\mu=m_{\beta} \text {. }
$$

На этапе уравнивания результатов геодезических измерений она вычисляется по формуле

$$
\mu_{Y P A B}=\sqrt{\frac{\sum_{1}^{n} \mathrm{P} \cdot V \cdot \mathrm{V}}{r}},
$$

где $\mathrm{P}$ - веса выполненных измерений, вычисляемые по стандартным правилам метода 
наименьших квадратов; V - поправки в измерения, получаемые в результате уравнивания пространственной геодезической сети; r число избыточных измерений в геодезическом построении.

Совпадение результатов уравнивания (5) и априорно установленной точности проектируемого измерительного средства (4) оп- ределяет достоверность выполненной оценки точности проекта геодезического построения.

Результатом уравнивания геодезических измерений в пространственном построении является вектор поправок к приближенным координатам определяемых пунктов $\Delta \mathrm{X}_{\mathrm{X}, \mathrm{Y}, \mathrm{Z}}$, вычисляемый по формуле

$$
\Delta \mathrm{X}_{X, Y, Z}=-\left(\mathrm{A}^{\mathrm{T}} \cdot \mathrm{P} \cdot \mathrm{A}\right)^{-1} \cdot \mathrm{A}^{\mathrm{T}} \cdot \mathrm{P} \cdot L
$$

где $\mathrm{L}$ - вектор свободных членов уравнений поправок в измерения, выполненные в пространственном геодезическом построении и вычисляемые как разность между значением, вычисленным по приближенным координатам определяемых пунктов, и результатом измерений.

В исходных выражениях (3) и (6) элементы матрицы коэффициентов параметрических уравнений поправок А, которые относятся к горизонтальным углам и длинам линий, вычисляются в соответствии с уравнениями

$$
\begin{gathered}
V_{\beta_{\mathrm{K}^{\prime}}}=\left(a_{k j}-a_{k i}\right) \Delta \mathrm{X}_{\mathrm{K}}+\left(b_{k j}-b_{k i}\right) \Delta Y_{\mathrm{K}}+a_{j k} \cdot \Delta \mathrm{X}_{J}+b_{j k} \cdot \Delta Y_{J}-a_{i k} \cdot \Delta \mathrm{X}_{i}-b_{i k} \cdot \Delta Y_{i}+l_{\beta} ; \\
V_{L_{i j}}=-\cos \alpha_{i j} \cdot \Delta \mathrm{X}_{i}-\sin \alpha_{i j} \cdot \Delta Y_{i}+\cos \alpha_{i j} \cdot \Delta \mathrm{X}_{J}+\sin \alpha_{i j} \cdot \Delta Y_{J}+l_{L},
\end{gathered}
$$

где $V_{\beta}, V_{L}-$ поправки в измеренные значения горизонтальных углов и длин линий, полученные в результате уравнивания; $l_{\beta}, l_{L}$-сводные члены уравнений поправок, являющиеся компонентами вектора $\mathrm{L} ; k, i, j$ - индексы параметрического уравнения, соответствующие номерам пунктов, образующих запроектированные измерения; $\Delta X_{i}, \Delta Y_{i}, \Delta X_{J}, \Delta Y_{J}, \Delta X_{K}, \Delta Y_{K}$ - поправки к приближенным значениям координат определяемых пунктов; $a_{J K}, b_{J K}-$ коэффициенты уравнения поправок, вычисляемые по формулам

$$
a_{j k}=\rho \frac{\sin \alpha_{j k}}{L_{j k}} ; \quad b_{j k}=-\rho \frac{\cos \alpha_{j k}}{L_{j k}},
$$

где $\alpha_{K J}, L_{K J}$ - соответственно дирекционный угол и длина линии между пунктами $K$ и $J$.

Отметим, что на этапе априорной оценки точности проекта пространственной МСС свободные члены в уравнениях (7) отсутствуют и параметрические уравнения поправок превращаются в параметрические уравнения.

Для математической обработки результатов измерений в пространственной сети необходимо получить параметрическое уравнение поправок для вертикального угла $v$, который схематически показан на рис. 1.

Представим вертикальный угол $v$ как функцию пространственных координат двух пунктов межевой сети сгущения О и А:

$$
v=f\left(\mathrm{X}_{O}, Y_{O}, Z_{O}, \mathrm{X}_{A}, Y_{A}, Z_{A}\right)=\operatorname{arctg} \frac{Z_{A}-Z_{O}}{\sqrt{\left(X_{A}-X_{O}\right)^{2}+\left(Y_{A}-Y_{O}\right)^{2}}} .
$$




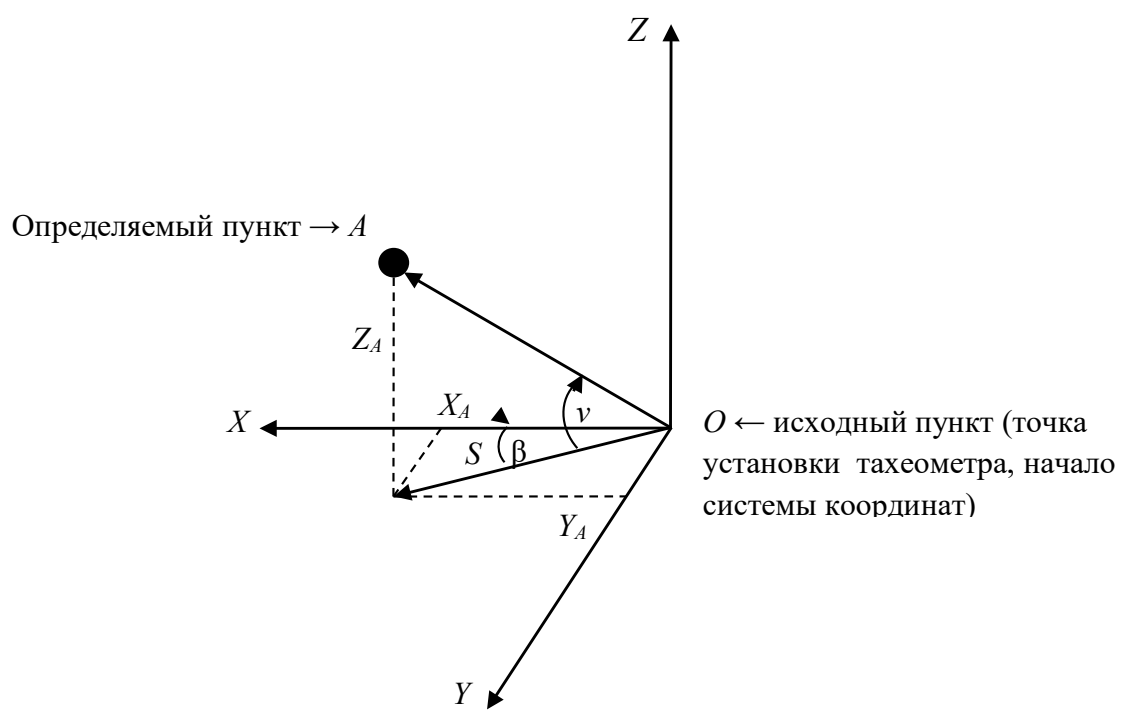

Рис. 1. Представление вертикального угла

как функции пространственных координат двух пунктов МСС

Если начало системы координат перенести в пункт О, то уравнение (9) преобразуется к более простому виду

$$
v=f\left(\mathrm{X}_{A}, Y_{A}, Z_{A}\right)=\operatorname{arctg} \frac{Z_{A}}{\sqrt{X_{A}^{2}+Y_{A}^{2}}} .
$$

В общем виде параметрическое уравнение поправок для вертикального угла будет выглядеть как

$$
V_{v}=\left(\frac{d f}{d \mathrm{X}_{\mathrm{A}}}\right) \Delta \mathrm{X}_{A}+\left(\frac{d f}{d Y_{\mathrm{A}}}\right) \Delta Y_{A}+\left(\frac{d f}{d Z_{\mathrm{A}}}\right) \Delta Z_{A}+l_{v},
$$

где значения частных производных по соответствующим параметрам (коэффициенты параметрического уравнения поправок) могут быть вычислены по формулам

$$
\begin{gathered}
\frac{d f}{d \mathrm{X}_{\mathrm{A}}}=-\frac{\mathrm{X}_{\mathrm{A}} \cdot Z_{\mathrm{A}}}{\left(X_{A}^{2}+Y_{A}^{2}+Z_{A}^{2}\right) \cdot \sqrt{X_{A}^{2}+Y_{A}^{2}}} \\
\frac{d f}{d Y_{\mathrm{A}}}=-\frac{Y_{\mathrm{A}} \cdot Z_{\mathrm{A}}}{\left(X_{A}^{2}+Y_{A}^{2}+Z_{A}^{2}\right) \cdot \sqrt{X_{A}^{2}+Y_{A}^{2}}} \\
\quad \frac{d f}{d Z_{\mathrm{A}}}=\frac{\sqrt{X_{A}^{2}+Y_{A}^{2}}}{\left(X_{A}^{2}+Y_{A}^{2}+Z_{A}^{2}\right)} .
\end{gathered}
$$

В пространственной МСС результаты измерений могут быть представлены вектором, который состоит из трех подвекторов:

$$
y=\left\{y_{\beta}, y_{\gamma}, y_{L}\right\}^{T}=\left\{\beta_{1}, \beta_{2} \ldots \beta_{n} ; \gamma_{1}, \gamma_{2} \ldots \gamma_{n} ; L_{1}, L_{2} \ldots L_{n}\right\}^{T} \text {, }
$$


где $n$ - число пунктов МСС, на которых выполнены традиционные наземные геодезические измерения.

Веса компонентов вектора измерений $y$, являющиеся диагональными элементами матрицы $P$ в уравнениях (3) и (6), с учетом условия (4) предлагается вычислять по формулам

$$
\mathrm{P}_{\beta}=\frac{\mu^{2}}{m_{\beta}^{2}}=\frac{m_{\beta}^{2}}{m_{\beta}^{2}}=1 ; \quad \mathrm{P}_{v}=\frac{\mu^{2}}{m_{v}^{2}}=\frac{m_{\beta}^{2}}{m_{v}^{2}}=K ; \quad \mathrm{P}_{L}=\frac{\mu^{2}}{m_{L}^{2}}=\frac{m_{\beta}^{2}}{m_{L}^{2}}=K_{1} .
$$

где $K, K_{1}$ - коэффициенты, которые предлагается устанавливать на этапе оценки точности проекта в зависимости от выбираемого измерительного технологического средства; $m_{\beta}, m_{L}$, $m_{v}$ - точность измерения элементов пространственной геодезической сети электронным тахеометром.

Результатом уравнивания является вектор пространственных координат определяемых пунктов МСС (параметров) размерностью $1 \times 3 \mathrm{t}$

$$
\mathrm{X}_{(X, Y, Z)}=\left\{X_{1}, Y_{1}, Z_{1}, \ldots \ldots \ldots \ldots \ldots X_{t}, Y_{t}, Z_{t}\right\}^{T}
$$

с корреляционной матрицей вида

$$
K_{(X, Y, Z)}=m_{\beta}^{2}\left\{\begin{array}{cccccccc}
Q_{X_{1}} & Q_{X_{1} Y_{1}} & Q_{X_{1} Z_{1}} & \cdot & Q_{X_{1} X_{t}} & Q_{X_{1} Y_{t}} & Q_{X_{1} Z_{t}} \\
& Q_{Y_{1}} & Q_{Y_{1} Z_{1}} & \cdot & Q_{Y_{1} X_{t}} & Q_{Y_{1} Y_{t}} & Q_{Y_{1} Z_{t}} \\
& & Q_{Z_{1}} & \cdot & Q_{Z_{1} X_{t}} & Q_{Z_{1} Y_{t}} & Q_{Z_{1} Z_{t}} \\
& & \cdot & \cdot & \cdot & \cdot & \cdot \\
& & & & Q_{X_{t}} & Q_{X_{t} Y_{t}} & Q_{X_{t} Z_{t}} \\
& & & & & & Q_{Y_{t}} & Q_{Y_{t} Z_{t}} \\
& & & & & & & Q_{Z_{t}}
\end{array}\right\} .
$$

Максимальная сумма диагональных элементов определит наиболее слабый пункт пространственной сети, относительно которого необходимо оценить соответствие полученных уравненных координат целям и задачам кадастровых работ, выполняемых для ведения 3Dкадастра:

$$
m_{i}=m_{\beta} \cdot \sqrt{\left(Q_{X_{i}}+Q_{Y_{i}}+Q_{Z_{i}}\right)} \text { MAX }, \quad m_{i} \leq m_{(X, Y, Z)_{\mathrm{HOPM}}},
$$

где $i$ - индекс, который обозначает номер наиболее слабого пункта, относительно которого оценивается точность пространственной сети.

Если на точность параметров геодезической сети устанавливаются раздельные допуски на плановую и высотную составляющую, как это часто имеет место на производстве, уравнение (17) преобразуется к виду

$$
\begin{aligned}
& m_{(X, Y) i}=m_{\beta} \cdot \sqrt{\left(Q_{X_{i}}+Q_{Y_{i}}\right)_{\mathrm{MAX}}} ; m_{(X, Y) i} \leq m_{(X, Y) \mathrm{HOPM}} \\
& m_{(Z) i}=m_{\beta} \cdot \sqrt{Q_{Z_{i}}} ; \quad m_{(Z) i} \leq m_{(Z) \mathrm{HOPM}} .
\end{aligned}
$$


Отметим, что уравнения (17) и (18) позволяют оценить точность параметров МСС относительно ближайшего исходного пункта первой ступени ОМС. Для нашего варианта построения МСС нормативный допуск устанавливается на точность взаимного положения пунктов внутри кадастрового квартала. В этом случае, для оценки точности корреляционную матрицу (16) необходимо представить в виде

$$
K_{F}=F \cdot K_{(X, Y, Z)} \cdot F^{T},
$$

где $F$ - матрица частных производных оцениваемых функций (взаимного положения определяемых пунктов в пространственной сети) по параметрам [14].

С использованием выражений (18) на основании следа матрицы $K_{F}$ возможно определить пункты МСС, которые характеризуются максимальной СКО и относительно которых оценивается соответствие МСС целям кадастровых работ

$$
K_{F}=\left\{\begin{array}{ccc}
m_{X i X j}^{2} & K_{X i Y j} & K_{X i Z j} \\
& m_{Y i Y j}^{2} & K_{Y i Z j} \\
& & m_{Z i Z j}^{2}
\end{array}\right\}_{\text {MAX }},
$$

где $i, j$ - индексы, определяющие названия пунктов МСС, которые характеризуются максимальным значением СКО взаимного положения; $K_{X i Y j}$ - корреляционный момент, определяющий тесноту корреляционных связей между соответствующими элементами матрицы.

Следовательно, критерий на соответствие построенной в кадастровом квартале МСС целям кадастровых работ будет выглядеть следующим образом:

$$
\begin{gathered}
m_{(X, Y) i-j}=\sqrt{m_{X i X j}^{2}+m_{Y i Y j}^{2}-2 \cdot K_{X i Y j}} ; \quad m_{(X, Y) i-j} \leq m_{(X, Y)_{\mathrm{HOPM}}} \\
m_{(Z) i-j}=m_{Z i Z j}^{2} ; \quad m_{(Z) i-j} \leq m_{(Z)_{\mathrm{HOPM}}} .
\end{gathered}
$$

Получение неудовлетворительных результатов, разумеется, при отсутствии грубых ошибок в геодезических измерениях, обусловливается использованием измерительного технологического оборудования, не соответствующим по точности целям выполнения кадастровых работ.

Исключение такого негативного аспекта при построении МСС возможно на стадии проектирования, когда определена конфигурация геодезической сети и, следовательно, может быть вычислена матрица $A$ в исходном выражении (3), а также установлен нормативный допуск СКО взаимного положения наиболее слабых пунктов (критерий 2). Исходя из этого концептуального положения в уравнении (3) неизвестной является матрица $P$, которую предлагается априорно устанавливать, используя поставленное условие (14). Следовательно, решая уравнение (3), получаем соответствующие весовые коэффициенты, которые позволяют вычислить СКО единицы веса и, следовательно, необходимую точность проектируемого измерительного технологического оборудования:

$$
\begin{gathered}
m_{(X, Y, Z) \mathrm{HOPM}}=\mu \cdot \sqrt{\left(Q_{X_{i}}+Q_{Y_{i}}+Q_{Z_{i}}\right)_{\mathrm{MAX}}} ; \mu=\frac{m_{(X, Y, Z) \mathrm{HOPM}}}{\sqrt{\left(Q_{X_{i}}+Q_{Y_{i}}+Q_{Z_{i}}\right)_{\mathrm{MAX}}}} ; \\
m_{\beta}=\mu, \quad m_{L}=\frac{\mu}{\sqrt{K_{1}}} ; \quad m_{v}=\frac{\mu}{\sqrt{K}} .
\end{gathered}
$$


При установлении нормативного допуска на СКО взаимного положения пунктов имеем следующее выражение:

$$
\begin{gathered}
m_{(X, Y, Z)_{i-j} \mathrm{HOPM}}=\mu \cdot \sqrt{\left(Q_{X_{i-j}}+Q_{Y_{i-j}}+Q_{Z_{i-j}}-2\left(Q_{X_{i} X_{j}}+Q_{Y_{i} Y_{j}}+Q_{Z_{i} Z_{j}}\right)\right)_{\mathrm{MAX}}} ; \\
\mu=\frac{m_{(X, Y, Z) \mathrm{HOPM}}}{\sqrt{\left(Q_{X_{i-j}}+Q_{Y_{i-j}}+Q_{Z_{i-j}}-2\left(Q_{X_{i} X_{j}}+Q_{Y_{i} Y_{j}}+Q_{Z_{i} Z_{j}}\right)\right)_{\mathrm{MAX}}}} \\
m_{\beta}=\mu ; m_{L}=\frac{\mu}{\sqrt{K_{1}}} ; m_{v}=\frac{\mu}{\sqrt{K}} .
\end{gathered}
$$

Таким образом, уравнения (22) и (23) позволяют, исходя из заданной нормативной СКО параметров, вычислить необходимую точность измерения элементов МСС и выбрать соответствующее измерительное технологическое оборудование.

Если в предлагаемом алгоритме проектирования и уравнивания использовать рекуррентную формулу вычисления матрицы весовых коэффициентов, то возможно под имеющееся в наличии измерительное технологическое оборудование подобрать методом итерации наилучшую конструкцию МСС, соответствующую установленному нормативному допуску.

Достоинством предложенного математического алгоритма является выполнение следующих концептуальных положений:

1) предвычисление необходимой точности измерений и математическая обработка выполненных на местности геодезических измерений осуществляется по единому математическому алгоритму, что обеспечивает достоверность полученных результатов при оценке точности проекта МCC;

2) при вычислении весов геодезических измерений (уравнение (14)) предусмотрена возможность определения оптимального соотношения между ними, что обусловливает выбор измерительного технологического оборудования при фиксированной конструкции МСС, исходя из установленной нормативной точности параметров геодезического построения;

3) использование при определении матрицы (3) рекуррентной формулы позволит при выбранном измерительном технологическом оборудовании подобрать оптимальное количество избыточных измерений в МСC, что обеспечит минимальную трудоемкость при построении геодезической сети.

\section{Заключение}

Реализация предложенного алгоритма позволит, на наш взгляд, решить следующие научно-технические задачи:

1) на этапе проектирования пространственного геодезического построения выбирать технологическое измерительное оборудование, позволяющее создавать в кадастровом квартале МСС, которая обеспечит заданную нормативно точность определения пространственных параметров объектов недвижимости, расположенных в пределах кадастрового квартала соответствующего территориального образования;

2) относительно построенной в кадастровом квартале МСС и закоординированных характерных точек контуров ОКС с нормативной точностью восстанавливать утраченные границы земельных участков в пространственной системе координат;

3) на основе уравненных координат пунктов МСС и характерных точек контуров ОКС создавать в территориальном образовании единое геопространство, позволяющее в пространственной системе координат решать не только научно-технические задачи, связанные с выполнением кадастровых работ, но и обеспечивать градостроительную деятельность. 


\section{БИБЛИОГРАФИЧЕСКИЙ СПИСОК}

1. Бойко Е. Г., Аджадж Абдул Разак. Уравнения поправок в наземных пространственных геодезических сетях // Изв. вузов. Геодезия и аэрофотосъемка. - 1991. - № 6. - С. 11-17.

2. Карпик А. П. Методологические и технологические основы геоинформационного обеспечения территорий : монография. - Новосибирск : СГГА, 2004. - 260 с.

3. Карпик А. П., Лисицкий Д. В. Электронное геопространство - сущность и концептуальные основы // Геодезия и картография. - 2009. - № 5. - С. 41-44.

4. Карпик А. П., Хорошилов В. С. Сущность геоинформационного пространства территорий как единой основы развития государственного кадастра недвижимости // Изв. вузов. Геодезия и аэрофотосъемка. - 2012. - № 1. - С. 134-136.

5. Карпик А. П. Системная связь устойчивого развития территорий с его геодезическим информационным обеспечением // Вестник СГГА. - 2010. - Вып. 1 (12). - С. 3-11.

6. Маркузе Ю. И. Алгоритм для уравнивания геодезических сетей на ЭВМ. - М. : Недра, 1989. - 248 с.

7. Маркузе Ю. И., Ха Минь Хоа. Рекуррентное уравнивание геодезических сетей с применением метода квадратных корней // Изв. вузов. Геодезия и аэрофотосъемка. - 1991. - № 6. - С. 3-11.

8. Обиденко В. И. Разработка и исследование методики определения формы и размеров территорий по геопространственным данным: дисс. ... канд. техн. наук. - Новосибирск : СГГА, 2012. - 200 с.

9. Абу Дака Имад. Математическая обработка и анализ точности наземных пространственных геодезических сетей методами нелинейного программирования и линейной алгебры: дисс. ... канд. техн. наук. - Новополоцк, 1998. - 150 с.

10. Нейман Ю. М. К вопросу о математической обработке разнородных измерений // Изв. вузов. Геодезия и аэрофотосъемка. - 2008. - № 2. - С. 7-22.

11. Создание модели трехмерного кадастра недвижимости в России. $\mathrm{G} 2 \mathrm{G} 10 / \mathrm{RF} / 9 / 1$. Заключительный отчет [Электронный pесурс]. - Режим доступа : https://portal.rosreestr.ru/wps/portal/cc_news?news_id=16202\&news_line_id=11662.

12. Аврунев Е. И., Гиниятов А. И. Концептуальный подход к геодезическому обеспечению 3D- кадастра // Вестник СГУГиТ. - 2020. - Т. 25, № 4. - С. 152-158.

13. Метелева М. В. Разработка и исследование методики координатного обеспечения кадастровой деятельности в территориальных образованиях : дисс. ... канд. техн. наук. - Новосибирск : СГУГиТ.2015. $-150 \mathrm{c}$.

14. Аврунев Е. И. Геодезическое обеспечение государственного кадастра недвижимости : монография. - Новосибирск : СГГА, 2010. - 144 с.

15. Шануров Г. А., Лашков Н. П., Шакмеев Р. Р. Об оценке точности геодезической сети, созданной сочетанием космических и наземных методов измерений // Изв. вузов. Геодезия и аэрофотосъемка. 2002. - № 4.- C. 12-21.

Получено 19.08.2021

(C) Е. И. Аврунев, А. И. Гиниятов, А. И. Каленицкий, 2021

\section{DESIGN AND EQUALIZATION OF SPATIAL GEODETIC CONSTRUCTIONS INTENDED FOR CREATING A THREE-DIMENSIONAL CADASTRE}

\section{Evgeny I. Avrunev}

Siberian State University of Geosystems and Technologies, 10, Plakhotnogo St., Novosibirsk, 630108, Russia, Ph. D., Director, Institute of Cadastre and Environmental Management, phone: (383)344-31-73, e-mail: kadastr204@yandex.ru

\section{Artur I. Giniyatov}

Siberian State University of Geosystems and Technologies, 10, Plakhotnogo St., Novosibirsk, 630108, Russia, Ph. D. Student, Department of Cadastre and Territorial Planning, phone: (383)344-31-73, e-mail: ita1095@mail.ru

\section{Anatoly I. Kalenitsky}

Siberian State University of Geosystems and Technologies, 10, Plakhotnogo St., Novosibirsk, 630108, Russia, D. Sc., Professor, Department of Space Physical Geodesy, phone: (913)767-73-49, e-mail: kadastr204@yandex.ru 
The article proposes a mathematical algorithm based on the least squares method for calculating the necessary measurement accuracy in a spatial geodetic construction intended for performing cadastral works when conducting a 3D cadastre in a territorial entity. The proposed algorithm allows, based on the specified accuracy of the relative position of real estate objects in the cadastral quarter, to select the necessary technological measuring equipment for building a spatial boundary density network $(\mathrm{BDN})$ on the ground for geodetic support of cadastral works. The use of the developed algorithm for equalizing the results of geodetic measurements will ensure the reliability of the calculated parameters of capital construction objects and the creation on their basis of a single geospatial space necessary for solving various scientific and technical problems, the corresponding territorial entity.

Keywords: 3D cadastre, real estate objects, algorithm, matrix, boundary density network, parameters, coordinates, spatial coordinate system, mean square error, specified accuracy

\section{REFERENCES}

1. Boyko E. G., \& Ajaj Abdul Razak. (1991). Correction equations in terrestrial spatial geodetic networks. Izvestiya vuzov. Geodeziya i aerofotos"emka [Izvestiya vuzov. Geodesy and Aerophotosurveying], 6, 11-17 [in Russian].

2. Karpik, A. P. (2004). Metodologicheskie i tekhnologicheskie osnovy geoinformatsionnogo obespecheniya territoriy [Methodological and technological foundations of GIS software territories]. Novosibirsk: SSGA Publ., 260 p. [in Russian].

3. Karpik, A. P., \& Lisitsky D. V. (2009). Electronic geospatial-the essence and conceptual foundations. Geodeziya i kartografiya [Geodesy and Cartography], 5, 41-44 [in Russian].

4. Karpik, A. P., \& Khoroshilov, V. S. (2012). Essence of the geographic information space of territories as a single basis for the development of the state real estate cadastre. Izvestiya vuzov. Geodeziya i aerofotos"emka [Izvestiya vuzov. Geodesy and Aerophotosurveying], 1, 134-136 [in Russian].

5. Karpik, A. P. (2010). System connection sustainable development of the territories with his geodesic information security. Vestnik SGGA [Vestnik SSGA], 1(12), 3-11 [in Russian].

6. Markuse, Yu. I. (1989). Algoritm dlya uravnivaniya geodezicheskikh setey na EVM [Algorithm for equalizing geodetic networks on a computer]. Moscow: Nedra Publ., 248 p. [in Russian].

7. Markuze, Yu. I., \& Ha Min Hoa. (1991). Recurrent equalization of geodetic networks using the square roots method. Izvestiya vuzov. Geodeziya i aerofotos"emka [Izvestiya vuzov. Geodesy and Aerophotosurveying], 6, 3-11 [in Russian].

8. Obidenko, V. I. (2012). Development and research of methods for the determination of the shape and size of territories geospatial data. Candidate's thesis. Novosibirsk: SSGA Publ., 200 p. [in Russian].

9. Abu Daka Imad. (1998). Mathematical processing and analysis of the accuracy of ground-based spatial geodesic networks by methods of nonlinear programming and linear algebra. Candidate's thesis. Novopolotsk, 150 p. [in Russian].

10. Neiman Yu. M. (2008). On the question of mathematical processing of heterogeneous measurements. Izvestiya vuzov. Geodeziya i aerofotos"emka [Izvestiya vuzov. Geodesy and Aerophotosurveying], 2, 7-22 [in Russian].

11. Creating a model of a three-dimensional real estate cadastre in Russia. G2G10/RF/9/1. Final report. (n. d.). Retrieved from https://portal.rosreestr.ru/wps/portal/cc_news?news_id=16202\&news_line_id=11662.

12. Avrunev, E. I., \& Giniyatov, A. I. (2020). Conceptual approach to geodesic support for creating a threedimensional cadastre. Vestnik SGUGiT [Vestnik SSUGT], 25(4), 152-158 [in Russian].

13. Meteleva, M. V. (2015). Development and research of methods of coordinate support of cadastral activity in territorial formations. Candidate's thesis. Novosibirsk: SSUGT Publ., 150 p. [in Russian].

14. Avrunev, E. I. (2010). Geodezicheskoe obespechenie Gosudarstvennogo kadastra nedvizhimosti [Geodesic support of the state real estate cadastre]. Novosibirsk: SSGA Publ., 144 p. [in Russian].

15. Shanurov, G. A., Lashkov, N. P., \& Shakmeev, R. R. (2002). On the assessment of the accuracy of the geodetic network created by a combination of space and ground-based measurement methods. Izvestiya vuzov. Geodeziya i aerofotos"emka [Izvestiya vuzov. Geodesy and Aerophotosurveying], 4, 12-21 [in Russian].

Received 19.08.2021

(C) E. I. Avrunev, A. I. Giniyatov, A. I. Kalenitsky, 2021 
УДК 504.1:502.1

DOI: $10.33764 / 2411-1759-2021-26-5-135-144$

\section{ПРЕДЛОЖЕНИЯ ПО ОХРАНЕ ЗЕМЕЛЬ ОТ НЕГАТИВНОГО ВОЗДЕЙСТВИЯ ТЕХНОГЕННЫХ МИНЕРАЛЬНЫХ ОБРАЗОВАНИЙ}

\section{Ирина Анатольевна Басова}

Тульский государственный университет, 300012, Россия, г. Тула, пр. Ленина, 92, доктор технических наук, зав. кафедрой геоинженерии и кадастра, тел. (4872)73-44-38, e-mail: biajis20051@yandex.ru

\section{Дмитрий Олегович Прохоров}

Тульский государственный университет, 300012, Россия, г. Тула, пр. Ленина, 92, кандидат технических наук, доцент кафедры геоинженерии и кадастра, тел. (4872)25-47-25, e-mail: 9202779115@mail.ru

\section{Сергей Васильевич Пьянков}

Пермский государственный национальный исследовательский университет, 614068, г. Пермь, ул. Букирева, 15, доктор географических наук, профессор, проректор по научной работе и инновациям, тел. (342)2-396-852, pyankovsv@gmail.com

Рассматриваются процессы, влияющие на кадастровую стоимость земельных участков, в результате действия которых происходит загрязнение земель, расположенных вокруг техногенных минеральных образований. Масштаб проблемы показан на примере Тульской области, в которой наследием от разработки Подмосковного угольного бассейна остались на поверхности большие объемы пустых пород в виде терриконов. Дается оценка способам уменьшения этого загрязнения, снижения экологических рисков, ликвидации накопленного вреда с точки зрения их экологической эффективности и экономической целесообразности, позволяющим в дальнейшем увеличить кадастровую стоимость земельных участков, находившихся в зоне влияния техногенных минеральных образований. Предлагается способ консервации и изоляции техногенных минеральных образований, обеспечивающий более эффективное снижение негативного влияния на окружающие земли, в том числе земли населенных пунктов и земли сельскохозяйственного назначения.

Ключевые слова: кадастровая стоимость, загрязнение земель, охрана земель, техногенное минеральное образование, рекультивация, ликвидация, консервация, земельный участок

\section{Введение}

Вопросам учета экологического состояния территории при кадастровой оценке земельных участков в настоящее время уделяется большое внимание. Работы [1-4] показывают важность использования экологической составляющей при определении кадастровой стоимости объектов недвижимости.

Одним из негативных экологических факторов, понижающих стоимость земельных участков, является загрязнение окружающей природной среды вредными веществами от различных негативных воздействий в результате хозяйственной деятельности человека [1]. Таким образом, только наличие на территории техногенного минерального образования (ТМО) должно быть отражено в кадастровой стоимости окружа- ющих его земельных участков, так как влияние ТМО вызывает деградацию земель, т. е. изменение функций почвы, количественное и качественное ухудшение ее свойств, постепенное снижение и утрату плодородия.

\section{Алгоритм решения проблемы}

Масштаб проблемы можно оценить на примере Тульской области. Промышленная добыча бурого угля в Подмосковном угольном бассейне началась в 1920-х гг. Максимальная добыча в бассейне была достигнута в шестидесятые годы - более 40 млн. т в год. Добыча в основном была сосредоточена в Тульской области. Помимо угля шахты выдавали на поверхности пустые породы в объеме порядка 10-20\% от добычи. 
На территории Тульской области располагалось более 130 действующих шахт, возле каждой из которых вырастали ТМО в виде терриконов. С 1929 г. на территории Подмосковного бассейна накопился большой объем техногенных отложений - примерно 160-180 млн м ${ }^{3}$, который занимает порядка 350-400 га земельных угодий, а с учетом ареалов загрязнений - 5-6 тыс. га [5-9]. В состав техногенных отложений входят обломки бурого угля (до 12 \%), минеральные образования - пирит, марказит, сидерит.

Техногенные минеральные образования Подмосковного угольного бассейна по площади, объему и времени воздействия на окружающую среду представляют собой серьезную проблему для окружающих земель [10].
В зоне влияния ТМО основными процессами, вызывающими загрязнение земель вредными веществами, являются [11]:

- ветровая эрозия пород ТМО;

- водная эрозия пород ТМО;

- деформация ТМО - осыпи и обвалы пород ТМО, создающие дополнительные поверхности для эрозионных процессов;

- фильтрация воды через тело ТМО в водоносные горизонты.

Для понимания остроты проблемы необходимо показать всю сложность происходящих процессов.

Различают водную эрозию, проявляющуюся в размывах и смывах пород, и ветровую эрозию или дефляцию, состоящую в выдувании пород ТМО. Смыв и выдувание пород (рис. 1) называют еще плоскостной, а размыв пород - линейной эрозией [12].

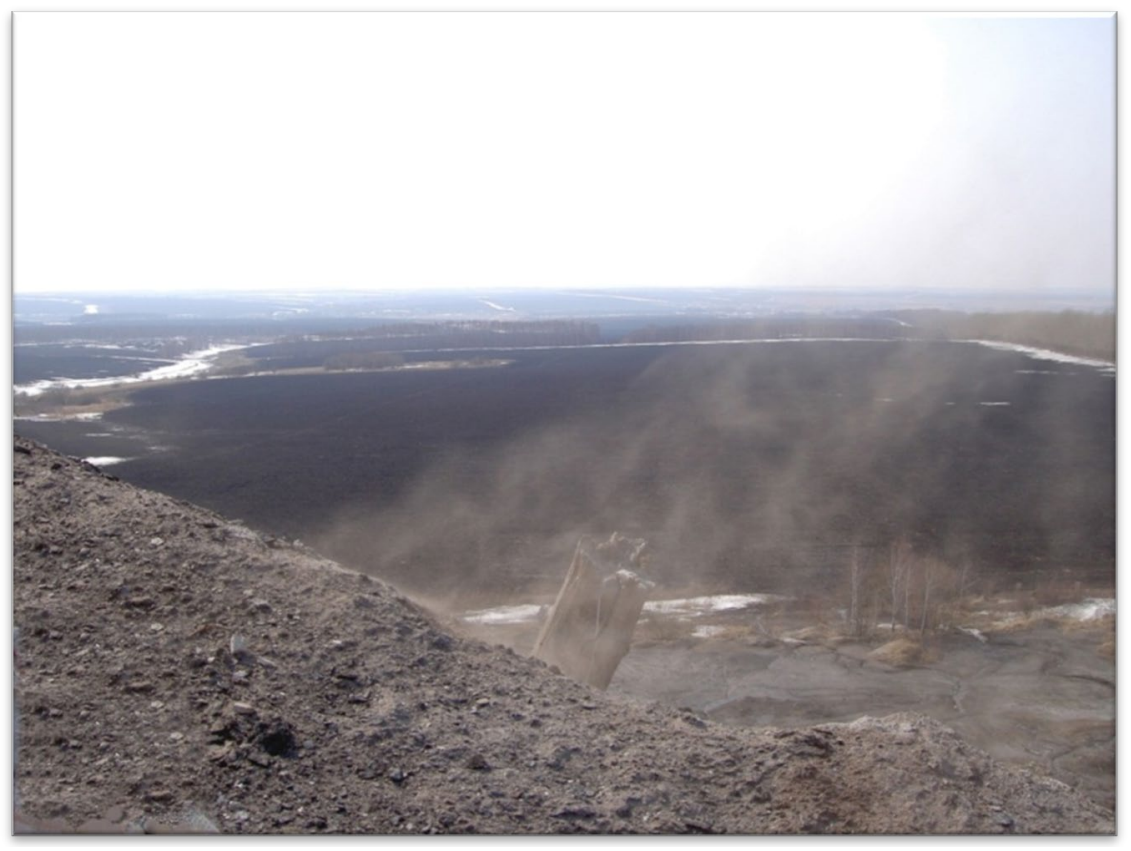

Рис. 1. Пыление породного отвала шахты № 16

Интенсивность выдувание пород ТМО зависит:

- от скорости ветра;

- параметров ТМО;

- устойчивости пород;

- наличия растительного покрова;

- особенностей рельефа.

Смыв и размыв пород ТМО происходит в результате дождевого (ливневого) и талого стока (рис. 2). При смыве затрагиваются поверхностные горизонты пород; размыв пород - более глубокий процесс, проявляющийся в виде формирования различного рода промоин и рытвин. Смыв и размыв пород при снеготаянии отличаются меньшими проявлениями, но большей длительностью, чем при дождевом стоке. Продолжительность процессов смыва и размыва пород ТМО при 
дождях гораздо меньше, чем при снеготаянии, и измеряется минутами и часами, а количество смываемых пород - больше. Поверхностный поток воды на склоне обладает определенной кинетической энергией, кото- рая пропорциональна массе воды и скорости ее стекания. Часть энергии расходуется на разрушение (размыв) пород, их отдельных комочков, а также на перенос разрушенного материала [13].

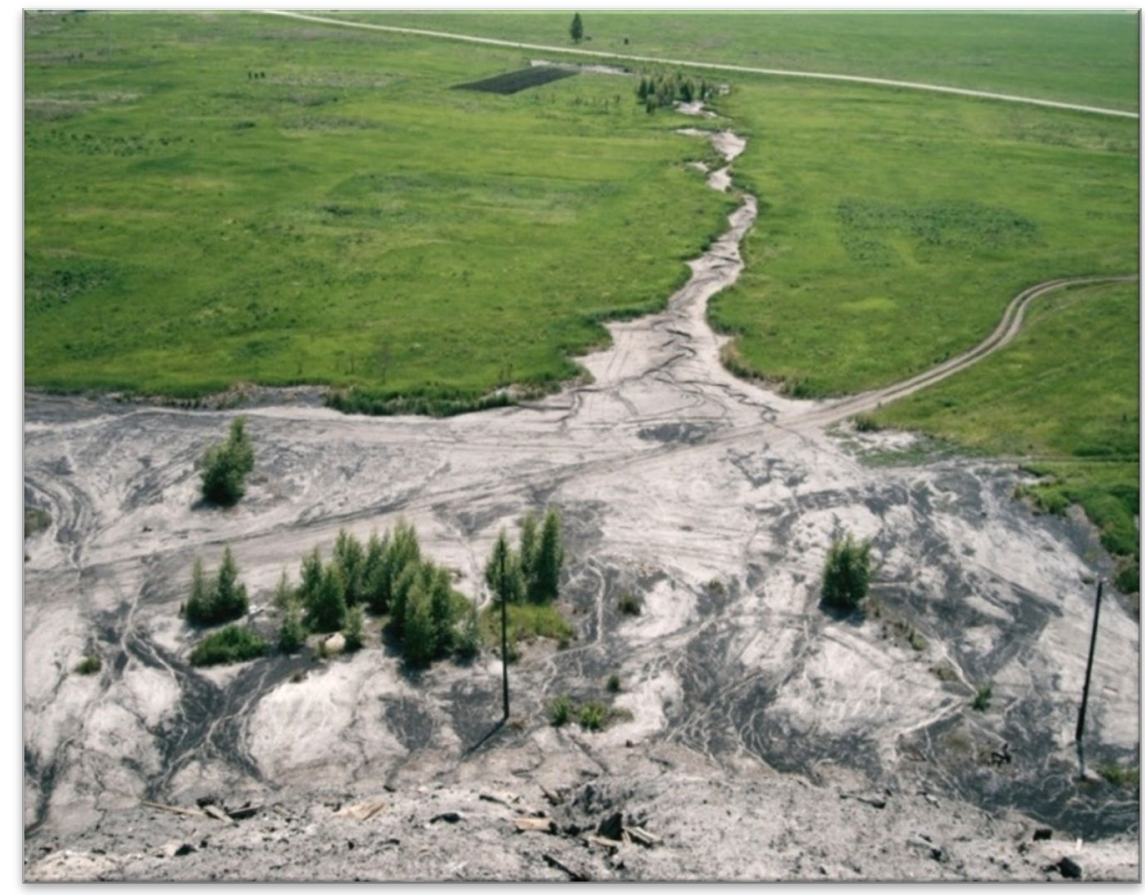

Рис. 2. Южный сток с породного отвала шахты № 67

Ветровая и водная эрозия могут проявляться совместно при различном чередовании процессов, например:

- после стока талых вод (в конце марта начале апреля) происходят смыв и размыв пород, далее (в конце мая - начале июня) следуют их иссушение и выдувание;

- после иссушения пород (май) происходят ливневые осадки (июнь, июль), и как результат - переувлажнение, смыв и размыв пород.

Деформации ТМО также появляются в комплексе с водной и ветровой эрозией под действием гравитации. По внешнему проявлению деформации ТМО можно разделить на следующие виды [14]:

- осыпи из отдельных частиц и кусков породы. Сползают по откосу к подошве ТМО, могут возникать, когда угол естественного откоса ТМО превышает угол внутреннего трения пород, слагающих ТМО;

- размывы, просадки и трещины (разломы) ТМО могут явиться следствием как не- устойчивости их оснований, так и горения ТМО отдельными ячейками;

- оползни - смещения (скольжения) массы пород, слагающих ТМО вниз по склону под влиянием силы тяжести. Оползни следует рассматривать как результат нарушения равновесия пород под воздействием выветривания или переувлажнения их атмосферными осадками или подземными водами, процесса горения пород ТМО, а также действия внешних сил (сейсмические толчки, увеличение нагрузки в верхней части склона и др.);

- обвалы - это отрывы и перемещения масс пород вниз по склону, их опрокидывание и дробление. Оползни происходят в результате ослабления связности пород и действия силы тяжести. Их возникновению способствует неправильное ведение работ при разборке ТМО, которое сводится к образованию крутых или вертикальных откосов.

Фильтрация воды через тело ТМО в водоносные горизонты вызывает вертикаль- 
ную миграцию фильтрата ТМО в почву его основания. Для ТМО характерно образование жидкой фазы, появлению которой предшествует вода, накапливающаяся в результате выпадения атмосферных осадков. Вода, просачиваясь сквозь породную массу, уносит с собой растворимые вещества, образуя фильтрат, который поступает в грунтовые воды [15].

Рассмотренные процессы оказывают воздействие на земли всех категорий в зоне влияния ТМО. Особенно важно учитывать влияние этих процессов при определении кадастровой стоимости земельных участков категорий - «земли населенных пунктов» и «сельскохозяйственные земли». Для земель населенных пунктов еще одним важным фактором, влияющим на кадастровую стоимость земельных участков, является эстетическая и рекреационная ценность территории [1].

Для охраны земель от негативного влияния ТМО необходимо осуществлять деятельность, направленную на уменьшение загрязнения территории, снижения экологических рисков, ликвидацию накопленного вреда [16].

Если задачи уменьшения загрязнения территории и снижения экологических рисков можно решить с помощью только рекультивационных мероприятий [17], то для ликвидации накопленного вреда во многих случаях необходимо производить либо консервацию, либо ликвидацию ТМО.

Рекультивация земель [18] - мероприятия по предотвращению деградации земель и (или) восстановлению их плодородия посредством приведения земель в состояние, пригодное для их использования в соответствии с целевым назначением и разрешенным использованием, в том числе путем устранения последствий загрязнения почв, восстановления плодородного слоя почвы, создания защитных лесных насаждений.

Рекультивацию нарушенных в результате воздействия ТМО земель характеризуют в основном направлением и технологией технического и биологического этапов (рис. 3).

Направление и технологию рекультивации выбирают исходя из типа нарушенных земель, вида нарушений, агрохимических характеристик грунтов-субстратов, пригодно- сти пород ТМО для биологической рекультивации. Затраты на рекультивацию земель, нарушенных в результате воздействия ТМО, тоже зависят от вышеперечисленных факторов. Затраты могут быть умеренными, а могут быть настолько значительными, что при высокой токсичности пород ТМО и санитарно-гигиеническом направлении рекультивации могут сравниться с затратами на ликвидацию ТМО.

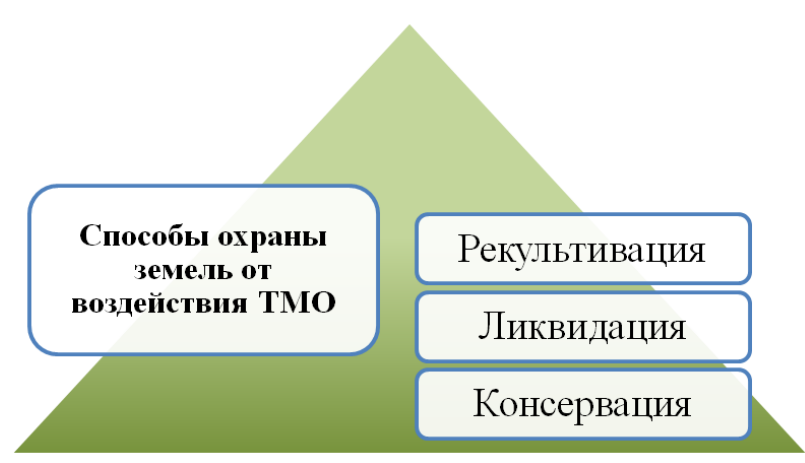

Рис. 3. Способы охраны земель от воздействия техногенных минеральных образований

Ликвидацию ТМО можно осуществить, если поблизости есть пространство для размещения пород ТМО, например, выработанный карьер. Также полная разборка возможна при вовлечении большей части пород ТМО в переработку для извлечения полезных компонентов и использовании пород в качестве сырья или материалов в других видах деятельности. Ликвидация ТМО - наиболее действенный, но самый дорогостоящий способ ликвидации накопленного вреда $[19,20]$.

Еще одним способом для достижения желаемых результатов по ликвидации накопленного вреда при оптимальных затратах является консервация ТМО (рис. 3). Консервация техногенного минерального образования позволяет в дальнейшем при более благоприятных обстоятельствах (например, появились средства или новые технологии для переработки и извлечения полезных компонентов из пород ТМО и т. д. [21-23]) перейти к его полной ликвидации. Кроме этого, при консервации, в отличие от рекультивации, запас сырья TMO будет сохранен за счет изоляции ТМО от 
взаимодействия с агрессивными природными факторами, которые могут повлечь не только количественные потери пород в результате ветровой и водной эрозии, но и качественные в результате изменения пород под воздействием негативных биохимических и физикохимических процессов, инициированных проникновением воды, кислорода и микроорга- низмов в тело ТМО. Существует различные способы консервации ТМО, которые достаточно эффективны в борьбе с ветровой и водной эрозией пород, но ни один из этих способов не может остановить вертикальную миграцию фильтрата уже сформированных ТМО в грунтовые воды, которые, в свою очередь, загрязняют окружающие земли.

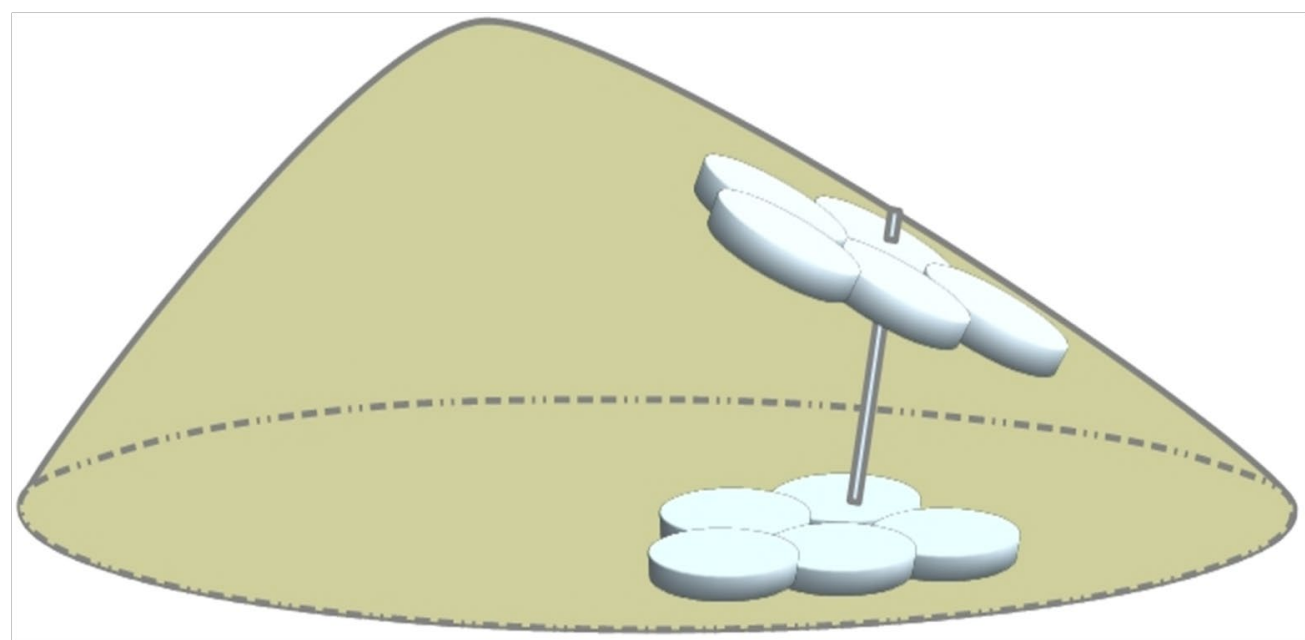

Рис. 4. Формирование изоляционных слоев породобетона в теле техногенного минерального образования

Предлагаемый нами способ консервации и изоляции позволяет в полном объеме защитить окружающие земли от вредного воздействия ТМО [24].

Основной целью способа консервации и изоляции является расширение технических возможностей для эффективного снижения влияния токсичных компонентов техногенных минеральных образований на окружающую среду.

Для достижения поставленной цели реализуются следующие процессы (рис. 5):

- на поверхности техногенного образования производится разметка сетки для бурения скважин;

- по намеченной сетке осуществляется бурение до расчетной глубины пилотных скважин;

- производится нагнетание под высоким напором водоцементного раствора, что позволяет струей с высокой кинетической энергией резать и перемешивать породы и формировать изолирующий породобетонный массив.

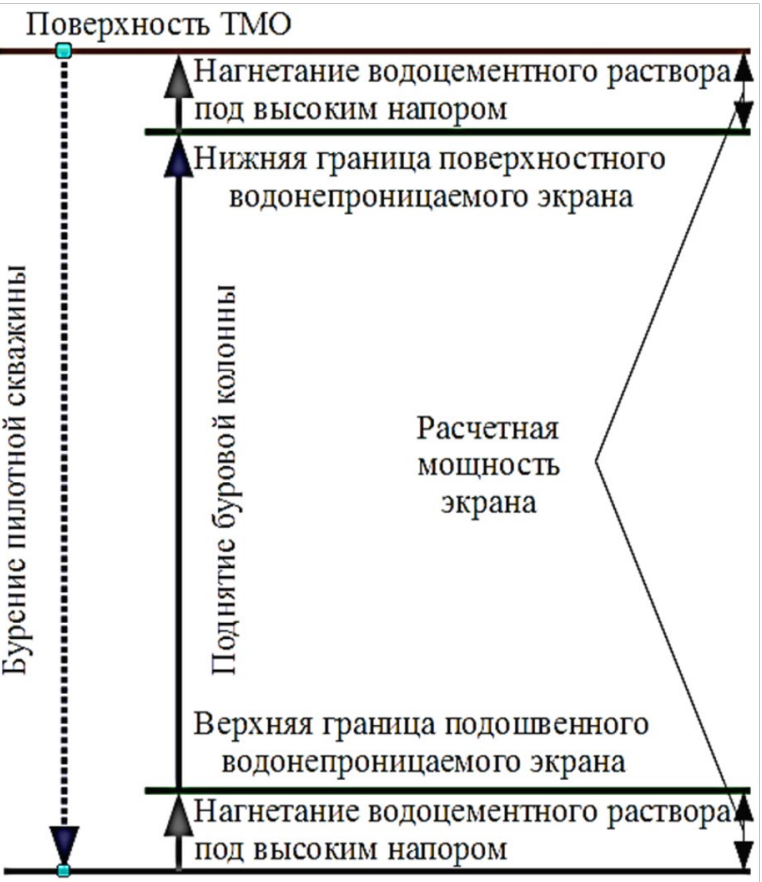

Расчетная глубина нижней границы подошвенного экрана

Рис. 5. Схема формирования породобетонного экрана 
Размеры сетки скважин рассчитывают таким образом, чтобы массивы породобетона соседних скважин формировались с перекрытием, необходимым для образования сплошного водонепроницаемого экрана.

Нагнетание водоцементного раствора под высоким напором осуществляется при подъеме буровой колонны через струеформирующие насадки, которые направлены перпендикулярно оси пробуренной скважины. При этом колонна вращается с частотой 10-25 об./мин. Струя водоцементного раствора с высокой кинетической энергией режет и перемешивает породы, формируя цилиндрический массив из породобетона с диаметром, во много раз превышающим диаметр скважины. Нагнетание водоцементного раствора прекращают после доведения мощности водонепроницаемого экрана до необходимой. Далее продолжают поднимать буровую колонну и при достижении нижней границы поверхностного водонепроницаемого экрана возобновляют нагнетание высоконапорного водоцементного раствора. Производится создание водонепроницаемого экрана на (у) поверхности техногенного образования (рис. 4).

Данный способ является уникальным и самым эффективным среди способов консервации и изоляции и позволяет:

- осуществить высокотехнологичное формирование эффективных водонепроницаемых экранов под основаниями и на поверхностях (у поверхностей) техногенных образований;

- устранить вредное влияние ТМО и сохранить окружающие земли.

Использование данного способа делает консервацию ТМО более конкурентоспособной по отношению к рекультивации или полной разборке ТМО. Основным отличием консервации ТМО от рекультивации является сохранение их для последующей разработки. При этом запас сырья ТМО будет сохранен за счет изоляции ТМО от взаимодействия с агрессивными природными факторами, которые приводят не только к физиче- ским потерям массы горных пород терриконов в результате ветровой и водной эрозии, но и к снижению важных потребительских свойств ее компонентов в результате трансформации под воздействием негативных физико-химических и биохимических процессов, инициированных проникновением воды, кислорода и микроорганизмов в тело терриконов, описанных в [23].

Учитывая значительные объемы средств, требующихся на проведение рекультивации, ликвидации и консервации ТМО, затраты на данные виды работ следует предусматривать при построении финансовой модели работы угледобывающего предприятия. Одним из возможных путей решения данного вопроса является финансирование проектов по рекультивации или консервации ТМО с дальнейшим получением из складированных в них горных пород целевых продуктов за счет фонда устойчивого развития (ликвидационного фонда) угледобывающего предприятия [25]. Надо понимать, что затраты на охрану земель от негативного влияния ТМО будут возвращаться при повышении кадастровой стоимости земельных участков.

\section{Заключение}

Применение способа консервации и изоляции позволит обеспечить достаточно высокий уровень экологической безопасности в районе расположения ТМО путем снижения их негативного влияния на окружающие земли, в том числе земли населенных пунктов и земли сельскохозяйственного назначения, за счет существенного уменьшения водной и ветровой эрозии пород ТМО, деформаций ТМО и фильтрации воды через тело ТМО в водоносные горизонты. При существенном улучшении экологической ситуации за счет применения способа консервации и изоляции ТМО повышается эколого-экономическая ценность земель [26] и увеличивается кадастровая стоимость земельных участков[1, 4].

\section{БИБЛИОГРАФИЧЕСКИЙ СПИСОК}

1. Попп Е. А. Методическое обеспечение учета экологического состояния территории при кадастровой оценке объектов недвижимости // Интерэкспо ГЕО-Сибирь-2016. ХІІ Междунар. науч. конгр. : Междунар. науч. конф. «Экономическое развитие Сибири и Дальнего Востока. Экономика природо- 
пользования, землеустройство, лесоустройство, управление недвижимостью» : сб. материалов в 3 т. (Новосибирск, 18-22 апреля 2016 г.). - Новосибирск : СГУГиТ. Т. 2. - С. 204-209.

2. Татаренко В. И., Попп Е. А. О необходимости учета влияния экологической составляющей на кадастровую стоимость объектов недвижимости на территории населенных пунктов // Изв. вузов. Геодезия и аэрофотосъемка. - 2014. - № 4/С. - С. 165-170.

3. Трубина Л. К. Некоторые аспекты учета экологической составляющей при оценке объектов недвижимости // Регулирование земельно-имущественных отношений в России: правовое и геопространственное обеспечение, оценка недвижимости, экология, технологические решения : сб. материалов Национальной научно-практической конференции. - Новосибирск: СГУГиТ, 2018. - Т. 1. - С. 149-152.

4. Сизов А. П., Хабаров Д. А. Прогнозирование стоимости сельскохозяйственных земель Краснодарского края с учетом экологической ситуации // Модели и технологии природообустройства (региональный аспект). - 2017. - № 4. - С. 96-103.

5. Тимакова М. С. Историко-географические особенности и современные проблемы развития Подмосковного угольного бассейна (на примере территории Тульской области) // Изв. Тульского государственного университета. Науки о Земле. - 2013. - Вып. 2. - С. 136-146.

6. Соколов Э. М., Качурин Н. М., Мелехова Н. И. Рекультивация отвалов отработанных шахт подмосковного бассейна // Изв. Тульского государственного университета. Науки о Земле. - 2010. Вып. 1. - С. 102-105.

7. Калаева С. 3., Богданов С. М., Лукин Н. О., Огер А. А. Породные отвалы угольных шахт России // Изв. Тульского государственного университета. Науки о Земле. - 2016. - Вып. 1. - С. 3-23.

8. Kachurin N. M., Vorobev S. A., Shkuratckiy D. N., Bogdanov S. M. Environmental Danger of Worked and Liquidated Coal Mines Open Areas // 5th International Symposium Mining and Environmental Protection (10-13 June 2015). - Vrdnik. Serbia, 2015. - P. 141-149.

9. Качурин Н. М., Соломатин А. П., Рыбак Л. Л., Рыбак В. Л. Проблемы экологической безопасности освоения месторождений при подземной добыче угля // Изв. Тульского государственного университета. Науки о Земле. - 2012. - Вып. 2. - С. 17-31.

10. Басова И. А., Ионина М. А., Глухова Е. Н. Геоэкологическое состояние почвенного покрова в горнопромышленных регионах // Изв. Тульского государственного университета. Науки о Земле. 2010. - Вып. 1. - С. 16-20.

11. Зубова Л. Г., Зубов А. Р., Зубов А. А., Харламова А. В., Воробьев С. Г., Макаришина Ю. И., Буняченко В. В. Терриконы. - Луганск : Изд-во «Ноулидж», 2015. - 712 с.

12. Комонов С. В., Комонова Е. Н. Ветровая эрозия и пылеподавление. Курс лекций. - Красноярск : Изд-во СФУ, 2008. - 192 с.

13. Заславский М. Н. Эрозия почв. - М. : Мысль, 1979. - С. 228-241.

14. Ступин А. Б., Аревадзе И. Ю. Оценка геодинамического состояния, прогнозирование и управление геоекологической безопасностью породних отвалов // Вісник СумДУ. Серія «Технічні науки». 2008. - № 2. - C. 106-109.

15. Посохов Е. В. Формирование химического состава подземных вод (основные факторы). - Л. : ГИ, 1969. - 335 с.

16. Гайдай М. Ф., Вайсман Я. И. Оценка негативного воздействия террикоников на экологическую ситуацию в угледобывающих районах и пути его снижения // Экологические системы и приборы. 2015. - Вып. 12. - С. 11-21.

17. Tichanek F., Tichanek R. Contribution to the solution of thermally active reclamation of coal waste heaps // 14th International Multidisciplinary Scientific GeoConference SGEM Proceedings. - Albena, 2014. P. 777-791.

18. Земельный кодекс Российской Федерации [Электронный ресурс] : федер. закон от 25.10.2001 № 136-ФЗ. - Доступ из справ.-правовой системы «КонсультантПлюс».

19. Технологические схемы рекультивации терриконов и плоских породных отвалов шахт и обогатительных фабрик / ВНИИОСуголь. - Пермь : ВЦ Статуправления, 1981. - 158 с.

20. Шевченко Е. Н., Киселев Н. Н., Филатов В. Ф., Дуброва Н. А. Проект технологии захоронения породных отвалов // Наукові праці УкрНДМІ НАН України. - 2014. - № 14. - С. 143-149.

21. Макаров А. Б. Техногенные месторождения минерального сырья // Соросовский образовательный журнал. - 2000. - № 8. - С. 76-80.

22. Баталин Б. С., Белозерова Т. А., Гайдай М. Ф. Строительная керамика из террикоников Кизеловского угольного бассейна // Стекло и керамика. - 2014. - № 3. - С. 8-10. 
23. Вайсман Я. И., Гайдай М. Ф. Разработка технологии консервации террикоников в целях снижения их негативного воздействия на окружающую среду и сохранения ресурсного потенциала // Вестник Пермского национального исследовательского политехнического университета. Геология. Нефтегазовое и горное дело. - 2016. -Т. 15, № 19. - С. 175-174.

24. Патент РФ № 2636174. Способ консервации и изоляции промышленных отвалов. Ковалев Р. А., Головин К. А., Прохоров Д. О. - Опубл. 21.11.2017. - Бюл. № 33.

25. Шматко С. И. О мерах по комплексному развитию угольной отрасли Российской Федерации и его законодательному обеспечению // Горная промышленность. - 2010. - № 6. - С. 14-20.

26. Кудряшова С. Я. Экологические факторы эколого-экономической оценки земель // Интерэкспо ГЕО-Сибирь-2013. IX Междунар. науч. конгр. : Междунар. науч. конф. «Экономическое развитие Сибири и Дальнего Востока. Экономика природопользования, землеустройство, лесоустройство, управление недвижимостью» : сб. материалов в 4 т. (Новосибирск, 15-26 апреля 2013 г.). - Новосибирск : СГГА, 2013. Т. 2. - C. 27-31.

Получено 08.07.2021

(С) И. А. Басова, Д. О. Прохоров, С. В. Пьянков, 2021

\section{PROPOSALS FOR THE PROTECTION OF LAND FROM THE NEGATIVE IMPACT OF TECHNOGENIC MINERAL FORMATIONS}

\section{Irina A. Basova}

Tula State University, 92, Prospect Lenin St., Tula, 300012, Russia, D. Sc., Head of the Department of Geoengineering and Cadastre, phone: (4872)73-44-38, e-mail: biajis20051@yandex.ru

\section{Dmitry O. Prokhorov}

Tula State University, 92, Prospect Lenin St., Tula, 300012, Russia, Ph. D., Associate Professor, Department of Geoengineering and Cadastre, phone: (4872)25-47-25, e-mail: 9202779115@mail.ru

\section{Sergey V. Pyankov}

Perm State National Research University, 15, Bukireva St., Perm, 614068, Russia, D. Sc., Vice-Rector for Research and Innovation, phone: (342)2-396-852, e-mail: pyankovsv@gmail.com

The article considers the processes affecting the cadastral value of land plots, as a result of which occurs land contamination around technogenic mineral formations. The scale of the problem is shown on the example of the Tula region, where large volumes of waste rocks in the form of waste heaps remained on the surface as a legacy from the development of the Moscow Region coal basin. The article gives an assessment of the ways to reduce this pollution, reduce environmental risks, eliminates accumulated harm from the point of view of their environmental efficiency and economic feasibility, which will further increase the cadastral value of land plots located in the zone of influence of technogenic mineral formations. The article proposes a method for the conservation and isolation of man-made mineral formations, which ensures a more effective reduction of the negative impact on the surrounding lands, including the lands of settlements and agricultural lands.

Keywords: cadastral value, land pollution, land protection, technogenic mineral formation, reclamation, elimination, conservation, land plot

\section{REFERENCES}

1. Popp, E. A. (2016). Cadastral valuation of real property units: techniques for taking into account ecological state of territory. In Sbornik materialov Interekspo GEO-Sibir'-2016: Mezhdunarodnoy nauchnoy konferentsii: T. 2. Ekonomicheskoe razvitie Sibiri i Dal'nego Vostoka. Ekonomika prirodopol'zovaniia, zemleustroistvo, lesoustroistvo, upravlenii e nedvizhimost'iu [Proceedings of Interexpo GEO-Siberia-2016: International Scientific Conference: Vol. 2. Economic Development of Siberia and the Far East. Enviromental Economics, Land Management, Forestry Management and Property Management] (pp. 204-209). Novosibirsk: SSUGT Publ. [in Russian]. 
2. Tatarenko, V. I., \& Popp, E. A. (2014). The need to consider the impact of environmental component on the cadastral value of the property in the residential areas. Izvestiya vuzov. Geodeziya $i$ aerofotos"emka [Izvestiya vuzov. Geodesy and Aerophotosurveying], S/4, 165-170 [in Russian].

3. Trubina L. K. (2018). Some aspects of taking into account the environmental component in the appraisal of real estate objects. In Sbornik materialov Nacional'noj nauchno-prakticheskoj konferencii: T. 1. Regulirovanie zemel'no-imushhestvennyh otnoshenij v Rossii: pravovoe i geoprostranstvennoe obespechenie, ocenka nedvizhimosti, jekologija, tehnologicheskie reshenija [Proceedings of National Scientific and Practical Conference: Vol. 1. Regulation of Land and Property Relations in Russia: Legal and Geospatial Support, Real Estate Valuation, Ecology, Technological Solutions] (pp. 149-152). Novosibirsk: SSUGT Publ. [in Russian].

4. Sizov, A. P., \& Khabarov, D. A. (2017). Forecasting the value of agricultural land in the Krasnodar Territory, taking into account the environmental situation. Modeli i tehnologii prirodoobustrojstva (regional'nyj aspekt) [Models and Technologies of Environmental Management (Regional Aspect)], 4, 96-103 [in Russian].

5. Timakova, M. S. (2013). Historical and geographical features and modern problems of the development of the Moscow region coal basin (on the example of the territory of the Tula region). Izvestija Tul'skogo gosudarstvennogo universiteta. Nauki o Zemle [Bulletin of the Tula State University. Earth Sciences], 2, 136146 [in Russian].

6. Sokolov, E. M., Kachurin, N. M., \& Melekhova, N. I. (2010). Reclamation of waste dumps of mines near Moscow. Izvestija Tul'skogo gosudarstvennogo universiteta. Nauki o Zemle [Bulletin of the Tula State University. Earth Sciences], 1, 102-105 [in Russian].

7. Kalaeva, S. Z., Bogdanov, S. M., Lukin, N. O., Oger, A. A. (2016). Waste heaps of coal mines in Russia. Izvestija Tul'skogo gosudarstvennogo universiteta. Nauki o Zemle [Bulletin of the Tula State University. Earth Sciences], 1, 3-23 [in Russian].

8. Kachurin, N. M., Vorobev, S. A., Shkuratckiy, D. N., \& Bogdanov, S. M. (2015). Environmental Danger of Worked and Liquidated Coal Mines Open Areas. 5th International Symposium Mining and Environmental Protection, 10-13 June 2015 (pp. 141-149). Vrdnik. Serbia.

9. Kachurin, N. M., Solomatin, A. P., Rybak, L. L., \& Rybak, V. L. (2012). Problems of the Environmental Safety of Deposits Development in Underground Coal Mining. Izvestija Tul'skogo gosudarstvennogo universiteta. Nauki o Zemle [Bulletin of the Tula State University. Earth Sciences], 2, 17-31 [in Russian].

10. Basova, I. A., Ionina, M. A., \& Glukhova, E. N. (2010). Geoecological state of soil cover in mining regions. Izvestija Tul'skogo gosudarstvennogo universiteta. Nauki o Zemle [Bulletin of the Tula State University. Earth Sciences], 1, 16-20 [in Russian].

11. Zubova, L. G., Zubov, A. R., Zubov, A. A., Kharlamova, A. V., Vorobiev, S. G., Makarishina, Yu. I., \& Bunyachenko, V. V. (2015). Terrikony [Waste heaps]. Lugansk: "Noulidzh" Publ., 712 p. [in Russian].

12. Komonov, S. V., \& Komonova, E. N. (2008). Vetrovaja jerozija i pylepodavlenie [Wind erosion and dust suppression]. Krasnoyarsk: SFU Publ., 192 p. [in Russian].

13. Zaslavsky, M. N. (1979). Jerozija pochv [Soil erosion] (pp. 228-241). Moscow: Mysl' Publ. [in Russian].

14. Stupin, A. B., \& Arevadze, I. Yu. (2008). Assessment of geodynamic condition, forecasting and management of geoecological safety of waste heaps. Bulletin of Sumy State University, 2, 106-109 [in Ukrainian].

15. Possokhov, E. V. (1969). Formirovanie himicheskogo sostava podzemnyh vod (osnovnye faktory) [Formation of the chemical composition of groundwater (main factors)]. Leningrad: GI Publ., 335 p. [in Russian].

16. Gaidai, M. F., \& Vaisman, Ya. I. (2015). Evaluation of the negative impact of waste heaps on the ecological situation in coal-mining regions and ways to reduce it. Jekologicheskie sistemy i pribory [Ecological Systems and Devices], 12, 11-21 [in Russian].

17. Tichanek, F., \& Tichanek, R. (2014). Contribution to the solution of thermally active reclamation of coal waste heaps. 14th International Multidisciplinary Scientific GeoConference SGEM Proceedings (pp. 777791).

18. Federal Law of November 25, 2001 No. 136-FZ. The Land Code of the Russian Federation. Retrieved from ConsultantPlus online database [in Russian].

19. Technological schemes for reclamation of waste heaps and flat waste dumps of mines and processing plants / VNIIOSugol [Tehnologicheskie shemy rekul'tivacii terrikonov i ploskih porodnyh otvalov shaht $i$ obogatitel'nyh fabrik/VNIIOSugol']. (1981). Perm: VC Statupravlenija Publ., 158 p. [in Russian]. 
20. Shevchenko, E. N., Kiselev, N. N., Filatov, V. F., \& Dubrova, N. A. (2014). Project of technology of burial of waste heaps. Scientific Works of UkrNDMI NAS of Ukraine, 14, 143-149 [in Ukrainian].

21. Makarov, A. B. (2000). Technogenic deposits of mineral raw materials. Sorosovskij obrazovatel'nyj zhurnal [Sorosovsky Educational Journal], 8, 76-80 [in Russian].

22. Batalin, B. S., Belozerova, T. A., \& Gaidai, M. F. (2014). Building ceramics from mounds of Kizelovsky coal basin. Steklo i keramika [Glass and Ceramics], 3, 8-10 [in Russian].

23. Weissman, J. I., \& Gaidai, M. F. (2016). Development of technology for conservation of waste heaps in order to reduce their negative impact on the environment and preserve resource potential. Vestnik Permskogo nacional'nogo issledovatel'skogo politehnicheskogo universiteta. Geologija. Neftegazovoe i gornoe delo [Bulletin of the Perm National Research Polytechnic University. Geology. Oil and Gas and Mining], 15(19), 175-174 [in Russian].

24. Kovalev, R. A., Golovin, K. A., \& Prokhorov, D. O. (2017). Method of conservation and isolation of industrial dumps. Patent of the Russian Federation No. 2636174

25. Shmatko, S. I. (2010). On measures for the integrated development of the coal industry of the Russian Federation and its legislative support. Gornaja promyshlennost' [Mining Industry], 6, 14-20 [in Russian].

26. Kudryashova, S. Ya. (2013). Ecological factors of land resources economic estimation. In Sbornik materialov Interekspo GEO-Sibir'-2013: Mezhdunarodnoy nauchnoy konferentsii: T. 2. Ekonomicheskoe razvitie Sibiri i Dal'nego Vostoka. Ekonomika prirodopol'zovaniia, zemleustroistvo, lesoustroistvo, upravlenii e nedvizhimost'iu [Proceedings of Interexpo GEO-Siberia-2013: International Scientific Conference: Vol. 2. Economic Development of Siberia and the Far East. Enviromental Economics, Land Management, Forestry Management and Property Management] (pp. 27-31). Novosibirsk: SSGA Publ. [in Russian].

Received 08.07.2021

(C) I. A. Basova, D. O. Prokhorov, S. V. Pyankov, 2021 
УДК 332.334(470.24)

DOI: $10.33764 / 2411-1759-2021-26-5-145-155$

\section{ПРОГНОЗ ДИНАМИКИ ПЛОЩАДЕЙ ЗЕМЕЛЬ СЕЛЬСКОХОЗЯЙСТВЕННОГО НАЗНАЧЕНИЯ И ОПТИМИЗАЦИЯ ЗЕМЕЛЬНЫХ ОТНОШЕНИЙ НА ТЕРРИТОРИИ НОВГОРОДСКОЙ ОБЛАСТИ}

\section{Артём Олегович Белоусов}

Санкт-Петербургский государственный аграрный университет, 196601, Россия, г. Пушкин, Петербургское шоссе, 2, аспирант кафедры землеустройства, тел. (996)945-56-17, e-mail: star042112@mail.ru

\section{Владимир Леонидович Богданов}

Санкт-Петербургский государственный аграрный университет, 196601, Россия, г. Пушкин, Петербургское шоссе, 2, доктор биологических наук, профессор кафедры землеустройства, тел. (911)913-87-77, e-mail: lab.naz.eco@gmail.com

В статье раскрывается проблема нерационального использования земель сельскохозяйственного назначения и земельных отношений в Новгородской области. Важнейшим признаком такого использования является ежегодное сокращение площадей этой категории. На основе применения авторами метода SPACE-анализа по оценке уровня развития сельского хозяйства Новгородской области с учетом ее природно-ресурсного потенциала было определено положение этого региона в Северо-Западном Федеральном округе как региона с низким сельскохозяйственным производством, а также выявлен ряд проблем в сфере земельных отношений региона, препятствующих рациональному землепользованию. С целью выявления этих проблем авторами применен метод экстраполяции ряда динамики с расчетом оптимистичного и пессимистичного путей развития земельных отношений в области. В результате авторами систематизированы основные причины разрушения земельных отношений в Новгородской области (естественные, организационно-экономические и социальные), а также разработаны направления совершенствования использования земель сельскохозяйственного назначения в Новгородской области, в том числе посредством применения рентных механизмов, с целью достижения рационального использования таких земель.

Ключевые слова: рациональное землепользование, земли сельскохозяйственного назначения, SPACE-анализ, прогнозирование использования земель, метод экстраполяции ряда динамики, земельные отношения, дифференциальная рента

\section{Введение}

Проведенные в последние два десятилетия в нашей стране социально-экономические преобразования, в том числе в сфере земельных отношений, негативно повлияли на рациональное использование земель сельскохозяйственного назначения [1], которые, прежде всего, выражаются в сокращении площадей пахотных земель. Данная статья посвящена актуальному вопросу - выявлению причин и дальнейшему прогнозу изменения площадей земель сельскохозяйственного назначения как основы продовольственной безопасности страны и устойчивого развития сельских регионов.

Как в целом по Российской Федерации (далее - РФ), так и в отдельных ее субъектах, площади сельскохозяйственных земель сокращаются [2], что свидетельствует о наличии проблем в сфере земельных отношений и управлении земельными ресурсами, а также о нерациональности использования этих земель.

Одну из ключевых функций в сфере управления земельными ресурсами, позволяющую оперативно и своевременно принимать управленческие решения, выполняет прогнозирование, которое с одной стороны представляет собой практическую деятельность, с другой - научную, направленную на выявление наиболее эффективного варианта и возможных альтернатив будущего развития.

Объектом исследования в данной статье выступают земли сельскохозяйственного назначения Новгородской области. 


\section{Материалы и методы}

При работе над исследованием использовались следующие методы: аналитический, расчетный, метод системного анализа и экстраполяции ряда динамики, с помощью которых простроен прогноз использования земель сельскохозяйственного назначения в Новгородской области и разработаны основные направления совершенствования использования данных земель в регионе.

Информационной основой в данном исследовании послужили сведения территориальных органов Росреестра по Новгородской области, а также сведения, размещенные на официальном сайте Правительства Новгородской области и инвестиционном портале региона.

\section{Результать}

С целью наиболее полного и наглядного отображения состояния развития сельского хозяйства в Новгородской области нами предлагается применение SPACE-анализа c адаптацией (внедрением разработанных нами показателей) к оценке уровня развития сельского хозяйства с учетом природно-ресурсного потенциала региона. Данный анализ используется нами для определения современного положения региона среди всех субъектов Северо-Западного федерального округа (далее - СЗФО).

В процессе SPACE-анализа формируются четыре группы факторов, отражающие положение региона [3]. Каждая группа факторов включает в себя ряд определенных показателей, которые оцениваются по пятибалльной шкале посредством использования экспертного метода. В связи с этим необходимым является расчет количества экспертов $(m)$, которые будут привлечены к исследованию, а также расчет достоверности их оценок посредством определения вариационного размаха $(R)$, среднего квадратического отклонения $(\sigma)$ и коэффициента вариации $\left(V_{\sigma}\right)$, который не должен превышать $33 \%$.

Количество экспертов определяется по формуле

$$
m=\sqrt{n},
$$

где $m$ - количество экспертов; $n$ - количество оцениваемых объектов.

Количество необходимых экспертов составляет 5 человек, так как общее число оцениваемых показателей, включенных в SPACEанализ, -25 . При этом экспертами в данном исследовании выступают ученые и сотрудники профильных организаций Новгородской области, которые способны оценить реальное положение региона и уровень развития сельского хозяйства. Достоверность экспертной оценки определена посредством расчета вышеуказанных показателей, главным из которых является коэффициент вариации, рассчитанный по формуле

$$
V_{\sigma}=\left(\frac{\sigma}{x_{\mathrm{cp}}}\right) \cdot 100 \%,
$$

где $V_{\sigma}-$ коэффициент вариации; $\sigma$ - среднее квадратическое отклонение; $x_{\text {cp }}$ - среднее арифметическое совокупности вариант.

Согласно произведенным расчетам коэффициент вариации совокупности экспертных оценок не превышает 33 \%, что свидетельствует о достоверности, однородности и возможности практического применения экспертных оценок.

В табл. 1 приведены разработанные нами показатели, их балльная оценка параметров в зависимости от уровня развития Новгородской области и в сравнении со сходными показателями в других регионах СЗФО посредством экспертных оценок $[2,4,5]$.

На основании данных, представленных в табл. 1, для более наглядного представления полученных результатов построена матрица SPACE-анализа, которая представлена на рис. 2.

В результате нами сделан вывод, что Новгородская область имеет относительно низкие показатели развития сельского хозяйства. Такое положение обуславливается экономическими проблемами, ухудшением социальной ситуации на селе, переувлажненностью и низким плодородием пахотных земель, мелкоконтурностью угодий, отсутствием инвестиций и создания кооперации в рамках кластера. При этом в случае дальнейшего ухудшения социально-экономической ситуации 
в регионе возможно изменение его положения в СЗФО на оборонительное, которое влечет за собой практически уход с рынка со сме- ной специализации региона, определенный механизм парирования угроз и давления со стороны других регионов [3].

Таблица 1

Значения анализируемых показателей матрицы SPACE-анализа для Новгородской области

\begin{tabular}{|c|c|c|c|}
\hline Факторы & Показатели & Значения & Оценка \\
\hline \multirow{8}{*}{$\begin{array}{l}\text { Финансовое } \\
\text { положсение }\end{array}$} & Уровень заработной платы & 30623 руб. & 2 \\
\hline & Инвестиции в сельское хозяйство & За 3 года - 4 620,8 мрд руб. & 3 \\
\hline & Размер страхования сельского хозяйства & $40-60 \%$ от урожая с 1 га & 2 \\
\hline & Сельскохозяйственная продукция региона & 24,9 млрд руб. & 4 \\
\hline & Индекс производства & $103,40 \%$ & 3 \\
\hline & Вклад в продукцию СЗФО & Сельское хозяйство - $12 \%$ & 3 \\
\hline & Доля сельского хозяйства в ВПР & $11 \%$. & 3 \\
\hline & $\begin{array}{l}\text { Итого: } \\
\end{array}$ & \multicolumn{2}{|l|}{2,86} \\
\hline \multirow{10}{*}{$\begin{array}{l}\text { Конкурентные } \\
\text { преимущества }\end{array}$} & Качество продукции & Высокое & 5 \\
\hline & Уровень технологий & Низкий & 3 \\
\hline & Распаханность сельхозугодий & $61,40 \%$ & 3 \\
\hline & $\begin{array}{l}\text { Наличие развитых промышленных предприятий } \\
\text { в сельском хозяйстве }\end{array}$ & $\begin{array}{l}\text { ООО «Белгранкорм», Агрохол- } \\
\text { динг «Устьволмский», др. }\end{array}$ & 2 \\
\hline & Качество сельхозугодий & Осушенные - 38,5 \% & 2 \\
\hline & Транспортная доступность & $\begin{array}{l}15163 \text { км (11 } 082 \text { км с твердым } \\
\text { покрытием) }\end{array}$ & 4 \\
\hline & Освоенность сельхозугодьями & $90 \%$ & 5 \\
\hline & \multirow{2}{*}{ Обеспеченность населения жильем } & Население - 593232 чел. & \multirow{2}{*}{5} \\
\hline & & Жилая S - 9098 978,15 м² & \\
\hline & Итого: & \multicolumn{2}{|l|}{3,63} \\
\hline \multirow{6}{*}{$\begin{array}{c}\text { Степень } \\
\text { стабильности } \\
\text { внешней среды }\end{array}$} & Темпы инфляции & В декабре 2020 г. - 5,6 \% & 3 \\
\hline & Давление со стороны других регионов & $\begin{array}{l}75 \text { \% всех товаров в регионе им- } \\
\text { портируется }\end{array}$ & 3 \\
\hline & Технологические изменения в АПК & $\begin{array}{l}\text { Реализуется } 8 \text { инновационных } \\
\text { проектов }\end{array}$ & 3 \\
\hline & Препятствия для доступа на рынок & $\begin{array}{l}\text { Отсутствие крупных промышлен- } \\
\text { ных предприятий }\end{array}$ & 3 \\
\hline & Инвестиции государства & $\begin{array}{l}\text { В сельское хозяйство - } 288527,5 \\
\text { тыс. руб. }\end{array}$ & 3 \\
\hline & Итого: & 3 & \\
\hline \multirow{7}{*}{$\begin{array}{l}\text { Привлекатель- } \\
\text { ность }\end{array}$} & \multirow[b]{2}{*}{ Потенциал использования ресурсов } & Земли запаса - 102,5 тыс. га & \multirow[b]{2}{*}{4} \\
\hline & & $\begin{array}{l}\text { Фонд перераспределения - } \\
240,7 \text { тыс. га }\end{array}$ & \\
\hline & Уровень технологий & Низкий & 3 \\
\hline & $\begin{array}{l}\text { Производительность предприятий в сельском хо- } \\
\text { зяйстве }\end{array}$ & $\begin{array}{l}\text { Мясо - } 151,2 \text { тыс. т }(94,4 \%) \text {, мо- } \\
\text { локо - 65,6 тыс. т }(91,6 \%) \text {, яйца - } \\
224,6 \text { млн. шт. }(97,2 \%)\end{array}$ & 3 \\
\hline & Урожайность & По картофелю - 180,1 ц/га & 4 \\
\hline & $\begin{array}{l}\text { Степень освоенности территории сельхозугодь- } \\
\text { ями }\end{array}$ & $15 \%$ & 3 \\
\hline & Итого: & 3,4 & \\
\hline
\end{tabular}




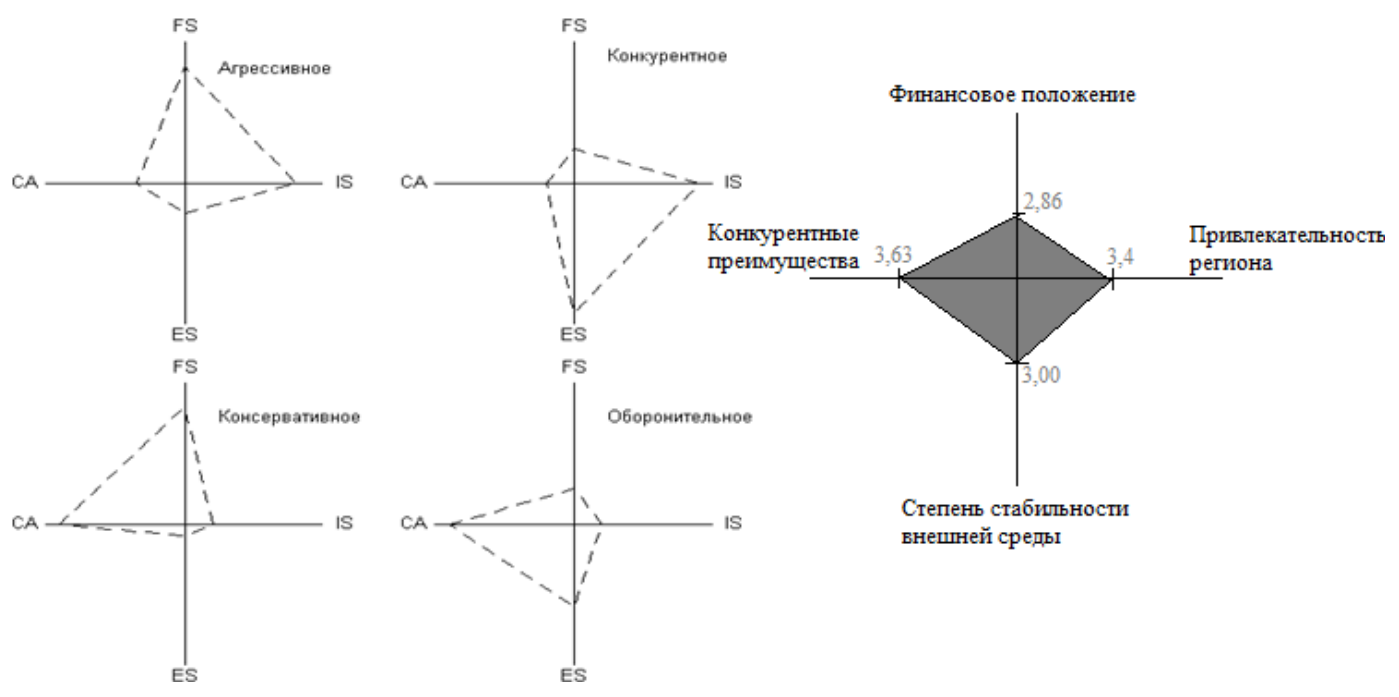

Рис. 1. Матрица SPACE-анализа Новгородской области

С целью дальнейшего подтверждения существования проблем в сфере земельных отношений и необходимости их изменения применен метод экстраполяции ряда динамики. В научном сообществе исследованием данного метода на протяжении нескольких лет занимаются такие ученые как Т. Н. Бабич, И. А. Козьева, Э. Н. Кузьбожев, И. В. Шмитд, Е. М. Четыркин и др.

Суть метода и главная его особенность заключается в том, что закономерность изменяемого объекта для определенного периода в прошлом сохранится и в будущем. Пригодность практического применения метода определяет коэффициент детерминации, который должен быть выше 0,7 [6]. Точность прогноза определяет интервальная оценка, которая рассчитывается по следующей формуле:

$$
M=C \cdot G,
$$

где $M$ - интервальная оценка; $C$ - ошибка метода; $G$ - коэффициент Стьюдента.

Границы доверительного интервала определяются по формуле

$$
Y_{\partial}=Y_{t} \pm M
$$

где $Y_{\partial}$ - значения доверительного интервала; $Y_{t}$ - теоретическое значение; $M$ - интервальная оценка.
С целью определения точности метода экстраполяции ряда динамики рассчитывается ошибка метода по формуле

$$
C=\sqrt[3]{\frac{\sum_{t=1}^{n}\left(Y_{t}-\bar{Y}\right)^{2}}{n-1}},
$$

где $Y_{t}$ - фактические значения показателя; $Y$ - теоретическое значение; $n$ - количество наблюдений.

При прогнозировании использования земель методом экстраполяции необходимо учитывать, что срок, на который строится прогноз, не должен быть больше базисного периода. Для Новгородской области выбран период до 2024 г. Сведения о динамике распределения площадей отдельных категорий земельного фонда Новгородской области за последние пять лет, в которых происходят основные изменения, представлены в табл. 2.

Таким образом, земли сельскохозяйственного назначения ежегодно выбывают из хозяйственного оборота посредством их перевода в другие категории, что свидетельствует о нерациональности их использования [7]. Однако в регионе не наблюдается притока населения с целью расширения границ населенных пунктов, а также в последние несколько лет не ведется крупное строительство для перевода в земли специального назначения. При этом закрываются существующие 
предприятия, но в связи с тем, что данные земли находятся в собственности и забрасываются, то происходит перевод в данную ка- тегорию из земель сельскохозяйственного назначения ввиду их удобного использования под строительство.

Таблийа 2

Динамика структуры земельного фонда Новгородской области за последние пять лет

\begin{tabular}{|c|c|c|c|c|c|c|}
\hline \multirow{2}{*}{ Категория земель } & \multicolumn{5}{|c|}{ Площадь, тыс. га } & \multirow{2}{*}{$\begin{array}{c}\text { Изменение } \\
\text { площади, тыс. } \\
\text { га }\end{array}$} \\
\hline & 2016 г. & 2017 г. & 2018 г. & 2019 г. & 2020 г. & \\
\hline Земли сельскохозяйственного назначения & 919,7 & 919,4 & 919,2 & 917,4 & 916,1 & $-3,6$ \\
\hline Земли населенных пунктов & 163,7 & 163,7 & 163,7 & 165,2 & 166,4 & 2,7 \\
\hline $\begin{array}{c}\text { Земли промышленности и иного } \\
\text { специального назначения }\end{array}$ & 46,3 & 46,6 & 46,8 & 47,1 & 47,2 & 0,9 \\
\hline
\end{tabular}

Необходимо оценить возможности изменения земель сельскохозяйственного назначения с учетом сложившихся негативных тенденций с целью подтверждения целесообразности реструктуризации земельных отношений. Сформировавшиеся негативные тенденции изменения сельскохозяйственных земель в настоящее время доказывают, что сложился ряд проблем в сфере земельных отношений, а экстраполирование существующих тенденций способно с помощью математических расчетов доказать необходимость изменения всей системы земельных отношений. В табл. 3 приведен расчет прогнозной модели для каждой из выбранной нами группы земель.

Таблицุа 3

Прогнозные модели изменения площадей земель сельскохозяйственного назначения

\begin{tabular}{|c|c|c|c|}
\hline Трендовые зависимости & Уравнение модели & $\mathrm{R}^{2}$, ед. & Ошибка, \% \\
\hline \multicolumn{4}{|c|}{ Земли сельскохозяйственного назначения } \\
\hline Линейная & $y=-0,92 x+921,12$ & 0,8806 & 0,042 \\
\hline Экспоненциальная & $y=921,12 e^{-0,001 x}$ & 0,8804 & 0,042 \\
\hline Логарифмическая & $y=-2,058 \ln (x)+920,33$ & 0,7117 & 0,121 \\
\hline Полиномиальная 2-й степени & $y=-0,2571 x^{2}+0,6229 x+919,32$ & 0,9769 & 0,019 \\
\hline Степенная & $y=920,33 x^{-0,002}$ & 0,7115 & 0,077 \\
\hline $\begin{array}{l}\text { Оптимальная - Полиномиальная 2-й } \\
\text { степени }\end{array}$ & $y=-0,2571 x^{2}+0,6229 x+919,32$ & 0,9769 & 0,019 \\
\hline \multicolumn{4}{|c|}{ Сельскохозяйственные угодья } \\
\hline Линейная & $y=-0,47 x+830,91$ & 0,8836 & 0,024 \\
\hline Экспоненциальная & $y=830,91 e^{-6 e-04 x}$ & 0,8835 & 0,026 \\
\hline Логарифмическая & $y=-1,052 \ln (x)+830,51$ & 0,7154 & 0,069 \\
\hline Полиномиальная 2-й степени & $y=-0,1357 x^{2}+0,3443 x+829,96$ & 0,9867 & 0,018 \\
\hline Степенная & $y=830,51 x^{-0,001}$ & 0,7152 & 0,044 \\
\hline $\begin{array}{l}\text { Оптимальная - Полиномиальная 2-й } \\
\text { степени }\end{array}$ & $y=-0,1357 x^{2}+0,3443 x+829,96$ & 0,9867 & 0,018 \\
\hline \multicolumn{4}{|c|}{ Пашня } \\
\hline Линейная & $y=-0,45 x+511,49$ & 0,8126 & 0,053 \\
\hline Экспоненциальная & $y=511,49 \mathrm{e}^{-9 E-04 x}$ & 0,8124 & 0,054 \\
\hline Логарифмическая & $y=-0,974 \ln (x)+511,07$ & 0,615 & 0,103 \\
\hline Полиномиальная2-ой степени & $y=-0,1786 x^{2}+0,6214 x+510,24$ & 0,9917 & 0,011 \\
\hline Степенная & $y=511,07 x^{-0,002}$ & 0,6148 & 0,080 \\
\hline $\begin{array}{l}\text { Оптимальная - Полиномиальная 2-ой } \\
\text { степени }\end{array}$ & $y=-0,1786 x^{2}+0,6214 x+510,24$ & 0,9917 & 0,011 \\
\hline
\end{tabular}


Выбранные группы земель в дальнейшем будут сокращаться с высокой степенью вероятности, так как $R^{2}$ для рассматриваемых земель больше 0,9 , при этом ошибка прогнозной модели минимальна и составляет около
0,01 \%, что свидетельствует о возможности практического применения трендовых зависимостей.

В табл. 4 представлен расчет перспективной площади для выбранных категорий земель.

Таблица 4

Расчет прогнозной площади отдельных групп земель в Новгородской области до 2024 г.

\begin{tabular}{|c|c|c|c|c|c|c|}
\hline Год & $\begin{array}{c}\text { Прогноз- } \\
\text { ная пло- } \\
\text { щадь, тыс. } \\
\text { га }\end{array}$ & $\begin{array}{c}\text { Критерий } \\
\text { Стьюдента }\end{array}$ & $\begin{array}{c}\text { Ошибка } \\
\text { метода } \\
\text { (C) }\end{array}$ & $\begin{array}{c}\text { Интервальная } \\
\text { оценка }\end{array}$ & $\begin{array}{l}\text { Оптимистичный } \\
\text { прогноз, тыс. га }\end{array}$ & $\begin{array}{c}\text { Пессимистичный } \\
\text { прогноз, тыс. га }\end{array}$ \\
\hline \multicolumn{7}{|c|}{ Земли сельскохозяйственного назначения } \\
\hline 2021 & 913,80 & \multirow{4}{*}{3,58} & \multirow{4}{*}{0,236} & \multirow{4}{*}{0,84} & 914,6 & 913,0 \\
\hline 2022 & 911,08 & & & & 911,9 & 910,2 \\
\hline 2023 & 907,85 & & & & 908,7 & 907,0 \\
\hline 2024 & 904,10 & & & & 904,9 & 903,3 \\
\hline \multicolumn{7}{|c|}{ Сельскохозяйственные угодья } \\
\hline 2021 & 827,14 & \multirow{4}{*}{4,23} & \multirow{4}{*}{1,177} & \multirow{4}{*}{4,98} & 832,1 & 822,2 \\
\hline 2022 & 825,72 & & & & 830,7 & 820,7 \\
\hline 2023 & 824,03 & & & & 829,0 & 819,1 \\
\hline 2024 & 822,07 & & & & 827,0 & 817,1 \\
\hline \multicolumn{7}{|c|}{ Пашня } \\
\hline 2021 & 507,54 & \multirow{4}{*}{4,85} & \multirow{4}{*}{1,545} & \multirow{4}{*}{7,49} & 515,0 & 500,0 \\
\hline 2022 & 505,84 & & & & 513,3 & 498,3 \\
\hline 2023 & 503,78 & & & & 511,3 & 496,3 \\
\hline 2024 & 501,37 & & & & 508,9 & 493,9 \\
\hline
\end{tabular}

Оптимистичный прогноз для земель сельскохозяйственного назначения основывается на повышении качественного состояния земель посредством мелиорации, улучшения плодородия земель, создания рынка сбыта сельскохозяйственной продукции и т. д. [8]. Пессимистичный прогноз развития сельского хозяйства возможен для Новгородской области, если в ближайшее время не будут предприняты меры как на государственном, так и на местном уровне по коренному изменению земельных отношений, направленных посредством определенных механизмов на стимулирование сельскохозяйственных производителей к вовлечению земель в хозяйственный оборот [9].

Таким образом, исходя из сложившейся тенденции изменения площадей рассматриваемых земель, можно сделать вывод, что при таком же нерациональном использовании земель сельскохозяйственного назначения их площадь к 2024 г. сократится на 12 тыс. га.
Даже по оптимистичному пути развития земельных отношений в регионе площадь данных земель к 2024 г. продолжит сокращаться на 11,2 тыс. га, что доказывает необходимость изменения системы земельных отношений.

\section{Обсуждение}

В результате проведенных математических исследований выявлено, что в Новгородской области современные земельные отношения не содержат механизмов к мотивации совершенствования системы земледелия. Инструменты, которые заложены в основу земельных отношений, не направлены в реальной жизни на рациональное использование земель [10]. В регионе наблюдается снижение уровня производительности сельскохозяйственных предприятий, который является одним из критериев рациональности использования земель, происходит выбытие земель 
сельскохозяйственного назначения из оборота в результате деградационных процессов, что свидетельствует о неэффективности системы земледелия.

Ежегодно в Новгородской области снижается индекс производства сельскохозяйственной продукции, уменьшается количество организаций, занимающихся сельскохозяйственной деятельностью, которая является одной из приоритетных в регионах, где преобладают сельские поселения. Сложившееся положение в регионе обусловлено рядом естественных организационно-экономических и социальных причин. На рис. 2 нами систематизированы и выделены основные причины развала земельных отношений в регионе.

Сложившаяся ситуация в Новгородской области свидетельствует о том, что земель- ные отношения не содержат стимулов к развитию системы земледелия. Математические методы (экстраполяция) использовались не для построения ориентиров в развитии, а для реструктуризации земельных отношений.

Таким образом, у производителей сельскохозяйственной продукции в Новгородской области отсутствуют стимулы и мотивирующие рычаги, которые способствовали бы к побуждению использования земель в регионе. В связи с тем, что наиболее доходные способы использования земли (например, промышленное строительство) приводят к обесцениванию земель сельскохозяйственного назначения, за последние пять лет количество заявлений о переводе сельскохозяйственных земель под иные цели увеличилось на $15 \%$. В результате нарушается баланс конкурентных сил на межотраслевом уровне.

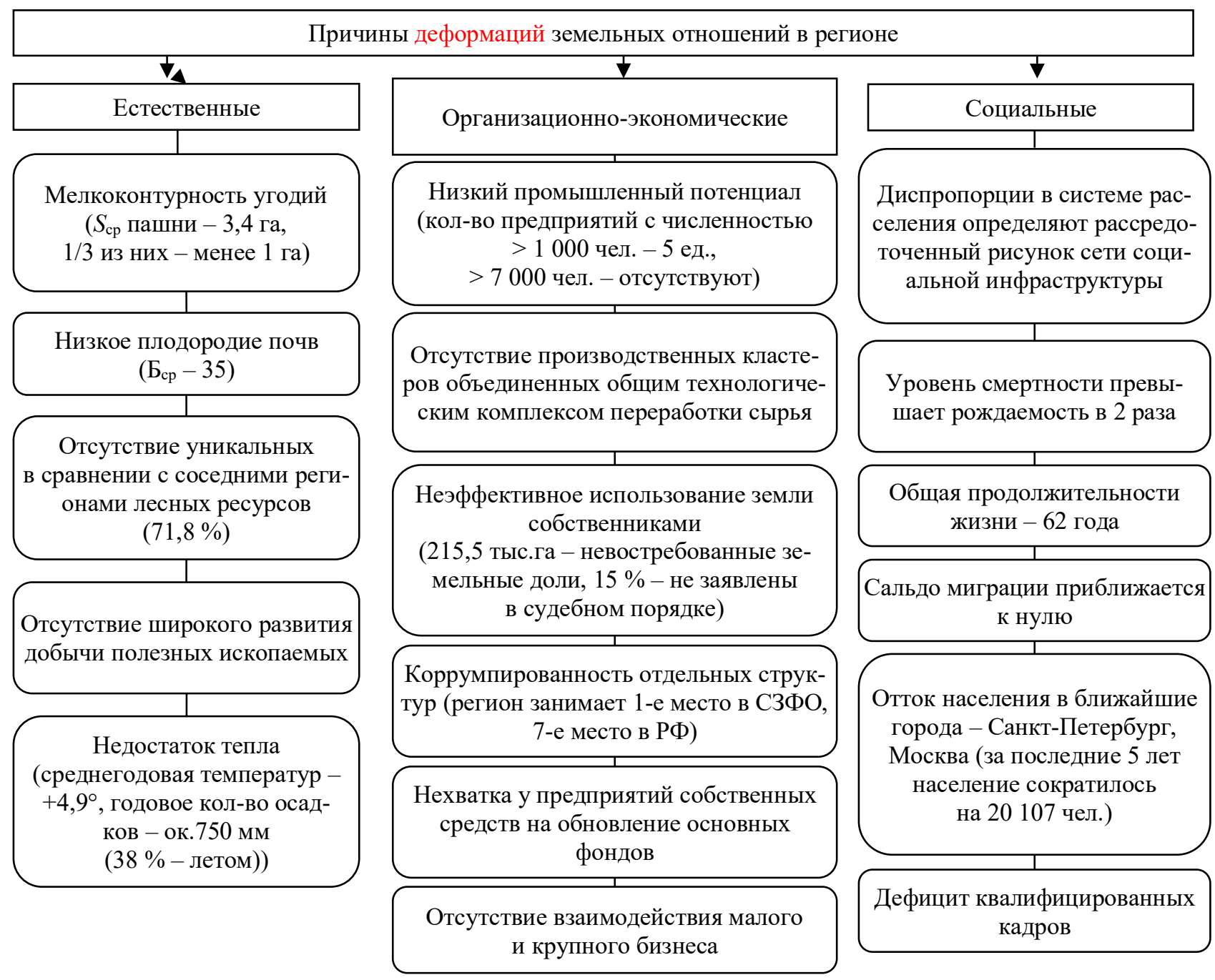

Рис. 2. Причины деформаций земельных отношений в Новгородской области 
Данные причины в целом приводят к формированию экономических проблем в регионе: увеличению дефицита бюджета региона, который по состоянию на 01.01.2021 в Новгородской области составляет 976 млн руб.; поступление налоговых платежей за отчетный период составляет 24,0 млрд руб. (на 6,6 \% ниже уровня прошлого года) [4].

\section{Выводы}

Таким образом, необходимо коренное преобразование земельных отношений посредством применения рентных механизмов, направленных на ориентацию землепользования в условиях развития рыночной экономики. Также необходимо развитие конкуренции, отсутствие которой приводит к обостре- нию и нарастанию экономико-правовых противоречий в стране.

Главной проблемой является отсутствие пропорциональной связи между земельными доходами и затратами на совершенствование системы земледелия. Научным сообществом доказано, что при одинаковых затратах промышленности и сельского хозяйства средства в промышленности окупаются быстрее [11-14], в связи с этим сельское хозяйство находится в менее выгодных условиях. В то же время для сельскохозяйственного производства предусмотрено страхование рисков, поэтому сельское хозяйство способно стать более привлекательным. На наш взгляд, дифференцированная налоговая политика должна применяться ко всем собственникам сельскохозяйственных земель путем изъятия определенного вида ренты (табл. 5).

Таблий 5

Плата за пользование землей сельскохозяйственного назначения

\begin{tabular}{|c|c|c|c|}
\hline Субъект & $\begin{array}{c}\text { Вид } \\
\text { платежа }\end{array}$ & $\begin{array}{c}\text { Форма изъятия } \\
\text { платежа }\end{array}$ & Форма дохода субъекта \\
\hline $\begin{array}{c}\text { Собственник земельного } \\
\text { участка, являющийся сель- } \\
\text { скохозяйственным произ- } \\
\text { водителем }\end{array}$ & \multirow[t]{2}{*}{$\begin{array}{l}\text { Земельный } \\
\text { налог }\end{array}$} & \multirow[t]{2}{*}{$\begin{array}{c}\text { дифференциальная } \\
\text { рента I }\end{array}$} & $\begin{array}{c}\text { Абсолютная рента, средняя } \\
\text { норма прибыли, дифференци- } \\
\text { альная рента II }\end{array}$ \\
\hline $\begin{array}{c}\text { Собственник, не использу- } \\
\text { ющий землю }\end{array}$ & & & Абсолють \\
\hline $\begin{array}{c}\text { Землевладелец, землеполь- } \\
\text { зователь }\end{array}$ & \multirow[t]{2}{*}{$\begin{array}{l}\text { Арендная } \\
\text { плата }\end{array}$} & \multirow{2}{*}{$\begin{array}{c}\text { Абсолютная рента, } \\
\text { Дифференциальная } \\
\text { рента I }\end{array}$} & \multirow[t]{2}{*}{$\begin{array}{c}\text { Средняя норма прибыли, диф- } \\
\text { ференциальная рента II }\end{array}$} \\
\hline Арендатор & & & \\
\hline
\end{tabular}

Таким образом, изъятие объективного размера земельного налога и арендной платы способствует эффективному хозяйствованию. В связи с этим нельзя допустить повышения интенсификации сельскохозяйственного производства путем нерационального внесения удобрений и применения агротехники. Необходимо установить повышенные цены на экологически чистую продукцию [15], внедрить налоговые льготы для предприятий, производящих продукцию с соблюдением предельно допустимых норм внесения агрохимикатов. Полученные в результате увеличения налоговой базы средства необходимо распределять на восстановление состояния земель, в том числе и на частичную ком- пенсацию предприятиям, чьи доходы снизились в результате консервации земель.

С целью изменения земельных отношений в Новгородской области необходимо также осуществить следующие мероприятия:

1) создать технологические кластеры, которые будут сочетать научно-технический и производственно-технологический потенциалы, ориентированные на устойчивый внутренний и внешний рынки. В связи с этим появится возможность создания высокотехнологичных производств. При этом необходимо, чтобы данные кластеры находились в форме частно-государственного партнерства;

2) создать систему взаимоотношений по установлению сельскохозяйственной коопе- 
рации и агропромышленной интеграции, которая позволит значительно снизить затраты, в том числе транспортные, играющие огромную роль в сельскохозяйственном производстве;

3) с целью привлечения населения в регион необходимо развивать агробизнес с возможностью внедрения и участия в полном цикле сельскохозяйственного производства;

4) существующим хозяйствам необходимо внедрять новые сорта и технологии в свое производство, применять новые способы переработки сырья;

5) необходимо воссоздать производства на базе реорганизованных льнозаводов в муниципальной собственности с привлечением инвесторов;

6) необходимо ориентироваться на зональную систему земледелия с учетом природно-ресурсного потенциала отдельных районов, а также использовать имеющиеся биоресурсы.
На наш взгляд, создание даже одного сельскохозяйственного предприятия, который включал бы в себя весь цикл производства с последующей переработкой в условиях изменения земельных отношений посредством внедрения рентных механизмов, способно изменить сложившуюся социально-экономическую ситуацию в регионе. Наиболее выгодной отраслью может стать картофелеводство, которое менее прихотливо к сложившимся условиям региона; такая отрасль позволит задействовать новую трудовую силу. Государственная поддержка простимулирует вовлечение неиспользуемых ресурсов в оборот.

Таким образом, в данном исследовании осуществлена разработка некоторых разделов схемы землеустройства субъекта РФ, которая является предплановым проектным документом и предназначена для разработки комплексной системы мероприятий, направленных на рациональное и эффективное использование земель региона.

\section{БИБЛИОГРАФИЧЕСКИЙ СПИСОК}

1. Хлыстун В. Н. Развитие земельных отношений в агропромышленном комплексе // Вестник Российской академии наук. - 2019. - Т. 89, № 7. - С. 669-677.

2. Официальный сайт Федеральной службы государственной регистрации, кадастра и картографии [Электронный ресурс]. - Режим доступа : https://rosreestr.ru (дата обращения 18.04.2021).

3. Белоусов А. О., Уварова Е. Л. Применение методик SPACE и SWOT-анализа для оценки территории Демянского района Новгородской области // Материалы І междунар. науч.-практ. конф. факультета землеустройства ВГАУ. - 2019. - С. 43-49.

4. Официальный сайт Правительства Новгородской области [Электронный ресурс]. - Режим доступа : https://www.novreg.ru/ (20.04.2021).

5. Официальный сайт Инвестиционного портала Новгородской области [Электронный ресурс]. Режим доступа : https://novgorodinvest.ru/ (20.04.2021).

6. Непоклонов В. Б., Хабарова И. А., Хабаров Д. А., Аверьянова Е. А., Гилюк А. В., Абдугапирова И. Ф., Киойбаш В. А. Использование экономико-математических методов и моделей для землеустроительных целей // Междунар. сельскохозяйственный журнал. - 2017. - № 6. - С. 30-33.

7. Рогатнев Ю. М. Новый этап развития землепользования и земельных отношений в пореформенный период // Землеустройство, кадастр и мониторинг земель. - 2017. - № 8. - С. 5-12.

8. Гарманов В. В., Шишов Д. А., Сулин М. А., Заварин Б. В., Павлова В. А., Глейзер В. И., Терлеев В. В., Уварова Е. Л., Осипов А. Г., Богданов В. Л., Баденко В. Л. Управление сельскохозяйственным землепользованием: прикладные аспекты : монография. - СПб. : СПбГАУ, 2018. Часть 1. - 247 с.

9. Карпик А. П., Жарников В. Б., Ларионов Ю. С. Рациональное землепользование в системе современного пространственного развития страны, его основные принципы и механизмы // Вестник СГУГиТ. - 2019. - Т. 24, № 4. - С. 232-246.

10. Липски С. А. Для восстановления деградированных и нарушенных земель требуется обновленное законодательное регулирование // Землеустройство, кадастр и мониторинг земель. - 2018. - № 11. C. 45-49.

11. Ефимова Г. А., Ефимова С. В., Булгаков П. Е. Рентный механизм развития аграрной кооперации // Качественный рост российского агропромышленного комплекса: возможности, проблемы и перспективы : материалы деловой программы XXVII междунар. агропромышленной выставки 
«АГРОРУСЬ-2018» (Санкт-Петербург, конгрессно-выставочный центр «ЭКСПОФОРУМ», 21-24 августа 2018 г.). - СПб. : СПбГАУ, 2018. - 318 с.

12. Уварова Е. Л. Сущность и современное содержание рационального и эффективного использования земельных ресурсов // Вестник факультета землеустройства Санкт-Петербургского государственного аграрного университета. - 2016. - № 2. - С. 24-27.

13. Ефимова Г. А., Ефимова С. В. Реализация принципов земельного законодательства в аграрных отношениях в РФ // Агропромышленный комплекс России: состояние, тенденции и перспективы развития, подготовка кадров. - 2019. - С. 24-28.

14. Vulević T., Todosijević M., Dragović N., Zlatic M. Land use optimization for sustainable development of mountain regions of western Serbia [Electronic resource] // Journal of Mountain Science. - 2018. - Vol. 15. - P. 1471-1480. - Mode of access : https://doi.org/10.1007/s11629-017-4777-1.

15. Миклашевская О. В., Сизов А. П. Совершенствование государственной политики в сфере пространственного развития сельскохозяйственных территорий // Актуальные вопросы землепользования и управления недвижимостью : сб. статей Всероссийской науч.-практ. конф. (с междунар. участием). 2019. - C. 343-352.

Получено 30.04.2021

(C) А. О. Белоусов, В. Л. Богданов, 2021

\section{METHOD FOR CALCULATING THE FORECAST OF THE DYNAMICS OF AGRICULTURAL LAND AREAS IN THE NOVGOROD REGION}

\section{Artem O. Belousov}

Saint-Petersburg State Agrarian University, 2, Peterburgskoe Shosse St., Pushkin, St. Petersburg, 196601, Russia, Ph. D. Student, Department of Land Management, phone: (996)945-56-17, e-mail: star042112@mail.ru

\section{Vladimir L. Bogdanov}

Saint-Petersburg State Agrarian University, 2, Peterburgskoe Shosse St., Pushkin, St. Petersburg, 196601, Russia, D. Sc., Professor, Department of Land Management, phone: (911)913-87-77, e-mail: lab.naz.eco@gmail.com

The article reveals the problem of irrational use of agricultural land and land relations in the Novgorod region. The most important sign of such use is the annual reduction in the area of this category. Based on the use of the SPACE analysis method by the authors to assess the level of agricultural development in the Novgorod region, taking into account its natural resource potential, the position of this region in the North-Western Federal District was determined as with low agricultural production, and a number of problems in the field of land relations in the region that hinder rational land use were identified. In order to identify these problems, the authors used the method of extrapolating a number of dynamics with the calculation of optimistic and pessimistic ways of developing land relations in the region. As a result, the authors systematized the main reasons for the destruction of land relations in the Novgorod region into natural, organizational, economic and social ones, and also developed directions for improving the use of agricultural land in the Novgorod region, including through the use of rental mechanisms, in order to achieve the rational use of such land.

Keywords: rational land use, agricultural land, SPACE analysis, land use forecast, method of extrapolation of a number of dynamics, land relations, differential rent

\section{REFERENCES}

1. Khlystun, V. N. (2019). Development of land relations in the agro-industrial complex. Vestnik rossiyskoy akademii nauk [Bulletin of the Russian Academy of Sciences], 89(7), 669-677 [in Russian].

2. The official website of the Federal service for state registration, cadastre and cartography. (n. d.). Retrieved from https://rosreestr.ru (accessed 18.04.2021) [in Russian].

3. Belousov, A. O., \& Uvarova, E. L. (2019). Application of SPACE and SWOT analysis methods for assessing the territory of the Demyansky district of the Novgorod region. In Sbornik materialov I mezhdu- 
narodnoy nauchno-prakticheskoy konferentsii fakul'teta zemleustroystva VGAU [Proceedings of the I International Scientific and Practical Conference of the Faculty of Land Management of VGAUJ (pp. 43-49).

4. The official website of the Government of the Novgorod region. (n. d.). Retrieved from https://www.novreg.ru/ (accessed 20.04.2021).

5. Official website of the Investment portal of the Novgorod region. (n. d.). Retrieved from https://novgorodinvest.ru/ (accessed 20.04.2021).

6. Nepoklonov, V. B., Khabarova, I. A., Khabarov, D. A., Averyanova, E. A., Gilyuk, A. V., Abdugapirova, I. F., \& Kioibash, V. A. (2017). The use of economic and mathematical methods and models for land management purposes. Mezhdunarodnyy sel'skokhozyaystvennyy zhurnal [International Agricultural Journal], 6, 30-33 [in Russian].

7. Rogatnev, Yu. M. (2017). A new stage in the development of land use and land relations in the postreform period. Zemleustroystvo, kadastr i monitoring zemel' [Land Management, Cadastre and Land Monitoring], 8, 5-12 [in Russian].

8. Garmanov, V. V., Shishov, D. A., Sulin, M. A., Zavarin, B. V., Pavlova, V. A., Gleyzer, V. I., Terleev, V. V., Uvarova, E. L., Osipov, A. G., Bogdanov, V. L., \& Badenko, V. L. (2018). Upravlenie sel'skokhozyaystvennym zemlepol'zovaniem: prikladnye aspekty: T. Ch. 1 [Management of agricultural land use. applied aspects: Vol. Part 1]. Saint Petersburg: Saint Petersburg State Agrarian University Publ., 247 p. [in Russian].

9. Karpik, A. P., Zharnikov, V. B., \& Larionov, Yu. S. (2019). Rational land use in the system of modern spatial development of the country, its basic principles and mechanisms. Vestnik SGUGiT [Vestnik SSUGT], 24(4), 232-246 [in Russian].

10. Lipsky, S. A. (2018). For the restoration of degraded and disturbed lands, updated legislative regulation is required. Zemleustroystvo, kadastr i monitoring zemel' [Land Management, Cadastre and Land Monitoring], 11, 45-49 [in Russian].

11. Efimova, G. A., Efimov, S. V., \& Bulgakov, P. E. (2018). Rent a mechanism for the development of agricultural cooperative societies. In Sbornik materialov delovoy programmy XXVII mezhdunarodnoy agropromyshlennoy vystavki "AGRORUS'-2018": Kachestvennyy rost rossiyskogo agropromyshlennogo kompleksa: vozmozhnosti, problemy i perspektivy [Proceedings of the Business Program of the XXVII International Agricultural Exhibition "AGRORUS - 2018": Qualitative Growth of the Russian Agroindustrial Complex: Opportunities, Problems and Prospects] (318 p.). Saint Petersburg: Saint Petersburg State Agrarian University Publ. [in Russian].

12. Uvarova, E. L. (2016). The essence and modern content of rational and effective use of land resources. Vestnik fakul'teta zemleustroystva Sankt-Peterburgskogo gosudarstvennogo agrarnogo universiteta [Bulletin of the Faculty of Land Management of the Saint Petersburg State Agrarian University], 2, 24-27 [in Russian].

13. Efimova, G. A., \& Efimova, S. V. (2019). Implementation of the principles of land legislation in agrarian relations in the Russian Federation. Agropromyshlennyy kompleks Rossii: sostoyanie, tendentsii i perspektivy razvitiya, podgotovka kadrov [Agroindustrial Complex of Russia: State, Trends and Prospects of Development, Training of Personnel] (pp. 24-28) [in Russian].

14. Vulević, T., Todosijević, M., Dragović, N., \& Zlatic M. (2018). Land use optimization for sustainable development of mountain regions of western Serbia. Journal of Mountain Science, 15, 1471-1480. Retrieved from https://doi.org/10.1007/s11629-017-4777-1.

15. Miklashevskaya, O. V., \& Sizov, A. P. (2019). Improvement of state policy in the sphere of spatial development of agricultural territories. In Sbornik statey Vserossiyskoy nauchno-prakticheskoy konferentsii (s mezhdunarodnym uchastiem): Aktual'nye voprosy zemlepol'zovaniya i upravleniya nedvizhimost'yu [Proceedings of the All-Russian Scientific and Practical Conference (with International Participation)] (pp. 343-352).

Received 30.04.2021

(C) A. O. Belousov, V. L. Bogdanov, 2021 
УДК [349.41:632.123.1]+614.8

DOI: $10.33764 / 2411-1759-2021-26-5-156-168$

\section{АКТУАЛЬНЫЕ ВОПРОСЫ НОРМАТИВНО-ПРАВОВОГО И ТЕХНОЛОГИЧЕСКОГО ОБЕСПЕЧЕНИЯ КАДАСТРОВЫХ РАБОТ ПО УСТАНОВЛЕНИЮ ГРАНИЦ ЗОН ЗАТОПЛЕНИЯ И ПОДТОПЛЕНИЯ ДЛЯ ЗАЩИТЫ ОБЪЕКТОВ НЕДВИЖИМОСТИ ОТ ЧРЕЗВЫЧАЙНЫХ СИТУАЦИЙ}

\section{Алексей Викторович Дубровский}

Сибирский государственный университет геосистем и технологий, 630108, Россия, г. Новосибирск, ул. Плахотного, 10, кандидат технических наук, зав. кафедрой кадастра и территориального планирования, тел. (383)-361-01-09, e-mail: avd5@ssga.ru.

\section{Елена Андреевна Скоринская}

Верхне-Обское бассейновое водное управление, 630087, Россия, г. Новосибирск, ул. Немировича-Данченко, 167, ведущий специалист-эксперт, тел. (383)314-89-15, e-mail: bvu_501@ngs.ru

\section{Александр Раднажапович Батуев}

Иркутский национальный исследовательский технический университет, 664074, Россия, г. Иркутск, ул. Лермонтова, 83, доктор географических наук, профессор кафедры маркшейдерского дела и геодезии, тел. (902)766-56-08, e-mail: arbatuev.irk@yandex.ru

\section{Вячеслав Георгиевич Колмогоров}

Сибирский государственный университет геосистем и технологий, 630108, Россия, г. Новосибирск, ул. Плахотного, 10, доктор технических наук, профессор-консультант кафедры геоматики и инфраструктуры недвижимости, тел. (383)361-07-09, e-mail: kaluzhin@mail.ru

\section{Леонид Александрович Пластинин}

Иркутский национальный исследовательский технический университет, 664074, Россия, г. Иркутск, ул. Лермонтова, 83, доктор технических наук, научный руководитель Центра космических технологий и услуг, профессор кафедры маркшейдерского дела и геодезии, тел. (950)122-27-23, e-mail: irkplast@mail.ru

\section{Валерий Иванович Татаренко}

Сибирский государственный университет геосистем и технологий, 630108, Россия, г. Новосибирск, ул. Плахотного, 10, доктор экономических наук, профессор кафедры техносферной безопасности, тел. (383)344-42-00, e-mail: v.i.tatarenko@ssga.ru

В Российской Федерации с 2014 г. ведутся работы по установлению зон затопления и подтопления вблизи водных объектов. Законодательно установлено внесение сведений о границах этих зон в Единый государственный реестр недвижимости, однако не решен ряд нормативно-правовых и технологических вопросов по установлению зон затопления и подтопления и данные работы не выполнены в полном объеме. В статье выполнен анализ руководящих нормативных документов, а также принятых в 2019 г. поправок, призванных усовершенствовать процедуру установления зон затопления и подтопления. В качестве аргументации актуальности работ по определению зон затопления и подтопления рассмотрены примеры катастрофических наводнений на территории Российской Федерации, которые причинили миллиардные убытки государству, а также собственникам объектов недвижимости. Обоснована необходимость компьютерного прогнозного моделирования чрезвычайных ситуаций, связанных с затоплением территорий и определением границ геопространства чрезвычайной ситуации - зон затопления и подтопления. Приведена технологическая схема действий для определения геопространства чрезвычайной ситуации. Построены цифровые прогнозные модели зон затопления на территории Новосибирска при катастрофическом затоплении. Приведена информация о зарегистрированной геоинформационной базе данных зон затопления населенных пунктов Новосибирской области в результате сезонного паводка. Для оптимизации процессов внесения информации о зонах затопления и подтопления в Единый государственный реестр недвижимости разработана и внедрена в производство ра- 
бот Верхне-Обского бассейнового водного управления технологическая схема по установлению зон затопления и подтопления. Показано положительное влияние определения и закрепления в государственном информационном ресурсе сведений о границах зон затопления и подтопления. В частности, эта информация позволяет выполнить оценку территориальной устойчивости пространственных структур земельно-имущественных комплексов. На основании статистических данных об ущербе изза наводнений сделан вывод о необходимости снижения налогов на недвижимость в зонах возможного проявления чрезвычайных ситуаций и перераспределения финансовых средств собственников недвижимости для страхования имущества.

Ключевые слова: объекты недвижимости, земельно-имущественные комплексы, геоинформационные системы, кадастровые работы, зоны затопления, зоны подтопления, гидротехническое сооружение, обеспеченность паводка, чрезвычайная ситуация, градостроительная деятельность, территориальное управление, защита населения

\section{Введение}

В настоящее время чрезвычайные ситуации, связанные с затоплением территорий, имеют широкое распространение. Их негативное влияние сопровождается существенными экономическими потерями как со стороны государства, так и со стороны отдельных владельцев объектов недвижимости. Это обусловлено тем, что при затоплении резко ухудшаются свойства земельных участков, а находящиеся на них объекты недвижимости могут потерять часть от своей рыночной стоимости. Снижение стоимости может происходить вплоть до полного обесценивания объекта недвижимости, например, из-за его разрушения или нанесения ущерба, не подлежащего восстановлению. Важнейшее свойство земель, проявляющееся в плодородии, также может существенно утратиться вследствие затопления. Последствия могут заключаться в переувлажнении и заболачивании почвы, ее загрязнении как продуктами разрушения конструктивных элементов объектов недвижимости, так и в результате попадания в почву твердых коммунальных отходов или опасных химических веществ (например, пестицидов, нитратов с сельскохозяйственных угодий или золы и шлака с предприятий топливно-энергетического комплекса). Высокую угрозу при наводнении представляет размыв мест утилизации потенциально опасных биологических веществ (например, биологических отходов с животноводческих и птицеводческих ферм и т. п.).

При описании территории, на которой во3никла чрезвычайная ситуация, связанная с наводнением, необходимо точно обозначить контуры и указать характеристики зон затопления. Границы зон затопления (33) и зон подтопления (ЗП) с 2014 г. подлежат определению, и информация по ним вносится в Единый государственный реестр недвижимости $[1,2]$. Сведения о границах таких зон включают графическое представление зоны и координаты характерных точек. Благодаря этому появилась возможность информационного обеспечения всех хозяйствующих субъектов о потенциальной опасности наводнений на территории их деятельности, а также перспективного планирования мероприятий по предотвращению этих чрезвычайных ситуаций. Несмотря на важность проведенных государством преобразований законодательной базы, регулирующей нормативно-правовые особенности установления 33 и ЗП, ежегодно выявляется более 250 нарушений в установлении этих зон только на территории Новосибирской области. В связи с этим актуальной является разработка технологического обеспечения кадастровых работ по установлению границ 33 и ЗП для защиты объектов недвижимости от чрезвычайных ситуаций.

\section{Методы и объект исследования}

При выполнении исследований в работе были использованы следующие научные методы исследований: системный подход и системный анализ, методы геоинформационного анализа и проектирования, нормативноправовое обеспечение земельного, водного и градостроительного законодательств РФ. 
Для практической апробации результатов исследования были использованы данные по ЧС на территории города Новосибирска, полученные департаментом по чрезвычайным ситуациям и мобилизационной работе мэрии Новосибирска, данные о паводковой обстановке Верхне-Обского бассейнового водного управления, а также собственные разработки Сибирского государственного университета геосистем и технологий: прогнозная модель затопления территории города Новосибирска в результате разрушения дамбы Новосибирского водохранилища, модель паводковой обстановки при критическом уровне воды в реке Оби, а также модели затопления и подтопления населенных пунктов Новосибирской области.

\section{Результаты исследования и их обсуждение}

В советской России жилищное строительство являлось важнейшей отраслью народного хозяйства. Приоритетной задачей государства было обеспечение в короткие сроки граждан жильем, при этом вопросам регулирования градостроительной деятельности не уделялась должного внимания. Отсутствие такой необходимости можно объяснить и тем, что земли принадлежали государству, большая часть возводимого жилья предполагалась для временного использования. Лишь с восстановлением института частной собственности вопросы градостроительства и выбора безопасных экологически комфортных условий для расположения объектов недвижимости приобрели особую актуальность. В 1992 г. был принят первый федеральный закон «О регулировании градостроительства в Российской Федерации», а впоследствии в 1998 г. - первый Градостроительный кодекс [3].

Долгое время строительство и размещение объектов недвижимости вблизи водных объектов основывалось на главном принципе - соблюдение режима водоохранных зон, прибрежных защитных полос (В3, ПЗП), который периодически подвергался изменениям в сторону «упрощения» самого режима, требований к порядку определения, а также уменьшения размера границ В3 и ПЗП. Сдерживающим механизмом размещения объектов вблизи водоемов служит береговая полоса водного объекта, которая, согласно действующему законодательству, является территорией общего пользования [2].

Так как большинство зон с особыми условиями использования территорий (ЗОУИТ) считаются установленными и отображаются на публичной кадастровой карте, схемах территориального планирования, градостроительного зонирования со дня внесения в ЕГРН, при проведении оценочных работ по определению кадастровой и рыночной стоимости объектов недвижимости не учитывается факт нахождения объекта в ЗОУИТ, а также ограничения на его использование, что повышает спрос на территории вблизи водных объектов, но не исключает рисков [4]. Согласно отчету компании «Авито», в 2019 г. спрос на недвижимость вблизи водоемов в среднем по регионам вырос на $38 \%$, а стоимость, например, в Ленинградской области повысилась на 9 \%, в Новосибирской области стоимость увеличилась на 8,7 \%, в Ставропольском крае на 10,6 \% [5].

Еще одной причиной осложнения прохождения паводков и наводнений являются гидродинамические аварии. Это аварии, связанные с выходом из строя гидротехнических сооружений (ГТС). Наибольшую опасность представляют водонапорные ГТС, представленные плотинами малых и средних водохранилищ. Большинство из малых и средних водохранилищ было построено в 1960-70-е гг. и часть их имеет статус бесхозных ГТС. Это ГТС, сведения о которых не вносились в Российский регистр гидротехнических сооружений, не поставленные на учет как объекты недвижимости. Как правило, к таким бесхозным ГТС, представляющим потенциальную опасность, относятся сельскохозяйственные пруды, используемые для местных нужд, не имеющие проектной документации [6]. ГТС, которые используются для энергетики, промышленности, транспорта, к бесхозным относятся редко. Они подлежат строгому надзору различных органов: Ростехнадзора, МЧС, Минстроя, Росприроднадзора, Минприроды и ряда других. Такие ГТС имеют декларации 
безопасности, паспорта ГТС, правила использования и другие документы. Но аварии на них случаются нередко, а масштабы значительны. Причинами таких аварий являются ошибки в эксплуатации, несоблюдение установленных норм и правил, износ ГТС, ошибки при проектировании.

Например, в результате паводков в Иркутской области прорвало защитную дамбу на реке Ии в городе Тулуне, а затем под напором воды не выдержала дамба на реке
Оке, что значительно осложнило прохождение дождевого паводка в 2019 г. и привело к разрушительным последствиям (рис. 1). В результате наводнения погибли 25 человек, без вести пропавшими числятся 11. Всего в Тулунском, Тайшетском, Нижнеудинском и Чунском районах было затоплено почти 11 тысяч домов, в которых живут 34,2 тыс. человек, 8 тыс. из них - дети. Число нуждающихся в материальной помощи достигло почти 38 тыс. человек $[7,8]$.

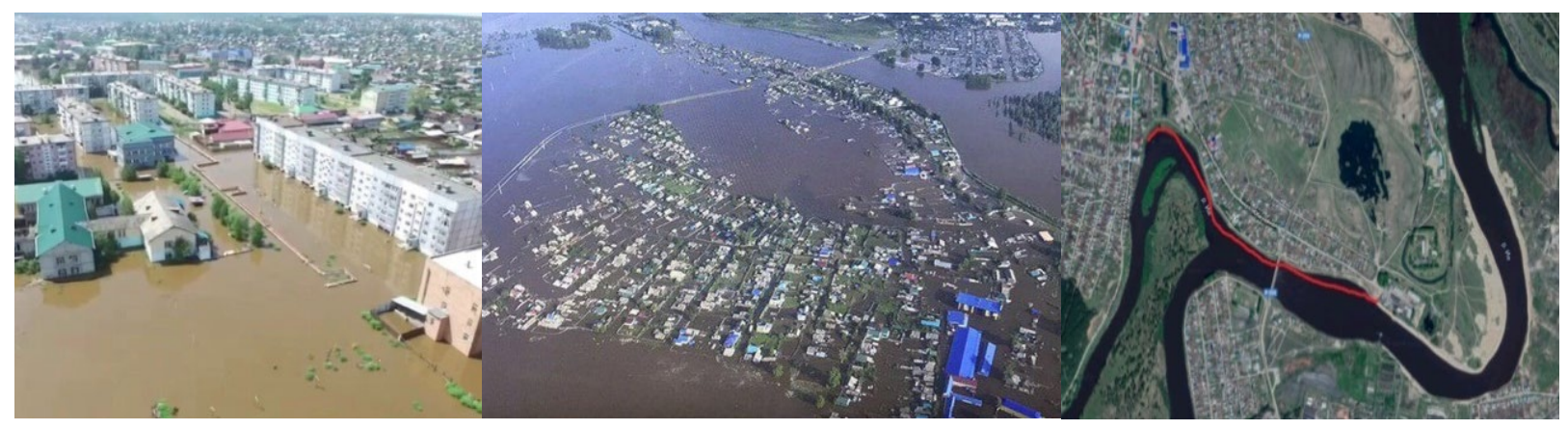

Рис. 1. Фотоиллюстрации последствий наводнения в городе Тулуне (красной линией показано положение разрушенной под напором воды дамбы)

Дамба в Тулуне разрушилась под действием паводковых вод, так как была спроектирована из расчета максимального поднятия воды 9 м, на основании 100-летних наблюдений. При этом пик поднятия 7 м был отмечен в 1984 г. В 2019 г. уровень воды поднялся на $14 \mathrm{M}$.

Последствия прохождения крупных паводков за последние 20 лет в СФО на таких реках, как Кондома в Кемеровской области (города Новокузнецк, Осинники, Калтан), в вышеупомянутой Иркутской области указали на ряд проблем, а также на ряд неурегулированных земельным, градостроительным законодательством вопросов, осложняющих процесс оказания помощи населению, защите населения и территорий от подобных ЧС. Например, отсутствие зарегистрированных прав собственности или утрата в результате ЧС правоустанавливающих документов затрудняет или делает невозможным процесс признания жилых помещений непригодными для проживания, восстановления утраченного имущества, оценки нанесенного ущерба муниципальному образованию в целом.
Все эти факторы в совокупности обосновали необходимость совершенствования механизма защиты территорий и объектов недвижимости от негативного влияния вод с проведением комплекса кадастровых, землеустроительных и инвентаризационных работ. По поручению президента в 2017 г. правительству совместно с органами МЧС и органами государственной власти субъектов РФ необходимо в кратчайшие сроки принять меры по реализации противопаводковых мероприятий, защиты населения от ЧС [8].

Исходя из анализа содержания Водного кодекса, защитить население и объекты инфраструктуры, недвижимости от затоплений, подтоплений возможно [9]:

- путем строительства инженерной защиты на освоенных территориях, в предполагаемых зонах ЧС, связанных с наводнениями и подтоплениями;

- путем запрета возведения новых объектов на паводко-опасных участках.

Таким образом, возникает главная задача - определить границы зон затопления, подтопления (границы 33, 3П). 
В 2014 г. вступило в силу постановление Правительства, устанавливающее правила определения границ зон затопления, подтопления, которое впоследствии дважды претерпевает изменения: в 2016 г., после исключения зон затопления, подтопления из объектов землеустройства и отнесения их к ЗОУИТ, и в 2019 г., в части контроля выполнения работ и их сроков [10]. Принципиальными отличиями действующей редакции № 3 от постановления в редакции № 2 от 17.05.2016 являются:

- включение территориального управления Росреестра как согласующего органа при установлении границ 33 и ЗП для водных объектов;

- установление пятидневного срока для направления сведений в Государственный вод- ный реестр и ЕГРН, уведомление органов местного самоуправления о принятии решения об установлении границ 33 и ЗП для водных объектов, МЧС о внесении сведений в ЕГРН;

- требования к территориям, входящим в границы 33 и ЗП.

Порядок установления границ 33, ЗП показан на рис. 2. Согласно постановлению, 33, ЗП могут быть установлены или изменены решением Федерального агентства водных ресурсов на основании предложений министерства природных ресурсов субъекта РФ и органа местного самоуправления и сведений, содержащих графическое описание местоположения границ, этих зон, перечень координат характерных точек границ [10].

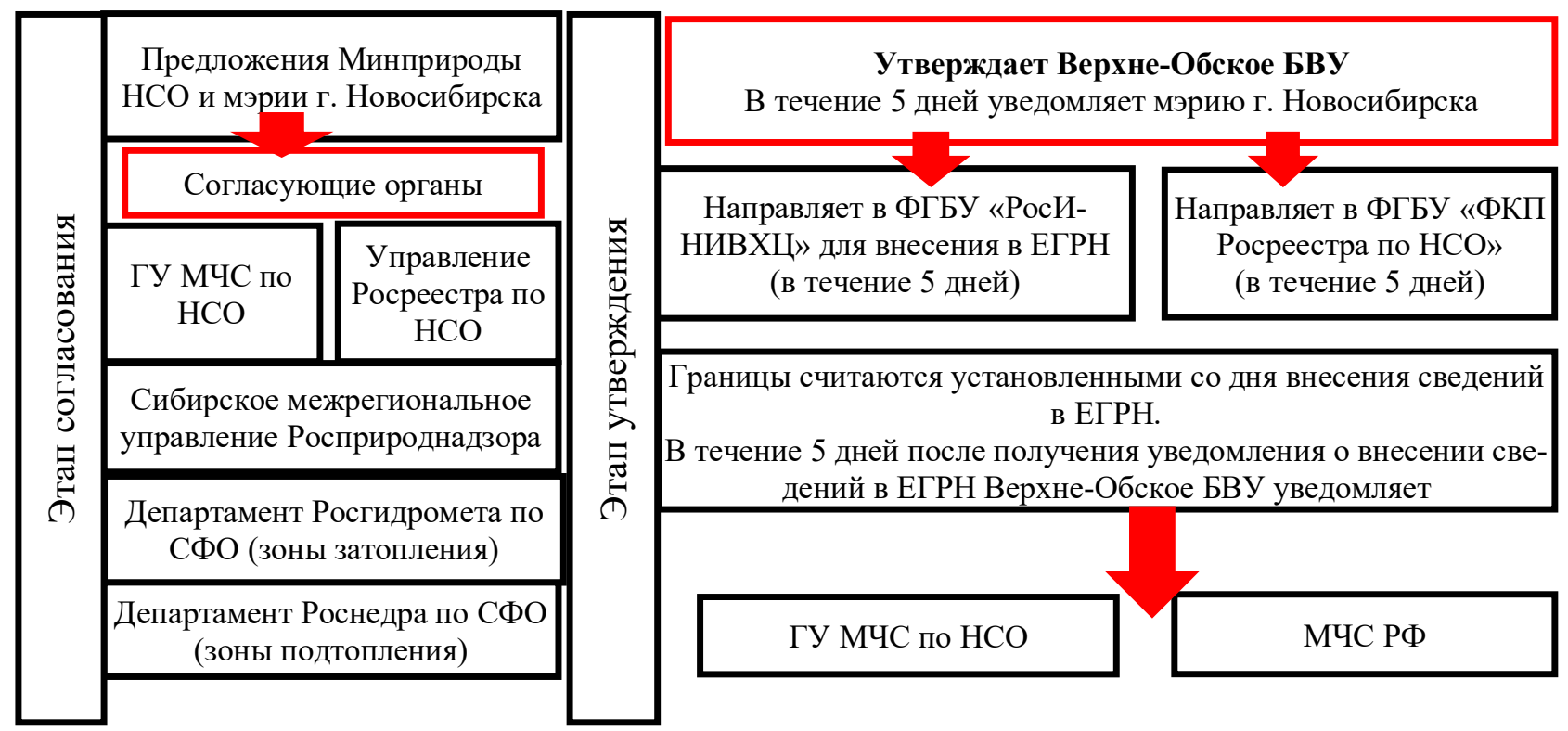

Рис. 2. Порядок установления границ 33, ЗП на примере НСО

Кроме задачи разработки технологии установления 33 и ЗП нерешенным остается вопрос о порядке изменения или прекращении существовании этих зон. В постановлении говорится о том, что зоны могут прекратить свое существование лишь одновременно с прекращением существования водного объекта. Граница зоны может быть изменена только в результате:

- возникновения аварий или иных ЧС, в результате прохождения паводка $1 \%$ обеспеченности (1 раз в 100 лет);

- сложной ледовой обстановки, пропуска вод в катастрофически большом количестве (не реже 1 раза в 10 лет);
- внесение изменений в документы территориального планирования, градостроительного зонирования и документацию по планировке территорий.

При этом отсутствует возможность корректировать границу 33, ЗП при искусственном изменении русла и дна водных объектов, строительстве объектов инженерной защиты территорий. Это значит, что территории, обеспеченные инженерной защитой, также будут находиться в зоне затопления, подтопления.

Постановление Правительства РФ существенно ограничивает территории, в отноше- 
нии которых допустимо определять границы зон затопления и подтопления. Новая редакция постановления внесла изменения в требования к территориям, входящим в границы 33, ЗП. Ранее в пункте 1 а) на незарегулированных водотоках (на реках, ручьях, каналах, на которых отсутствуют гидроузлы или отдельные ГТС, регулирующие естественный сток) выделялись зоны, затапливаемые в результате ледовых заторов и зажоров, а также зоны, затапливаемые при паводках повторяемостью раз в 1, 3, 5, 10, 25 и 50 лет. Теперь на таких водотоках определяются зоны при половодьях и паводках только однопроцентной обеспеченности, то есть повторяемостью 1 раз в 100 лет. Поэтому приобретая имущество, возведенное до установления границ 33, 3П вблизи водных объектов без инженерной защиты от наводнений и паводков, нельзя в полной мере оценить риски утраты и возможность компенсации в результате частичного или полного разрушения объекта недвижимости.

Пункт 1 д) указывает на необходимость определять границы 33, ЗП для территорий нижних бьефов гидроузлов при пропуске паводков расчетной обеспеченности гидроузла. Например, г. Новосибирск находится в нижнем бьефе Новосибирского гидроузла. Новосибирский гидроузел состоит из Новосибирского водохранилища, здания ГЭС, плотины
ГЭС и судоходного шлюза, имеет первый класс опасности (ГТС чрезвычайно высокой опасности). Расчетная обеспеченность гидроузла $0,01 \%$, согласно техническому проекту и «Правилам эксплуатации водохранилища Новосибирской ГЭС». Это значит, что он способен пропустить паводок в таком объеме, который повторяется 1 раз в 10 тыс. лет. Определить объем пропуска и уровень воды при таком паводке крайне трудно, расчеты основываются на математической модели максимальных паводков за историю наблюдения. Например, для Новосибирского водохранилища по моделям весеннего половодья 1937 и 1969 гг., согласно проектным и расчетным характеристикам, при паводке 0,01 \% пропускная способность Новосибирского гидроузла через турбины ГЭС, водосливную плотину холостых сбросов, донные водосбросы и шлюзовой канал составляет около 23 тыс. м $^{3} / \mathrm{c}$, при среднем ежегодном расходе $-2000 \mathrm{~m}^{3} / \mathrm{c}$ и максимальном за последние шесть лет - $6246 \mathrm{~m}^{3} / \mathrm{c}$, при притоке $7500 \mathrm{~m}^{3} / \mathrm{c}$ (паводок $50 \%$ обеспеченности, повторяемостью 1 раз в 50 лет, 2015 г.). При уровне воды в реке Оби 350 380 см и объеме сброса около $3800 \mathrm{~m}^{3} / \mathrm{c}$ начинается затопление садовых товариществ Первомайского района: СНТ «Геолог», СНТ «Геофизик», СНТ «Дорожник», СНТ «Театральный», отображенных на рис. $3[11,12]$.

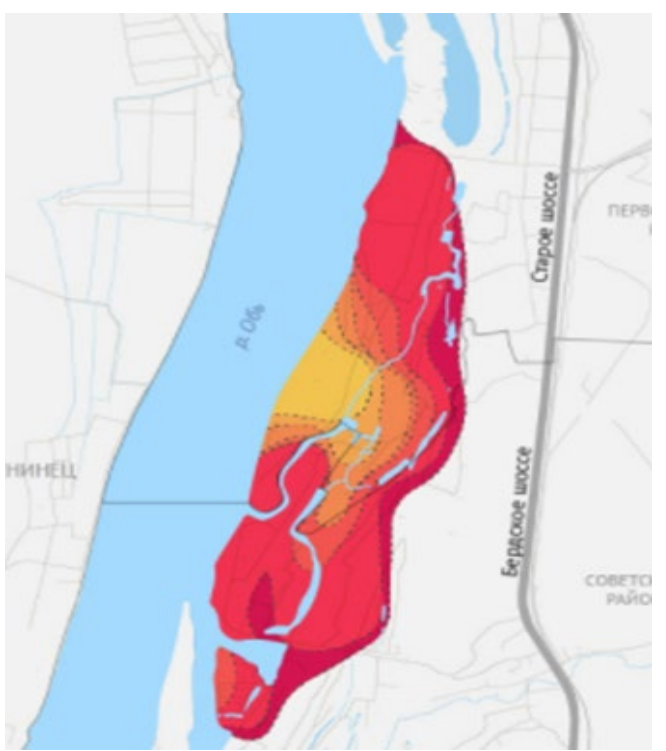

a)

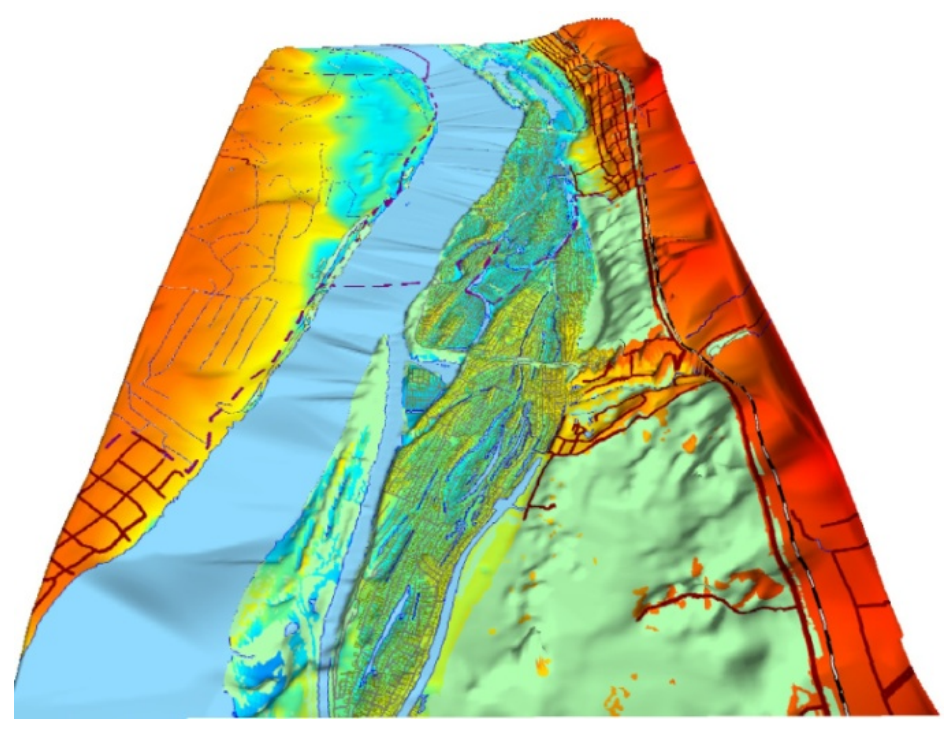

б)

Рис. 3. Иллюстрация 33 и ЗП на территории Советского

и Первомайского районов Новосибирска:

a) границы 33 и ЗП при сезонном паводке; б) объемная модель территории в 33 и ЗП) 
Затруднительно объяснить целесообразность определения такой границы, так как под ограничения использования объектов недвижимости и хозяйственной деятельности будут попадать огромные территории. При этом ограничения для всех территорий, попадающих в зоны затопления, при разной обеспеченности паводков одинаковы. Очевидно, что для каждой зоны затопления необходимо вводить разные виды ограничений, основываясь на особенностях прохождения паводков и характеристик самих территорий и водного объекта. Кроме того, обеспечить инженерной защитой территорию, подверженную катастрофическому паводку, проходящему 1 раз в 10 тыс. лет, крайне сложно, а порой это является нерешаемой инженерной и строительной задачей. К тому же требование защитить территорию от паводка $0,01 \%$ противоречит своду правил «Градостроительство. Планировка и застройка городских территорий», поскольку указывает на необходимость строительства инженерной защиты застроенных или подлежащих застройке территорий от паводка $1 \%$ обеспеченности, повторяемостью 1 раз в 100 лет [13]. В 2020 г. такая зона затопления и прилегающая к ней зона подтопления были утверждены и внесены в ЕГРН, что послужило требованиям правообладателей недвижимости в их границах защитить территории от негативного влияния вод или пересмотреть размеры установленных границ зон.

С подобными требованиями с 2017 г. в суды общей юрисдикции обращались жители Алтайского края, которым было отказано в выдаче разрешений на строительство индивидуальных жилых домов на участках, принадлежащих им на праве собственности до того, как в отношении таких участков были установлены границы 33, 3П [14].

Определение границ 33 для нижних бьефов гидроузлов, особенно таких крупных, как Новосибирский гидроузел, имеющий чрезвычайно высокий класс опасности, не может основываться только на нормах, указанных в постановлении. Если рассматривать Новосибирск, то сложность определения территорий, попадающих в 33, ЗП, заключается в том, что ниже плотины ГЭС находятся и другие водные объекты, которые впадают в реку Обь и могут усложнить прохождение паводка, или наоборот, высокий уровень воды в реке Оби может вызвать подъем уровня воды в водных объектах (не только притоков первого порядка) и привести к затоплению и подтоплению территорий. Руководствуясь нормами постановления, невозможно учесть влияние водных объектов друг на друга при различной гидрометеорологической обстановке и не имеющих гидравлической связи. В результате в ЕГРН вносятся сведения не в полном объеме, что может являться причиной разрешения строительства объектов недвижимости на потенциально опасных территориях.

Кроме того, постановление Правительства предусматривает определение границ зон подтопления, прилегающих к зоне затопления. Предусматривается определение границ только на тех территориях, где подтопления вызваны высоким уровнем вод в поверхностном водном объекте и поднятием уровня грунтовых вод. Определение территорий с отрицательными формами рельефа, близким расположением к поверхности подземных водных объектов (водоносных горизонтов, бассейнов подземных вод, месторождений подземных вод) не предусматривается. При этом не существует никаких других документов, указывающих на необходимость и регламентирующих порядок определения таких зон. Такие территории останутся не определенными и не изученными, а объекты недвижимости и инфраструктуры не защищенными, пока не будут внесены соответствующие изменения в требования к территориям, входящим в 33, ЗП.

В настоящее время определен перечень ограничений, одинаковых как для зон затопления, так и для зон подтопления:

- размещение новых населенных пунктов и строительство объектов капитального строительства без обеспечения инженерной защиты таких населенных пунктов и объектов от затопления, подтопления;

- осуществление авиационных мер по борьбе с вредными организмами;

- использование сточных вод в целях регулирования плодородия почв;

- размещение кладбищ, скотомогильников, объектов размещения отходов производства и потребления, химических, взрывчатых, 
токсичных, отравляющих и ядовитых веществ, пунктов их хранения и захоронения.

При этом характер воздействия вод на здания, строения, сооружения при затоплении и подтопления грунтовыми водами разный. По этой причине необходимо разработать и нормативно закрепить разные виды запретов, касающихся ведения хозяйственной деятельности на таких территориях [14].

Для того чтобы в полном объеме определить территории муниципальных образований, подверженных затоплению, подтоплению и внести сведения в ЕГРН, необходимо пересмотреть требования к территориям в отношении которых определяются границы 33, 3П. Определить границы зон затопления и подтопления для искусственно регулируемых водных объектов невозможно, основываясь на сведениях об отметках высот территорий и сведениях о расходах и уровне воды при разной обеспеченности паводка. Необходимо создание гидродинамической модели, которая будет учитывать и различные условия, которые оказывают влияние на характер и размеры затопления территорий. Например, этими факторами могут быть: плотность застройки территорий, количество и места установки мостовых сооружений, характеристика подземных водных объектов, тип и свойства грунтов и слагающих пород, другие водные объекты.

При создании цифровых имитационных гидрологических моделей и определении прогнозных зон затопления предлагается оперировать понятием геопространства чрезвычайной ситуации (ГЧС). ГЧС - это ограниченное факторами влияния чрезвычайной ситуации множество пространственных объектов, процессов и явлений. Для характеристики ГЧС предлагается использовать различные классификационные признаки. Для определения территориальной локализации ГЧС применима традиционная классификация ЧС на глобальные, континентальные, региональные, локальные. Определяя распространение ЧС, следует различать геопространство ЧС, которая произошла в географической, геологической, космической среде. ГЧС по распространению может охватывать несколько сред. Ранжирование ЧС по величине ущерба также является одной из важных классификационных характеристик, однако этот показатель не оказывает прямого влияния на определение ГЧС как пространственно-временную зону ЧС. Ущерб может быть фактическим и прогнозным. Как правило, величина прогнозного ущерба определяется по значению максимального распространения ГЧС. Временной фактор может значительно расширить локализацию ГЧС. Для создания цифровой модели ГЧС необходимо не только определить пространственную границу ЧС, но и исследовать влияние ЧС на различные природные среды. Схема последовательности действий для определения геопространства чрезвычайной ситуации показана на рис. 4 [15].

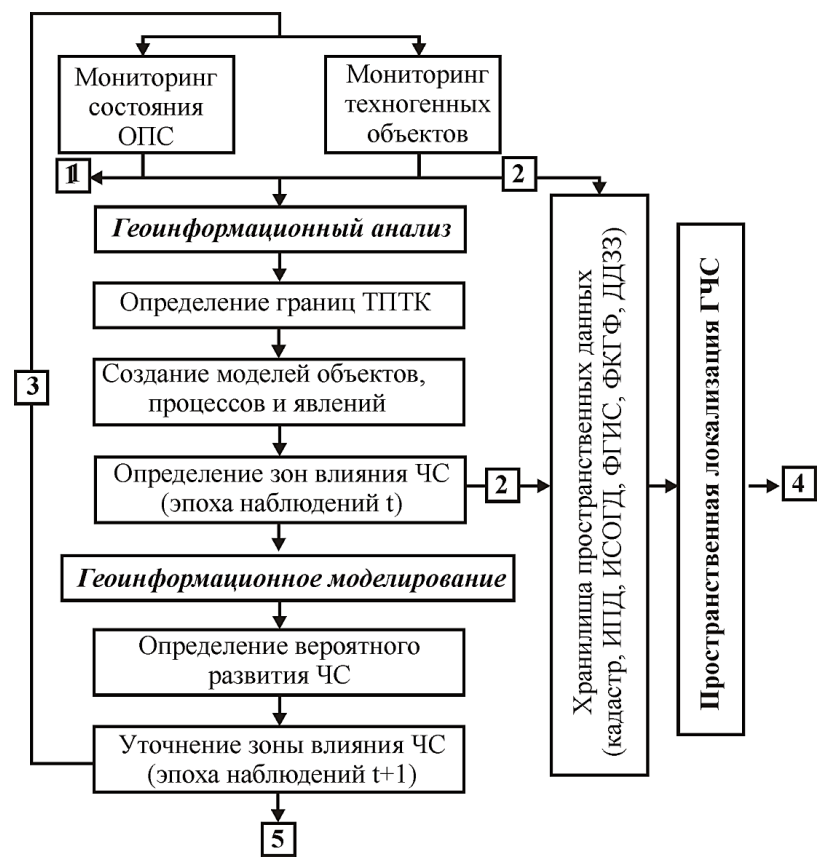

Рис. 4. Пространственная локализация ГЧС

На рис. 4 цифрами обозначены следующие этапы работ МЧС: 1 - предупреждение развития ЧС на этапе мониторинга территории; 2 - передача данных мониторинга в государственные хранилища пространственных данных (информация получает статус государственной); 3 - цикл постоянных наблюдений за состоянием природной и техногенной сферы; 4 - комплекс мер по ликвидации последствий ЧС; 5 - оповещение населения, принятие мер по минимизации воздействия ЧС.

Прогнозная модель зон затопления при катастрофическом паводке на примере территории Новосибирска показана на рис. 5. 


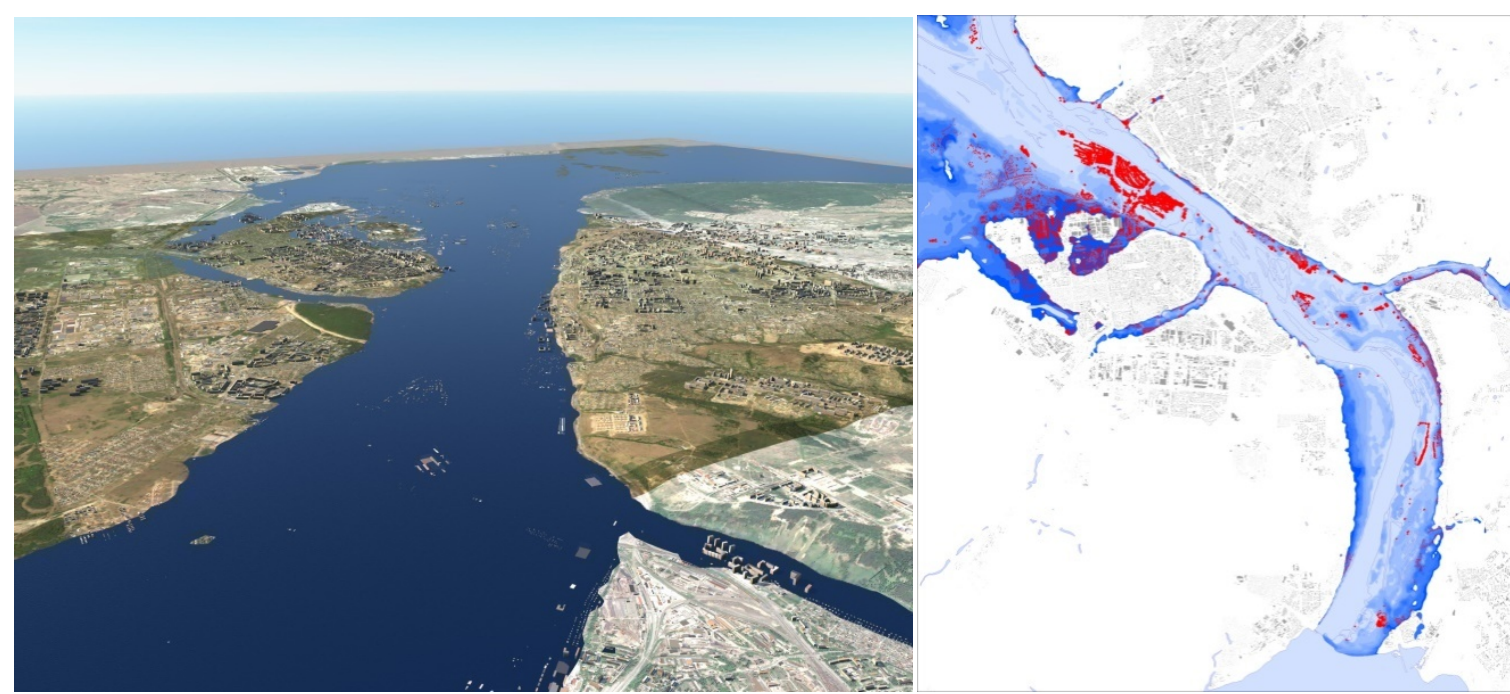

Рис. 5. Прогнозная модель зон затопления при катастрофическом паводке на примере территории Новосибирска. Красными контурами показаны объекты недвижимости, попадающие в прогнозную зону затопления

\section{Заключение}

Определение ГЧС позволяет планировать территориальную устойчивость с использованием геоинформационных систем и осуществлять как превентивные меры защиты территории от ЧС, так и полностью свести к минимуму возможные последствия ЧС при недопущении расположения объектов недвижимости в ГЧС $[15,16]$.

Подводя итоги, можно сделать выводы о том, что определение границ 33, ЗП позволяет:

- осуществлять эффективное планирование территорий с учетом рисков возникновения ЧС;

- обосновать необходимость строительства гидротехнических объектов и обеспечить территории инженерной защитой от затоплений, подтоплений;

- в короткие сроки оказывать помощь населению, имущество которого полностью или частично разрушено, при утрате правоустанавливающих документов в результате ЧС;

- на основании сведений ЕГРН об объектах, попадающих в 33, 3П, оценивать масштабы ущерба для планирования бюджета на осуществление мероприятий по ликвидации последствий ЧС;

- определять размер страхового платежа и сумму страхования для имущества с учетом рисков утраты или повреждения имущества в результате негативного влияния вод.

Также следует учесть, что с 2020 г. в России вступил в силу закон о страховании жилья граждан. По данным аналитиков, в России застраховано от ЧС только $8 \%$ объектов жилой недвижимости, тогда как в США и Европе этот показатель достигает $90 \%$. Одна из причин низкой заинтересованности собственников в страховании недвижимости заключается в отсутствии информации о возможных ЧС и их последствиях. Новый закон направлен на выполнение работ по определению наиболее актуальных для каждого региона рисков возникновения ЧС. При точном определении прогнозных зон ГЧС возможно введение сниженных ставок налога на недвижимость, находящуюся в этих зонах. Это, в свою очередь, позволит перенаправить полученные в результате экономии на налогах финансовые средства на страхование объектов недвижимости, находящихся в прогнозных зонах ГЧС.

Работы по установлению 33 и ЗП приобретают особую актуальность в свете состоявшегося 27.09.2021 заседания Совета безопасности РФ и выступления Президента РФ В. В. Путина о необходимости скорейшего рассмотрения и принятия федерального закона «О стратегическом планировании» и «Стратегии национальной безопасности». 
В рамках этих документов планируется регламентировать стратегические направления безопасности как для территории России, так и ее граждан, защитив их от внешних и внутренних угроз, в том числе от чрезвычайных ситуаций. Президент подчеркнул, что для сохранения устойчивого развития государства необходимо осуществлять стратегическое планирование с применением современных средств анализа, моделирования и прогнозирования, в том числе раннего выявления и предотвращения возможных негативных событий и чрезвычайных ситуаций природного и антропогенного характера [17].

\section{БИБЛИОГРАФИЧЕСКИЙ СПИСОК}

1. Клюшниченко В. Н., Москвин В. Н., Татаренко В. И. К вопросу о ведении Единого государственного реестра недвижимости в России // Вестник СГУГиТ. - 2018. - Т. 23, № 3. - С. 240-248.

2. Бударова В. А., Воронина Е. А., Дубровский А. В., Кустышева И. Н., Малыгина О. И., Мартынова Н. Г., Торсунова О. Ф. Нормативно-правовые особенности установления водоохранных зон и прибрежных защитных полос (на примере территории Новосибирской области) // Вестник СГУГиТ. - 2020. T. 25, № 1. - С. 222-238. doi: 10.33764/2411-1759-2020-25-1-222-238.

3. Градостроительный кодекс Российской Федерации от 29.12.2004 № 190-Ф3 (ред. от 31.07.2020) (с изм. и доп., вступ. в силу с 28.08.2020 г. ) [Электронный ресурс]. - Доступ из справ.-правовой системы «КонсультантПлюс».

4. Дубровский А. В., Верещака Т. В., Батин П. С., Малыгина О. И. Разработка подхода к кадастровой оценке объектов недвижимости в зонах возможного проявления стихийных бедствий и чрезвычайных ситуаций [Электронный ресурс] // ИнтерКарто. ИнтерГИС. Геоинформационное обеспечение устойчивого развития территорий : материалы Междунар. конф. - М. : Изд-во Московского университета, 2020, T. 26, ч. 1. - С. 190-202. - Режим доступа: https://doi.org/10.35595/2414-9179-2020-1-26-190-202.

5. РБК. Недвижимость. [Электронный ресурс]. - Режим доступа: https://realty.rbc.ru/news/ 5eba7c799a79475b7abbe540?utm_source=yxnews\&utm_medium=desktop. - Загл. с экрана.

6. О безопасности гидротехнических сооружений [Электронный ресурс] : федер. закон от 21.07.1997 № 117-Ф3 (ред. от 29.07.2018 г.). - Доступ из справ.-правовой системы «КонсультантПлюс».

7. О введении режима чрезвычайной ситуации на территории Иркутской области [Электронный pecypc] : указ губернатора Иркутской области от 27.06.2019 № 134-уг. - Режим доступа : http://publication.pravo.gov.ru/Document/View/3800201906270010. - Загл. с экрана.

8. Перечень поручений по итогам совещания по ликвидации последствий паводков и пожаров от 15.05.2017 [Электронный ресурс]. - Режим доступа: http://www.kremlin.ru/acts/assignments /orders/54579. - Загл. с экрана.

9. Водный кодекс Российской Федерации № 74-Ф3 (ред. от 31.10.2016) [Электронный ресурс]. Доступ из справ.-правовой системы «КонсультантПлюс».

10. О зонах затопления, подтопления (вместе с Положением о зонах затопления, подтопления) [Электронный ресурс] : постановление Правительства РФ от 18.04.2014 № 360 (ред. от 07.09.2019 г.). - Доступ из справ.-правовой системы «КонсультантПлюс».

11. Графики установления режимов работы Новосибирского водохранилища [Электронный ресурс]. - Режим доступа: http://vobvunsk.ru/index.php?option=com_content\&view= article\&id $=1217 \&$ Itemid $=66$.

12. Карпик А. П., Ветошкин Д. Н., Арбузов С. А., Дубровский А. В. База данных «Геоинформационная база данных зон затопления населенных пунктов Новосибирской области в результате сезонного паводка». Свидетельство о государственной регистрации базы данных № 2020622844.

13. СП 42.13330.2016. Свод правил. Градостроительство. Актуализированная редакция СНиП 2.07.01-89. [Электронный ресурс]. - Доступ из справ.-правовой системы «КонсультантПлюс».

14. Решение № 2A-598/2017 2А-598/2017 M-487/2017 М-487/2017 от 29.12.2017 по делу № 2A-598/2017 [Электронный ресурс]. - Режим доступа: https://sudact.ru/regular/doc/CQwP1T6C7hHZ/. - Загл. с экрана.

15. Карпик А. П., Ким Э. Л., Дубровский А. В. Анализ природных и техногенных особенностей геопространства чрезвычайной ситуации // Итерэкспо ГЕО-Сибирь-2012. VIII Междунар. науч. конгр. : Междунар. науч. конф. «Геодезия, геоинформатика, картография, маркшейдерия» : сб. материалов в 3 т. (Новосибирск, 10-20 апреля 2012 г.,). - Новосибирск : СГГА, 2012. Т. 3. - С. 171-177. 
16. Каганович А. А. Планирование территориальной устойчивости с использованием геоинформационных систем // Изв. Санкт-Петербургского государственного аграрного университета. - 2017. № 1 (46). - С. 203-207.

17. Стратегическое планирование должно учитывать защиту россиян от угроз - В.В. Путин [Электронный ресурс] : Заседание Совбеза РФ 27.09.2021. - Режим доступа: https://www.m24.ru/news/vlast/27092021/184730? utm source=CopyBuf.

Получено 11.08.2021

(C) А. В. Дубровский, Е. А. Скоринская, А. Р. Батуев,

В. Г. Колмогоров, Л. А. Пластинин, В. И. Татаренко, 2021

\title{
RELEVANT ISSUES OF LEGAL AND REGULATORY AND TECHNOLOGICAL SUPPORT OF CADASTRAL WORKS FOR DETERMIING FLOODING AND UNDERFLOODING ZONE BOUNDARIES FOR THE PROTECTION OF REAL ESTATE OBJECTS IN EMERGENCIES
}

\author{
Alexey V. Dubrovsky \\ Siberian State University of Geosystems and Technologies, 10, Plakhotnogo St., Novosibirsk, 630108, Russia, \\ Ph. D., Head of the Department of Cadastre and Territorial Planning, phone: (383)361-01-09, \\ e-mail: avd5@ssga.ru
}

\section{Elena A. Skorinskaya}

Upper Ob Basin Water Management, 167, Nemirovich-Danchenko St., Novosibirsk, 630087, Russia, Leading Specialist, Expert, phone: (383)314-89-15, e-mail: bvu_501@ngs.ru

\section{Alexander R. Batuev}

Irkutsk National Research Technical University, 83, Lermontov St., Irkutsk, 664074, Russia, D. Sc., Professor, Department of Mine Surveying and Geodesy, phone: (902)766-56-08, e-mail: arbatuev.irk@yandex.ru

\section{Vyacheslav G. Kolmogorov}

Siberian State University of Geosystems and Technologies, 10, Plakhotnogo St., Novosibirsk, 630108, Russia, D. Sc., Professor, Department of Department of Geomatics and Property \& Infrastructure, phone: (383)361-07-09, e-mail: kaluzhin@mail.ru

\section{Leonid A. Plastinin}

Irkutsk National Research Technical University, 83, Lermontov St., Irkutsk, 664074, Russia, D. Sc., Professor, Department of Mine Surveying and Geodesy, Scientific Adviser of Space Technology and Services Center, phone: (950)122-27-23, e-mail: irkplast@mail.ru

\section{Valeriy I. Tatarenko}

Siberian State University of Geosystems and Technologies, 10, Plakhotnogo St., Novosibirsk, 630108, Russia, D. Sc., Professor, Department of Technosphere Safety, phone: (383)344-42-00, e-mail: v.i.tatarenko@ssga.ru

Since 2014 the Russian Federation has been carrying out the works for determining flooding and underflooding zones near water objects. It is legally stated that the information about the boundaries of such zones must be inserted into the Unified State Real Estate Register. However, the range of legal and regulatory and technological issues in determining the boundaries of flooding zones has not yet been solved and the works have not been completed to the full extent. The article performs the analysis of governing regulatory documents as well as the amendments accepted in 2019 , devoted to the improvement of the procedure for determining flooding and under flooding zones. As the argument of relevance of determining flooding and underflooding zones were considered the examples of catastrophic floods on the territory of the Russian Federation, which caused billion-ruble losses to the state as well as to the real estate owners. The article substantiates the necessity of computer-based forecasting modeling of emergencies, related to flooding of territories and determining the boundaries of the emergency geospace - the flooding and underflooding zones. The article draws the technological scheme of the actions for determining emergency geospace. There have been built the digital forecast- 
ing models of the flooding zones on the territory of the Novosibirsk city in disastrous flood. There has been drawn the information about the registered geodata base of flooding zones in residential areas of the Novosibirsk region during seasonal river floods. To optimize the processes of entering information about flooding and underflooding zones into the unified state register of real estate, a technological scheme for establishing flooding and flooding zones has been developed and introduced into the work of the Verhne-Obskoj Basin Water Management. There has been shown the positive impact of determination and registration in state informational resource of the data about flooding and underflooding zone boundaries. In particular this information allows to perform the evaluation of territorial stability of land-property complex spatial structures. On the basis of statistical data on damage due to floods, there has been drawn the conclusion about the necessity of tax reduction on real estate in areas of possible emergencies and redistribution of funds of real estate owners for property insurance.

Keywords: real estate objects, land-property complexes, geoinformational systems, cadastral works, flooding zones, underflooding zones, hydraulic structure, underflood probability, emergency, urban development, territorial management, population protection

\section{REFERENCES}

1. Klyushnichenko, V. N., Moskvin, V. N., \& Tatarenko, V. I. (2018). On the question of maintenance of the Unified state register of real estate in Russia. Vestnik SGUGiT [Vestnik SSUGT], 23(3), 240-248 [in Russian].

2. Budarova, V. A., Voronina, E. A., Dubrovsky, A. V., Kustysheva, I. N., Malygina, O. I., Martynova, N. G., \& Torsunova, O. F. (2020). About the Problems of Violation of Legal Regime of Land Use in the Riparian Zones (on the Example of Novosibirsk Reservoir). Vestnik SGUGiT [Vestnik SSUGT], 25(1), 222-238 [in Russian].

3. Town-planning code of the Russian Federation of December 29, 2004 No. 190-FZ (ed. of July 31, 2020) (with the changes and additions which have come into force since August 28, 2020). Retrieved from ConsultantPlus online database [in Russian].

4. Dubrovsky, A. V., Vereshchaka, T. V., Batin, P. S., \& Malygina, O. I. (2020). Development of an approach to the cadastral assessment of real estate in areas of possible manifestations of natural disasters and emergencies. In Sbornik materialov Mezhdunarodnoy konferentsii InterKarto. InterGIS: T. 26, ch. 1. Geoinformatsionnoe obespechenie ustoychivogo razvitiya territoriy [Proccedings of International Conferences InterKarto. InterGIS: Vol. 26, Part 1. Geoinformation Support of Sustainable Development of Territories] (pp. 190-202). Moscow: Moscow University Publ. Retrieved from https://doi.org/10.35595/2414-9179-2020-1-26190-202 [in Russian].

5. RBC. Real estate. (n. d.). Retrieved from https://realty.rbc.ru/news/5eba7c799a79475b7abbe540? utm source=yxnews\&utm medium=desktop [in russian].

$\overline{6}$. Federal Law of July 21, 1997 No. 117-FZ (ed. of July 29, 2018). About safety of hydraulic engineering constructions. Retrieved from ConsultantPlus online database [in Russian].

7. Decree of the Governor of the Irkutsk region of June 27, 2019 No. 134-ug. About introduction of a mode of an emergency situation in the territory of the Irkutsk region. Retrieved from http://publication.pravo.gov.ru/Document/View/3800201906270010 [in Russian].

8. The list of instructions following the meeting on the elimination of the consequences of floods and fires of May 15, 2017. Retrieved from http://www.kremlin.ru/acts/assignments/orders/54579 [in Russian].

9. Water Code of the Russian Federation No. 74-FZ (ed. October 31, 2016). Retrieved from ConsultantPlus online database [in Russian].

10. Resolution of the Government of the Russian Federation of April 18, 2014 No. 360 (ed. of September 07, 2019). About zones of flooding, flooding (together with Regulations on zones of flooding, flooding). Retrieved from ConsultantPlus online database [in Russian].

11. Schedules for establishing the operating modes of the Novosibirsk Reservoir. (n. d.). Retrieved from http://vobvunsk.ru/index.php?option=com_content\&view=article\&id=1217\&Itemid=66 [in Russian].

12. Karpik, A. P., Vetoshkin, D. N., Arbuzov, S. A., \& Dubrovsky, A. V. Certificate of state registration of the database No. 2020622844. Database "Geoinformation database of flood zones of settlements of the Novosibirsk region as a result of seasonal flood" [in Russian].

13. Code of Practice. SP 42.13330.2016. Code of rules. Urban planning. Updated edition of SNiP 2.07.0189. Retrieved from ConsultantPlus online database [in Russian]. 
14. Decision № 2A-598/2017 2A-598/2017 M-487/2017 M-487/2017 of December 29, 2017 in the case No. 2A-598/2017. Retrieved from https://sudact.ru/regular/doc/CQwP1T6C7hHZ/ [in Russian].

15. Karpik, A. P., Kim, E. L., \& Dubrovsky, A. V. (2012). Analysis of natural and man-made features of the geospatial emergency. In Sbornik materialov Interekspo GEO-Sibir'-2012: Mezhdunarodnoy nauchnoy konferentsii: T. 3. Geodeziya, geoinformatika, kartografiya, marksheyderiya [Proceedings of Interexpo GEOSiberia-2012: International Scientific Conference: Vol. 3. Geodesy, Geoinformatics, Cartography, Mine Surveying] (pp. 171-177). Novosibirsk: SSGA Publ. [in Russian].

16. Kaganovich, A. A. (2017). Planning for territorial sustainability using geographic information systems. Izvestiya Sankt-Peterburgskogo gosudarstvennogo agrarnogo universiteta [Izvestiya Saint-Petersburg State Agrarian University], 1(46), 203-207 [in Russian].

17. Meeting of the Security Council of the Russian Federation on September 27, 2021. Strategic planning must take into account the protection of Russians from threats - V. V. Putin. Retrieved from https://www.m24.ru/news/vlast/27092021/184730?utm_source=CopyBuf [in Russian].

Received 11.08.2021

(C) A. V. Dubrovsky, E. A. Skorinskaya, A. R. Batuev,

V. G. Kolmogorov, L. A. Plastinin, V. I. Tatarenko, 2021 
УДК 631.58:631.6.02

DOI: $10.33764 / 2411-1759-2021-26-5-169-179$

\section{ТЕОРЕТИЧЕСКИЕ И МЕТОДОЛОГИЧЕСКИЕ ОСНОВЫ ОХРАНЫ СЕЛЬСКОХОЗЯЙСТВЕННЫХ УГОДИЙ В СИСТЕМЕ БИОЛОГИЧЕСКОГО ЗЕМЛЕДЕЛИЯ}

\section{Юрий Степанович Ларионов}

Сибирский государственный университет геосистем и технологий, 630108, Россия, г. Новосибирск, ул. Плахотного, 10 , доктор сельскохозяйственных наук, профессор кафедры экологии и природопользования, тел. (383)361-08-86, e-mail: larionov42@mail.ru

\section{Константин Станиславович Байков}

Центральный Сибирский ботанический сад СО РАН, 630090, Россия, г. Новосибирск, ул. Золотодолинская, 101, доктор биологических наук, главный научный сотрудник, e-mail: kbaikov2017@mail.ru

\section{Валерий Борисович Жарников}

Сибирский государственный университет геосистем и технологий, 630108, Россия, г. Новосибирск, ул. Плахотного, 10 , кандидат технических наук, профессор, директор регионального информационного центра, тел. (383)361-05-66, e-mail: v.b.jarnikov@ssga.ru

Целью работы является исследование возможностей и разработка рекомендаций по формированию устойчивого сельскохозяйственного землепользования, прежде всего в отношении охраны и защиты сельскохозяйственных угодий в системе биологического земледелия (биоземледелия). Охарактеризованы основные положения биоземледелия, его роль в реализации закона плодородия почв, обусловливающего новое видение теоретического и методологического обоснования принципов формирования устойчивых агроландшафтов. Основным результатом исследования определена система базовых мер по охране почв, обеспечивающая сохранность их плодородия в системе биологического земледелия на основе корнеоборота и регулирования эдафитных и эпифитных процессов и включающая: чередование культур на каждом поле и севообороте с различными типами корневых систем; оставление зеленой биомассы на поле с заделкой ее в верхний слой почвы и созданием мульчи; проведение агролесомелиоративных мероприятий, обеспечивающих дополнительные условия для взаимодействия биоты и косной материи; сохранение и накопление влаги (воды) как основного энергоинформационного компонента агроэкосистемы в корнеобитаемом слое почвы; сохранение целостности пахотного и других горизонтов почвы с обитающими в них и на прилегающих участках живых организмов (в биоценозе); биологическую регуляцию роста и развития культурных растений для обеспечения их защиты; проведение биостимуляции процессов разложения органических остатков. Указанное представляет собой основное содержание системы охраны почв сельскохозяйственных угодий, стабильного сохранения их плодородия в системе биоземледелия, способного стать в недалеком будущем основой экологически выверенного сельскохозяйственного производства.

Ключевые слова: устойчивое землепользование, почва, агроландшафт, методология, принципы, биотическая регуляция, приоритет, комплексная оценка

\section{Введение}

История развития земледелия представляет собой естественный процесс смены ранее используемых систем земледелия на новые, более технологичные и экономически эффективные, начатый в давние времена, но понастоящему осмысленный агрономической наукой в середине XVIII в. [1]. Этот процесс носит объективный характер и зависит от условий, в которых развиваются националь- ные экономики, сельскохозяйственное и агропромышленное производство в целом, другие отрасли. Сегодня под системой земледелия понимается комплекс взаимосвязанных технологических, мелиоративных и организационноэкономических мероприятий, направленных на эффективное использование земель в общей стратегии природопользования.

В историческом аспекте выделяют следующие системы земледелия: примитивные, паровая, травопольная, плодосменная, почвозащит- 
ная, адаптивно-ландшафтная, No-Till, индустриально-технологическая. При этом каждая система включает в себя ряд простых подсистем: организацию земельной территории и севооборотов, технологию возделывания культур, систему обработки почвы, систему удобрений, борьбы с сорняками, болезнями и вредителями и многие другие.

Для настоящего периода, характеризующегося глобальным экологическим кризисом, существенным изменением климата, негативной динамикой объема и качества сельскохозяйственных угодий, в первую очередь плодородия, вопрос разработки новой идеологии и отвечающей ей системы земледелия приобрел очевидную актуальность.

Снижение плодородия, обусловленное недостатками существующей системы охраны и защиты сельскохозяйственных угодий, не способной в должном масштабе предотвратить изменение $\mathrm{pH}$ почв, распространение водной и ветровой эрозии, опустынивание, засоление и другие процессы деградации почв, определили проблему поиска новой научной парадигмы и ее практической актуализации взамен (последовательно по времени, месту и содержанию) существующей индустриально-технологической системы, прослужившей человеку более века и уже не отвечающей всему спектру современных требований землепользования, в том числе эколого-экономического характера [2].

Определенные успехи отечественного сельского хозяйства не успокаивают специалистов, хорошо знающих его проблемы, в том числе обусловленные все более возрастающими и одновременно снижающими свою эффективность объемами минеральных удобрений и средств защиты растений [3]. Активная химизация полей становится одним из самых негативных факторов их экологического состояния, все более обостряет проблему качества основных видов продовольствия, примеры которых становятся все более многочисленными $[4,5]$.

Средняя урожайность зерновых в стране составляет около 2,5 тонн с гектара пашни (т/га), а в отдельных, входящих в житницу страны регионах нередко не дотягивает до 2 т/га. Конечный результат (а это более 100 млн т. зерновых) обусловлен в основном индустриальным, далеко не оптимальным вариантом хозяйствова- ния крупнейших по объемам сельскохозяйственных угодий землевладельцев страны, в то время как малый и средний бизнес с трудом выходит на окупаемость своих затрат.

В этой связи в сельскохозяйственном производстве пришло время делать ставку (и этот процесс уже начался) на принципиально новые инновационные решения, обеспечивающие не только стабильность, но и повышение плодородия почв, рост качества урожая, базирующегося на новых, природоподобных технологических основах. К их числу следует отнести положения биологического (нередко называемого органическим) земледелия, а также основополагающие принципы формирования плодородия почв, составившие содержание одноименного закона, сформулированного и развиваемого одним из авторов настоящей статьи [5]. Полагаем, что закон плодородия почв и принципы биоземледелия определяют естественный ход научно-технического прогресса в данной отрасли науки и практики, направлены на интенсификацию отечественного производства и служат достижению приоритетных национальных целей, сформулированных Президентом РФ В. В. Путиным в 2019 г. Реализация новых подходов позволит улучшить состояние сельскохозяйственных угодий, перейти к их сертификации и масштабному производству экологически чистой, востребованной на рынках продукции, повысить экономическую эффективность сельскохозяйственного производства.

\section{Материалы и методы исследования}

В качестве исходных использованы материалы многолетней научно-практической деятельности авторов в области биологии, почвоведения, агрономии и генетики сельскохозяйственных культур, разработки и реализации проектов землеустройства и кадастровой деятельности, обобщения своих результатов и результатов статистики. В качестве теоретических методов - абстракция, идеализация, синтез, обобщения, системные подход и анализ; в качестве экспериментальных - наблюдение, сбор, систематизация и обработка результатов, в том числе дистанционного зондирования, экономической, сельскохозяйственной и земельно-кадастровой статистики [6-12]. Отме- 
тим также использование философско-методологических оснований науки, подчеркивающих неизбежность и назревшую необходимость смены траекторий развития ее наиболее социально значимых отраслей [13-15].

\section{Результаты исследования}

Современные культурные растения в значительной мере унаследовали приуроченность их диких предков к определенным природногеографическим и экологическим условиям. Поэтому оценка плодородия даже одной и той же почвы под разные культуры может существенно различаться.

При этом почва благодаря своим особым качествам играет огромную роль в существовании биосферы Земли. Она является особым природным телом и выступает как важная среда для существования огромного количества видов живых организмов. Находясь в состоянии непрерывного обмена веществом и энергией с атмосферой, биосферой, гидросферой и литосферой, фитоценоз и почвенный покров выступают как незаменимые условия поддержания сложившегося на Земле равновесия, столь необходимого для развития и существования всех многообразных форм жизни. Одновременно почва выступает мощнейшим антропогенным фактором, обладая свойством плодородия и выступая как основное средство производства в сельском и лесном хозяйствах [16-18].

В агрохимии и практическом земледелии, принято считать, что урожаи культур формируются преимущественно за счет минеральных элементов самой почвы, значимость органического вещества (OB) определяется, прежде всего, его ролью в формировании питательного режима почвы, через минерализацию и гумификацию его. Существует также мнение, что ухудшение баланса гумуса, содержания углерода в почве и отсутствие оптимального сочетания элементов минерального питания для каждой культуры, в конкретных почвенно-климатических и агроэкологических условиях, в определенные фазы роста и развития есть главные причины недобора урожаев и низкой стабильности земледелия $[19,20]$. Считаем, что это достаточно общие представления, по- скольку для каждой культуры и множества агроэкологических условий в каждый конкретный момент и фазу развития растений существуют свои оптимальные показатели и их соотношения, тем более в сочетании с биотой почвы и ее свойствами. Поэтому целенаправленный процесс управления агроэкологической системой сложен, но возможен с использованием адекватных условиям ее продукционных процессов интегральных показателей.

В интенсивном земледелии управление продукционным процессом растений осуществляется в основном с помощью минеральных удобрений, пестицидов и регуляторов роста растений. Ценность ОВ сводится, как правило, к его промежуточной роли лишь к способности улучшать агрофизические, водно-физические, технологические и фитосанитарные свойства почвы. Главная роль отдается процессам химизации. Данное обстоятельство и определяет поиск нового, отвечающего современной эпохе, решения.

Усиливающаяся неустойчивость продуктивности полей, повсеместное падение плодородия почв при возрастающих требованиях к экологизации сельскохозяйственной отрасли диктуют необходимость смены старых и установления новых подходов к ведению земледелия. Успешное разрешение поставленной проблемы по восстановлению почвенного плодородия, устранение и минимизация влияния основных негативных факторов современного земледелия в значительной степени обусловлено сложившимися представлениями о природе высоких урожаев - практически предельного уровня интенсификации и широкой химизации сельскохозяйственного производства $[12,16,17]$.

При этом специалистам хорошо известны результаты микроморфологических исследований, показавших, что даже небольшие дозы минеральных удобрений (30-45 кг/га) отрицательно влияют на микроструктуру почвы: уплотняют упаковку микроагрегатов, снижают водоудерживающую способность почв и, как результат, урожайность возделываемых культур [5, 18-20]. Изменения в почве под влиянием отдельных технологий связаны с потерей гумуса, усилением подвижности минеральных элементов, водно-физических 
свойств, других качеств. Это ведет к деградации почв, их биоты и абиотических систем, нормальное функционирование которых во многом зависит от их физико-химических свойств и органического вещества, содержащегося в почве [5, 6, 18, 19].

Детальный анализ современной ситуации, выполненный в работе [17], показал все большую зависимость далеко не сверхвысоких урожаев большинства распространенных культур от объемов вносимых в почвы минеральных удобрений, еще более усугубляемую их энергетическими эквивалентами [20].

Принципиально изменить ситуацию способно биоземледелие с его основными принципами, в том числе определяемыми законом плодородия почв, понимаемое нами как управляемый процесс возделывания культурных растений со стабильно поддерживаемым плодородием почвы в конкретных агроэкологических условиях, во взаимодействии почвы с различными видами растений, животных и микроорганизмов, обеспечивающих их защиту от болезней, вредителей и сорных растений биологическим путем, в основе которого лежит синтез органического вещества и его трансформация в различные почвенные органо-минеральные формы. Следует также подчеркнуть, что почва в данном процессе играет важнейшую объектно-предметную роль, обеспечивая устойчивую взаимосвязь своего вещественного состава - живой и косной материи с биосферой планеты на основе круговорота вещества и энергии $[5,8]$.

Новая методология выдвигает в основу земледелия следующие принципы: корнеоборот чередование в пределах поля растений с различными типами корневых систем взамен минеральным удобрениям и пестицидам - химическим загрязнителям окружающей среды, снижающих плодородие почв; регулирование эдафитных и эпифитных процессов, определяющих биологическую защиту растений от вредителей, болезней и сорняков, дополняющее действие принципа искусственного отбора в виде ограниченного набора культурных растений в севообороты (плодосмен), связанного с хозяйственной целесообразностью одновидовых посевов, а также борьбой с сорными растениями, болезнями и вредителями химическими методами.
Биоземледелие основывается на эволюционно-генетическом и эколого-генетическом принципах взаимодействия косной и живой материи, обусловивших формирование различных видов почв и их плодородие на планете. Несоблюдение этих принципов в процессе сельскохозяйственного производства: использование почв под посев чистых культур без значительного расширения генетического разнообразия агроценозов на основе межи внутривидового взаимодействия растений, животных, микроорганизмов в конкретной агроэкосистеме; функционирование их по принципу искусственного, а не естественного отбора, лежащего в основе существования экосистем и биосферы в целом, ведет к деградации и падению почвенного плодородия.

Становится очевидным, что основным фактором почвенного плодородия является органическое вещество, консервирующее энергию Солнца в химически связной форме и являющееся главным источником энергии для развития различных живых форм - растений и животных, а также почвы и ее плодородия. Основным источником первичного OB, поступающего в почву под естественным фитоценозом, являются остатки растений. Количество их зависит от вида растительных сообществ, увеличиваясь от зоны тундры к зоне широколиственных лесов в 5-6 раз. Максимальное ежегодное количество растительного материала поступает в почвы умеренно засушливой степи (примерно в 2 раза больше, чем под лесами и колками). В сухой степи, в полупустыне и пустыне поступление в почву ОВ резко уменьшается; в субтропической и тропической зонах значительно повышается. Фактически ОВ почвы это отмершие остатки растений, микроорганизмов, почвенных животных и продуктов их жизнедеятельности. Первичное ОВ, поступившее в почву, подвергается сложным превращениям, включающим процессы разложения, вторичного синтеза в форме микробной плазмы и гумификации. Сочетание названных процессов приводит в биологически активных почвах к образованию сложной смеси органических веществ, включающей: малоразложившиеся растительные остатки с сохранившейся структурой, промежуточные продукты разложения органических остатков (например, лигнин), 
коллоидные комплексы собственно гумусовых веществ, или остаточного происхождения, растворимые органические соединения, которые минерализируются (или полимеризируются).

Сегодня четко показано [1, 3-6], что взаимодействие такого сложного конгломерата органических веществ с минеральной частью почвы представляет собой существеннейшую черту почвообразовательного процесса.

Растительные остатки зерновых культур содержат питательных веществ меньше, чем растительные остатки бобовых. Озимая пшеница, ячмень, овес содержат в корнях 0,91,3\% азота, 0,2-0,3\% фосфора, в пожнивных остатках - 0,4-0,9 \% азота и $0,1-0,2 \%$ фосфора. В корневых остатках гороха, фасоли содержится 1,2-2 \% азота, 0,2-0,8 \% фосфора, 0,3-1,9 \% калия, а в пожнивных остатках, соответственно, 0,7-1,7 \%, 0,3$0,5 \%$ и $0,5-1,2 \%$.

Корни и стерневые остатки растений после отмирания разлагаются в результате деятельности микроорганизмов и фауны почвы. Микрофлора использует органический материал в качестве источника пищи и энергии. На ход и скорость разложения влияют, вопервых, внешние условия среды, зависящие от типа почвы и климата, влажности, температуры, $\mathrm{pH}$ почвы, содержание в ней кислорода и питательных веществ и, во-вторых, химический состав растительных остатков.

Особое значение имеет отношение $\mathrm{C}: \mathrm{N}$ в органическом веществе. Свежее органическое вещество растительных остатков с узким отношением C : N стимулирует развитие микрофлоры почвы, которая за 7-15 дней разлагает ее полностью, так как является для микрофлоры доступным источником питания с высоким содержанием азота.

Как же с позиций методологии биоземледелия формируется само плодородие почв связанное в первую очередь с разложением органического вещества - минерализацией и гумификацией - накоплением сложного органо-минерального комплекса?

Обобщая научное знание о почве, отметим особую роль в почвообразовании наличия минеральной материнской (литогенной) основы, органических растительных остатков, живых почвенных организмов и зеленых растений.
Указанные факторы способны при наличии определенного гидротермического режима определить комплекс должного уровня активности почвенных и иных гео- и биохимических процессов взаимодействия продуктов жизнедеятельности растений и микроорганизмов с минеральными соединениями материнской породы, превращения породы в почву, создания требуемых условиями плодородия органо-минеральных комплексов, формирования почвенного плодородия, синтеза и разрушения органического вещества, концентрации элементов зольного и азотного питания растений, ряда других. Следует подчеркнуть, что все это осуществляется на основе эволюционного и эколого-генетических принципов существования живого в биосфере [1-6].

При этом синтезированное органическое вещество является основной формой энергии, используемой живой материей в процессе ее эволюции, и одновременно связующим звеном живой и косной материи в биосфере. Именно ОВ, поступающее в почву в виде растительных остатков и подвергнутое биотой биохимическим преобразованиям, обусловливает многообразие свойств почвы, в том числе плодородие, а также регулирует фактически все биохимические процессы клетки, активизирует поглощение ультрафиолетового излучение растениями, ускоряя процесс фотосинтеза в листьях, приобретающих интенсивную зеленую окраску $[5,6]$. ОВ содержит в своем составе целый ряд ценных микроэлементов (медь, цинк, бор, марганец, молибден, кобальт), которые при разложении образуют с гуминовыми веществами комплексы, легко усваиваемые растениями, и именно гуминовые вещества наиболее эффективно транспортируют микроэлементы в растение.

Последующая минерализация ОВ кратно увеличивает в почве содержание легко растворимых в воде калийных, азотных и фосфорных соединений, позволяет уменьшить дозу вносимого NPK до 80 \%. Биохимические преобразования органических веществ в гуминовые вещества активизируют обменные процессы в растительных организмах, стимулируют синтез этих веществ, повышающих устойчивость растения к различным стрессам и улучшающих качество собираемого урожая. 
Учитывая все вышеперечисленное, можно сделать вывод, что ОВ и активность биоты почвы позволяют поддерживать почвенное плодородие, улучшать урожайность и ее сохранность; защитить растения от бактериальных и грибковых заболеваний, усилить развитие корневой системы растений и их дыхание, повысить устойчивость растений к неблагоприятным факторам внешней среды (засуха, избыточное увлажнение, заморозки); производить более качественную в экологическом отношении продукцию (с высоким содержанием витаминов, сахаров и других ценных веществ); повысить эффективность минеральных удобрений (сократить их дозы на 50-80 \%) и пестицидов (сократить до 40-70 \%) и многое другое.

Обобщая вышеизложенное, кратко раскрывающее физико-химическую, почвоведческую и агрономическую сущность исследуемых процессов, можно сделать вывод, что ОВ, восстанавливая в почве баланс утраченной урожаем органики, поддерживает как стабильность ее плодородия, так и сам процесс существования и эволюционного развития.

\section{Обсуждение результатов}

Представленный материал в целом дает представление об основном содержании теоретико-методологической концепции формирования и сохранения плодородия почв в системе биологического земледелия. Ключевыми факторами здесь являются основные условия обеспечения плодородия, положенные в основу одноименного закона: поддержание баланса ОВ, в последующем трансформирующегося в сложные, требуемые растениями органо-минеральные комплексы; использование в севооборотах растений, обеспечивающих корнеоборот с перемещением нужных для питания растений элементов из нижних в верхние горизонты почвы; регулирование эдафитных и эпифитных процессов с использованием современных биопрепаратов, обеспечивающих основной комплекс защиты почве и культурным растениям.

Биоземледелие в данном случае следует трактовать как комплекс мероприятий по сохранению и повышению плодородия почвы, урожайности сельскохозяйственных культур, основанный на использовании естественных почвообразовательных процессов, направленных на создание устойчивых агробиогеоценозов и не нарушающих ход естественных биогеохимических круговоротов в агроландшафтах и природных процессов в биосфере.

$\mathrm{C}$ целью отражения практики управления круговоротами элементов питания, принципов и признаков обеспечения плодородия почв в агроэкосистемах, выявляемых в процессе осуществления его мониторинга, полезна формулировка биоземледелия, отражающая его научно-технологическую суть и представляющая биоземледелие управляемым человеком процессом возделывания культурных растений и повышения плодородия почвы в конкретных агроэкологических условиях, во взаимодействии с дополнительными видами растений (участвующими в корнеобороте, сидератами и др.), животными и микроорганизмами, а также регулированием эдафитных и эпифитных процессов в агроценозе, обеспечивающих биологическую защиту почвы и растений от болезней, вредителей и сорняков.

Наиболее подходящими для корнеоборота и использования в качестве поукосных, пожнивных и сидеральных культур для центральных районов страны и Западной Сибири следует отнести в первую очередь такие культуры, как люцерна, люпин, горох, вика, клевер, рапс, сурепица, редька масличная, донник и др.

Формируя таким образом на основе корнеоборота набор культур, обеспечивающий оптимальный баланс органического вещества почвы с учетом его количества и качества в любой почвенно-климатической зоне страны, мы создаем надежную базу плодородия почвы и гарантию стабильных и высоких урожаев возделываемых культур фактически без внесения минеральных удобрений и не создавая традиционных агроэкосистемных проблем.

С позиций методологии корнеоборот как принцип биоземледелия моделирует эволюционно-экологический процесс целенаправленного меж- и внутривидового взаимодействия живых организмов между собой и косной материей в агроценозе. Агроценотическое разнообразие практически отражает эволюционнои эколого-генетические принципы формирования почвы как геологического объекта на ос- 
нове кругооборота веществ и энергии, принципов естественного и искусственного отборов растительных и других сообществ. Такой подход раскрывает процесс повышения плодородия почв в сельскохозяйственном производстве за счет накопления необходимых элементов питания для возделываемых культур. А моделируемые межвидовые и внутривидовые взаимодействия живых организмов в процессе корнеоборота могут быть усилены целенаправленным применением биологических методов защиты растений и почвы, активнее запускающих процессы гумификации и минерализации органического вещества в почве (обеспечивающих круговорот химических элементов в ней) регулирующие механизмы экологической и биологической безопасности возделываемых культурных растений; с экологической точки зрения - деструкторов органических остатков, регуляторов численности энтомофагов, фитофагов, возбудителей болезней и сорных растений.

Таким образом, биоземледелие с реализацией принципа корнеоборота становится управляемым человеком процессом возделывания сельскохозяйственных растений, повышения их урожайности на основе накопления нужных макро- и микроэлементов, стабильного сохранения и наращивания плодородия почв и защиты возделываемых растений на эволюционном и эколого-генетическом принципах их существования.

Методологически суть биоземледелия, обсуждаемого в качестве основной системы земледелия недалекого будущего, также достаточно обоснована: его элементы понятны, апробированы, их механизмы в разное время подтверждены теорией и практикой $[12,21-$ 24], поэтому стоит задача системно их осмыслить и технологически объединить на основе представленной нами концепции. Именно системный анализ принципов биологического земледелия, его природных форм, принципов и методов, поиск возможных природоподобных дополнений, а также наиболее общих условий рациональной реализации компонентов позволило сформулировать концептуальное положение - закон почвенного плодородия, определившего общий подход к обеспечению почвенного плодородия произвольной агросистемы.
Дадим агроэкологическую трактовку закона в следующем виде: плодородие почвы в любой агроэкологической зоне пропорционально балансу органического вещества в ней и подвижных минеральных элементов, включает процессы синтеза органического вещества и всей биоты в агроэкосистеме, трансформации его в сложные органо-минеральные комплексы, обеспечивающие малые круговороты химических элементов в биосфере.

Закон плодородия почвы соответствует эволюционно- и эколого-генетическому принципам возникновения и существования почвы, показывает теоретически обоснованный механизм создания антропогенно устойчивого агроэкологического комплекса, разработки новых технологий, повышающих потенциальный и эффективный ресурс биосферы и сельскохозяйственного производства на основе управления плодородием почв и фитосанитарным состоянием агроэкосистем.

В наблюдаемом сегодня вытеснении или сильном подавлении отдельных компонентов биоценоза кроется опасность выхода почвенного сообщества на новый экологический уровень, где процессы почвообразования будут протекать только в очень узких интервалах физических и химических показателей почв. Это приведет к еще большей зависимости эффективного и потенциального плодородия от климатических условий, к снижению устойчивости урожаев, которое наблюдается не только в Западной Сибири. Дальнейшее применение средств химизации в целях повышения урожайности сельскохозяйственных культур усилит расшатывание агробиогеоценозов.

Остановимся еще на одном факторе плодородия почвы - воде $\left(\mathrm{H}_{2} \mathrm{O}\right)$. Воду следует отнести к важнейшему из элементов питания, так как нарушение водообмена между биотой и косной материей ставит под угрозу эффективный обмен биосферных веществ и энергии, ведет к резкому снижению продуктивности сельскохозяйственных растений и деградации почвы. Следует помнить, что все живые организмы состоят на 70-90 \% и более из воды. Следует обратить внимание на воду как на информационный фактор, обеспечивающий гармонизацию роста и развития живых организмов. Заметим, что эти свойства воды почти не 
изучены. Вода в процессе ее участия в метаболических процессах выполняет помимо функции растворителя функцию информационную, которая обуславливает весь процесс синтеза органического вещества на планете, на каждом поле, в каждом организме и в каждой его клетке. Ее изомерная и кластерная структура способна передавать и хранить информацию о многих биохимических процессах и влиянии на них внешних факторов.

Отсюда следует вывод: биохимические и информационные свойства воды, обеспеченность ею всей биоты почвы являются главным условием формирования почвенного плодородия и урожайности сельскохозяйственных растений.

Отметим еще два фактора роста плодородия. Первый: создавая методологическую основу будущих технологий биоземледелия, следует отметить, что скорость процессов разложения и вторичного синтеза в форме микробной плазмы и гумификации органических остатков в почве зависит прежде всего от их состава, поэтому регулирование биологического разнообразия на основе корнеоборота и управления эдафическими и эпифитными процессами является основой биоземледелия; это убедительно показала агрохимия: чем больше в растительных остатках содержание легко расщепляемых микроорганизмами веществ, особенно водорастворимых, чем уже соотношение углерода и азота (C:N), тем интенсивнее подвергается органическое вещество микробиологическому распаду.

Второй фактор говорит о том, что в почве при выращивании растений происходят одновременно два противоположных процесса: накопление органического вещества и его разложение. Интенсивностью обоих процессов, их соотношением определяются конечные результаты (т. е. баланс органического вещества в агроценозе), по которым оценивают влияние данной культуры в севообороте или в монокультуре на почву. Если конечный результат положительный, за культурой признаются свойства улучшать плодородие почвы, и наоборот; причем на процесс разрушения органического вещества влияют не столько сами культуры, сколько биота почвы и приемы их возделывания.
Все вышесказанное свидетельствует о необходимости специализированного мониторинга почвенного плодородия с уточнением целей и содержания задач, стоящих перед специалистами данного профиля. Мониторинг позволит отслеживать уровень и качество воздействия на плодородие почв сельскохозяйственных технологий, а также оперативнее разрабатывать и внедрять новые экологически безопасные технологии, что очень важно для многих миллионов гектаров сельскохозяйственных земель.

\section{Выводы}

В результате проведенного исследования обсуждена система биологического земледелия, выступающая современной инновационной моделью недалекого будущего не только отечественного, но и мирового земледелия. На основе обсуждения принципов управления плодородием почв, продуктивности растений и устойчивости агроценозов в данной системе, теоретическую и методологическую основу которой составляет закон плодородия почв, сформулирована система мер по охране и защите почв; в первую очередь сбережения, восстановления и улучшения их плодородия.

Основным мерами, обеспечивающими решение данной задачи, определены:

- чередование культур на каждом поле севооборота с различными типами корневых систем: мочковатой, промежуточной, стержневой, относящихся к различным видам согласно существующей систематики растений;

- чередование культур в севообороте: плодосмен, пожнивные, поукосные культуры и сидераты с обязательным оставлением их биомассы на поле, заделкой ее в верхний слой почвы и созданием мульчи, а также агролесомелиоративных меропиятий, обеспечивающих дополнительные условия для тесного взаимодействие биоты и косной материи;

- сохранение и накопление влаги (воды) как основного энергоинформационного компонента агроэкосистемы в корнеобитаемом слое почвы;

- сохранение целостности пахотного и других горизонтов почвы, обитающих в ней и на прилегающих участках живых организмов, (в биоценозе); 
- биологическая регуляция роста и развития культурных растений для обеспечения их защиты от фитофагов, возбудителей болезней, сорных растений, а также проведение биостимуляции процессов разложения оганических остатков;

- основным механизмом контроля результативности предложенных мер должен стать инструментальный, в основном с применением методов дистанционного зондирования сельскохозяйственных угодий, мониторинг почв.
- экологические и биосферные последствия, так как их влияние распространяется на сотни миллионов гектар.

Таким образом, реализация современной системы охраны сельскохозяйственных угодий обусловливает особое внимание к системе биологического земледелия, принципы которого, как и содержание закона плодородия почв, становятся теоретической и методологической основой нового технологического уклада сельскохозяйственного производства.

\section{БИБЛИОГРАФИЧЕСКИЙ СПИСОК}

1. Березин Л. В., Кленов Б. М., Леонова В. В. Экология и биология почв. - Омск : ОмГАУ, 2008. - 122 с.

2. Каштанов А. Н. Сохраним и преумножим плодородие земли // Земледелие. - 1999. - № 3. - С. 7-8.

3. Татаринцев Л. М., Татаринцев В. Л., Кирякина Ю. Ю. Организация современного землепользования на эколого-ландшафтной основе : монография. - Барнаул : Изд-во АГАУ, 2011. - 106 с.

4. Конев А. А. Система биологизации земледелия. - Новосибирск : НГАУ, 2004. - 51 с.

5. Ларионов Ю. С. Биоземледелие и закон плодородия почв. - Омск : СГГА, ОмГАУ, 2012. - 207 с.

6. Яшутин Н. В., Дробышев А. П., Хоменко А. И. Биоземледелие (научные основы, инновационные технологии и машины). - Барнаул : АГАУ, 2008. - 191 с.

7. Киреев А. К. Концепция развития систем земледелия Казахстана // Глобальные изменения климата и биоразнообразия : материалы II Международного конгресса. - Алматы : КазНИИЗиР, 2015. - С. 108-112.

8. Ларионов Ю. С. Альтернативные подходы к современному земледелию и наращиванию плодородия почв (новая парадигма) // Вестник СГГА. - 2013. - Вып 1 (21). - С. 49-60.

9. Рунов Б. А., Пильникова Н. Основы технологии точного земледелия: зарубежный и отечественный опыт. - М. : Росинформагротех, 2010. - 120 с.

10. Захарова Н. И. Мониторинг почв земель сельскохозяйственного назначения : сущность, цели и задачи // Вестник ПАГС. - 2012. - № 312. - С. 117-121.

11. Жарников В. Б., Ларионов Ю. С. Мониторинг плодородия земель сельскохозяйственного назначения как механизм их рационального использования // Вестник СГУГиТ. - 2017. - Т. 22, № 1. - С. 203-210.

12. Гончаров П. А., Гамзиков Г. П., Каличкин В. К., Ашмарина А. Ф., Христоф Ю. А. Методология системного проведения научных исследований в растениеводстве, земледелии и защите растений : метод. положения. - Новосибирск : СО РАСХН, 2014. - 77 с.

13. Варламов А. А., Гальченко С. А., Клюшин П. В. Современные проблемы развития агропромышленного комплекса России // Аграрная Россия. - 2015. - № 6. - С. 18-22.

14. Аграрная реформа в постсоветской России. - М. : Депо, 2015. - 352 с.

15. Волков С. Н, Комов Н. В., Хлыстун В. Н. Как достичь эффективного управления земельными ресурсами в России? // Международный сельскохозяйственный журнал. - 2015. - № 3. - С. 3-7.

16. Хабарова И. А., Непоклонов В. Б. Российский и зарубежный опыт прогнозирования и планирования использования земель // Изв. вузов. Геодезия и аэрофотосъемка. - 2017. - № 3. - С. 100-104.

17. Липчиу Н. В., Гагай И. В. Эффективность использования земель в сельскохозяйственных организациях Краснодарского края // Политематический сетевой электронный научный журнал Кубанского государственного аграрного университета. - 2014. - № 96. - С. 422-431.

18. Красницкий В. М., Шмидт А. Г. Динамика плодородия пахотных почв Омской области и эффективность использования средств его повышения в современных условиях // Достижения науки и техники АПК. - 2016. - № 7. - С. 34-37.

19. Садикова Г. С., Бурханова Д. У. Изменение показателей плодородия орошаемых луговых почв под влиянием биоудобрений // Аграрная наука - сельскому хозяйству : IX Международная научнопрактическая конференция : сборник статей в 3 кн. - Барнаул : АГАУ, 2014. Кн. 2. - С. 237-239.

20. Масютенко Н. П., Чуян Н. А., Бахирев Г. И. и др. Система показателей оценки экологической емкости агроландшафтов для формирования экологически устойчивых агроландшафтов / Рос. акад. с.-х. наук, Всерос. науч.-исслед. ин-т земледелия и защиты почв от эрозии. - Курск : ВНИИЗиЗПЭ РАСХН, 2011. -42 с.

21. Савельев А. А., Григорьян Б. Р., Добрынин Д. В., Мухарамина С. С., Кулагина В. И., Сахабиев И. А. Оценка почвенного плодородия по данным дистанционного зондирования // Ученые записки Казанского университета. - 2012. - Т. 154, кн. 3. - С. 158-172. 
22. Об утверждении Порядка осуществления государственного мониторинга земель сельскохозяйственного назначения [Электронный ресурс] : приказ Министерства сельского хозяйства РФ от 24.12.2015 № 664. - Доступ из справ.-правовой системы «КонсультанПлюс».

23. Методика расчета почвенного плодородия [Электронный ресурс] : Приказ Министерства сельского хозяйства РФ от 06.07.2017 № 32. - Доступ из справ.-правовой системы «КонсультантПлюс».

24. Министерство сельского хозяйства НCO [Электронный ресурс]. - Режим доступа : https://mcx.nso.ru/.

Получено 25.07.2021

(C) Ю. С. Ларионов, К. С. Байков, В. Б. Жарников, 2021

\section{THEORETICAL AND METHODOLOGICAL BASIS OF AGRICULTURAL AREAS PROTECTION IN THE SYSTEM OF BIOLOGICAL FARMING}

\section{Yurij S. Larionov}

Siberian State University of Geosystems and Technologies, 10, Plakhotnogo St., Novosibirsk, 630108, Russia, D. Sc., Professor, Department Ecology and Environmental Management, e-mail: larionov42@mail.ru

\section{Konstantin S. Baikov}

Central Siberian Botanical Garden SB RAS, 101, Zolotodolinskaya St., Novosibirsk, 630090, Russia, D. Sc., Chief Researcher, e-mail: kbaikov2017@mail.r

\section{Valeriy B. Zharnikov}

Siberian State University of Geosystems and Technologies, 10, Plakhotnogo St., Novosibirsk, 630108, Russia, Ph. D., Professor, Department of Cadastre and Territorial Planning, phone: (383)361-05-66, e-mail: v.b.jarnikov@ssga.ru

The aim of the work is to study the possibilities and develop recommendations for the formation of sustainable agricultural land use, primarily in relation to the protection and preservation of agricultural land in the system of biological farming (bio-farming). The article characterizes the fundamentals of bio-agriculture, the role in its implementation of the law of soil fertility (Yu. S. Larionov, 2010), which determines a new vision of the theoretical and methodological substantiation of the principles for the formation of sustainable agricultural landscapes. The main result of the research is determined as the system of basic land protection measures, which provides land fertility in the system of biological farming based on root turnover and regulation of edaphytic and epiphytic processes, and includes: the crop rotation of different root system types on each field; green manuring and mulching; performing agricultural melioration measures, providing additional conditions for interaction of biota and inert matter; saving and collecting of water, as the basic energoinformational component of the agroecosystem in root layer; preservation of the integrity of arable and other soil horizons with living organisms living in them and in adjacent areas (in the biocenosis); biological regulation of the growth and development of cultivated plants to ensure their protection; carrying out biostimulation of the organic residues decomposition processes. This is the main content of the soil protection system of agricultural land, the stable preservation of their fertility in the system of bio-farming, which can become the basis of ecologically verified agricultural production in the near future.

Keywords: sustainable land use, soil, methodology, principles, biotic regulation, priority, complex evaluation

\section{REFERENCES}

1. Berezin, L. V., Klenov, B. M., \& Leonova, V. V. (2008). Ehkologiya i biologiya pochv [Ecology and soil biology]. Omsk: OmGAU Publ., 122 p. [in Russian].

2. Kashtanov, A. N. (1999). Keep and multiply the fertility of the earth. Zemledelie [Agriculture], 3, 7-8 [in Russian].

3. Tatarincev, L. M., Tatarincev, V. L., \& Kiryakina, Yu. Yu. (2011). Organizaciya sovremennogo zemlepol'zovaniya na ehkologo-landshaftnoj osnove [The organization of modern land use on the ecological-landscape basis]. Barnaul: AGAU Publ., 106 p. [in Russian].

4. Konev, A. A. (2004). Sistema biologizatsii zemledeliya [The system of biologization of agriculture]. Novosibirsk: Novosibirsk GAU Publ., 51 p. [in Russian]. 
5. Larionov, Yu. S. (2012). Biozemledeliye i zakon plodorodiya pochv [Biozemusleie and the law of soil fertility]. Omsk: SSGA Publ., OmGAU Publ., 207 p. [in Russian].

6. Yashutin, N. V., Drobyshev, A. P., \& Khomenko, A. I. (2008). Biozemledeliye (nauchnyye osnovy, innovatsionnyye tekhnologii i mashiny) [Bio-farming (scientific foundations, innovative technologies and machines)]. Barnaul: AGAU Publ., 191 p. [in Russian].

7. Kireyev, A. K. (2015). The concept of development of agriculture systems in Kazakhstan In Sbornik materialov II Mezhdunarodnogo kongressa: Global'nyye izmeneniya klimata i bioraznoobraziya [Proceedings of the II International Congress: Global Climate Change and Biodiversity] (pp. 108-112). Almaty: KazNIIZiR Publ. [in Russian].

8. Larionov, Yu. S. (2013). Alternative approaches to the modern soil cultivation and improvement of soil fertility (new paradigm). Vestnik SGUGiT [Vestnik SSUGT], 1(21), 49-60 [in Russian].

9. Runov, B. A., \& Pil'nikova, N. (2010). Osnovy tekhnologii tochnogo zemledeliya: zarubezhnyy i otechestvennyy opyt [Basics of precision farming technology: foreign and domestic experience]. Moscow: Rosinformagrotekh Publ., 120 p. [in Russian].

10. Zakharova, N. I. (2012). Monitoring of Agricultural Land Soils: the Subject Matter, Targets, and Tasks. Vestnik PAGS [The Bulletin of the Volga Region Institute of Administration], 31, 227-121 [in Russian].

11. Larionov, Ju. S., \& Zharnikov, V. B. (2017). Soil fertility monitoring of agricultural purpose lands as a mechanism of their rational use. Vestnik SGUGiT [Vestnik SSUGT], 22(1), 203-210 [in Russian].

12. Goncharov, P. A., Gamzikov, G. P., Kalichkin, V. K., Ashmarina, A. F., \& Khristof, Yu. A. (2014). Metodologiya sistemnogo provedeniya nauchnykh issledovaniy $v$ rasteniyevodstve, zemledelii i zashchite rasteniy [Methodology of systematic research in crop production, agriculture and plant protection: methodological provisions]. Novosibirsk: Siberian Branch of Russian Academy of the Agricultural Sciences Publ., 77 p. [in Russian].

13. Varlamov, A. A., Galichenko, S. A., \& Klyushin, P. V. (2015). Modern problems of development of agricultural complex in Russia. Agrarnaya Rossiya [Agricultural Russia], 6, 18-22 [in Russian].

14. Agrarnaya reforma v postsovetskoy Rossii [Agrarian reform in post-Soviet Russia]. (2015). Moscow: Depo Publ., 352 p. [in Russian].

15. Volkov, S. N., Komov, N. V., \& Khlystun, V. N. (2015). How to achieve effective land management in Russia? Mezhdunarodnyi selskokhoziaistvennyi zhurnal [International Agricultural Journal], 3, 3-7 [in Russian]

16. Khabarova, I. A., \& Nepoklonov, V. B. (2017). Russian and foreign experience in forecasting and planning of land use. Izvestiya vuzov. Geodeziya i aerofotos"emka [Izvestiya vuzov. Geodesy and Aerophotosurveying], 3, 100-104 [in Russian].

17. Lipchu, N. V., \& Gagay, I. V. (2014). Efficiency of land use in agricultural organizations of the Krasnodar Territory. Politematicheskii setevoi elektronnyi nauchnyi zhurnal Kubanskogo gosudarstvennogo agrarnogo universiteta [Polythematic Online Scientific Journal of Kuban State Agrarian University], 96, 422-431 [in Russian].

18. Krasnitsky, V. M., \& Schmidt, A. G. (2016). Dynamics of Fertility of Arable Soils in Omsk Region and Efficiency of Use of Means for Its Increase under Modern Conditions. Dostizheniya nauki i tekhniki APK [Achievements of Science and Technology of AICis], 7, 34-37 [in Russian].

19. Sadikova, G. S., \& Burkhanova, D. U. (2014). The change in the fertility indicators of irrigated meadow soils under the influence of bio-fertilizers. In Sbornik statey IX Mezhdunarodnoy nauchno-prakticheskoy konferentsii: Kniga 2. Agrarnaya nauka-sel'skomu khozyaystvu [Proceedings of the IX International Scientific and Practical Conference: Book 2. Agrarian Science to Agriculture] (pp. 237-239). Barnaul: AGAU Publ. [in Russian].

20. Masyutenko, N. P., Chuyan, N. A., Bakhirev G. I. \& etc. (2011). Sistema pokazateley otsenki ekologicheskoy yemkosti agrolandshaftov dlya formirovaniya ekologicheski ustoychivykh agrolandshaftov [The system of indicators for assessing the ecological capacity of agricultural landscapes for the formation of environmentally sustainable agricultural landscapes]. Kursk: AllRussian Research Institute of Agriculture and Soil Protection Against Erosion Russian Academy of the Agricultural Sciences Publ., 42 p. [in Russian].

21. Saveliev, A. A., Grigorian, B. R., Dobrynin, D. V., Mukharamina, S. S., Kulagina, V. I., \& Sakhabiev, I. A. (2012). Earth remote sensing for soil fertility monitoring. Uchenyye zapiski Kazanskogo universiteta [Scientific Notes of the Kazan University], 154(3), 158-172 [in Russian].

22. Order of the Ministry of Agriculture of the Russian Federation of December 24, 2015 No. 664. On approval of the Procedure for the implementation of state monitoring of agricultural lands Retrieved from ConsultantPlus online database [in Russian].

23. Order of the Ministry of Agriculture of the Russian Federation dated July 6, 2017 No. 32. Method of calculating soil fertility. Retrieved from ConsultantPlus online database [in Russian].

24. Ministry of Agriculture of the Novosibirsk Region. (n. d.). Retrieved from https://mcx.nso.ru/. 
УДК 004.032.26:332.6

DOI: $10.33764 / 2411-1759-2021-26-5-180-190$

\section{О ПРИМЕНЕНИИ ИСКУССТВЕННЫХ НЕЙРОННЫХ СЕТЕЙ ПРИ ГОСУДАРСТВЕННОЙ КАДАСТРОВОЙ ОЦЕНКЕ ЗЕМЕЛЬНЫХ УЧАСТКОВ}

\section{Екатерина Николаевна Лосева}

Сибирский государственный университет геосистем и технологий, 630108, Россия, г. Новосибирск, ул. Плахотного, 10, аспирант кафедры кадастра и территориального планирования; Новосибирский государственный университет экономики и управления, 630099, Россия, г. Новосибирск, ул. Каменская, 56, преподаватель кафедры экологической безопасности и управления природопользованием, тел. (923) 122-14-77, e-mail: loseva_katty@mail.ru

\section{Наталья Олеговна Митрофанова}

Сибирский государственный университет геосистем и технологий, 630108, Россия, г. Новосибирск, ул. Плахотного, 10, кандидат технических наук, доцент кафедры кадастра и территориального планирования, тел. (923)137-18-88, e-mail: north-easter@yandex.ru

В целях повышения эффективности работ, в результате которых определяется кадастровая стоимость объектов недвижимости, предлагается использование современных технологий, в частности, использование нейронных сетей. Автоматизация определения кадастровой стоимости позволит сократить время оценки, увеличить производительность и качество, а также учесть все индивидуальные особенности недвижимости, в отношении которой производится оценка. Предметом исследования является расчет кадастровой стоимости земельных участков с применением искусственной нейронной сети. Объект исследования: земельные участки категории земель населенных пунктов в границах города Новосибирска, выделенные в два сегмента: сегмент 2 «Жилая застройка (среднеэтажная и многоэтажная)», сегмент 13 «Садоводство и огородничество, малоэтажная жилая застройка». Задачи исследования: отбор факторов, оказывающих влияние на кадастровую стоимость недвижимости и их дифференциация; сбор актуальной информации о недвижимости; подготовка данных для создания искусственной нейронной сети. В результате исследования были выявлены основные и дополнительные ценообразующие факторы и проведена их дифференциация для дальнейшей разработки искусственной нейронной сети, способной рассчитывать кадастровую стоимость объектов недвижимости в автоматизированном режиме.

Ключевые слова: кадастровая оценка, проблемы оценки недвижимости, земельные участки, кадастр, муниципальное управление, искусственная нейронная сеть, автоматизация кадастровой оценки

\section{Введение}

Важным показателем эффективности управления земельно-имущественным комплексом муниципального образования является доход от налога на имущество. Такой налог может быть установлен только на то имущество, котоpoе признано объектом налогообложения, то есть сведения о нем внесены в Единый государственный реестр недвижимости (далее - ЕГРН).

В данной работе особое внимание будет уделено проблемам в области государственной кадастровой оценки объектов недвижимости и ценообразующим факторам, на основании которых рассчитывается кадастровая стоимость. Так как результаты кадастровой оценки служат для формирования планов в целях развития политики в области управления муниципальным образованием, а земельный налог является доходной частью бюджета муниципального образования, то кадастровая стоимость является одной из главных характеристик объектов недвижимости (далее - ОН) [1]

Для каждого объекта недвижимости могут быть рассчитаны как рыночная, так и кадастровая стоимость, имеющие разные цели определения, однако разница между ними может превышать десятки процентов.

Рыночная стоимость объектов недвижимости подвергается постоянным изменениям в зависимости от спроса, предложения и из- 
меняющихся ценообразующих факторов, влияющих на нее в данный момент времени.

Кадастровая стоимость рассчитывается с учетом, в том числе, информации о рыночной стоимости и неразрывно связана с качественными и количественными характеристиками объекта недвижимости, но при этом является неизменной в промежутке между периодичными оценками. Такая оценка до настоящего времени проводилась не реже одного раза в три года и не чаще одного раза в пять лет, а начиная с 2022 г. - каждые четыре года для земельных участков и с 2023 г - для объектов капитального строительства [2]. Длительные периоды между оценками приводят к снижению актуальности ее результатов, однако изза большого количества объектов и массового характера оценки проводить ее чаще не представляется возможным, за исключением отдельных случаев переоценки.

Согласно изменениям, внесенным в Налоговый кодекс Российской Федерации, с 2019 г. кадастровой стоимостью считается имеющаяся в ЕГРН стоимость по состоянию на 1 января, а при ее корректировке налоговой базой останется значение в системе ЕГРН [3, 4]. Этот факт повышает роль оперативности при корректировке кадастровой стоимости.

Таким образом, при поиске путей рациональных методов кадастровой оценки на современном этапе считаем, что необходимо проанализировать современное законодательство в области государственной кадастровой оценки, выявить проблемы, связанные с государственной кадастровой оценкой земельных участков, рассмотреть возможность использования нейронных сетей для проведения оценки и повышения объективности кадастровой стоимости.

\section{Методология}

Нормативные документы, регулирующие проведение государственной кадастровой оценки объектов недвижимости, предлагают примерный перечень ценообразующих факторов, при учете которых предполагается снижение субъективности кадастровой оценки [5-8].

После вступления в силу с 01.01.2017 Федерального закона № 237 «О государственной кадастровой оценке» от 03.07.2016 (далее Закон о ГКО) начал действовать переходный период до 01.01.2020, в котором кадастровая оценка регулировалась одновременно двумя законами: Законом № 237-Ф3 и Законом № 135-Ф3 [2, 9]. Согласно новому закону на территории муниципальных образований создаются государственные бюджетные учреждения, призванные реализовывать полномочия, связанные с определением кадастровой стоимости недвижимости; в соответствии с Законом о ГКО и формируется институт государственных оценщиков, которые на постоянной основе занимаются кадастровой оценкой недвижимости. В настоящее время на территории Новосибирской области создано государственное бюджетное учреждение «Центр кадастровой оценки и бюро технической инвентаризации» (ГБУ НСО «ЦКО и БТИ») [10]. Надзорные полномочия за деятельностью оценщиков и бюджетных учреждений возложены на Росреестр $[2,11]$.

Практика проведения оценки в соответствии с новым законодательством еще не сформировалась, однако следует предполагать, что оценщики столкнутся с рядом проблем, так как бюджетные учреждения продолжат применять технологии массовой оценки.

Проблемы, выявленные при исследовании технологии массовой кадастровой оценки:

- ошибки в исходных кадастровых сведениях;

- работа оценщика;

- внешнее влияние;

- исчисление налога;

- унифицированный подход;

- отсутствие механизмов контроля качества оценки.

Ошибки в исходных кадастровых сведениях. Согласно методическим указаниям о государственной кадастровой оценке (далее - МУ ГКО) и Закону о ГКО, все без исключения объекты из перечня должны быть оценены на основе актуальной кадастровой информации. Так, если при внесении сведений в кадастр была допущена ошибка, то эти данные будут использованы при расчете [14]. Такие ошибки появляются в связи с обработкой множества данных в момент внесения ин- 
формации в ЕГРН или же в связи с постоянным переходом на различное программное обеспечение для ведения базы данных.

Так как оценщики работают только с той информацией, которую получают из ЕГРН, у них нет возможности проверить достоверность данных или, в случае обнаружения ошибки, исправить ее. Если исходные данные были изначально неправильными, то и результат получится недостоверным. Ответственность за качество исходной информации возлагается на орган регистрации.

Работа оценщика. Как в любой работе, профессионализм исполнителя не исключает допуск не только арифметических ошибок, но и случайных, которые могут быть связаны с невнимательным отношением к проверке результатов расчетов и нагрузкой при обработке большого объема информации. При анализе отчетов об оценке, находящихся в открытом доступе на сайте Росреестра, авторами было выявлено, что были случаи, когда объекты с идентичными характеристиками и местоположением имеют абсолютно разную кадастровую стоимость. В таких ситуациях очень сложно оспаривать результаты оценки [14].

Внешнее влияние. Напряженные отношения между государством и обществом могут привести к влиянию участников процесса оценки на оценщика. Это приводит к частным судебным спорам. Завышенная кадастровая стоимость нарушает права налогоплательщиков, а заниженная кадастровая стоимость уменьшает доходную часть бюджета муниципального образования.

Исчисление налога. Логично полагать, что налог на недвижимость должен зависеть от характеристик объекта и его окружения в данный момент времени. Чем больше объект стоит на рынке и имеет преимущественные характеристики, тем больше должен быть налог, и наоборот. Налог рассчитывается на основе значения кадастровой стоимость актуальной на первое января года налогового периода. Поэтому, если в течение года изменились характеристики и рыночная стоимость объекта, налог останется неизменным, пока кадастровая стоимость не будет пересмотрена.

Например, многоквартирный дом и все помещения были оценены в 2018 г. в связи с вводом в эксплуатацию здания. Кадастровая стоимость была установлена, и следующая переоценка должна осуществляться не ранее, чем через три года. Но в 2019 г. рядом с домом проложили дорогу, по которой есть прямой доступ к деловому центру города. Рыночная цена на квартиры в этом доме резко увеличилась, но кадастровая стоимость осталась неизменной, а значит, муниципалитет упускает доход.

Подобные примеры можно привести в отношении земельных участков, когда рядом с ними прокладывают коммуникации, например, газопровод. В этом случае рыночная стоимость сразу изменяется в большую сторону, тогда как кадастровая стоимость изменится только в результате проведения очередного этапа оценки.

Унифицированный подход. Для целей массовой оценки бюджетные учреждения группируют объекты недвижимости в соответствии с определенными характеристиками, такими как местоположение, вид разрешенного использования и т. д. Однако при оценке объекта недвижимости в набор ценообразующих факторов должны быть включены только те, которые оказывают существенное влияние на стоимость объектов оценки и могут быть достоверно определены и объективно измерены [1]. Очевиден тот факт, что физически невозможно осмотреть все объекты и проанализировать техническую документацию, а оценка осуществляется на основе данных, содержащихся в ЕГРН и независимо от качества и достоверности этих сведений [14].

Согласно приказу департамента имущества и земельных отношений Новосибирской области в 2021 г. кадастровой оценке подлежат участки категории земель населенных пунктов. Однако в связи с окончательным вступлением в силу Закона о ГКО в 2022 г. все земельные участки подлежат обязательной переоценке с целью актуализации данных. Это значит, что колоссально возрастет нагрузка на бюджетное учреждение, в чьи обязанности входит осуществление государственной кадастровой оценки на территории Новосибирской области $[2,10,14]$. Результатом такой работы может стать огромное количество ошибок, которые в дальнейшем приведут к увеличению судебных споров. 
Отсутствие механизмов контроля качества оценки. На сегодняшний день инструменты контроля качества кадастровой оценки не регламентированы нормативными правовыми актами. Если исходную кадастровую информацию контролирует Росреестр, то итоговые результаты оценки не проверяются по причине отсутствия кадровых, временных и иных ресурсов.

В случае, если собственник выявил факт завышения кадастровой стоимости, то это можно рассматривать в качестве индивидуального контроля, тогда единственным решением остается подача заявления о пересмотре кадастровой стоимости. Но такой точечный контроль составляет лишь малую долю, чаще завышенная стоимость остается незамеченной. Считаем, что при определении кадастровой стоимости должен быть соблюден баланс публичных и частных интересов, который предполагает, что результаты расчета кадастровой стоимости будут такими, чтобы удовлетворять потребности муниципалитета и в то же время не ущемлять права налогоплательщиков. Если кадастровая стоимость занижена, это упущенная прибыль муниципалитета, а значит снижение эффективности управления. Если кадастровая стоимость завышена, то налог значительно повышается, что приводит к частым судебным спорам.
В соответствии со статьей 24.18 Закона о ГКО результаты определения кадастровой стоимости могут быть оспорены в суде и комиссии по рассмотрению споров о результатах определения кадастровой стоимости, которая формируется Росреестром (далее - комиссия) [2].

Главными причинами для подачи заявления о пересмотре кадастровой стоимости объектов недвижимости за 2020 г., по результатам анализа отчетов Росреестра, явились:

- недостоверность сведений об объекте недвижимости, использованных при определении его кадастровой стоимости;

- установление рыночной стоимости объектов недвижимости на дату определения их кадастровой стоимости;

- единичные методологические ошибки [14, 16-19].

Согласно Государственному (национальному) докладу о состоянии и использовании земель в Российской Федерации, в 2019 г. количество принятых заявлений об оспаривании кадастровой стоимости в отношении земельных участков на всей территории страны составило 24977 заявлений на общую сумму 1,09 трлн рублей. При этом анализ результатов работы комиссии показал, что суммарная кадастровая стоимость снизилась на 39,1\%. Подробная информация, в разрезе последних четырех лет, представлена в табл. 1.

Таблищуа 1

Результаты оспаривания кадастровой стоимости земельных участков на территории Российской Федерации

\begin{tabular}{|c|c|c|c|c|c|c|}
\hline Год & $\begin{array}{c}\text { Кол-во } \\
\text { заявлений, } \\
\text { принятых } \\
\text { к рассмотрению, } \\
\text { шт. }\end{array}$ & $\begin{array}{c}\text { Кол-во } \\
\text { участков, } \\
\text { шт. }\end{array}$ & $\begin{array}{c}\text { Кол-во } \\
\text { удвлетворенных } \\
\text { заявлений, шт. }\end{array}$ & $\begin{array}{c}\text { Оспариваемая } \\
\text { кадастровая } \\
\text { стоимость, } \\
\text { трлн руб. }\end{array}$ & $\begin{array}{c}\text { Кадастровая } \\
\text { стоимость } \\
\text { после } \\
\text { оспаривания, } \\
\text { трлн руб. }\end{array}$ & $\begin{array}{c}\text { Показатель } \\
\text { изменения } \\
\text { кадастровой } \\
\text { стоимости, \% }\end{array}$ \\
\hline 2019 & 24977 & 43134 & 16486 & 1,09 & 0,66 & $-39,1$ \\
\hline 2018 & 29531 & 49946 & 17720 & 2,20 & 1,80 & $-20,7$ \\
\hline 2017 & 46712 & 92594 & 28332 & 5,10 & 3,80 & $-26,0$ \\
\hline 2016 & 24502 & 92121 & 13469 & 3,70 & 2,50 & $-31,9$ \\
\hline
\end{tabular}

Анализ результатов Комиссии в Новосибирской области показал, что более чем 70 \% заявлений о снижении кадастровой стоимости удовлетворяются и снижают кадастровую стоимость почти на $50 \%[11,14]$. Это говорит о том, что существующие методики оценки недостаточно эффективны. 


\section{Результаты и их производственное значение}

В целях повышения эффективности кадастровой оценки недвижимости в части финансовых затрат и временных ресурсов предложено разработать искусственную нейронную сеть (далее - ИНС). Такая сеть имеет возможность с большой скоростью анализировать множество входных данных и получать наиболее точный расчет кадастровой стоимости земельных участков с учетом индивидуальных особенностей объекта. Схема работы ИНС представлена на рис. $1[12,13]$.

На данный момент нейронные сети находят свое применение для целей расчета рыночной стоимости объектов недвижимости. Исследования проводились на территории городов Пермь, Екатеринбург и Смоленской области. При этом объектами исследования являются квартиры и прогнозирование их рыночной стоимости [20, 21].

Авторы предполагают, что ИНС возможно использовать и для кадастровой оценки земельных участков. Для этого необходимо:

- определить набор ценообразующих факторов;

- собрать исходные данные для обучения ИНС;

- провести исследование и на основе полученных данных сделать вывод о возможности внедрения разработанной технологии на производстве.
При кажущейся простоте земельный участок является достаточно сложным объектом с важнейшей характеристикой - местоположением. При этом на стоимость также влияет окружение, социально-экономическое развитие и наличие инженерного благоустройства [22].

Выбор факторов производился на основе анализа МУ ГКО, актуальных отчетов о государственной кадастровой оценке, данных Росреестра о недвижимом имуществе и исследований ученых в области кадастровой оценки $[7,8,14,23,24]$. Анализируя работы, которые исследуют влияние различных факторов на формирование стоимости объектов недвижимости, были выделены:

- основные ценообразующие факторы;

- дополнительные факторы, которые не входят в основную группу, но имеют достаточное влияние на большинство отобранных для эксперимента участков [8].

Согласно МУ ГКО, стоимость зависит не просто от вида разрешенного использования участка, а именно от фактического использования, которое определяется путем обследования объекта [6]. Немаловажным фактором выступают находящиеся на участке коммуникации, а для определения их наличия необходима информация о прохождении границ участков. Поэтому очень важно, чтобы как можно больше земель было вовлечено в хозяйственный оборот, то есть поставлено на учет в органах регистрации.

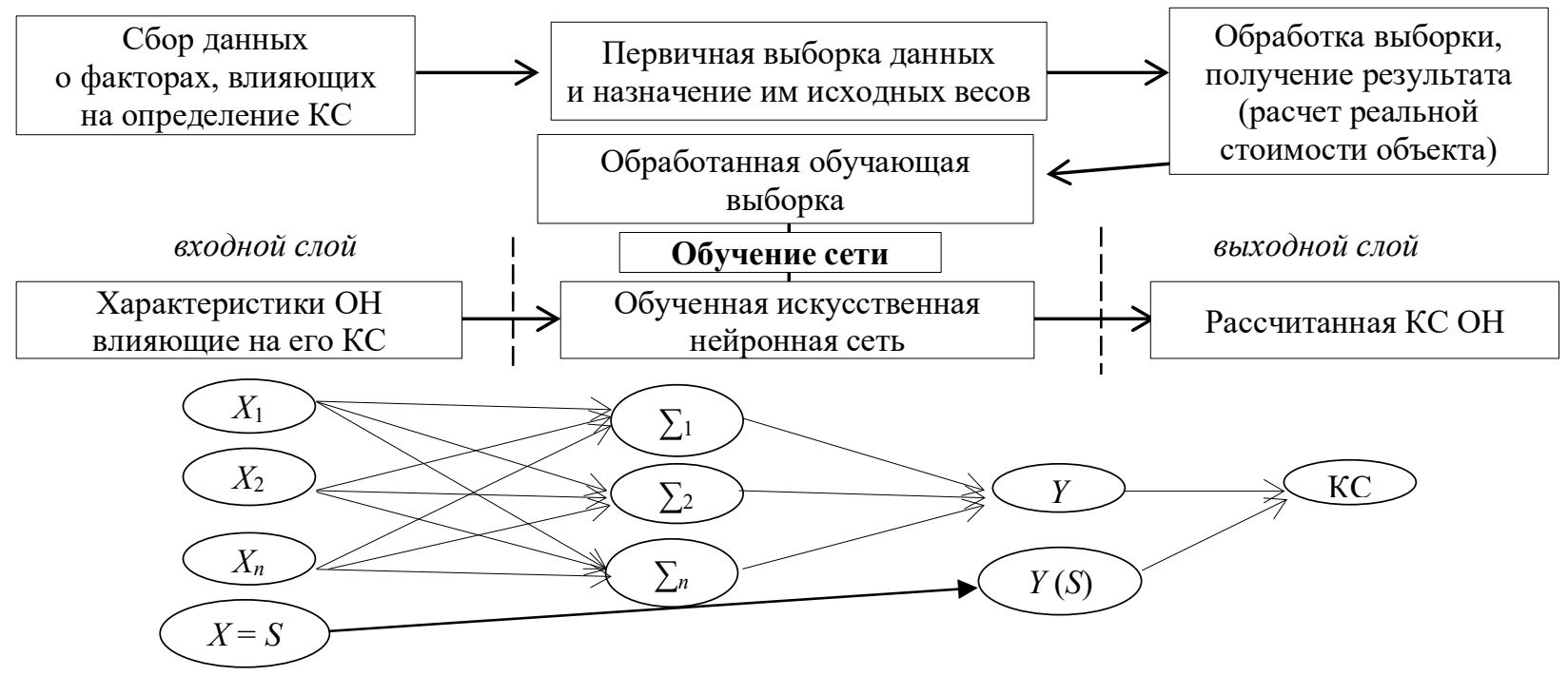

Рис. 1. Схема работы искусственной нейронной сети 
В целях разработки искусственной нейронной сети авторами обрабатываются данные о земельных участках, собранные из различных источников.

Основным информационным ресурсом является Единый государственный реестр недвижимости. Также исходные материалы были по- лучены из общедоступных интернет-ресурсов, таких как N1.ru, Яндекс.Недвижимость. Информация об инфраструктуре и доступности объектов анализировалась с помощью геоинформационной системы $2 Г И С$.

Факторы сгруппированы и представлены в табл. 2.

Таблища 2

Факторы, используемые при разработке искусственной нейронной сети в целях расчета кадастровой стоимости земельных участков, и источники получения информации о них

\begin{tabular}{|c|c|c|c|c|c|}
\hline $\begin{array}{c}\text { Ценообразующий } \\
\text { фактор }\end{array}$ & \multicolumn{3}{|c|}{ Дифференцированные признаки } & Критерий оценки & $\begin{array}{c}\text { Источник } \\
\text { информа- } \\
\text { ции } \\
\end{array}$ \\
\hline Категория земель & \multicolumn{3}{|c|}{ Земли населенных пунктов } & - & ЕГРН \\
\hline Сегмент & \multicolumn{3}{|l|}{$\begin{array}{l}-02: 000 \\
-13: 000 \\
\end{array}$} & - & МУ ГКО \\
\hline $\begin{array}{l}\text { Вид разрешенного ис- } \\
\text { пользования }\end{array}$ & $\begin{array}{l}-2.5 \\
-2.6 \\
-21\end{array}$ & & $\begin{array}{l}-2.1 .1 \\
-2.2 \\
-2.3\end{array}$ & - & ЕГРН \\
\hline $\begin{array}{l}\text { Код расчета видов ис- } \\
\text { пользования }\end{array}$ & $\begin{array}{l}-02: 050 \\
-02: 051 \\
-02: 060 \\
-02: 061 \\
-02: 010 \\
\end{array}$ & & $\begin{array}{l}-02: 011 \\
-02: 013 \\
-02: 014 \\
-02: 020 \\
-02: 021\end{array}$ & - & МУ ГКО \\
\hline Учтенная площадь & \multicolumn{2}{|c|}{ - } & - & - & ЕГРН \\
\hline $\begin{array}{l}\text { Фактическое использова- } \\
\text { ние }\end{array}$ & \multicolumn{2}{|c|}{$\begin{array}{l}\text { Согласно фактиче- } \\
\text { скому использова- } \\
\text { нию участка }\end{array}$} & - & - & ЕГРН \\
\hline Рыночная стоимость & \multicolumn{3}{|l|}{-} & Стоимость, руб. & $\begin{array}{l}\text { Интернет- } \\
\text { ресурс }\end{array}$ \\
\hline Стоимость за 1 кв. м & \multicolumn{3}{|l|}{-} & Стоимость, руб. & $\begin{array}{l}\text { Интернет- } \\
\text { ресурс }\end{array}$ \\
\hline Кадастровая стоимость & \multicolumn{3}{|l|}{-} & Стоимость, руб. & ЕГРН \\
\hline УПКС & \multicolumn{3}{|l|}{-} & Показатель, руб. & ЕГРН \\
\hline \multirow{2}{*}{$\begin{array}{l}\text { Близость к деловому цен- } \\
\text { тру }\end{array}$} & \multicolumn{3}{|c|}{ Локальный центр } & Расстояние & $2 Г И С$ \\
\hline & \multicolumn{3}{|c|}{ Центр муниципального образования } & Расстояние & $2 Г И С$ \\
\hline \multirow{3}{*}{ Автомобильная дорога } & Классификация & & $\begin{array}{l}\text { редеральная; } \\
\text { иуниципальная; } \\
\text { иестная; } \\
\text { пастная }\end{array}$ & Выбор & $2 Г И С$ \\
\hline & Тип покрытия & & $\begin{array}{l}\text { ссфальт; } \\
\text { бетон; } \\
\text { ылучшенное грунтовое по- } \\
\text { ытие; } \\
\text { без покрытия } \\
\end{array}$ & Выбор & $2 Г И С$ \\
\hline & \multicolumn{3}{|l|}{ Удаленность } & Расстояние & $2 Г И С$ \\
\hline \multirow[t]{2}{*}{$\begin{array}{l}\text { Транспортная } \\
\text { доступность }\end{array}$} & Классификация & & $\begin{array}{l}\text { к/д вокзал; } \\
\text { иетро; } \\
\text { становка автобуса; } \\
\text { становка трамвая }\end{array}$ & Наличие (да / нет) & $2 Г И С$ \\
\hline & \multicolumn{3}{|l|}{ Удаленность } & Расстояние & $2 Г И С$ \\
\hline Водные объекты & Классификация & $\begin{array}{l}-\mathrm{M} \\
-\mathrm{O} \\
-\mathrm{p} \\
-\mathrm{ml} \\
-3 \mathrm{a}\end{array}$ & $\begin{array}{l}\text { море; } \\
\text { зеро; } \\
\text { трка; } \\
\text { труд; } \\
\text { атопленный карьер }\end{array}$ & Наличие (да / нет) & $2 Г И С$ \\
\hline
\end{tabular}


Окончание табл. 2

\begin{tabular}{|c|c|c|c|c|c|}
\hline \multicolumn{2}{|c|}{$\begin{array}{c}\text { Ценообразующий } \\
\text { фактор }\end{array}$} & \multicolumn{2}{|c|}{ Дифференцированные признаки } & Критерий оценки & $\begin{array}{l}\text { Источник } \\
\text { информа- } \\
\text { ции }\end{array}$ \\
\hline \multirow{5}{*}{$\begin{array}{l}\text { Социально- } \\
\text { культурные } \\
\text { объекты }\end{array}$} & \multirow{3}{*}{$\begin{array}{l}\text { Объекты } \\
\text { здравоохра- } \\
\text { нения } \\
\end{array}$} & \multicolumn{2}{|l|}{ Удаленность } & Расстояние & $2 Г И С$ \\
\hline & & Классификация & $\begin{array}{l}\text { - поликлиника; } \\
\text { - больница }\end{array}$ & Наличие (да / нет) & $2 Г И С$ \\
\hline & & \multicolumn{2}{|l|}{ Удаленность } & Расстояние & $2 Г И С$ \\
\hline & \multirow[t]{2}{*}{$\begin{array}{l}\text { Объекты } \\
\text { культурно- } \\
\text { бытового } \\
\text { назначения }\end{array}$} & Классификация & $\begin{array}{l}\text { - торговый центр; } \\
\text { - продовольственный мага- } \\
\text { зин; } \\
\text { - школа; } \\
\text { - детский сад; } \\
\text { - спортивный комплекс }\end{array}$ & Наличие (да / нет) & 2 2ГИС \\
\hline & & \multicolumn{2}{|l|}{ Удаленность } & Расстояние & 2 2ГИС \\
\hline \multirow{2}{*}{\multicolumn{2}{|c|}{ Зоны рекреации }} & Классификация & $\begin{array}{l}\text { - лесной массив; } \\
\text { - парковая зона; } \\
\text { - набережная; } \\
\text { - пляж }\end{array}$ & Наличие (да / нет) & $2 Г И С$ \\
\hline & & \multicolumn{2}{|l|}{ Удаленность } & Расстояние & $2 Г И С$ \\
\hline \multirow{2}{*}{\multicolumn{2}{|c|}{ Железные дороги }} & Классификация & $\begin{array}{l}\text { - грузовая; } \\
\text { - пассажирская; } \\
\text { - смешанного назначения; } \\
\text { - пригородная; } \\
\text { - тупиковая }\end{array}$ & Наличие (да / нет) & $2 Г И С$ \\
\hline & & \multicolumn{2}{|l|}{ Удаленность } & Расстояние & $2 Г И С$ \\
\hline \multirow{5}{*}{\multicolumn{2}{|c|}{ Коммуникации }} & \multicolumn{2}{|l|}{ Водоснабжение } & Наличие (на участке / рядом) & 2 2ГИС \\
\hline & & \multirow{2}{*}{\multicolumn{2}{|c|}{ Газоснабжение }} & Наличие (на участке / рядом) & $2 Г И С$ \\
\hline & & & & Наличие (на участке / рядом) & $2 Г И С$ \\
\hline & & \multicolumn{2}{|l|}{ Канализация } & Наличие (на участке / рядом) & $2 Г И С$ \\
\hline & & \multicolumn{2}{|l|}{ Теплоснабжение } & Наличие (на участке / рядом) & $2 Г И С$ \\
\hline \multirow{2}{*}{\multicolumn{2}{|c|}{ Загрязнение территории }} & Классификация & \begin{tabular}{|l} 
- свалка \\
- полигон ТБО \\
- промышленный объект
\end{tabular} & Наличие (да / нет) & 2 2ГИС \\
\hline & & \multicolumn{2}{|l|}{ Удаленность } & Расстояние & $2 Г И С$ \\
\hline \multicolumn{2}{|c|}{ Форма участка } & \multicolumn{2}{|c|}{$\begin{array}{l}\text { - правильная фигура } \\
\text { - имеет острые углы }\end{array}$} & Выбор критерия & ЕГРН \\
\hline
\end{tabular}

Таким образом, в результате исследования применения ИНС для расчета кадастровой стоимости земельных участков была составлена таблица факторов, которые были дифференцированы в целях дальнейшего обучения ИНС. Влияние таких факторов, как «рельеф» и «почва», желательно учитывать для земель садоводства и огородничества, но получить указанные сведения на сегодняшний день крайне сложно, поскольку мониторинг территорий проводится редко и фрагментарно, а существующие почвенные карты не актуальны, поскольку не проводятся работы по их обновлению.

Массовая кадастровая оценка объектов недвижимости - это трудоемкий процесс, который включает в себя сбор большого массива актуальных данных о множестве объектов недвижимости. Оценка предполагает обоснование выбора метода оценки, использование различных факторов, влияющих на стоимость и проверки качества оценки.

Искусственная нейронная сеть податлива для уточнения факторов, выявленных в ходе оценки. В работе представлены факторы, используемые для расчета кадастровой стоимости участков. Однако если применять данную методику для участков других категорий земель, необходимо уточнить ценообразующие факторы. Так, для участков земель населенных пунктов важным фактором будет расстояние до административного центра, в то время как для земель сельскохозяйственного назначения определяющим фактором будет качество почв. 


\section{Выводы}

В статье были рассмотрены проблемы в области государственной кадастровой оценки объектов недвижимости. На основе анализа нормативно-правовых документов и научных работ в области кадастровой оценки выявлены основные и дополнительные ценообразующие факторы и проведена их дифференциация для дальнейшей разработки ИНС.

Разработка нейронной сети для целей кадастровой оценки земельных участков позволит:

- снизить субъективность оценщика при выборе метода оценки и исключить административное давление;

- повысить объем обрабатываемой информации, за счет чего появляется возмож- ность увеличения количества оцениваемых объектов без потери качества и увеличения затрат на рабочую силу;

- увеличить оперативность перерасчета кадастровой стоимости при необходимости ее корректировки за счет изменения характеристик объекта в ЕГРН;

- улучшить качество результатов кадастровой оценки и возможность оценки качества, что снизит количество судебных споров об изменении кадастровой стоимости объектов недвижимости.

Рассмотренные вопросы позволяют сделать вывод о прямой взаимосвязи количества учтенных объектов недвижимости и объективности результатов кадастровой оценки с экономическим состоянием муниципального образования.

\section{БИБЛИОГРАФИЧЕСКИЙ СПИСОК}

1. Лосева Е. Н. Кадастровая оценка как фактор эффективности управления муниципальным образованием // сб. материалов Международной научной конференции «Технические и естественные науки» (26 января 2020 г.). - СПб. : ГНИИ «Нацразвитие», 2020. - С. 41-44.

2. О государственной кадастровой оценке [Электронный ресурс] : федер. закон от 03.07.2016 № 237-ФЗ. - Доступ из справ.-правовой системы «КонсультантПлюс».

3. Налоговый кодекс Российской Федерации (часть вторая) [Электронный ресурс] : федер. закон от 05.08.2000 № 117-Ф3. - Доступ из справ.-правовой системы «КонсультантПлюс».

4. Положение о земельном налоге на территории города Новосибирска [Электронный ресурс] : Приложение к решению городского Совета от 25.10.2005 № 105. - Доступ из справ.-правовой системы «КонсультантПлюс».

5. Об установлении единой даты начала применения на территории Новосибирской области порядка определения налоговой базы по налогу на имущество физических лиц исходя из кадастровой стоимости объектов налогообложения [Электронный ресурс] : закон Новосибирской области от 31.10.14 № 478-O3. - Режим доступа: http://docs.cntd.ru/document/465706933.

6. Методические указания «О государственной кадастровой оценке» [Электронный ресурс] : приказ Министерства экономического развития России от 12.05.2017 № 226. - Доступ из справ.-правовой системы «КонсультантПлюс».

7. Методические указания по государственной кадастровой оценке земель населенных пунктов [Электронный ресурс] : приказ Министерства экономического развития и торговли РФ от 15.02.2007 № 39. - Доступ из справ.-правовой системы «КонсультантПлюс».

8. Дубровский А. В., Ильиных А. Л., Малыгина О. И., Москвин В. Н., Вишнякова А. В. Анализ ценообразующих факторов, оказывающих влияние на кадастровую стоимость недвижимости // Вестник СГУГиТ. - 2019. - Т. 24, № 2. - С. 150-169.

9. Об оценочной деятельности в Российской Федерации [Электронный ресурс] : федер. закон от 29.07.1998 № 135-ФЗ (ред. от 03.08.2018). - Доступ из справ.-правовой системы «КонсультантПлюс».

10. Официальный сайт Центра кадастровой оценки и бюро технической инвентаризации» (ГБУ НСО «ЦКО и БТИ») [Электронный ресурс]. - Доступ из справ.-информационной системы «Яндекс».

11. Митрофанова Н. О., Лосева Е. Н. Влияние качества кадастровой оценки на эффективность управления муниципальными образованиями // Регулирование земельно-имущественных отношений в России: правовое и геопространственное обеспечение, оценка недвижимости, экология, технологические решения : сб. материалов Национальной научно-практической конференции (Новосибирск, 17-19 ноября 2020 г.). - Новосибирск : СГУГиТ, 2020. 
12. Borankulova G. S., Tungatarova A. T. Artificial neural network features [Electronic resource] // Teoretical and applied science. - 2019. - Vol. 4. - P. 71-74. - Mode of access: elibrary_39211311_60568368.pdf.

13. Peter N. J., Okagbue H. I., Obasi E. C. M., Akinola A. O. (2020). Review on the application of artificial neural networks in real estate valuation // International journal of adwanced trends in computer science and engineering. - 2020. - Vol. 9, Issue 3. - P. 2918-2925.

14. Ильиных А. Л., Пименова В. Р. Проблемные вопросы определения кадастровой стоимости недвижимости // Регулирование земельно-имущественных отношений в России: правовое и геопространственное обеспечение, оценка недвижимости, экология, технологические решения : сб. материалов Национальной научно-практической конференции (Новосибирск, 17-19 ноября 2020 г.). - Новосибирск : СГУГиТ, 2020.

15. О проведении государственной кадастровой оценки земельных участков из категории земель населенных пунктов, расположенных на территории Новосибирской области [Электронный ресурс] : Приказ департамента имущества и земельных отношений Новосибирской области от 27.07.2020 № 2194. - Доступ из справ.-информационной системы «Яндекс».

16. Государственный (национальный) доклад о состоянии и использовании земель в Российской Федерации в 2016 г. [Электронный ресурс]. - Режим доступа : https://rosreestr.gov.ru/site/activity/ gosudarstvennyy-natsionalnyy-doklad-o-sostoyanii-i-ispolzovanii-zemel-rossiyskoy-federatsii/.

17. Государственный (национальный) доклад о состоянии и использовании земель в Российской Федерации в 2017 г. [Электронный ресурс]. - Режим доступа : https://rosreestr.gov.ru/site/activity/ gosudarstvennyy-natsionalnyy-doklad-o-sostoyanii-i-ispolzovanii-zemel-rossiyskoy-federatsii/.

18. Государственный (национальный) доклад о состоянии и использовании земель в Российской Федерации в 2018 г. [Электронный ресурс]. - Режим доступа : https://rosreestr.gov.ru/site/activity/ gosudarstvennyy-natsionalnyy-doklad-o-sostoyanii-i-ispolzovanii-zemel-rossiyskoy-federatsii/.

19. Государственный (национальный) доклад о состоянии и использовании земель в Российской Федерации в 2019 году [Электронный ресурс]. - Режим доступа : https://rosreestr.gov.ru/site/activity/ gosudarstvennyy-natsionalnyy-doklad-o-sostoyanii-i-ispolzovanii-zemel-rossiyskoy-federatsii/.

20. Питулин С. С. Применение нейронных сетей для прогноза динамики цен на недвижимость в Смоленской области // Журнал NOVAINFO.RU. - Москва, 2019. - C.4-6.

21. Алексеева А. О., Харитонова В. А., Ясницкий В. Л. Разработка концепции комплексного нейросетевого моделирования процессов массовой оценки и сценарного прогнозирования рыночной стоимости жилой // Изв. вузов. Инвестиции. Строительство. Недвижимость. - Иркутск, 2018. - С. 11-22.

22. Ильиных А. Л., Киселева А. О., Колесников А. А. Использование дифференцированных характеристик при вычислении кадастровой стоимости земель населенных пунктов с применением открытых геоданных // Интерэкспо ГЕО-Сибирь-2015. XI Междунар. науч. конгр. : Междунар. науч. конф. «Экономическое развитие Сибири и Дальнего Востока. Экономика природопользования, землеустройство, лесоустройство, управление недвижимостью»: сб. материалов в 4 т. (г. Новосибирск, 13-25 апреля 2015 г.). - Новосибирск : СГУГиТ, 2015. Т. 3. - С. 121-126.

23. Лосева Е. Н. Анализ характеристик объектов недвижимости, подлежащих внесению в ЕГРН // Интерэкспо ГЕО-Сибирь. XVI Междунар. науч. конгр. : Международная научно-технологическая конференция студентов и молодых ученых «Молодежь. Инновации. Технологии» : сб. материалов в 8 т. (Новосибирск, 18 июня-8 июля 2020 г.). - Новосибирск : СГУГиТ, 2020. Т. 7, № 2. - С. 36-42.

24. Аврунев Е. И., Козина М. В., Попов В. К. Исследование факторов стоимости земель урбанизированных территорий // Вестник СГУГиТ. - 2018. - Т. 23, № 2. - С. 130-142.

\section{USE OF ARTIFICIAL NEURAL NETWORKS IN THE STATE CADASTRAL VALUATION OF LAND PLOTS}

\section{Ekaterina N. Loseva}

Siberian State University of Geosystems and Technologies, 10, Plakhotnogo St., Novosibirsk, 630108, Russia, $\mathrm{Ph}$. D. Student, Department of Cadastre and Territorial planning; Novosibirsk State University of Economics and Management, 56, Kamenskaya St., Novosibirsk, 630099, Russia, Lecturer, Department of Environmental Safety and Management, phone: (923)122-14-77, e-mail: loseva_katty@mail.ru 


\section{Natalia O. Mitrofanova}

Siberian State University of Geosystems and Technologies, 10, Plakhotnogo St., Novosibirsk, 630108, Russia, $\mathrm{Ph}$. D., Associate Professor, Department of Cadastre and Territorial Planning, phone: (923)137-18-88, e-mail: kadastr-204@yandex.ru

At present, real estate cadastral valuation is carried out in large volumes and at regular intervals, which may reduce the objectivity and relevance of the results of such a valuation. In other words, the traditional cadastral valuations do not meet the current needs of society. The solution may be to use new techniques and technologies, such as neural networks. The automation of the cadastral valuation will reduce the estimation time, increase productivity and quality, and take into account all the individual characteristics of the property being evaluated. The subject of research is the calculation of the cadastral value of land plots using an artificial neural network. The object of this research is residential area land plots within the Novosibirsk boundaries which were divided into two segments: segment 2 "Residential constructions (mid-rise and high-rise)", segment 13 "Horticulture, low-rise residential constructions". The tasks of the research: the determination of factors which influence the cadastral value of real estate and their differentiation; accumulation of up-to-date information about real estate; preparation of data for creation of artificial neural network. And as a result were revealed the basic and additional cost-affecting factors, which then were differentiated for further development of artifitial neural network capable of calculating the cadastral value in automated mode.

Keywords: cadastral valuation, problems of real estate valuation, land plots, cadastre, municipal administration, artificial neural network, automation of cadastral valuation

\section{REFERENCES}

1. Loseva, E. N. (2020). Cadastral assessment as a factor of efficiency of municipal education management. In Sbornik materialov Mezhdunarodnoy nauchnoy konferentsii: Tekhnicheskie i estestvennye nauki [Proceedings of the International Scientific Conference: Technical and Natural Sciences] (pp. 41-44). SaintPetersburg: GNII "Natsrazvitie" Publ. [in Russian].

2. Federal Law of July 03, 2016 No. 237-FZ. On the state cadastral valuation. Retrieved from ConsultantPlus online database [in Russian].

3. Federal Law of the Russian Federation of August 05, 2000 No. 117-FZ. Tax Code of the Russian Federation (part two). Retrieved from ConsultantPlus online database [in Russian].

4. Appendix to the decision of the City Council Regulations on land tax in the territory of the city of Novosibirsk of October 25, 2005 No. 105. Retrieved from ConsultantPlus online database [in Russian].

5. Law of the Novosibirsk Region of October 10, 2014 No. 478-OZ. On the establishment of a single start date for the application in the Novosibirsk region of the procedure for determining the tax base for the tax on property of individuals based on the cadastral value of taxable objects. Retrieved from http://docs.cntd.ru/document/465706933 [in Russian].

6. Order of the Ministry of Economic Development in the Russian Federation of December 05, 2017 No. 226. Methodological instructions "On the state cadastral assessment". Retrieved from ConsultantPlus online database [in Russian].

7. Order of the Ministry of Economic Development and Trade of the Russian Federation No. 39 of February 15, 2007. On approval of methodical instructions on state cadastral valuation of the lands of settlements. Retrieved from ConsultantPlus online database [in Russian].

8. Dubrovsky, A. V., Ilinykh, A. L., Malygina, O. I., Moskvin, V. N., \& Vishnyakova, A. V. (2019). Analysis of price-forming factors influencing the cadastral value of real estate. In Vestnik SGUGiT [Vestnik SSUGT], 22(2), 150-169 [in Russian].

9. Federal Law of July 29, 1998 No. 135-FZ. On appraisal activity in the Russian Federation. Retrieved from ConsultantPlus online database [in Russian].

10. Official site of the centre of the cadastral valuation and the Bureau of technical inventory (n. d.). Retrieved from Yandex reference information system.

11. Mitrofanova, N. O., \& Loseva, E. N. Influence of the quality of cadastral valuation on the effectiveness of municipal management. In Sbornik materialov Nacional'noj nauchno-prakticheskoj konferencii: Regulirovanie zemel'no-imushhestvennyh otnoshenij v Rossii: pravovoe i geoprostranstvennoe obespechenie, ocenka nedvizhimosti, jekologija, tehnologicheskie reshenija [Proceedings of National Scientific and Practical Con- 
ference: Regulation of Land and Property Relations in Russia: Legal and Geospatial Support, Real Estate Valuation, Ecology, Technological Solutions]. Novosibirsk: SSUGT Publ. [in Russian].

12. Borankulova, G. S., \& Tungatarova, A. T. (2019). Artificial neural network features. Teoretical and Applied Science, 4, 71-74. Retrieved from elibrary_39211311_60568368.pdf.

13. Peter, N. J., Okagbue, H. I., Obasi, E. C. M., \& Akinola, A. O. (2020). Review on the application of artificial neural networks in real estate valuation. International Journal of Adwanced trends in Computer Science and Engineering, 9(3), 2918-2925.

14. Ilinykh, A. L., \& Pimenova, V. R. (2020). Problematic issues of determining the cadastral value of real estate. In Sbornik materialov Nacional'noj nauchno-prakticheskoj konferencii: Regulirovanie zemel'noimushhestvennyh otnoshenij v Rossii: pravovoe i geoprostranstvennoe obespechenie, ocenka nedvizhimosti, jekologija, tehnologicheskie reshenija [Proceedings of National Scientific and Practical Conference: Regulation of Land and Property Relations in Russia: Legal and Geospatial Support, Real Estate Valuation, Ecology, Technological Solutions]. Novosibirsk: SSUGT Publ. [in Russian].

15. Order of the Department of Property and Land Relations of the Novosibirsk region of July 27, 2020 No. 2194. About carrying out the state cadastral assessment of land plots from the category of land of settlements located in the territory of the Novosibirsk region. Retrieved from Official site of Department of Property and Land Relations of the Novosibirsk region. [in Russian].

16. State (national) report on the state and use of land in the Russian Federation in 2016. Retrieved from https://rosreestr.gov.ru/site/activity/gosudarstvennyy-natsionalnyy-doklad-o-sostoyanii-i-ispolzovanii-zemelrossiyskoy-federatsii/ [in Russian].

17. State (national) report on the state and use of land in the Russian Federation in 2017. Retrieved from https://rosreestr.gov.ru/site/activity/gosudarstvennyy-natsionalnyy-doklad-o-sostoyanii-i-ispolzovanii-zemelrossiyskoy-federatsii/ [in Russian].

18. State (national) report on the state and use of land in the Russian Federation in 2018. Retrieved from https://rosreestr.gov.ru/site/activity/gosudarstvennyy-natsionalnyy-doklad-o-sostoyanii-i-ispolzovanii-zemelrossiyskoy-federatsii/. [in Russian].

19. State (national) report on the state and use of land in the Russian Federation in 2019. Retrieved from https://rosreestr.gov.ru/site/activity/gosudarstvennyy-natsionalnyy-doklad-o-sostoyanii-i-ispolzovanii-zemelrossiyskoy-federatsii/ [in Russian].

20. Pitulin, S. S. (2019). Application of neural networks for forecasting the dynamics of real estate prices in the Smolensk region. Magazine NOVAINFO.RU (pp. 4-6) Moscow [in Russian].

21. Yasnitsky, V. L., Kharitonova, V. A., \& Yasnitsky, V. L. (2018). Development of the concept of complex neural network modeling of mass assessment processes and scenario forecasting of the market value of residential real estate. Izvestija Vuzov. Investicii. Stroitel'stvo. Nedvizhimost' [Izvestiya Vuzov. Investment. Construction. Realty] (pp. 11-22). Irkutsk [in Russian].

22. Ilyinykh, A. L., Kiseleva, A. O., \& Kolesnikov, A. A. (2015). Differentiated characteristics for calculating cadastral value of settlements lands by current Open Geodata. Information system for state cadastre of immovable property: development of cartographic database. In Sbornik materialov Interekspo Geo-Sibir'2015: Mezhdunarodnoy nauchnoy konferentsii: T. 3: Ekonomicheskoe razvitie Sibiri i Dal'nego Vostoka. Ekonomika prirodopol'zovaniya, zemleustroistvo, lesoustroistvo, upravlenie nedvizhimost'yu [Proceedings of Interexpo GEOSiberia-2015: International Scientific Conference: Vol. 3. Economic Development of Siberia and the Far East. Enviromental Economics, Land Management, Forestry Management and Property Management] (pp. 121-126). Novosibirsk: SSUGT Publ. [in Russian].

23. Loseva, E. N. (2020). Analysis of the characteristics of real estate objects subject to registration in the Unified State Register of Legal Entities. In Sbornik materialov Interekspo Geo-Sibir'-2020: Mezhdunarodnoj nauchno-tehnologicheskoj konferencii studentov i molodyh uchenyh: T. 7, no. 2. Molodezh'. Innovacii. Tehnologii [Proceedings of Interexpo GEOSiberia-2015: International Scientific and Technological Conference of Students and Young Scientists: Vol. 7, No. 2. Youth. Innovation. Technologies] (pp. 36-42). Novosibirsk: SSUGT Publ. [in Russian].

24. Avrunev, E. I., Kozina, M. V., \& Popov, V. K. (2018). Research of factors of land value in urbanized territories. Vestnik SGUGiT [Vestnik SSUGT], 23(2), 130-142 [in Russian].

Received 24.03.2021

(C) E. N. Loseva, N. O. Mitrofanova, 2021 
УДК 349.41

DOI: $10.33764 / 2411-1759-2021-26-5-191-200$

\section{СУДЕБНАЯ ЗЕМЛЕУСТРОИТЕЛЬНАЯ ЭКСПЕРТИЗА В ОТНОШЕНИИ ЗДАНИЯ, САМОВОЛЬНО РЕКОНСТРУИРОВАННОГО В КОНТУРЕ ОТДЕЛЬНОГО ПОМЕЩЕНИЯ}

\section{Иван Викторович Пархоменко}

Управление Федеральной службы государственной регистрации, кадастра и картографии по Новосибирской области, 630091, Россия, г. Новосибирск, ул. Державина, 28, кандидат технических наук, заместитель руководителя, e-mail: iv_uy@ngs.ru

\section{Дарья Васильевна Пархоменко}

Сибирский государственный университет геосистем и технологий, 630108, Россия, г. Новосибирск, ул. Плахотного, 10, доцент кафедры кадастра и территориального планирования, тел. (913)900-19-50, e-mail:dara8@inbox.ru

На практике в судах зачастую возникает вопрос о необходимости проведения судебной землеустроительной экспертизы в отношении зданий, самовольная реконструкция в которых произведена в контуре отдельных помещений. С одной стороны, законодательство указывает на необходимость экспертизы, а с другой стороны, правообладатели такого помещения недоумевают, почему они должны исследовать весь объект капитального строительства, если они изменили параметры только одного помещения. В статье разъясняется необходимость такой экспертизы. Отдельного внимания заслуживает также самовольная реконструкция в контуре индивидуального жилого дома, в результате которой образуются новые объекты прав (жилые или многоквартирные дома). Этот исключительный случай описан в статье. Кроме того, описываются технические аспекты государственного кадастрового учета реконструированных зданий в контуре отдельных помещений, дана классификация реконструкции для этих целей. Авторами предлагается разграничение кадастрового учета образуемого и изменяемого объекта, государственный кадастровый учет которого производится в результате реконструкции. Также приводится авторский алгоритм проведения судебной землеустроительной экспертизы в отношении самовольной реконструкции здания, помещение в котором изменило контур самого здания.

Ключевые слова: землеустроительная судебная экспертиза, кадастровый учет, помещение, реконструкция, самовольная постройка, объект капитального строительства, здание

\section{Введение}

Объектом капитального строительства в теории строительных наук признается здание (жилое, нежилое и многоквартирные дома), сооружение и объект незавершенного строительства $[1,2]$. Указанием на их капитальность является наличие фундамента и (или) наличие прочной связи с землей $[3,4]$. При этом известно, что не каждый объект капитального строительства является объектом недвижимости, но верно и обратное утверждение [5].

Помещением в здании является часть объема этого здания, которая имеет определенное назначение и ограничена строительными конструкциями [6]. Помещения с точки зрения кадастрового учета можно условно разделить на те, которые являются составной частью другого объекта (здания, сооружения, другого помещения), и те, которые могут являться самостоятельным объектом прав $[5,7]$. В настоящей статье речь пойдет только о последних. Для того чтобы стать самостоятельным объектом прав, помещение должно обладать двумя основными признаками:

- обособленность - наличие замкнутого объема контура в виде стен, перегородок;

- изолированность - возможность исключить доступ в помещение [8], т. е. отсутствие сквозных проходов через помещение, функциональная самостоятельность.

В случае наличия в здании прав собственности на помещения исключается возможность регистрации прав на здание; цель этой нормы для нежилых зданий (например, офисных) - избежание двойной принадлежности прав. Запрещена регистрация права на многоквартирный дом как на здание. 
Самовольная реконструкция, как и законная реконструкция, может быть произведена только в объекте капитального строительства в силу самого понятия реконструкции [1], предполагающего изменение физических параметров такого объекта $[9,10]$. То есть самовольная реконструкция, в случае если она осуществлена в контуре отдельного помещения, не может считаться реконструкцией помещения, а признается реконструкцией здания в контуре отдельного помещения.

Все виды экспертизы, связанные с узакониванием самовольной реконструкции, усложняются в том случае, если в здании имеются два и более различных собственников помещений, а реконструкция произведена в контуре лишь одного из них.

Целью настоящей статьи является рассмотрение особенностей судебной землеустроительной экспертизы в отношении здания, самовольно реконструированного в контуре отдельного помещения.

Задачами авторы ставят рассмотрение:

- особенностей образования помещения из индивидуального жилого дома (далее - жилой дом);

- отдельных аспектов государственного кадастрового учета реконструированных зданий в контуре отдельных помещений;

- отдельных аспектов землеустроительной экспертизы в отношении здания, самовольно реконструированного в контуре отдельного помещения.

\section{Анализ проблематики}

Особым случаем для реконструкции является изменение статуса жилого дома в многоквартирный или несколько жилых. Преимущественно, узаконить такую реконструкцию возможно только в судебном порядке.

Мнение законодателя [1], Росреестра [11, 12], а также Верховного суда Российской Федерации [13] заключается в невозможности образования помещения из жилого дома. Так, из самого понятия, данного в Градостроительном кодексе РФ, следует, что жилой дом не подлежит разделу на несколько самостоятельных объектов прав. В то же время, если жилой дом претерпел реконструкцию и технически пере- стал быть единым объектом, в случае образования из него, например, многоквартирного дома или нескольких индивидуальных, такое преобразование допустимо. Такая техническая изоляция нескольких объектов включает следующие обязательные характеристики:

- изолированный вход;

- отсутствие прохода между изолированными помещениями или жилыми домами;

- противопожарные стены [14] (при образовании нескольких жилых домов);

- самостоятельные коммуникации и отсутствие зависимости одного изолированного объекта от другого в части коммуникаций;

- самостоятельный доступ с земельного участка (участков) на территории общего пользования);

- подходящее назначение: категория земель, вид разрешенного использования, принадлежность территориальной зоне;

- соответствие системе ограничений, предусмотренных зонами с особыми условиями использования территории, красными линиями [15-17].

В то же время практика администраций внутригородских районов города Новосибирска сводится к тому, что изменение статуса жилого дома допустимо только в судебном порядке. Иная картина в ряде муниципальных образований Новосибирского района: здесь встречается мнение о возможности изменения статуса актом органа местного самоуправления [18].

\section{Материалы и методы исследования}

Порядок государственного кадастрового учета, в том числе системность ведения Единого государственного реестра недвижимости, особенности подготовки технического плана и xml-схем в его составе указывает на то, каким образом технически возможно идентифицировать такой объект недвижимости как здание, реконструированное в контуре отдельного помещения. И здесь существует два подхода к кадастровому учету, каждый из которых имеет право на существование:

- рассмотрение реконструкции как образования нового объекта;

- рассмотрение реконструкции как преобразования уже существующего объекта. 
При этом подходе принципиально отличаются жизненные циклы объекта, что влияет на кадастровый учет (таблица) и на ряд других параметров [18-20].

Походы к кадастровому учету при реконструкции помещения в здании

\begin{tabular}{|c|c|c|}
\hline Критерий & $\begin{array}{c}\text { Реконструкция как образование } \\
\text { нового объекта }\end{array}$ & $\begin{array}{c}\text { Реконструкция как преобразование } \\
\text { существующего объекта }\end{array}$ \\
\hline $\begin{array}{l}\text { Идентификация нового объекта } \\
\text { в кадастровом учете }\end{array}$ & Образуемый объект & Изменяемый объект \\
\hline $\begin{array}{l}\text { Юридическая судьба «старых» } \\
\text { объектов }\end{array}$ & Прекращают существование & Меняют характеристики \\
\hline $\begin{array}{l}\text { Принадлежность при регистрации } \\
\text { прав }\end{array}$ & Возникновение новых прав & Существующие права \\
\hline
\end{tabular}

На территории Новосибирской области и в ряде других регионов такая операция считалась образованием нового объекта. Но с изменением законодательства [21] в практику входит рассмотрение реконструкции в качестве изменения существующего объекта.

В то же время наблюдается отсутствие xml-схем, необходимых для подготовки кадастровыми инженерами технического плана, подходящих для описанных целей. Но схема, применимая для образования нового здания, допускает эту концепцию (рис. 1).

Так, параметр «<Method $>9$ » указывает на иное образование объекта, включая реконструкцию здания и образование нового помещения в нем.

В то же время реконструкции помещения в здании можно классифицировать различным образом (рис. 2).

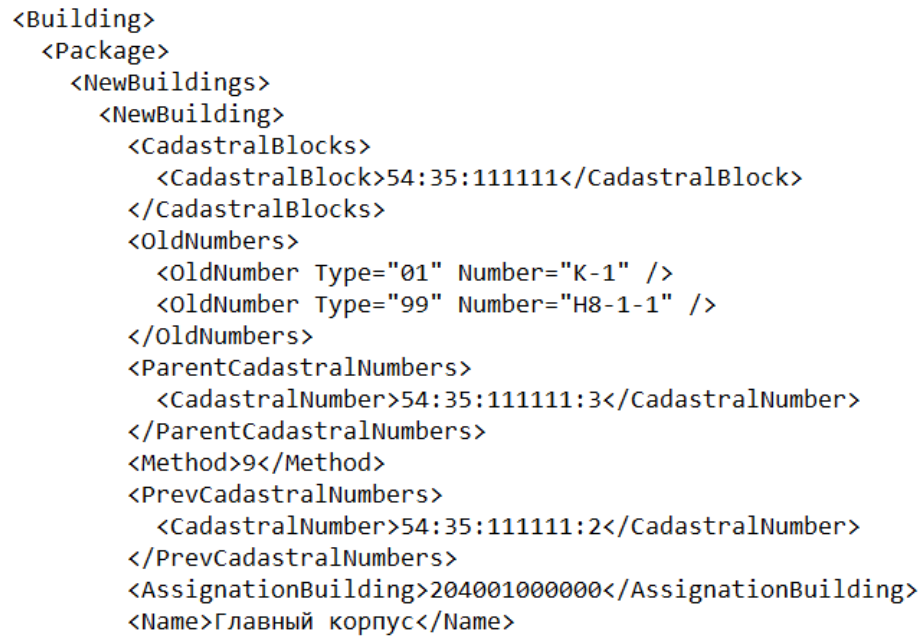

Рис. 1. Фрагмент xml-схемы, применяемой для образования нового здания

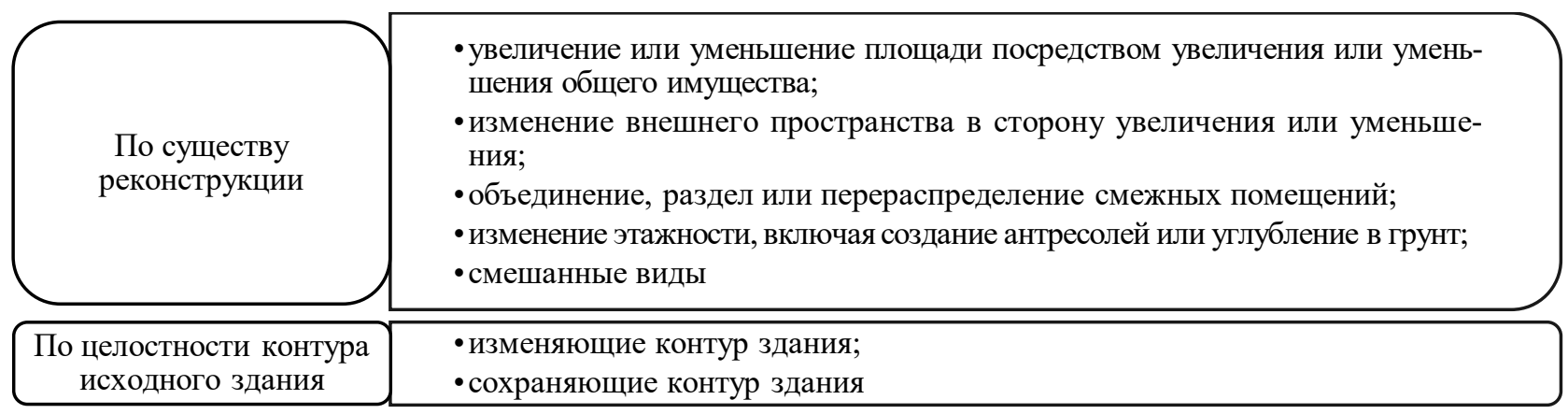

Рис. 2. Классификация реконструкции помещения в здании для целей государственного кадастрового учета 
По мнению авторов, реконструкции, связанные с объединением, разделом или перераспределением смежных помещений, а также реконструкции, изменяющие контур здания, должны рассматриваться как новые объекты и в кадастровом учете [22] считаться образованием новых объектов. Все остальные виды реконструкции должны считаться изменением существующих объектов.

\section{Ход исследования}

В связи с обозначившимися особенностями учетно-регистрационных действий в отношении объекта актуализируется вопрос всех видов строительной экспертизы в направлениях санитарно-эпидемиологической, пожарной и строительной безопасности [23-25], а для некоторых объектов и регионов - специального вида экспертизы, в первую очередь экологической [26]. И представляется очевидным, что исследование проводится в отношении в первую очередь здания, и только во вторую - в отношении того контура (помещения), в котором произведена реконструкция.

Вместе с тем формулировка ст. 222 Гражданского кодекса Российской Федерации [27] указывает на необходимость соблюдения норм земельного и градостроительного законодательства при возведении самовольной постройки (самовольная реконструкция считается одним из видов самовольной постройки), включая проверку:

- наличие необходимых в силу закона согласований, разрешений при возведении (создании) объекта;

- отсутствие нарушения градостроительных и строительных норм и правил;

- соответствие градостроительным и строительным нормам и правилам, действующим на дату выявления самовольной постройки.

Таким образом, наличие реконструкции в контуре помещения в здании и узаконивание права в судебном порядке, требует обязательного проведения землеустроительной (кадастровой) экспертизы указанного здания.

Ниже рассмотрен авторский алгоритм землеустроительного заключения в отношении самовольной реконструкции здания, помещение в котором изменило контур самого здания (идентифицирующие признаки объ- екта изменены для сохранения конфиденциальности) [28-30].

1. Определяется контур помещения относительно исходного контура здания (рис. 3).

Цель действия состоит в следующем:

- наглядно отразить проекцию нового контура помещения на земную поверхность;

- в случае отсутствия в Едином государственном реестре недвижимости сведений о геодезических координатах здания отразить проекцию здания на земную поверхность;

- указать на необходимость экспертизы измененного контура;

- обратить внимание суда на изменение контура [31-33].

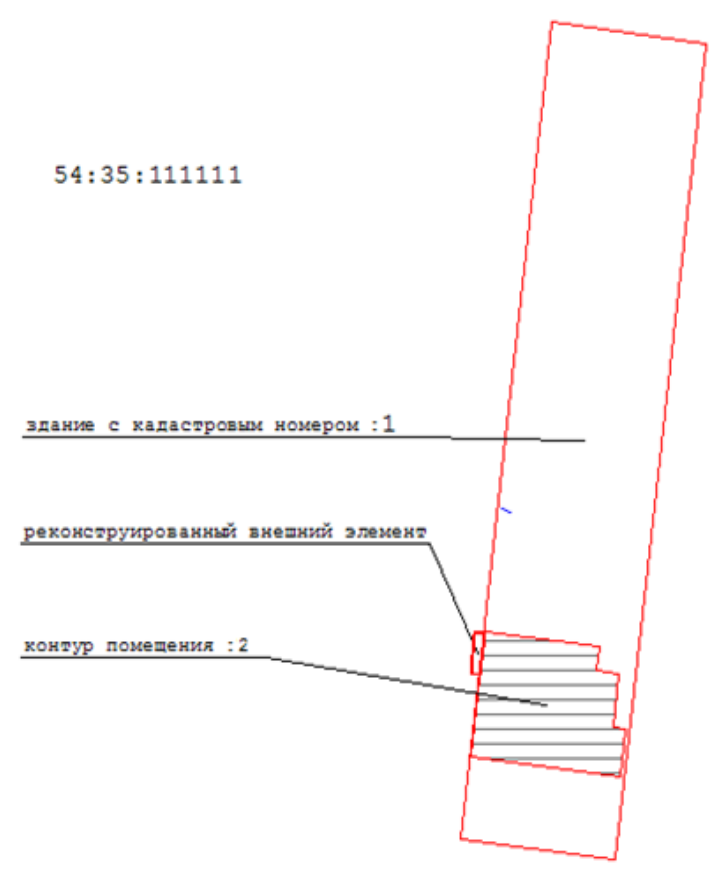

Рис. 3. Изображение контура помещения относительно исходного контура здания

2. Уточняется территориальная зона и наличие иных зон (при наличии) в отношении земельного участка, на котором находится реконструированное здание (рис. 4).

Цель действия: определение критериев, которым должна соответствовать самовольная постройка [34].

3. Определяется регламент территориальной зоны посредством анализа соответствующих правил землепользования и застройки.

Цель действия: уточнить конкретные критерии для анализа соответствия. 


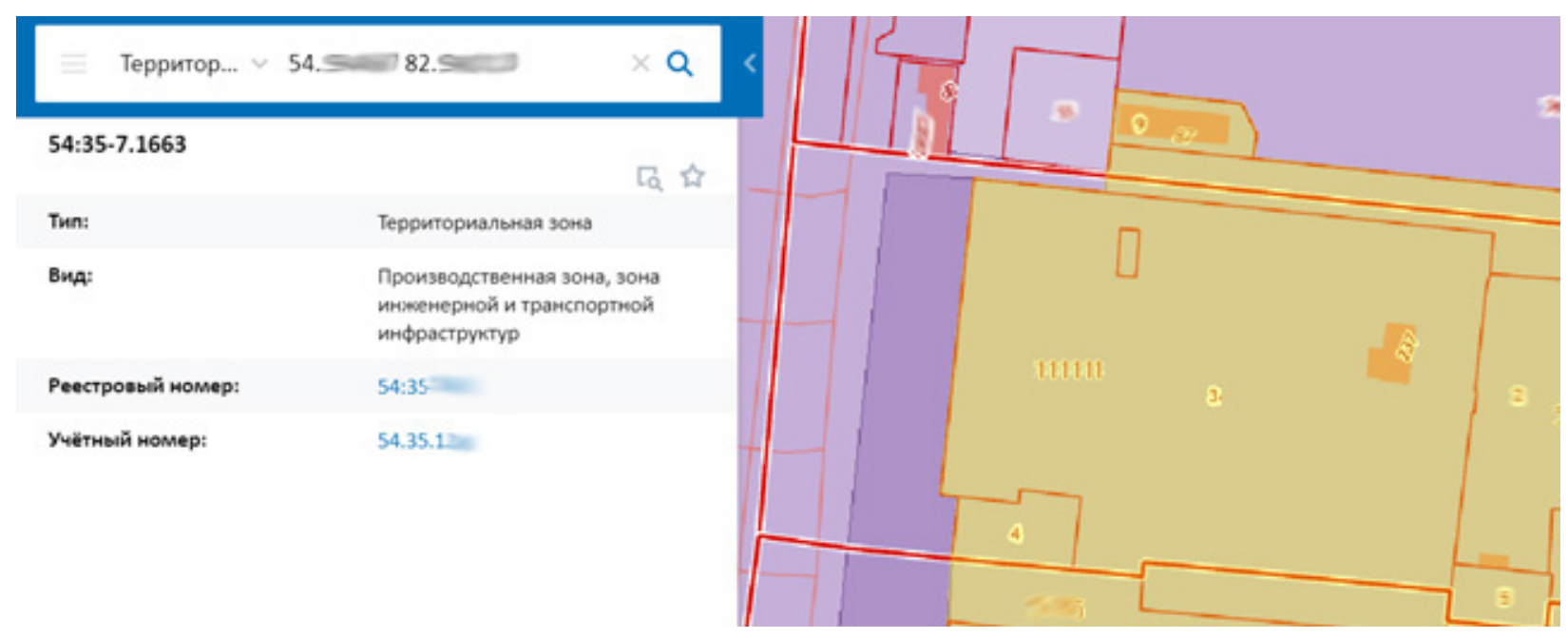

Рис. 4. Определение территориальной зоны и ограничений для земельного участка

4. Производится анализ отдельных параметров реконструированного здания, таких как размеры отступов, процент застройки, процент озеленения и прочее (в зависимости от регламентов) (рис. 5).

Цель действия: определение параметров произведенной застройки.

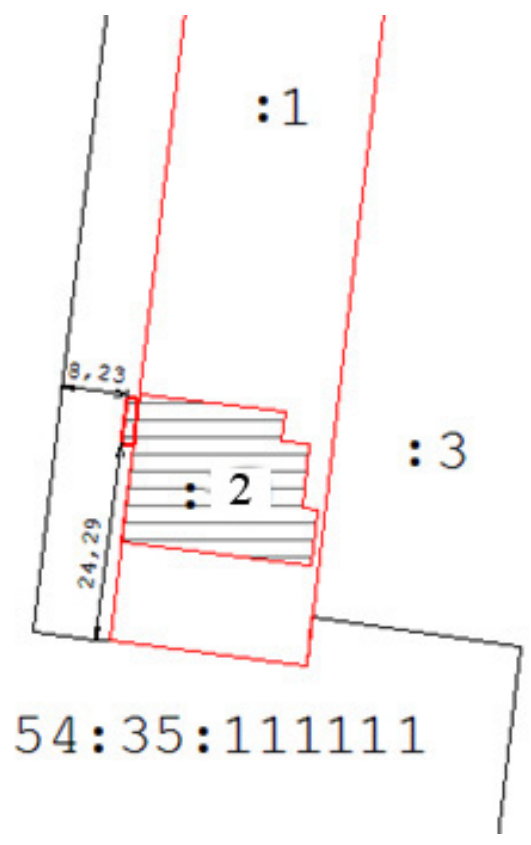

Рис. 5. Измерение минимальных отступов реконструированного здания от границ земельного участка [35]

5. Производится сопоставление, анализ и заключение о соответствии произведенной реконструкции режиму территории и назначению земельного участка [36].

Представленный авторский алгоритм землеустроительного заключения в отношении самовольной реконструкции здания, помещение в котором изменило контур здания, позволяет сделать анализ соответствия реконструированного здания градостроительному и земельному законодательству наглядным, доступным для суда и сторон, проверяемым с научной точки зрения. 


\section{Заключение}

На основании изложенного можно сделать вывод о том, что реконструкции, связанные с объединением, разделом или перераспределением смежных помещений, а также реконструкции, изменяющие контур здания, должны рассматриваться как новые объекты и в кадастровом учете считаться образованием новых объектов. Все остальные виды реконструкции зданий в контурах помещений должны считаться изменением существующих объектов.

Кроме того, авторы представили алгоритм произведения землеустроительного заключения в отношении самовольной реконструкции здания, помещение в котором изменило контур здания, обладающий признаками наглядности, доступности, проверяемости.

\section{БИБЛИОГРАФИЧЕСКИЙ СПИСОК}

1. Градостроительный кодекс Российской Федерации от 29.12.2004 № 190-Ф3 // Собрание законодательства РФ. - 2005. - № 1 (часть 1). - Ст. 16.

2. Карпик А. П., Лисицкий Д. В., Байков К. С., Осипов А. Г., Савиных В. Н. Геопространственный дискурс опережающего и прорывного мышления // Вестник СГУГиТ. - 2017. - Т. 22, № 4. - С. 53-67.

3. О применении судами некоторых положений раздела I части первой Гражданского кодекса Российской Федерации [Электронный ресурс] : Постановление Пленума Верховного Суда РФ от 23.06.2015 № 25. - Доступ из справ.-правовой системы «Консультант Плюс».

4. Жуков Б. Н. Геодезический контроль сооружений при эксплуатации и реконструкций : учеб. пособие для студентов. - Новосибирск, 1994. - 126 с.

5. Максименко Л. А. Типология объектов недвижимости. Подготовка планов зданий в графическом редакторе AutoCAD : учеб.-метод. пособие. - Новосибирск : СГУГиТ, 2017. - 175 с.

6. Технический регламент о безопасности зданий и сооружений: федер. закон от 30.12.2009 № 384Ф3 // Собрание законодательства РФ. - 2010. - № 1. - Ст. 5.

7. О государственной регистрации недвижимости : федеральный закон от 13.07.2015 № 218-Ф3 // Собрание законодательства РФ. - 2015. - № 29 (часть I). - Ст. 4344.

8. О направлении писем по вопросу, связанному с изолированностью и обособленностью помещений в здании или квартире [Электронный ресурс] : Письмо Росреестра от 09.01.2014 №14-исх/00072ГЕ/14. - Доступ из справ.-правовой системы «Консультант Плюс».

9. Карпик А. П., Лифашина Г. В., Репин А. С. Технология строительства. Расчет вероятной осадки и крена фундамента здания, составление проекта вертикальной планировки квартала жилой застройки, чтение архитектурно-строительных чертежей : лаб. практикум. - Новосибирск : СГУГиТ, 2016.

10. Дементьева О. А., Середович А. В. Применение наземного лазерного сканирования в комплексе изыскательских работ по реконструкции технологических объектов // ГЕО-Сибирь-2009 : V Междунар. науч. конгр. : сб. материалов в 6 т. (Новосибирск, 20-24 апреля 2009 г.) - Новосибирск : СГГА, 2009. T. 1, ч. 1. - C. $144-148$.

11. О рассмотрении обращения [Электронный ресурс] : письмо Управления Росреестра по Калужской области № 13/1-00256/21 от 23.06.2021. - Доступ из справ.-правовой системы «Консультант Плюс».

12. Об осуществлении учетно-регистрационных действий на части жилого дома [Электронный ресурс] : письмо Управления Росреестра по Новосибирской области № 01-01-26-0285/21 от 07.07.2021 . Доступ из справ.-правовой системы «Консультант Плюс».

13. Кассационное определение Верховного Суда РФ от 20.02.2019 № 15-КГ18-54. [Электронный ресурс]. - Доступ из справ.-правовой системы «Консультант Плюс».

14. Технический регламент о требованиях пожарной безопасности: федер. закон от 22.07.2008 № 123-Ф3 // Собрание законодательства РФ. - 2010. - № 30 (часть 1). - Ст. 3579.

15. Клюшниченко В. Н., Мартынов Г. П., Юрина Г. И. Об определении площади земельного участка в условиях отсутствия требуемого координатного обеспечения // Вестник СГУГиТ - Т. 26, № 3. C. $138-146$.

16. Гиниятов И. А. Мониторинг земель и объектов недвижимости : учеб. пособие в 2 ч. - Новосибирск : СГУГиТ, 2017. Ч. 2. - 130 с.

17. Федоров, А. И., Лебедев О. В. Особенности выполнения геодезических работ при реконструкции сооружений АЭС // ГЕО-Сибирь-2007 : сб. материалов III Междунар. науч. конгр. (Новосибирск, 25-27 апреля 2007 г.). - Новосибирск : СГГА, 2007. Т. 1, ч. 1. - С. 88-91. 
18. Жарников В. Б., Стегниенко Е. С. О содержании взаимодействия территориальных органов Росреестра и Федеральной налоговой службы в целях совершенствования налогово-бюджетной политики государства // Вестник СГУГиТ - Т. 26, № 2. - С. 147-154.

19. Zhuravleva L. A., Fedyunina T. V., Evsyukova L. Yu., Rusinov A. V., Kolganov D. A., Pototskaya L. N. Features of investing in reconstruction of reclamation objects by the example of irrigation systems of the saratov region // Revista Turismo Estudos \& Práticas. - 2020. - № S4. - P. 19.

20. Biryukov A. N., Kravchenko I. N., Dobryshkin E. O., Biryukov Yu. A., Kondrashchenko V. I. Efficiency evaluation of apartment houses reconstruction with optimizational criteria application // International Journal for Computational Civil and Structural Engineering. - 2020. -T. 16. № 1. - P. 14-24.

21. О внесении изменений в Федеральный закон «О государственной регистрации недвижимости» и отдельные законодательные акты Российской Федерации: федер. закон от 30.04.2021 № 120-Ф3 // Собрание законодательства РФ. - 2021. - № 18. - С. 3064.

22. Митрофанова Н. О. Современные тенденции совершенствования системы ведения государственного кадастра недвижимости // Интерэкспо ГЕО-Сибирь-2012. VIII Междунар. науч. конгр. : Междунар. науч. конф. «Экономическое развитие Сибири и Дальнего Востока. Экономика природопользования, землеустройство, лесоустройство, управление недвижимостью»: сб. материалов в 4 т. (Новосибирск, 10-20 апреля 2012 г.). - Новосибирск: СГГА, 2012. Т. 3. - С. 115-120.

23. Бутырин А. Ю., Статива Е. Б., Манухина О. А. Восемь законов логики для судебного экспертастроителя [Электронный ресурс] // Теория и практика судебной экспертизы. - 2021. - Т. 16, № 1. C. 19-32. - Режим доступа : https://doi.org/10.30764/1819-2785-2021-1-19-32.

24. Голдзицкая Е. Ю. Теория и практика судебной экспертизы. - Иркутск : Байкальский государственный университет. Институт повышения квалификации, 2020.

25. Карпик А. П., Лисицкий Д. В. Перспективы развития геодезического и картографического производства и новая парадигма геопространственной деятельности // Вестник СГУГиТ. - 2020. - Т. 25, № 2. - C. 19-29.

26. Карпик А. П., Хорошилов В. С. Сущность геоинформационного пространства территорий как единой основы развития государственного кадастра недвижимости // Изв. вузов. Геодезия и аэрофотосъемка. - 2012. - № 2/1. - С. 134-136.

27. Гражданский кодекс Российской Федерации (часть первая) : федер. закон от 30.11.1994 № 51-ФЗ // Собрание законодательства РФ. - 1994. - № 32. - Ст. 3301.

28. Карпик А. П., Мусихин И. А., Ветошкин Д. Н. Интеллектуальные информационные модели территорий как эффективный инструмент пространственного и экономического развития // Вестник СГУГиТ. - Т. 26, № 2. - С. 155-163.

29. Гиниятов И. А., Антипов И. Т., Антонович К. М., Асташенков Г. Г., Вылегжанина В. В. О некоторых результатах выявления реестровых ошибок, препятствующих государственной регистрации прав // Вестник СГУГиТ. - 2018. - Т. 23, № 2. - С. 143-153.

30. Малиновский М. А., Иванова Т. В. К вопросу применения Віт-технологии при разработке проекта реконструкции и планировки территории образовательного учреждения // Интерэкспо ГЕОСибирь. XVI Междунар. науч. конгр. : Международная научно-технологическая конференция студентов и молодых ученых «Молодежь. Инновации. Технологии» : сб. материалов в 8 т. (Новосибирск, 18 июня -8 июля 2020 г.). - Новосибирск : СГУГиТ, 2020. Т. 7, № 2. - С. 83-88.

31. Аврунев Е. И. Использование активных базовых станций при выполнении кадастровых работ в отношении объектов недвижимости // Вестник СГУГиТ. - 2019. - Т. 24, № 1. - С. 135-145.

32. Тарарин А. М. Цифровая трансформация градостроительной деятельности // Вестник СГУГиТ. - 2021. - Т. 26, № 1. - С. 110-121.

33. Дубровский А. В., Ершов А. В. Элементы геоинформационного обеспечения инвентаризационных работ // Вестник СГУГиТ. - 2017. - Т. 22, № 4. - С. 100-112.

34. Гумарова А. Ф. Комплексная реконструкция сложившейся застройки: принципы и особенности // Евразийский Союз Ученых. Серия: экономические и юридические науки. - 2021 - № 6 (87). - С. 10-12.

35. Земельный Кодекс Российской Федерации от 25.10.2001 № 136-Ф3 // Собрание законодательства РФ. - 2001. - № 44. - Ст. 4147.

36. Антонов Е. С., Лисицкий Д. В., Янкелевич С. С. Теоретико-методологическое представление прямого перехода от геоинформации к геознаниям // Вестник СГУГиТ. - 2021. - Т. 26, № 2. - С. 82-90.

Получено 04.08.2021

(C) И. В. Пархоменко, Д. В. Пархоменко, 2021 


\section{GEODETIC EXPERT EVIDENCE OF A BUILDING AFTER UNAUTHORISED RENOVATION IN THE CIRCUIT OF A SEPARATE ROOM}

\section{Ivan V. Parkhomenko}

Department of the Federal Service for State Registration, Cadastre and Cartography in the Novosibirsk Region, 28, Derzhavina St., Novosibirsk, 630091, Russia, Ph. D., Deputy Head, e-mail: iv_uy@ngs.ru

\section{Daria V. Parkhomenko}

Siberian State University of Geosystems and Technologies, 10, Plakhotnogo St., Novosibirsk, 630108, Russia, Ph. D., Associate Professor, Department of Legal and Social Sciences, phone: (913)900-19-50, e-mail: dara8@inbox.ru

In practice, in the courts, the question often arises about the need for a geodetic expert evidence in relation to buildings, unauthorized reconstruction of which was carried out in the contour of separate premises. On the one hand, the legislation indicates the need for such expert evidence, and on the other hand, the right holders of such a premises are perplexed why they should investigate the entire capital facilities if they have changed the parameters of only one premise. The article explains why such expert evidence is necessary. The unauthorized reconstruction in the contour of an individual residential building, as a result of which new rights objects are formed (residential or apartment buildings), also deserves special attention. This exceptional case is described in the article. In addition, the article describes technical aspects of the state cadastral registration of reconstructed buildings in the contour of individual rooms, and proposes a classification of reconstruction for these purposes. The authors propose a distinction between the cadastral registration of the formed and the changed object, the state cadastral registration of which is carried out as a result of reconstruction. Also, the article presents the author's algorithm for conducting geodetic expert evidence in relation to unauthorized reconstruction of a building, the room in which changed the outline of the building itself.

Keywords: geodetic expert evidence, cadastral registration, room, reconstruction, unauthorized construction, capital facility, building

\section{REFERENCES}

1. Federal Law of December 29, 2004 No 190-FZ. Urban Planning Code of the Russian Federation. Retrieved from ConsultantPlus online database [in Russian].

2. Karpik, A. P., \& Lisitsky, D. V. (2020). Prospects for the development of geodesic and cartographic production and the new paradigm of geospatial activity. Vestnik SGUGiT [Vestnik SSUGT], 25(2), 19-29 [in Russian].

3. Resolution of the Plenum of the Supreme Court of the Russian Federation of June 23, 2015 No 25. On the application by the courts of certain provisions of section I of part one of the Civil Code of the Russian Federation. Retrieved from ConsultantPlus online database [in Russian].

4. Zhukov, B. N. (1994). Geodezicheskij kontrol' sooruzhenij pri jekspluatacii i rekonstrukcij [Geodetic control of structures during operation and reconstruction]. Novosibirsk, 126 p. [in Russian].

5. Maksimenko, L. A. (2017). Tipologiya ob"ektov nedvizhimosti. Podgotovka planov zdanii v graficheskom redaktore AutoCAD [Typology of real estate objects. Preparation of building plans in the graphic editor AutoCAD]. Novosibirsk: SSUGT Publ., 175 p. [in Russian].

6. Federal Law of Desember 30, 2009 No. 384-FZ. (2010). Sobranie Zakonodatel'stva Rossiyskoy Federatsii [Assembly of the Russian Federation], No. 1, Art. 5 [in Russian].

7. Federal law of July 13, 2015 No. 218-FZ. On state registration of real estate. (2015). Sobranie Zakonodatel'stva Rossiyskoy Federatsii [Assembly of the Russian Federation], No. 29 (Part I), Art. 4344 [in Russian].

8. Letter of Rosreestr of January 09, 2014 No. 14-out/00072-GE/14. On the direction of letters on the issue related to the isolation and isolation of premises in a building or apartment Retrieved from ConsultantPlus online database [in Russian].

9. Karpik, A. P., Lifashina, G. V., \& Repin, A. S. (2016). Tekhnologiia stroitel'stva. Raschet veroiatnoi osadki i krena fundamenta zdaniia, sostavlenie proekta vertikal'noi planirovki kvartala zhiloi zastroiki, chtenie arkhitek-turno-stroitel'nykh chertezhei [Construction technology. Calculation of the probable settlement and 
tilt of the building foundation, drawing up a draft of the vertical layout of a residential area, reading architectural and construction drawings]. Novosibirsk: SSUGT Publ. [in Russian].

10. Dementyeva, O. A., \& Seredovich, A. V. (2009). The use of ground-based laser scanning in the complex of survey works for the reconstruction of technological objects. In Sbornik materialov GEO-Sibir'-2009: T. 1, ch. 1 [GEO-Siberia-2009: Vol. 1, Part 1] (pp. 144-148). Novosibirsk: SSGA Publ. [in Russian].

11. Kaluga region Rosreestr Letter of June 23, 2021 No. 13/1-00256/21. About consideration of the appeal. Retrieved from ConsultantPlus online database [in Russian].

12. Novosibirsk region Rosreestr Letter of July 7, 2021 No. 01-01-26-0285/21. On the implementation of registration and registration actions on a part of a residential building. Retrieved from ConsultantPlus online database [in Russian].

13. Cassational determination of the Supreme Court of the Russian Federation of February 20, 2019 No. 15-KG18-54. Retrieved from ConsultantPlus online database [in Russian].

14. Federal Law of July 22, 2008 No. 123-FZ. Technical regulations on fire safety requirements. (2010). Sobranie Zakonodatel'stva Rossiyskoy Federatsii [Assembly of the Russian Federation], No. 30 (Part 1), Art. 3579 [in Russian].

15. Klyushnichenko, V. N., Martynov, G. P., \& Yurina, G. I. (2021). On the determination of the area of the land plot in the absence of the required coordinate support. Vestnik SGUGiT [Vestnik SSUGT], 26(3), $138-146$ [in Russian].

16. Giniyatov, I. A. (2017). Monitoring zemel' i ob"ektov nedvizhimosti: Ch. 2 [Monitoring of lands and real estate objects: Part 2]. Novosibirsk: SSUGT Publ., 130 p. [in Russian].

17. Fedorov, A. I., \& Lebedev, O. V. (2007). Features of the performance of geodetic works during the reconstruction of NPP structures. In Sbornik materialov GEO-Sibir'-2007: T. 1, ch. 1 [GEO-Siberia-2007: Vol. 1, Part 1] (pp. 88-91). Novosibirsk: SGGA Publ. [in Russian].

18. Zharnikov, V. B., \& Stegnienko, E. S. (2021). On the content of interaction between the territorial bodies of Rosreestr and the Federal Tax Service in order to improve the fiscal policy of the state. Vestnik SGUGiT [Vestnik SSUGT], 26(1), 147-154 [in Russian].

19. Zhuravleva, L. A., Fedyunina, T. V., Evsyukova, L. Yu., Rusinov, A. V., Kolganov, D. A., \& Pototskaya, L. N. (2020). Features of investing in reconstruction of reclamation objects by the example of irrigation systems of the saratov region. Revista Turismo Estudos \& Práticas, S4, P. 19.

20. Biryukov, A. N., Kravchenko, I. N., Dobryshkin, E. O., Biryukov, Yu. A., \& Kondrashchenko, V. I. (2020). Efficiency evaluation of apartment houses reconstruction with optimizational criteria application. International Journal for Computational Civil and Structural Engineering, 16(1), 14-24.

21. Federal Law of April 30, 2021 No. 120-FZ. On amendments to the Federal Law "On state real estate registration" and certain legislative acts of the Russian Federation. (2021). Sobranie Zakonodatel'stva Rossiyskoy Federatsii [Assembly of the Russian Federation], No. 18, Art. 3064 [in Russian].

22. Mitrofanova N. O. (2012). Modern trends in improving the system of the state cadastration maintaining. In Sbornik materialov Interekspo GEO-Sibir'-2015: Mezhdunarodnoy nauchnoy konferentsii: T. 3. Ekonomicheskoe razvitie Sibiri i Dal'nego Vostoka. Ekonomika prirodopol'zovaniia, zemleustroistvo, lesoustroistvo, upravlenii e nedvizhimost'iu [Proceedings of Interexpo GEO-Siberia-2015: International Scientific Conference: Vol. 3. Economic Development of Siberia and the Far East. Enviromental Economics, Land Management, Forestry Management and Property Management] (pp. 115-120). Novosibirsk: SSGA Publ. [in Russian].

23. Butyrin, A. Yu., Stativa, E. B., \& Manukhina, O. A. (2021). Eight laws of logic for a forensic expertbuilder. Teoriia i praktika sudebnoi ekspertizy [Theory and Practice of Forensic Examination], 16(1), 19-32. Retrieved from https://doi.org/10.30764/1819-2785-2021-1-19-32.

24. Goldzitskaya, E. Yu. (2020). Teoriia i praktika sudebnoi ekspertizy [Theory and practice of forensic examination]. Irkutsk: Baikal State University. Institute for Advanced Studies [in Russian].

25. Karpik, A. P., \& Lisitsky, D. V. (2020). Prospects for the development of geodetic and cartographic production and a new paradigm of geospatial activity. Vestnik SGUGiT [Vestnik SSUGT], 25(2), 19-29 [in Russian].

26. Karpik, A. P., \& Khoroshilov, V. S. (2012). The essence of the geoinformation space of territories as a single basis for the development of the state cadastre of real estate. Izvestiya vuzov. Geodeziya $i$ aerofotos"emka [Izvestiya vuzov. Geodesy and Aerophotosurveying], 2/1, 134-136 [in Russian].

27. Federal Law of November 30, 1994 No. 51-FZ. Civil Law of the Russian Federation. (1994). Sobranie Zakonodatel'stva Rossiyskoy Federatsii [Assembly of the Russian Federation], No. 32, Art. 3301 [in Russian]. 
28. Karpik, A. P., Musikhin, I. A., \& Vetoshkin, D. N. (2021). Intellectual information models of territories as an effective tool for spatial and economic development. Vestnik SGUGiT [Vestnik SSUGT], 26(2), 155-163 [in Russian].

29. Giniyatov, I. A., Antipov, I. T. , Antonovich, K. M., Astashenkov, G. G., \& Vylegzhanina, V. V. (2018). On some results of identifying registry errors that prevent state registration of rights. Vestnik SGUGiT [Vestnik SSUGT], 23(2), 143-153 [in Russian].

30. Malinovsky, M. A., \& Ivanova, T. V. (2020). On the issue of using Bim-technology in the development of a project for the reconstruction and planning of the territory of an educational institution. In Sbornik materialov Interekspo GEO-Sibir'-2020: Mezhdunarodnoy Mezhdunarodnoi nauchno-tekhnologicheskoi konferentsiia studentov i molodykh uchenykh: T. 7, no. 2. Molodezh'. Innovatsii. Tekhnologii [Proceedings of Interexpo GEO-Siberia-2020: International Scientific and Technological Conference of Students and Young Scientists: Vol. 7, No. 2. Youth. Innovation. Technologies] (pp. 83-88). Novosibirsk: SSUGT Publ. [in Russian].

31. Avrunev, E. I. (2019). Use Of Active Basic Stations In The Performance Of Cadastral Works With Respect To Real Estate Objects. Vestnik SGUGiT [Vestnik SSUGT], 24(1), 135-145 [in Russian].

32. Tararin, A. M. (2021). Digital transformation of urban planning. Vestnik SGUGiT [Vestnik SSUGT], 26(1), 110-121 [in Russian].

33. Dubrovskiy, A. V., \& Ershov, A. V. (2017). Elements of inventory works geoinformation support. Vestnik SGUGiT [Vestnik SSUGT], 22(4), 100-112 [in Russian].

34. Gumarova, A. F. (2021). Complex reconstruction of the existing development: principles and features. Eurasian Union of Scientists. Series: economic and legal sciences [Eurasian Union of Scientists. Series: Economic and Legal Sciences], 6(87), 10-12 [in Russian].

35. Federal Law of October 25, 2001 No. 136-FZ. Land Code of the Russian Federation. (2001). Sobranie Zakonodatel'stva Rossiyskoy Federatsii [Assembly of the Russian Federation], No. 44, Art. 4147 [in Russian].

36. Antonov E. S., Lisitsky D. V., \& Yankelevich S. S. (2021). Theoretical and methodological representation of the direct transition from geoinformation to geoscience. Vestnik SGUGiT [Vestnik SSUGT], 26(2), 82-90 [in Russian].

Received 04.08.2021

(C) I. V. Parkhomenko, D. V. Parkhomenko, 2021 